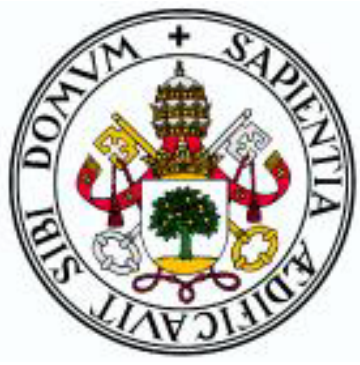

Universidad de Valladolid

Tesis Doctoral

\title{
Evaluación del Aprendizaje Organizativo en los Centros Tecnológicos y Gestión del Conocimiento Sectorial en Castilla y León
}





\title{
Facultad de Ciencias Económicas y Empresariales Departamento de Economía Aplicada
}

\author{
Doctorando: \\ D. Pedro Martín Lerones
}

Directoras:

Dña. Josefa Eugenia Fernández Arufe - Catedrática de Economía Aplicada Dña. Rosario Pedrosa Sanz - Profesora Titular de Política Económica 

A mis padres y esposa.

Lo que soy, y adonde llego, a vosotros lo debo. 

Where is the wisdom we have lost in knowledge?. Where is the knowledge we have lost in information?.

Thomas Stearns Eliot 



\section{Agradecimientos}

En un mundo como el que vivimos, no se entienden las inversiones a largo plazo, y menos aún si de ellas no se obtienen grandes beneficios materiales. Por eso, nunca tendré palabras, ni serán tampoco suficientes, para recompensar el ánimo insuflado por mis padres y la paciencia demostrada por mi esposa en la realización de este trabajo.

Lo importante requiere tiempo para hacerse. Este valor, acompañado del saber propio de la experiencia, ha venido de la mano de mis directoras. Junto a ellas, debo además agradecer la supervisión y ayuda desinteresada de otras personas en determinados campos en que son un referente. Así, quiero dejar constancia de: Diego Moñux Chércoles, Mónica Antón Freile y Laura Caballero Fombellida, de la Fundación CARTIF; Fco. Javier Gómez González, Guillermo Aleixandre Mendizábal, José Carlos Cobos Hernández y Raúl de Diego Vallejo, de la Universidad de Valladolid; y Nekane Aramburu Goya, de la Universidad de Deusto.

En lo personal, el apoyo de Alberto, $\mathrm{M}^{\mathrm{a}}$. Eugenia y Beatriz, mis hermanos, también es digno de mención. A ellos se ha sumado el afecto y un sincero "¿qué tal va eso?" de los buenos amigos: Sergio Saludes Rodil, Isaac García Incertis y los lejanos Miguel Ángel González González y Juan Videla.

Que nunca se pierda la ilusión y la sonrisa con que veo entre mis manos el fruto de estos años. 



\section{Índice General}

Índice General.

Índice de Figuras.

Índice de Tablas.

Introducción y Objetivos

\section{Capítulo I: Precisiones Conceptuales}

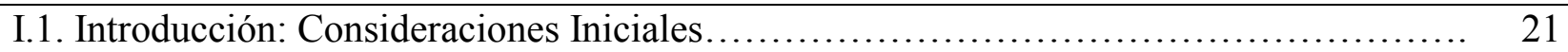

I.2. El Concepto de Conocimiento........................................... 21

I.2.1. Clases de Conocimiento......................................... 23

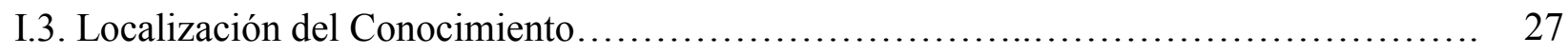

I.4. La Producción y Transmisión de Conocimiento............................... 29

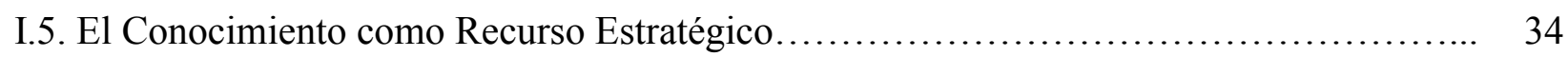

I.5.1. El Capital Intelectual.......................................... 36

I.5.2. La Medición del Capital Intelectual................................... 40

I.6. El Aprendizaje Organizativo.............................................. 46

I.6.1. El Enfoque del Cambio............................................ 49

I.6.2. El Enfoque del Conocimiento................................... 51

I.6.3. El Enfoque Mixto del Cambio y del Conocimiento....................... 52

I.6.4. Corrientes de Pensamiento Actuales y Propuesta de un Nuevo Enfoque......... 54

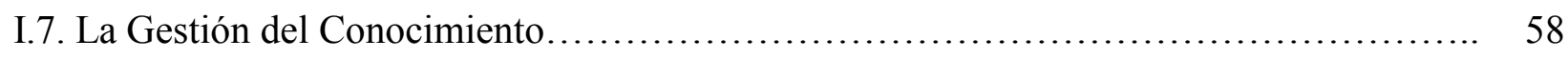

I.7.1. Modelos de Gestión del Conocimiento................................... 62

\section{Capítulo II: El Sistema de Conocimiento en Castilla y León}

II.1. Introducción: Consideraciones Iniciales........................................ 77

II.2. La Generación de Conocimiento en Castilla y León................................ 78

II.3. La Transmisión de Conocimiento en Castilla y León............................. 83

II.4. Especificidades Sectoriales y Locales del Conocimiento en Castilla y León........... 87 
II.5. Los Sectores Clave de la Economía de Castilla y León........................... 93

II.5.1. El Sector Agroalimentario..................................... 93

II.5.2. El Sector de Automoción........................................... 96

II.5.3. El Sector de las Tecnologías de la Información y las Comunicaciones........ 100

II.5.4. El Sector de Conservación del Patrimonio................................ 102

II.5.5. El Sector de la Biotecnología................................... 104

II.6. La Política de I+D+i en Castilla y León....................................... 106

Capítulo III: Caracterización y Enfoque del Aprendizaje Organizativo en los Centros

\section{Tecnológicos}

III.1. Introducción: Consideraciones Iniciales.

III.2. El Aprendizaje Organizativo como Base de la Gestión del Conocimiento y el Capital Intelectual.

III.3. Los Retos Actuales de la Gestión en las Organizaciones.

III.3.1. La Gestión del Cambio en las Organizaciones.....

III.3.2. La Gestión del Conocimiento en las Organizaciones.

III.4. El Aprendizaje Organizativo frente a la Capacitación.

III.5. Predisposición Individual al Aprendizaje Organizativo. ...

III.6. El Desarrollo del Aprendizaje Organizativo.

III.6.1. El Marco de Progreso de los Centros Tecnológicos.

III.6.2. Necesidad de la Modelización Dinámica del Aprendizaje Organizativo en los Centros Tecnológicos.

\section{Capítulo IV: Modelado Entrópico de la Evolución del Aprendizaje Organizativo}

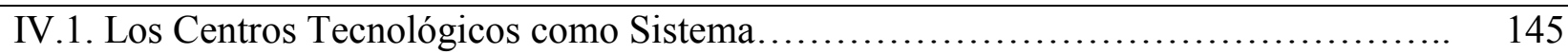

IV.2. Los Centros Tecnológicos como Sistema Termodinámico......................... 149

IV.3. Metodología de Estudio.................................................. 158

IV.3.1. Los Bucles de Realimentación y sus Demoras......................... 158

IV.3.2. Relación entre Organización Social y Sistema Abierto para los Centros Tecnológicos........................................................ 160

IV.3.3. Aplicación de la Teoría del Caos..................................... 167

IV.3.3.1. El Nacimiento de la Teoría del Caos.......................... 168 
IV.3.3.2. Los Atractores........................................ 170

IV.3.3.3. Los Mapas de Retardo................................... 174

IV.3.3.4. Significado y Características del Caos en los Centros Tecnológicos................................................. 175

IV.3.4. Aplicación de la Teoría de los Sistemas Alejados del Equilibrio............ 177

IV.3.5. Caracterización de la Complejidad en los Centros Tecnológicos............ 180

IV.3.6. La Autopoiesis como Forma de Organización en los Centros Tecnológicos......................................................... 182

IV.3.6.1. Entidad de la Autopoiesis.................................... 182

IV.3.6.2. Aplicación de la Teoría de la Autopoiesis..................... 183

IV.4. Modelo Entrópico de Sostenibilidad de los Centros Tecnológicos via el Aprendizaje

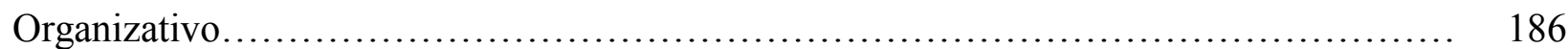

\section{Capítulo V: Los Actores Psico-Sociológicos del Aprendizaje Organizativo}

V.1. Los Actores Internos y Externos del Aprendizaje Organizativo en los Centros Tecnológicos.

V.2. Descripción de los Actores Internos del Aprendizaje Organizativo en los Centros Tecnológicos.

V.2.1. La Motivación y su Fomento

V.2.2. Influencia de las Creencias en el Desarrollo de Proyectos de I+D+i......... 201

V.2.3. Control, Gestión y Distribución Temporal del Investigador................ 203

V.2.4. La Inteligencia Emocional......................................... 207

V.2.5. La Importancia de la Jerarquía..................................... 211

V.3. Descripción de los Actores Externos del Aprendizaje Organizativo en los Centros Tecnológicos................................................................... 215

V.3.1. La Inteligencia Profesional y Proactiva................................ 216

V.3.2. La Formación en los Ingenieros de I+D+i........................... 219

V.3.3. Esfera de Actuación................................................ 223 
Capítulo VI: Correlación de los Actores Psico-Sociológicos y Formulación para la Valoración Entrópica de la Evolución del Aprendizaje Organizativo

VI.1. Necesidad de Correlación de los Actores Psico-Sociológicos

VI.2. Relación Matemática entre Entropía, Información e Indicadores del Aprendizaje Organizativo

VI.3. Indicadores Internos para el Aprendizaje Organizativo en los Centros Tecnológicos..

VI.3.1. Especialización de Actividades.

VI.3.2. Capacidad para la $\mathrm{I}+\mathrm{D}+\mathrm{i}$

VI.3.3. Infraestructuras y Equipamientos que Favorecen la Creación de Conocimiento.

VI.3.4. Clima Interno.

VI.3.5. Eficacia y Productividad.

VI.4. Indicadores Externos para el Aprendizaje Organizativo en los Centros Tecnológicos.

VI.4.1. Conectividad y Proyección.

VI.4.2. Intensidad de Innovación.

VI.4.3. Acciones Formativas Relacionadas con $\mathrm{I}+\mathrm{D}+\mathrm{i}$.

VI.4.4. Orientación al Mercado. ...

VI.4.5. Impacto Científico-Técnico.

VI.4.6. Impacto Industrial.

VI.5. Consideraciones y Formulación Finales.

\section{Capítulo VII: Líneas para la Gestión del Conocimiento en las PYMEs de Castilla y León}

VII.1. Introducción: Consideraciones Iniciales.

VII.2. Directrices para el Sector Agroalimentario

VII.2.1. Análisis Previo.

VII.2.2. Focalización en las Áreas de Interés.

VII.2.3. Propuesta de Valor

VII.2.4. Benchmarking.

VII.3. Directrices para el Sector de Automoción.

VII.3.1. El Referente de las Grandes Empresas: RENAULT-Palencia. 
VII.3.2.1. Propuesta Metodológica de Gestión del Conocimiento........... 299

VII.3.2.2. Las Fuentes del Conocimiento............................ 302

VII.3.2.3. Gestión Paralela de los Recursos Humanos..................... 303

VII.3.2.4. Mejoras Esperadas........................................ 305

VII.4. Directrices para el Sector de las Tecnologías de la Información y las

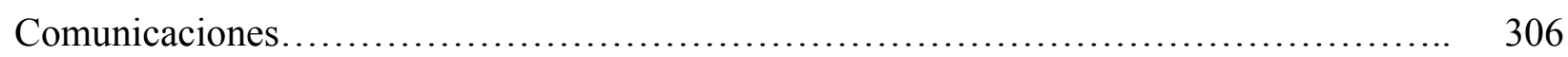

VII.4.1. Modo de Proceder en las Empresas.................................. 307

VII.4.2. Las Fuentes del Conocimiento..................................... 309

VII.4.3. Los Instrumentos.......................................... 311

VII.4.4. Obstáculos Presentados.......................................... 312

VII.4.5. Beneficios Esperados y Forma de Evaluación.......................... 313

Conclusiones y Futuras Líneas de Investigación....................................................... 319

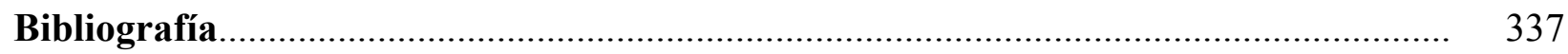

Anexo A: Definiciones de Investigación, Desarrollo Tecnológico e Innovación.......... 355

Anexo B: Demostración de la No-Equivalencia de los Conceptos de Entropía y Desorden.............................................................. 363 


\section{Índice de Figuras}

Figura 1: La Economía en Red........................................................................... 12

Figura 2: La Pirámide de la Inteligencia Humana....................................................... 26

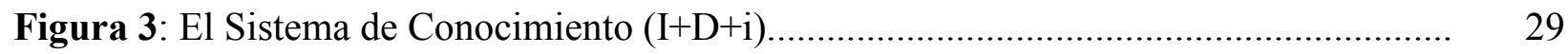

Figura 4: Recursos, Capacidades y Ventajas Competitivas............................................... 35

Figura 5: Balanced Scorecard o Cuadro de Mando Integral............................................. 43

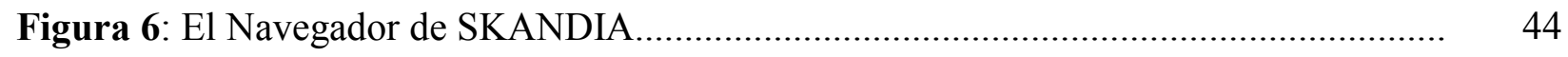

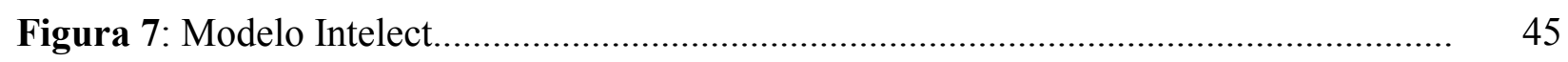

Figura 8: Modelo Intelect: El Capital Intelectual......................................................... 46

Figura 9: La "Triada" Conceptual............................................................................... 59

Figura 10: Generación de Beneficios a Través de la Gestión del Conocimiento.................. $\quad 60$

Figura 11: La Gestión del Conocimento como Proceso Sistémico...................................... 62

Figura 12: Procesos de Conversión del Conocimiento........................................................ 63

Figura 13: La Espiral de Creación del Conocimiento Organizativo.................................... 64

Figura 14: Modelo Knowledge Management Assessment Tool (KMAT).................. 66

Figura 15: Reto Estratégico de la Organización Basado en el Conocimiento...................... 69

Figura 16: Proceso de Formación de la Estrategia: Modelo Dinámico Basado en el

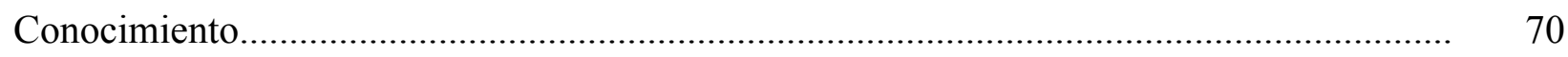

Figura 17: Los Procesos de Dirección Estratégica del Conocimiento (PDEC): Modelo

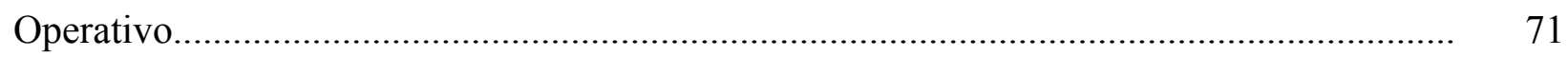

Figura 18: Benavides y Quintana: Proceso de Gestión del Conocimiento.......................... 73

Figura 19: Contexto de las Políticas de Ciencia y Tecnología en Castilla y León............... 107

Figura 20: Relación entre los Conceptos de Dato, Información, Conocimiento y Capital

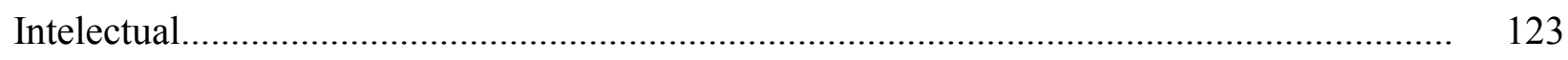

Figura 21: Clasificación de Miller sobre los Sistemas Vivos............................................. 146

Figura 22: La Aparición de Propiedades Emergentes en un Centro Tecnológico................. 148

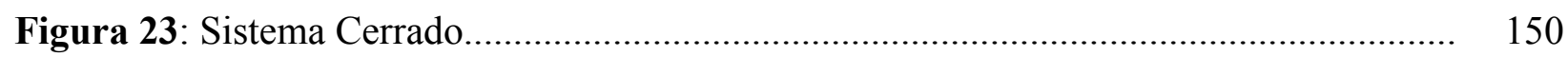

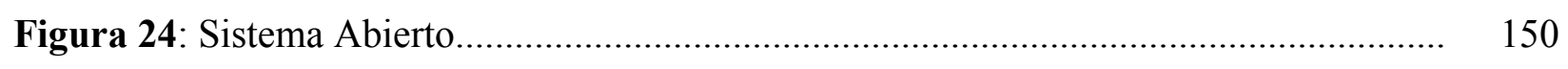

Figura 25: Sistema Aislado................................................................................... 151 
Figura 26: La Mariposa o Atractor de Lorenz.

Figura 27: Ejemplo de Dinámica Relacional entre Centros Tecnológicos y su Financiación.

Figura 28: Equivalencias entre los Conceptos Necesarios para Abordar el Modelo Entrópico del Aprendizaje Organizativo en los Centros Tecnológicos.

Figura 29: Interacciones que Conforman los Actores Internos y Externos del Aprendizaje Organizativo en los Centros Tecnológicos.

Figura 30: Jerarquía de Necesidades de Maslow.

Figura 31: Período de Evaluación para la Valoración Entrópica del Aprendizaje Organizativo

Figura 32: Fases Metodológicas para la Implantación de un Sistema de Gestión del Conocimiento en PYMEs del Sector Agroalimentario.

Figura 33: Influencia de la Implantación de un Sistema de Gestión del Conocimiento en la Producción de Vehículos de las Fábricas de RENAULT en Castilla y León.

Figura 34: Fases Metodológicas para la Implantación de un Sistema de Gestión del Conocimiento en PYMEs del Sector Automoción.

Figura 35: Fases Metodológicas para la Implantación de un Sistema de Gestión del Conocimiento en el Sector de las Tecnologías de la Información y las Comunicaciones. 


\section{Índice de Tablas}

Tabla 1: Rasgos de las Sociedades Preindustrial, Industrial y Postindustrial..................... 11

Tabla 2: Manifestaciones del Conocimiento Tácito y Explícito....................................... 25

Tabla 3: Cambios en la Producción del Conocimiento........................................................ 33

Tabla 4: Diferencias entre Activos Tangibles e Intangibles.............................................. 37

Tabla 5: El Capital Intelectual...................................................................................... 40

Tabla 6: Balanced Scorecard o Cuadro de Mando Integral: Principales Indicadores.......... 42

Tabla 7: El Navegador de SKANDIA: Principales Indicadores del Capital Intelectual....... $\quad 44$

Tabla 8: La Evolución del Proceso de Aprendizaje............................................................ 49

Tabla 9: Dimensiones Conceptuales y Categorías del Conocimiento..................................... 68

Tabla 10: Generación y Transmisión de Conocimiento en Castilla y León.......................... 80

Tabla 11: Tipología Sectorial de Pavitt y Ampliación de Soete y Miozzo........................... 90

Tabla 12: Indicadores Básicos de I+D según tipo de Empresa (2002).............................. 92

Tabla 13: Hitos en la Política de I+D+i de la Junta de Castilla y León............................... 108

Tabla 14: Programas y Líneas de Actuación Asociadas en la Estrategia Regional de $\mathrm{I}+\mathrm{D}+\mathrm{i}$ de Castilla y León para con la I+D................................................................................. 112

Tabla 15: Programas y Líneas de Actuación Asociadas en la Estrategia Regional de I+D+i de Castilla y León para con la Innovación............................................................................ 113

Tabla 16: Diferencias entre la Vieja y la Nueva Economía............................................... 280 


\section{Introducción y Objetivos}

Como elemento exógeno al proceso productivo, el conocimiento siempre ha estado presente, se ha utilizado y se ha valorado en todas las sociedades. La capacidad de inventar e innovar, de crear a su vez nuevos conocimientos y nuevas ideas, ha alimentado históricamente al desarrollo.

Desde sus mismos albores, la humanidad ha podido progresar gracias a la posesión de ciertos tipos de conocimientos (cómo construir instrumentos, dónde cazar, cómo cultivar, etc.) y se ha ocupado de lo que el medievalista francés G. Duby denominaba "la búsqueda incesante de instrumentos de saber" [David y Foray-2002: 11]. Además, en todo momento han existido organizaciones e instituciones eficaces para su creación y difusión.

En un pasado no tan lejano, economistas de la talla de Adam Smith, Alfred Marshall, Friedrich List, Joseph A. Schumpeter o Friedrich Hayek, por poner sólo algunos ejemplos, ya se refirieron a él desde diferentes perspectivas $\mathrm{y}$, apoyándose en la comprensión de las técnicas de producción, la disponibilidad de recursos y las características de los mercados, reconocieron su importancia para la prosperidad y el crecimiento de las economías.

Por tanto, la noción de que el conocimiento es el elemento más valioso para la sociedad y el factor más importante en los procesos económicos no es nueva en la historia económica, como tampoco lo es la de que la inteligencia es la clave que explica el sentido de las transformaciones sociales y de los avances tecnológicos [Bueno-2003: 3].

Sin embargo, el protagonismo, el papel y el significado que el término conocimiento ha ido cobrando a partir de la segunda mitad de la pasada centuria es relativamente diferente al que venía manteniendo hasta entonces, y ha ido creciendo conforme se han ido acortando los ciclos de vida de los productos y aumentado las presiones para la implantación de una mayor sofisticación técnica y directiva [Benavides Velasco y Quintana García-2003: 1]. 
Nos hallamos ante el comienzo de un nuevo ciclo, una nueva economía: la Economía del Conocimiento, en la que los activos intangibles (el conocimiento, las capacidades, la propiedad intelectual, etc.) y su gestión (como proceso de creación, desarrollo, difusión y explotación de aquéllos) relegan a un segundo plano a los activos tangibles imperantes en los procesos de creación de valor de las anteriores economías: agraria (tierra) e industrial (recursos naturales, capital físico y trabajo humano).

Puesto que las reglas imperantes en ella las crean el conocimiento, el tiempo y la información y su distribución entre las distintas unidades que componen el sistema económico, es posible definirla como aquella economía que se basa directamente en la producción, distribución y uso de información y conocimiento [OCDE-1996]. Su consolidación está generando importantes cambios (ideológicos, culturales, institucionales y políticos) en los conjuntos sociales y en las relaciones del individuo con su entorno, así como dando forma a una nueva sociedad: la denominada Sociedad del Conocimiento ${ }^{1}$, caracterizada por la continua aparición de nuevos saberes y por el permanente desarrollo de factores intelectuales.

A esta nueva economía se llega tras una sucesión de etapas (Tabla 1), de profundas transformaciones en algunos de los componentes fundamentales de las actividades de los países desarrollados?

Su origen se sitúa en los años setenta del siglo $\mathrm{XX}$, a medida que la industria se automatiza y el sector servicios crece de forma espectacular. Durante los años ochenta, esta situación se acentúa, de forma que, a principios de los noventa, se culmina el paso desde el sistema económico nacido de la revolución industrial (centrado en la optimización de los sistemas industriales, la productividad y la racionalización en la organización del trabajo, entre otros aspectos) a un nuevo sistema postindustrial, cuyo principal recurso estratégico lo constituye el capital humano e intelectual.

\footnotetext{
${ }^{1}$ Término acuñado por Peter F. Drucker, en 1993.

2 A los países en vías de desarrollo no se traslada la gestión del conocimiento, sino la producción industrial, agrícola y ganadera, en bruto.
} 
TABLA 1

RASGOS DE LAS SOCIEDADES PREINDUSTRIAL, INDUSTRIAL Y POSTINDUSTRIAL

\begin{tabular}{|c|c|c|c|}
\hline & $\begin{array}{c}\text { SOCIEDAD } \\
\text { PREINDUSTRIAL } \\
\text { O } \\
\text { EXTRACTIVA }\end{array}$ & $\begin{array}{c}\text { SOCIEDAD } \\
\text { INDUSTRIAL } \\
\text { O DE } \\
\text { FABRICACIÓN }\end{array}$ & $\begin{array}{c}\text { SOCIEDAD } \\
\text { POSTINDUSTRIAL O } \\
\text { DE } \\
\text { PROCESO }\end{array}$ \\
\hline $\begin{array}{c}\text { ACTIVIDAD } \\
\text { PREDOMINANTE }\end{array}$ & Agricultura & Industria & Servicios \\
\hline $\begin{array}{c}\text { RECURSO } \\
\text { TRANSFORMADO } \\
\text { PRINCIPAL }\end{array}$ & Fuerzas naturales & Energía & Información \\
\hline $\begin{array}{c}\text { RECURSO } \\
\text { ESTRATÉGICO }\end{array}$ & Materias primas & Capital financiero & $\begin{array}{l}\text { Conocimientos: capital } \\
\text { humano e intelectual }\end{array}$ \\
\hline $\begin{array}{l}\text { EJE DEL SISTEMA } \\
\text { TECNOLÓGICO }\end{array}$ & Manual-artesanal & $\begin{array}{c}\text { Hierro-vapor-textil. } \\
\text { Electro-mecánico- } \\
\text { químico }\end{array}$ & $\begin{array}{l}\text { Información- } \\
\text { telecomunicaciones- } \\
\text { multimateriales- } \\
\text { biotecnología }\end{array}$ \\
\hline BASE ENERGÉTICA & Fuerzas naturales & Carbón, petróleo & Multienergías \\
\hline PRINCIPIO AXIAL & Costumbre-tradición & Crecimiento económico & $\begin{array}{l}\text { Codificación de los } \\
\text { conocimientos teóricos }\end{array}$ \\
\hline
\end{tabular}

FUENTE: Benavides Velasco y Quintana García [2003:6]

En este nuevo escenario, se asiste sucesivamente a:

1. Un acrecentamiento de la importancia de la información y las tecnologías que la gestionan y aplican. Se acuñan, entonces, las expresiones "Era de la Información” y "Sociedad de la Información

2. Un acortamiento del ciclo de vida de los productos y las tecnologías.

3. Un aumento de la importancia de la dimensión intangible de los productos.

4. Una fase de "inmaterialización” de la economía [Benavides Velasco y Quintana García-2003: 3], en la que la demanda, los consumidores, el mercado y los principios de competitividad cobran especial protagonismo.

\footnotetext{
3 Teniendo en cuenta a Caracostas y Muldur [1998], Sociedad de la Información y Sociedad del Conocimiento no son conceptos equivalentes. El resultado de un aprendizaje, i.e.: conocimiento, es un concepto mucho más amplio que el de información, como se mostrará más adelante.
} 
5. Finalmente, a una etapa identificada como "economía en red". Ello implica tanto la interconexión de la tecnología como la de los seres humanos a través de ella, para generar cambios trascendentales en la creación de bienestar y desarrollo social [Tapscott-1997]. Se trata de una era de promesas/peligros ${ }^{4}$ potenciales (Figura 1), en la que las interacciones entre los individuos y las organizaciones se hacen cada vez más necesarias para gestionar un entorno altamente complejo, cambiante (en tecnologías, sistemas, procesos, productos, tendencias, etc.) y de difícil predicción.

FIGURA 1

\section{LA ECONOMÍA EN RED}

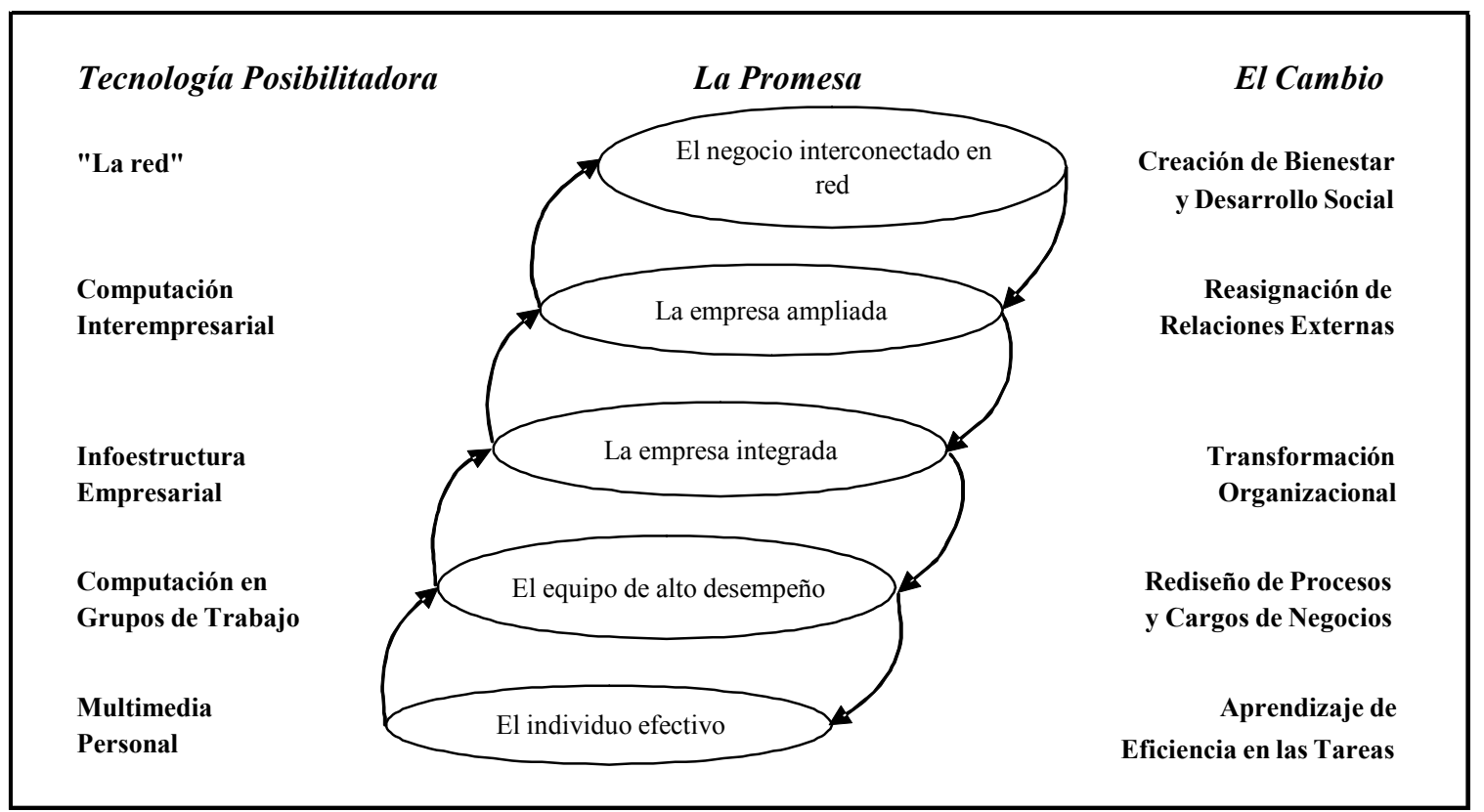

FUENTE: Tapscott [1997: 73]

Todo un conjunto de factores, externos e internos, contribuyen a explicar la aparición de este escenario [Montuschi-2002: 6; Teece-2000: 5-9; Wiig-2000: 10-12]. La globalización y liberalización de los mercados; el rápido cambio tecnológico y la difusión de las Tecnologías de la Información y de las Comunicaciones (TICs); la sofisticación de la demanda, de los competidores y de los proveedores; o el fortalecimiento de los regímenes de propiedad intelectual sobresalen entre los primeros. Los cuellos de botella en la efectividad empresarial (derivados de las limitaciones en los flujos de trabajo, información, etc.); la creciente importancia de las capacidades dinámicas (habilidades gerenciales y cognitivas que permiten discernir, reconocer

\footnotetext{
${ }^{4}$ Para los individuos, organizaciones y sociedades que se quedan rezagados el castigo es veloz y severo.
} 
errores estratégicos y realizar ajustes para la consecución del éxito) [Teece, Pisano y Schuen-1997]; o la necesidad de entender las funciones cognitivas humanas, entre los segundos.

De entre todos ellos, uno de los más relevantes ha sido, sin duda, la rápida evolución de las tecnologías de la información y de las comunicaciones, por cuanto, al eliminar barreras físicas y temporales, ha facilitado a las personas y organizaciones estar en continua comunicación, aumentar de forma notable el acceso a la información, establecer colaboraciones entre ellas $y$, en definitiva, mejorar e intensificar el conocimiento y la capacidad de aprender.

Consecuentemente, la economía del conocimiento presenta cuatro rasgos fundamentales [Bueno-2003: 5; Benavides Velasco y Quintana García-2003: 7; Vickery-1999: 169]:

a. Está integrada por empresas y trabajadores "intelectuales", agentes que producen, almacenan, intercambian y consumen conocimientos. Las unidades de negocio se centran, mayormente, en su "núcleo de actividad", se especializan, y aumentan los vínculos horizontales entre sí para la subcontratación o la externalización de actividades. Los empleados están mejor formados y tienen mayor responsabilidad. Actúan y trabajan con el intelecto o con la mente. Tienen más polivalencia en su especialidad y una mayor rotación en el trabajo. Los grupos de trabajo reducidos, autónomos o autogestionados, se hacen más comunes. El poder para actuar es menos dependiente de modelos jerárquicos de autoridad.

b. Produce, básicamente, un conjunto de servicios, desarrollos y aplicaciones de naturaleza intelectual o intangible. Tienen un carácter heterogéneo y presentan serias dificultades de medición.

c. Se basa en la incorporación del conocimiento en el activo de las empresas y en el propio sistema económico nacional, a través de todo tipo de organización pública o privada y de sus procesos de creación de valor; así como en un alto grado de interconexión, en virtud del desarrollo de nuevos medios de comunicación (internet, 
telefonía móvil, comunicación vía satélite, etc.). La digitalización de la información ha potenciado las posibilidades de colaboración dentro y entre las organizaciones.

d. Finalmente, constituye un elemento clave de la competitividad de una nación, de una región o de una empresa. En una economía cada vez más global, en la que los flujos de información presentan costes decrecientes, el número de mercados es mayor, los productos y el trabajo se liberalizan, los flujos financieros internacionales se desregulan, y la innovación, la tecnología y los activos intangibles tienen una importancia fundamental para mantener la competitividad.

Se puede afirmar, por tanto, que en este siglo XXI, los cambios sociales pueden ser más importantes para el éxito o fracaso de una organización y de sus ejecutivos que el devenir económico. Estos cambios constituirán las principales amenazas y las principales oportunidades para cualquier organización, grande o pequeña, de negocios o sin ánimo de lucro, americana, europea, asiática, australiana,... Sus directivos, para poder explotar las mutaciones económicas como oportunidades para las referidas organizaciones, tendrán que comprender la realidad de la sociedad que viene y basar su política y sus estrategias en ella [Drucker-2003: 10-11].

Los Jefes de Estado y de Gobierno de la Unión Europea (UE), reconociendo que las perspectivas que ofrece la economía del conocimiento plantean importantes retos y oportunidades, definieron, en la Cumbre de Lisboa de Marzo de 2000, un ambicioso objetivo estratégico, que sería reafirmado en posteriores Consejos Europeos: acelerar la transformación económica para que en 2010 la Unión Europea se convierta en "la economía basada en el conocimiento más dinámica y competitiva del mundo, capaz de un crecimiento económico duradero, creador de empleo y dotado de una mejor cohesión social”.

Dos años más tarde, en la Cumbre de Barcelona, de Marzo de 2002, conscientes de la enorme y creciente diferencia existente entre las inversiones en investigación, desarrollo tecnológico e innovación $(\mathrm{I}+\mathrm{D}+\mathrm{i})$ de la Unión Europea y las de sus principales competidores (Estados Unidos y Japón), acordaron un nuevo objetivo que ayudase a conseguir el de Lisboa: aumentar el gasto global en $\mathrm{I}+\mathrm{D}+\mathrm{i}$, con la finalidad de alcanzar 
el 3\% del PIB en 2010. Dos tercios de esta nueva inversión deberían provenir del sector privado.

El primero de Agosto de 2003, la COMISIÓN EUROPEA [2003a: 25-27], en su acción piloto "Regiones del Conocimiento" en el ámbito del desarrollo tecnológico, la cooperación entre universidades y la investigación de ámbito regional, reconocía, explícitamente, que la mejora del conocimiento y una mayor difusión de la tecnología a nivel regional pueden ser una de las vías más eficaces del crecimiento económico, y que la proximidad geográfica, al seguir constituyendo uno de los principales factores que favorecen los intercambios intelectuales, comerciales $y$ financieros, influye poderosamente en el proceso de innovación.

Consecuentemente, evidenciaba que las regiones (motores del crecimiento económico) serán las claves para lograr los anteriores objetivos de Lisboa y Barcelona. Éstas constituyen la base espacial de las agrupaciones de operadores de investigación e innovación (clusters), formados a su vez por empresas innovadoras, universidades, centros de investigación, organismos de desarrollo local y otras entidades de apoyo.

Las estructuras de las referidas agrupaciones constituyen una base de desarrollo de conocimientos que permite consolidar infraestructuras, al tiempo que añade una dimensión cultural. Son un ejemplo de creación de redes en las que las partes establecen sólidas e interdependientes relaciones, que varían desde la transferencia de conocimientos o las transacciones económicas, hasta los simples contactos personales, en cuyo caso tienen como efecto colateral la transmisión casual de conocimientos.

Las más eficaces son, a juicio de la Comisión, las que cuentan con enlaces multisectoriales y organizaciones de diversos perfiles; las que combinan la industria, la administración pública y organizaciones no gubernamentales, además de otros agentes relacionados con la ciencia (universidades, centros de investigación, parques tecnológicos, polos de desarrollo tecnológico, entidades innovadoras que actúen como centros de servicios y centros de competencia y difusión). 
Conscientes de estas apreciaciones y de que en la Comunidad Autónoma de Castilla y León existen importantes carencias y dificultades (tanto por la pequeña dimensión de la mayor parte de sus empresas, como por el hecho de que las actividades empresariales de corte tradicional son las más comunes), la presente Tesis Doctoral: Evaluación del Aprendizaje Organizativo en los Centros Tecnológicos y Gestión del Conocimiento Sectorial en Castilla y León, persigue alcanzar los tres objetivos siguientes, con la firme convicción de que las innovaciones, actualizaciones e implantaciones de tecnología constituyen una de las bases de la competitividad empresarial de la referida Comunidad:

I. Modelizar el Aprendizaje Organizativo, con el doble propósito de generar competencia y competitividad en $\mathrm{I}+\mathrm{D}+\mathrm{i}$ en los Centros Tecnológicos de Castilla y León, y que las mismas reviertan a las empresas a las que prestan servicios. El modelo elaborado será extrapolable a otros Centros Tecnológicos nacionales, con la simple obtención de las medidas que proponen los indicadores y factores que lo constituyen.

II. Contribuir a acrecentar el éxito de los Centros Tecnológicos en la implantación industrial de prototipos, procesos y metodologías fruto de la investigación científico-técnica, con especial incidencia en la automatización de procesos (al ser los que generan mayores beneficios). Este hecho redundará en una mayor demanda de proyectos, en la integración en redes europeas de ciencia y tecnología, y en la consiguiente generación de actividades de $\mathrm{I}+\mathrm{D}+\mathrm{i}$ que contribuyan al sostenimiento y ampliación económica de los Centros Tecnológicos de Castilla y León.

III. Que dichos centros obtengan primacía y relevancia a escala nacional en el ámbito de la Gestión del Conocimiento y el Capital Intelectual, de forma paralela y complementaria a la Gestión de la Innovación. 
Para cumplir con estos objetivos, el trabajo se ha dividido en 7 capítulos:

- El primero se dedica al estudio teórico del conocimiento y su producción, acercándonos a su conceptualización, a su localización, a su obtención, transmisión y posible medición.

- El segundo, describe la base de conocimiento de Castilla y León, determinándose cómo se articula su Sistema de Conocimiento, qué especificidades locales y sectoriales presenta, y cuál es la acción institucional en aquél.

- En el tercero se establecen los nexos entre el Aprendizaje Organizativo, la Gestión del Conocimiento y el Capital Intelectual, caracterizando y contextualizando el primero en los Centros Tecnológicos y justificando la necesidad de su modelización dinámica.

- El cuarto articula el modelado de la evolución del Aprendizaje Organizativo, a fin de obtener indicadores de la consistencia o inconsistencia de las labores desarrolladas por los Centros Tecnológicos y su continuidad. Para ello, se emplearán y relacionarán la Teoría General de Sistemas, el concepto de Entropía, la Teoría del Caos, la Teoría de los Sistemas Alejados del Equilibrio y la Teoría de la Autopoiesis.

- El quinto establece los actores psico-sociológicos que discurren como actuadores del Aprendizaje Organizativo para un Centro Tecnológico, en sus acepciones interna y externa.

- En el sexto, los actores psico-sociológicos se correlan con una serie de indicadores relacionados con información datada y accesible en un Centro Tecnológico, en sus respectivas vertientes interna y externa. De esta manera, se da lugar a una formulación pragmática y objetiva para la valoración entrópica de la evolución del Aprendizaje Organizativo en dichas organizaciones. 
- Por último, el objetivo del séptimo capítulo es, de forma complementaria a los anteriores, establecer las directrices para la Gestión del Conocimiento en las Pequeñas y Medianas Empresas (PYMEs 5 ) castellanas y leonesas que se enmarcan en los tres principales sectores estratégicos de la economía regional: agroalimentario; automoción; y tecnologías de la información y de las comunicaciones.

El hilo conductor global parte del enfoque mixto del cambio y del conocimiento en el Aprendizaje Organizativo. A él se aplica, contextualmente, la Dinámica de Sistemas y las Ciencias de la Complejidad, bajo la consideración de que los Centros Tecnológicos constituyen la fuente de la que manan las capacidades competitivas y de adecuación a las nuevas tecnologías de las pequeñas y medianas empresas regionales que solicitan sus servicios. Esta tarea es, a su vez, factible si, como se observa en el modelo entrópico que se propone, crece y prolifera el Aprendizaje Organizativo en dichos Centros, como base para una adecuada Gestión del Conocimiento, y como filosofía extensiva a las PYMEs más representativas de los sectores clave en los que se apoya la economía de Castilla y León.

\footnotetext{
${ }^{5}$ La Comisión Europea aplica la definición europea actualizada de PYME, adoptada en mayo de 2003 (Comisión Recommendation 2003/361/EC), y que se empezó a utilizar a partir del 1 de Enero de 2005, donde las micropymes son un caso particular.
}

Dicha definición mantiene los límites de número de empleados que definen las categorías de microempresa y de PYME como tal, fijados en la anterior (y primera) definición de la Comisión, de Abril de 1996, a la que sustituye. Sin embargo, eleva considerablemente los límites financieros (volumen de negocio y balance general), debido al incremento de la inflación y de la productividad desde 1996.

\begin{tabular}{|c|c|c|c|}
\hline Categoría de empresa & $\begin{array}{c}\text { Número de empleados } \\
\text { (no varía) }\end{array}$ & Volumen de negocio & Balance general \\
\hline Mediana empresa & $<250$ & $\begin{array}{c}\leq 50 \text { millones de } € \\
\text { (en 1996: 40 millones) }\end{array}$ & $\begin{array}{c}\leq 43 \text { millones de } € \\
\text { (en 1996: 27 millones) }\end{array}$ \\
\hline Pequeña empresa & $<50$ & $\begin{array}{c}\leq 10 \text { millones de } € \\
\text { (en } 1996: 7 \text { millones) }\end{array}$ & $\begin{array}{c}\leq 10 \text { millones de } € \\
\text { (en 1996: 5 millones) }\end{array}$ \\
\hline Microempresa & $<10$ & $\begin{array}{c}\leq 2 \text { millones de } € \\
\text { (sin definir en 1996) }\end{array}$ & $\begin{array}{c}\leq 2 \text { millones de } € \\
\text { (sin definir en 1996) }\end{array}$ \\
\hline
\end{tabular}

La definición de la UE de PYME debe ser aplicada por todos los organismos comunitarios: el Banco Europeo de Inversiones (BEI) y el Fondo Europeo de Inversiones (FEI), y en el contexto de los programas la legislación comunitaria. Además, recomienda a los Estados miembros su utilización. 
Capítulo I:

Precisiones Conceptuales 
Pedro Martín Lerones Evaluación del Aprendizaje Organizativo en los Centros Tecnológicos y Gestión del Conocimiento Sectorial en Castilla y León 


\section{I.1. Introducción: Consideraciones Iniciales}

El conocimiento es un concepto complejo, amplio y abstracto que, desde la antigua Grecia ${ }^{6}$, ha generado numerosos debates en la filosofía occidental sobre cómo acceder a él, cómo generarlo y qué métodos podían considerarse adecuados para su validación o verificación.

Además, desde que Sidney Winter pusiera de manifiesto, en 1987, la existencia de una "insuficiencia de lenguaje" y "una carencia importante de la terminología y de los esquemas conceptuales apropiados" para analizar el papel que desempeña en la economía, apenas se ha progresado en la definición de una terminología aceptable en este sentido [Lundvall-1999:16], aún cuando el número de publicaciones relevantes al respecto venga aumentado de forma considerable.

El objetivo de este capítulo consiste en introducir algunos conceptos y definiciones que sustenten la presente Tesis Doctoral.

\section{I.2. El Concepto de Conocimiento}

Definir el conocimiento no resulta fácil, por cuanto, al ser un concepto multidimensional que ha ido variando con el transcurso del tiempo, puede llevarse a

\footnotetext{
${ }^{6}$ Aunque existen antecedentes aún más remotos relacionados con la teoría del conocimiento (sofistas y atomistas), probablemente fue Platón quien formuló y desarrolló, junto con Sócrates, allá por el siglo $\mathrm{V}$ a.C., la primera teoría detallada del conocimiento, respondiendo, de esta forma, a los sofistas que cuestionaban la posibilidad de un conocimiento fiable y objetivo. Ambos creían que este último, innato al individuo e independiente de cualquier tipo de experiencia particular, era alcanzable por medio de la razón y algo más que la mera opinión [Montuschi-2001a: 5-6]. Las ideas o formas, propiedades abstractas no materiales, eternas e inmutables que existen en el alma de cada persona aún antes de su nacimiento, constituían los objetos de aquél. Aristóteles, discípulo de Platón, coincidió con su maestro en que el conocimiento abstracto era superior a cualquier otro tipo de conocimiento, pero discrepaba en cuanto al método adecuado para alcanzarlo. A él se llegaba a través de un proceso de abstracción y constituía el "conocimiento básico", fundamento de todo el conocimiento. Permitía derivar, de acuerdo con las "reglas de la lógica", tres conceptos o formas diferentes, a partir de objetos concretos: epistèmé (conocimiento universal y teórico); technè (conocimiento instrumental, en un contexto específico y relacionado con la práctica); y phronesis ("sabiduría práctica", conocimiento normativo basado en la experiencia, en un contexto específico y relacionado con el sentido común) [Lundvall-1999: 18]. Obsérvese, entonces, que Aristóteles fue ya el primero en marcar la distinción entre Ciencia (derivada de epistèmé) y Tecnología (derivada de technè).
} 
cabo desde múltiples perspectivas (biológica, psicológica, sociológica, filosófica o epistemológica y económica), que se relacionan y complementan en una estructura lógica, propia del sistema que configuran.

Desde un punto de vista epistemológico ${ }^{\text {}}$, es una especie de creencia (lo que uno no cree, no puede ser conocimiento). Además, tiene que ser verdadera (las creencias incorrectas tampoco se pueden considerar conocimiento) y debe estar justificada. Contiene, por tanto, una serie de elementos subjetivos y objetivos [Hansson-2002: 48].

Implica la conciencia de un objeto (una cosa, un hecho, un principio), que puede pertenecer al orden físico, mental o metafísico; presupone un juicio implícito o explícito; puede ser alcanzado de forma inmediata (a priori), o a través de la investigación, la observación y el pensamiento (a posteriori); y ha de reunir dos condiciones indispensables: la verdad y la certidumbre. Puede definirse, entonces, como el proceso humano y dinámico que consiste en justificar una creencia personal hacia la certeza.

Es, fundamentalmente, una capacidad cognoscitiva ${ }^{\mathrm{B}}$. Capacita a las personas para realizar actividades intelectuales o manuales a partir de la información disponible. No debe confundirse, por tanto, con esta última [Nonaka y Byosiere-2000; Vilaseca Requena, Torrent i Sellens y Lladós-2001; David y Foray-2002], es decir con el flujo de mensajes anclado a las convicciones del sujeto a partir del que se genera el conocimiento; con el conjunto de datos, estructurados y formateados, pero inertes e inactivos hasta que no se utilizan por quienes tienen el conocimiento suficiente para interpretarlos y manipularlos. Las principales diferencias entre información y conocimiento han sido señaladas por Rivero Rodrigo [2000: 8] de la forma siguiente:

\footnotetext{
${ }^{7}$ La epistemología (teoría del conocimiento), expresión acuñada durante la primera mitad del siglo XIX en Alemania, constituye una de las áreas básicas de la filosofía analítica contemporánea, que se ocupa de la naturaleza, los fundamentos, las condiciones de posibilidad y los límites del conocimiento [Vilaseca Requena, Torrent i Sellens y Lladós-2001: 10].

${ }^{8}$ Ocupa el más bajo de los seis niveles cognoscitivos que fijaba, en 1956, la "taxonomía de Bloom" en materia de objetivos educacionales: comprensión, aplicación, análisis, síntesis, evaluación y conocimiento. Los cinco niveles superiores constituyen las "capacidades y habilidades intelectuales" que permiten a la persona operar con los contenidos archivados en su mente [Montuschi-2001a: 2-3].
} 
- La información no confiere una capacidad a quien la ostente, como sí lo hace el conocimiento.

- La información puede existir en sí misma, sin un sujeto que la posea, elemento, este último, imprescindible en el conocimiento.

- La transmisión de la información puede ser inmediata, sólo requiere un soporte adecuado. En cambio, la del conocimiento implica un proceso de enseñanza, en el que desempeña un importante papel la experimentación.

La información y el conocimiento aparecen en la literatura económica en dos contextos microeconómicos diferentes: (a) como base de las decisiones racionales de los agentes económicos individuales y (b) como activo productivo (factor y producto, a la vez), en cuyo ámbito resultan fundamentales las propiedades de transferibilidad en el espacio, en el tiempo y entre las personas.

Todo ello conforma dos corrientes de pensamiento ${ }^{0}$ que, aunque puedan parecer contrarias, plantean las mismas cuestiones: ¿puede o no transferirse el conocimiento?, ¿es fácil o difícil de transferir? y ¿cuáles son los mecanismos de transmisión?. A su resolución contribuyen los diferentes tipos de conocimiento que se analizan a continuación.

\section{I.2.1. Clases de Conocimiento}

En función del nivel que se tome en consideración, el conocimiento humano puede clasificarse en cinco categorías principales: común u ordinario (experiencia vital), técnico o profesional (praxiológico), pseudocientífico (emocional-ideológico), científico (teórico) y filosófico (lógico-semántico) [Bueno-2003: 15]. Se trata de formas diferentes de observar los dos tipos fundamentales de conocimiento que se derivan del enfoque

\footnotetext{
${ }^{9}$ Una se refiere a la dimensión público/privada del conocimiento y al papel que desempeña el gobierno en su generación. La otra, a la formación de los distritos industriales y al carácter local del conocimiento [Lundvall-1999: 16-17].
} 
propuesto por el químico-filósofo-economista Michael Polanyi [1958, 1966] sobre su concepción $\frac{10}{10}$ el conocimiento explícito y el conocimiento tácito. Ambos tipos hacen referencia al grado en que algunos de los elementos que lo componen pueden ser escritos y transferidos.

El primero (explícito) es el conocimiento objetivo y racional y puede ser expresado en un lenguaje formal y sistemático (palabras, oraciones, números,...). Es fácil de transmitir a través de la interacción social (tipo aprendiz-maestro) y, frecuentemente, está disponible a un precio bajo o inexistente. Se suele identificar, también, como conocimiento codificado, puesto que se caracteriza por el desarrollo de una serie de normas o estándares que permiten su interpretación.

El segundo (tácito), es el exponente de un conocimiento personal, no articulado, difícil de formalizar y comunicar. Cuenta con elementos técnicos y cognoscitivos basados en la experiencia, habilidades prácticas de todo tipo, creencias, imágenes, estrategias cognitivas más o menos inconscientes (intuiciones, modelos mentales,...), supuestos filosóficos difíciles de expresar, talento para la comunicación, etc. No está codificado y ha recibido también distintas denominaciones, tales como "conocimiento individual implícito" o "conocimiento incorporado".

Ambos tipos de conocimiento se complementan [Nonaka y Takeuchi-1995] y su interacción es evolutiva [Spender-1996], por cuanto las decisiones de los individuos se toman según convenga a cada realidad histórica y económica específica. De este modo, la frontera entre ellos es porosa y flexible, permitiendo el movimiento entre sus

\footnotetext{
${ }^{10}$ Se basa en tres tesis:
}

- Un conjunto articulado de reglas o algoritmos no alcanza para explicar el descubrimiento verdadero.

- El conocimiento es público y, dado que es construido por seres humanos, es personal en gran medida y contiene emociones; y

- Existe un conocimiento que subyace en el explícito y que es más fundamental que él mismo: es el conocimiento tácito.

Polanyi sostiene que todo el conocimiento es tácito o está enraizado en él. 
dominios. Sus distintas manifestaciones o vertientes, susceptibles de comparación entre sí, figuran en la Tabla 2.

TABLA 2

MANIFESTACIONES DEL CONOCIMIENTO TÁCITO Y EXPLÍCITO

\begin{tabular}{||c|c||}
\hline Conocimiento Tácito & Conocimiento Explícito \\
\hline \hline Experimental (incorporado) & Racional (vinculado a la mente) \\
Simultáneo (relativo al aquí y ahora) & Secuencial (relativo al allí y entonces) \\
Analógico (derivado de la práctica) & Digital (vinculado a la teoría) \\
\hline
\end{tabular}

FUENTE: Nonaka, Toyama y Byosière [2001]

Otros autores [Lundvall y Johnson-1994; OCDE-1996] han propuesto cuatro modalidades de conocimiento que tienen, de hecho, sus raíces en la filosofía griega: saber qué (know-what), saber por qué (know-why), saber cómo (know-how) 11 y saber quién (know-who).

El "saber qué" se refiere al conocimiento de los hechos. Está próximo a lo que comúnmente se denomina información y es el más fácil de transferir. El "saber por qué" se refiere al conocimiento de los principios y las leyes de la naturaleza, la mente humana y la sociedad. El "saber cómo", a las cualificaciones, a las habilidades o

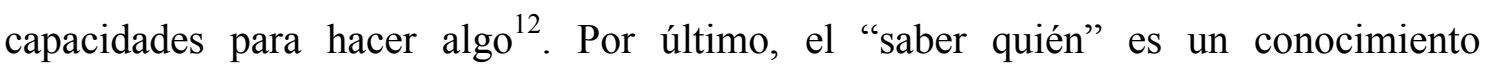
socialmente incorporado que implica información sobre quién sabe qué y quién sabe hacer qué, así como la capacidad social para cooperar y comunicarse con distintas clases de personas y expertos.

Las dos primeras modalidades (know-what y know-why) pueden obtenerse a través de libros, informes y bases de datos. Además, han sido identificadas por algunos autores con el conocimiento codificado. En cambio, las dos últimas (know-how y know-who) se

\footnotetext{
${ }^{11}$ Aunque la correspondencia no sea del todo completa, el know-why sería similar al epistèmé aristotélico y el know-how equivaldría al technè. La phronesis, tercera de las categorías de Aristóteles, se relacionaría con la ética y la importancia de la confianza en el ámbito del aprendizaje.

${ }^{12}$ La capacidad, sinónimo de aptitud y suficiencia, no debe confundirse con la habilidad, entendida como destreza o maña, puesto que esta última requiere de la primera para realizarse.
} 
generan mediante la experiencia práctica y se asimilan con el tácito [Montuschi-2001: 18-19; Medellín Cabrera-2002: 4].

No obstante, desde las dos últimas décadas del siglo pasado venimos siendo testigos de excepción, a la vez que actores, de una incesante espiral de nuevos conocimientos, conceptos, términos y signos, más o menos claros y evidentes, que se han ido integrando en las hélices de la economía actual, propiciando más y más complejidad, confusión y moda, tanto intelectual como profesional, generando, de forma acelerada, un cierto desorden cognitivo y semántico. Con el fin de ayudar a eliminar este desorden, el profesor Bueno Campos [2001a: 36-38] ha propuesto una estructura teorética piramidal de seis niveles (Figura 2), para facilitar la superación de la citada "jungla semántica" y vertebrar los conceptos fundamentales, ya de por sí interconectados, a través de un conjunto de relaciones lógico-semánticas.

\section{FIGURA 2}

\section{LA PIRÁMIDE DE LA INTELIGENCIA HUMANA}

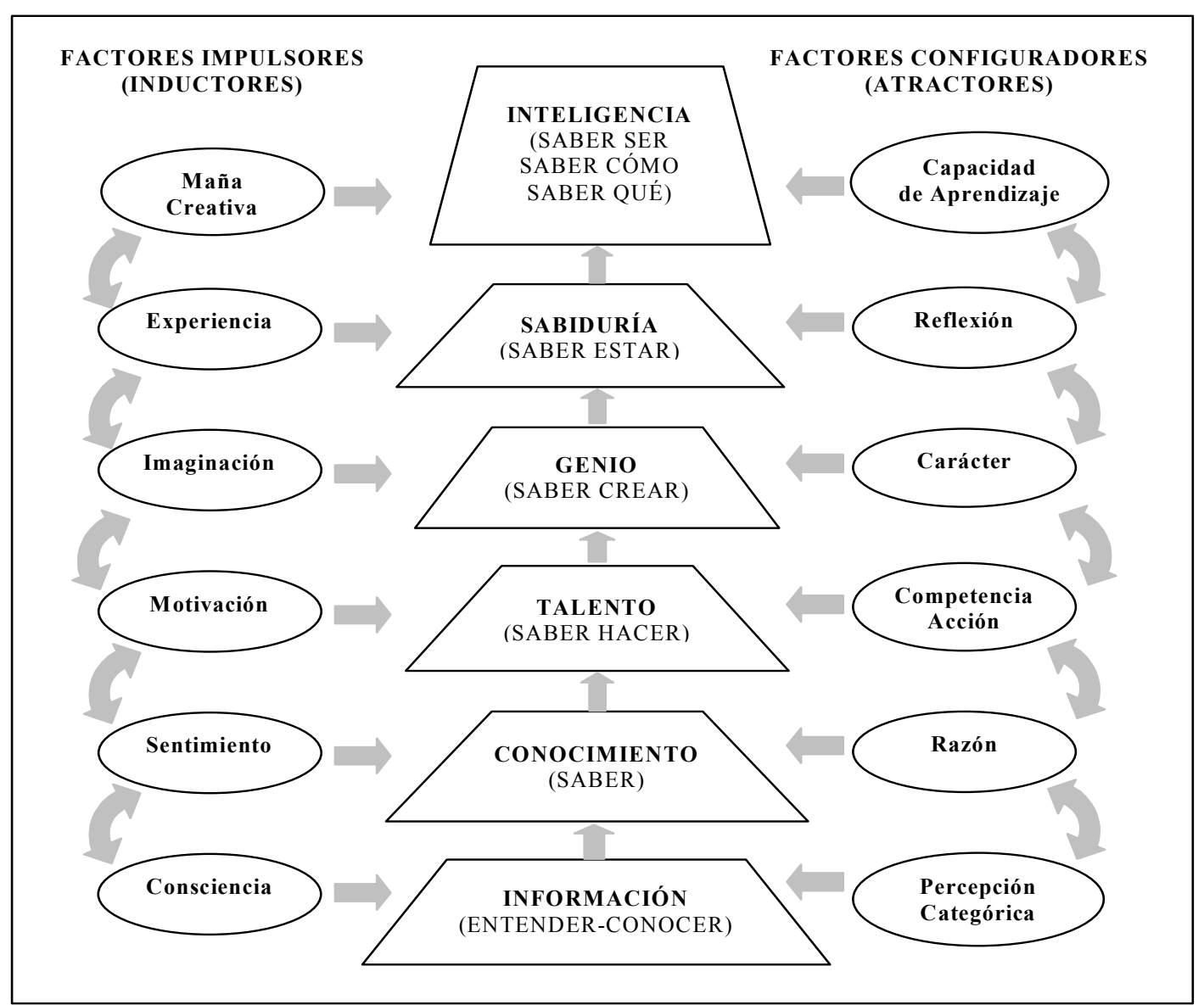

FUENTE: Bueno Campos [2001a: 37] 
En el primer nivel (parte inferior de la referida estructura) sitúa la información, concepto que asocia a la función de entender y conocer a partir del conjunto de datos estructurados o con significado para el sujeto en un momento concreto. En el segundo, el conocimiento, como función de saber, algo más que entender en su dimensión básicamente epistemológica. En el tercero, el talento, como función del saber hacer, algo más que saber. En el cuarto, el genio, como función de saber crear, dependiendo del carácter de la persona. En el quinto, la sabiduría, como función del saber estar del sujeto. Por último, en el sexto, la inteligencia, como función del saber ser, del saber cómo y del saber qué; concepto que resume las escalas conceptuales anteriores y que implica una amplia gama de habilidades y aspectos: es la capacidad de salirse de los límites del instinto y generar nuevas soluciones a los problemas [Gould y Gould-1994].

\section{I.3. Localización del Conocimiento}

Algunos investigadores, como Nonaka y Takeuchi [1995] o Grant [1996], consideran que sólo el individuo es capaz de crear conocimiento en sentido estricto, y relegan a las organizaciones y demás colectivos sociales a su simple aplicación.

Otros [Nelson y Winter-1982; Spender-1996; Nahapiet y Ghoshal-1998; Lam-2000], en cambio, extienden la capacidad para generar conocimiento y el aprendizaje también a las organizaciones. Se plantea entonces la cuestión de si los distintos niveles colectivos tienen o no una identidad propia, distinta de la simple colección coordinada de entidades creadoras de conocimiento de orden menor [Kogut y Zander-1996].

Varias razones justifican la adopción de esta segunda postura [Martín De Castro, López Sáez y Navas López-2004: 27-28]:

(1) Si los grupos de personas están formados por individuos y éstos tienen la capacidad de crear conocimiento, aquéllos (grupos) poseen las mismas propiedades que los elementos que los componen (individuos). Consecuentemente, las organizaciones, como conjunto de diferentes equipos, 
grupos o departamentos, son, también, capaces de crear conocimiento. Asimismo, el entorno en el que se ve inmersa la empresa, como sistema de orden máximo, formado por distintas organizaciones y agentes con los que tiene contacto, puede considerarse, igualmente, una entidad creadora de conocimiento a la que se puede atribuir la capacidad de aprendizaje.

(2) La combinación de conocimientos tiene un carácter sinérgico. Supone un incremento de la productividad de los conocimientos especializados de los individuos y da lugar a elementos de conocimiento superiores a la simple suma de los subelementos en los que se basan.

El proceso de creación de conocimiento puede desarrollarse, por tanto, en cuatro niveles ontológicos: el individuo, el grupo, la organización y el entorno interorganizativo. Dentro de estos niveles se incluyen los conocimientos especializados de las unidades que los integran, así como los conocimientos relativos a la forma de coordinarlos.

Distinguir entre estos cuatro niveles implica considerar que cada uno de ellos tiene objetivos propios y unas capacidades características para la creación de conocimiento. Se ordenan, según Kogut y Zander [1996], mediante una lógica sistémica: los objetivos de un nivel inferior constituyen subobjetivos para los niveles superiores que lo contienen; y la formación de las capacidades de los niveles superiores se realiza a través de la apropiada combinación y coordinación de las de los niveles inferiores.

En este contexto, y como se expondrá detalladamente en el capítulo IV, las organizaciones son sistemas abiertos (sin fronteras), multi-niveles, que no se dedican a la simple captación de factores productivos, sino al mantenimiento de relaciones orgánicas y dinámicas con otras entidades que producen y aplican conocimiento [Spender-1996]. Aunque este último tiene su origen en los individuos, su condición de miembros de una organización hace que no deban ser contemplados aisladamente, sino como integrantes de una red de relaciones más o menos estructuradas, en la que los conocimientos son compartidos por medio de la interacción hasta llegar a trascender a la organización. Ésta constituye, por tanto, un medio eficiente para la transferencia y creación de conocimiento [Kogut y Zander-1992]. 


\section{I.4. La Producción y Transmisión de Conocimiento}

El conocimiento en un entorno geográfico dado se desarrolla y difunde a través de lo que se denomina el Sistema de Conocimiento, una estructura que integra la Investigación (I), el Desarrollo Tecnológico (D) y la Innovación (i) (Anexo A), es decir, las interacciones que se producen entre el sistema científico (representado por la universidad y los centros de investigación), el sistema tecnológico (centros de desarrollo y transferencia tecnológica entre la universidad y la industria), el sistema productivo (la industria en sentido amplio) y el sistema institucional (instituciones públicas y privadas existes en un territorio concreto) (Figura 3).

FIGURA 3

EL SISTEMA DE CONOCIMIENTO (I+D+i)

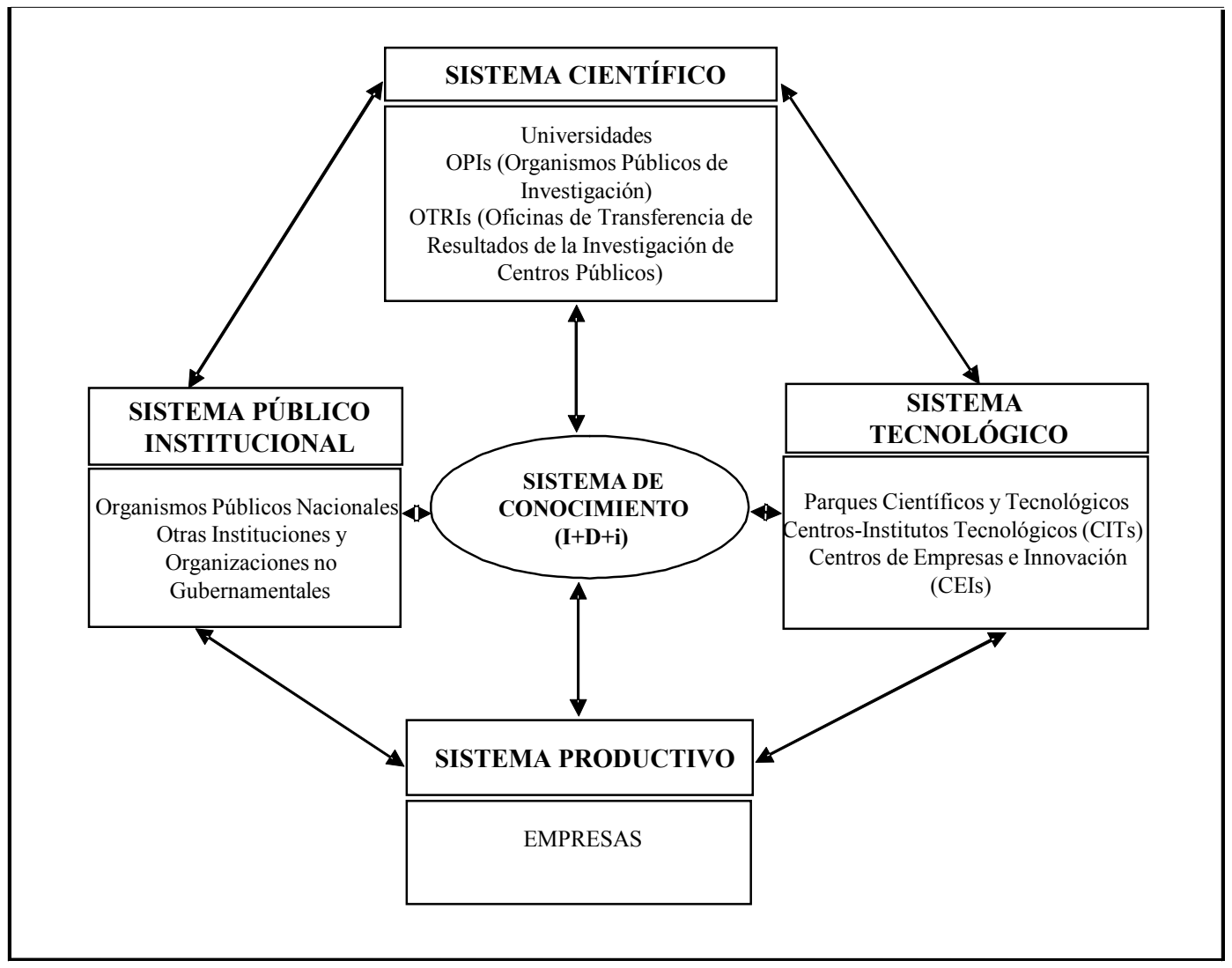

FUENTE: Bueno Campos [2001a: 26]

Las organizaciones del Sistema Ciencia-Tecnología-Industria, las del Sistema PúblicoInstitucional de Innovación, las personas y los grupos (esto es, los directivos y empleados de las organizaciones, así como los ciudadanos y colectivos sociales 
relacionados con ellas) constituyen sus agentes sociales. Juntos configuran el contexto en el que se desarrolla la generación de conocimiento y la innovación. Difieren entre sectores, regiones y países. En general, se especializan de acuerdo con su base de conocimiento. El modo específico de innovación de cada uno refleja las diferencias institucionales existentes y ha cambiado con el transcurso del tiempo (Tabla 3). Las especificidades en la generación de conocimiento reflejan combinaciones únicas de especialización tecnológica y estructura institucional.

En cuanto a los espacios que conforman el Sistema de Conocimiento, cabe diferenciar entre las dos categorías siguientes:

- Ámbitos de creación e intercambio de conocimiento: "bas" organizativos, portales o plataformas webs, parques científicos y tecnológicos, así como mercados de conocimiento.

○ "Bas" organizativos: espacios interpersonales y colectivos para compartir, aprender y crear conocimiento [Nonaka y Kono-1998]. En esta misma línea, se puede hablar también de los "espacios blancos" de las organizaciones [Rummler y Brache-1991], en los que se pueden integrar "comunidades de conocimiento" o determinados modelos cooperativos para compartir las mejores prácticas entre sus miembros [Bueno-2001b].

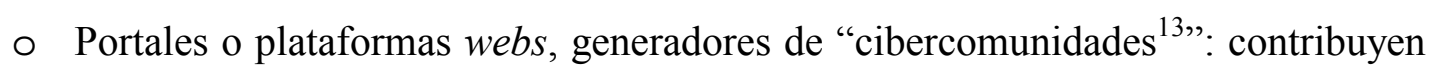
a impulsar el flujo de conocimientos, la recombinación de saberes y la articulación de actores e instituciones, con base en experiencias interactivas [Medina Vásquez-2002: 12]; así como a fortalecer el desarrollo territorial, por cuanto facilitan la creación de espacios regionales de conocimiento, paso previo a la creación de verdaderos sistemas regionales de innovación.

\footnotetext{
${ }^{13}$ Una comunidad virtual se distingue por el intercambio de información entre sus usuarios, relacionado con la calidad de la presencia en internet y, si cabe, el tipo de modelo de negocio empleado. Reviste tres características básicas: un foco de interés específico entre sus miembros, integra contenido y comunicación, y se centra en informaciones procedentes de sus propios participantes [Medina Vásquez2002: 10].
} 
○ Parques científicos y tecnológicos: espacios con centros de investigación e infraestructuras para relacionar las actividades científico-tecnológica y empresarial.

○ Mercados de conocimiento: espacios económicos y organizativos para intercambiar recursos o activos intangibles [Rummler y Brache-1991; Daverport y Prusak-1998; Bueno-2001b].

- Ámbitos de difusión y aplicación de conocimiento: regiones, clusters, ciudades y barrios, empresas y organizaciones, comunidades de prácticas y grupos de trabajo.

- Regiones: el redescubrimiento de la región como base de la vida social y económica coincide, a principios de los años ochenta del siglo XX, con el devenir de modos de producción post-fordista. A partir de entonces, la cuestión territorial ha pasado a ser un elemento central para entender la dinámica de los sistemas productivos e innovativos, $\mathrm{y}$ ha ido cobrando gran fuerza entre los economistas, políticos y organismos internacionales la perspectiva de que el conocimiento se localiza en la región y se enraíza tanto en la mano de obra local, como en las instituciones y organizaciones de la zona [Marshall-1923].

○ Clusters: son, por definición, una concentración geográfica (no necesariamente coincidente con la división política y administrativa vigente en un territorio) de empresas e instituciones interconectadas en torno a un campo particular, cuyos límites los determina la complementariedad existente entre ellas y los sectores a que pertenecen. Promueven una nueva forma de agrupación, distinta a la tradicional, que afecta a la competitividad de las empresas y organizaciones en tres direcciones: incrementando la productividad, dirigiendo y promoviendo la innovación y estimulando la creación de nuevas empresas.

○ Ciudades y barrios: el proceso de generación y difusión del conocimiento tiene unas características típicamente urbanas, como son la creatividad propia de entornos complejos y la fertilización cruzada de ideas entre sectores, actividades o agentes de muy distinta naturaleza [Jacobs-1969]. Las ciudades, como 
acumulación localizada de conocimiento, facilitan esa acción creativa y posibilitan altas cotas de interacción social sobre las que tejer de manera permanente el proceso de generación de nuevo conocimiento [Trullén, Lladós y Boix-2002:142].

○ Empresas y organizaciones: constituyen, igualmente, medios eficientes para la difusión y aplicación del conocimiento.

○ Comunidades de prácticas y grupos de trabajo: las primeras son asociaciones de personas constituidas orgánicamente por sí mismas para intercambiar información y conocimiento o para producir algún tipo de bien o servicio, en el entorno laboral o fuera de él. Su rasgo distintivo es la existencia de relaciones de participación mutua muy densas que se organizan en torno a la práctica que se comparte. Pueden ser consideradas como un tipo especial de equipo, que emplea un lenguaje común y mantiene una dinámica de cooperación que estimula el rendimiento en términos de aprendizaje y trabajo. Reúnen tres características: un compromiso mutuo (conlleva la existencia de una red de relaciones recíprocas, diversas y complejas para hacer algo conjuntamente); una empresa conjunta (implica una responsabilidad mutua, una interpretación común y una respuesta local basada en ritmos propios) y un repertorio compartido (expresa una experiencia común que se ha producido o adoptado con el tiempo, bajo la forma de estilos, discursos, conceptos, instrumentos y acciones que denotan o connotan la identidad de sus miembros) [Medina Vásquez-2002: 8]. 
TABLA 3

CAMBIOS EN LA PRODUCCIÓN DEL CONOCIMIENTO

\begin{tabular}{|c|c|c|}
\hline CARACTERÍSTICAS & MODO TRADICIONAL & $\begin{array}{l}\text { NUEVO MODO DE } \\
\text { PRODUCCIÓN }\end{array}$ \\
\hline $\begin{array}{l}\text { Definición y solución de } \\
\text { Problemas }\end{array}$ & $\begin{array}{l}\text { En relación con las normas } \\
\text { cognitivas y } \\
\text { gobiernan la investigación } \\
\text { básica o la ciencia } \\
\text { académica }\end{array}$ & $\begin{array}{l}\text { En el contexto de aplicaciones } \\
\text { concretas, útiles para los diversos } \\
\text { intereses de los agentes implicados } \\
\text { (industria, gobierno y sociedad en } \\
\text { general) }\end{array}$ \\
\hline Investigación & $\begin{array}{l}\text { Disciplinar. } \\
\text { Producción de conocimiento } \\
\text { homogénea }\end{array}$ & $\begin{array}{l}\text { Transdisciplinar. } \\
\text { Producción de conocimiento } \\
\text { heterogénea }\end{array}$ \\
\hline Organización & $\begin{array}{l}\text { Jerárquica. } \\
\text { Especializada (por tipo de } \\
\text { institución) }\end{array}$ & $\begin{array}{l}\text { El conocimiento se crea en una gran } \\
\text { variedad de organizaciones e } \\
\text { instituciones (laboratorios, institutos, } \\
\text { empresas multinacionales, } \\
\text { universidades, etc.), nacionales e } \\
\text { internacionales, de carácter } \\
\text { transitorio. No está institucionalizado }\end{array}$ \\
\hline Difusión de resultados & 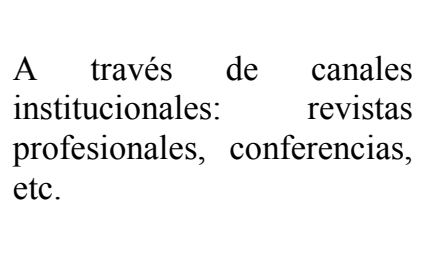 & $\begin{array}{l}\text { Primero se difunden a los que han } \\
\text { participado en su generación. Después } \\
\text { entran a formar parte de otras } \\
\text { configuraciones, a medida que sus } \\
\text { pioneros abordan nuevos problemas } \\
\text { en contextos diferentes }\end{array}$ \\
\hline Financiación & Esencialmente institucional & $\begin{array}{l}\text { A partir de múltiples organizaciones, } \\
\text { públicas y privadas, que muestran una } \\
\text { gama muy diversa de exigencias y } \\
\text { expectativas }\end{array}$ \\
\hline Evaluación de impacto social & $\begin{array}{l}\text { Ex-post, en el momento de } \\
\text { la interpretación o de la } \\
\text { difusión de resultados }\end{array}$ & $\begin{array}{l}\text { Ex-ante, en la definición de problemas } \\
\text { y en el establecimiento de las } \\
\text { prioridades de investigación. La } \\
\text { responsabilidad social impregna todo } \\
\text { el proceso de producción de } \\
\text { conocimiento }\end{array}$ \\
\hline Control de calidad & $\begin{array}{l}\text { Se determina, } \\
\text { fundamentalmente, por los } \\
\text { juicios emitidos por los } \\
\text { compañeros en la revisión } \\
\text { de las contribuciones hechas } \\
\text { por los individuos. Para ello, } \\
\text { se realiza una cuidadosa } \\
\text { selección de quienes se } \\
\text { juzgan competentes para } \\
\text { actuar como iguales, lo que } \\
\text { viene determinado, en parte, } \\
\text { por sus contribuciones } \\
\text { previas a la disciplina }\end{array}$ & $\begin{array}{l}\text { La calidad viene determinada por un } \\
\text { conjunto más amplio de criterios que } \\
\text { refleja la amplia composición social } \\
\text { del sistema de revisión. Su proceso de } \\
\text { control incorpora una diversa gama de } \\
\text { expertos (intelectuales, sociales, } \\
\text { económicos o políticos) relacionados } \\
\text { con los problemas a solucionar }\end{array}$ \\
\hline
\end{tabular}

FUENTE: Adaptado de Gibbons et al. [1997: 11-21] 


\section{I.5. El Conocimiento como Recurso Estratégico}

La consideración de la empresa como un sistema abierto, en permanente contacto con su entorno, supuso, durante varias décadas, que los factores externos a ella (competidores potenciales, productos sustitutivos, proveedores, etc.) fueran los determinantes fundamentales de su competitividad. Dichos factores no explicaban, sin embargo, las diferentes rentabilidades que obtenían numerosas organizaciones situadas en el mismo entorno competitivo, por lo que empezaron a tenerse en cuenta sus propias condiciones internas para justificar las diferencias.

Es en este contexto cuando empieza a cobrar especial relevancia en la literatura económica de los años ochenta del siglo XX la Teoría de los Recursos y Capacidades, al centrar su atención en el análisis de los activos que poseen las organizaciones en un momento determinado, en las diferentes características que presentan, y en la importancia que tienen para explicar sus resultados [Wernerfelt-1984]. Considera a la empresa como una combinación única de recursos y capacidades, tangibles e intangibles, de carácter diverso (Figura 4).

El conocimiento es uno de esos recursos, con características específicas que dificultan su imitación y su transferencia. Éste ha ido acaparando, gradualmente, la atención de todas las organizaciones, al reunir todo un conjunto de requisitos que lo hacen especialmente importante para ellas: se puede almacenar, utilizar, movilizar y desarrollar.

Además, constituye su principal fuente de diferenciación en un entorno altamente complejo, dinámico y de difícil predicción, cada vez más competitivo y global; produce beneficios sustanciales; permite innovar; y otorga a las empresas posiciones de ventaja en el mercado, de forma sostenida en el tiempo.

Se trata, por tanto, de un recurso estratégico en la creación de valor en la organización que se concreta en un conjunto de factores inmateriales agrupados bajo la denominación de Capital Intelectual y que puede revestir múltiples formas, tales como: 


\section{FIGURA 4}

RECURSOS, CAPACIDADES Y VENTAJAS COMPETITIVAS

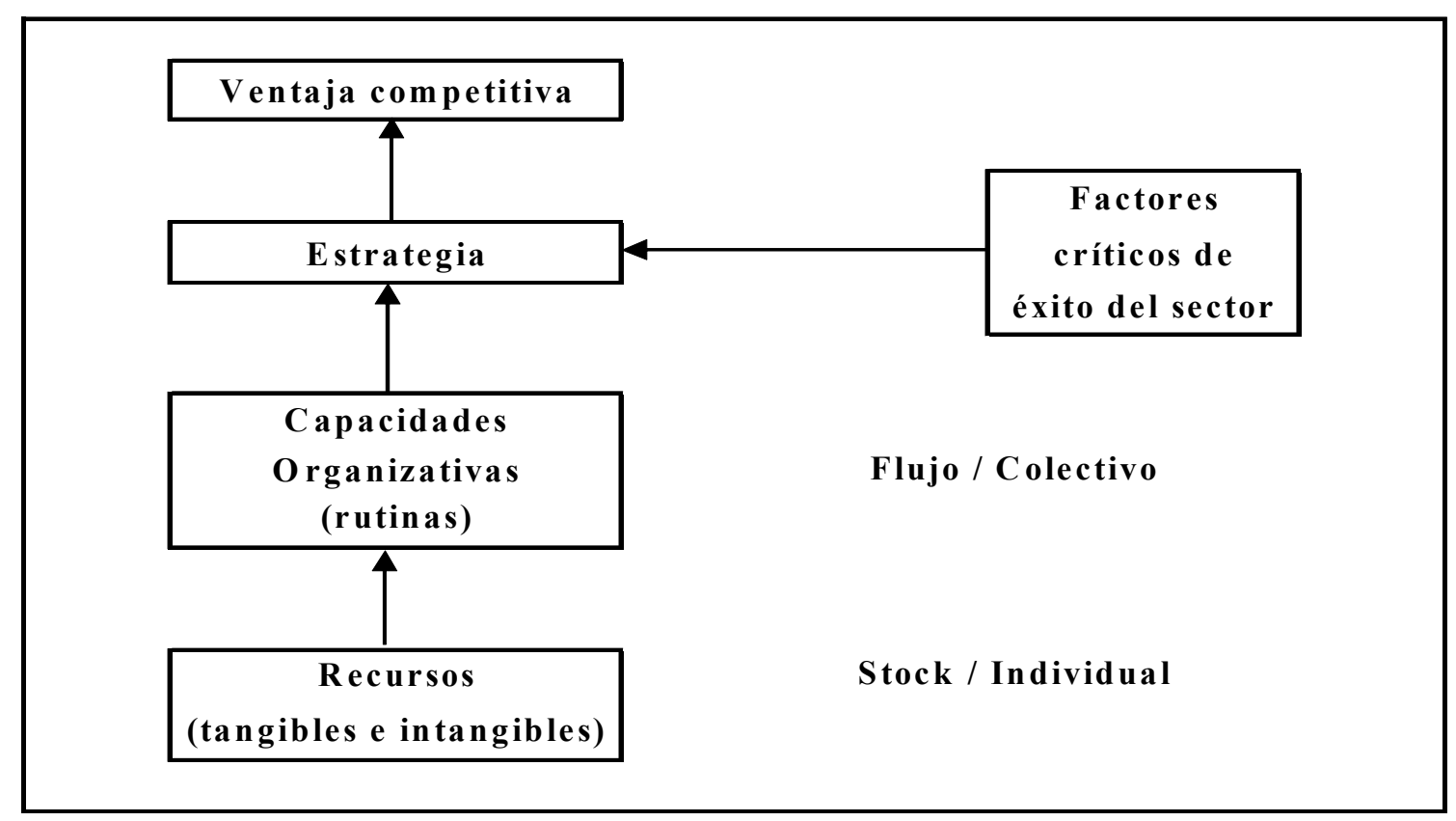

FUENTE: Grant [1996]

- Conocimiento individual y colectivo: las personas, a nivel individual, utilizan, en función del contexto en que se mueven, capacidades básicas, modelos mentales, escalas de valores, esquemas de evaluación y planes de acción para afrontar las situaciones que se les presentan. Análogamente, el conocimiento colectivo es la capacidad de un grupo de individuos para afrontar las situaciones que tienen ante sí.

- Conocimiento externo e interno: el primero tiene su origen en las necesidades de los potenciales clientes y exige una constante atención al mercado para identificar nuevas oportunidades. El segundo es característico de cada organización [Andreu y Sieber-1999: 66].

- Conocimiento declarativo, procesal y causal: el declarativo es descriptivo y señala qué es algo. El procesal indica cómo debe ser realizada una determinada actividad, en tanto que el causal explica por qué ocurre un determinado hecho [Gallupe-2001].

- Conocimiento contenido y esquemático: este último no existe en ausencia de un contexto organizativo, mientras que el conocimiento contenido no depende de la 
existencia de una organización, dado que reside en sus empleados, clientes, etc. [Holsapple y Joshi-1999].

\section{I.5.1. El Capital Intelectual}

El Capital Intelectual (Intellectual Capital) es el conocimiento organizativo, es decir, el conocimiento acumulado por la empresa en un determinado periodo de tiempo en relación con sus productos, servicios, procesos, mercados y clientes. Es una interpretación de la información basada en la experiencia, habilidades y competencias [Bollinger y Smith-2001: 9].

Engloba activos intangibles y capacidades estratégicas valiosos $\frac{14}{14}$ que no aparecen valorados en los documentos contables y que, en ocasiones, ni siquiera están correctamente identificados por los gestores de la empresa. Son heterogéneos, difíciles de medir y además tienen la capacidad de generar valor añadido e importancia específica para cada organización (Tabla 4).

En función de su contenido básico, puede revestir diversas formas: capital humano (genérico y específico), capital estructural (organizativo y tecnológico) y capital relacional (de negocio o comercial y social o comunicacional), aunque, como han puesto de manifiesto Hidalgo Nuchera, León Serrano y Pavón Morote [2002: 74], sus fronteras no están muy definidas y exista una interacción continua entre todas ellas. Muy recientemente se discute, también, sobre la necesidad de añadir nuevos capitales (emprendedor y cultural).

El Capital Humano incluye el conjunto de conocimientos (explícitos o tácitos) útiles que poseen las personas y equipos que integran una empresa [Martín De Castro y García Muiña-2003: 9], así como su capacidad para regenerarlos (su capacidad de aprender)

\footnotetext{
${ }^{14}$ Para que un recurso o capacidad pueda ser considerado valioso, estratégico o crítico, según la Teoría de Recursos y Capacidades, debe ser escaso, relevante, duradero, transferible, complementario, difícil de imitar, sustituir o comercializar y apropiables por la empresa las rentas que genere su explotación. La misma Teoría considera que el conocimiento aglutina los siguientes rasgos característicos: relevancia, transferibilidad, imitabilidad, sustituibilidad, capacidad de agregación, apropiabilidad y especialización, siendo, además, indispensable en la producción [Benavides Velasco y Quintana García-2003: 18-19, 3132].
} 
[EUROFORUM-1998: 35]. Es la base de la generación de las restantes formas de Capital Intelectual y el recurso intangible por excelencia, dado que es indisociable de su portador y está vinculado con la adecuación de los individuos a las necesidades cambiantes del mercado y, consecuentemente, de la organización.

TABLA 4

DIFERENCIAS ENTRE ACTIVOS TANGIBLES E INTANGIBLES

\begin{tabular}{|c|c|c|}
\hline CARACTERÍSTICAS & ACTIVOS TANGIBLES & ACTIVOS INTANGIBLES \\
\hline VISIBILIDAD & $\begin{array}{l}\text { Son fácilmente identificables en } \\
\text { virtud de su apariencia física }\end{array}$ & $\begin{array}{l}\text { Son de difícil observación en la } \\
\text { realidad, al estar basados en la } \\
\text { información y el conocimiento. No } \\
\text { tienen soporte físico }\end{array}$ \\
\hline DURABILIDAD & $\begin{array}{l}\text { Tienden a depreciarse con el uso y } \\
\text { el tiempo }\end{array}$ & El valor aumenta con su utilización \\
\hline CUANTIFICACIÓN & $\begin{array}{l}\text { Son fácilmente identificables y } \\
\text { evaluables }\end{array}$ & $\begin{array}{l}\text { Presentan problemas para su } \\
\text { medición y evaluación }\end{array}$ \\
\hline CONTABILIZACIÓN & $\begin{array}{l}\text { Su valor figura en los estados } \\
\text { financieros contables }\end{array}$ & $\begin{array}{l}\text { Su valor no está incorporado a los } \\
\text { estados contables de la empresa }\end{array}$ \\
\hline ACUMULACIÓN & Rápida & $\begin{array}{l}\text { Lenta y costosa, a partir de de la } \\
\text { propia experiencia y de la historia de } \\
\text { la empresa }\end{array}$ \\
\hline TRANSFERIBILIDAD & $\begin{array}{l}\text { En su mayoría son fácilmente } \\
\text { transferibles }\end{array}$ & $\begin{array}{l}\text { En su mayoría son difícilmente } \\
\text { transferibles, al no ser codificables } \\
\text { y/o derivados de la coordinación de } \\
\text { diversos recursos }\end{array}$ \\
\hline IMITABILIDAD & Imitables con relativa facilidad & $\begin{array}{l}\text { Son de difícil imitación cuando } \\
\text { poseen carácter tácito o están } \\
\text { cubiertos con medidas de protección }\end{array}$ \\
\hline COMPRA-VENTA & $\begin{array}{l}\text { Existe un mercado de activos } \\
\text { tangibles }\end{array}$ & $\begin{array}{l}\text { No suele existir un mercado de } \\
\text { intangibles }\end{array}$ \\
\hline APROPIABILIDAD & $\begin{array}{l}\text { La propiedad es fácilmente } \\
\text { identificable }\end{array}$ & $\begin{array}{l}\text { Sobre parte de ellos se puede } \\
\text { establecer derechos de propiedad. } \\
\text { Sobre otros, como conocimientos y } \\
\text { habilidades personales, es difícil la } \\
\text { apropiabilida }\end{array}$ \\
\hline $\begin{array}{l}\text { VALOR DE } \\
\text { LIQUIDACIÓN }\end{array}$ & Cierto & $\begin{array}{l}\text { Nulo en bastantes casos. Carecen de } \\
\text { valor ante la posibilidad de } \\
\text { desaparición de la empresa }\end{array}$ \\
\hline
\end{tabular}

FUENTE: Adaptado de Benavides Velasco y Quintana García [2003: 20] y Navas López [2000: 5-8] 
El capital humano hace referencia, básicamente, a todos aquellos elementos (experiencia, motivación, habilidad de razonamiento y decisión, lealtad, polivalencia, flexibilidad, cultura de empresa, etc.) adquiridos por el individuo que incrementan su productividad y el valor de su contribución a la empresa. Su identificación y valoración constituye, por tanto, una tarea bastante difícil.

Por sus diferentes implicaciones desde el punto de vista de la gestión empresarial, se suelen distinguir dos tipos de capital humano: genérico y específico [Fernández Sánchez, Montes Peón y Vázquez Ordaz-1998: 86-87]. El primero es igual de valioso en cualquier actividad productiva. El segundo, lo es tan sólo en el contexto de una empresa en particular; se adquiere a través de la experiencia y del aprendizaje, de la interacción con otros miembros de la organización, de la enseñanza explícita y de los programas de formación que imparte la propia empresa.

El Capital Estructural se concibe como la transformación del capital humano que permite la creación de riqueza en la organización. Es el conocimiento que se queda en esta última cuando los empleados se marchan, explicitándolo, sistematizándolo e internalizándolo para ayudar a incorporar, formar y mantener el capital humano aditivo, esto es, las rutinas, la forma de funcionar, la propiedad intelectual, la tecnología disponible, etc. De él depende, consecuentemente, tanto su eficacia $\frac{15}{15}$ como su eficiencia $\frac{16}{16}$ Su alcance es interno a la empresa, pero externo a las personas, y aglutina dos componentes principales: el capital organizativo (o capital proceso) y el capital tecnológico (también denominado capital innovación).

El Capital Organizativo o de Proceso es la habilidad que presentan las organizaciones para integrar y desarrollar sus competencias en nuevos y flexibles métodos [Bontis1999: 448]. Hace referencia a aquellos componentes del capital estructural (valores, cultura, sistemas, protocolos y procedimientos, etc.) que describen las acciones y el modo de hacer las cosas en un esfuerzo por trasladar, transferir y capitalizar el capital

\footnotetext{
${ }^{15}$ Entendemos por eficacia el hecho de cuestionarse si lo que se hace es lo que realmente debería hacerse.

16 Entendemos por eficiencia la capacidad de hacer cada vez mejor las cosas que se ejecutan en el momento presente.
} 
humano. Gran parte de este conocimiento se refleja en los principios y valores que conforman la cultura empresarial [Benavides Velasco y Quintana García-2003: 49].

En cambio, el Capital Tecnológico o Capital Innovación es la habilidad estructural de la empresa para crear futuras innovaciones y riqueza; todo "un conjunto sistematizado de conocimientos aplicados a las diferentes áreas del ser humano, unidos para la consecución de un fin, que es la creación o invención de algo, que puede ser desde la fabricación o mejora de un producto hasta la simplificación o el cambio de un determinado proceso" [Navas López-1994: 33]. Una parte de él (patentes, modelos de utilidad, marcas comerciales, copyright, etc.) tiene características que lo hacen susceptible de protección legal, a través de los derechos de la propiedad intelectual.

Por último, el Capital Relacional es el conocimiento del entorno aplicado a la organización (base y valor de marca). Es la habilidad de esta última para interactuar positivamente con la comunidad empresarial y animar, así, al capital humano y estructural. Hace referencia a aquellos intangibles que se relacionan con los clientes, proveedores y otros agentes económicos de su entorno (lealtad de los clientes, reputación de la empresa, notoriedad de la marca, etc.). Entre ellos está alcanzando una importancia creciente la creación de acuerdos de cooperación y alianzas estratégicas, como medio para propagar, compartir y generar conocimientos entre las empresas.

Algunos autores lo separan en capital de negocio o comercial y en capital social o comunicacional [Martínez García, Peñalver Martínez y Salamanca García-2002: 7]. El Capital de Negocio o Comercial se centraría en las relaciones de la empresa con clientes y proveedores, así como en el conocimiento de su grado de satisfacción. El Capital Social o Comunicacional, en cambio, en sus actividades de comunicación con el exterior. Resalta la importancia que tienen las redes de relaciones interpersonales como base de la confianza, la cooperación y la acción colectiva [Martín De Castro, López Sáez y Navas López- 2004: 28].

La Tabla 5 sintetiza las modalidades del Capital Intelectual analizadas y recoge algunas de sus principales notas diferenciadoras. 
TABLA 5

EL CAPITAL INTELECTUAL

\begin{tabular}{|c|c|c|c|c|c|c|}
\hline & \multicolumn{2}{|c|}{$\begin{array}{l}\text { CAPITAL } \\
\text { HUMANO }\end{array}$} & \multicolumn{2}{|c|}{$\begin{array}{l}\text { CAPITAL } \\
\text { ESTRUCTURAL }\end{array}$} & \multicolumn{2}{|c|}{$\begin{array}{c}\text { CAPITAL } \\
\text { RELACIONAL }\end{array}$} \\
\hline & Genérico & Específico & Organizativo & Tecnológico & $\begin{array}{c}\text { De } \\
\text { negocio }\end{array}$ & Social \\
\hline BASE & \multicolumn{2}{|c|}{ Intelectual } & \multicolumn{2}{|c|}{ Rutinas } & \multicolumn{2}{|c|}{ Relaciones } \\
\hline ALCANCE & \multicolumn{2}{|c|}{$\begin{array}{l}\text { Interno a los } \\
\text { empleados }\end{array}$} & \multicolumn{2}{|c|}{$\begin{array}{c}\text { Interno a la empresa. } \\
\text { Lazos intraorganizativos }\end{array}$} & \multicolumn{2}{|c|}{$\begin{array}{c}\text { Relaciones externas } \\
\text { a la organización. } \\
\text { Lazos } \\
\text { interorganizativos }\end{array}$} \\
\hline PARÁMETRO & \multicolumn{2}{|c|}{ Volumen } & \multicolumn{2}{|c|}{ Eficiencia } & \multicolumn{2}{|c|}{ Longevidad } \\
\hline $\begin{array}{l}\text { DIFICULTAD DE } \\
\text { COMUNICACIÓN }\end{array}$ & \multicolumn{2}{|c|}{ Alta } & \multicolumn{2}{|c|}{ Media } & \multicolumn{2}{|c|}{ Muy alta } \\
\hline
\end{tabular}

FUENTE: Adaptado de Bontis [1999]

\section{I.5.2. La Medición del Capital Intelectual}

Uno de los grandes problemas que presenta el Capital Intelectual es realizar una adecuada medición de los activos intangibles o variables que lo componen [Ordóñez De Pablos-2004]. La necesidad de medir dicho capital es manifiesta por varias razones [Benavides Velasco y Quintana García-2003: 55]:

- Conocer el origen de las ventajas competitivas y recursos financieros de las empresas, así como el gap existente entre sus activos disponibles y los que son requeridos para lograr la posición estratégica deseada.

- Conocer por qué una compañía u organización vale más de lo que indican sus cuentas anuales, preocupación manifiesta de inversores, instituciones, analistas, clientes, proveedores, etc.

Sin embargo, la medición del Capital Intelectual no resulta una tarea fácil de llevar a cabo. Los intangibles pueden medirse en términos de inputs, es decir, de inversiones y esfuerzos destinados a producir bienes y servicios para el consumo futuro, o de activos generados por dichas inversiones y esfuerzos. 
Las inversiones en tecnología (investigación, desarrollo e innovación: $\mathrm{I}+\mathrm{D}+\mathrm{i}$ ); recursos humanos (formación y educación de los trabajadores); capital organizativo (estructuras de organización interna, redes externas de proveedores y clientes); marketing y reputación (marcas, líneas de producto, exploración y desarrollo de mercados); software y tecnologías de la información han captado la atención de los empresarios, por ser intangibles que contribuyen a la creación de los activos más útiles [Vickery-1999: 163]. Pero, ¿cómo identificar y medir tales activos en el ámbito de las organizaciones?.

Las propuestas se han multiplicado en este sentido a raíz de los trabajos pioneros de Kaplan y Norton [1992], Stewart [1994], Brooking [1996], Sveiby [1997], y Edvinsson y Malone [1999], dando lugar a la aparición de numerosos modelos, sistemas, informes, índices, indicadores y metodologías, fundamentalmente a instancias de empresas consultoras (ERNEST \& YOUNG, THE TECHNOLOGY BROKER, etc.), instituciones financieras y compañías de seguros (SKANDIA ASF como más significativa), o de empresas de alta tecnología (HEWLETT PACKARD, DOW CHEMICAL, MERCK, NOVA CARE, etc.).

Sin pretender ser exhaustivos, pasaremos a exponer, a continuación algunas de las iniciativas que han gozado de un mayor predicamento, aunque teniendo en cuenta, eso sí, que son aplicables, principalmente a grandes empresas y no a las PYMEs, destinatarias últimas de nuestra investigación: el Balanced Business Scorecard (Cuadro de Mando Integral) y el Navigator (Navegador) de SKANDIA, en el ámbito internacional, y el Modelo Intelect, en el nacional.

El primero, Balanced Scorecard o Cuadro de Mando Integral [Kaplan y Norton-1992], al objeto de medir los resultados obtenidos por la organización en un determinado periodo, integra indicadores financieros (de pasado) e indicadores no financieros (de futuro) (Tabla 6) en un esquema que permite a sus directivos entender las interdependencias existentes entre sus elementos, así como su coherencia con la estrategia y la visión de la organización (Figura 5). 
TABLA 6

BALANCED SCORECARD O CUADRO DE MANDO INTEGRAL: PRINCIPALES INDICADORES

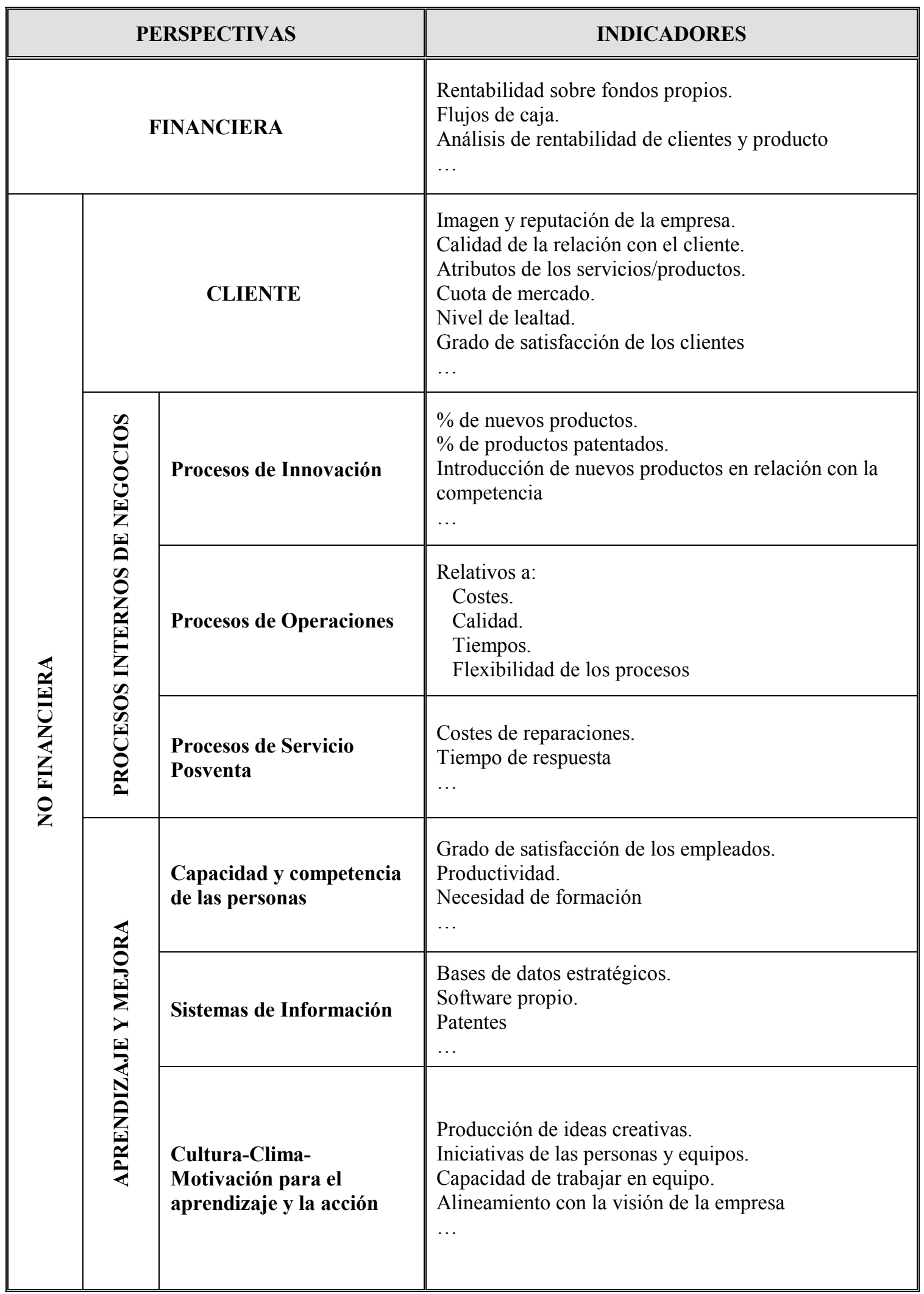

FUENTE: Kaplan y Norton [1992] 
FIGURA 5

BALANCED SCORECARD O CUADRO DE MANDO INTEGRAL

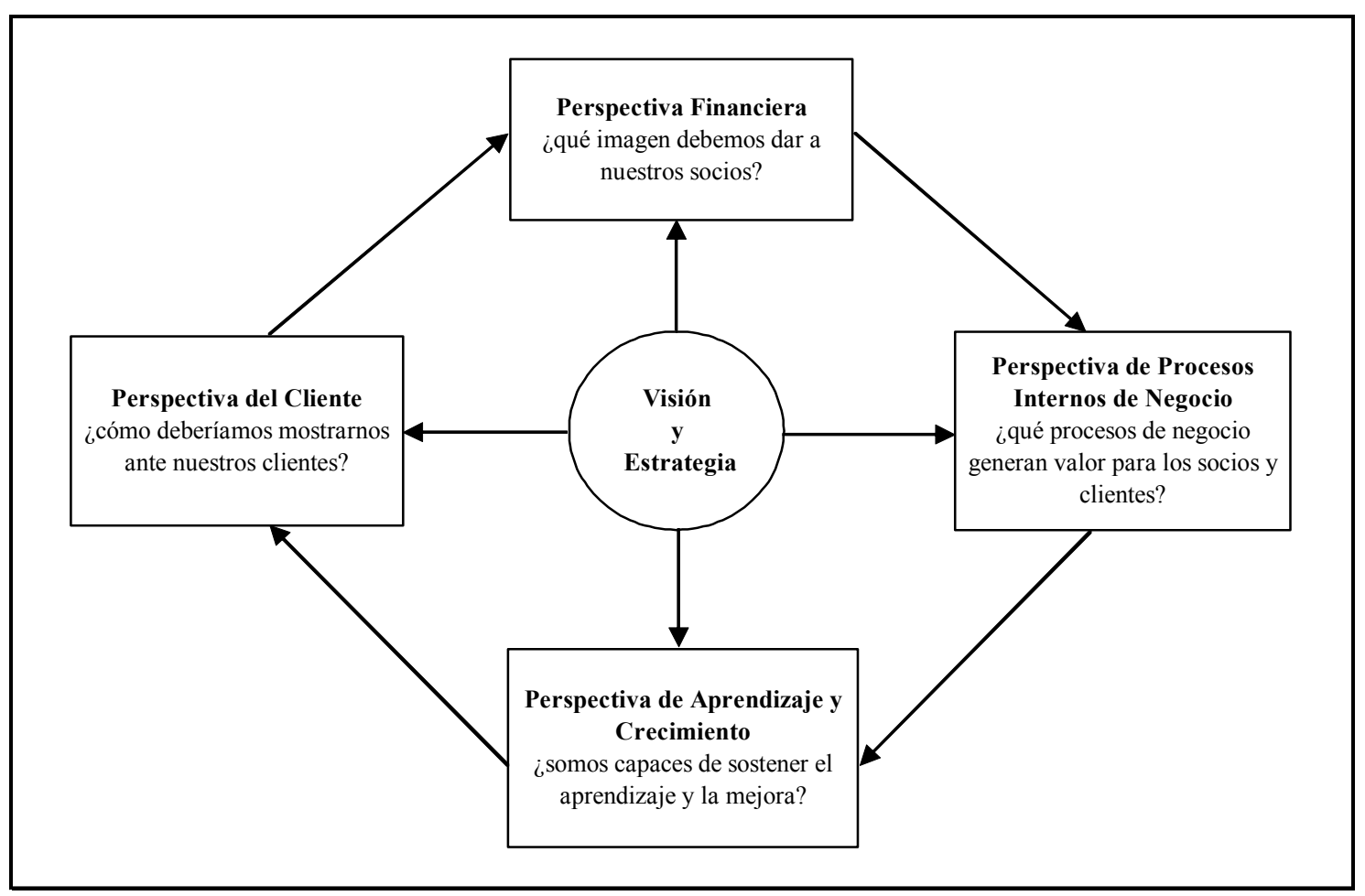

FUENTE: Kaplan y Norton [1992]

El segundo, esto es, el modelo de Capital Intelectual de la empresa sueca de seguros SKANDIA, conocido como Navegador (Navigator) (Figura 6), constituye el primer esfuerzo por sistematizar, por un lado, un método para incorporar la variable tiempo y crear valor de forma sostenida y, por otro, todo un conjunto de indicadores clave para medir los activos intangibles de una organización (Tabla 7).

Este modelo parte de que el valor de mercado está integrado por el Capital Financiero (balance de situación) y el Capital Intelectual (constituido por el Capital Humano (conocimientos y habilidades de las personas que configuran la organización) y el Capital Estructural (conocimientos explicitados por la organización, integrado, a su vez por los Clientes, los Procesos y la Capacidad de Innovación).

El enfoque financiero representa el pasado de la empresa. Las relaciones con los clientes y los procesos de negocio, el presente; y la capacidad de innovación y adaptación, el futuro. Por último, el enfoque humano constituye el centro del modelo y de la organización. 
FIGURA 6

\section{EL NAVEGADOR DE SKANDIA}

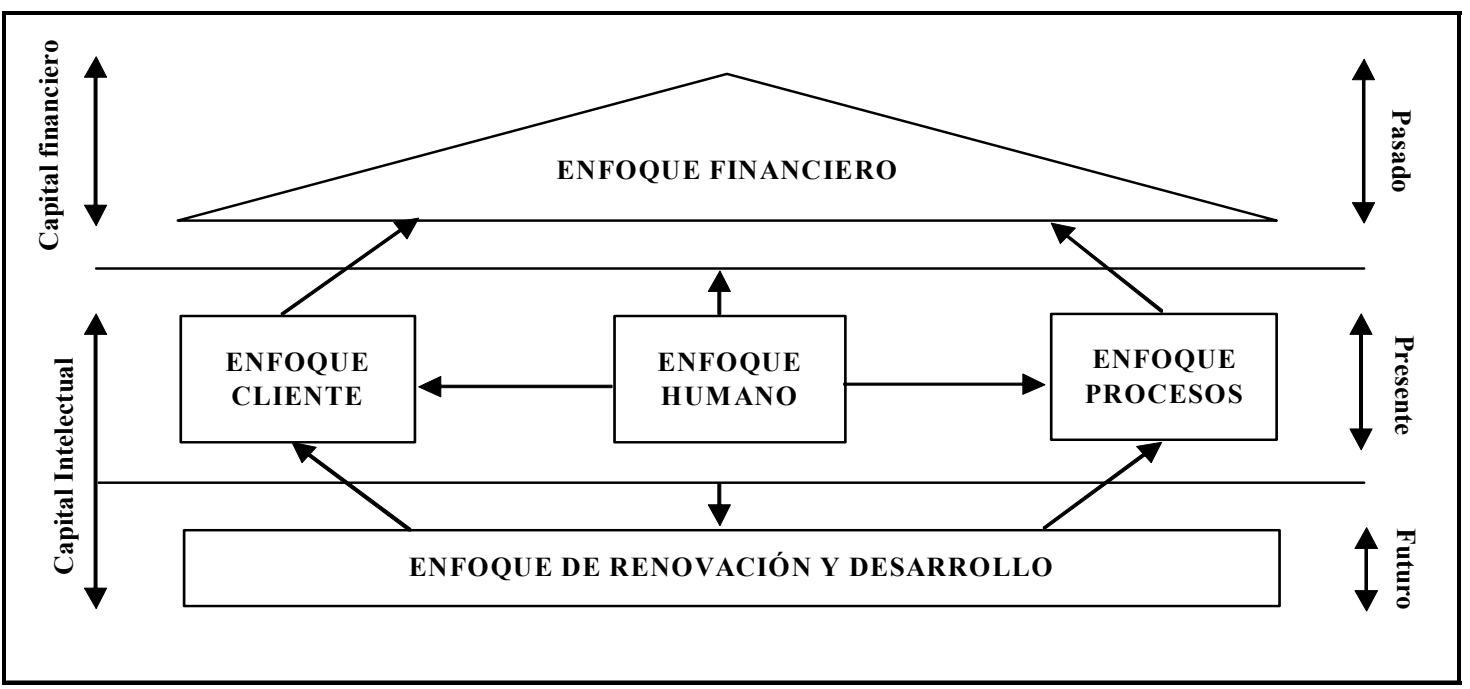

FUENTE: Edvinsson y Malone [1999]

TABLA 7

EL NAVEGADOR DE SKANDIA:

PRINCIPALES INDICADORES DEL CAPITAL INTELECTUAL

\begin{tabular}{|c|c|c|}
\hline \multicolumn{2}{|c|}{ CAPITAL INTELECTUAL } & INDICADORES \\
\hline \multicolumn{2}{|c|}{ CAPITAL HUMANO } & $\begin{array}{l}\text { Número de empleados. } \\
\text { Número de directivos. } \\
\text { Número de mujeres directivas. } \\
\text { Promedio de edad de los empleados. }\end{array}$ \\
\hline \multirow{3}{*}{ 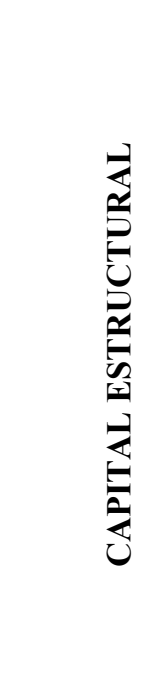 } & Clientes & $\begin{array}{l}\text { Cuota de mercado. } \\
\text { Clientes perdidos. } \\
\text { Días dedicados a visitar a los clientes. } \\
\text { Ventas anuales/clientes } \\
\ldots\end{array}$ \\
\hline & Procesos & $\begin{array}{l}\text { Ordenadores personales/empleados. } \\
\text { Gastos en Tecnologías de Información y de las } \\
\text { Comunicaciones/ empleados. } \\
\text { Meta de calidad empresarial. } \\
\text { Meta rendimiento/calidad empresarial } \\
\ldots\end{array}$ \\
\hline & Capacidad de Innovación & $\begin{array}{l}\text { Gasto de marketing/cliente. } \\
\text { Gasto en I+D/ gasto administrativo. } \\
\text { Gato en formación/empleado. } \\
\text { Inversión en desarrollo de nuevos mercados. } \\
\text { Inversión en apoyo y formación de nuevos productos }\end{array}$ \\
\hline
\end{tabular}

FUENTE: Edvinsson y Malone [1999] 
El tercero, el modelo Intelect [EUROFORUM-1998], constituye el primer esfuerzo realizado en España para acercar el valor explicitado de la empresa a su valor de mercado (Figura 7), así como ofrecer información sobre la capacidad de la organización para generar resultados sostenibles $\underline{17}$, mejoras constantes y crecimiento a largo plazo.

FIGURA 7

MODELO INTELECT

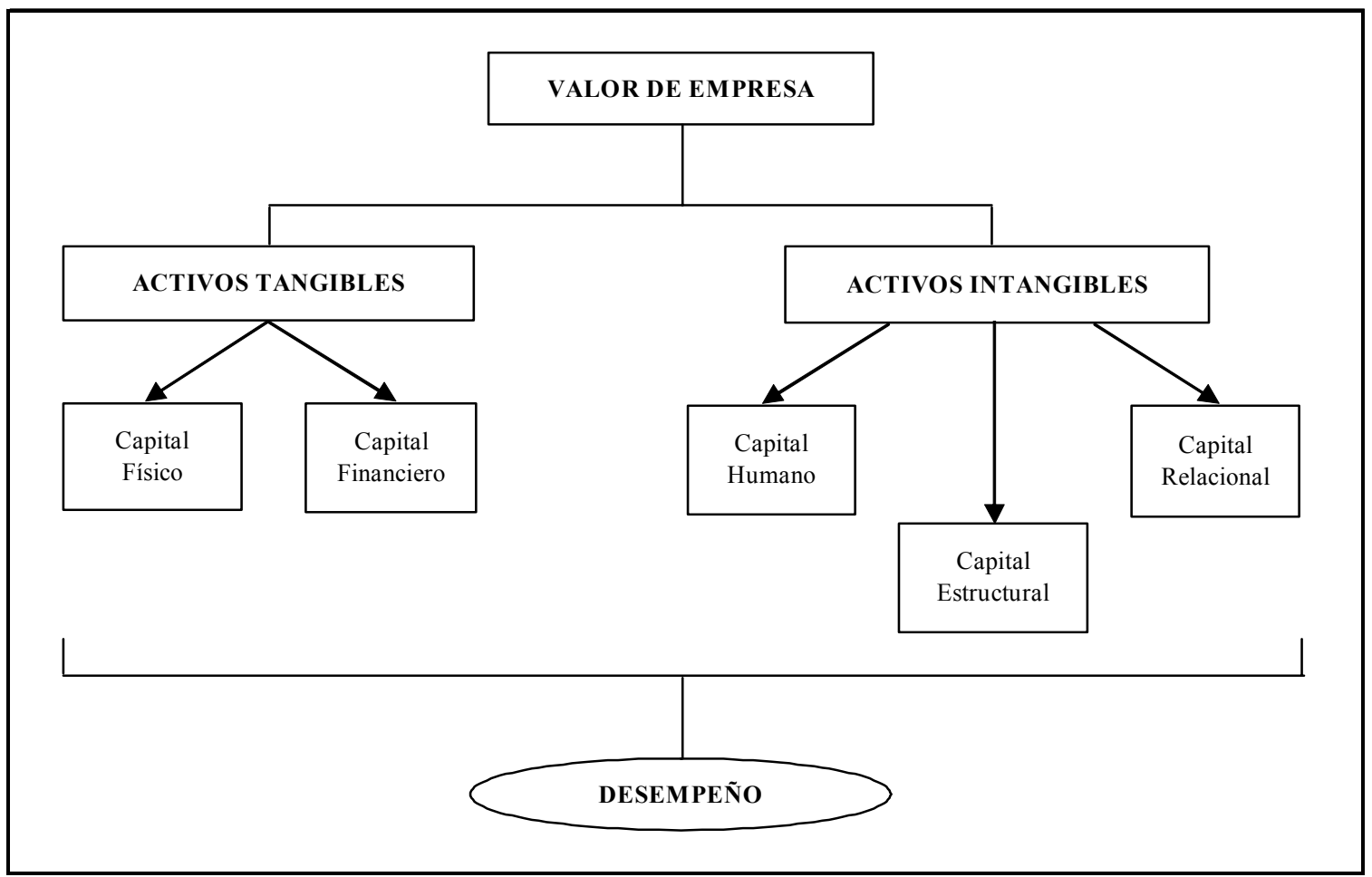

FUENTE: EUROFORUM [1998]

Agrupa los activos intangibles en tres grandes bloques: Capital Humano, Capital Estructural y Capital Relacional. Cada uno de ellos debe ser medido con una dimensión temporal que integre el momento actual y, sobre todo, el futuro previsible de la empresa.

El modelo, además, tiene una visión sistémica y dinámica. Enlaza el Capital Intelectual (Figura 8) con la estrategia de la organización. Es abierto, flexible y aplicable a cada empresa. Trata de cuantificar sus resultados y los procesos que los generan; y combina distintas unidades de medida.

\footnotetext{
${ }^{17}$ Entendemos por sostenibilidad de una organización el mantenimiento y progresión en el tiempo de sus funciones, teniendo un sentido de continuidad.
} 
FIGURA 8

MODELO INTELECT: EL CAPITAL INTELECTUAL

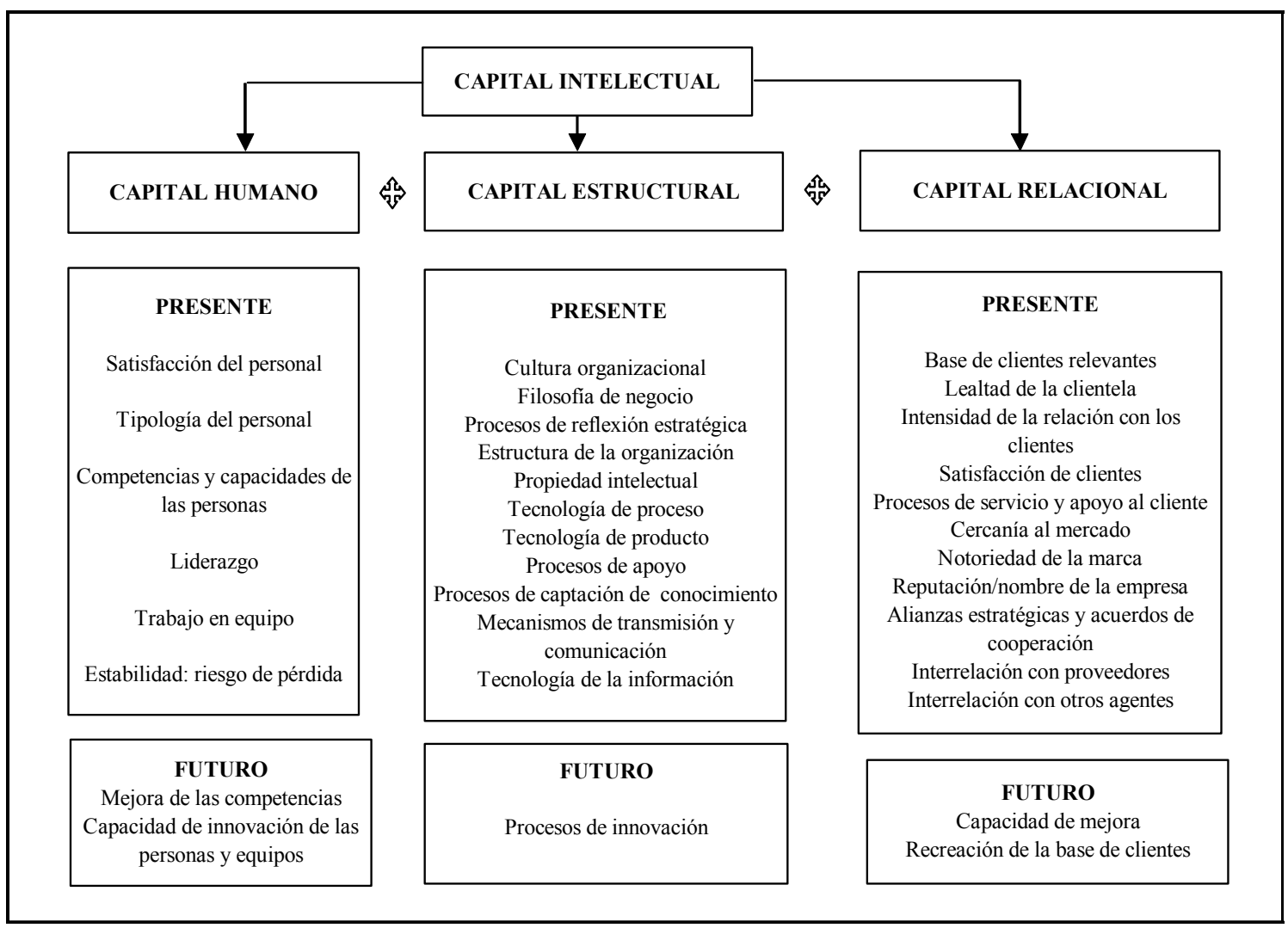

FUENTE: EUROFORUM [1998]

\section{I.6. El Aprendizaje Organizativo}

El interés de las organizaciones por el Capital Intelectual ha ido evolucionado en tres direcciones: la medición de éste, el Aprendizaje Organizativo y la Gestión del Conocimiento. Como veremos más adelante, se trata de conceptos relacionados y complementarios.

Genéricamente el término "aprendizaje" designa situaciones muy diversas. Además, entre varios sujetos sometidos a un mismo aprendizaje, se constatan en ocasiones diferencias considerables debidas a factores personales como la edad, la inteligencia, la motivación y la actitud más o menos activa de cada individuo [Pelechano-1980]. A su vez, el aprendizaje puede llevarse a cabo en tres niveles complementarios: individuos, 
grupos y organizaciones. Utilizando las ideas de Inhelder [1975] y Bleger [1977], ahondemos previamente en sus vertientes individual y grupal.

La primera es independiente e inherente a cada persona, según las circunstancias en que le ha tocado en suerte desarrollarse. El sujeto va forjando su propio estilo, ritmo y metodología de aprendizaje, junto con todos aquellos mecanismos que favorezcan su independencia intelectual y, a la vez, le hacen estar constantemente aprendiendo a aprender.

Por su parte, el aprendizaje grupal tiene su origen en el hecho de que toda persona se encuentra inmersa en una dinámica de métodos participativos en todos los aspectos de su vida cotidiana, pero depende siempre de los valores individuales que cada una de ellas haya ido aprendiendo. Se articula por diferentes vías:

- Social: se refiere al desarrollo de la capacidad de convivir y organizarse en comunidad. Se trata de aprender a trabajar en grupo, desarrollar actividades de colectivismo, de respeto a los demás, y de ayuda mutua.

- Intelectual: se manifiesta en la toma de decisiones, el análisis de problemas complejos, el desarrollo de habilidades de tipo profesional, el desarrollo del pensamiento creador, etc.

- Moral: hace referencia a la autodisciplina, a la responsabilidad personal, a la formación de convicciones orientadas al cumplimiento del deber social, etc.

Obsérvese, entonces, que los aprendizajes individual y grupal son el resultado de procesos cognitivos personales mediante los que se asimila información (hechos, conceptos, procedimientos, valores, etc.), que luego se pueden aplicar en contextos diferentes a aquellos en los que se produjeron. Ambos constituyen una actividad individual, aunque se desarrollen en un contexto social y cultural, de ahí la dependencia de las vertientes señaladas. Se construyen, de este modo, nuevas representaciones mentales en significación y función, es decir, conocimiento, tanto original, como la consolidación, reestructuración o eliminación del ya existente [Pozo-1989]. 
En lo que al nivel organizacional se refiere, realmente las organizaciones aprenden de sus individuos, los cuales aplican sus conocimientos a las tareas que les son asignadas. No obstante, buena parte de los conocimientos adquiridos por éstos deben ser compartidos e integrados en el grupo en el que trabajan antes de constituir una base para la acción, llegando a trascender a otros grupos y, finalmente, a la propia organización. Igualmente, los individuos, para el desarrollo de sus cometidos, pueden recibir conocimientos de su grupo de trabajo, de otros equipos y de la organización de la que forman parte.

Consecuentemente, el aprendizaje es el proceso de construcción del conocimiento. A su vez, el conocimiento adquirido puede modificar nuestro modo de aprender.

Sin embargo, como señala Garvin [2003], durante muchos años ha sido imposible dar una definición clara del aprendizaje en una acepción que implique productividad económica. Existía consenso entre los investigadores en que es un proceso que requiere tiempo y que se relaciona con la adquisición de conocimiento y la mejora del rendimiento de la empresa, pero no lo había en otros muchos aspectos. Algunos autores creían, por ejemplo, que requiere un cambio de conducta. Otros afirmaban, en cambio, que basta con una nueva forma de razonar. Algunos hablaban de la necesidad previa de procesar la información, mientras que otros proponían las ideas compartidas, las rutinas empresariales e, incluso, la memoria.

En su evolución, apareció el concepto de Aprendizaje Mediante la Práctica (learning by doing), que demostró que la eficiencia de una unidad de producción aumentaba con el número de unidades producidas, es decir, con la experiencia. Posteriormente, el de Aprendizaje Mediante el Uso (learning by using) justificaría por qué la eficiencia de aquella se incrementaba a lo largo del tiempo utilizando sistemas complejos, en tanto que el de Aprendizaje Mediante la Interacción (learning by interacting) subrayaría la forma en que la interacción entre productores y usuarios de la innovación fortalecía la capacidad de ambos. Un análisis más reciente del aprendizaje mediante la práctica se centra en cómo el hecho de enfrentarse a nuevos problemas en el proceso productivo desencadena la investigación y el aprendizaje, lo que implica la interacción entre varias partes en la búsqueda de una solución [Lundvall-1999: 28]. 
Sólo a través del aprendizaje individual y de procesos de captación, estructuración y transmisión de conocimiento corporativo, podemos llegar a hablar de Aprendizaje Organizativo (Organizational Learning), que requiere instrumentos o mecanismos que dejen convertir el conocimiento de las personas y equipos de la empresa en conocimiento colectivo. Permite aumentar las capacidades de una organización para reducir la brecha entre los conocimientos existentes en ella y los que son necesarios para responder eficientemente a las exigencias percibidas del entorno. Vendrá especificado por la complejidad de la tarea a realizar y por su novedad, dando lugar a resultados diferentes en términos de aprendizaje (Tabla 8).

Procedemos, seguidamente, a analizar, de forma sintetizada, las principales perspectivas desde las que se ha sido abordado el Aprendizaje Organizativo: el enfoque del cambio, el enfoque del conocimiento y la perspectiva mixta entre las dos anteriores.

TABLA 8

LA EVOLUCIÓN DEL PROCESO DE APRENDIZAJE

\begin{tabular}{|c|c|c|c|}
\hline \multirow{2}{*}{$\begin{array}{c}\text { Complejidad } \\
\text { De la tarea }\end{array}$} & Baja & $\begin{array}{c}\text { Aprendizaje } \\
\text { a corto plazo }\end{array}$ & $\begin{array}{c}\text { Bajo nivel } \\
\text { de aprendizaje }\end{array}$ \\
\cline { 2 - 4 } & Alta & $\begin{array}{c}\text { Aprendizaje } \\
\text { durante un largo periodo }\end{array}$ & $\begin{array}{c}\text { Bajo nivel } \\
\text { de aprendizaje }\end{array}$ \\
\hline \multirow{2}{*}{} & Nueva & Antigua \\
\cline { 2 - 3 } & \multicolumn{2}{|c|}{ Tipo de tarea } \\
\hline
\end{tabular}

FUENTE: Canals [1991: 43]

\section{I.6.1. El Enfoque del Cambio}

Entre el conjunto de autores que centran sus investigaciones en el análisis del Aprendizaje Organizativo, algunos identifican la organización que aprende con la que es capaz de cambiar y vinculan el Aprendizaje Organizativo a su capacidad de cambio, asociándolo, bien a la capacidad de la organización para adaptarse a su entorno (visión adaptativa), o bien a la promoción de su propia transformación (visión proactiva). Como consecuencia de ello, en esta perspectiva coexisten dos enfoques: el adaptativo y el proactivo. 
El enfoque adaptativo engloba las aportaciones que consideran el Aprendizaje Organizativo como un proceso de adaptación al entorno por parte de la organización [Cyert y March-1963; Cangelosi y Dill-1965; Duncan-1974; March y Olsen-1976; Duncan y Weiss-1979; Hedberg-1981]. Algunas de ellas enmarcan su estudio dentro de un modelo estímulo-respuesta: la organización aprende a partir del conocimiento y la experiencia generados en su interacción con el entorno y adapta sus actuaciones mediante un procedimiento de ensayo-error [March y Olsen-1976; Duncan y Weiss1979; Hedberg-1981].

En cambio, las contribuciones del enfoque proactivo relacionan el concepto de Aprendizaje Organizativo con la capacidad de la organización para transformarse y cambiar [Shrivastava-1981, 1983; Swieringa y Wierdsma-1992; Kim-1993a y 1993b] e identifican la organización que aprende, por poner algunos ejemplos, con:

- Aquel tipo de organización capaz de provocar su propia transformación o de construir su propia realidad [Senge-1990].

- Aquélla que aprende continuamente y se transforma a sí misma [Watkins y Marsick1993: 8].

- Las empresas que agresiva y sistemáticamente trabajan para desarrollar su capacidad de aprendizaje y, por consiguiente, su habilidad para adaptarse y transformarse continuamente [Redding y Catalanello-1994: xi].

La visión que subyace en esta concepción es la de la organización considerada como un sistema autopoiético, que se caracteriza por su capacidad para auto-renovarse y cambiar, así como por ser un sistema proactivo: el cambio es impulsado por la propia organización y no por la presión ejercida por el entorno.

Obsérvese, entonces, que los estudios relacionados con el enfoque adaptativo del Aprendizaje Organizativo se llevan a cabo, mayoritariamente, durante los años sesenta y setenta del siglo XX, mientras que la casi totalidad de los que se enmarcan en el 
enfoque proactivo se realizan en los años ochenta y noventa, si se exceptúa el trabajo de Miles y Randolph [1980].

\section{I.6.2. El Enfoque del Conocimiento}

En la década de los ochenta y, sobre todo, en la de los noventa del siglo pasado es, también, cuando se empieza a vincular el Aprendizaje Organizativo a aspectos relacionados con la gestión y manejo del conocimiento en las organizaciones [Nonaka y Johansson-1985; Nonaka-1988, 1991; Amponsem-1991; Huber-1991; Marengo-1991; Quinn-1992; Andreu y Ciborra-1994, 1995, 1996; Revilla-1995; Nonaka y Takeuchi1995; Nonaka e Ichijo-1997; Nonaka, Reinmoeller y Senoo-1998]. En concreto, a:

- Las formas en que las empresas construyen, aumentan y organizan el conocimiento y las rutinas alrededor de sus actividades y dentro de sus culturas [Dodgson-1993: $377]$.

- Los procesos de creación de nuevo conocimiento en el seno de los individuos y grupos dentro de una empresa, y los procesos para potenciar el conocimiento eficazmente dentro de la organización y entre organizaciones [Sánchez y Heene1997: 8].

Para estos autores, el Aprendizaje Organizativo se corresponde con los procesos o modos a través de los que la organización crea o construye conocimiento y amplia, a su vez, la base que posee. En esta misma línea, Nonaka y Takeuchi [1995]; Nonaka e Ichijo [1997]; Nonaka, Reinmoeller y Senoo [1998] consideran que la creación de conocimiento es el núcleo central de aquél.

En cambio, los restantes investigadores que relacionan el concepto de Aprendizaje Organizativo con el manejo de conocimiento en la organización lo hacen desde una óptica distinta, centrándose en aspectos diferentes al de la creación de conocimiento organizativo. 
En particular, Amponsem [1991] asocia el Aprendizaje Organizativo al proceso a través del cual el conocimiento individual se convierte en conocimiento de toda la organización, siguiendo un modelo de cinco etapas orientado a asegurar la conversión apuntada. Nonaka y Takeuchi [1995] integran los conocimientos generados en los planos individual y organizativo a través de la "espiral de creación de conocimiento" (apartado 1.7.1.). Huber [1991] se centra en la adquisición de conocimiento por la organización. Marengo [1991] y Andreu y Ciborra [1994, 1995, 1996], entre otros, consideran el Aprendizaje Organizativo como el proceso de generación de nuevas competencias organizativas, $\mathrm{y}$, consecuentemente, de creación de conocimiento. Finalmente, autores como Revilla [1995] o Andreu y Sieber [1998] lo enlazan con el proceso de resolución de problemas. A su juicio, el aprendizaje de la organización es consecuencia de la ampliación de su base de conocimientos, derivada, a su vez, de la incorporación del conocimiento generado en los procesos de resolución de problemas organizativos.

\section{I.6.3. El Enfoque Mixto del Cambio y del Conocimiento}

Por último, y también fundamentalmente en la última década del siglo XX, el análisis del Aprendizaje Organizativo es abordado por algunos investigadores asumiendo la doble perspectiva del cambio y el conocimiento. Entre ellos sobresale Nonaka. Interesado, especialmente, en el estudio de los problemas asociados a la creación de conocimiento organizativo, imputa a las organizaciones que aprenden, no sólo la capacidad de crear conocimiento, sino, también, la capacidad de cambio. Dualidad que se deduce de la definición que adopta al respecto:

- Una organización que evoluciona continuamente es una organización que aprende. Transforma el flujo de información en un stock de conocimiento, lo difunde a otros departamentos y estimula la autoorganización sistemática de la información [Nonaka-1988: 70].

Análogamente, en la definición que aporta Schaff-Johnson [1993: 29], el conocimiento se configura como un recurso clave y atribuye a la organización que aprende la capacidad de "producirse a sí misma": 
- Es una nueva forma organizativa emergente (opuesta a la jerárquica tradicional) que reconoce el conocimiento y los trabajadores del conocimiento como el nuevo recurso principal del planeta. Produce algo (producto/servicio), además de producirse a sí misma.

Esto último implica admitir que la referida organización tiene propiedades autoorganizativas y que es capaz de impulsar su propio cambio (enfoque proactivo). Llega a la conclusión de que posee características de sistema complejo y, por consiguiente, que es capaz de desarrollar niveles crecientes de desorden a partir de los que genera un nuevo orden. Por ello, siguiendo la definición anterior, no sólo puede producir determinados productos o servicios, sino que, también, puede producirse a sí misma. Precisamente, debido a su carácter de sistema complejo, es capaz de configurarse de una forma distinta cuando alcanza niveles altos de desequilibrio o desorden, es decir, cuando roza el límite del caos. Consecuentemente, ubica el concepto de organización que aprende en la perspectiva de la Teoría del Caos, lo mismo que Nonaka $\frac{18}{1}$.

Aparte de Schaff-Johnson y Nonaka, otros destacados autores que asumen la doble perspectiva del cambio y del conocimiento son los siguientes:

○ Garvin [1993: 80]: Una organización que aprende es una organización experta en la creación, adquisición y transferencia de conocimiento, así como en la modificación de su conducta para adaptarse a las nuevas ideas y conocimientos.

○ Mayo y Lank [1994: 7]: Una organización que aprende aprovecha toda la capacidad intelectual, el conocimiento y la experiencia disponible, con el fin de evolucionar continuamente en beneficio de todos sus grupos de interés.

○ Nevis, DiBella y Gould [1995: 74]: Una organización que aprende persigue diligentemente una base de conocimiento que aumenta constantemente. Este

\footnotetext{
${ }^{18}$ Ciertamente, Nonaka considera que el conocimiento se crea en situaciones próximas al caos y que su creación implica la re-creación de la propia organización. La capacidad de generar conocimiento y de transformación que caracterizan a una organización que aprende están vinculadas, por tanto, a su condición de sistema complejo y, por consiguiente, caótico [Nonaka-1988, 1991; Nonaka y Takeuchi1995].
} 
conocimiento permite el desarrollo de las competencias y el cambio incremental o transformacional.

○ Marquardt [1996: 19]: Una organización que aprende, sistemáticamente definida, es una organización que aprende poderosa y colectivamente y que se transforma continuamente para recoger, gestionar y utilizar mejor el conocimiento para el éxito de la empresa.

Todos ellos coinciden en atribuir a la referida organización la capacidad de utilizar su base de conocimiento para evolucionar y cambiar. Por tanto, el aprendizaje de la organización está asociado tanto al cambio del comportamiento organizativo, como a la creación de una base de conocimiento que lo soporte.

Para terminar, Probst y Büchel [1995] enlazan el concepto de aprendizaje con el cambio en el sistema de conocimiento de la organización, así como con la modificación del marco común de referencia asumido por los miembros de la misma. Es decir, para estos autores, el Aprendizaje Organizativo implica el replanteamiento de la "teoría organizativa en uso" (perspectiva del cambio/enfoque proactivo) y, por tanto, el cambio profundo del comportamiento de la organización. Por otra parte, el aprendizaje implica una mutación de la base de conocimiento organizativa (perspectiva del conocimiento).

\section{I.6.4. Corrientes de Pensamiento Actuales y Propuesta de un Nuevo Enfoque}

Los apartados I.6.2 y I.6.3 nos han permitido observar cómo la década de los noventa del siglo XX dio lugar a dos perspectivas de estudio en cuanto al Aprendizaje Organizativo: la del conocimiento, y la mixta del cambio y el conocimiento. Ahora bien, resulta necesario saber cómo se ha abordado su estudio desde aquella década hasta el momento presente. Destacamos dos tendencias en este sentido:

1. La búsqueda de los elementos constitutivos del Aprendizaje Organizativo, su dinámica, vertientes y causas, así como su influencia en la generación y transmisión del Conocimiento en las organizaciones. 
2. La aplicación de las dos perspectivas indicadas a problemas y entidades reales, hecho que está conformando las corrientes de pensamiento sobre la Gestión del Conocimiento efectiva de las organizaciones y la nueva figura del gestor.

En cuanto a la primera de las tendencias indicadas, Popper y Lipshitz [2000] tratan las similitudes y diferencias entre el aprendizaje individual y el organizacional, las condiciones que promueven el Aprendizaje Organizativo, cuando éste es factible, así como su relación con la organización que aprende. En esta línea, Fernández Ramos, Pérez Martín y Martín Cruz [2004], valoran las prácticas de trabajo en equipo que favorecen el aprendizaje, y por ende, la toma de buenas decisiones empresariales. Para ello, realizan un experimento en el que se controlan las variables del entorno con un grupo de alumnos de último curso de la Licenciatura en Administración de Empresas. De este modo, se permite la identificación de los aspectos cognitivos y de comportamiento que se ven implicados en el aprendizaje, tanto en el individuo, como en el equipo.

Por su parte, Akgun, Lynn y Byrne [2003] estudian el Aprendizaje Organizativo desde la perspectiva de la cognición social, entendiéndolo como resultado de las interacciones recíprocas que resultan de los procesos de adquisición, diseminación e implementación del conocimiento, junto con la formación de juicios, la memoria, el modo de pensar, el desaprendizaje, la inteligencia, la improvisación y las emociones. Todo ello, conectado por la cultura organizacional $\stackrel{19}{\text {. }}$.

\footnotetext{
${ }^{19}$ Atendiendo a Siliceo, Casares y González [1999], se entiende por cultura organizacional el sistema de significados compartidos por la gran mayoría de los miembros de una organización, y que distingue a ésta de otras.

La mayor parte de las organizaciones tiene una cultura dominante y diversas subculturas. Cuando se habla de cultura organizacional, se habla de cultura dominante. Las subculturas dentro de la organización reflejan problemas, situaciones y experiencias que comparten sus miembros.

Si las organizaciones no tuvieran una cultura dominante y estuvieran compuestas únicamente por diferentes subculturas, no existiría una interpretación uniforme de la conducta considerada como aceptable o inaceptable. Ahora bien, una cultura organizacional de compartición del conocimiento permite que los miembros de una organización originen y fomenten una cultura dominante que incluya valor a lo que cada uno de ellos sabe. De este modo, se generaría un sentido de identidad con intereses superiores a los personales, ya que el conocimiento producido sería en beneficio de toda la organización. La cultura organizacional sería, así, un gran aglutinante social que mantendría unida aquella.
} 
El papel que juega la voluntad en el conocimiento y el aprendizaje, cómo ésta interviene en las competencias para la práctica profesional y los caminos que llevan al éxito organizacional, son aspectos abordados por Rowland [2004].

Martín de Castro, López Sáez y Navas López [2004] estudian los procesos de creación y transferencia del conocimiento en las organizaciones, asimilable al proceso de Aprendizaje Organizativo, al objeto de deducir las pautas que debe seguir una aproximación teórica que explique adecuadamente dichos procesos.

Asimismo, la aplicación de la Dinámica de Sistemas a la resolución de problemas económicos y organizacionales ha sido abordada por Sterman [2000]. En esta línea de aplicación de teorías de la Física, Jashapara [2005] estudia el Aprendizaje Organizativo, junto con la tecnología, la cultura y la estrategia como pilares de la Gestión del Conocimiento para la creación de un marco teórico interdisciplinar que guíe a conceptuar dicha gestión ante el limitado papel que tiene de momento la Teoría de la Información en esta línea.

En cuanto a la segunda de las tendencias actuales reseñadas en el estudio del Aprendizaje Organizativo, es remarcable la profusa y creciente literatura sobre la Gestión del Conocimiento basada en el aprendizaje organizacional en diferentes campos profesionales y empresariales. Así, diversos autores, entre los que destacan Frydman et al. [2000], tratan de cubrir el salto entre la teoría y la praxis diaria de las organizaciones que aprenden. Estos, establecen de manera clara los principios en que debe fundarse el Aprendizaje Organizativo en dichas organizaciones, y explican las técnicas de liderazgo que se requieren para dar lugar a las organizaciones que aprenden.

Lynn, Reilly y Akgun [2000] destacan por su investigación sobre la metodología de 281 equipos profesionales de todas partes del mundo que trabajan en el desarrollo de nuevos productos, examinándose su habilidad para aprender, emplear su conocimiento y ofrecer resultados. 
Gorelick, Milton y April [2004] abordan los desafíos y oportunidades que plantea el Aprendizaje Organizativo y la Gestión del Conocimiento, con casos tipo que señalan las mejores prácticas de compañías de relevancia en la aplicación de tales términos.

Sobre la creación de líderes transformacionales partiendo de la figura tradicional del directivo, son destacables los trabajos de Ritchie-Dunham y Rabbino [2001], así como Zulauf [2001], que nos indican cómo implementar el cambio a toda la empresa a través de estos líderes. De hecho, ya desde finales del siglo XX se observaban estudios en donde se aborda cómo los directivos o gerentes de una empresa pueden administrar el conocimiento (donde el Aprendizaje Organizativo tiene un papel esencial) e incorporar dicha gestión a la estrategia de la misma, siendo destacable Drew [1999].

Señalamos, además, como último campo de acción, la utilización del Aprendizaje Organizativo para generar rentabilidad económica. Así, Therin [2002] analiza la relación entre aquél y la innovación en pequeñas empresas de alta tecnología. Respecto a grandes compañías (como exponente de la globalización económica mundial actual), se incluyen autores como Marsik [2002] y Rolland [2002].

Por tanto, habida cuenta de las múltiples perspectivas bajo las que es posible enfocar el Aprendizaje Organizativo, en el presente trabajo de investigación nos decantaremos por asumir las aportaciones de Schaff-Johnson [1993], Nonaka [1988, 1991] y Nonaka y Takeuchi [1995], ya comentadas en el apartado I.6.3. Varias razones nos impulsan a ello:

- Poseen la doble óptica de generación de conocimiento y de transformación, factores que, en la situación socio-económica actual, consideramos no pueden abordarse de modo separado como hacen los respectivos enfoques, individualmente considerados, del cambio (apartado I.6.1) y del conocimiento (apartado I.6.2).

- Al ubicar el concepto de organización que aprende en la Teoría del Caos, se permite su examen desde una perspectiva científica (empleando el concepto termodinámico de Entropía) y, consiguientemente, objetiva. 
Ahora bien, hasta ahora, las perspectivas del Aprendizaje Organizativo, entre las que figura la adoptada como base para nuestra investigación, conciernen casi en su totalidad a aquellas contribuciones que se sitúan en el ámbito organizativo del aprendizaje, siendo todavía incipientes y no consensuadas sus definiciones en el ámbito individual, el grupal, y la interacción entre ambos. Tampoco se describen completamente sus vertientes interna y externa a las organizaciones, constatándose además su debate en aspectos procesales humanos no cuantificables. Por ello, el modelo que elaboraremos para evaluar el Aprendizaje Organizativo pretende salvar estos aspectos, siempre teniendo en cuenta su particularización a Centros Tecnológicos de la Comunidad Autónoma de Castilla y León.

\section{I.7. La Gestión del Conocimiento}

La información, el conocimiento y el aprendizaje son, como se ha visto, cuestiones consustanciales a las personas. Ahora bien, para competir con efectividad en una economía en red, basada en los activos intangibles derivados del "conocimiento en acción" y del uso de las nuevas tecnologías, las organizaciones tienen que aprender a generar, identificar, empaquetar, evaluar, valorar, compartir y administrar aquellos conocimientos que generan valor a los diversos actores que intervienen en sus operaciones cotidianas.

Además, deben alinear dichas actividades con la estrategia corporativa, de negocios y funcional de la organización, teniendo siempre presente el futuro deseado, el entorno competitivo y las cadenas de valor en las que está inmersa (Figura 9).

En este contexto, la Gestión del Conocimiento (Knowledge Management) puede definirse como la capacidad de una organización para administrar la creación, la difusión, la adaptación y la utilización de conocimientos valiosos y para integrarlos en negocios, sistemas, procesos, productos y servicios [Medellín Cabrera-2002: 9]. Por otra parte, como las capacidades y conocimientos de una organización son parte sustancial de su Capital Intelectual, la Gestión del Conocimiento es una actividad clave 
en la configuración de dicho Capital Intelectual en aquella, esto es, el conjunto de competencias personales, organizativas, tecnológicas y relacionales conocidas $\mathrm{y}$ medidas a través de indicadores genéricos y específicos.

La Gestión del Conocimiento implica un proceso sistemático de búsqueda, selección, organización, filtrado, canalización y aplicación de la información disponible en la organización, así como de las habilidades y conocimientos de sus miembros, con la finalidad de focalizar el Capital Intelectual en un aumento de su productividad y competitividad (Figura 10).

FIGURA 9

LA "TRIADA" CONCEPTUAL

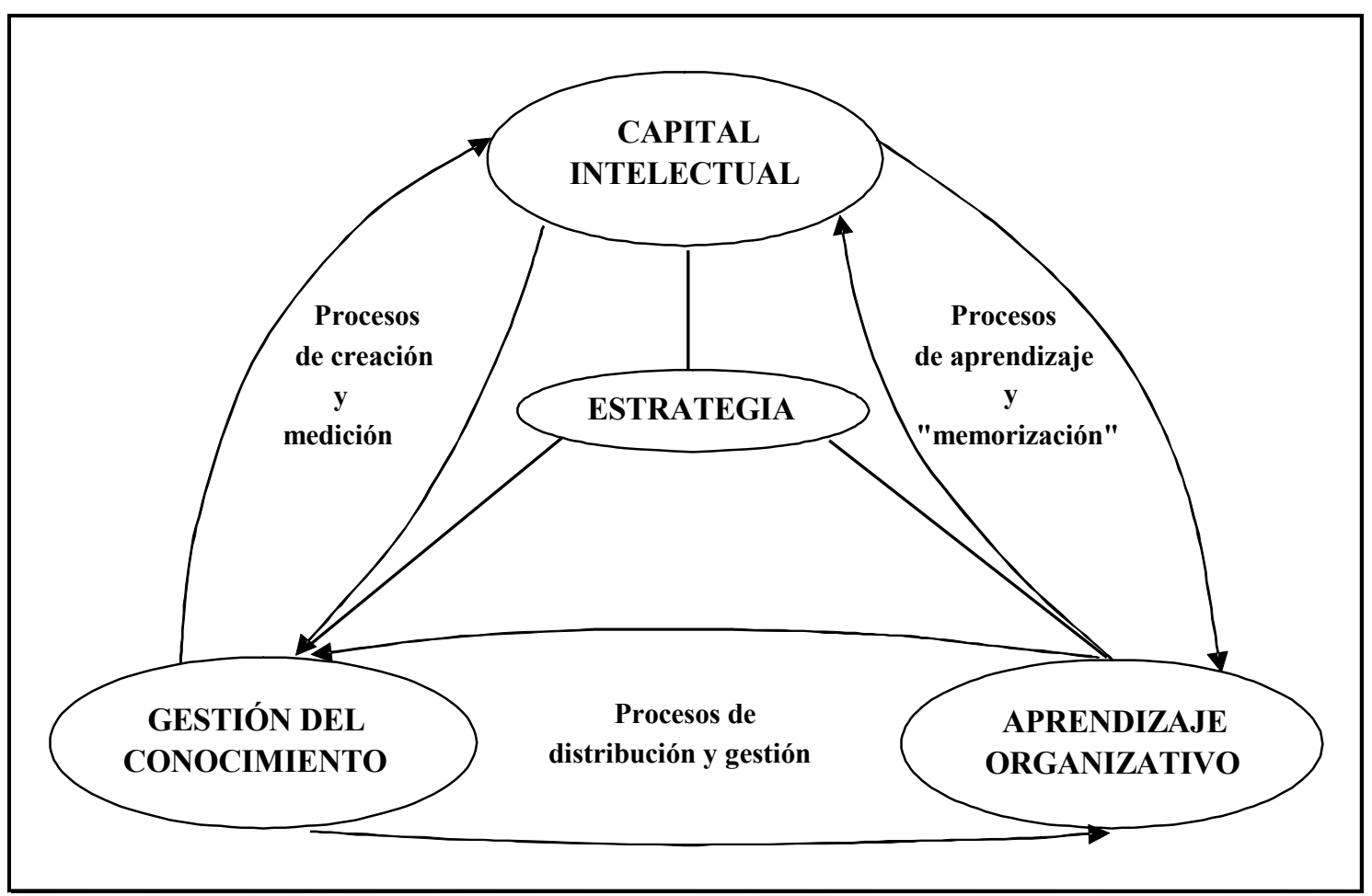

FUENTE: Bueno [2003: 21]

Se trata, por tanto, de un concepto dinámico, es decir, de un flujo. No se limita a la mera gestión del stock de conocimiento existente, sino que promueve la generación de otros nuevos, capaces de atender a las necesidades emergentes. 


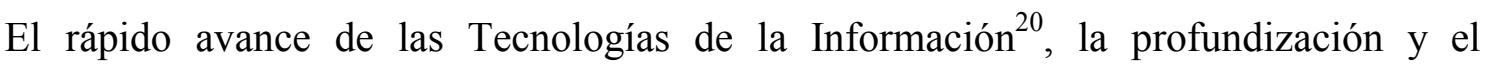
desarrollo de nuevos paradigmas relacionados con las diversas formas de conocimiento, y la aplicación de técnicas de desarrollo personal y organizativo han facilitado su nacimiento (mediados de los años ochenta del siglo XX) y posterior expansión (desde los años noventa) [Rivero Rodrigo-2000: 6; Serradell López y Juan Pérez-2003: 3].

\section{FIGURA 10}

GENERACIÓN DE BENEFICIOS A TRAVÉS DE LA GESTIÓN DEL CONOCIMIENTO

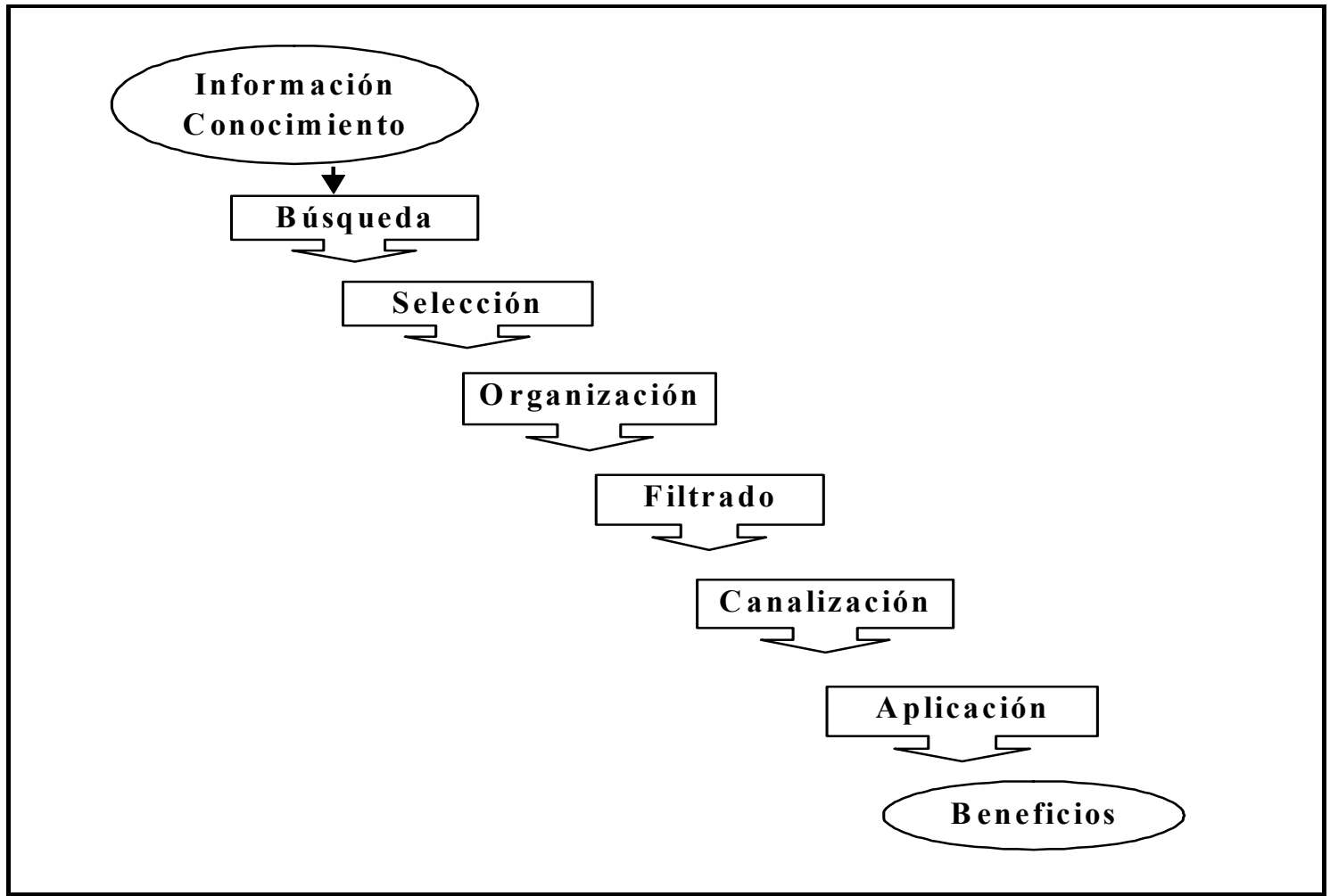

FUENTE: Perán González y Miguel Hernando [1999]

Por otra parte, al revestir dos facetas: la de administrar el conocimiento disponible (Knowledge Management, en sentido estricto) y la capacidad de aprender mediante la

\footnotetext{
${ }^{20}$ En las últimas décadas, las tecnologías de la información diseñadas para asistir a los trabajadores de las empresas y a los profesionales, han dejado de ser sistemas encaminados simplemente a procesar grandes cantidades de información y difundirla entre todos los directivos de una organización (Sistemas de Información para Administración o MIS: Management Information Systems), para convertirse, primero, en sistemas centrados en proporcionar a los encargados de tomar decisiones instrumentos para analizar las decisiones ad hoc (Sistemas de Ayuda a la Decisión o DSS: Decisión-Support Systems) y, después, en sistemas diseñados para proporcionar a los altos cargos y a los mandos intermedios una información relevante y actualizada, frecuentemente en tiempo real (Sistemas de Información Ejecutiva o EIS: Executive Information Systems). Cada uno de estos sistemas ha aportado mejoras más o menos importantes, a nivel individual y empresarial, y aún se revelan como componentes vitales de las inversiones que realizan las organizaciones [Alavi y Leidner-2002: 17].
} 
generación de nuevos conocimientos (learning organization), presenta un carácter sistémico y específico. Su finalidad es adquirir, organizar y comunicar tanto el conocimiento tácito como explícito de los empleados de una organización, para que otros empleados puedan hacer uso de él y ser, así, más productivos y eficaces en su trabajo.

El principal reto de la Gestión del Conocimiento no es tanto la creación de éste como su captura e integración. De hecho, el conocimiento tiene poco valor para una organización si no se comparte. El intercambio de conocimiento entre empleados, clientes y socios comerciales supone un beneficio potencial que se traduce en una mejora del servicio al cliente, en tiempos de entrega más cortos, y en una colaboración más estrecha dentro de la propia empresa o con otros socios comerciales [Barnes-2002: 2]. La habilidad para integrar, aplicar y gestionar el conocimiento especializado de los miembros de una organización de forma estratégica se convierte, así, en una fuente importante de ventaja competitiva [Grant-1996].

En la Figura 11 se representan tres flujos de conocimiento y la evaluación del conocimiento o competencias esencias totales creadas $\left(A_{4}\right)$. El primer flujo $\left(A_{1}\right)$ muestra la adquisición de conocimientos del exterior, generalmente explícitos, necesarios para llevar a cabo la actividad. El segundo $\left(\mathrm{A}_{2}\right)$ indica cómo la organización es capaz de crear conocimiento propio (explícito o tácito). Este output servirá de input en sucesivos procesos de transformación para la consecución de nuevos conocimientos. El tercer flujo $\left(\mathrm{A}_{3}\right)$ representa la internalización del conocimiento (de naturaleza tácita, normalmente) o las capacidades desarrolladas que se incorporan como "rutinas organizativas" o "procesos de acción" y que dotan a la empresa de la capacidad de aprender. 
FIGURA 11

LA GESTIÓN DEL CONOCIMIENTO COMO PROCESO SISTÉMICO

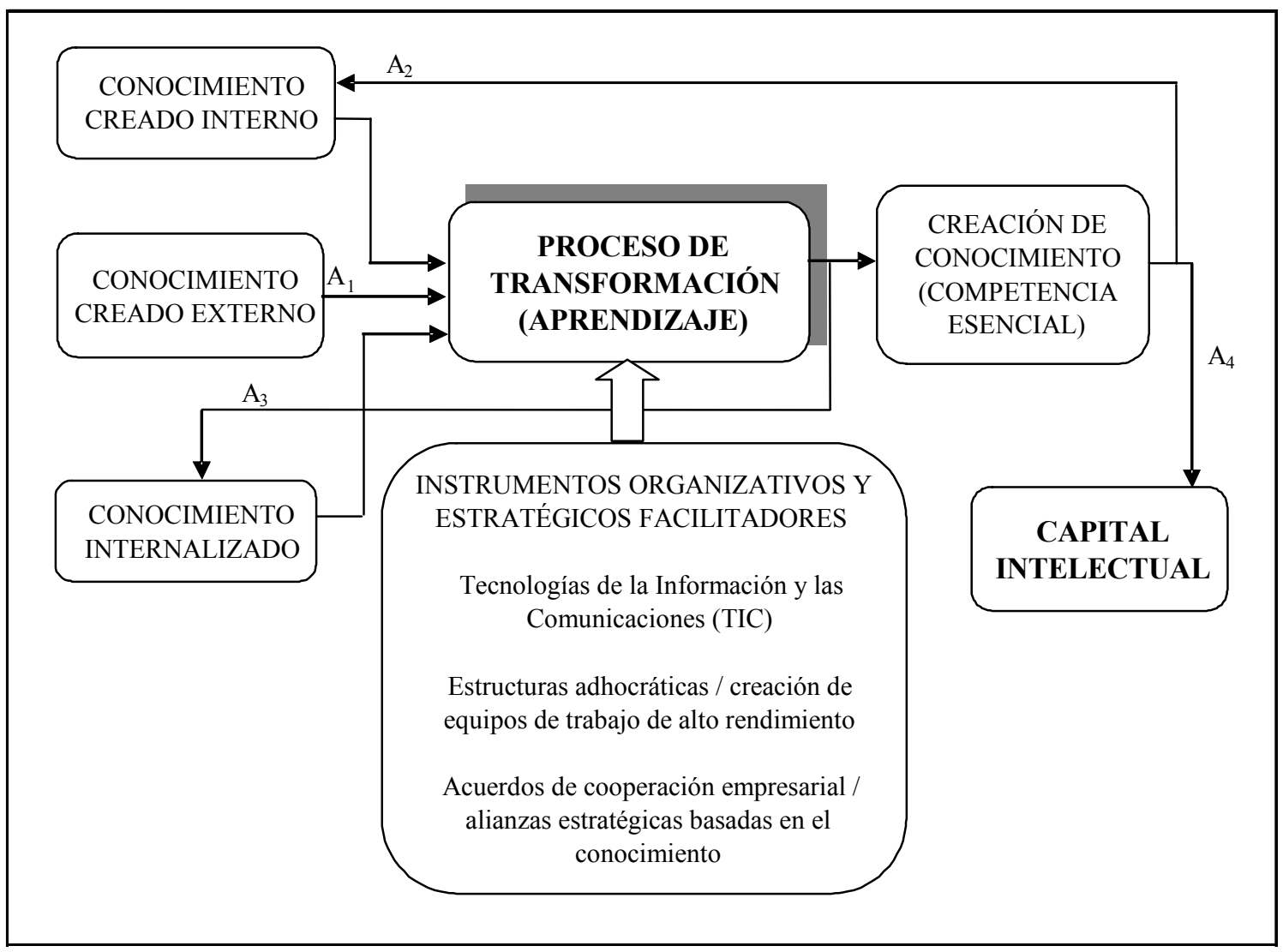

FUENTE: Bueno [2003: 17] y Benavides Velasco y Quintana García [2003:36]

Los flujos $A_{2}$ y $A_{3}$ son posibles gracias a la existencia de un proceso de aprendizaje, el cual expresa la capacidad de la organización (individual y de equipo) para incorporar nuevas ideas, nociones, saberes o competencias en las personas, sistemas y procesos que desarrolla.

\section{I.7.1. Modelos de Gestión del Conocimiento}

Una de las aportaciones más relevantes en este aspecto es la de Nonaka [1994]. Su modelo de creación del conocimiento es el más conocido y aceptado, y describe los caminos por los que se genera, transfiere y re-crea en las organizaciones. Asume las dos formas de conocimiento ya descritas al comienzo de este capítulo (tácito y explícito); una interacción dinámica (transferencia) y una continua; tres niveles de agregación social (individual, grupo y contexto); y cuatro procesos de "conversión del 
conocimiento" que, en conjunto, configuran el llamado modelo SECI (Socialización, Exteriorización, Combinación e Interiorización) (Figura 12):

- Socialización: el conocimiento tácito puede ser transferido de una persona a otra cuando se comparten colectivamente experiencias.

- Exteriorización: el conocimiento tácito se vuelve explícito y adopta la forma de metáforas, analogías, conceptos, hipótesis o modelos. Se genera por el diálogo o la reflexión colectiva y es la actividad esencial en la creación del conocimiento.

- Interiorización: el individuo absorbe y convierte el conocimiento explícito en conocimiento tácito.

- Combinación: utilización de varios tipos y fuentes de conocimiento codificado con el objetivo de crear nuevo conocimiento. Es un proceso de sistematización de conceptos con el que se genera un sistema de conocimiento. Los individuos intercambian conocimientos a través de documentos, reuniones de trabajo, conversaciones telefónicas, redes de comunicación, etc.

FIGURA 12

PROCESOS DE CONVERSIÓN DEL CONOCIMIENTO

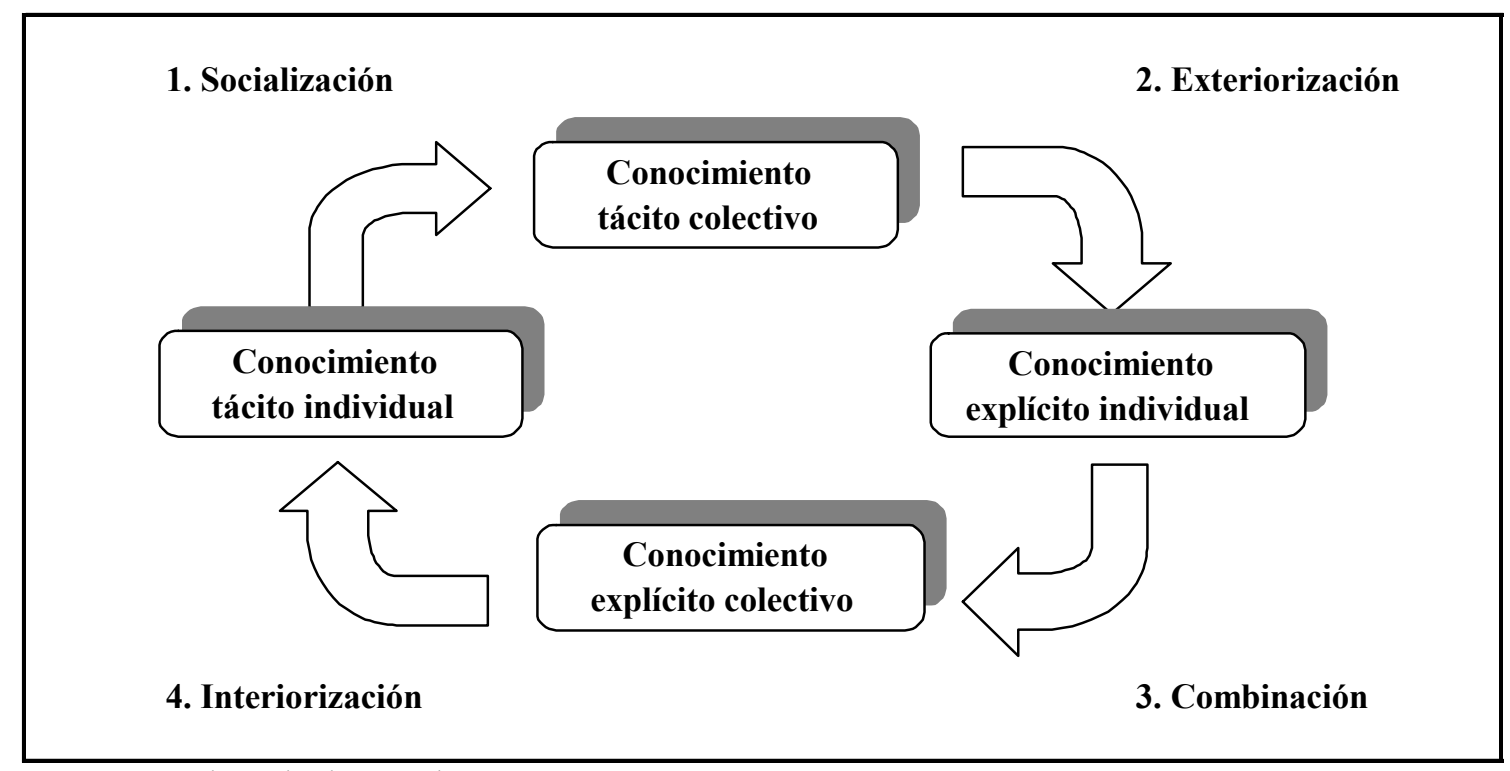

FUENTE: Adaptado de Nonaka [1994] 
La principal aportación de Nonaka ha sido la interacción dinámica entre las formas de conocimiento y los niveles organizacionales. Propone que "la espiral" resultante del intercambio del conocimiento tácito y explícito (Figura 13) es la clave de la creación y re-creación del Capital Intelectual. Las organizaciones deberían reconocer su importancia y poner en marcha los mecanismos que hagan posible esta espiral.

\section{FIGURA 13}

\section{LA ESPIRAL DE CREACIÓN DEL CONOCIMIENTO ORGANIZATIVO}

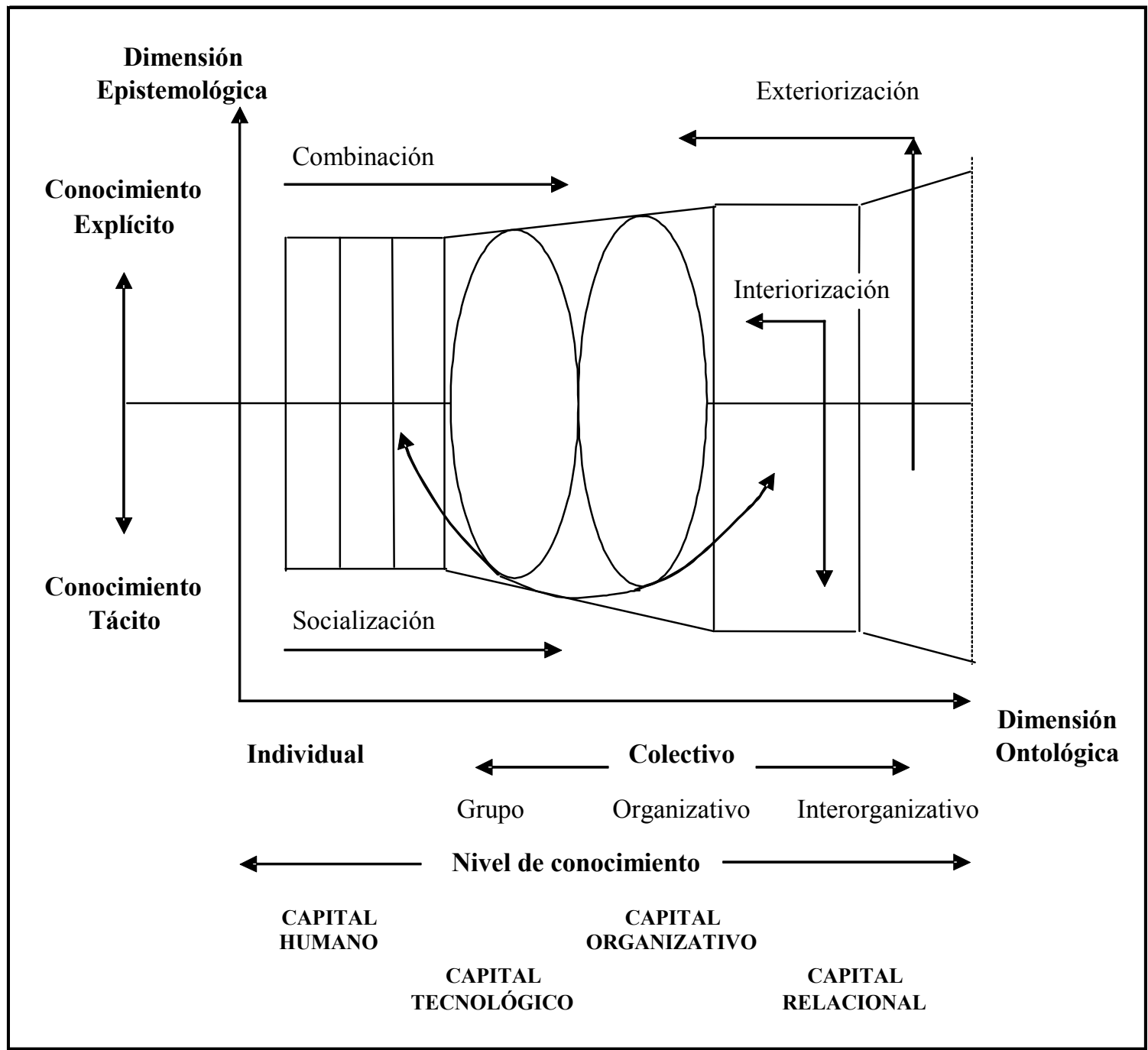

FUENTE: Adaptado de Nonaka y Takeuchi [1995: 73]

En esta línea, la compañía ARTHUR ANDERSEN identificó, en 1997, dos tipos de sistemas para acelerar la transferencia (desde los individuos a la organización y desde ésta a los individuos) y el uso de conocimiento, a fin de generar ventajas competitivas: 
(1) Sharing Networks: acceso a comunidades de práctica (foros virtuales) sobre los temas de mayor interés de un determinado servicio o industria; y ambientes de aprendizaje compartido virtuales (on line, bases de discusiones, etc.) o reales (workshops, proyectos, etc.).

(2) Knowledge Space: bases de datos documentales donde se almacenan desde las prácticas más destacables (conocimientos sobre procesos basados en la experiencia), hasta metodologías, informes, etc.

Más tarde, en 1999, esa misma compañía, junto con APQC, desarrolló el modelo Knowledge Management Assessment Tool (KMAT), un instrumento de evaluación y diagnóstico que se apoya en cuatro facilitadores del proceso de administración del conocimiento organizacional:

- Liderazgo: comprende la estrategia de la organización, cómo define su negocio y el uso del conocimiento para reforzar sus competencias críticas.

- Cultura: refleja cómo enfoca y favorece el aprendizaje y la innovación, incluyendo todas aquellas acciones que refuerzan el comportamiento abierto al cambio y al nuevo conocimiento.

- Tecnología: analiza cómo equipa a sus miembros para que se puedan comunicar fácilmente y con mayor rapidez.

- Medición: incluye la medición del Capital Intelectual y la forma en que se distribuyen los recursos para potenciar el conocimiento que alimenta el crecimiento.

Los pasos mediante los que la organización identifica las brechas de conocimiento y ayuda a capturar, adoptar y transferir el conocimiento necesario para agregar valor al cliente y potenciar los resultados se agrupan bajo la denominación de "proceso" (Figura 14). 
FIGURA 14

MODELO KNOWLEDGE MANAGEMENT ASSESSMENT TOOL (KMAT)

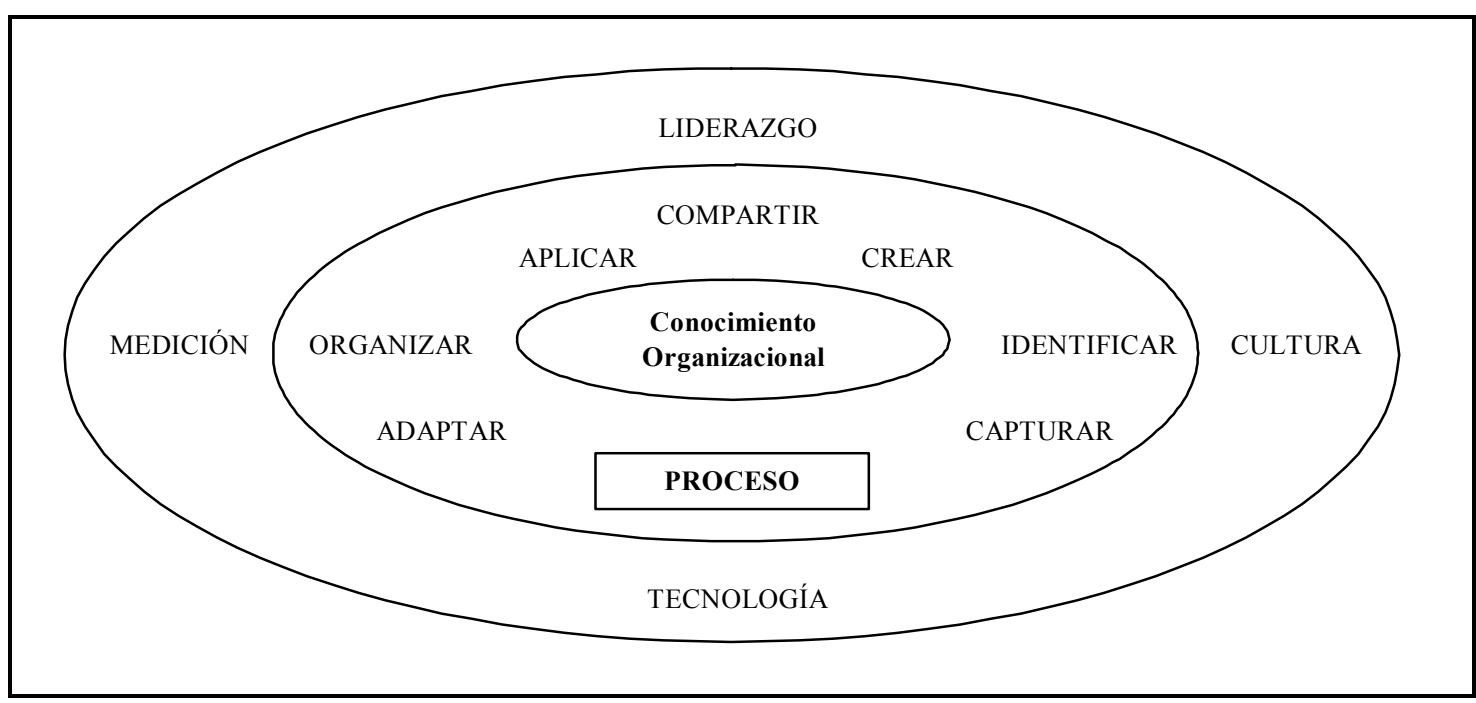

FUENTE: ARTHUR ANDERSEN [1999]

Paralelamente, Nonaka y Kono [1998], en su intento por mostrar que el conocimiento es dependiente de su contexto y no puede ser separado de su espacio, introducirían el concepto de Ba que, en la Gestión del Conocimiento, es un lugar para la conversión dinámica del mismo y las relaciones emergentes, definiendo cuatro tipos posibles: de origen, de interacción, virtual y de ejercicio.

El "Ba de origen" sería un espacio en donde los individuos compartirían sentimientos, emociones, experiencias y modelos mentales. El de "interacción", el lugar donde el conocimiento tácito sería convertido en explícito, a través del diálogo y la metáfora. El "virtual", un espacio de interacción en un mundo virtual que implicaría la combinación de conocimiento explícito nuevo y existente para generar una mayor cantidad de aquel, a través de la organización. Por último, el "Ba de ejercicio", un lugar que facilitaría la conversión del conocimiento explícito en tácito.

Para llevar a cabo el proceso de conversión del conocimiento, según los mencionados autores, serán necesarios unos sistemas, estructuras y cultura organizacional que favorezca el desarrollo de sus cuatro fases (socialización, exteriorización, combinación e interiorización). 
En la actualidad, aunque todavía no se dispone de una aproximación teórica de carácter general que describa adecuadamente el proceso mediante el que se llevaría a cabo la generación y difusión de conocimiento, las principales propuestas aparecidas en los últimos años indican que en él habría que tener en cuenta, al menos, los cuatro elementos básicos que se detallan a continuación [Martín De Castro, López Sáez y Navas López-2004: 25]:

(1) La dimensión epistemológica del conocimiento: éste se crea y expande a través de la interacción social de conocimiento tácito y explícito.

(2) La dimensión ontológica: el conocimiento se puede crear a nivel individual, de grupo, organizativo e interorganizativo.

(3) La distinción entre procesos de creación y transferencia de conocimiento dentro de cada nivel identificado (procesos intraniveles) y entre diferentes niveles (procesos interniveles).

(4) La distinción entre procesos de amplificación y de realimentación para lograr una lógica de aprendizaje dual, epistemológica y ontológica.

En este contexto, Bueno Campos [2002], partiendo de las dimensiones y categorías del conocimiento definidas en la Tabla 9: epistemológica (explícito y tácito: técnico-experto y cognitivo), ontológica (individual y social), sistémica (interno y externo) y estratégica (visión, recurso y capacidad); también del reto estratégico y la pauta de respuesta al mismo por parte de la organización (Figura 15), así como del papel que desempeñan los flujos de conocimiento en cada una de las etapas del proceso estratégico de aquélla (Figura 16), propone un modelo operativo, integrador de algunas de las mejores prácticas conocidas, con el fin de orientar los procesos que tenga que llevar a cabo la nueva dirección (gestión) estratégica del conocimiento (Figura 17).

En él se identifican las diferentes dimensiones del conocimiento, relacionadas con cada una de las fases de la estrategia corporativa y observables en los correspondientes flujos, generando una interacción social y una forma de compartir específica, explicadas por el 
llamado índice NICI y dibujadas por los mapas de conocimiento que identifican y relacionan las personas, grupos y la propia organización en sus conexiones externas, a la vez que las caracterizan dentro de la red que configuran.

TABLA 9

DIMENSIONES CONCEPTUALES Y CATEGORÍAS DEL CONOCIMIENTO

\begin{tabular}{|c|c|c|}
\hline Dimensiones Conceptuales & \multicolumn{2}{|r|}{ Categorías o clases de conocimiento } \\
\hline \multirow[b]{2}{*}{ EPISTEMOLÓGICA } & Explícito & Objetivo, formulado y codificado \\
\hline & Tácito & $\begin{array}{l}\text { Técnico-experto: experimental, simultáneo y } \\
\text { dependiente del contexto. } \\
\text { Cognitivo: subjetivo, emocional y comprometido }\end{array}$ \\
\hline \multirow{2}{*}{ ONTOLÓGICA } & Individual & Poseído por la persona \\
\hline & Social & Poseído por los grupos y la organización \\
\hline \multirow{2}{*}{ SISTÉMICA } & Información & Proceso de tratamiento de datos \\
\hline & Conocimiento & Resultado para crear nuevo conocimiento (output) \\
\hline \multirow{3}{*}{ ESTRATÉGICA } & Visión & Básicamente tácito-cognitivo \\
\hline & Recurso & Básicamente explícito \\
\hline & Capacidad & Básicamente tácito técnico-experto \\
\hline
\end{tabular}

FUENTE: Bueno y Salmador [2000; 2001]

El índice NICI es un acrónimo que define el Nivel de Información 21 , de Complejidad 22 y de Imaginación ${ }^{23}$ que sirven para analizar el contenido de cada conocimiento implicado [Bueno-2001c]. Pretende explicar cómo en todo programa de dirección (gestión) del conocimiento hay que saber integrar numerosas cuestiones que se derivan del conocimiento en acción y cómo surgen, entonces, dificultades de diseño, de operatividad y de puesta en marcha, según las categorías de información, conocimientos, planos de imaginación y de talento que es preciso introducir [Bueno2003: 24].

\footnotetext{
${ }^{21}$ Referida al volumen de conocimientos básicos utilizados como inputs, objeto de gestión.

22 Atendiendo a las características del conocimiento en su visión de sistema complejo adaptativo, matizando los enfoques y modos de su posible gestión.

${ }^{23}$ Representativa del talento, de la creatividad, descripción y reto necesarios en el proceso de creación de conocimiento.
} 
FIGURA 15

RETO ESTRATÉGICO DE LA ORGANIZACIÓN BASADO EN EL CONOCIMIENTO

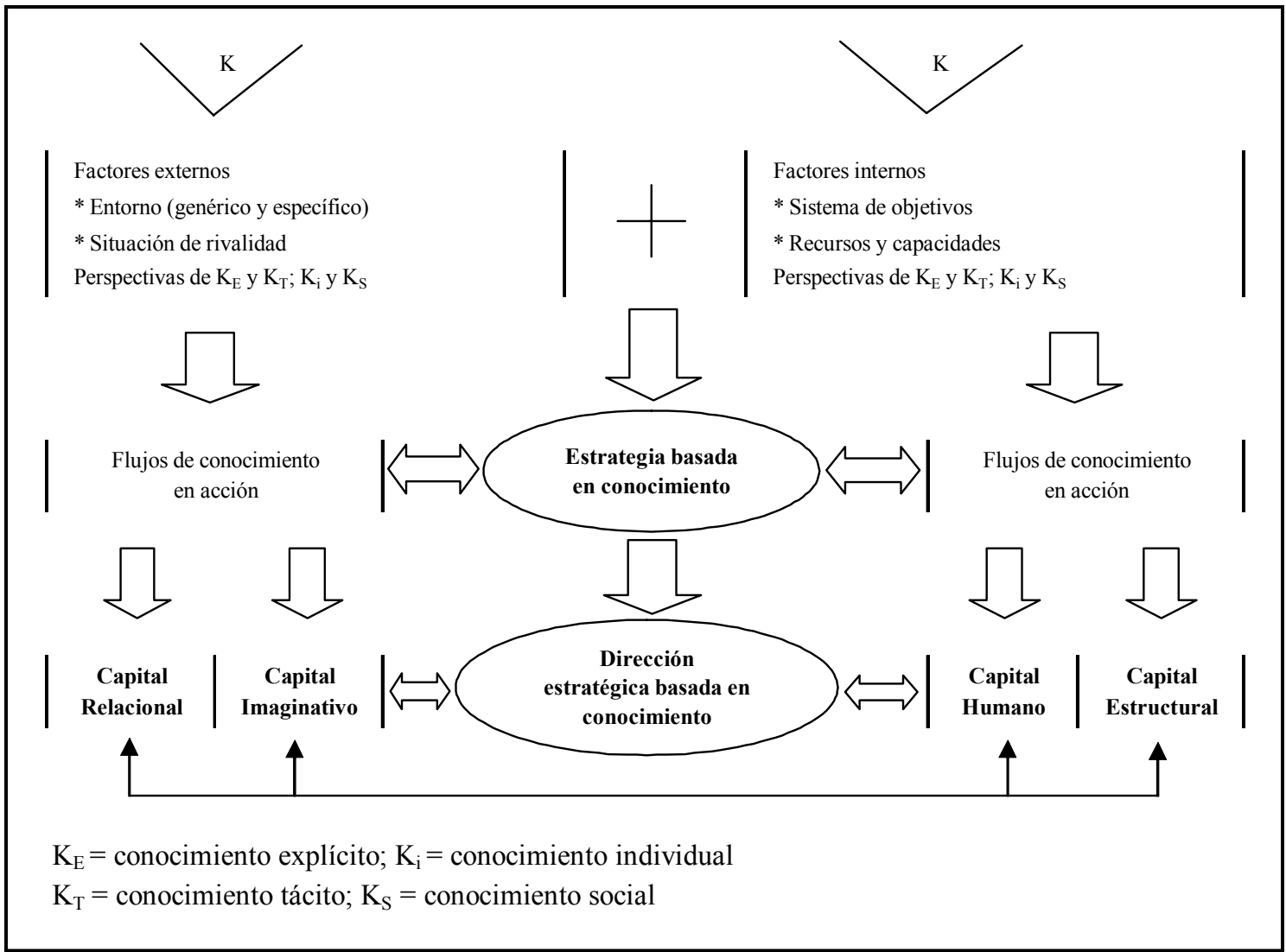

FUENTE: Bueno Campos [2002: 107]

La calificación que otorga a los flujos de conocimiento resulta vital para el diseño de las tecnologías o herramientas de tratamiento de la información, de los modelos cognitivos que expliquen la complejidad y de los modelos de creatividad necesarios para desarrollar la imaginación y, en definitiva, la innovación; además del diseño de los sistemas operativos de gestión y de los procesos de aprendizaje en cada uno de los aspectos mencionados.

Permite pasar, en última instancia, a la correspondiente evaluación y gestión del Capital Intelectual de la organización, teniendo en cuenta, eso sí, la influencia y alcance de los derechos de propiedad de los conocimientos involucrados en cada uno de sus componentes: 
FIGURA 16

PROCESO DE FORMACIÓN DE LA ESTRATEGIA:

\section{MODELO DINÁMICO BASADO EN EL CONOCIMIENTO}

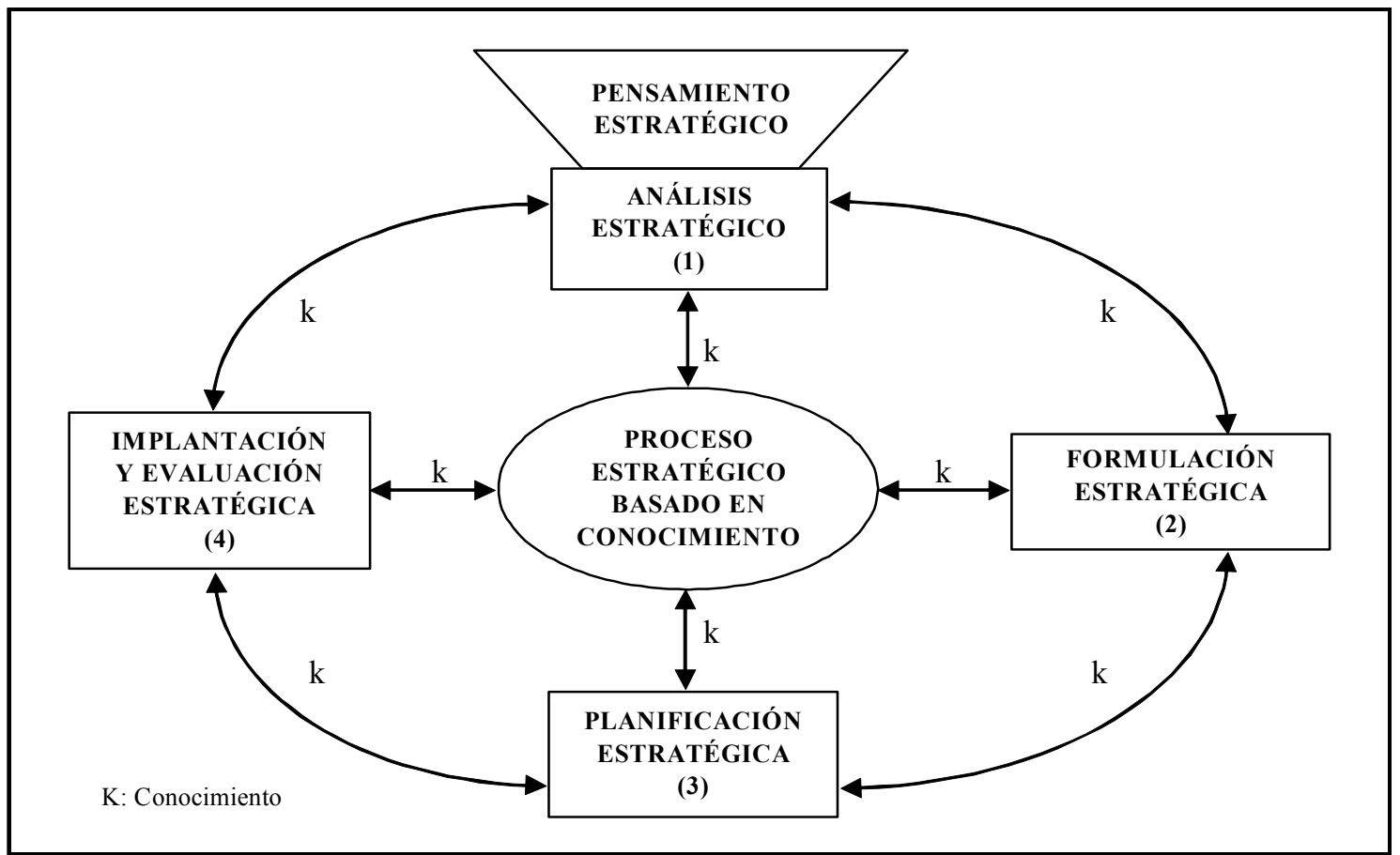

FUENTE: Bueno, Casani y Lizcano [1999] y Bueno Campos [2002]

- El conocimiento del Capital Humano es, básicamente, propiedad de los individuos. $\mathrm{Su}$ gestión presenta problemas éticos y procedimentales, aunque una parte de él puede estar en copropiedad con la organización, según las características de los contratos de colaboración y la propia co-evolución de los procesos de aprendizaje que haya tenido el conocimiento de las personas en su participación organizativa.

- El conocimiento del Capital Estructural es propiedad de la organización, salvo aquella parte desarrollada entre las personas (individual y colectivamente).

- El conocimiento existente y desarrollado por el Capital Imaginativo presenta dificultades de demarcación en cuanto a los derechos entre el individuo y la organización, pareciendo razonable que se deba hablar, fundamentalmente, de copropiedad, a tenor de las relaciones contractuales establecidas entre ellos. 
FIGURA 17

LOS PROCESOS DE DIRECCIÓN ESTRATÉGICA DEL CONOCIMIENTO (PDEC): MODELO OPERATIVO

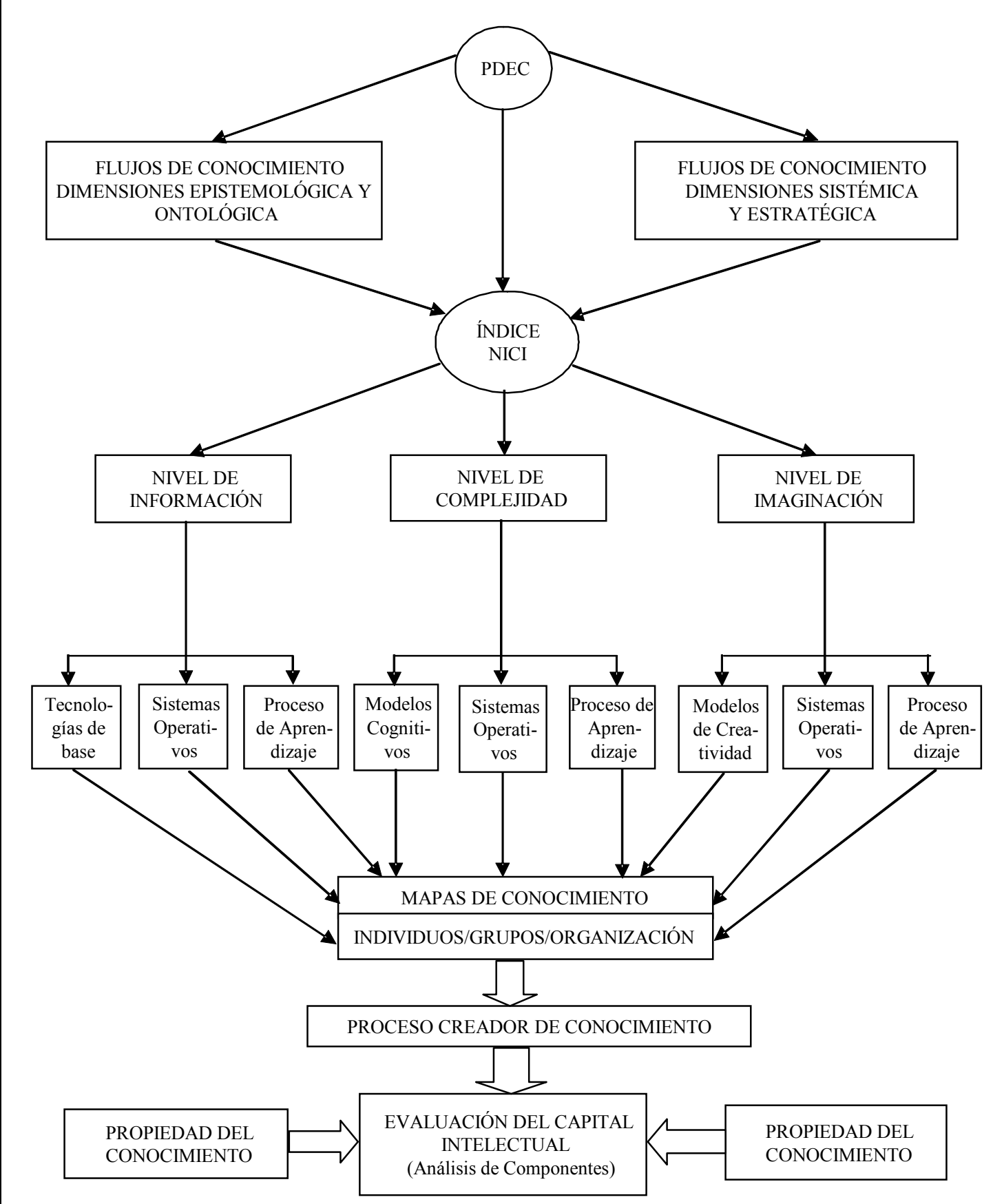

FUENTE: Bueno Campos [2002: 110]

- Lo mismo sucede con el identificado y evaluado por el Capital Relacional, dada la indeterminación o borrosidad de las fronteras existentes entre la organización y los agentes del mercado. Consecuentemente, resulta razonable, igualmente, que el régimen sea de copropiedad, explicable según los contratos o acuerdos vigentes. 
El "Programa de Dirección del Conocimiento" permitiría, entonces, racionalizar los procesos de la organización y ser más eficientes en la gestión de sus recursos y capacidades, desarrollar las capacidades de sus individuos, motivarlos y comprometerlos, mejorar la calidad total, evitar crisis y conflictos organizativos, así como crear ventaja competitiva sostenible y resultados más eficientes [Bueno-2003: 2425].

Además, debería llevarse a cabo con prudencia, sensibilizando a los sujetos críticos del conocimiento de la entidad y procurando el compromiso de la alta dirección en el momento considerado oportuno por la organización, sabiendo elegir, además, aquel área que tenga un carácter estratégico o influyente en la competitividad organizativa y que, al mismo tiempo, asegure su gestionabilidad con éxito.

Finalmente, Benavides Velasco y Quintana García [2003: 75-91] consideran que el proceso de Gestión del Conocimiento se compone de cinco etapas: identificación y medición; generación; captura y almacenaje; acceso y transferencia; y aplicación e integración del conocimiento (Figura 18).

Para valorar el éxito del proceso completo proponen utilizar como indicadores la viabilidad del conocimiento generado, la medida en que ayuda a resolver problemas, su grado de aceptación por los miembros de la organización, el coste de explotación, y su valor potencial. Por otro lado, el número de patentes y el de productos en fase de desarrollo o ya introducidos en el mercado, constituirían posibles medidas concretas para la evaluación de las actividades innovadoras.

Por último, los referidos autores aconsejan informar sobre los resultados obtenidos de la gestión del Capital Intelectual, tanto a los grupos internos como externos a la organización, para motivar a su personal, mejorar su posición estratégica, generar confianza en los inversores y obtener reducciones en el coste del capital. 
FIGURA 18

BENAVIDES Y QUINTANA: PROCESO DE GESTIÓN DEL CONOCIMIENTO

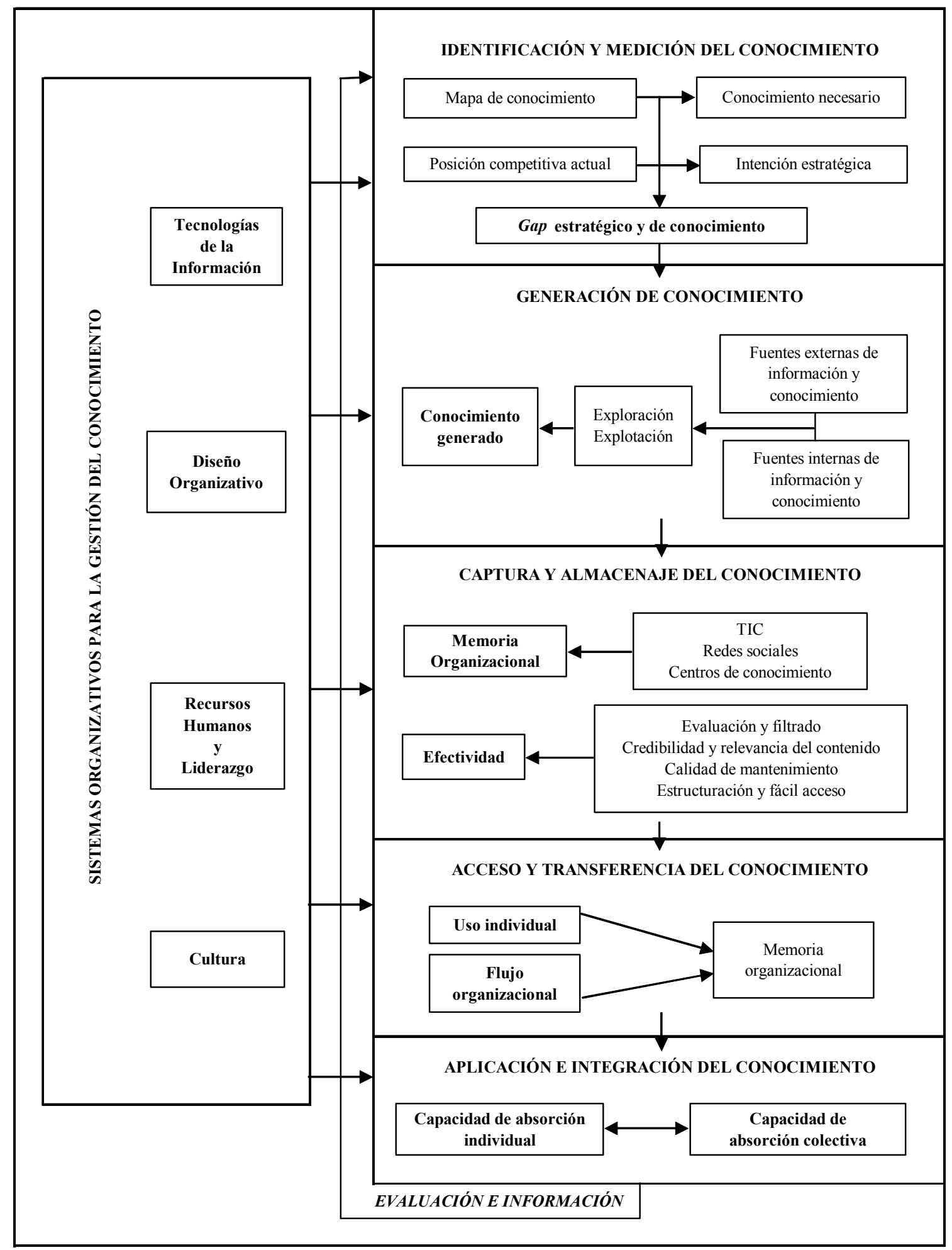

FUENTE: Benavides Velasco y Quintana García [2003: 76] 
Pedro Martín Lerones Evaluación del Aprendizaje Organizativo en los Centros Tecnológicos y Gestión del Conocimiento Sectorial en Castilla y León 
Capítulo II: EI Sistema de Conocimiento en Castilla y León 
Pedro Martín Lerones Evaluación del Aprendizaje Organizativo en los Centros Tecnológicos y Gestión del Conocimiento Sectorial en Castilla y León 


\section{II.1. Introducción: Consideraciones Iniciales}

Establecida, en el capítulo precedente, la naturaleza del conocimiento, su producción y transmisión entre los agentes implicados, así como su gestión dentro de las organizaciones, este segundo capítulo examina los rasgos esenciales que caracterizan al Sistema de Conocimiento de Castilla y León.

Consecuentemente, para cumplir con este objetivo, trataremos de responder a las siguientes preguntas: qué agentes generan el conocimiento en Castilla y León, qué organismos existen para facilitar la transmisión/difusión del conocimiento, y quiénes utilizan (real o potencialmente) ese conocimiento en la Comunidad Autónoma. Analizaremos, seguidamente, las especificidades sectoriales y locales de Castilla y León, sus sectores económicos estratégicos, así como la labor institucional que se está llevando a cabo en materia de $\mathrm{I}+\mathrm{D}+\mathrm{i}$.

En este sentido, y de acuerdo a lo establecido en el apartado I.4, el análisis de cualquier Sistema de Conocimiento, desde la perspectiva de los agentes que participan en él, permite diferenciar tres grupos relevantes:

1. Organizaciones del Sistema Ciencia-Tecnología-Industria: incluye las Universidades, los Organismos Públicos de Investigación (OPIs), los Organismos de Transferencia de Resultados de la Investigación (OTRIs), los Parques Científicos y Tecnológicos, los Centros/Institutos Tecnológicos, los Centros de Empresas e Innovación (CEIs) y las Empresas mismas.

2. Organizaciones del Sistema Público-Institucional de Innovación: lo configuran las administraciones y organizaciones, públicas y privadas, relacionadas con la innovación.

3. Personas y Grupos: aglutina a directivos y empleados de las organizaciones, junto a ciudadanos y colectivos sociales relacionados con ellas. 
No obstante, ciertos organismos, como es el caso de la Fundación COTEC [1998], efectúan una agrupación de actores diferente a la anterior: empresas, administraciones públicas, infraestructuras tecnológicas, organismos públicos de investigación y entorno (sustento socioeconómico de todos los anteriores).

\section{II.2. La Generación de Conocimiento en Castilla y León}

Las universidades y demás organismos públicos de investigación, los centros de innovación y tecnología y las empresas que realizan actividades de $\mathrm{I}+\mathrm{D}+\mathrm{i}$ en sus propios departamentos son los principales agentes responsables de la generación de conocimiento en un territorio.

Actualmente, Castilla y León cuenta con ocho Universidades (Tabla 10): cuatro públicas (Burgos, León, Salamanca y Valladolid) y cuatro privadas (Pontificia de Salamanca, SEK de Segovia, Católica de Ávila y Miguel de Cervantes de Valladolid), siendo reseñable que en estas últimas tiene más relevancia la docencia que la investigación. Su participación en las actividades de $\mathrm{I}+\mathrm{D}+\mathrm{i}$ es elevada (en 2003, ejecutaban el $38,1 \%$ del gasto en esa materia y empleaban al $81,8 \%$ de los investigadores, según INEBASE), si se compara con la media nacional (30,2\% y 65,2\%, respectivamente). Se deduce de ello, claramente, que constituyen una fuente de conocimiento de primer orden para la Comunidad Autónoma.

También se localizan en Castilla y León dos Organismos Públicos de Investigación (OPIs) en sentido estricto 24 , dependientes del Estado, y 38 instituciones vinculadas a la

\footnotetext{
${ }^{24}$ El Consejo Superior de Investigaciones Científicas (CSIC), con cinco centros vinculados a él en la Comunidad Autónoma: Estación Agrícola Experimental (EAE, en León); Instituto de Microbiología Bioquímica (IMB); Instituto de Biología Molecular y Celular del Cáncer (IBMCC); Instituto de Recursos Naturales y Agrobiología (IRNASA) (Salamanca), e Instituto de Biología y Genética Molecular (IBGM, en Valladolid), junto con siete unidades asociadas: Instituto Universitario de Historia "Simancas"; Instituto de Historia de la Ciencia; Grupo de Evolución Humana; Grupo de Química del Estado Sólido; Grupo de Nutrición; Instituto de Oftalmobiología Aplicada y Unidad de Investigación Clínica y Biopatología Experimental. El otro OPI referido es el Centro de Investigaciones Energéticas, Medioambientales y Tecnológicas (CIEMAT), que ubica en Lubia (Soria) su Centro de Desarrollo de Energías Renovables (CEDER).
} 
Administración Autonómica 25 (Tabla 10). Los primeros surgieron a raíz de la publicación de la Ley de la Ciencia, de 14 de abril de 1986, con el propósito de ser un instrumento directo para la implantación de la Política Científica y Tecnológica. Las segundas se dedican a la realización de actividades de $\mathrm{I}+\mathrm{D}+\mathrm{i}$, análisis y ensayo.

Por otra parte, los Centros de Innovación y Tecnología (CITs) constituyen un referente esencial para la generación de conocimiento en su ámbito de influencia. Legalmente los configuran personas jurídicas constituidas sin fines lucrativos, que estatutariamente tengan por objeto contribuir al desarrollo y fortalecimiento de la capacidad competitiva de las empresas en el ámbito de la tecnología y la innovación. Deben, además, ser reconocidos y registrados como tal por la Comisión Interministerial de Ciencia y Tecnología (CICYT), tras acreditar el cumplimiento de los requisitos establecidos a tales efectos. En Castilla y León coexisten nueve de ellos 26 . Atienden las necesidades tecnológicas de las entidades y empresas que lo solicitan, desarrollan proyectos de $\mathrm{I}+\mathrm{D}+\mathrm{i}$, prestan asistencia y servicios tecnológicos, colaboran en la transferencia de resultados de investigación entre los OPIs y las empresas, fomentan y desarrollan la investigación cooperativa entre estas últimas, y realizan cualquier otra actividad cuyo resultado sea mejorar su nivel tecnológico y lograr favorecer su posición en los mercados.

\footnotetext{
${ }^{25}$ Estación Enológica de Castilla y León (Valladolid); Estación Tecnológica de la Leche (Palencia); Estación Tecnológica de la Carne de Castilla y León (Salamanca); Laboratorio Agrario Regional (Burgos); Centro de Control de la Patata de Siembra de Castilla y León (Burgos); Centro de Investigación del Toro de Lidia (Salamanca); Centro de Pruebas de Porcino de Castilla y León (Segovia); Instituto Tecnológico Agrario de Castilla y León (ITA, en Valladolid); Laboratorio Pecuario y de Sanidad Animal Regional (instalaciones en todas las provincias); Centro Regional de Diagnóstico (Salamanca); Centro Regional de Control de Calidad (instalaciones de control en todas las provincias); Laboratorio Regional de Combustibles (LARECOM, en León); Laboratorio Regional de Medio Ambiente (LAREMA, en Burgos); Laboratorio de Metrología (Burgos); Laboratorio de Verificación (Ávila y Valladolid); Centro de Selección y Mejora Genética de Ovino y Caprino (Zamora); Laboratorios EET (Burgos, León y Salamanca); Centro de Selección y Reproducción Animal (León) y Centro de Investigación y Experiencias Forestales (Soria).

${ }^{26}$ El Instituto Tecnológico de Castilla y León (ITCL, en Burgos); el Centro Tecnológico de Miranda de Ebro (CTM, en la provincia de Burgos); el Instituto de Biotecnología (INBIOTEC, en León); la Asociación de Investigación Energética y Minera (ENERMITEC, en León); la Fundación Centro Tecnológico de Cereales de Castilla y León (CETECE, en Palencia); la Fundación Centro de Investigación y Desarrollo en Automoción (CIDAUT, en Valladolid- Parque Tecnológico de Boecillo); el Centro de Automatización, Robótica, Tecnología de la Información y de la Fabricación (CARTIF, Valladolid- Parque Tecnológico de Boecillo); el Centro Regional para el Desarrollo de las Telecomunicaciones de Castilla y León (CEDETEL, Valladolid- Parque Tecnológico de Boecillo) y la Asociación de Investigación para la Mejora del Cultivo de la Remolacha Azucarera (AIMCRA, en Valladolid).
} 
TABLA 10

GENERACIÓN Y TRANSMISIÓN DE CONOCIMIENTO EN CASTILLA Y LEÓN

\begin{tabular}{|c|c|c|}
\hline PRINCIPALES AGENTES & $\mathbf{N}^{\mathbf{0}}$ & LOCALIZACIÓN DE INSTALACIONES \\
\hline \multicolumn{3}{|c|}{ GENERADORES DE CONOCIMIENTO } \\
\hline \multicolumn{3}{|l|}{ Universidades } \\
\hline Públicas & 4 & Burgos, León, Salamanca y Valladolid \\
\hline Privadas & 4 & Ávila, Salamanca, Segovia y Valladolid \\
\hline \multicolumn{3}{|c|}{ Otros Organismos de Investigación del Sector Público } \\
\hline Dependientes del Estado & 6 & $\begin{array}{l}\text { León (1), Salamanca (3), Soria (1) y } \\
\text { Valladolid (1) }\end{array}$ \\
\hline Dependientes de la Administración Autonómica & 38 & $\begin{array}{l}\text { Ávila (3), Burgos (7), León (5), Palencia (3), } \\
\text { Salamanca (6), Segovia (3), Soria (3), } \\
\text { Valladolid (5) y Zamora (3) }\end{array}$ \\
\hline \multicolumn{3}{|c|}{ Centros de Innovación y Tecnología (CITs) reconocidos y no reconocidos legalmente por la CICYT } \\
\hline Centros de Desarrollo Tecnológico & 6 & Burgos (2), León (1) y Valladolid (3) \\
\hline Otros Centros Tecnológicos & 43 & $\begin{array}{l}\text { Burgos (2), León (10), Palencia (1), } \\
\text { Salamanca (9), Segovia (1) y Valladolid (20) }\end{array}$ \\
\hline Entidades acreditadas por la ENAC & 34 & $\begin{array}{l}\text { Burgos (6), León (2), Palencia (2), } \\
\text { Salamanca (3), Soria (1), Valladolid (19) y } \\
\text { Zamora (1) }\end{array}$ \\
\hline Empresas con Departamento de $I+D$ & 125 & Todas las provincias \\
\hline \multicolumn{3}{|c|}{ TRANSMISORES DE CONOCIMIENTO } \\
\hline OTRIs & 12 & $\begin{array}{l}\text { Burgos (2), León (1), Palencia (1), } \\
\text { Salamanca (2) y Valladolid (6) }\end{array}$ \\
\hline Centros de Transferencia de Innovación & 1 & Valladolid \\
\hline Incubadoras de Empresas & 6 & $\begin{array}{l}\text { Burgos, León, Salamanca ( } 2 \text {, en proyecto), } \\
\text { Segovia (en proyecto) y Valladolid }\end{array}$ \\
\hline Fundaciones Universidad-Empresa & 4 & Burgos, León, Salamanca y Valladolid \\
\hline \multicolumn{3}{|l|}{ Parques Tecnológicos y Científicos } \\
\hline Parques Tecnológicos & 3 & Burgos (en construcción), León y Valladolid \\
\hline Parques Científicos & 1 & Salamanca (en construcción) \\
\hline Asociaciones Empresariales & 21 & Todas las provincias \\
\hline Cámaras de Comercio & 14 & Todas las provincias \\
\hline
\end{tabular}

FUENTE: Pedrosa Sanz, Aleixandre Mendizábal y Martín Lerones [2005]

Entre los múltiples organismos que se asientan en los CITs sobresalen los Centros Tecnológicos, esto es, aquellos que no tienen una representación mayoritaria de las administraciones públicas en su propiedad o en sus órganos de gobierno. Cuentan con una organización similar a la de una empresa privada (aunque disfrutan, normalmente, 
de un importante apoyo público) [Giral Mañas-1999]; suelen tener un tamaño reducido [Barceló y Roig-1999]; actúan, principalmente, en el ámbito regional [Mas y Cubells1997]; y su capacidad para desarrollar actividades de $\mathrm{I}+\mathrm{D}+\mathrm{i}$ es, generalmente, importante. Su punto de encuentro es la Federación Española de Entidades de Innovación y Tecnología (FEDIT), creada en 1995.

Desde su aparición en Castilla y León, los Centros Tecnológicos han experimentado grandes transformaciones y una fuerte consolidación. Junto a los seis Centros de Desarrollo Tecnológico existentes (CARTIF, CEDETEL, CIDAUT, CTM, ITCL -vinculados a la FEDIT- e INBIOTEC), la Comunidad Autónoma cuenta, aproximadamente, con otros 43 de muy diversa naturaleza ${ }^{27}$ y de menor peso en las

${ }^{27}$ Se describen por provincias:

- En Burgos: Centro Tecnológico de Ciencia y Tecnología de los Alimentos (CECYTA); e Instituto de la Construcción de Castilla y León (ICCL).

- En León: Instituto de Toxicología de Castilla y León (INTOXCAL); Instituto de Automática y Fabricación (IAF); Instituto de Ciencia y Tecnología de los Alimentos (ICYTAL); Central de Investigación Leonesa, S.L. (CENILESA); Instituto de Desarrollo Ganadero (INDEGA); Instituto de Medio Ambiente (IMA); Instituto de Recursos Naturales (INRENA); Instituto de Investigaciones Biomédicas (INBIOMED); Instituto Tecnológico de la Pizarra de Castilla y León (INTEC); y Laboratorio de Técnicas Instrumentales e Instalación Radiactiva (LTI).

- En Palencia: Instituto Tecnológico Agrario y Alimentario (ITAGRA).

- En Salamanca: Centro de Investigación y Desarrollo Tecnológico del Agua (CIDTA); Centro de Investigaciones Lingüísticas (CILUS); Centro de Investigación del Cáncer (CIC); Centro Tecnológico de Diseño Cultural y de Desarrollo de las Comunicaciones; Centro Hispano-Luso de Investigaciones Agrarias; Centro Tecnológico Multimedia; Centro de Investigación en Ciencias del Comportamiento (CICCO); Instituto Interuniversitario de Neurociencias de Castilla y León; e Instituto de Investigación del Cáncer.

- En Segovia: Fundación Centro Nacional de Vidrio (CNV).

- En Valladolid: Instituto de Investigación y Desarrollo Tecnológico Industrial (ITI); Instituto de las Tecnologías Avanzadas de la Producción (ITAP); Laboratorio de Técnicas Instrumentales (LTI); Centro de Tecnología Azucarera (CTA); Asociación de Investigación para la Mejora del Cultivo de la Remolacha Azucarera (AIMCRA); Centro de Investigación de la Baja Atmósfera (CIBA); Instituto de Oftalmobiología Aplicada (IOBA); Instituto de Tecnología y Gestión Medioambiental (ITEGMA); Centro Universitario Tecnológico de Sistemas de Información Geográfica y Teledetección; Instituto de Ciencias Médicas (ICIME); Instituto Interuniversitario de Neurotecnología y Técnicas Afines (INYTA); Instituto Universitario de Informática Forense (IUFI); Instituto de Endocrinología y Nutrición (IEN); Instituto Interuniversitario de Neurociencias de Castilla y León; Instituto Universitario de Urbanística; Instituto de Farmacoepidemiología (IFE); Instituto de la Edificación "Juan de Villanueva"; Instituto de Estudios sobre el Alcohol y las Drogas (INEAD); Instituto de la Calidad en la Sanidad (ICAS) e Instituto Español de Arquitectura (Universidades de Alcalá y Valladolid, con sede en esta última institución). 
actividades regionales de $\mathrm{I}+\mathrm{D}+\mathrm{i}$, pero de vital importancia para articular la oferta tecnológica regional. Unidos a ellos, coexisten múltiples Entidades de Ensayo, Calibración, Inspección y Certificación de Productos, algunas de las cuales están reconocidas por la Entidad Nacional de Acreditación (ENAC)

Por último, son destacables, como generadores de conocimiento, las Empresas que disponen de un departamento propio de $\mathrm{I}+\mathrm{D}$ identificable dentro de su estructura. A diferencia de las instituciones anteriormente señaladas, persiguen aprovecharse del conocimiento creado por su organización mediante su utilización en el proceso productivo (evitando con ello la difusión de ese conocimiento) y/o poniendo en el mercado productos o procesos innovadores. En Castilla y León, según una encuesta realizada a 1.855 empresas innovadoras regionales, el 17,1\% (125 firmas) de las que contestaron (732 sociedades) contaban con departamento de I+D (Tabla 10), siendo su presencia más elevada en sectores como los de industria química (52,6\%), construcción (50\%), fabricación de productos de caucho y materias plásticas $(39,1 \%)$, vehículos de motor $(34,8 \%)$ e industria de construcción de maquinaria y equipo mecánico $(33,3 \%)$ [Perán González y Miguel Hernando-2000].

\footnotetext{
${ }^{28}$ Según tipo de entidad:
}

- Laboratorios de Ensayo: Fábrica Nacional de Moneda y Timbre, Galeno \& Vidal, Laboratorio Agrario Regional de la Junta de Castilla y León, y Gestión y Control del Ruido, en Burgos; ENDESA-Servicio de Laboratorio, en León; Laboratorio Interprofesional Lechero de Castilla y León (LILCYL) y Fundación Centro Tecnológico de Cereales de Castilla y León, en Palencia; AQUIMISA S. L. y ENUSA Industrias Avanzadas, S.A., en Salamanca; Laboratorio de Salud Pública de Soria, en Soria; Azucarera Ebro, S.L., Laboratorio de Acústica-Audiotec, Laboratorio de Ensayos Industriales de Castilla y León (LEICAL), Centro Regional de Control de Calidad de la Junta de Castilla y León, Servicio de Investigación y Tecnología Agraria-ITA, Estación Enológica de Castilla y León-ITA, Laboratorio de Análisis y Estudios MedioambientalesCARTIF, Laboratorio de Ensayos de Choque-CIDAUT e Inzamac Asistencias Técnicas, S.A., en Valladolid; Laboratorio de Salud Pública de Zamora, en Zamora.

- Laboratorios de Calibración: Laboratorios Butec, S. L. y Laboratorio Calibración Insitu Burgos, S.L., en Burgos; Laboratorio de Metrología y Calibración Dimensional de la Universidad de Valladolid, Laboratorio de Calibración Eléctrica de Castilla y León (LALECAL), y Laboratorio de Metrología y Calibración de Presión y Temperatura (TERMOCAL), en Valladolid.

- Entidades de Inspección: I.P. Control, S.L., en León; Inspección Técnica de Vehículos Castellana, S.A., Seguridad Industrial, Medioambiente y Calidad, S.L. (SIMECAL), Ingeniería de Gestión Industrial, S.L. (INGEIN), Audiotec Aislamientos Acústicos, S.A. e Investigación y Control de Calidad, S.A., en Valladolid.

- Entidades de Certificación de Productos: Certificadores de Calidad, S.L., en Salamanca; Entidad Productos Alimentos Certificados, S.L. y Certificaciones de Castilla y León, S.L., en Valladolid. 


\section{II.3. La Transmisión de Conocimiento en Castilla y León}

La transmisión de conocimiento no es un proceso automático. Exige tiempo y esfuerzo a los actores implicados en ella. Las Oficinas de Transferencia de Resultados de Investigación, los Centros de Transferencia de Innovación, las Incubadoras de Empresas, las Fundaciones Universidad-Empresa, los Parques Tecnológicos y Científicos, las Asociaciones Empresariales o las Cámaras de Comercio son los principales.

Las Oficinas de Transferencia de Resultados de Investigación u Oficinas de Transferencia de Tecnología (OTRIs/OTTs) son unidades creadas para llevar a cabo tareas de intermediación, con el fin de dinamizar y fomentar las relaciones entre los agentes que configuran el sistema científico y su entorno empresarial. En Castilla y León hay $12^{-9}$ (Tabla 10). Se localizan en las universidades, los organismos públicos de investigación y los Centros Tecnológicos. Disponen de bases de datos de conocimientos explícitos, infraestructuras y ofertas de $\mathrm{I}+\mathrm{D}+\mathrm{i}$ de sus respectivas instituciones.

Los Centros de Transferencia de Innovación tienen como objetivos la promoción de la innovación y el estímulo del intercambio de la investigación entre organizaciones. Además, pueden ejercer funciones de asesoramiento, consulta y capacitación profesional. Sus clientes son principalmente PYMEs, pero, también, grandes empresas, centros de investigación, centros tecnológicos y universidades de su área de influencia. En la actualidad, forman parte de la Red Europea de Centros de Enlace para la Innovación $\underline{30}$ (IRC Network), a fin de mejorar la competitividad de las empresas y

${ }^{29}$ AIMCRA (Valladolid), CARTIF (Valladolid), CEDETEL (Valladolid), ITAGRA (Palencia), CIDAUT (Valladolid), ITCL (Burgos), Universidad de León (León), Fundación INTRAS (Valladolid), Universidad de Burgos (Burgos), Universidad de Salamanca (Salamanca), Universidad Pontificia de Salamanca (Salamanca) y Universidad de Valladolid (Valladolid).

30 En 1995, la Comisión Europea estableció la llamada Red Europea de Centros de Enlace para la Innovación (IRC network). Desde 2004 consta de 71 consorcios o IRCs (Innovation Relay Centres), formados por más de 200 organismos en toda Europa, incluyendo la UE, Bulgaria, Chipre, República Checa, República Eslovaca, Eslovenia, Estonia, Hungría, Islandia, Israel, Letonia, Lituania, Noruega, Polonia, Rumania, Suiza y Turquía. Estos IRCs han sido creados para estimular la transferencia de tecnología entre los países integrantes de la red y promover los servicios innovadores. A su vez constan de una plantilla que posee amplios conocimientos del perfil tecnológico y económico de las compañías y regiones a quien prestan servicio. 
contribuir a la consolidación de la infraestructura europea de apoyo profesional a la innovación. GALACTEA es el único Centro de Enlace existente en la Comunidad Autónoma (Tabla 10). Se ubica en la Sociedad Parques Tecnológicos de Castilla y León, S.A. (Boecillo, Valladolid) y abarca las Comunidades Autónomas de Asturias, Cantabria, Castilla y León y Galicia, siendo la Fundación para el Fomento de la Investigación Científica Aplicada y la Tecnología de Asturias (FICYT) la entidad coordinadora. GALACTEA ofrece gratuitamente a sus clientes los siguientes servicios: localización de tecnologías interesantes en el ámbito europeo; localización de clientes en Europa que puedan acceder a tecnologías generadas en las Autonomías aludidas; e información sobre programas europeos, redes europeas y financiación de la innovación.

Las Incubadoras de Empresas, también denominadas Centros de Innovación o Centros de Empresas e Innovación (CEIs), se orientan a apoyar la creación de unidades productivas innovadoras, desarrollar las ya existentes, promover la innovación y favorecer la implantación de nuevas actividades, sectores y tecnologías. Dado que suelen ser el resultado de la participación de los principales agentes locales y regionales para el desarrollo económico (públicos y privados), constituyen un instrumento en el que confluyen múltiples intereses: de la universidad (fuente principal de Capital Intelectual), del empresariado (naciente o consolidado), de las PYMEs y grandes empresas (a través de las llamadas spin-offs, que abordaremos con posterioridad) y de aquellas fuentes de financiación que encuentran en su entorno potenciales proyectos de interés.

Se hayan integradas en la Asociación Nacional de Centros Europeos de Empresas e Innovación (ANCES), afiliada, a su vez, a la Red Europea EBN (European BIC Business and Innovation Centres- Network). En la Comunidad Autónoma, el Centro Europeo de Empresas e Innovación de Castilla y León (CEEICAL, S.A.), creado en 1989, cuenta con dos incubadoras, ubicadas respectivamente en el Parque Tecnológico de Boecillo (Valladolid, 30 empresas instaladas) y en el Polígono Industrial de Onzonilla (León, 14 sociedades). El Centro Europeo de Empresas e Innovación de Burgos, surgido en 1994, posee una incubadora (ubicada en la referida ciudad), estando en proyecto otras tres (dos en Salamanca y una en Segovia) (Tabla 10). Por su parte, las 
Cámaras de Comercio (a través de la Fundación INCYDE y con subvención parcial de la Unión Europea), han puesto en marcha además un programa para la creación de viveros de empresas $\frac{31 \text {. }}{\text {. }}$

Las Fundaciones Universidad-Empresa (FUEs) son entidades sin ánimo de lucro nacidas como órgano de mediación y acercamiento de empresas y universidades. Tienen como objetivo abrir vías de diálogo y colaboración en temas de interés común, centran sus actuaciones en las áreas de la transferencia tecnológica, la formación especializada, las prácticas educativas, el fomento del empleo, la sensibilización social, la difusión de la información y las actividades internacionales. Las cuatro fundaciones autonómicas son: la de Burgos (Fundación General de la Universidad de Burgos); la de León (Fundación General de la Universidad de León y Empresa - FGULEM); la de Salamanca (Fundación General de la Universidad-Empresa de Salamanca - FGUSAL), participando también en ella la Universidad Pontificia; y la de Valladolid (Fundación General de la Universidad de Valladolid - FGUVA) (Tabla 10).

Por otra parte, los Parques Tecnológicos son organizaciones creadas para incrementar la cultura de la innovación y la competitividad de las empresas e instituciones generadoras de saber instaladas en su recinto o asociadas a él. La terminología utilizada por los responsables de estas iniciativas distingue entre Parques Tecnológicos y Parques Científicos. El primero de esos términos se utiliza, generalmente, para los promovidos por los gobiernos regionales, con el fin de alcanzar un mayor desarrollo en las Comunidades Autónomas. El segundo, para los que se impulsan desde las universidades. En Castilla y León funcionan dos Parques Tecnológicos (año 2005): el de Boecillo (en la provincia de Valladolid), operativo desde 1992, y el de León 32 (operativo desde Febrero de 2005), en las inmediaciones de dicha capital. Se haya en fase de construcción el Parque Tecnológico de Burgos 33 , en la localidad de Villafría,

\footnotetext{
${ }^{31}$ En Valladolid (en funcionamiento); en Cuéllar (Segovia) y Salamanca (ambas en ejecución); en Ávila, Burgos, Soria y Zamora (en fase de estudio).

32 En Noviembre de 2000, el Ayuntamiento de León y GESTURCAL (Gestión Urbanística de Castilla y León) firmaron un convenio para el desarrollo del Parque Tecnológico de la ciudad de León.

${ }^{33}$ En Abril de 2005, la Consejería de Economía de la Junta de Castilla y León; los Ayuntamientos de Burgos y Cardeñajimeno; y GESTURCAL (Gestión Urbanística de Castilla y León) firmaron un convenio para la promoción, ejecución y gestión de dicho Parque.
} 
que estará operativo hacia el 2008, con la colaboración del gobierno regional (Tabla

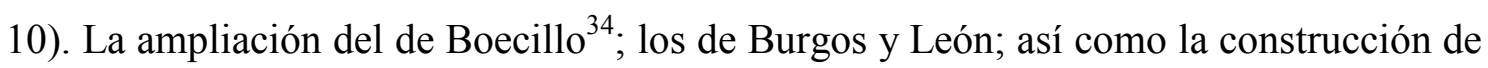
un Parque Científico en Salamanca, para aprovechar las investigaciones que cuentan con una mayor relevancia en su recinto universitario (la Biotecnología agraria y la Medicina), serán gestionados por la sociedad pública Parques Tecnológicos de Castilla y León, S.A.

Las Asociaciones Empresariales, son organizaciones profesionales de carácter confederativo e intersectorial sin ánimo de lucro. Entre otras funciones, prestan o coordinan servicios de soporte a la innovación (de intermediación, difusión, formación, etc.). En la Comunidad Autónoma se articulan, principalmente, a través de la Confederación de Organizaciones Empresariales de Castilla y León (CECALE), que

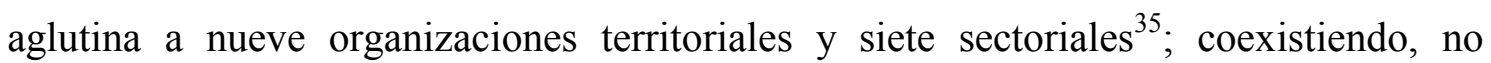
obstante, con otras de cierta importancia, como por ejemplo: AETICAL (Asociación Empresarial de las Tecnologías de Información y Comunicaciones de Castilla y León), AEMTA Agrupación de Sociedades Laborales de Castilla y León), PINACAL (Asociación de Productores de Piedra Natural de Castilla y León), EFCL (Asociación Empresa Familiar de Castilla y León) y CEFS (Círculo de la Empresa Familiar de Salamanca) (Tabla 10).

\footnotetext{
${ }^{34}$ En el Parque Tecnológico de Boecillo, a finales de 2003, se ubicaban alrededor de 100 empresas; tres Centros Tecnológicos (CARTIF, CEDETEL y CIDAUT); la incubadora de empresas CEEICAL, S.A.; el Centro Europeo de Información Empresarial en Castilla y León; la Oficina Regional de la Red de Centros de Enlace para la Innovación; y la División de Innovación y Tecnología del Promotor.

${ }^{35}$ Las territoriales son las siguientes: Confederación Abulense de Empresarios (CONFAE); Federación de Asociaciones Empresariales de Burgos (FAE); Federación Leonesa de Empresarios (FELE); Confederación Palentina de Organizaciones Empresariales (CPOE); Confederación de Organizaciones de Empresarios Salmantinos (CONFAES); Federación Segoviana de Empresarios (FES); Federación de Organizaciones Empresariales Sorianas (FOES); Confederación Vallisoletana de Empresarios (CVE); y Confederación de Asociaciones de Empresarios Zamoranos (CEOE-CEPYME).

Las sectoriales: Confederación de Comercio de Castilla y León (CONFERCO); Confederación Castellano Leonesa de la Construcción (CCLC); Asociación Castellano Leonesa de Empresas de Ingeniería y Consultoras (ACALINCO); Federación Castellano Leonesa de Empresarios de Ambulancias (ALECA); Federación de Asociaciones de Academias de Enseñanza (FACLAE); Asociación de Laboratorios Acreditados de Castilla y León (ALCAL); y Confederación de Empresarios de la Madera de Castilla y León (CEMCAL).
} 
Finalmente, las Cámaras de Comercio ejercen de intermediarias entre las empresas y las instituciones, para promover el comercio, la exportación y la internacionalización de las unidades productivas. Al mismo tiempo, les ofrecen información y asesoramiento para facilitar su modernización. Castilla y León dispone de una red de 14 Cámaras Oficiales de Comercio e Industria (Tabla 10), situadas en Arévalo, Astorga, Ávila, Béjar, Briviesca, Burgos, León, Miranda de Ebro, Palencia, Salamanca, Segovia, Soria, Valladolid y Zamora. Todas ellas conforman e integran el Consejo Regional, con sede en Valladolid.

\section{II.4. Especificidades Sectoriales y Locales del Conocimiento en Castilla y León}

La base del conocimiento está fragmentada y conformada por depósitos semipúblicos, cuyo acceso está repartido de forma territorial, profesionalmente y a través de redes. Ninguno de los diferentes tipos de conocimiento analizados en el apartado I.2.1. (knowwhat, know-why, know-how y know-who) tiene un carácter ni estrictamente público ni estrictamente privado, desde el punto de vista económico, difiriendo, además, en términos de grado y de forma [Lundvall-1999: 19-23]:

- El know-what puede no estar disponible para aquellas personas que no están conectadas con las redes sociales o de telecomunicaciones adecuadas.

- Para que el acceso al know-why científico sea efectivo, el usuario debe invertir en adquirir la capacidad de absorción necesaria para ello.

- Dado que la forma en la que una persona (u organización) hace las cosas refleja su personalidad (o la de la organización), el know-how es el que presenta un acceso público más limitado.

- El know-who se basa en una combinación de información y relaciones sociales. Éstas relaciones son personales y, por definición, no públicas. No se pueden transferir y no se pueden comprar ni vender en el mercado. 
Por otra parte, y también teniendo en cuenta lo expuesto en el apartado I.2.1, el conocimiento codificado (explícito) es un conocimiento potencialmente compartido; en tanto que el no codificado (tácito) se mantiene privado, al menos, hasta que puede ser adquirido en una interacción directa con su poseedor.

Estos importantes atributos del conocimiento (público/privado, codificado/no codificado) sugieren la posibilidad de que, en función de las características de su base de conocimiento, coexistan sectores con marcadas diferencias entre sí. De este modo, según la taxonomía elaborada por Pavitt [1984], la producción de conocimiento se refleja en el carácter, el modo y el resultado del proceso de innovación, pudiéndose distinguir entre:

- Sectores intensivos en economías de escala (alimentación, cemento, etc.): las empresas mantienen una fabricación en masa y procesos productivos continuos. Centran sus actividades innovadoras en el desarrollo de tecnología más eficiente para el proceso productivo.

- Sectores dominados por suministradores especializados (ingenierías, máquinaherramienta, proveedores de software, etc.): llevan a cabo frecuentes innovaciones de producto, generalmente en colaboración con sus clientes.

- Sectores dominados por productores basados en la ciencia (industria química, electrónica, biotecnología, etc.): desarrollan tanto nuevos productos como nuevos procesos, en estrecha colaboración con las universidades.

- Sectores dominados por los proveedores (textil, mueble, etc.): las empresas desarrollan pocas innovaciones importantes por sí mismas. Las obtienen de otras empresas.

El problema de esta taxonomía es que no recoge adecuadamente el carácter, el modo y el resultado del proceso de innovación en el sector servicios. Por ello, Soete y Miozzo [1990], incluyeron este aspecto (Tabla 11), dando lugar a la siguiente tipología de empresas de servicios: 
- Empresas con redes físicas a gran escala: los servicios que se prestan tienen una naturaleza tangible (transporte y distribución).

- Empresas con redes de información: los servicios se materializan en información codificada (finanzas, seguros y comunicaciones).

- Empresas suministradoras especializadas y/o basadas en la ciencia: incluye a todos los proveedores de servicios que tienen una fuerte vinculación con la $\mathrm{I}+\mathrm{D}$ y las tecnologías de la información y de la comunicación.

- Empresas dominadas por los proveedores de equipos y sistemas técnicos: no son muy innovadoras y dependen de la adquisición de innovaciones de proceso de sus proveedores. Pueden dividirse, a su vez, en empresas de servicios personales (reparaciones, limpieza, venta al por menor, hostelería y restauración) y de servicios públicos y/o sociales (educación, sanidad y administraciones públicas).

En Castilla y León, el conocimiento generado, tanto dentro como fuera de su ámbito de influencia, revierte a los responsables de su creación y la Sociedad en su conjunto. A su vez, es utilizado por las organizaciones, en su búsqueda de innovaciones de distinta naturaleza. Ahora bien, el sector productivo al que pertenecen, la rama de actividad en la que se ubican y su tamaño, condicionan la capacidad y aprovechamiento del mismo. 
TABLA 11

TIPOLOGÍA SECTORIAL DE PAVITT Y AMPLIACIÓN DE SOETE Y MIOZZO

\begin{tabular}{|c|c|c|c|}
\hline \multicolumn{2}{|c|}{ TAXONOMÍA DE PAVITT } & & \\
\hline Elemento Característico & Sectores & & \\
\hline Economías de escala & $\begin{array}{l}\text { Acero, } \\
\text { Automóvil,... }\end{array}$ & & \\
\hline $\begin{array}{l}\text { Proveedores } \\
\text { especializados }\end{array}$ & $\begin{array}{l}\text { Ingeniería mecánica, } \\
\text { Instrumentos, ... }\end{array}$ & & \\
\hline Ciencia & $\begin{array}{l}\text { Electrónica, } \\
\text { Electricidad, } \\
\text { Química,... }\end{array}$ & & \\
\hline \multirow{2}{*}{ Proveedores } & $\begin{array}{l}\text { Agricultura, } \\
\text { Construcción, } \\
\text { Manufacturas } \\
\text { tradicionales,... }\end{array}$ & & \\
\hline & $\begin{array}{l}\text { Servicios a empresas, } \\
\text { Servicios financieros, } \\
\text { Servicios profesionales }\end{array}$ & \multicolumn{2}{|c|}{ TAXONOMÍA DE SOETE Y MIOZZO } \\
\hline & & $\begin{array}{c}\text { Elemento } \\
\text { Característico }\end{array}$ & Sectores \\
\hline & & $\begin{array}{l}\text { Redes físicas de gran } \\
\text { escala }\end{array}$ & $\begin{array}{l}\text { Transporte, } \\
\text { Distribución, ... }\end{array}$ \\
\hline & & $\begin{array}{l}\text { Redes de } \\
\text { Información }\end{array}$ & $\begin{array}{l}\text { Finanzas, Seguros, } \\
\text { Comunicaciones,... }\end{array}$ \\
\hline & & $\begin{array}{l}\text { Proveedores } \\
\text { especializados y/o } \\
\text { basados en la ciencia }\end{array}$ & $\begin{array}{l}\text { Software, } \\
\text { Servicios avanzados } \\
\text { a empresas,... }\end{array}$ \\
\hline & & \multirow{2}{*}{$\begin{array}{l}\text { Proveedores de } \\
\text { equipos y sistemas } \\
\text { técnicos }\end{array}$} & $\begin{array}{l}\text { Limpieza, } \\
\text { Reparación, } \\
\text { Hostelería, } \\
\text { Venta Minorista,... }\end{array}$ \\
\hline & & & $\begin{array}{l}\text { Educación, Sanidad, } \\
\text { Administraciones } \\
\text { Públicas,... }\end{array}$ \\
\hline
\end{tabular}

FUENTE: Gallouj [2002]

En este sentido, según INEBASE, la estructura sectorial del Valor Añadido Bruto $\left(\mathrm{VAB}^{\frac{36}{6}}\right)$ de Castilla y León pone de manifiesto un mayor peso relativo de los sectores

\footnotetext{
${ }^{36}$ Mide la producción final generada por los diferentes agentes que componen un entramado económico.
} 
agrario e industrial que con respecto al conjunto nacional, así como una fuerte heterogeneidad provincial. La significativa importancia de la agricultura de Castilla y León resulta especialmente acusada en Ávila y Zamora (entendidas como provincias). La de la industria, en Burgos, León, Palencia y Valladolid; en tanto que los servicios, destacan en Ávila, Salamanca y Segovia. Además, dentro del sector industrial (de especial trascendencia en las actividades de $\mathrm{I}+\mathrm{D}+\mathrm{i}$, al ser, tradicionalmente, su principal responsable), sobresalen por su participación en el VAB: “Alimentación, Bebidas y Tabaco" y "Fabricación de Material de Transporte"; seguidas ya a cierta distancia, de las actividades vinculadas a "Energía Eléctrica, Gas y Agua" y "Extracción de Productos Energéticos, Otros Minerales y Refino de Petróleo”. Todas ellas están más fuertemente implantadas en la Comunidad Autónoma que en España. Lo mismo sucede con las de "Caucho y Plástico" y "Madera y Corcho".

En cuanto a la dimensión de las empresas castellanas y leonesas, predominan fuertemente las que tienen un tamaño muy reducido. Concretamente, sólo un $0,1 \%$ de ellas cuenta con un número igual o superior a 200 empleados $(0,18 \%$ en el ámbito nacional) $\mathrm{y}$, dentro de las PYMEs, las micropymes (0-9 trabajadores) son más abundantes en la región $(95,27 \%)$ que en España $(93,94 \%)$. Ciertamente, el dominio de estas últimas (especialmente acusado en las provincias de Ávila (96,69\%), Zamora (96,53\%), Palencia (95,91\%), León $(95,65 \%)$, Salamanca $(95,39 \%)$ y del 95,32\% en Segovia) no favorece las actividades innovadoras en la Comunidad Autónoma este tipo de sociedades más problemas en este sentido.

Además, aunque en principio las empresas de mayor tamaño sean las más capacitadas para generar y gestionar conocimiento (por los recursos humanos que movilizan), ni todas las provincias, ni todas las ramas de actividad estarían en igualdad de condiciones para llevar a cabo estas tareas. Ello es debido a la elevada concentración provincial y

\footnotetext{
${ }^{37}$ El esfuerzo regional en innovación es inferior al nacional. De hecho, no se aprecia una tendencia convergente entre tales dos espacios geográficos cuando se analiza el porcentaje de la cifra de ventas dedicado a innovación. A nivel sectorial, sobresale la intensidad innovadora de las empresas castellanas y leonesas de "Maquinaria y Equipo Mecánico", "Material y Equipo Eléctrico, Electrónico y Óptico", "Productos Minerales no Metálicos Diversos", "Madera y Corcho" y, en menor medida, de "Alimentación, Bebidas y Tabaco". En cambio, la de las vinculadas a "Material de Transporte" y "Caucho y Materias Plásticas", dos de las principales ramas de la actividad regional, se encuentra por debajo de la de su respectiva media estatal, síntoma de debilidad sectorial y/o de dependencia tecnológica del exterior.
} 
sectorial que se detecta en la distribución de las organizaciones industriales de 100 ó más empleados localizada en Castilla y León. Concretamente, según INEBASE, en el año 2003, Burgos (32,8\%), Valladolid (24,2\%) y León (16,7\%), absorbían el 73,7\% de las mismas. Análogamente, las actividades de "Alimentación, Bebidas y Tabaco" (24,2\%), "Fabricación de Material de Transporte" (10,6\%) y "Metalurgia y Productos Metálicos" (9,6\%), suponen el 44,4\% de tales organizaciones.

La descomposición del gasto total regional en $\mathrm{I}+\mathrm{D}$, por tipo de empresa, efectuado en 2002, aparece en la Tabla 12. El 77,71\% del mismo era realizado por 33 sociedades de servicios de alta tecnología (el 36,14\% en el contexto español), dando empleo a 1.005 trabajadores en Equivalencia a Jornada Completa (EJC) (el 70,03\% del total castellano y leonés; un 37,70\% en España). En cambio, las 13 firmas manufactureras autonómicas de alta tecnología ejecutaban el 3,90\% del gasto en investigación y desarrollo (el $30,59 \%$ en el conjunto del Estado) y utilizaban a 100 empleados a tiempo completo (el $6,97 \%$ del total regional; un $25,03 \%$ en todo el territorio nacional); mientras que las 39 unidades productivas de media-alta tecnología generaban el 18,79\% del referido gasto (el $33,27 \%$, en España) y daban empleo al $23 \%$ del personal en equivalencia a jornada completa (el 37,27\% en el territorio nacional).

\section{TABLA 12}

INDICADORES BÁSICOS DE I+D SEGÚN TIPO DE EMPRESA (2002)

\begin{tabular}{|c|c|c|c|c|c|c|}
\hline \multirow[b]{2}{*}{ Tipo de Empresa } & \multicolumn{3}{|c|}{ Castilla y León } & \multicolumn{3}{|c|}{ España } \\
\hline & $\begin{array}{c}\mathrm{N}^{\circ} \\
\text { Empresas } \\
(\%)\end{array}$ & $\begin{array}{c}\text { Gastos en } \\
\text { I+D } \\
(\text { miles } €) \\
(\%)\end{array}$ & $\begin{array}{c}\text { Personal } \\
\text { en EJC } \\
(\%)\end{array}$ & $\begin{array}{c}\mathrm{N}^{\mathbf{0}} \\
\text { Empresas } \\
(\%)\end{array}$ & $\begin{array}{c}\text { Gastos en } \\
\text { I+D } \\
(\text { miles } €) \\
(\%)\end{array}$ & $\begin{array}{c}\text { Personal } \\
\text { en EJC } \\
(\%)\end{array}$ \\
\hline $\begin{array}{l}\text { Manufacturas de Alta } \\
\text { Tecnología } 1\end{array}$ & $\begin{array}{c}13 \\
(15,30)\end{array}$ & $\begin{array}{l}5.214 \\
(3,90)\end{array}$ & $\begin{array}{c}100 \\
(6,97)\end{array}$ & $\begin{array}{c}532 \\
(17,86)\end{array}$ & $\begin{array}{l}875.885 \\
(30,59)\end{array}$ & $\begin{array}{c}9.950 \\
(25,03)\end{array}$ \\
\hline $\begin{array}{l}\text { Servicios de Alta } \\
\text { Tecnología }\end{array}$ & $\begin{array}{c}33 \\
(38,82)\end{array}$ & $\begin{array}{l}103.354 \\
(77,71)\end{array}$ & $\begin{array}{c}1.005 \\
(70,03)\end{array}$ & $\begin{array}{c}877 \\
(29,44)\end{array}$ & $\begin{array}{l}1.034 .920 \\
(36,14)\end{array}$ & $\begin{array}{l}14.987 \\
(37,70)\end{array}$ \\
\hline $\begin{array}{l}\text { Manufacturas de } \\
\text { Media-Alta Tecnología }\end{array}$ & $\begin{array}{c}39 \\
(45,88)\end{array}$ & $\begin{array}{l}25.117 \\
(18,79)\end{array}$ & $\begin{array}{c}330 \\
(23,00)\end{array}$ & $\begin{array}{c}1.570 \\
(52,70)\end{array}$ & $\begin{array}{c}952.636 \\
(33,27)\end{array}$ & $\begin{array}{l}14.818 \\
(37,27)\end{array}$ \\
\hline Total & $\begin{array}{c}85 \\
(100,00)\end{array}$ & $\begin{array}{l}133.685 \\
(100,00)\end{array}$ & $\begin{array}{c}1.435 \\
(100,00)\end{array}$ & $\begin{array}{c}2.979 \\
(100,00)\end{array}$ & $\begin{array}{c}2.863 .441 \\
(100,00)\end{array}$ & $\begin{array}{c}39.755 \\
(100,00)\end{array}$ \\
\hline
\end{tabular}

Industria Farmacéutica; Maquinaria de Oficina y Material Informático; Componentes Electrónicos; Aparatos de Radio, TV y Comunicaciones; Instrumentos Médicos, de Precisión, Óptica y Relojería; Construcción Aeronáutica y Espacial.

${ }^{2}$ Correos y Telecomunicaciones; Actividades Informáticas; Investigación y Desarrollo.

3 Industria Química (excepto Farmacia); Maquinaria y Equipo; Maquinaria y Aparatos Eléctricos; Industria del Automóvil; Otro Material de Transporte.

FUENTE: INEBASE [Instituto Nacional de Estadística] 


\section{II.5. Los Sectores Clave de la Economía de Castilla y León}

La importancia cuantitativa que revisten los sectores Agroalimentario y de Automoción, así como la relevancia estratégica que tienen para Castilla y León, requieren una mayor atención. Lo mismo sucede con otras actividades que, aunque situadas a mucha distancia de las anteriores, están adquiriendo una gran proyección en la Comunidad Autónoma, habiendo merecido incluso una atención específica en la Estrategia Regional de Innovación 2002-2006 [JUNTA DE CASTILLA Y LEÓN-2002b]: las tecnologías de la información y las telecomunicaciones; la conservación del patrimonio; y la biotecnología. Tratemos a todos ellos en los apartados subsiguientes $\frac{68}{\text {. }}$

\section{II.5.1. EI Sector Agroalimentario}

La industria agroalimentaria de Castilla y León está estrechamente ligada a sus producciones agropecuarias. Hasta la década de los sesenta del siglo pasado era muy tradicional, vinculada al mundo rural, de muy pequeño tamaño (prácticamente familiar) y de carácter local. Desde entonces, la agricultura y la ganadería han ido desarrollando una producción más moderna e industrializada, con mayor orientación hacia procesos de transformación y distribución. Además, desde 1990, existe un considerable interés por la calidad y estandarización de los productos. Hoy en día, la agroalimentación es muy importante, no ya sólo por el empleo que genera (el mayor en los núcleos rurales), sino

\footnotetext{
${ }^{38}$ La Estrategia Regional de Innovación 2002-2006 [JUNTA DE CASTILLA Y LEÓN-2002b], incluye, también, el novedoso sector aeronáutico, centrado en cinco empresas que intervienen en la fabricación de piezas del avión de pasajeros "Airbus-380" (A380): ARESA, quien, a mediados del año 2005, continúa en fase de implantación en el Parque Tecnológico de Boecillo (Valladolid): diseña y fabrica diferentes elementos interiores de timones horizontales y verticales, costillas y refuerzos del ala, y costillas y refuerzos del cajón de torsión; CASTILLA AERO, en Miranda de Ebro (Burgos): es la responsable de la estructura que ubica los sistemas vitales del aparato, así como el tren principal de aterrizaje del A380; INDEX Ingeniería, también en Miranda de Ebro (Burgos): realiza ingeniería de diapositivas y mecanismos del avión; INMAPA Aeronáutico, en Venta de Baños (Palencia): diseña y fabrica utillajes especiales para determinadas piezas del avión; y NICOLÁS CORREA, en Burgos: ha desarrollado y fabricado máquinas y herramientas para el mecanizado de conjuntos metálicos.

Con un claro favorecimiento hacia su actividad por parte de la Administración regional, las referidas empresas carecen de peso económico de importancia sectorial, aunque sí lo supongan desde el punto de vista de las tecnologías avanzadas. Debido a lo embrionario de su estado, al no existir precedentes o bases derivadas de otros sectores castellanos y leoneses para el aeronáutico, junto con la consiguiente falta de datos al respecto, no abordaremos éste más que en la presente mención de su posible desarrollo futuro.
} 


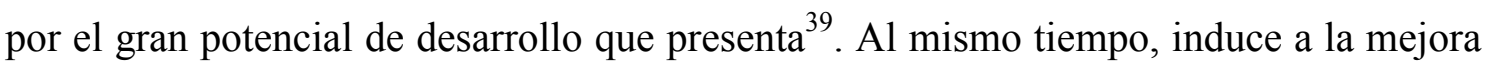
de otros sectores, especialmente a la agricultura [Kallas y Gómez-Limón Rodríguez2004].

En la actualidad, constituye el principal sector industrial de dicha Comunidad Autónoma. De acuerdo con INEBASE (datos referidos a 2003), genera en torno a la cuarta parte de su VAB industrial no energético (el 14,49\% en España). Da empleo al $24,44 \%$ de las personas ocupadas en la industria manufacturera (el 14,57\% en el ámbito nacional); ejecuta el 24,16\% del gasto total en innovación (el 10,36\% en el conjunto del Estado) y es responsable, en un 39,53\%, del que realizan las PYMEs industriales de Castilla y León (el 14,47\% en todo el territorio nacional). A su vez, el gasto que lleva a cabo en innovación representa el 5,39\% del VAB del sector alimentario de la referida Comunidad Autónoma (el 2,56\% en España).

El sector agroalimentario está presente en las nueve provincias castellanas y leonesas. En ellas coexisten dos tipos de industrias. En uno predomina la primera transformación y sus empresas (habitualmente de gran tamaño y vinculadas de forma creciente a capital extranjero) se ubican en los principales núcleos de población, en su entorno y en los ejes de comunicación que atraviesan la Comunidad Autónoma. El otro viene marcado por las producciones diferenciales y la pequeña dimensión empresarial ${ }^{40}$ [MAPA-2003: 509].

Presenta, además, otros problemas, como la dificultad para acceder a recursos humanos de alta cualificación o las restricciones financieras y de posicionamiento en el mercado. Sólo unos pocos grupos de gran entidad (cuyo núcleo lo constituyen EBRO-PULEVA, PASCUAL y CAMPOFRÍO) desempeñan un papel clave, arrastrando consigo a las PYMEs del sector, especialmente las cercanas a sus fábricas. Estos grupos son los que

\footnotetext{
${ }^{39}$ Condicionado, no obstante, según Moreno Rodríguez [2005], por el calentamiento global que ya se observa en el planeta, y los inciertos cambios climáticos en que este hecho derivará en España.

${ }^{40}$ La pequeña dimensión empresarial es un hecho preponderante tanto en el contexto castellano y leonés, como en el ámbito nacional y europeo. En 2003, tomando como base el Directorio Central de Empresas (DIRCE), del INE, el 86,96\% de las empresas agroalimentarias de Castilla y León $(3.329 ; 33.275$ en España) tenían menos de 10 empleados (el $82,75 \%$ en todo el territorio español) y sólo el $2,1 \%$ más de 50 (el 3,39\% en el conjunto del Estado).
} 
aportan verdadero valor al mismo, adentrándose en mercados extranjeros, haciendo extensivas las exigencias y estándares de calidad a las PYMEs, y favoreciendo el desarrollo de nuevos sistemas de gestión que contribuyan a su crecimiento paulatino. Consecuentemente, la agrupación de microempresas en otras entidades de mayor tamaño, más productivas y competitivas, es una de las claves de la agroalimentación en Castilla y León. Sólo en estas últimas tiene sentido hablar de Gestión del Conocimiento, pues en el caso de las microempresas, el simple sostenimiento de las mismas no permite tal posibilidad.

Por otra parte, exceptuando a las grandes empresas indicadas anteriormente, se observa un retraso en las áreas de diseño y marketing. La competitividad del sector agroalimentario de Castilla y León pasa, entonces, por flexibilizar su estructura productiva y darle un soporte tecnológico robusto y puntero, con el apoyo de los Centros Tecnológicos. Este hecho, se agrava en las PYMEs, donde las exigencias de $\mathrm{I}+\mathrm{D}+\mathrm{i}$ precisan de cuantiosas inversiones que no pueden acometer.

Para desarrollar la estructura productiva de las PYMEs es necesario, en primer lugar, tener una oferta agrícola de calidad, al ser la materia prima la clave del éxito de las empresas del sector [COMISIÓN EUROPEA-2002a]. En segundo, cualificar adecuadamente a su capital humano, activo principal de estas PYMEs, a través de programas de formación en la innovación y haciendo que las empresas ubicadas en las áreas rurales de Castilla y León tengan acceso a estas acciones, dada su importancia para el asentamiento poblacional en las mismas [Blanco et al.-2002; Perán González, Antón Freile y Caballero Fombellida -2004]. En tercero, analizar las posibilidades que ofrecen las nuevas tecnologías en el sector, por cuanto pueden solventar la carencia de infraestructuras en esos núcleos (especialmente las zonas periféricas de las provincias de León, Zamora y Salamanca). Dichas tecnologías suponen un cambio en el modelo de negocio (al que las empresas se tienen que adaptar de modo global), pero que las PYMEs no saben asumir. Por último, incorporar esas nuevas tecnologías en la logística y distribución, dado que abre nuevos caminos para obtener ventajas competitivas [Blanco et al.-2000]. No en vano, los agentes de desarrollo local, los grupos de acción local y las propias corporaciones municipales, entre otros colectivos, deberán ser los impulsores del desarrollo y del empleo en las zonas rurales de la Castilla y León. Así 
figura en el borrador del "Libro Blanco del Desarrollo Local y el Empleo de Castilla y León", que está elaborando el gobierno de dicha Comunidad Autónoma, y que fue presentado el 3 de Agosto de 2005 ante el Consejo Económico y Social.

\section{II.5.2. EI Sector de Automoción}

El sector de automoción es el segundo en importancia de Castilla y León. Según datos de INEBASE en 2003, absorbe el 20,84\% de su VAB industrial no energético (el $11,89 \%$ en el ámbito nacional); da empleo al $12,97 \%$ de las personas ocupadas en la industria manufacturera (el $8,53 \%$ en España); ejecuta el $25,01 \%$ de su gasto total en innovación (el 23,84\% en el conjunto del Estado); y es responsable, en un 1,24\%, del que realizan las PYMEs industriales de la región (el 3,03\% en todo el territorio nacional); representando el gasto que lleva a cabo en innovación el 6,52\% del VAB del sector de Material de Transporte autonómico (el 13,58\% en España). Además, aglutina, por sí solo, la mitad del comercio exterior castellano y leonés (concretamente, el $59,57 \%$ de las exportaciones y el 46,53\% de las importaciones, en 2001) [JUNTA DE CASTILLA Y LEÓN-2003c].

En 2003, contaba con 158 empresas (179 establecimientos industriales ${ }^{4}$ ), entre plantas de montaje y suministradoras de piezas y componentes, el 7,05\% del total nacional (2.241 sociedades), según el Directorio Central de Empresas (DIRCE), del Instituto Nacional de Estadística. Ahora bien, sólo cuatro de ellas tenían la categoría de grandes unidades productivas: RENAULT España (Valladolid y Palencia), IVECO-PEGASO (Valladolid), GRUPO ANTOLÍN (Burgos) y NISSAN Vehículos Industriales (Ávila). En su conjunto, daban empleo a cerca de 24.000 trabajadores, constituyendo una fuente de gran riqueza industrial, por su capacidad de arrastre de la economía de la referida Comunidad Autónoma. En el extremo opuesto, 98 empresas (el 62,02\% del total regional) ostentaban el carácter de microempresas. Entre ambos grupos se situaba un bloque intermedio de firmas auxiliares: BENTELER España, S.A. (Burgos), HUF

\footnotetext{
${ }^{41}$ De acuerdo con el INE, se considera establecimiento industrial a toda unidad productiva de carácter industrial situada en un mismo emplazamiento geográfico, con las unidades satélites y auxiliares de ella dependientes situadas en sus inmediaciones, y en la cual trabajan una o varias personas por cuenta de la misma empresa. Además, un establecimiento tiene carácter industrial si su actividad principal pertenece a las divisiones 1 a 4 de la CNAE (Clasificación Nacional de Actividades Económicas de España).
} 
España (Soria), ZF Ansa Lemforder (Burgos), JOHNSON CONTROLS (Valladolid), GESTAMP (Palencia), etc.

El sector de automoción y sus componentes se apoya en la inversión extranjera de grandes multinacionales, despuntando, entre las anteriormente indicadas, RENAULT y NISSAN. Estas dos firmas conforman un gran grupo tractor, especialmente tras la alianza entre ambas 2 . Crean en su derredor un importante y concentrado núcleo de PYMEs para su suministro, que, en conjunto, forman el $80 \%$ de aquél [JUNTA DE CASTILLA Y LEÓN-2002b].

El sistema de distribución just in time, con sus premisas de cero defectos, cero retrasos y cero excedentes (stocks), ha supuesto una verdadera revolución para este sector desde los años noventa del siglo pasado. En el contexto de la nueva economía, ha modificado conceptos firmemente arraigados sobre calidad, productividad, servicio y el recién incorporado término "medio ambiente", arrastrando consigo a las PYMEs dedicadas y cortando drásticamente el hilo existencial de las más tradicionales e inmovilistas [Perán González y Antolín Giraldo-1999]. Por idéntico motivo, los cambios en las formas de gestión y producción en los últimos años se han traducido en una reducción del número de proveedores con que cuentan las grandes firmas, pero a quienes se exige más resultados, responsabilidad y más involucración en el proceso de montaje. Así, la reducción gradual de precios que recientemente ha sufrido la automoción, ha sido trasladada a los fabricantes de componentes [UGT-2002].

En este contexto, el ingreso de España en la UE, en 1986, y, desde entonces, la cada vez mayor competencia y calidad de producto exigida por la paulatina incorporación de nuestro país a la dinámica europea y la globalización económica, ha mermado su ritmo

42 El 27 de Marzo de 1999, en Tokio (Japón), Louis Schweitzer (director general de RENAULT) y Yoshikazu Hanawa (presidente de NISSAN), anuncian el nacimiento de la Alianza entre ambas firmas. Esta Alianza RENAULT-NISSAN no tiene equivalente en el resto de grupos automovilísticos mundiales. Se trata de un modelo de colaboración entre dos empresas que mantienen su propia identidad. Sus principios se fundan en la confianza y respeto mutuos, con una organización transparente. La Alianza asegura un proceso claro en la toma de decisiones, garantizándose así la capacidad de reacción, la responsabilidad y un alto rendimiento. También atrae y retiene los mejores talentos, propone condiciones de trabajo atractivas y desafíos tentadores. Genera para sus accionistas una retribución interesante y hace uso de las mejores prácticas de gobierno [Global-RENAULT-2005]. 
de crecimiento, al ser más barata la fabricación en otros países recién incorporados a la UE o candidatos a ello [Rodríguez Enríquez-2002]. España, tiene la desventaja añadida de ser un país periférico de Europa, con lo que los costes logísticos son más elevados.

Estos hechos constituyen una amenaza constante para el empleo, por lo que la Junta de Castilla y León ha optado por la creación del denominado Foro de Automoción de

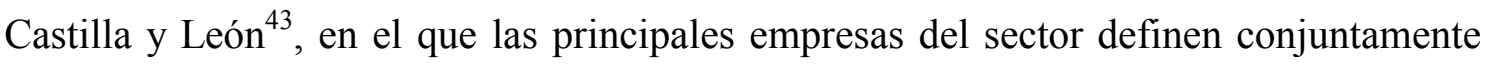
vías de actuación para el desarrollo y sostenimiento del mismo. En esta línea va orientada una amplia oferta de desarrollo tecnológico e innovación en la que juegan un importante papel los Centros Tecnológicos de la Comunidad Autónoma, aunque algunas áreas de significativo interés, como la ingeniería de procesos, los sistemas de documentación técnica (con los sistemas informáticos asociados), y la integración de la electrónica en los componentes de automoción, aún no están desarrollados en el grado que debieran [Ondategui-2002]. Ello puede ser debido a la incipiente cualificación de los Centros Tecnológicos en este sentido, que siempre se han decantado por la mejora productiva convencional, así como la preferente dedicación de las PYMEs a las labores de apoyo en que están especializadas. En estas últimas, aunque el uso de las tecnologías de la información y las comunicaciones es algo cotidiano, se posponen entonces muchos de sus proyectos en nuevas tecnologías, con la consiguiente pérdida de competitividad a escala internacional. No obstante, las exigentes necesidades en $\mathrm{I}+\mathrm{D}+\mathrm{i}$ de las grandes firmas y su focalización en las áreas de interés especificadas, constituye un "aviso" para servicios avanzados de consultoría e ingeniería.

En cuanto a las expectativas del sector de automoción y componentes en Castilla y León, debe tenerse presente la incidencia que está teniendo en el mismo la legislación instaurada en el año 2003, relativa a la distribución selectiva de vehículos, una vez finalizada la vigencia del sistema de exención en bloque ${ }^{44}$ [Tsoraklidis-2002], así como

\footnotetext{
43 Constituido por: GRUPO ANTOLÍN, GESTAMP Palencia, IVECO PEGASO, LINGOTES ESPECIALES, JOHNSON CONTROLS, NISSAN Vehículos Industriales, PLASTIC OMNIUM, RENAULT, ANSA LEMFÖRDER y el Centro Tecnológico CIDAUT.

${ }^{44}$ El sistema de exención en bloque, vigente hasta el año 2003, permitía a los fabricantes de automóviles mantener contratos de exclusividad de venta con sus concesionarios.
} 
el Reglamento del reciclado de los vehículos al final de su vida útil (Vehículo Fuera de Uso-VFU) [IHOBE-2003].

Como dificultades para el sector en un futuro próximo destacamos las siguientes:

1. La amenaza de nuevos y fuertes competidores; la sustitución de componentes mecánicos por electrónicos; y los rápidos cambios tecnológicos. Estos últimos pueden tomarse como amenaza $u$ oportunidad, dependiendo de quien les haga frente, y ante los que tienen mucho que decir los Centros Tecnológicos (en su aportación de $\mathrm{I}+\mathrm{D}+\mathrm{i}$ ), así como la Administración Autonómica (en su asesoramiento en directrices internacionales e inyección de fondos de formación y adaptación).

2. El incremento del poder negociador de los proveedores y los clientes.

3. La cada vez mayor duración de los componentes de automoción. Reorientará a las PYMEs hacia estrategias para la destrucción específica sin contaminantes de aquellos o reutilización de los mismos, incluso como nueva perspectiva profesional a medio plazo.

4. La liberalización del sector. Ha de suponer una oportunidad de negocio, pero, también, fuertes dificultades para las PYMEs que no puedan adaptarse.

Puede afirmarse, en suma, que el sector de automoción de Castilla y León se encuentra en una fase de cambios constantes, incrementos de la productividad y la competitividad, y fuertes presiones en los plazos de entrega. Debe pensarse en una gestión inteligente, adaptada a las exigencias ya comentadas en el contexto de la nueva economía, y donde deben tenerse en cuenta las opiniones y experiencia de cada trabajador para hacer fluir el conocimiento y proceder a su gestión. 


\section{II.5.3. El Sector de las Tecnologías de la Información y las Comunicaciones}

La notoriedad que se le otorga a las tecnologías de la información y las comunicaciones hay que buscarla en el importante crecimiento que han experimentando en los primeros años del tercer milenio (ritmo superior al 6\% anual entre 2000-2002); en el potencial de crecimiento que ofrecen; en su repercusión sobre la innovación de otros sectores; y en su contribución a la vertebración del vasto territorio en el que actúan. En Castilla y León, en el año 2000, el sector de las tecnologías de la información y las comunicaciones aportaba un 2,6\% al VAB regional, y empleaba directamente a más de 12.000 personas, destacando especialmente el subsector informático, que de modo particular, presenta un crecimiento medio anual del empleo superior al 18\% [JUNTA DE CASTILLA Y LEÓN-2002b: 65]. Por su parte el sector de las tecnologías de la información y las comunicaciones ejecuta el $0,99 \%$ del gasto empresarial nacional en innovación. La incorporación de las tecnologías indicadas a todos los ámbitos de nuestra vida (incluido el doméstico): manejo de ordenadores personales, uso indiscriminado de la telefonía móvil, etc., son, en gran medida, los responsables de estas cifras.

Según el DIRCE, en 2003, había instaladas 785 sociedades mercantiles en la Comunidad Autónoma (el 2,94\% de las registradas en España): 724 (el 92,23\%) relacionadas con las actividades "Informáticas y Conexas" y las restantes 61, con las "Telecomunicaciones". Entre ellas figuraba un núcleo formado por delegaciones de grandes-medianas empresas de Telefonía (VODAFONE y TELEFÓNICA I+D, básicamente); Telecomunicaciones (RETECAL ${ }^{\frac{45}{4}}$ la única sociedad de todo el subsector que empleaba a más de 200 trabajadores en la Comunidad Autónoma, TELESTANT y ZENER Comunicaciones); e Informática (CPI: Central de Procesos Informáticos ${ }^{46}$, DIVISA Informática y Telecomunicaciones). El resto lo conformaban micropymes de forma mayoritaria $(96,56 \%)$, que ejercían como subcontratistas del núcleo anteriormente reseñado y que tenían su sede social fuera de la región. A todas les

\footnotetext{
${ }^{45}$ Adquirida, en diciembre de 2003, por CABLEUROPA, S.A. (ONO), empresa dedicada a la provisión de servicios integrados por banda ancha.

${ }^{46}$ En 2003, se constituyó el grupo INGENIUS TEAM, a partir de la unión de cuatro compañías: ALCEST, TQM, CPI y CPI-Formación.
} 
prestan sus servicios en $\mathrm{I}+\mathrm{D}+\mathrm{i}$ Centros Tecnológicos como CEDETEL (el más activo hasta 2003); CARTIF, CIDAUT e ITCL en áreas relacionadas con procesos industriales; y CILUS en el campo de los contenidos digitales.

Aunque incipiente, otro subsector prometedor de las tecnologías de la información y las comunicaciones en Castilla y León, por las oportunidades de negocio que posee, es el de los contenidos digitales. Ello es debido al sedimento de la industria editorial en la Comunidad Autónoma y nuestro patrimonio histórico-artístico, cuya difusión, simulación y estudio virtual es un importante aliciente.

El desarrollo de Castilla y León depende del completo despliegue de las infraestructuras de las telecomunicaciones en un territorio extenso, todavía poco vertebrado, con dispersión de asentamientos urbanos y gran masa de pequeñas localidades cada vez más despobladas, y a las que es imposible satisfacer en su demanda de vías de comunicación convencional efectiva [Pérez Fernández-2004]. El esfuerzo en este campo ha sido muy importante, pero requiere de un cambio de mentalidad en la población, que en muchos casos puede resultar convulsivo para las áreas rurales (especialmente de la zona periférica de las provincias de León, Zamora y Salamanca), donde incluso la implantación de las tecnologías de la información y las comunicaciones resulta poco atractiva, como ayuda laboral, a la juventud que puede contribuir a su sostenimiento poblacional.

Este avance debe ser muy rápido, pues el período de vida de la tecnología cada vez es más breve y requiere de mayores inversiones. Por estos motivos, el papel de la Administración regional es vital, debiendo hacer de árbitro entre empresas, Centros Tecnológicos y universidades, así como entre la oferta tecnológica y las empresas, a la par que debe mejorar las infraestructuras y la formación de las personas dentro de las PYMEs que se originen por y para Castilla y León [JUNTA DE CASTILLA Y LEÓN2003a; JUNTA DE CASTILLA Y LEÓN-2004]. Estas personas estarían luego capacitadas para cambiar la inercia regional, a la vez que, también con el consiguiente soporte de la Administración, dieran lugar a otras PYMEs que ofrecieran oportunidad en la Comunidad Autónoma a las personas mejor formadas que tradicionalmente han tenido que buscar su vida laboral fuera de Castilla y León. De este modo, se crearía 
mayor riqueza y empleo, e incluso las actuales PYMEs de origen extraregional que prestan su servicio al núcleo sectorial, consolidarían su posición contribuyendo a este crecimiento.

Todo ello viene parejo a otra necesidad a tener en cuenta: la estimulación de la demanda en el sector. Para que las empresas del mismo puedan desarrollarse, es necesario, también, ese cambio cultural al que aludimos, permitiendo incorporar la totalidad del tejido industrial de Castilla y León a la sociedad de la información. Teniendo en cuenta lo establecido en el estudio de los sectores precedentes, la demanda de las empresas regionales es actualmente limitada, hecho que influye a la falta de empuje en la oferta [Escobar Espinar-2000; Fundación AUNA-2003]. Consecuentemente, es necesario que las empresas líderes de cada sector desarrollen proyectos de relieve en tecnologías de la información y las comunicaciones que sirvan de ejemplo y modelo.

\section{II.5.4. EI Sector de Conservación del Patrimonio}

Por lo que respecta al sector de Conservación del Patrimonio, la sola relación de "bienes declarados de interés cultural" en Castilla y León, integrada por un número considerable de monumentos 47 y bienes como tal, cuyo extraordinario interés les ha hecho formar

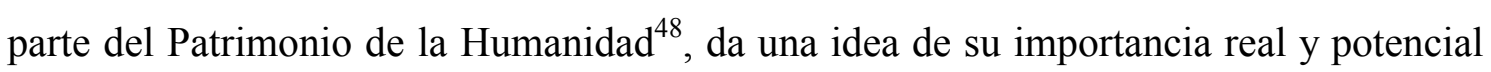
[Wattenberg-1996: 479-551; JUNTA DE CASTILLA Y LEÓN-2003b]. A ellos hay que sumar, además, los grandes contingentes etnográficos, muebles, documentales y bibliográficos de la Comunidad Autónoma.

Tan abundante patrimonio, en cantidad y calidad, exige un considerable volumen de recursos para su identificación, valoración, protección, mantenimiento, restauración y difusión. El potencial turístico y, consecuentemente, económico que representa, junto a

\footnotetext{
47 Encabezados por sus 11 catedrales, y seguidos por: conjuntos, sitios y jardines históricos; construcciones defensivas (castillos y fortalezas); parajes pintorescos; zonas arqueológicas; entornos de protección; $\mathrm{y}$ arte rupestre.

${ }^{48}$ Tal es el caso de las ciudades viejas de Segovia, Ávila y Salamanca; la catedral de Burgos; el Camino de Santiago; y, más recientemente, las zonas arqueológicas de las Médulas (León) y Atapuerca (Burgos) [Pedrosa Sanz y Miranda Escolar-2001: 111]. Pretende añadirse a esta lista el Románico Norte, que comprende un conjunto de 54 monumentos de dicho estilo artístico sitos en el septentrión de las provincias de Palencia y Burgos, así como del sur de la Comunidad de Cantabria.
} 
la creciente sensibilidad y aprecio de los ciudadanos por su conservación, traen consigo una constante demanda de actuaciones en dicho sentido.

Este sector ha surgido como consecuencia de la diversificación de negocio, concretamente sobre patrimonio monumental, de las empresas constructoras con arraigo en la Comunidad Autónoma 49 . Esta diversificación tiene su origen en las grandes perspectivas de futuro que ofrece la cultura como motor de desarrollo económico y cohesión social en Europa, hecho propiciado por la consideración del patrimonio como prioridad temática creciente desde el V Programa Marco de la UE. Ello supone para Castilla y León una importante y realista oportunidad de crecimiento económico y de empleo [Vicente Hernández-2004]. El sector se está articulando, fundamentalmente, sobre PYMEs y se concentra sobre todo en Valladolid, seguido en orden de importancia por Burgos, León y Salamanca [JUNTA DE CASTILLA Y LEÓN-2002b: 64-65].

También es reseñable el papel que están ejerciendo los Centros Tecnológicos con potencial para ello, al objeto de mejorar la capacidad de innovación de las empresas dedicadas o transfiriéndoles tecnología punta, siendo CARTIF el más destacable $\stackrel{\square}{\text {. }}$.

Las empresas del sector están intentando abrirse camino demostrando su valía mediante el desarrollo de proyectos focalizados en estructuras significativas en la Comunidad Autónoma, sobre las que existen grandes exigencias de fidelidad geométrica reproductiva, textura, color y material empleado en las labores realizadas. No obstante, el objetivo a medio plazo es la gestión integral del patrimonio, existiendo ya centros con actividad en esta área, y que deben consolidarse. Así, destacamos la Fundación del Patrimonio Histórico de Castilla y León; la Facultad de Estudios del Patrimonio Cultural de la Universidad SEK (Segovia); el Instituto de la Construcción de Castilla y León (ICCL); y el Instituto Español de Arquitectura. Particularmente, del llamado

\footnotetext{
${ }^{49}$ Sobresalen en este sentido: COLLOSA (Valladolid), RESALTA (Parque Tecnológico de BoecilloValladolid), ambas pertenecientes al Grupo BITRÉBOL; CABERO (Valladolid); y ERCOSA (Valladolid).

${ }^{50}$ Posee el Laboratorio de Digitalización 3D+Color, nacido en 2004, que presta servicios de valor añadido, basados en tecnología óptica, orientados a la medición láser tridimensional y del color real de piezas, edificios y entornos de interés artístico o arquitectónico.
} 
Románico Norte, su temática histórico-artística, y las intervenciones en su área geográfica, se viene ocupando la Fundación Santa Mª la Real.

El impulso definitivo del sector pasa por el desarrollo de habilidades y capacidades que cubran el abanico profesional necesario para la conservación, restauración, duplicación y gestión del patrimonio histórico-artístico.

\section{II.5.5. El Sector de la Biotecnología}

El creciente interés por el desarrollo de la biotecnología en Castilla y León, todavía muy incipiente, radica en el potencial que ofrece su sector agroalimentario, el más importante del tejido industrial regional, como se ha visto en el apartado II.5.1. Cuenta, actualmente, con un pequeño núcleo de empresas $\frac{11}{1}$, con personal de elevada cualificación y buen nivel de conocimiento y uso de los mecanismos de apoyo a la innovación [Olazaran y Gómez Uranga-2001], aunque, en consonancia con la tendencia observada en el territorio nacional, fuertemente dependientes del exterior [AndreossoO'Callaghan-2003]. No obstante, también se localizan en él ciertos elementos autóctonos singulares, vinculados fundamentalmente a la capacidad y experiencia de su oferta en I+D+i: CECYTA y LAREMA, en Burgos; INBIOTEC, Instituto Biomar, INTOXCAL, ICTAL, EAE y Laboratorios Ovejero, en León; ITAGRA, en Palencia; CIC e IBMCC, en Salamanca; IOBA, IBGM e ITA, en Valladolid; etc. (apartado II.2).

Aspectos que ya pueden abordarse con los desarrollos actuales de la biotecnología son los siguientes [JUNTA DE CASTILLA Y LEÓN-2002b]:

- Seguridad alimentaria (vigilancia de la salud humana por consumo de alimentos).

\footnotetext{
${ }^{51}$ Según el $4^{\circ}$ Informe Anual de la Asociación Española de Bioempresas (ASEBIO), el perfil de una empresa española de biotecnología es el siguiente: da trabajo a 10-20 empleados; tiene titulación superior más del $80 \%$ de su plantilla; dedica a I+D más del $25 \%$ de sus recursos humanos; tiene menos de 5 años de actividad; se localiza prioritariamente en Madrid o Barcelona; está vinculada a universidades o centros de investigación; la propiedad mayoritaria es del equipo fundador, con presencia de capital riesgo; posee cartera de patentes; realiza ventas mayoritarias en servicios y pocos o ningún producto; su cartera de clientes es fundamentalmente nacional y posee líneas de negocio en más de un sector. A pesar del importante crecimiento que han experimentado en los últimos años, son pocas las que poseen un tamaño mínimo suficiente para afrontar con garantías el reto de la internacionalización.
} 
- Desarrollo de métodos nuevos, rápidos y de fácil manejo para la identificación de variedades y productos derivados relacionados con las denominaciones de origen.

- Detección rápida y efectiva de contaminantes en un mundo donde cada vez está más en boga el cuidado medioambiental, la higiene y la optimización productiva.

- Detección e identificación de los derivados de los productos transgénicos.

- Procesos aplicados a la transformación de alimentos.

Teniendo en cuenta estos factores, para la verdadera implantación en Castilla y León de un sector biotecnológico con entidad propia y peso en la economía regional, se ha de prestar atención a dos aspectos [JUNTA DE CASTILLA Y LEÓN-2002b]:

1. Creación de una estructura empresarial muy especializada, lo que exige importantes desembolsos económicos (a la par que inciertos resultados). Esta situación, sin garantías de beneficios a corto plazo para los empresarios involucrados, no contribuye al afloramiento definitivo de la estructura empresarial indicada, por lo que debe darse un decidido apoyo desde la Administración regional hasta que las empresas originadas tengan cierta entidad y presenten adecuada viabilidad y generación de empleo a medio plazo.

2. Fortalecer y mejorar la oferta en $\mathrm{I}+\mathrm{D}$, pues la biotecnología requiere estar permanentemente en la vanguardia científico-tecnológica. En este sentido, la Universidad, cuya presencia en el sector en la actualidad es meramente figurativa, debe tener un papel más activo e incentivar la actitud emprendedora de alumnos e investigadores, facilitando los medios materiales que se requieran.

Por último, las empresas que conformen el sector biotecnológico deben tener una adecuada política de patentes, para lo que se requiere de personal cualificado y competente. 


\section{II.6. La Política de I+D+i en Castilla y León}

Generalmente, dentro de la acción pública, en el terreno de las actividades de $\mathrm{I}+\mathrm{D}+\mathrm{i}$ se ha dado lugar a diferentes acepciones que, aún estando vinculadas, deben ser diferenciadas debido a que cada una se focaliza en un campo específico. Así, es necesario distinguir la política de innovación, de la tecnológica y la científica, que ponen en marcha un gran número de instrumentos concretos, no excluyentes, y que abarcan diferentes áreas.

- La política de innovación se orienta a facilitar el éxito de los proyectos de las empresas para el desarrollo y comercialización de nuevos productos y procesos, estando muy vinculada con la competitividad empresarial. Al profundizar en el análisis de esta área de la acción pública aparecen solapamientos con otras políticas gubernamentales, destacándose, fundamentalmente, la política de apoyo a las PYMEs y la política regional.

- La política tecnológica promueve actuaciones orientadas a la incorporación de tecnología a la industria, conectando y articulando la capacidad de generación de conocimiento del mundo científico y el mundo empresarial. El núcleo de la actuación pública se referirá a la empresa de carácter privado, aunque algunos países cuentan con un sector público empresarial que debe ser considerado a la hora de diseñar dicha política ${ }^{52}$. La política tecnológica debe concertarse con la política industrial, pues tal sector es el sustrato sobre el que debe germinar la tecnología.

- La política científica está dirigida al conocimiento científico, con el fin primordial de explorar la frontera del conocimiento, sin preocuparse por las incidencias prácticas de los resultados obtenidos. Esta actividad se desarrolla principalmente en universidades o en organismos públicos de investigación (véanse apartados II.1 y II.2), siendo sus resultados puestos a disposición del conjunto de la sociedad. Por

\footnotetext{
${ }^{52}$ Ejemplos claros son las empresas destinadas a la fabricación de material y tecnología militar (Defensa), o los astilleros del sector naval, en la práctica totalidad de los países europeos con salida al mar.
} 
esta razón, es necesario el sostenimiento directo de toda una infraestructura pública al efecto y un apoyo a los laboratorios industriales. El sector público es su principal fuente de financiación, el origen de sus directrices, el agente responsable de su ejecución, así como de los criterios sobre cómo debe ser orientada y qué objetivos deben perseguirse.

Centrándonos en el caso particular de Castilla y León, las políticas públicas de $\mathrm{I}+\mathrm{D}+\mathrm{i}$ que la afectan se realizan desde diferentes niveles de gobierno, cada uno con distintas competencias (Figura 19).

\section{FIGURA 19}

\section{CONTEXTO DE LAS POLÍTICAS DE CIENCIA Y TECNOLOGÍA EN CASTILLA Y LEÓN}

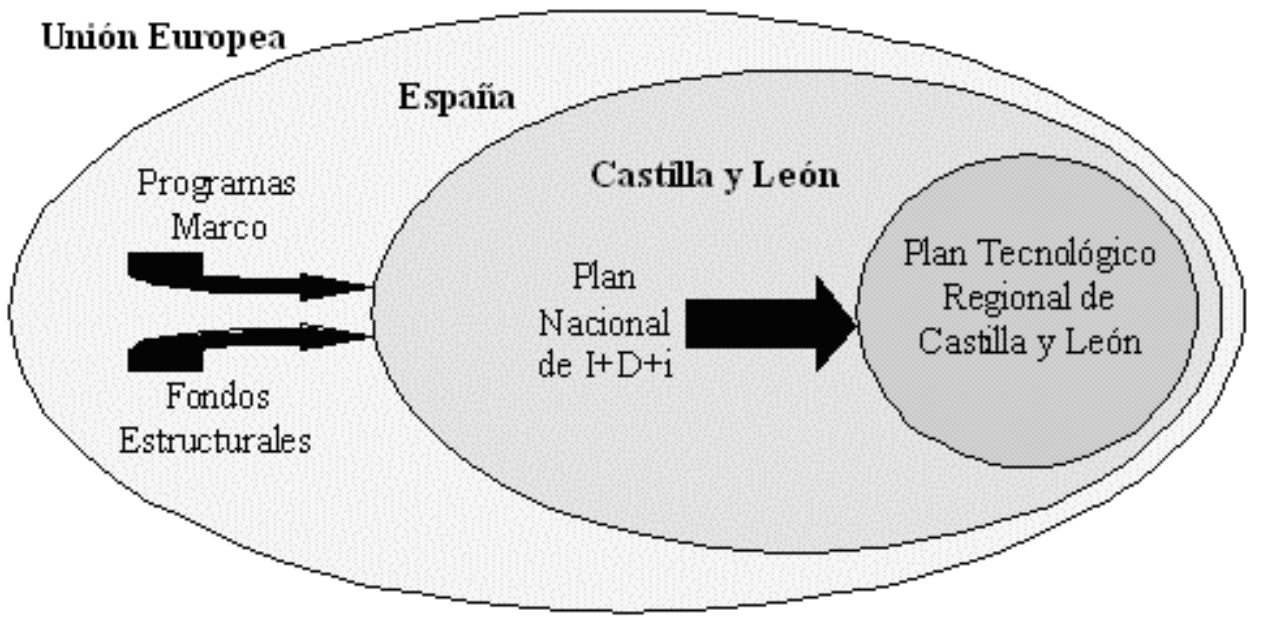

FUENTE: Adaptado de CARTIF [2005: 22]

Por tanto, para conseguir los resultados más eficientes posibles es necesario implicar a todos los agentes, verificándose, además, que las funciones asignadas a cada uno estén adecuadamente distribuidas. Tradicionalmente, la acción principal se ha desarrollado a escala nacional, pero en la actualidad, tanto la globalización de la actividad, como la descentralización política y administrativa han potenciado la presencia de otros agentes. Así destacamos, por un lado, los responsables públicos regionales, que tendrán una mayor posibilidad de llevar a buen puerto las políticas iniciadas. Y, por otro, las instituciones europeas, que persiguen una mejor articulación de las políticas y la cooperación entre agentes en el ámbito europeo. Estas instituciones europeas están ganando peso paulatino por la cantidad de recursos que poseen y utilizan. Los niveles 
descritos no son estancos, más bien puede hablarse de un entramado institucional, pues los niveles superiores se apoyan de una manera decidida en los restantes para la gestión de las intervenciones.

De esta forma, el análisis de la política científico-tecnológica de Castilla y León, que podría estar sintetizada en su Plan o Estrategia Regional, debe considerarse dentro la política equivalente nacional, que tiene su máximo exponente en el Plan Nacional de $\mathrm{I}+\mathrm{D}+\mathrm{i}, \mathrm{y}$, que a su vez, debe contemplarse en un contexto superior: la Unión Europea, donde se desarrollan diversas actuaciones, principalmente a través de los Programas Marco y los Fondos Estructurales.

El desarrollo de la política castellana y leonesa de $\mathrm{I}+\mathrm{D}+\mathrm{i}$ es relativamente joven, al requerir cierto tiempo el establecimiento de una adecuada estructura institucional. Así, aunque el Parque Tecnológico de Boecillo (Valladolid) fue creado en 1988 $\frac{53}{\text {, }}$ contituyéndose rápidamente en uno de los pilares del esfuerzo público para fomentar la mejora de la capacidad regional en $\mathrm{I}+\mathrm{D}+\mathrm{i}$, y desarrollándose medidas paralelas en el campo de la formación y de apoyo a la educación superior, la política de $\mathrm{I}+\mathrm{D}+\mathrm{i}$ de Castilla y León no comenzó propiamente su andadura hasta la promulgación de la Orden de 2 de Marzo de 1990, sobre Incentivos Tecnológicos para las Empresas (Tabla $13)$.

TABLA 13

HITOS EN LA POLÍTICA DE I+D+i DE LA JUNTA DE CASTILLA Y LEÓN

\begin{tabular}{||l|r||}
\hline Ley de Creación del Parque Tecnológico de Boecillo & 1988 \\
\hline Orden de Incentivos Tecnológicos para las Empresas & 1990 \\
\hline Creación de la Red de Centros Tecnológicos de Castilla y León & 1992 \\
\hline Creación de la Agencia de Desarrollo Económico de Castilla y León & 1994 \\
\hline Plan Tecnológico Regional (PTR) 1997-2000 & 1997 \\
\hline Creación de la Comisión de Coordinación de Ciencia y Tecnología & 2001 \\
\hline $\begin{array}{l}\text { Ley de Fomento y Coordinación General de la Investigación Científica, Desarrollo e } \\
\text { Innovación Tecnológica (I+D+i) en Castilla y León }\end{array}$ & 2002 \\
\hline Estrategia Regional de I+D+i (ERI) 2002-2006 & 2002 \\
\hline
\end{tabular}

FUENTE: Elaboración Propia

\footnotetext{
${ }^{53}$ Dato suministrado por la Sociedad Parques Tecnológicos de Castilla y León, S.A. No obstante, la génesis de la organización que lo iba a gestionar fue posterior, siendo la Ley 10/92, de 28 de Noviembre, donde consta la creación de la empresa pública Parque Tecnológico de Boecillo, S.A. (BOCYL n 234, 4/12/1990).
} 
En línea con la apuesta que suponía el Parque Tecnológico de Boecillo, se intenta potenciar y estructurar la capacidad científico-técnica local mediante la creación o mejora de centros de investigación, laboratorios y otras infraestructuras tecnológicas, a través de la creación de la Red de Centros Tecnológicos Asociados en Castilla y León, en $1992^{\frac{54}{4}}$. Con esta red se perseguía, por un lado, favorecer la articulación de la oferta tecnológica que los Centros ofrecían y, por otro, una administración más eficiente y con una adecuada gestión de las ayudas públicas a dichos Centros.

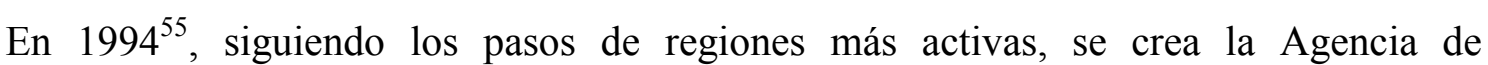
Desarrollo Económico (ADE), convirtiéndose en el centro de la política de $\mathrm{I}+\mathrm{D}+\mathrm{i}$ y concentrándose en ella la mayoría de los elementos hasta ese momento dispersos.

En 1997, se aprueba el Plan Tecnológico Regional (1997-2000), fruto de una medida comunitaria (Regional Innovation Strategy-RIS), cofinanciado por la Unión Europea. Este Plan, dirigido a las empresas y a las infraestructuras tecnológicas de Castilla y León, buscaba aglutinar todas las actuaciones relativas a la promoción y desarrollo de la innovación. A través de esta estrategia global se perseguía movilizar a todos los agentes regionales en la búsqueda de objetivos comunes, y se materializaba el compromiso firme de la Junta de Castilla y León en este ámbito. Dichos objetivos [JUNTA DE CASTILLA Y LEÓN-1997] fueron: reordenar y potenciar la oferta tecnológica; articular las necesidades y las demandas empresariales; desarrollar la colaboración entre los agentes del sistema regional de innovación; aprovechar y potenciar la disponibilidad de capital humano; facilitar el acceso de Castilla y León a las capacidades tecnológicas y de innovación disponibles en el entorno nacional e internacional; promover el enfoque integral de la innovación; $\mathrm{y}$, por último, el seguimiento y evaluación de forma continua de sus resultados.

Para alcanzar dichos objetivos, se estableció un conjunto de cinco programas: el primero, dirigido a fortalecer las infraestructuras tecnológicas y el adecuado funcionamiento del sistema de innovación regional; el segundo, orientado a fomentar la

\footnotetext{
${ }^{54}$ Ley 5/1992, de 18 de Diciembre (BOCYL n ${ }^{0}$ 247, 23/12/92).

${ }^{55}$ Ley 21/1994, de 15 de Diciembre.
} 
innovación tecnológica, tanto a través del desarrollo tecnológico como en su adquisición y utilización; el tercero, apoyando a la formación para potenciar la innovación tecnológica; el cuarto, fomentando la sensibilización de las empresas frente a la innovación y la mejor difusión de información sobre cuestiones tecnológicas; y, por ultimo, el quinto, centrado en la estructuración de la demanda empresarial, favoreciendo la cooperación y la formación de redes de empresas innovadoras [JUNTA DE CASTILLA Y LEÓN-1997]. Cada uno de los referidos programas se articuló en una serie de líneas de actuación, acodes con las marcadas por la propia ADE y la llamada “iniciativa PYME” [ADE-1998].

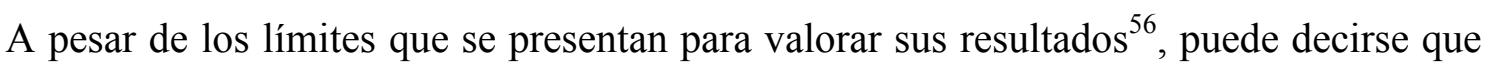
se han alcanzado importantes logros, ya que ha supuesto el inicio de una planificación estratégica para movilizar a los principales agentes regionales; el sector público regional ha cumplido sus compromisos y el sector privado ha incrementado sus actividades de $\mathrm{I}+\mathrm{D}+\mathrm{i}$, aunque en menor medida [Castillo y Haarich-2001]; ha permitido una mejor articulación del sistema de innovación regional; y, aunque todavía escaso, se aprecia un cambio de mentalidad sobre la relevancia de la $\mathrm{I}+\mathrm{D}+\mathrm{i}$. Como contrapartida, también se han detectado debilidades en su ejecución, entre las que, según Corral [2001], destacan: una visión muy generalista, con escasa orientación sectorial; la falta de coordinación entre Consejerías, que ha llevado a identificar el Plan con la División de Innovación de la ADE; y una insuficiente propaganda y comunicación, que ha reducido la visibilidad del Plan y no ha favorecido como debiera la proyección de las distintas infraestructuras tecnológicas regionales.

El compromiso de las autoridades de Castilla y León con la política de $\mathrm{I}+\mathrm{D}+\mathrm{i}$ mantiene una continuidad en el tiempo. Para ello se creó, en el año 2001, la Comisión Permanente de Ciencia y Tecnología de Castilla y León ${ }^{57}$. Se trata de una institución que tiene funciones de coordinación, planificación, seguimiento y evaluación en materia de $\mathrm{I}+\mathrm{D}+\mathrm{i}$

${ }^{56}$ De acuerdo con Castillo y Haarich [2001], se apuntan: la escasez de indicadores y estadísticas regionales de I+D; una relativa fiabilidad y homogeneidad de las estadísticas; la falta de indicadores de contexto definidos para comparar situaciones; la mala definición de indicadores cualitativos y falta de objetivos cuantitativos; así como la dificultad para tratar los datos obtenidos.

${ }^{57}$ Decreto 37/2001, de 15 de Febrero, junto con el Decreto 184/2001, de 28 de Junio, por el que se modifica el primero. 
y sociedad de la información. También, en el año 2002, se procedió a la aprobación de la Ley de Fomento y Coordinación General de la I+D+i en Castilla y León $\frac{4 .}{8}$

Además, a partir de las conclusiones del Plan Tecnológico Regional 1997-2000, y junto con el Plan de Desarrollo Económico de Castilla y León, la Junta de Castilla y León elaboró lo que sería el II Plan Tecnológico Regional, que recibe la denominación de Estrategia Regional de I+D+i de Castilla y León 2002-2006 (ERI).

Dicha Estrategia es el marco de referencia en el que se integran todas las actuaciones relativas a $\mathrm{I}+\mathrm{D}+\mathrm{i}$ de la Junta de Castilla y León, organizadas en una serie de líneas estratégicas dotadas de una lógica interna.

El objetivo final que persigue el gobierno regional con ella es triple [JUNTA DE CASTILLA Y LEÓN-2002a, 2002b, 2002c]:

- Impulsar y coordinar la investigación y la tecnología en Castilla y León.

- Potenciar el sistema de innovación regional.

- Crear lazos entre los dos procesos anteriores.

A partir de ese objetivo final se plantean un total de nueve programas estratégicos divididos en dos grandes ámbitos: I+D (Tabla 14), e innovación (Tabla 15).

${ }^{58}$ Ley 17/2002, de 19 de Diciembre. 


\section{TABLA 14}

PROGRAMAS Y LÍNEAS DE ACTUACIÓN ASOCIADAS EN LA ESTRATEGIA REGIONAL

DE I+D+i DE CASTILLA Y LEÓN PARA CON LA I+D

\begin{tabular}{|c|c|}
\hline Programas & Clave y líneas de actuación asociadas \\
\hline $\begin{array}{l}\text { Mejora de conexión } \\
\text { con el entorno }\end{array}$ & $\begin{array}{l}\text { - } \\
\text { - Puesta en marcha de una estrategia de comunicación. } \\
\text { investigación regional. } \\
\text { - Puesta en marcha de un sistema regional coordinado de apoyo a la } \\
\text { investigación. }\end{array}$ \\
\hline $\begin{array}{l}\text { Proyectos de } \\
\text { investigación }\end{array}$ & $\begin{array}{l}\text { Establecimiento de contratos con grupos de investigación consolidados que } \\
\text { trabajen en áreas de conocimiento excelente y/o con vinculación con sectores } \\
\text { estratégicos regionales }{ }^{1} \text {. } \\
\text { - Subvención para la realización de proyectos por parte de grupos noveles. }\end{array}$ \\
\hline Capital intelectual & $\begin{array}{l}\text { - } \quad \text { Creación de masa crítica investigadora en la región. } \\
\text { - } \quad \text { Prolongación de contratos de incorporación de doctores y tecnólogos a los } \\
\text { grupos de investigación. } \\
\text { - } \quad \text { Plan de apoyo a la movilidad del personal investigador. } \\
\text { - Subvenciones para la promoción de la gestión de la I+D. }\end{array}$ \\
\hline $\begin{array}{l}\text { Explotación de } \\
\text { resultados }\end{array}$ & $\begin{array}{l}\text { - Contratos para apoyar la creación dentro de las estructuras de interfaz y/o } \\
\text { grupos de investigación potentes de un perfil de gerente de la } \mathrm{I}+\mathrm{D}+\mathrm{i} \text {. } \\
\text { - } \quad \text { Foros de debate y /o ferias de investigación. } \\
\text { - Subvenciones para apoyar las tareas de asesoramiento y lanzamiento de las } \\
\text { siguientes actividades: inteligencia económica y tecnológica; creación de spin- } \\
\text { offs e incubadoras; creación y gestión de parques tecnológicos y científicos. }\end{array}$ \\
\hline $\begin{array}{l}\text { Instrumentos para la } \\
\text { investigación }\end{array}$ & $\begin{array}{l}\text { Establecimiento de subvenciones complementarias para mejorar el } \\
\text { - } \quad \text { Redes de información y comunicación para la investigación. } \\
\text { - } \quad \text { Creación y mejora de instalaciones para la investigación. } \\
\text { - } \quad \text { Personal de apoyo para los laboratorios. }\end{array}$ \\
\hline
\end{tabular}

${ }^{1}$ Los sectores estratégicos considerados son: agroalimentario, automoción, biotecnología, contenidos digitales y telecomunicaciones, a los que se añaden desde la perspectiva de la innovación: aeronáutico y conservación del patrimonio.

FUENTE: JUNTA DE CASTILLA Y LEÓN [2002a] 
TABLA 15

PROGRAMAS Y LÍNEAS DE ACTUACIÓN ASOCIADAS EN LA ESTRATEGIA REGIONAL

DE I+D+i DE CASTILLA Y LEÓN PARA CON LA INNOVACIÓN

\begin{tabular}{|c|c|}
\hline Programas & Clave y líneas de actuación asociadas \\
\hline Empresa innovadora & $\begin{array}{l}\text { - Innovar (plataforma innocal, e-plataformas, proyectos prioritarios de } \\
\text { investigación, programa CYL-TIC). } \\
\text { - Aprovechamiento de la fuerza innovadora de las empresas y organizaciones } \\
\text { líderes de la región. } \\
\text { - Avance en la incorporación de la cultura de la innovación en los entornos } \\
\text { geográficos menos dinámicos. }\end{array}$ \\
\hline $\begin{array}{l}\text { Oferta científico- } \\
\text { técnica competitiva }\end{array}$ & $\begin{array}{l}\text { - Marco de financiación estable para la racionalización de la oferta orientada a la } \\
\text { demanda empresarial. } \\
\text { - } \quad \text { Hacia un sistema cooperativo de innovación. } \\
\text { - } \quad \text { Impulso de la difusión y la transferencia de conocimiento. } \\
\text { - } \quad \text { Promoción de la vigilancia tecnológica y la prospectiva a medio plazo. }\end{array}$ \\
\hline Nuevos sectores & $\begin{array}{l}\text { - Herramientas de apoyo a la creación de empresas innovadoras de base } \\
\text { tecnológica. } \\
\text { Impulsar la promoción y el desarrollo del sector de las tecnologías de la } \\
\text { información y las comunicaciones y contenidos digitales. } \\
\text { - Poner en marcha un polo biotecnológico de excelencia. }\end{array}$ \\
\hline $\begin{array}{l}\text { Formar personas } \\
\text { capaces de generar y } \\
\text { transformar nuevo } \\
\text { conocimiento }\end{array}$ & $\begin{array}{l}\text { - Innovaciones pedagógicas en la enseñanza a todos los niveles y adaptación del } \\
\text { sistema educativo. } \\
\text { - } \quad \text { Potenciar la formación continua de nuevos trabajadores del conocimiento. }\end{array}$ \\
\hline
\end{tabular}

FUENTE: JUNTA DE CASTILLA Y LEÓN [2002b] 
Pedro Martín Lerones Evaluación del Aprendizaje Organizativo en los Centros Tecnológicos y Gestión del Conocimiento Sectorial en Castilla y León 
Capítulo III:

Caracterización y Enfoque del Aprendizaje Organizativo en los Centros Tecnológicos 
Pedro Martín Lerones Evaluación del Aprendizaje Organizativo en los Centros Tecnológicos y Gestión del Conocimiento Sectorial en Castilla y León 


\section{III.1. Introducción: Consideraciones Iniciales}

Algunos de los factores que vienen atenazando el dinamismo tecnológico de Castilla y León desde la última década del siglo XX, contribuyendo a la desintegración de su sistema ciencia-tecnología-industria, son los siguientes [Pedrosa Sanz et al.-1997]:

1. La elevada dependencia tecnológica del exterior de sus pequeñas, medianas y grandes empresas.

2. La escasez presupuestaria con que cuentan para financiar sus actividades de $\mathrm{I}+\mathrm{D}+\mathrm{i}$.

3. La mentalidad tradicional de las abundantes microempresas regionales y la ausencia en las mismas de una cultura asociacionista y emprendedora orientada hacia la innovación.

4. La insuficiente dotación de equipamiento y de personal altamente cualificado dedicado a la innovación en aquellas.

5. La desarticulación existente entre la oferta de $\mathrm{I}+\mathrm{D}+\mathrm{i}$ realizada desde los centros de investigación y las necesidades de las unidades productivas castellanas y leonesas.

6. La escasa demanda de tecnología local por parte de las Administraciones Públicas.

Como ya hemos visto en los capítulos precedentes, en una economía basada en la Gestión del Conocimiento, el Capital Intelectual y en los recursos intangibles, se hace esencial la existencia de infraestructuras de apoyo a la $\mathrm{I}+\mathrm{D}+\mathrm{i}$, especialmente en tejidos industriales y productivos en los que las empresas son mayoritariamente PYMEs de sectores de intensidad tecnológica media-baja, como es el caso de Castilla y León. 
Dentro de estas infraestructuras, destacan los Centros Tecnológicos $\underline{59}$, por el valor que pueden aportar, al transformar el saber generado por el sistema científico en valor para el sistema económico. Su misión se fundamenta en la Gestión del Conocimiento y en los recursos intangibles, cuya base es el Aprendizaje Organizativo. Estos Centros Tecnológicos guardan similitud con los Research and Technology Institutes (RTIs) que vienen proliferando en la Unión Europea desde la década de los ochenta del siglo XX y cuya problemática actual, actividades que desarrollan, los retos a los que se enfrentan, sus puntos fuertes y débiles, sus factores de éxito, así como los elementos esenciales para su planificación estratégica y de gestión administrativa, han sido analizados de forma comparativa en la literatura reciente.

En España, son escasos los trabajos tendentes a analizar este tipo de organizaciones, apareciendo siempre en las obras vinculadas a las infraestructuras soporte o las acciones públicas en materia de innovación [COTEC-1998], que suelen obviar que los activos físicos $\mathrm{y}$ financieros que abordan no tienen la capacidad de generar ventajas competitivas sostenibles en el tiempo. Alternativamente a este punto de vista, destacamos especialmente el estudio de Modrego Rico [2004], que permite clasificar y describir con detalle estos Centros, propone factores que derivan en los éxitos y fracasos de sus actividades, y formula modelos de financiación futura que puedan ayudarles a cumplir mejor la misión que tienen encomendada. Dicho estudio tiene en cuenta los activos intangibles, que aunque no contabilizan, son los que aportan verdadero valor a las organizaciones. Éstos son especialmente críticos y se hayan particularmente concentrados en los Centros Tecnológicos, como elementos encargados de la consecución práctica del saber científico-técnico.

Establecida la importancia de los intangibles, es necesario recordar que la mayoría de ellos suelen estar basados en la información, el aprendizaje y el conocimiento. Es en este punto donde podemos enlazar con el Aprendizaje Organizativo, que permitirá

\footnotetext{
${ }^{59}$ Tratados en el apartado II.2, el conjunto de actividades que pueden desarrollar son: proyectos de I+D+i, servicios tecnológicos, formación, difusión y consultoría, siendo el desarrollo tecnológico de carácter industrial el núcleo de sus funciones. En el caso de la Comunidad Autónoma de Castilla y León, cubren áreas científico-técnicas diversas, siendo los sectores económicos con los que más cooperan los de automoción y componentes, el agroalimentario, el de productos metálicos, el de productos químicos y el de telecomunicaciones [JUNTA DE CASTILLA Y LEÓN-2002a, 2002b].
} 
aumentar las capacidades de una organización, y en este caso de los Centros Tecnológicos, al desarrollar actividades científicas y de tecnología punta de cada vez mayor complejidad, donde se requiere de la adecuada sincronización de equipos multidisciplinares cuya consecución de objetivos revierta en ventajas competitivas y económicas para sus clientes.

En Europa, el enfoque sociedad de la información, centrado en las tecnologías, hoy ha dejado paso a una visión de sociedad del conocimiento, donde los aspectos sociales, los económicos y los tecnológicos han de ir unidos. Esta visión concuerda, perfectamente, con el programa de investigación europeo (VI Programa Marco: 2002-2006), y su continuidad en el próximo (VII Programa Marco: 2007-2013), por los que se rigen los Centros Tecnológicos.

Tras lo expuesto en el capítulo I, en el que ahora nos ocupa vamos a tratar de contextualizar y caracterizar el Aprendizaje Organizativo en los Centros Tecnológicos, a fin de poder articular, en los capítulos sucesivos, la modelización perseguida para su evaluación. Dicha modelización nos permitirá comprobar si las labores desarrolladas por aquellos se plasman en mayor competitividad para las empresas a que prestan servicios.

\section{III.2. El Aprendizaje Organizativo como Base de la Gestión del Conocimiento y el Capital Intelectual}

El postulado de que la tecnología valida la autoridad de las ciencias está sólidamente establecido en nuestra sociedad. De hecho, los defensores de la investigación pura lo esgrimen continuamente como argumento irrefutable cada vez que solicitan fondos para sus estudios.

En la publicidad, la inmaculada bata de laboratorio todavía representa la racionalidad científica como verdad objetiva que proporciona a los hombres dedicados a la Ciencia y 
la Tecnología (llamados Investigadores o Ingenieros de $\mathrm{I}+\mathrm{D}+\mathrm{i} \frac{60}{)}$ el don de la capacidad predictiva. En el momento que surja algún problema o peligro siempre se proporcionará la misma respuesta: la investigación proveerá, a condición de que se le suministre una buena inyección de fondos. Se sobreentiende que la ciencia tiene respuestas para todo: es una simple cuestión de tiempo y de dinero, como si la actividad científica (e incluso la técnica) pudiese planificarse según los estándares de la productividad, como si existiese un método que garantizase los descubrimientos. Resulta paradójico que no se concibe garantía que no venga de la Ciencia y, sin embargo, se observe que el resultado de sus actividades sea tan inesperado como esperado es lo que no termina de resultar.

Para tender el puente entre la I+D y la implantación industrial que ofrecen los Centros Tecnológicos, sobre todo en procesos de automatización (por su claro beneficio económico a empresas y el aumento de competitividad de las mismas), se requiere de algo más que una mera gestión administrativa de sus actividades. Dicho puente necesita de una esmerada Gestión del Conocimiento y un mimado Capital Intelectual, temas, en general, de gran importancia y valor estratégico en empresas y consultoras para aplicaciones avanzadas. Una búsqueda genérica en Internet demuestra el creciente interés y elevado número de estudios, congresos, publicaciones y organizaciones que se encuentran abordando estos aspectos a escala mundial. Todo ello en el seno de una profunda revolución tecnológica, en un momento en el que, de forma contínua, se habla de la sociedad del conocimiento y de la sociedad de la información.

\footnotetext{
${ }^{60}$ Según la OCDE [2003:99]: "Los investigadores son profesionales que se dedican a la concepción o creación de nuevos conocimientos, productos, procesos, métodos y sistemas, y también a la gestión de los proyectos respectivos".
}

Los investigadores se encuentran incluidos en el "Grupo Principal 2" de la clasificación internacional ISCO-88 (International Standard Classification of Occupations, año 1988), "Profesionales", así como en "Directores de Departamentos de I+D" (ISCO-88, 1237). Por convención, también se incluyen en estas categorías los miembros de las fuerzas armadas con formación equivalente y que realicen actividades de $\mathrm{I}+\mathrm{D}+\mathrm{i}$

Igualmente están incluidos los gestores y administradores que desarrollan actividades de planificación y gestión de los aspectos científicos y técnicos del trabajo de los investigadores. Normalmente, tienen una categoría igual o superior a la de las personas empleadas directamente como investigadores, tratándose a menudo de investigadores veteranos o a tiempo parcial.

Los títulos profesionales englobados bajo la denominación Investigador o Ingeniero de I+D+i varían de una institución a otra, de un sector a otro y de un país a otro.

También deben considerarse investigadores los estudiantes que una vez obtenida su titulación superior, participan en trabajos o actividades de $\mathrm{I}+\mathrm{D}+\mathrm{i}$ a la vez que preparan su doctorado. 
Teniendo en cuenta lo expuesto en el capítulo I, establezcamos, entonces, el lazo funcional entre los conceptos relacionados con la Gestión del Conocimiento, pues, en general, la terminología no ayuda a aclarar las relaciones entre ellos, $\mathrm{y}$, en ocasiones, se introducen las mismas ideas con denominaciones diferentes. Se permitirá, así, la constitución de un marco operativo adecuado cara a la modelización perseguida para el Aprendizaje Organizativo en los Centros Tecnológicos.

Es conocido que las organizaciones descubrieron, hace cierto tiempo, que los activos intangibles son los que aportan verdadero valor a las mismas. Estos activos intangibles, sabemos que son una serie de recursos que pertenecen a la organización, pero que no están valorados desde un punto de vista contable. También las capacidades que se generan en la organización son activos intangibles cuando los recursos empiezan a trabajar en grupo. En lugar de capacidades, se habla de procesos, o rutinas organizativas. Un hipotético ejemplo en los Centros Tecnológicos pudiera ser la congelación salarial para sus investigadores, como trabajadores ${ }^{61}$ de interés. En este

${ }^{61}$ Dentro del personal que trabaja en un Centro Tecnológico, cabe distinguir tres clases:

1. Los Ingenieros de $\mathrm{I}+\mathrm{D}+\mathrm{i}$ o Investigadores, anteriormente definidos, y que son los que ejecutan labores de $\mathrm{I}+\mathrm{D}+\mathrm{i}$, ofreciendo valor principal al Centro y garantizando su subsistencia.

2. Los Técnicos y Personal Asimilado: “...son personas cuyas tareas principales requieren conocimientos técnicos y experiencia en uno o varios campos de la Ingeniería, la Física, las Ciencias Biomédicas o las Ciencias Sociales y las Humanidades. Participan en la $I+D$ ejecutando tareas científicas y técnicas que requieren la aplicación de conceptos y métodos operativos, generalmente bajo la supervisión de los investigadores. El personal asimilado realiza los correspondientes trabajos de I+D bajo la supervisión de los investigadores en el campo de las Ciencias Sociales y las Humanidades" [OCDE-2003: 100].

Los Técnicos y el Personal Asimilado se incluyen en el "Grupo Principal 3" de la clasificación ISCO-88, "Técnicos y Profesionales Asociados", especialmente en los Subgrupos 31 ("Profesionales Asociados de la Física y la Ingeniería") y 32 ("Profesionales Asociados de las Ciencias de la Vida y de la Salud"). También se incluyen en ISCO-88, 3434, bajo "Profesionales Asociados de la Estadística, las Matemáticas y Ciencias Relacionadas".

3. Personal de Apoyo: “...incluye al personal de oficios, cualificado y sin cualificar, de oficina $y$ de secretaría que participa en los proyectos de $I+D$ o está directamente asociado a tales proyectos" [OCDE-2003: 101]. Estos trabajadores se encuentran clasificados en los "Grupos Principales 4, 6 y 8" de ISCO-88 ("Personal de Oficina", "Trabajadores Cualificados de Agricultura y Pesca” y “Operarios y Mecánicos de Instalaciones y Máquina”, respectivamente).

Se incluyen en esta categoría los gerentes y administradores que se ocupan principalmente de asuntos relacionados con la gestión económica, de personal y administración general, siempre que sus actividades sean de apoyo a la I+D+i. Se clasifican en el "Grupo Principal 2" de ISCO88, "Profesionales", así como en el "Grupo Secundario 343" ("Profesionales Asociados Administrativos", excepto 3434). 
sentido, el ahorro de tesorería se puede cuantificar rápidamente, pero no el de costes, porque hay que tener en cuenta, entre otros, el nivel de eficiencia en labores de $\mathrm{I}+\mathrm{D}+\mathrm{i}$, que dependerá de su grado de satisfacción.

El Aprendizaje Organizativo es un medio para que las organizaciones puedan resolver problemas cada vez más complejos. Cuando una serie de personas empiezan a trabajar en grupo, al principio se suelen producir problemas de coordinación. Cuando pasa un tiempo, se van afinando los procesos y cada vez se realiza mejor la tarea. El Aprendizaje Organizativo consiste, entonces, en aprender colectivamente a resolver problemas con una efectividad determinada.

Por su parte, la Gestión del Conocimiento es, en definitiva, la gestión de los activos intangibles que generan valor para la organización. La mayoría de estos intangibles tienen que ver con procesos relacionados, de una u otra forma, con la captación, estructuración y transmisión de conocimiento. Por tanto, la Gestión del Conocimiento tiene en el aprendizaje organizacional su principal herramienta, hecho que reconfirma nuevamente su carácter dinámico [Martínez García, Peñalver Martínez y Salamanca García-2002].

Llegados a este punto, es preciso explicitar cuál es la diferencia entre dato, información y conocimiento. Una primera aproximación sería que los datos están localizados en el mundo y el conocimiento está localizado en agentes (personas, organizaciones, etc.), mientras que la información adopta un papel mediador entre ambos conceptos.

Hay que reconocer que, en realidad, lo que fluye entre agentes distintos nunca es conocimiento como tal, sino datos y/o información. Es posible aproximar el conocimiento de dos agentes que comparten los mismos datos, pero debido a sus experiencias anteriores y a las diferencias en el modo de procesarlos (modelos mentales y modelos organizacionales), nunca tendrán las mismas tendencias para la acción, ni estados idénticos de conocimiento. Sólo podemos conseguir aproximaciones, ya que el contexto interno y externo de un agente siempre es diferente a otro. Esto es así, porque el conocimiento es información puesta dentro de un contexto y una experiencia. 
En definitiva, los datos, una vez asociados a un objeto y adecuadamente estructurados, se convierten en información. La información, asociada a un contexto y a una experiencia, se convierte en conocimiento. El conocimiento asociado a una persona y a una serie de habilidades personales, se convierte en sabiduría; $y$, finalmente, el conocimiento asociado a una organización y a una serie de capacidades organizativas se convierte en Capital Intelectual (Figura 20).

FIGURA 20

RELACIÓN ENTRE LOS CONCEPTOS DE DATO, INFORMACIÓN, CONOCIMIENTO Y CAPITAL INTELECTUAL

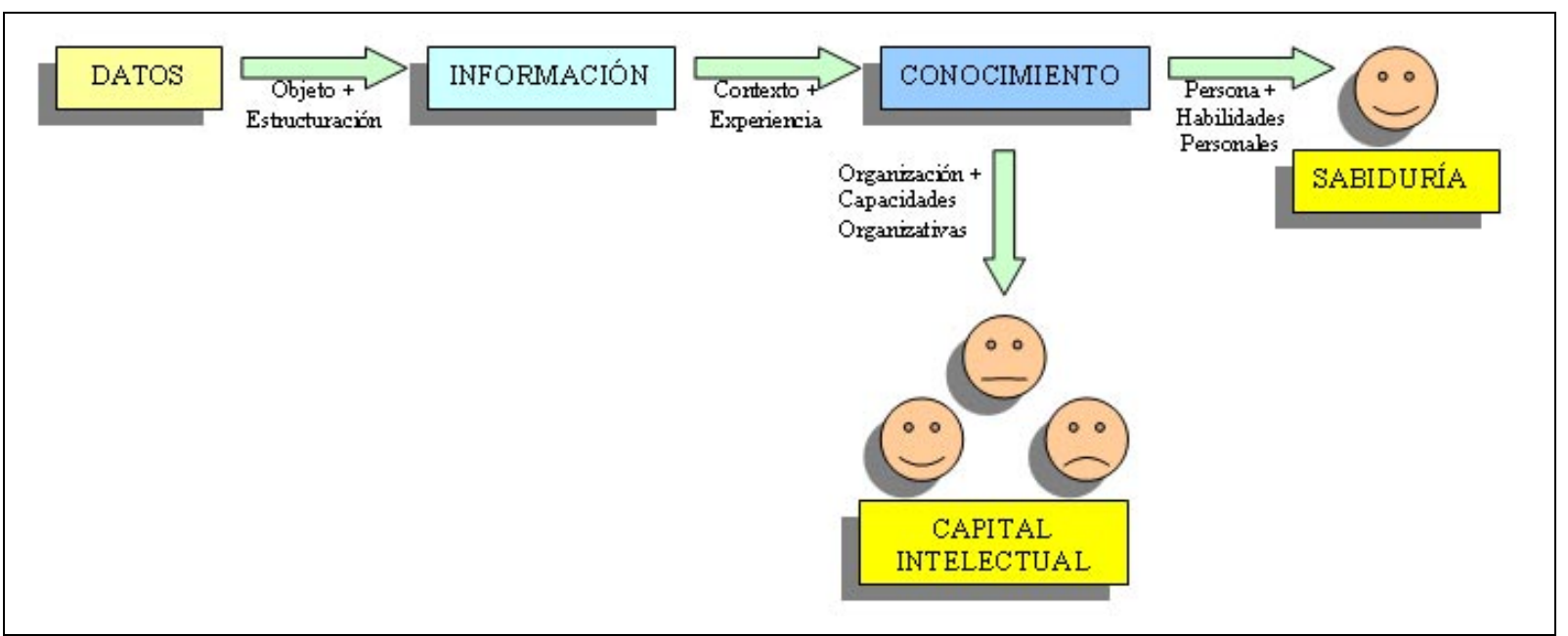

FUENTE: Elaboración propia

Éste último es un concepto casi contable. La idea es implementar modelos de medición de activos intangibles en las organizaciones, denominados habitualmente modelos de medición del Capital Intelectual [Boluda Manzanares-1999; Cañibano Calvo et al.2002], cuyos principales exponentes han sido analizados previamente. El problema de estos modelos es que dichos intangibles no pueden ser valorados mediante unidades de medida uniformes $\mathrm{y}$, por tanto, no se puede presentar una contabilidad de intangibles como tal. De cualquier forma, la medición del Capital Intelectual permite tener una imagen "instantánea" aproximada del valor de los intangibles de una organización. Su interés radica en determinar si éstos mejoran (tendencia positiva) o no (tendencia negativa), en períodos de tiempo comparables.

Por supuesto, no interesa analizar la tendencia de todos los activos intangibles de la organización, ya que sería un trabajo imposible de realizar en un periodo razonable de 
tiempo. El objetivo es determinar cuáles son los intangibles que aportan valor a la organización, para, posteriormente, realizar un seguimiento de los mismos.

Es posible, así, redefinir el concepto de Gestión del Conocimiento como aquel conjunto de procesos y sistemas que permiten que el Capital Intelectual de una organización aumente de forma significativa, mediante la gestión de sus capacidades de resolución de problemas de forma eficiente, y con el objetivo final de generar ventajas competitivas sostenibles en el tiempo.

Entonces el Aprendizaje Organizativo, la Gestión del Conocimiento y la medición del Capital Intelectual son, en suma, conceptos interconectados y complementarios. El Aprendizaje Organizativo es la base de una buena Gestión del Conocimiento, y ésta lo es para la generación de Capital Intelectual y de capacidades organizativas.

\section{III.3. Los Retos Actuales de la Gestión en las Organizaciones}

No cabe duda alguna de que estamos siendo testigos de la emergencia de nuevas realidades que están dibujando la fisonomía de las sociedades desarrolladas del presente siglo XXI:

1. Ya nadie cuestiona la realidad de que vivimos en un mundo telecomunicado, en esa "aldea global" de la que tanto se habla en los momentos actuales. El avance en las tecnologías de la información y las comunicaciones, está provocando la creación de un ciberespacio mundial [De Rosnay-1995], es decir, un espacio global de intercambio electrónico de información.

2. En el terreno económico, la globalización de la economía es un hecho innegable. Las empresas compiten en mercados mundiales y, en el caso de España, en el contexto de una unión económica y monetaria. 
3. La elevación del nivel de alfabetización de la población en los países desarrollados da lugar a que cada vez un mayor número de personas realicen trabajos relacionados con el manejo de información y conocimiento. Son los denominados "trabajadores del saber" [Drucker-1993, 2003].

4. Nos movemos, más allá de la producción fabril masiva, hacia un nuevo sistema de producción flexible y no masificado, basado en la información y la tecnología. Sus resultados finales no son miles de unidades estandarizadas de un producto, sino mercancías y servicios creados a medida del consumidor, hecho que ha configurado lemas como "stock cero" o "just in time" para las empresas. Gracias a las nuevas tecnologías de la información y las comunicaciones, es posible producir series cortas de productos muy variados y ajustados a las especificaciones del cliente a bajo coste [Toffler-1985].

En este escenario surgen y operan los Centros Tecnológicos de Castilla y León, cuya utilidad ya ha sido establecida. Su modo de proceder viene regido, en la actualidad, por el VI Programa Marco Europeo de Investigación de la Unión Europea 2002-2006, y que define la creación de un "Espacio Europeo de Investigación e Innovación" (European Research Area-ERA). En este Programa Marco se han definido los objetivos de impulsar la innovación que fomente la introducción de las empresas en la economía de la información y el conocimiento. El Área Europea de Investigación es promovida como extensión de los programas de innovación coordinada entre las empresas, los centros de investigación y también las administraciones, para lograr de esta forma una mejor estructura de intercambio de conocimientos $\frac{62}{6}$. Las Redes de Excelencia $\frac{63}{6}$ a las que debe

\footnotetext{
${ }^{62}$ Las fórmulas que tienen los países de la UE para cooperar en materias de I+D+i han ido modificándose en las últimas décadas. Así, en los años setenta del pasado siglo, predominaron las joint ventures y los acuerdos de colaboración científica, los cuales implicaban, de modo general, la creación de una empresa independiente. Las pérdidas y beneficios de esa empresa eran compartidos por las compañías firmantes del acuerdo oportuno, según el porcentaje del capital invertido. Desde la segunda mitad de los años ochenta del siglo XX, la fórmula de cooperación tecnológica más utilizada son los acuerdos sin intercambio de capital. De esta forma, dos o más empresas realizan proyectos conjuntos de $\mathrm{I}+\mathrm{D}+\mathrm{i}$ con objeto de intercambiar conocimientos, reducir costes y minimizar riesgos. Los participantes comparten las tecnologías y los resultados de las investigaciones realizadas, pero no el capital.

Otro instrumento de cooperación internacional de los VI y VII Programas Marco es la apertura del Área Europea de Investigación a terceros países. Ambos disponen de financiación específica para la cooperación con las empresas, investigadores e instituciones de estos países que participen en proyectos de $\mathrm{I}+\mathrm{D}+\mathrm{i}$.
} 
aspirar todo Centro Tecnológico que se precie, desarrollan una nueva cultura de compartir conocimientos y fomentan el trabajo colaborativo entre sus miembros como factor importante para el rápido desarrollo de la innovación en el sector empresarial y, a su vez, para el desarrollo sostenible $\sqrt{64}$ de la sociedad. De hecho, según establece MAEC [2004] en su Parte III, Título III, Capítulo III, sección 9a, "la Investigación y el Desarrollo Tecnológico son aspectos primordiales en la UE y así se expresa en su Constitución". Dada la importancia de los elementos antedichos, éstos se mantienen en el próximo VII Programa Marco 2007-2013 [COMISIÓN EUROPEA-2005]. No debe olvidarse que la $\mathrm{I}+\mathrm{D}+\mathrm{i}$ es una de las tres principales formas de invertir en conocimiento (las restantes son: los gastos en educación, y en tecnologías de la información y las comunicaciones).

En esta postura debe fundamentarse el crecimiento económico de la Unión Europea como hecho capital. Ello exige de una serie de reformas cuya insuficiencia actual pone

\footnotetext{
${ }^{63}$ Genéricamente, la excelencia se define como el modo sobresaliente de gestionar una organización y obtener resultados. Para ello, debe existir una orientación hacia consecuciones y hacia el cliente, liderazgo y perseverancia en objetivos, gestión por procesos y hechos, desarrollo e implicación de las personas, mejora continua, innovación, alianzas mutuamente beneficiosas y responsabilidad social.
}

Las Redes de Excelencia son uno de los principales instrumentos del VI y VII Programas Marco de la Unión Europea. Tienen por objetivo reforzar la excelencia científico-tecnológica de Europa, a través de una progresiva y duradera integración de las capacidades de investigación existentes o emergentes en dicho continente.

Cada red de excelencia persigue avanzar en una determinada área de conocimiento, agrupando en torno a ella una masa crítica de competencia, habilidades y recursos. El objetivo final es crear un centro virtual de excelencia e implementar un programa conjunto de actividades. La integración de las capacidades de investigación y de las actividades de cada miembro de la red es esencial, debiendo conducir a un mejor uso de los recursos de investigación, a través de una especialización de las actividades de sus miembros, complementariedad y uso de infraestructura compartida.

Las redes de excelencia también deben disponer de los recursos necesarios para propagar aquélla: diseminación de los resultados de sus actividades, training, networking, etc.

Un programa conjunto de actividades agrupará: un plan conjunto de investigación a largo plazo; actividades de integración (programación de tareas de investigación, creación de infraestructuras de uso común, movilidad e intercambios de personal, reubicación del mismo, grupos y equipamiento, y refuerzo de redes de comunicación electrónica); actividades para propagar la excelencia (diseminación, gestión del conocimiento y transferencia, formación para investigadores, actividades de comunicación y networking); y, finalmente, una estructura de gestión única y común.

${ }^{64}$ De acuerdo con Ricart et al. [2002], el desarrollo sostenible es aquel avance de la sociedad que crea valor económico, medioambiental y social a corto y largo plazo, contribuyendo de esa forma al aumento del bienestar y al auténtico progreso de las generaciones presentes y futuras, tanto en su entorno inmediato como en el planeta en general. 
de manifiesto que la misma no se está acercando al objetivo de convertirse en la economía más dinámica y competitiva del mundo antes de 2010. En siete de los ocho criterios fijados en el Consejo Europeo de Lisboa del 2000, sus estados miembros van a la zaga de EE.UU y de otros países de la OCDE [Cox-2003]. La única dimensión en la que aquélla va por delante es la de la "inclusión social". Sus mayores diferencias con EE.UU radican en el clima empresarial, las redes de industrias, la $\mathrm{I}+\mathrm{D}+\mathrm{i}$ y los servicios financieros.

Los empresarios europeos ya han advertido que sus empresas transferirán sus actividades de $\mathrm{I}+\mathrm{D}+\mathrm{i}$ fuera de la Unión Europea a menos que aprecien mejoras en el clima empresarial. Una llamada de advertencia, pues, procedente del "mundo real" [Cox-2003].

Podemos decir, entonces, que el mundo iniciado en el siglo XXI es muy distinto al que inauguró el siglo XX. Ante esta nueva realidad se presenta la difícil tarea de replantear el modo de diseñar y gestionar las empresas. Aunque se desconoce cómo serán exactamente las del mañana, así como los centros que en ellas vuelcan tecnología e innovación, sí sabemos que la supervivencia de ambos estará condicionada por su capacidad de aprender.

Las distintas concepciones organizativas que han orientado la práctica de la gestión han estado siempre impulsadas por los retos a que se enfrentan las organizaciones en cada momento. De acuerdo con Aramburu Goya [2000], dos son las perspectivas que consideraremos para tratar los principales retos actuales de la gestión de organizaciones: la del cambio, o la del conocimiento que se genera en las mismas.

\section{III.3.1. La Gestión del Cambio en las Organizaciones}

La concepción de las organizaciones como "máquinas" en el mundo industrial contribuyó a su adaptación al ritmo evolutivo que le fue propio. A mediados del siglo XX, el paso a un mundo postindustrial implicó la aceleración de este ritmo, provocada 


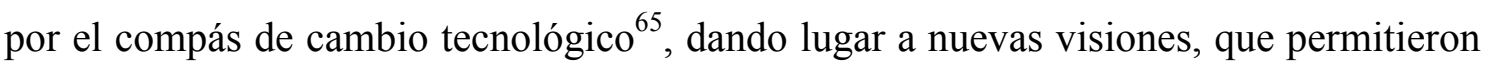
construir organizaciones ajustadas a ella. Consiguientemente, el cambio se convierte en una problemática fundamental, habiendo sido abordado desde distintas corrientes de pensamiento, en función de su concepción de la organización.

Inicialmente, en su búsqueda de referentes distintos a la máquina, máxime manejando entornos humanos, los profesionales de la gestión centran sus miradas en la Biología. Desde la metáfora orgánica, las organizaciones se entienden como sistemas abiertos a su entorno (hecho sobre el que profundizaremos en el siguiente capítulo), al que deben adecuarse para sobrevivir. Se origina así una perspectiva adaptativa. La preocupación esencial de esta corriente consiste en promover el desarrollo de las organizaciones, sobre la consideración de cambios planificados, con el propósito de adaptarse a las condiciones del entorno [Margulis y Raia-1974]. El problema de esta perspectiva radica en cómo encarar los cada vez más rápidos cambios, incluso súbitos o no previstos, tanto en el interior de la organización, como en el entorno en que se desenvuelve.

Surge, así, un enfoque desde un prisma proactivo, bajo otras concepciones organizativas. Focalizándose, también, en la metáfora orgánica, se toma en consideración a los organismos como sistemas autopoiéticos, es decir, con capacidad de autoorganización y, por ende, proactivos [Elkin y Schvarstein-1989; Ulisse y SageRipoll-1992; Probst y Büchel-1995]. Como veremos, el desarrollo actual de las Ciencias de la Complejidad lleva a la concepción de los Centros Tecnológicos como sistemas complejos a los que se atribuye capacidad de autoorganización. El cambio no es entonces un fenómeno externo al que deben adaptarse éstos en particular, sino que puede ser promovido internamente por los mismos, influyendo en su entorno. En el marco de la perspectiva proactiva surge el estudio reciente del Aprendizaje Organizativo. En el presente trabajo, se tomará en consideración la equivalencia entre sistema autopoiético y proactivo.

\footnotetext{
${ }^{65}$ Claros ejemplos de ello, reflejados ya en las enciclopedias, son: la rutinaria presencia y manejo en los domicilios particulares actuales de un ordenador personal, hecho propiciado por la integración de los circuitos electrónicos a gran escala, en torno a 1971; junto con la telefonía móvil, cuya introducción y generalización es considerada la innovación tecnológica más importante de los años noventa del siglo XX.
} 
Esta equivalencia es impulsada desde otro punto de vista, concretamente desde la Teoría del Caos, hecho que nos permite estudiar la evolución y cambio en las organizaciones (y Centros Tecnológicos, en particular), al aportar un esquema de análisis del comportamiento de las mismas de un modo que permite ampliar el dado exclusivamente bajo el tradicional enfoque psico-social.

Desde la perspectiva propuesta, se considera que la existencia de cierto nivel de caos en la organización puede incrementar su capacidad para crear un nuevo orden, es decir, para cambiar y regenerarse [Levy-1994; Guastello-1995; Kiel y Elliot-1996]. La concepción de las organizaciones como sistemas complejos no se ha aplicado ampliamente hasta la fecha, máxime en su particularización a tipos concretos de las mismas, de ahí que el estudio de los fenómenos de cambio y autoorganización desde la Teoría del Caos no hayan alcanzado, todavía, el desarrollo esperable. En nuestro caso, la perspectiva caótica nos va a permitir vincular los fenómenos de autoorganización a los estados alejados del equilibrio de los Centros Tecnológicos como sistemas complejos.

La comprensión de la tarea de gestión bajo una visión proactiva del Aprendizaje Organizativo es la más adecuada para encarar el cambio continuo.

\section{III.3.2. La Gestión del Conocimiento en las Organizaciones}

En el nuevo sistema de generación de riqueza, la celeridad con que una organización es capaz de manejar información, generar conocimiento y utilizar éste, constituye una variable crucial del mismo. Por esta razón, el estudio de la Gestión del Conocimiento en las organizaciones se ha convertido en un aspecto de interés para los gestores, donde las cuestiones que abordan son las siguientes [Nonaka y Takeuchi-1995; Stewart-1997; Davenport y Prusak-1998; Argote-1999; Cañibano Calvo et al.-2002; Canals-2003]:

1. Cómo puede una organización utilizar la información de manera eficiente y rápida.

2. Cómo puede una organización adquirir o generar nuevo conocimiento, transmitirlo, almacenarlo y aplicarlo adecuadamente. 
Entre las perspectivas desde las que se aborda la Gestión del Conocimiento en las organizaciones está la del Aprendizaje Organizativo, donde dicha cuestión es analizada considerando las organizaciones como sistemas con capacidad para el procesamiento de información y conocimiento.

Como conclusión de lo expuesto en los dos últimos apartados, puede afirmarse que la Gestión del Conocimiento en las organizaciones no ha sido considerada un reto relevante de la gestión hasta mediados de la década de los noventa del siglo XX. De ahí, que todavía estén en período de sedimentación las tendencias de pensamiento dirigidas a tratar de forma específica esta cuestión. No obstante, la corriente del Aprendizaje Organizativo aborda los dos retos actuales de la gestión: la del cambio y la del conocimiento en las organizaciones. La capacidad de aprendizaje es el pilar fundamental de las organizaciones eficientes, junto a la capacidad de renovación y generación de nuevo conocimiento, hecho particularmente importante en los Centros Tecnológicos.

\section{III.4. El Aprendizaje Organizativo frente a la Capacitación}

Los Centros Tecnológicos asignan, frecuentemente, los recursos destinados a la capacitación ${ }^{66}$ de sus investigadores (subvencionados, mayoritariamente, con fondos públicos) a dos apartados:

1. Una serie de acciones formativas, previamente aprobadas tras un diagnóstico de necesidades, que, incluso, pueden llegar a elaborar ellos mismos, en función de los proyectos que desempeña el área tecnológica ${ }^{67}$ la que se ubican.

2. Asistencias a congresos, seminarios, ferias tecnológicas y postgrados.

\footnotetext{
${ }^{66}$ Consiste en habilitar o hacer apto a un trabajador para el desempeño de sus funciones.

67 Todo aquel grupo de personas y medios asociados que desarrollan su actividad en torno a disciplinas científico-técnicas afines que permiten la ejecución de proyectos de $\mathrm{I}+\mathrm{D}+\mathrm{i}$.
} 
De acuerdo con Cardona Patau [2002], en ninguno de estos dos casos suele analizarse la relación entre la capacitación recibida y la mejora que supone en el desempeño del trabajo diario del investigador. La evaluación de esas actividades generalmente se limita a verificar el cumplimiento de expectativas y objetivos, claridad de las acciones formativas y adecuación de la metodología.

Adicionalmente, y transponiendo las ideas de Gupta [2003] y Coghlan [2004] a un Centro Tecnológico, se constata que, siguiendo el patrón general empresarial, en pocas ocasiones se proponen planes de acción para generar cambios proactivos en el mismo. Se espera, simplemente, que quien reciba esa capacitación tenga criterio suficiente para incorporar los conocimientos en el trabajo que desempeña. Este hecho se traduce en la praxis diaria en que transcurrido un cierto período de tiempo, es poco lo que se recuerda de la misma. En suma, el énfasis de los Centros Tecnológicos hacia los investigadores parece decantarse mayoritariamente hacia la capacitación, y no tanto en el Aprendizaje Organizativo.

Aunque, aparentemente, ambos sean conceptos similares, bajo ellos subyace una profunda reflexión sobre el desarrollo del Capital Intelectual como estrategia para añadir valor al Centro Tecnológico y aumentar su efectividad.

Para Castañeda Zapata [2002], la capacitación enfatiza en contenidos. El Aprendizaje Organizativo, en procesos grupales. En la primera, la pregunta más frecuente es qué se enseña. En el segundo, qué cambiamos. En la capacitación, la actitud suele ser receptiva. En el Aprendizaje Organizativo, tal actitud es aplicativa. Se observa, por tanto, que la capacitación no garantiza el Aprendizaje Organizativo, pero puede ser posible si existe un vínculo efectivo entre el alcance de sus contenidos y los procesos de cambio proactivo en el Centro Tecnológico, así como una cultura del compartir entre áreas tecnológicas, entendida como intercambio de información y conocimientos, a través de un ambiente que facilite el diálogo, la discusión, la observación, la imitación y 
la práctica [McGill, Scolum y Lei-1992]. Dicho ambiente debe ser promovido, ciertamente, por la Dirección del Centro $\frac{68}{\text {. }}$

Por otra parte, aún cuando los Centros Tecnológicos sólo aprenden a través de los investigadores, éste aprendizaje individual no garantiza el Aprendizaje Organizativo. Es más, el aprendizaje en dichos Centros no es el sumatorio de los aprendizajes de sus miembros. Al mismo tiempo, para evitar los posibles efectos negativos de la rotación de su personal, han de desarrollar visiones, valores y métodos propios, que tiendan a permanecer en estas organizaciones, independientemente de la entrada y salida de ellas de talento humano.

En relación con este último aspecto, y siguiendo a Herreros [1999] y Coghlan [2004], los Centros Tecnológicos cuentan con tres posibilidades para lograr que el Aprendizaje Organizativo, en la medida de lo posible, permanezca en ellos, compensando así, la rotación establecida:

- No dar más peso a la labor de las personas que transitoriamente participan en tareas de $\mathrm{I}+\mathrm{D}+\mathrm{i}$ (fundamentalmente becarios) que el formativo propio de su condición, y siempre en estrecha relación profesional con su tutor.

- Tener un sistema de documentación ágil y eficaz, que permita retomar labores desarrolladas con anterioridad por otras personas, con el mínimo coste temporal y la máxima eficacia en la formación.

- Promover, además, a todos los niveles, un ambiente de aprendizaje que propicie la aparición de personas interactuantes e interdependientes, dispuestas a compartir conocimiento, a observar e imitar buenas prácticas/hábitos y a retroalimentarse.

De esta forma, se deduce que el diálogo es el instrumento de creación de conocimiento. Con él, los aprendizajes individuales pasan a ser colectivos (hecho imprescindible en

${ }^{68}$ De modo general, la directiva de un Centro Tecnológico está compuesta mayoritariamente por investigadores veteranos o a tiempo parcial, que, básicamente, realizan labores de gestión y supervisión de las actividades de $\mathrm{I}+\mathrm{D}+\mathrm{i}$. 
cuestiones de $\mathrm{I}+\mathrm{D}+\mathrm{i}$, ante la interdisciplinariedad creciente de los avances científicotécnicos), como estrategia de mejora de la competitividad y de la relación costebeneficio, frente a la tradicional capacitación empresarial propia de las PYMEs de Castilla y León.

\section{III.5. Predisposición Individual al Aprendizaje Organizativo}

Como hemos establecido en el apartado anterior, aunque el Aprendizaje Organizativo no sea el sumatorio del aprendizaje de cada uno de los miembros del Centro Tecnológico, conviene tener en cuenta, sin embargo, los aspectos individuales que predisponen al mismo, sin tratar específicamente los factores que lo posibilitan en cada persona.

Estos aspectos individuales sientan la base de los actores internos de dicho aprendizaje en el seno del Centro Tecnológico, así como de las interacciones de éste con el exterior, de modo que, como veremos en capítulos venideros, a nivel grupal surgirá un comportamiento conjunto que nos permitirá hablar de Aprendizaje Organizativo y su valoración.

El investigador aprende para transformarse a sí mismo (para su cambio personal, profesional, organizacional, e, incluso, social) $y$, con ello, su entorno. Un papel importante en este aspecto lo juega la capacidad intelectual que pone de manifiesto su alto nivel académico (fundamentalmente titulados superiores de disciplinas científicas y técnicas y, en menor medida, doctores) [Modrego Rico-2004]. Lo que asimila tiene una utilidad concreta, favorece las relaciones interpersonales, sociales $\mathrm{y}$, por supuesto, laborales. Consecuentemente, pueden establecerse las siguientes consideraciones al respecto [Cardona Patau-2002]:

A. Es preciso que todo investigador conozca el por qué de la labor profesional que desarrolla. Esto implica conocer los beneficios que recibirá de su trabajo (y no exclusivamente los salariales o de incentivos), y el coste que le supondrá el no estar 
adecuadamente formado para desarrollar esa labor. En suma, el ingeniero de $\mathrm{I}+\mathrm{D}+\mathrm{i}$ debe tener necesidad de saber.

B. Es responsable de sus propias decisiones y de las consecuencias que de ellas se derivan para su desarrollo profesional. Su criterio debe ser siempre el de resultar de utilidad: ser capaz de desarrollar su misión en la ejecución de un proyecto, con el fin de actuar satisfactoriamente.

C. A lo largo de su vida profesional, va adquiriendo una amplia experiencia profesional de gran calidad en $\mathrm{I}+\mathrm{D}+\mathrm{i}$, lo que constituye una rica fuente de aprendizaje, debido, tanto a sus propias vivencias, como a las que observa dentro de su contexto. Cuanto más explícitas y compartidas se hagan estas experiencias, más se fijarán y se aprenderá de ellas (puesto que corresponden a la realidad diaria de su labor). Análogamente, el enriquecimiento del investigador será mayor, cuanto más variadas y distintas sean aquéllas, diferentes, eso sí, para cada persona, al ser distintas sus historias y habilidades. En último extremo, darán lugar a sabiduría y conocimiento, a nivel personal, y a Capital Intelectual, para el Centro Tecnológico.

D. El aprendizaje diario del investigador debe asentarse sobre la base de sus habilidades, comportamientos y problemas reales a los que se enfrenta.

E. Su motivación, determinada por factores extrínsecos e intrínsecos, tiene gran trascendencia. Los primeros vienen dados por las obligaciones derivadas de su quehacer en el área tecnológica a la que se adscribe, y otros aspectos exclusivamente laborales. Los segundos, los más importantes, aparecen cuando el participante se da cuenta, por si mismo, de la necesidad de aprender, de su responsabilidad, su buena disposición, el mejor desempeño en $\mathrm{I}+\mathrm{D}+\mathrm{i}$ y su voluntad real de querer hacerlo. No obstante, puesto que los factores extrínsecos condicionan a los intrínsecos y viceversa, la pauta de la Dirección hacia cada investigador es crucial, al tener que identificar el personal más relevante para conseguir los objetivos que se persiguen con la realización de proyectos en $\mathrm{I}+\mathrm{D}+\mathrm{i}$. 
Todas estas consideraciones confirman, nuevamente, que, más que favorecer la transmisión de conocimientos, se ha de impulsar, en cambio, la adquisición de los mismos, debiéndose diferenciar, otra vez, entre capacitación y aprendizaje. El clima de diálogo reinante en el Centro Tecnológico es, también aquí, trascendental para el aprendizaje. Los problemas del aprendizaje organizacional van a estar muy correlacionados con los de los propios investigadores a nivel individual, y con la visión global de su aportación y participación en todo el entramado organizativo del Centro Tecnológico.

\section{III.6. El Desarrollo del Aprendizaje Organizativo}

Dos son los aspectos a considerar en el desarrollo del Aprendizaje Organizativo en un Centro Tecnológico: el marco en el que éstos deben progresar, y la necesidad de efectuar una modelización dinámica de dicho aprendizaje.

\section{III.6.1. El Marco de Progreso de los Centros Tecnológicos}

Los Centros Tecnológicos, conscientes de su misión y de su presente, a la par que preocupados por su futuro, tienen, incuestionablemente, la obligación de aprender para responder, rápidamente, a los cambios tecnológicos externos que marcan su devenir, abordando el futuro de forma imaginativa. Sólo así podrán desempeñar, de modo efectivo, labores de $\mathrm{I}+\mathrm{D}+\mathrm{i}$ que reviertan en ventajas competitivas para las empresas a las que prestan servicio en Castilla y León, especialmente a las PYMEs.

Para ello, extendiendo las ideas de Herreros [1999], los Centros Tecnológicos necesitan no sólo saber cómo aprender, si no cómo aprender a aprender. Esfuerzos, buenas intenciones, recursos y tiempo no bastan para adquirir el aprendizaje que necesitan. Aún pudiendo poner todos los medios racionales disponibles en este empeño, siempre habrá de considerarse la amalgama irracional de sentimientos y percepciones personales de cada investigador, en su doble vertiente: social y laboral, que determinarán su trabajo diario, pues existe una mutua influencia y realimentación entre ambas. 
Ahora bien, y de acuerdo con el mismo autor, el Aprendizaje Organizativo no se concibe sin procesos de cambio, como ya se puso de manifiesto en páginas precedentes, y todo cambio implica miedo y ansiedad. Los seres humanos siempre se han asociado en tribus, clanes, religiones, etc., cuyo objetivo principal es la defensa ante los miedos y ansiedades que suponen su propia existencia. Goshal y Barlett [1989] establecen que las organizaciones, de forma general, no son ajenas a este deseo profundo de todos los seres humanos $\mathrm{y}$, de hecho, la empresa actual está cumpliendo un papel social preponderante $\frac{69}{\text {, }}$ ante el desprestigio de otras instituciones sociales, familiares $\mathrm{y}$ políticas. Los Centros Tecnológicos, en este contexto, tienen, además, que prestigiar y divulgar la Ciencia y la Tecnología, justificándose, así, la aportación pública de fondos que puedan obtener para desarrollar su cometido.

En la sociedad del conocimiento donde nos encontramos, el que las empresas persigan sus objetivos cambiando lleva a poner en tela de juicio la consecución de los mismos, especialmente en labores de $\mathrm{I}+\mathrm{D}+\mathrm{i}$. En estas condiciones el aprendizaje es muy duro, pero esto a su vez justifica la existencia de los Centros Tecnológicos.

Podemos plantearnos entonces cuál es el origen de esas emociones (ansiedad, incertidumbre, etc.) que tienen especial incidencia en los Centros Tecnológicos, y que son siempre fáciles de identificar y difíciles de reconocer. Según Gadner, Buber y Richards [2003], la respuesta hay que buscarla en la propia ansiedad de la empresa cliente de aquéllos, y en la incertidumbre que sobre ella genera su entorno:

1. Nuevos mercados y competidores.

2. La cada vez más costosa y acelerada adaptación a las tecnologías emergentes.

3. Nuevas demandas.

4. Ciclos de vida de los productos mucho más cortos.

\footnotetext{
${ }^{69}$ Un buen ejemplo lo constituye Google, una empresa de 51.000 millones de \$. Para anunciar su salida a bolsa, sus jefes, Larry Page y Sergey Brin, comunicaron a la SEC (Comisión de Valores de Estados Unidos) que "Google no es ni quiere ser una compañia convencional"..."Queremos hacer del mundo un lugar mejor"... "Una sociedad sana debe tener acceso a abundante, libre e imparcial información de calidad"..."Fomentaremos que nuestros empleados dediquen el 20\% de su horario a lo que creen que podría beneficiar a Google. Eso les anima a ser más creativos e innovadores". La filosofía de esta empresa es cuidar de sus empleados, su savia, por eso reciben "comida gratis, seguros médicos y lavadoras". Ciberp@ís [6 de Mayo de 2004: 6].
} 
5. Imposibilidad de planificación a medio y largo plazo.

6. Fusiones y adquisiciones.

7. Productos sustitutivos que crean nuevos mercados y destruyen los existentes.

8. Reducciones de plantilla.

Ciertamente, todos estos factores calan en la mente de los trabajadores de las PYMEs de la región, preguntándose por su futuro y el de su empresa; $y$, también, aunque en menor medida, en la de los de las grandes compañías (su poder económico ofrece mayores certezas, si bien una contratación temporal evidencia la duración de su actividad); ambas frente a la seguridad laboral de que disfruta tradicionalmente el funcionario público [De Diego Vallejo y Valdivieso Pastor-1998].

No obstante, y conforme con Gallego [2003], existen otras emociones con connotaciones positivas: la necesidad de afecto, de reconocimiento, de estima, de pertenencia, etc., que los Centros Tecnológicos han de proporcionar a sus trabajadores para compensar las anteriores. Los mencionados Centros son saludables en la medida en que son capaces, primero, de entender y, luego, de encauzar las emociones colectivas que les desvían de sus objetivos, debiendo estimular, por tanto, las de carácter positivo que acabamos de comentar.

En las actividades de $\mathrm{I}+\mathrm{D}+\mathrm{i}$, donde la experimentación, los prototipos y los estudios de viabilidad deben distinguirse frente a las actividades propias de una Ingeniería y sus productos llave en mano, la planificación, el control y la previsión de dichas actividades presenta elevados márgenes de error. Según Herreros [1999], no es casual que, cuanto mayores son los sentimientos de inseguridad en la realización de proyectos, mayor es la necesidad de creer en elementos de control, aferrándose, entonces, los Centros indicados a todas las certificaciones ISO ${ }^{20}$ vigentes que le sean adecuadas, para garantizar metodologías de ejecución (no necesariamente resultados válidos) que le sirvan de tarjeta de presentación y aval a sus clientes.

\footnotetext{
${ }^{70}$ Siglas correspondientes a International Standards Organization. Se trata de un organismo creado por Naciones Unidas en 1946, destinado a crear normas tipo que afecten a la medida de diferentes magnitudes y a la evaluación de procesos.
} 
La complejidad que caracteriza a los Centros Tecnológicos no tiene gestión ni control absolutos. Simplemente, como se deducirá del modelado entrópico del Aprendizaje Organizativo, obtendremos una estimación del estado de éste, nunca una medición del mismo. De acuerdo con Etkin [2003], la propia idea de control de un proyecto de $\mathrm{I}+\mathrm{D}+\mathrm{i}$ es una figuración, sirviendo sólo, cultural y políticamente, para satisfacer necesidades psicológicas.

Estos hechos implican una diferenciación en la estructura y en el funcionamiento interno de los Centros Tecnológicos, frente a la visión empresarial convencional, propia de las PYMEs equivalentes en tamaño en Castilla y León. Como establecen Auckenthaler y D'Huy [2003], éstas se caracterizan por las relaciones de autoridad, lo que en el caso de aquellos puede alimentar la transformación de los riesgos exteriores en amenazas interiores. De acuerdo con los trabajos de Senge [1990], y Senge y Sterman [1992], un equipo de investigadores avanzará muy poco si funciona bajo los principios de obediencia, y mucho si lo hace desde el compromiso personal y grupal. Se requiere, entonces, de una autoridad sustantiva, es decir, aquella que deriva de dirigir un equipo de alta cualificación y capacidad de trabajo.

La mutua lealtad y apoyo son, a juicio de De Geus [1997], dos de los requisitos de una buena relación entre los investigadores de un Centro Tecnológico en toda su escala jerárquica. Seguramente, sólo la afección y el respeto originado por el trabajo diario en equipo generarán buenas relaciones entre ellos. Esto implica, en definitiva, que un Centro Tecnológico debe ser, humanamente, horizontal.

Cuando no se eliminan las relaciones de autoridad convencionales, se diluye la necesidad de ayudar y de ser ayudados, imprescindible en las actividades de $\mathrm{I}+\mathrm{D}+\mathrm{i}$. Al intentar no mostrar vulnerabilidad técnica y humana en el desempeño de los proyectos en ejecución, se crean procesos psicológicos encubiertos en los investigadores que los separan de los demás y de la finalidad del Centro Tecnológico, resintiéndose, entonces, el trabajo efectivo diario que se lleva a cabo en el mismo. Consecuentemente, uno de los ejecutores fundamentales para conseguir un Aprendizaje Organizativo eficaz es la confianza [Herreros-1999]. 
Para afrontar los retos en $\mathrm{I}+\mathrm{D}+\mathrm{i}$ y estar permanentemente adaptados a los avances científico-tecnológicos, estas organizaciones suelen demandar a sus investigadores, además, que sean más abiertos, autodidactas y logren el título de Doctor, a fin de obtener un óptimo rendimiento en sus tareas [Modrego Rico-2004].

Podemos concluir este epígrafe afirmando que, en los Centros Tecnológicos, se espera un estilo de relación que facilite la contribución de los investigadores a los intereses de la organización, pudiendo adquirir experiencia y habilidades. Para John-Steiner [2000], las diferencias emocionales constituyen el núcleo de la creatividad relacional, de la misma forma que el pensamiento divergente es básico para la creatividad individual. No debe olvidarse que estas diferencias originarán episodios de conflicto, desacuerdo y separación, integrantes del hilo conductor del Aprendizaje Organizativo en aquéllos.

\section{III.6.2. Necesidad de la Modelización Dinámica del Aprendizaje Organizativo en los Centros Tecnológicos}

La sostenibilidad de los Centros Tecnológicos no consiste en tener en nómina a las mejores personas y las más preparadas en utilizar mejor la capacidad mental de que disponen, durante períodos de tiempo cada vez más prolongados. Siguiendo a De Geus [1997], han de contar con investigadores capaces de distinguir con claridad las opciones disponibles, inclinarse por la adecuada y saber llevarla adelante. Es, en este contexto, cuando estarán empleando el conocimiento.

No obstante, para que esto ocurra, los Centros Tecnológicos que así lo requieran, deben modificar algunos paradigmas organizativos. El que más prevalece, en la actualidad, está basado en el pensamiento mecanicista. De forma análoga a lo que observa Herreros [1999] para el mundo empresarial, cuando un Centro Tecnológico ha de afrontar proyectos de gran envergadura, casi siempre trata de descomponerlos en partes más manejables, ensamblando finalmente los resultados parciales para lograr una solución global. Sin embargo, puede afirmarse, categóricamente, que la suma de los obtenidos individualmente no será la de todo el conjunto.

\footnotetext{
$\overline{{ }^{71}}$ En el deporte, por ejemplo, el hecho de contar con jugadores sobresalientes no asegura el triunfo del equipo.
} 
El pensamiento sistémico hará ver que las distintas áreas científico-técnicas que conforman un Centro Tecnológico tienen escaso valor aisladamente, incluso sus investigadores, salvo cuando interactúan con las/os otras/os. Por ello, y continuando con la idea de Herreros [1999], aquél precisa de instrumentos de apoyo para la toma de decisiones que conviertan los datos, la información, el conocimiento y la sabiduría en diálogos de red, que fluyan continuamente tanto en su interior, así como entre él, sus alianzas y entorno (los consumidores finales de sus servicios). Para cumplir con este objetivo, habrán de darse los pasos siguientes:

- Conversar en equipo, entre miembros de la misma o distinta área que ejecutan un proyecto, ofreciendo, cada uno de ellos, visiones diferentes de la realidad abordada.

- Ser conscientes de las razones, visiones y modelos mentales de los demás, e intentar entenderlos.

- Crear el ambiente propicio para que cada persona pueda exteriorizar sus propios modelos mentales, sin temor a que sean infravalorados o se hagan propios y meritorios de otras personas.

De verificarse estos aspectos, se llegará a la obtención de una visión conjunta y consensuada resultante en Aprendizaje Organizativo, para anticipar el cambio (y no para atacarlo). Ello requiere identificar a tiempo los movimientos que se produzcan en el entorno, mediante la vigilancia ${ }^{22}$ y la prospección ${ }^{[3}$ tecnológicas [Escorsa i Castells y Maspons-2001; Navas López y Nieto Antolín-2003] en las líneas de I+D+i que, a su vez, cada área tecnológica mantenga vivas para desarrollar su actividad.

\footnotetext{
${ }^{72}$ La vigilancia tecnológica es el conjunto de acciones coordinadas de búsqueda, tratamiento (filtrado, clasificación, análisis) y distribución de la información obtenida de modo legal, que resulta útil a las distintas personas de una organización en su proceso de toma de decisiones, así como para alimentar su reflexión estratégica. Tiene miras de corto plazo, como observante del estado tecnológico en el momento presente.

${ }^{73}$ Desde la década de los noventa del siglo XX, los principales países industrializados han empezado a utilizar, sistemáticamente, técnicas de prospectiva tecnológica (technology foresight), a fin de conocer las tecnologías clave del desarrollo de una aplicación, sector, etc., cómo pueden afectar a la sociedad en que se desarrollan, y cuáles pueden ser los factores que las impulsen. Sus expectativas son a medio/largo plazo, y tiene un carácter de previsión.
} 
Las investigaciones realizadas por Ingvar [1985], aplicables a la mente humana, pero extrapolables a sus agrupaciones, evidencian que no se percibirán señales del mundo exterior, a menos que sean relevantes para alguna de las opciones de futuro que se hayan diseñado. Su repercusión en los Centros Tecnológicos y líneas predefinidas de I+D $+\mathrm{i}$ es inmediata, sin caer, según Sent [1999], en la falacia de dar lugar a dichas líneas en función de las "modas" y subvenciones correspondientes. Si las mencionadas líneas son consistentes, presentarán una adecuada continuidad (que llevará a bifurcaciones y adaptaciones progresivas) o un final natural, reconduciéndose así su trayectoria en función de la evolución científico-técnica. Consecuentemente, se necesita una modelización del Aprendizaje Organizativo que marque indicadores de la consistencia/inconsistencia de las labores desarrolladas en los Centros Tecnológicos y de su continuidad.

Los psicólogos aseguran que la mejor forma de aprender es jugando. Los juguetes son objetos transitorios que permiten experimentar sin riesgo. En el caso de las disciplinas científico-técnicas, y particularmente en los referidos Centros, previamente a proceder cualquier implantación industrial, se realiza una simulación o se construye un prototipo, al objeto de validar ciertos aspectos de interés. Sin embargo, en el estudio de aquellos en sí mismos, se experimenta y evalúa la realidad en la medida de lo posible, pero sin representaciones de la misma. Los modelos, y en concreto el que se persigue sobre el Aprendizaje Organizativo, son los objetos transitorios con los que podemos instruirnos sobre la realidad observada. Aunque se han venido utilizando en muchas actividades industriales desde los años sesenta del siglo XX, su aplicación a cuestiones estratégicas y organizativas, en entornos humanos (mediante la llamada Teoría General de Sistemas), reviste absoluta actualidad, máxime en los Centros Tecnológicos, en los que no existe referencia alguna al respecto.

En el intento por comprender la tecnología, cuando se comparan sus avances con los logrados por los sistemas humanos, se plantea entonces la pregunta de por qué se conocen más aquellos que éstos. Su respuesta se encuentra, probablemente, en el rechazo que supone aceptar que los entornos humanos pertenecen, de alguna forma, a la misma categoría que los sistemas físicos. 
Por consiguiente, ambos sistemas (humanos y físicos) coinciden en lo fundamental, aunque difieren en su grado de complejidad [Rapoport-1990]. Así, respondemos de forma orientada ante las acciones de otras partes del sistema, en contra de la aparente libertad ejercida en la toma de decisiones. Los seres humanos vivimos y conformamos entornos donde las acciones se basan en las condiciones actuales, a su vez las acciones afectan a las condiciones del momento, y la modificación de éstas proporciona el fundamento para las acciones siguientes. Esta es la visión que se aplicará a los Centros Tecnológicos en la presente Tesis Doctoral, esperando que con ella, éstos cumplan mejor con la misión para la que han sido concebidos.

La ventaja de la modelización sistémica estriba en que permite combinar aspectos tangibles con otros intangibles, hecho fundamental para comprobar cómo los recursos estratégicos tienen una fuerte interdependencia. También, ser más conscientes de los efectos de la retroalimentación. Con ello se propondrá un cambio de mentalidad: el Centro Tecnológico como organismo vivo. Efectivamente, en la naturaleza se observa que todo nace y va creciendo. El crecimiento es el resultado de la interacción de dos fuerzas: los procesos que generan ese crecimiento, y los que le impiden o paralizan.

Aplicado esta circunstancia a los Centros Tecnológicos, hemos de comprobar cómo el Aprendizaje Organizativo permite obtener mejores resultados en función del avance científico-técnico. Como establece Herreros [1999], el indicador más importante en este sentido es comprobar cómo los investigadores han encontrado nuevas formas de trabajar. Pero, también, deben tenerse en cuenta factores limitadores: el tiempo (trabajando siempre contra el reloj en la ejecución y entrega de proyectos de $\mathrm{I}+\mathrm{D}+\mathrm{i}$ ) y la relevancia (el Aprendizaje Organizativo tiene que importar, debiendo estar relacionado con los intereses y preocupaciones reales del Centro Tecnológico y sus miembros). Nunca debe olvidarse tampoco, que uno de los requisitos para aprender, individual o colectivamente, es “desaprender” [García Morales-2002]. 
Capítulo IV:

Modelado Entrópico de la Evolución del Aprendizaje

Organizativo 
Pedro Martín Lerones Evaluación del Aprendizaje Organizativo en los Centros Tecnológicos y Gestión del Conocimiento Sectorial en Castilla y León 
Analizados la caracterización y el contexto en el que se desarrolla el Aprendizaje Organizativo en los Centros Tecnológicos, el objetivo del presente capítulo será el planteamiento de un modelo de sostenibilidad de los mismos, en virtud del referido aprendizaje. Para ello, utilizaremos y conectaremos entre sí la Teoría General de Sistemas, el concepto de Entropía, la Teoría del Caos, la Teoría de los Sistemas Alejados del Equilibrio y la Teoría de la Autopoiesis.

\section{IV.1. Los Centros Tecnológicos como Sistema}

Se puede definir un sistema como un conjunto de elementos interactuantes de cuyas interacciones surge un comportamiento como un todo [Bertalanffy-1978]. Todo sistema presenta tres características estructurales básicas:

- Los elementos que lo componen.

- Las relaciones entre esos elementos.

- Los límites del propio sistema.

Consecuentemente, un sistema no está restringido a entidades materiales, sino que puede aplicarse a un todo genérico constituido por una serie de elementos que interactúan. Sobresalen, en este sentido, los sistemas reales, esto es, las entidades deducidas de la observación y cuya existencia es independiente del observador. Un ejemplo de ellos es el de un grupo, con sus diversos miembros. Un Centro Tecnológico, con sus diferentes empleados es, claramente, un sistema real.

El análisis de los sistemas es asunto de la llamada Teoría General de Sistemas, que halla su objeto en el estudio de las complejidades organizadas. Contempla, como su propio nombre indica, cualquier fenómeno formando parte de un sistema, pudiéndolo ser también, al menos potencialmente, por sí mismo. Un individuo, por ejemplo, puede ser considerado como parte integrante de un sistema mayor (un grupo de personas), siendo a su vez él mismo un sistema conformado por un conjunto de células. La clasificación que establece la Teoría de los Sistemas Vivos, de Miller [1978], es muy ilustrativa en 
este sentido: cada uno de sus ocho niveles contiene a los sistemas del nivel inferior (Figura 21).

FIGURA 21

CLASIFICACIÓN DE MILLER SOBRE LOS SISTEMAS VIVOS

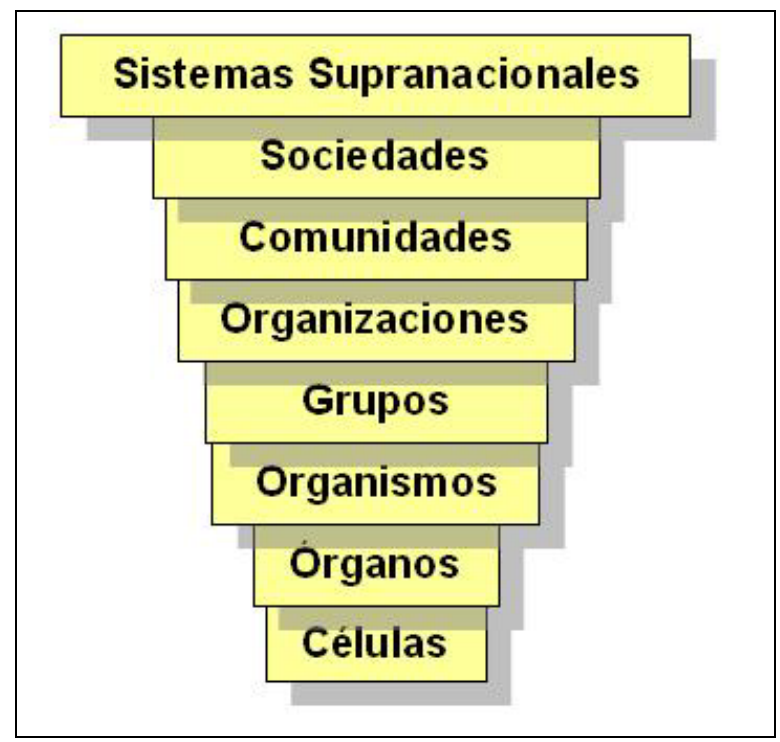

FUENTE: Elaboración propia

Por este motivo, es posible definir, sobre una misma realidad, diferentes sistemas, obedeciendo a los intereses y finalidad del observador, su experiencia en la materia que aborda, etc. Ello conduce a una concepción sobre la realidad denominada perceptivismo: el sujeto construye al objeto [Bertalanffy-1978].

La Teoría General de Sistemas se interesa más por los problemas de relación, estructura e interdependencia, que por los atributos constantes de los objetos; esto es, por los sistemas abiertos y sociales, en los que se da una fuerte interacción entre sus elementos [Rapoport-1990]. Con ello, enfatiza la aparición de propiedades emergentes no deducibles de los elementos del sistema por separado [Solé y Manrubia-2001a, 2001b].

Un Centro Tecnológico, por ejemplo, es capaz de llevar a cabo tareas de gran complejidad: analizar el desarrollo tecnológico de su entorno, diseñar, adaptar o construir máquinas adecuadas para un proyecto, o decidir la tecnología y/o proceso a llevar a cabo entre los múltiples existentes, entre otras. Pero, considerado uno a uno, ningún investigador puede acometer por sí sólo semejantes tareas. Ni siquiera, un área 
tecnológica específica per se, salvo que quiera caer en una elevada especialización, que puede llevarla a su desaparición a medio plazo, si sus desarrollos no son conducentes a una futura viabilidad industrial. Puede afirmarse, por tanto, que la vertebración conocimiento-comportamiento social del Centro Tecnológico emerge a partir de las interacciones de los investigadores, interna y externamente al área tecnológica a la que pertenecen (incluidos terceros), no siendo deducible de las propiedades de un individuo del Centro.

Adoptar esta postura implica oponerse al pensamiento de la Física Newtoniana. En ella, la aplicación de los procedimientos analíticos al estudio de cualquier sistema depende de dos factores:

- Inexistencia de interacciones entre las partes, o que tales interacciones sean tan poco importantes que pueden desecharse. Con ello se permite, en definitiva, el estudio de las partes por separado.

- Las relaciones entre las partes son lineales, para asegurar la condición de aditividad, por lo que la suma de los procesos parciales da lugar a un proceso global.

Puesto que las propiedades emergentes aludidas acaban influyendo, además, en los propios elementos del sistema, abogaremos, entonces, por una visión holística, es decir, por el estudio de los sistemas como entidades, más que como conglomerados de partes. Consecuentemente, un Centro Tecnológico será entendido como un sistema global del que resultan una serie de propiedades, fruto de las interacciones entre sus elementos característicos (que tomaremos como la mínima unidad discernible con potencial para ello y que ejecutan las labores propias de aquel: los investigadores), y entre éstos y el exterior del Centro en su actividad profesional, en función de su conocimiento, jerarquización, distribución en áreas tecnológicas y grado de relación y colaboración entre los mismos y su entorno (Figura 22).

Por otra parte, no todos los elementos que influyen en un sistema tienen el mismo peso para producir cambios en él. De hecho, pequeños cambios pueden producir grandes resultados, lo que conduce a buscar aquéllos cuyos actos y modificaciones en las 
estructuras puedan conducir a mejoras significativas y duraderas [Senge y Sterman1992]. Lo importante es, en consecuencia, analizar cuáles son y qué factores los determinan, tomando al Aprendizaje Organizativo como base de supervivencia para un Centro Tecnológico.

\section{FIGURA 22}

\section{LA APARICIÓN DE PROPIEDADES EMERGENTES EN UN CENTRO TECNOLÓGICO}

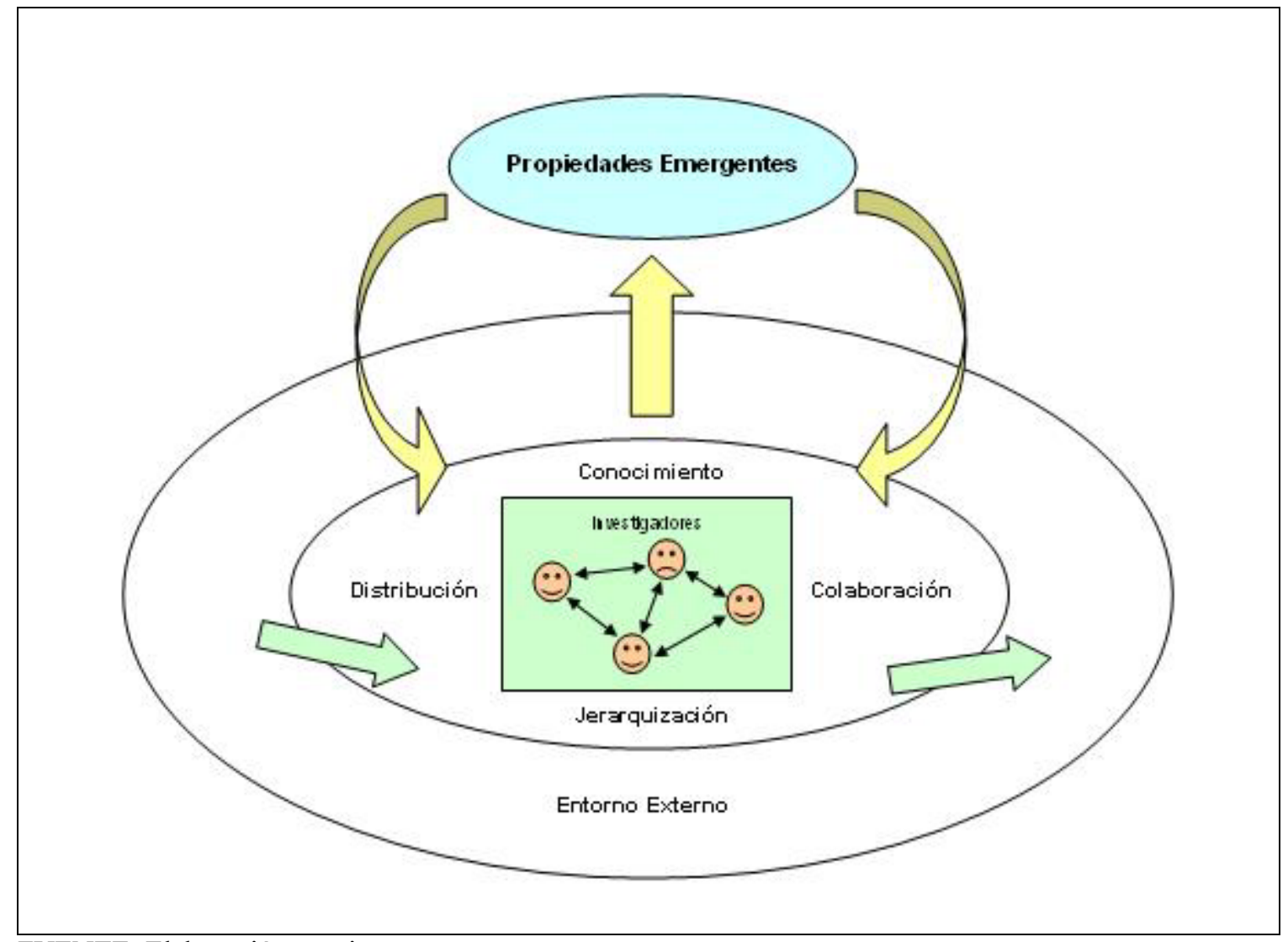

FUENTE: Elaboración propia

Para que la idea de Centro Tecnológico no resulte difícilmente ubicable en el contexto sistémico, tendremos en cuenta la clasificación que el economista K. Boulding [1956] proponía al respecto, distinguiendo nueve niveles distintos, ordenados de menor a mayor complejidad, entendida como el grado de diversidad o variabilidad de los elementos que conforman el sistema:

1. Estructuras estáticas: un cristal, un mapa de una ciudad, etc. 
2. Sistemas simples dinámicos: la atracción entre dos cuerpos, el movimiento planetario, etc.

3. Sistemas cibernéticos: por ejemplo los mecanismos de control mediante retroalimentación (como un termostato), o los procesos homeostáticos de un organismo vivo.

4. Estructuras con capacidad de autoperpetuarse, como una célula.

5. Organismos inferiores: una planta, que genera semillas, en las que va inserto el código genético para el posterior desarrollo del nuevo organismo, etc.

6. Sistemas animales.

7. Sistema humano.

8. Sistemas socioculturales: las organizaciones sociales, por ejemplo.

9. Complejidades por descubrir.

Las organizaciones $\mathrm{y}$, por tanto, los Centros Tecnológicos se enmarcan en el nivel octavo (sistemas socioculturales).

\section{IV.2. Los Centros Tecnológicos como Sistema Termodinámico}

Dado que, como acabamos de comprobar, un Centro Tecnológico puede ser tratado como un sistema, en el sentido propuesto por la Teoría General de Sistemas, consideremos, a continuación, la clasificación que sobre los mismos nos ofrece la Física: cerrados, abiertos y aislados. 
- En los sistemas cerrados se producen intercambios de energía, pero no de materia con el medio circundante (Figura 23). Un ejemplo lo constituye nuestro planeta, que intercambia radiaciones y calor con el exterior, pero no materia (si se exceptúa la caída ocasional de meteoritos y el lanzamiento de naves espaciales).

FIGURA 23

SISTEMA CERRADO

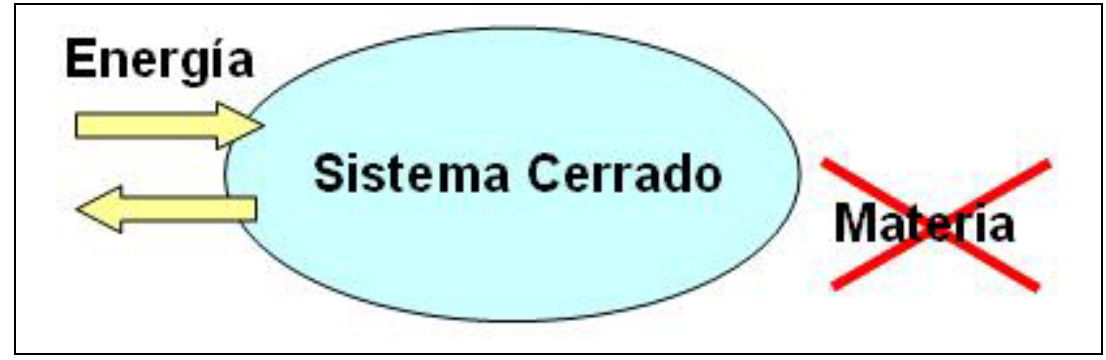

FUENTE: Elaboración propia

- En los sistemas abiertos, se producen intercambios de energía y materia con el medio circundante (Figura 24). Una empresa es un ejemplo: entrada y salida de personal (materia), entrada y salida de fuentes de energía, como agua, electricidad, posible expulsión de gases al aire libre, etc. El interés por el estudio de este tipo de sistemas, desde Bertalanffy hasta los actuales desarrollos de Prigogine, cobra en nuestros días una inusitada vitalidad.

FIGURA 24

SISTEMA ABIERTO

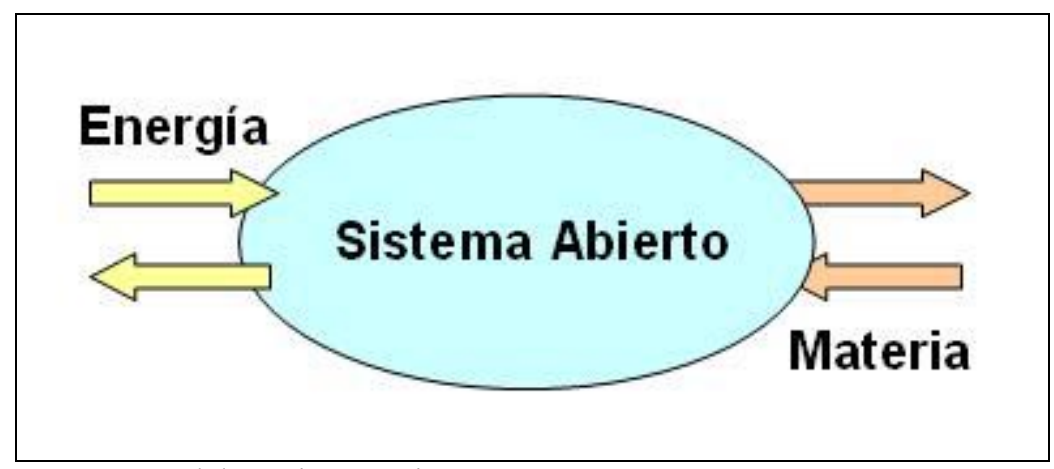

FUENTE: Elaboración propia

Ahora bien, cualquier entorno humano (en general, cualquier sistema vivo) presenta, además de los dos mencionados, intercambios de información con el medio, hecho constatado por la Teoría de la Información, de Shannon [1948]. La emisión, 
recepción y elaboración de mensajes está detrás de la mayoría de los fenómenos que nos rodean. Un Centro Tecnológico es, entonces, un sistema abierto.

- Por último, en los sistemas aislados no acontece ningún tipo de intercambio con el medio, ni de energía, ni de materia (Figura 25). Este es el caso del Universo, considerado en su totalidad.

FIGURA 25

SISTEMA AISLADO

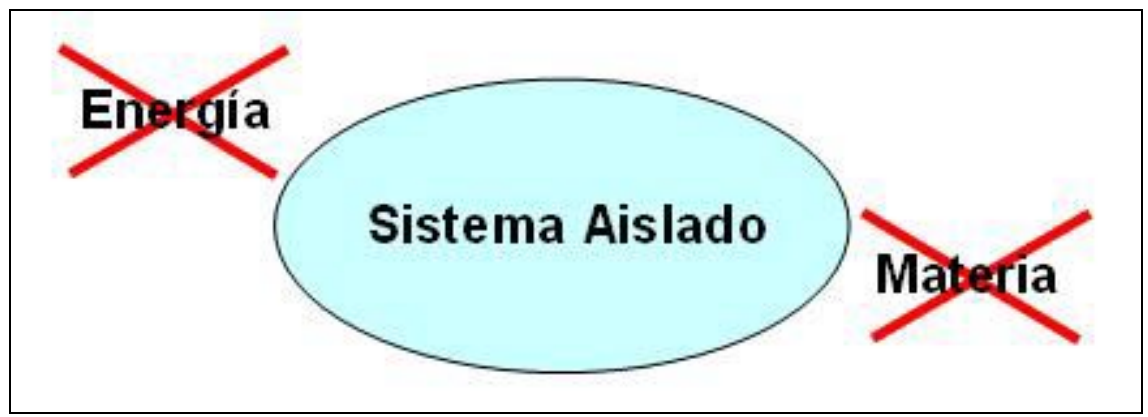

FUENTE: Elaboración propia

La Termodinámica es la parte de la Física que se interesa por los procesos de transformación de energía, tanto entre los elementos constituyentes de un conjunto, como entre éste y su entorno. Los principios básicos por los que se rige, son los que seguidamente exponemos:

El primer principio, formulado por Clausius en el siglo XIX, establecía que la energía del universo permanece constante. Es más que evidente, por la experiencia real, que en cualquier intercambio térmico, los cuerpos calientes se enfrían y no al revés. La gasolina que consume un coche para su funcionamiento, por ejemplo, propulsa el vehículo, reduciéndose, finalmente, a gases de combustión.

Debido, entonces, a que la distribución de energía parece que cambia de un modo irreversible, se estipula un segundo principio.

El segundo principio, formulado nuevamente por Clausius, establece que la entropía del universo aumenta hasta su valor máximo. La entropía $(S)$ recogería, entonces, el sentido natural del cambio en la distribución de la energía que se deriva del primer 
principio. No obstante, se cayó en la cuenta de que si en todo intercambio térmico se producen pérdidas de energía para fines útiles ( $S$ aumenta), llegaría un momento en el que ya no se dispondría de ninguna cantidad de energía utilizable. Se produciría la llamada muerte térmica: en el universo ya no habría energía que utilizar.

Para evitar este contratiempo, a finales del siglo XIX, Maxwell reinterpretaría el segundo principio de una manera probabilista. Este hecho fue aprovechado por Boltzmann, en 1909, para ampliar el concepto de entropía (considerándola una medida de la aleatoriedad) y proponer la siguiente fórmula para su cálculo [Boltzmann-1909; Brillouin-1960]:

$$
S=k_{B} \cdot \ln \Omega
$$

donde: $k_{B}$ es la constante de Boltzmann y $\Omega$ es una magnitud que mide hasta qué punto se halla dispersa la energía ( $\mathrm{n}^{\circ}$ de estados posibles para la misma).

Ilustremos esto con un sencillo ejemplo. Supongamos que lanzamos al aire una moneda cuatro veces. Hacemos un número de tiradas y cada una de ellas está constituida por esos cuatro lanzamientos. Sólo uno de los resultados posibles coincide con la configuración de cuatro caras (denotadas por C): CCCC. Sin embargo hay seis maneras de obtener un resultado con dos caras y dos cruces (denotadas por X): CCXX, CXCX, CXXC, XXCC, XCXC, XCCX. Según la expresión (1), la magnitud $\Omega$ es mayor para el resultado "dos caras dos cruces" $(\Omega=6)$, que para el resultado "cuatro caras" $(\Omega=1)$, puesto que hay un mayor número de maneras de llegar a aquél. En conclusión: mientras más aleatoria sea la situación final, más probable será, porque hay más configuraciones que conducen a ella. Dicha situación será, por tanto, más entrópica. 
Esta interpretación probabilista de la entropía presenta una ventaja sobre la interpretación termodinámica basada exclusivamente en el calor: permite extender el concepto de entropía a sistemas que nada tienen que ver con el intercambio térmico 74 . Así, el referente que expone las analogías entre los sistemas económicos y la Termodinámica, lo constituye el trabajo de Saslow [1999], ocupándose de dichos sistemas en estado de equilibrio ${ }^{75}$ de forma exclusiva, hecho que superaremos en la presente Tesis Doctoral. En consecuencia, el sentido probabilista de la entropía, observado ya en el ejemplo anterior, resulta ser de vital importancia, por cuanto, como iremos viendo, será aplicable a los Centros Tecnológicos.

Cabe hacer, entonces, la siguiente aseveración general respecto al segundo principio:

$$
S=\text { Probabilidad } \neq \text { Desorden }
$$

Un frecuentísimo y grave error en esta materia es relacionar el concepto probabilístico de entropía con el desorden de un sistema. Se asocia la aleatoriedad de un resultado con un mayor desorden del mismo, por el, a su vez, mayor número de posibilidades que conducen a él (véase el ejemplo anterior). Esto es absolutamente falso, pudiendo demostrarse matemáticamente que la entropía no está asociada al desorden de un sistema. No son conceptos equivalentes, por cuanto un sistema fuera del equilibrio (como demostraremos que es un Centro Tecnológico), puede ordenarse aumentando su entropía (Anexo B).

Vamos a postular, a continuación, una ecuación mucho más general que la (1), que nos permita trabajar con la entropía y caracterizar las probabilidades asociadas a estados internos de un sistema que dependan de cualquier tipo de vinculaciones con su entorno (ligaduras externas). Esta concepción alternativa será mucho más adecuada a la hora de

\footnotetext{
${ }^{74}$ En el momento presente, claramente se observa el salto del concepto de Entropía a todos los fenómenos humanos en que se argumenta su uso, así como a todos los fenómenos de interés para el hombre. Prueba de ello es la creciente aparición del término en la literatura científico-técnica, las ciencias experimentales y las sociales. También lo corrobora el hecho de la creación de páginas web con foros específicos en dicho sentido, entre las que sobresale Entropy [www.mdpi.org/entropy].

${ }^{75}$ En el equilibrio, no se requieren intercambios con el entorno, habiéndose alcanzado un estado de uniformidad.
} 
discutir la conexión que existe entre las propiedades macroscópicas (las que se observan en el conjunto del Centro Tecnológico), y las internas de las que son consecuencia.

Así, siendo $P=\left\{p_{1}, p_{2}, \ldots, p_{\Omega}\right\}$, la distribución de probabilidades asociada a los $\Omega$ sucesos independientes (o posibilidades) de una variable aleatoria discreta, donde $p_{i}$ es la probabilidad correspondiente al suceso i-ésimo, la entropía $(S)$ puede redefinirse como

$$
S=-k_{B} \cdot \sum_{i=1}^{\Omega} p_{i} \cdot \ln p_{i}
$$

Ecuación en donde: $\sum_{i=1}^{\Omega} p_{i}=1, \mathrm{y}$ de la que se deduce la (1), como caso particular, cuando se aplica a un sistema aislado

Nótese, además, que:

- Definimos $S$ para una distribución de probabilidad $P$.

- $S$ siempre es positiva $\left(p_{i} \leq 1 \forall i\right)$, excepto en los casos $p_{i}=0$ o $p_{i}=1$, donde vale cero 8

${ }^{76}$ Existen otras definiciones para la entropía, pero la dada de esta manera es la única que puede ser aplicada de modo general para abordar el estudio de un sistema. No obstante, como ha sido establecido, su definición debe postularse, pudiendo admitirse este hecho a través de las consideraciones de Von Neumann [1991] para explicar el proceso de medida en mecánica cuántica.

${ }^{77}$ Para dicho tipo de sistema, se define una función de la forma: $L=S+\lambda_{1}\left[\sum_{i} p_{i}-1\right]$ sobre la que se aplica el método de Lagrange (siendo $\lambda_{1} \in \mathfrak{R}$ un parámetro). Calculando la derivada parcial de $L$ respecto a $p_{i}$, y teniendo en cuenta la condición de normalización establecida para la ecuación (3), se deduce que todos los sucesos son igualmente probables: $p_{i}=\frac{1}{\Omega}$, con lo que llevando este resultado a la referida ecuación, se obtiene la (1).

${ }^{78}$ Para el caso en que $p_{i}=0$, se tiene en cuenta que: $\forall x \in \mathfrak{R} ; x \cdot \ln x \rightarrow 0$, con $x \rightarrow 0$. 
- $\quad S$ es una medida de la incertidumbre, pudiéndose utilizar el concepto de Información para eliminar una parte de dicha incertidumbre.

Veamos un pequeño ejemplo de aplicación, que da cuenta de la utilidad de la ecuación (3) y de su particularización en la (1): una persona que busca cómo llegar a un lugar se encuentra ante un cruce y no sabe por dónde continuar. ¿Cuáles serán la entropía y la incertidumbre o carencia de información en este caso?. Denotemos las cuatro direcciones posibles por las que puede optar el sujeto, como las correspondientes a los cuatro puntos cardinales: Norte, Sur, Este, Oeste. Habrá, entonces, cuatro posibilidades (cuatro sucesos), con lo que la distribución de probabilidades será $P=\left\{p_{\text {Norte }}, p_{\text {Sur }}, p_{E s t e}\right.$, $\left.p_{\text {Oeste }}\right\}=\{1 / 4,1 / 4,1 / 4,1 / 4\}$.

La entropía vendrá dada por:

$$
S=-k_{B} \cdot[0,25 \cdot \ln (0,25)+0,25 \cdot \ln (0,25)+0,25 \cdot \ln (0,25)+0,25 \cdot \ln (0,25)]=k_{B} \cdot \ln 4
$$

Pero, si algún transeúnte le indica el camino, la incertidumbre desaparecerá. En ese caso, la cantidad obtenida puede ser interpretada, por ejemplo, como el valor de la información "ir hacia el Norte" (si esa fue la indicación dada). Vemos, así, cómo los conceptos de entropía e incertidumbre están interrelacionados y cómo la información puede ser caracterizada como la "negaentropía". Si la información es una medida de lo que conocemos sobre un hecho, el concepto de entropía caracteriza el de incertidumbre. Ambas miden la aleatoriedad inherente a lo que advertimos en la realidad observada. Cuanto más improbable es un suceso (menor incertidumbre), mayor información ofrece.

Tratado el concepto de entropía, su significado y la formulación general que emplearemos para la misma, hagamos ahora la siguiente e importante observación: en su acepción original, el segundo principio de la Termodinámica está referido a los sistemas aislados (el Universo). Hemos establecido, en los párrafos precedentes, que un Centro Tecnológico es un sistema abierto, luego podemos preguntarnos hasta qué punto le es aplicable el segundo principio. 
Para responder a esta cuestión, seguiremos a Prigogine [1945], autor que formuló una extensión de dicho principio, aplicable tanto a sistemas abiertos, como a los cerrados o los aislados. Separa la producción de entropía interna del sistema, del flujo de entropía que ese sistema pueda intercambiar con su entorno, siendo olvidado este último aspecto por el segundo principio.

Expresado mediante ecuaciones diferenciales:

$$
d S=d S_{\mathrm{int}}+d S_{\text {ext }}
$$

donde: $d S$ da cuenta de los cambios de la entropía a lo largo del tiempo; $d S_{\text {int }}$ indica la producción de entropía debida a la irreversibilidad de los procesos que tienen lugar en el interior del sistema; y $d S_{\text {ext }}$ refleja el flujo de entropía que se produce en todo intercambio con el medio.

Apliquemos, a continuación, esta expresión, centrándonos, ya, exclusivamente, en los sistemas abiertos, al ser éste el entorno en el que desarrollamos nuestra investigación.

Cuando este tipo de sistema se encuentra en equilibrio, la entropía global se mantiene constante, al compensarse su producción interna con el flujo al exterior:

$$
d S=0 \Rightarrow d S_{e x t}=-d S_{\text {int }} \Rightarrow d S_{e x t}<0
$$

Dado que, en consonancia con el segundo principio, $d S_{\text {int }}>0$.

Además, en un sistema abierto pueden existir tres tipos de regímenes, según sea su situación respecto al equilibrio:

- En equilibrio: flujos y corrientes han eliminado diferencias entre las magnitudes a medir. Se ha alcanzado la uniformidad y el sistema deja de ser abierto, para convertirse en cerrado. Un cristal es una típica estructura en equilibrio. 
- En cuasi-equilibrio: este estado difiere poco del de equilibrio. En él, se mantienen pequeñas diferencias entre las magnitudes a medir dentro del sistema, para que permanezca en un ligero desequilibrio. Si esa perturbación es lo bastante pequeña, podemos analizar el sistema añadiendo una ligera corrección al correspondiente estado de equilibrio.

- Alejado del equilibrio: en este caso, las ligaduras que sostiene el sistema con su entorno mantienen unos valores que le obligan a alcanzar un estado lejos del equilibrio. En estas condiciones, pueden aparecer, espontáneamente, nuevas estructuras y tipos de organización, denominadas estructuras disipativas. Para que esto suceda, se precisan interacciones no lineales entre los elementos del sistema.

Un Centro Tecnológico es una entidad obligada a la innovación permanente y, por consiguiente, a su reorganización continua, estando sus investigadores forzados a formarse y a trabajar permanentemente con las últimas tecnologías, así como a extrapolarlas a su entorno, con elevadas cotas de riesgo en la efectividad de las tareas que se les demandan. Un Centro Tecnológico es, consecuentemente, un sistema alejado del equilibrio.

Recapitulando lo expuesto en este apartado, podemos afirmar, entonces, que un Centro Tecnológico es un sistema abierto desde el punto de vista termodinámico, sin que por ello estemos obligados a analizarle, únicamente, mediante magnitudes caloríficas, que, en ningún caso, serían de utilidad a nuestros propósitos. Le es aplicable, por tanto, el concepto de entropía, en sentido probabilístico, como medida de la incertidumbre sobre un hecho observado en él, teniendo en cuenta la formulación dada por las expresiones (1) y (3). Es, además, un sistema alejado del equilibrio, según la extensión del segundo principio de Prigogine. 


\section{IV.3. Metodología de Estudio}

En un Centro Tecnológico, el tiempo constituye una variable relevante, prestando atención a los elementos dinámicos del sistema. Deberemos, entonces, interesarnos por el estudio de esta dinámica, consecuencia, fundamentalmente, de las interacciones entre los investigadores que lo conforman, como elementos constitutivos de dicho sistema, así como entre estos y el medio externo.

Bajo esta perspectiva, un Centro Tecnológico viene determinado por su estructura, siendo, uno de los aspectos más destacados de su dinámica, el hecho de que las causas de los problemas que aparecen en él, como sistema social que es, no son debidas tanto a sucesos previos, como a su propia estructura.

Se puede concebir, así, a la Dinámica de Sistemas como un método para la construcción de modelos de aquél, donde la simulación puede jugar el papel de la teoría frente a la experiencia.

\section{IV.3.1. Los Bucles de Realimentación y sus Demoras}

Los humanos tendemos a pensar en función de relaciones causa-efecto, unidireccionalmente, olvidando relaciones más complejas. El concepto de realimentación que se originó en la Cibernética supuso una renovación en esa concepción de la causalidad.

Los bucles de realimentación van a permitir a un Centro Tecnológico responder ante imposiciones externas, influir en su entorno, adaptarse al mismo o mantenerse inalterable frente a molestos cambios. Conocer dichos bucles nos facilitará la determinación de los flujos de aprendizaje internos y externos, así como de los parámetros caracterizadores del Aprendizaje Organizativo en aquél.

Veamos primeramente, de modo general, en qué consisten los dos tipos de bucles de realimentación que vamos a tener en cuenta: negativos y positivos [Hamilton-1980]: 
- Bucles de realimentación negativos: son los que tienden a estabilizar al sistema, a mantenerlo en un estado concreto. Un termostato es un ejemplo de este tipo: se programa la calefacción de nuestro hogar para que la temperatura se mantenga a $22^{\circ}$ C. Cuando baja de esta cota, el termostato enciende los radiadores. Lo contrario sucede cuando se supera tal valor. La realimentación es evidente: la acción del termostato afecta a la calefacción, pero, también, ésta afecta al termostato.

- Bucles de realimentación positivos: son los que no mantienen el equilibrio, transportando al sistema hacia nuevos estados. Actúan de forma que la variación a que se somete el sistema se propaga a lo largo del bucle, reforzándola. Esto es lo que sucede cuando se acopla un sonido. La salida de audio que tiene lugar por el altavoz es captada por el micrófono, que la vuelve a introducir, produciéndose, en décimas de segundo, un molesto ruido.

Obviamente, en un Centro Tecnológico existen combinaciones de estos dos tipos de bucles. Junto a ellos, también deben tenerse en cuenta las demoras en las transmisiones (de información, de personal, etc.). Por ejemplo, la decisión de rebajar el precio de una oferta para desarrollar una determinada técnica, no suele tener un efecto inmediato en el número de empresas potenciales para su aplicación; o el tiempo que transcurre entre la realización de un pedido a una empresa proveedora del Centro y su recepción. En este último caso, las demoras en los sistemas de distribución industrial provocan oscilaciones en los pedidos, por lo que, desde una perspectiva gerencial, un mayor control de las mismas conduce, a su vez, a un mayor control de los plazos dados a un cliente para la ejecución de un proyecto de $\mathrm{I}+\mathrm{D}+\mathrm{i}$. Un último ejemplo, en este sentido, sería el de las decisiones que, a día de hoy, toman los políticos en materia de Ciencia y Tecnología. Afectarán al Centro Tecnológico en un futuro, ya sea próximo o dejando pasar un perceptible lapso de tiempo.

Teniendo en cuenta a Aracil [1993], las demoras nos sirven para explicar el alejamiento, en el tiempo y en el espacio, entre causas y efectos. 


\section{IV.3.2. Relación entre Organización Social y Sistema Abierto para los Centros Tecnológicos}

A diferencia de otras instituciones y formaciones sociales, un Centro Tecnológico posee

el siguiente conjunto de características definitorias como organización:

I. Composición basada en individuos (investigadores) y grupos interrelacionados (áreas tecnológicas con actividades específicas de $\mathrm{I}+\mathrm{D}+\mathrm{i}$ ).

II. Orientación hacia fines que guían las actividades a realizar (principalmente proyectos de $\mathrm{I}+\mathrm{D}+\mathrm{i}$ ), al objeto de lograr su propia subsistencia. Esto conlleva el desarrollo de políticas sobre los objetivos a perseguir, cómo perseguirlos y cómo preservarlos.

III. Implicaciones en la gestión convencional (se dirigen grupos de personas), en la de la innovación (por el continuo dinamismo y adaptación a las nuevas tecnologías) y, por último, en la científico-tecnológica (para el seguimiento y la consecución de la actividad en $\mathrm{I}+\mathrm{D})$.

IV. Diferenciación de funciones entre los miembros y áreas tecnológicas, como fruto de la persecución de unos intereses organizacionales cuya consecución precisa de división de tareas y ocupaciones.

V. Coordinación racional intencionada, necesaria para su integración, en orden a lograr sus fines.

VI. Continuidad, a lo largo del tiempo, en la actividad en $\mathrm{I}+\mathrm{D}+\mathrm{i}$.

VII. Ha de analizar la relación que mantiene con el entorno, como importante elemento definitorio y como sistema abierto que es.

Esta caracterización de los Centros Tecnológicos encaja, perfectamente, con su imagen de sistema termodinámico. Resulta evidente que de las interacciones entre sus 
investigadores, áreas tecnológicas y entorno surge un comportamiento conjunto. Los Centros Tecnológicos pueden pertenecer, además, a un sistema mayor (una red de Centros de I+D a escala europea, una vertebración en el sistema Ciencia-Tecnología de la región en que se localizan, etc.), o estar formados por subsistemas (áreas tecnológicas). En cualquiera de los casos, les es aplicable el concepto probabilístico de entropía (véase apartado IV.2).

Por otra parte, de acuerdo con la Teoría General de Sistemas, el interés por los Centros Tecnológicos como organización se centra en problemas de relación, de estructura e interdependencia, y no en sus atributos constantes. Se enfatiza, además, la fuerte dependencia entre los componentes del sistema, de tal forma que los cambios en una de sus partes acaban afectándole por completo. Ejemplo corriente de ello es la introducción y adaptación constante de sus puestos de trabajo a las nuevas tecnologías y técnicas.

Toda intervención organizativa debiera centrarse más en los procesos que en los contenidos. Por ello, en la literatura actual, lógicamente, proliferan más los estudios sobre cómo llevar a cabo liderazgos eficaces en las organizaciones (proceso), que los que analizan el perfil de los líderes (contenido).

En nuestra asimilación de los Centros Tecnológicos, como organización y como sistema, se ha de pensar en la aparición de propiedades emergentes. Cualquier proceso psicosocial que acontece en su interior (cultura de los investigadores $\frac{79}{\text {, estilos de }}$ liderazgo directivo, clima laboral, nivel de responsabilidad e implicación en los proyectos, participación, etc.) puede ser considerado un emergente organizacional. Dichos procesos emanan de las interacciones entre los investigadores, no se reducen al individuo y acaban influyendo, también, en ellos mismos [De Quijano y Navarro Cid1999, 2000].

El estudio de un Centro Tecnológico debe comenzar por la comprensión del sistema que configura en su totalidad, como ente global, para continuar con el de sus partes. Esto debe hacerse frente a la habitual investigación analítica, cuyo modo de proceder sería

\footnotetext{
${ }^{79}$ Entenderemos por cultura el conjunto de conocimientos que permitirán a los investigadores desarrollar su juicio crítico.
} 
justo la inversa. Además, como organización que es, cuenta con puntos de influencia clave, con componentes estratégicos. La mera participación de los investigadores en los procesos de trabajo diarios, y el saber escuchar sus indicaciones sobre los referidos procesos y las metodologías en $\mathrm{I}+\mathrm{D}+\mathrm{i}$ por parte de su directiva, a buen seguro que van acompañados de amplios efectos en la conducta organizativa: mejora de la solución de problemas, mayor satisfacción, mayor autorrealización, menor alineación, mejora de las relaciones directiva-investigadores, mejor desempeño, mayor motivación y mejora de las actitudes en el trabajo, menor rotación de personal en la ejecución de proyectos y, en general, mejora de la actividad del Centro Tecnológico. Todos estos aspectos configurarán relaciones y flujos, internos y externos, que determinarán los parámetros caracterizadores del Aprendizaje Organizativo, y nos conducirán a su valoración entrópica a lo largo del tiempo, como indicación de la sostenibilidad y el desarrollo del Centro Tecnológico como sistema.

Esta nueva perspectiva nos remite a los sistemas no lineales (aquellos cuyo todo no es igual a la suma de sus partes), donde pequeñas acciones pueden conseguir grandes efectos [Kosko-1994; Jiménez-Morales-2002], hecho conocido como "efecto mariposa", como veremos posteriormente.

Obsérvese que se establece, entonces, la siguiente equivalencia, donde debe prestarse atención al sentido de las flechas:

Sistema Termodinámicamente Abierto $\Leftarrow$ Centro Tecnológico $\Rightarrow$ Organización Social

Profundicemos en ella, basándonos en el estudio de Navarro Cid [2001], considerando, primeramente, al Centro Tecnológico como sistema abierto. En él:

1. Se importa energía y materia del exterior, en forma de recursos materiales, investigación, tecnología, innovación continua y capital humano. Ello es debido a que ninguna estructura social es autosuficiente. 
2. Los aspectos indicados en el punto anterior se modifican (reorganización del input), al realizarse trabajos en su interior (actividades de $\mathrm{I}+\mathrm{D}+\mathrm{i}$, etc.).

3. Se exportan resultados al exterior: conocimientos científico-técnicos, productos (nuevas máquinas y tecnologías), servicios (estudios de viabilidad, análisis y mejora de procesos, etc.), formación en las últimas tecnologías, y capital humano.

4. Se observan ciclos de acontecimientos que se repiten: el conocimiento, producto o servicio ofrecido y exportado por el Centro Tecnológico al exterior, proporciona la fuente de energía suficiente para la repetición del ciclo entrada-transformaciónsalida, con la aparición de los subsiguientes bucles de realimentación, externos e internos. Este ciclo debe generar entropía negativa, de vital importancia para el mantenimiento del sistema. Considerando la nomenclatura establecida en la ecuación (4), el flujo de entropía con el exterior $\left(d S_{\text {ext }}\right)$ debe ser mayor que la producción de entropía interna $\left(d S_{\text {int }}\right)$.

La cantidad de recursos empleados y requeridos por un Centro Tecnológico son el resultado de los utilizados en dos procesos [Leifer-1988; Brynjolfsson-1994; Fiedler, Grover y Teng-1996]:

4.1 Las interacciones con el entorno (intercambio de conocimiento; adquisiciones de material; contratación de nuevo personal; permuta, marcha o despido de personal existente; asistencia a ferias y congresos; publicaciones científicotécnicas; innovación; inyección económica pública o privada, etc.) y su aplicación a las actividades de $\mathrm{I}+\mathrm{D}+\mathrm{i}$ (conceptualización de metodologías y procesos; diseño y fabricación de componentes; asistencia técnica a instalaciones; su puesta en marcha; subida en cadencia; control de calidad de producto, etc.).

4.2 Sus actividades de sostenimiento (labores de $\mathrm{I}+\mathrm{D}+\mathrm{i}$, gestión de $\mathrm{I}+\mathrm{D}$ y de la innovación, así como difusión y publicidad, etc.).

Para que aquél sobreviva, debe cumplirse que: 


$$
d S_{\text {ext }}>d S_{\text {int }}
$$

Luego, la variación de entropía debida a los intercambios del mismo con el entorno, ha de ser mayor que la variación de entropía generada por las actividades organizacionales que implican su sostenimiento. Con ello, el Centro Tecnológico consigue mantener una razón favorable de inputs/outputs determinantes para su supervivencia y desarrollo.

5. Al ser un sistema abierto, el concepto de intercambio de información es un hecho a tener en cuenta. Hay inputs de este tipo (no únicamente energéticos o materiales), que no sólo dan indicaciones del entorno, sino, también, del propio funcionamiento del Centro Tecnológico, dando lugar a una realimentación negativa, que conduce a la organización hacia estados estables. De hecho, por su condición de sistema abierto, dichos Centros tenderán a incorporar, dentro de sus límites, los recursos externos que les son esenciales para su supervivencia.

6. Por la misma condición de sistema abierto, han de moverse hacia la diferenciación. Las pautas globales difusas deben reemplazarse por una continua evolución a funciones específicas especializadas. La distinción entre subsistemas "productivos" (áreas tecnológicas con especializaciones concretas en $\mathrm{I}+\mathrm{D}+\mathrm{i}$ ), encargados de transformar los inputs en outputs, y subsistemas de soporte (actividades de gestión e innovación), constituye, a modo de ejemplo, una diferenciación básica observable en el Centro Tecnológico. Como contrapartida a este proceso de diferenciación, se necesitan, en cambio, verdaderos esfuerzos de integración y coordinación entre sus partes.

7. Equifinalidad, que es la propiedad consistente en alcanzar un estado final por diferentes caminos, o, a partir de condiciones iniciales diferentes [Bertalanffy-1978].

Los sistemas abiertos tienen tendencia, además, a realizar transiciones hacia estados de mayor complejidad y estructuración. Teniendo en cuenta el concepto que sobre la misma se estableció al tratar los Centros Tecnológicos como sistema, la complejidad será entendida como autonomía respecto al medio y como capacidad de procesamiento 
de información. Esta tendencia se pone de manifiesto en cualquier sistema abierto, siendo un ejemplo muy ilustrativo, la complejidad orgánica acontecida a lo largo de la evolución biológica, pues, obviamente, es muy amplia la escala entre una bacteria y un ser humano [Wagensberg-1998]. En el caso de aquellos, la referida tendencia se pone de manifiesto en las muchas disciplinas científico-tecnológicas que pueden abarcar para cubrir la demanda en $\mathrm{I}+\mathrm{D}+\mathrm{i}$ del entorno en el que se proyecten, y cómo se constituyan las áreas tecnológicas correspondientes, para responder a tales necesidades.

Al objeto de completar la consideración establecida en la expresión (6), pasamos a indicar, a continuación, cuáles son las características propias de un Centro Tecnológico como organización social y subtipo de sistema abierto:

i. Sus estructuras sociales están configuradas, más que por partes físicas, por ciclos de acontecimientos. En un Centro Tecnológico ha de pensarse, mayormente, en corrientes de sucesos (procesos de trabajo, flujo de proyectos, etc.) y no en un determinado número de departamentos (típico organigrama).

ii. Es un sistema creado por el hombre y, por tanto, inventado. Por ello, tan pronto puede desaparecer, como sustituirse por esquemas más adecuados.

iii. Los lazos que mantienen a las personas vinculadas a él son de marcado carácter psicológico y social, más que biológico (a no ser que algunos trabajadores estén unidos por lazos familiares). Hablamos de necesidades como: la de pertenencia a una institución puntera, desmarcada de los trabajos habituales y de elevado nivel intelectual; de autoestima; de desarrollo personal y profesional; retribución aceptable y seguridad relativa.

iv. Un sistema de roles marca las líneas de conducta de sus miembros, haciéndolas previsibles. Este sistema transciende a las personas que lo forman, haciendo posible su continuidad, al margen de la de sus miembros. Este hecho es muy importante, por la elevada variabilidad de su personal, traduciéndose en que nadie es imprescindible, pero sí necesario. 
v. En su interior, se generan fuerzas que determinan su evolución a lo largo del tiempo. De las interacciones entre los investigadores, y entre éstos y su entorno externo, surge un comportamiento dinámico. Un aspecto muy importante para comprender su evolución es entender los bucles de realimentación que en él se presentan:

- Entre los "negativos", figuran los mecanismos de socialización, tendentes al mantenimiento de las normas impuestas existentes; la buena comunicación y armonía entre las áreas tecnológicas, para lograr la ejecución conjunta de un proyecto; los avances y aciertos en tales ejecuciones; el entendimiento investigador-directiva; la puesta en marcha de políticas restrictivas en el gasto en materiales y subcontrataciones, en períodos de escasez de proyectos; así como las políticas retributivas de incentivación a los investigadores.

- Entre los "positivos", los fenómenos asociados a la propagación de rumores; la excesiva continuación de investigadores en industrias para las que se desarrolla un mismo proyecto; el incumplimiento de los pliegos de condiciones con un cliente; la acumulación de problemas humanos y técnicos en la consecución de objetivos de las actividades desarrolladas; la falta de orientación en I+D; y las directrices cambiantes por parte de las áreas tecnológicas.

vi. El conflicto que surge entre intereses, políticas a largo plazo y políticas a corto plazo constituye otra de sus características, hecho que condiciona la toma de decisiones a escala directiva.

vii. Son sistemas intencionales: pueden elegir los objetivos a perseguir, las estrategias a diseñar, los principios y valores a defender, las líneas de $\mathrm{I}+\mathrm{D}+\mathrm{i}$ a acatar, el sistema de calidad, el tipo de estructura y diseño organizativo a tener. Pueden, igualmente, modificar estos aspectos en el momento que deseen o que así se requiera.

Tras lo explicado en el presente epígrafe, a continuación se exponen las distintas teorías científicas susceptibles de ser aplicadas en el análisis de los Centros Tecnológicos. 


\section{IV.3.3. Aplicación de la Teoría del Caos}

Desde la década de los setenta del siglo XX, cada vez son más las disciplinas que se han interesado por la Teoría del Caos. Se inició en la Matemática y la Física, extendiéndose rápidamente a la Química y, seguidamente, a la Biología, la Ecología y la Geología. Constituye, desde la década de los noventa del pasado siglo, una fuente inagotable de explicación de las tesis de disciplinas tan variadas como la Medicina, la Economía y otras Ciencias Sociales.

En general, cabe distinguir dos enfoques en los estudios del Caos:

1. El del orden oculto reinante en los sistemas que presentan dinámicas caóticas (denominados sistemas caóticos). Estos sistemas contienen lo que se denomina atractores extraños, raros patrones de orden, que ponen de manifiesto una elevada y rica organización donde, aparentemente, sólo parece existir aleatoriedad y azar. Este enfoque centra su atención en el propio Caos y, no tanto, en las estructuras organizadas que de él emergen. Algunos de los autores más representativos del mismo, afincados en los Estados Unidos, son: Edward Lorenz, Mitchell Feigenbaum, Benoît Mandelbrot y los miembros del llamado Grupo de Santa Cruz (Robert Shaw, Norman Packard, Doyne Farmer y James Crutchfield).

2. El que centra su atención en la aparición espontánea de orden, de autoorganización, en las estructuras que surgen en los sistemas que se alejan del equilibrio. $\mathrm{Su}$ representante más destacado es Ilya Prigogine, afincado en Europa.

Aunque la terminología empleada por ambos enfoques no siempre sea coincidente, en realidad, hablan de lo mismo, de sistemas complejos:

- Sistemas con dinámicas caóticas.

- Sistemas en los que pequeñas diferencias en las condiciones de partida provocan grandes diferencias en un estado posterior. 
- Sistemas con procesos no lineales.

- Sistemas en los que conviven estabilidad e inestabilidad.

- Sistemas alejados del equilibrio.

Puesto que, al tratar los Centros Tecnológicos como sistema termodinámico, ya se observó que eran sistemas alejados del equilibrio, consecuentemente, les es aplicable, directamente, la Teoría del Caos. Emplearemos, además, en su estudio, el enfoque de Prigogine [Nicolis y Prigogine-1977].

\section{IV.3.3.1. El Nacimiento de la Teoría del Caos}

Existe consenso en situar el nacimiento del estudio del Caos en un trabajo realizado por E. Lorenz [1963], meteorólogo del MIT (Massachusetts Institute of Technology), hecho significativo no sólo por su interés didáctico, sino, también, por el tratamiento equivalente que daremos a los Centros Tecnológicos en este contexto.

Lorenz creó una pequeña simulación informática sobre el clima, basándose en un conjunto de doce ecuaciones, con las que obtendría predicciones no lineales del tiempo. Para la Meteorología, la aparición del ordenador abrió una puerta a la esperanza de equiparar su disciplina con la Astronomía, en la que se realizaban predicciones, a siglos vista, con simples conocimientos trigonométricos.

El sistema de ecuaciones de Lorenz producía comportamientos no periódicos, ante la no linealidad de las mismas. En el clima, nunca se dan dos situaciones exactamente iguales (misma temperatura, nivel de humedad, velocidad y dirección de viento, etc.). Trabajando con esta simulación, decidió repetir algunos de sus cálculos e introdujo en el programa informático pertinente una secuencia que había salido impresa un poco antes. Volvió a poner en marcha la simulación y comprobó que los números resultantes no tenían nada que ver con los que se habían obtenido anteriormente. Por tanto, si la atmósfera real se comportaba como el sencillo modelo simulado, la predicción a largo plazo se hacía imposible. Lorenz comprendió, entonces, el vínculo existente entre la 
falta de periodicidad de un sistema y su impredecibilidad. Su conjunto de ecuaciones dieron lugar a la llamada "mariposa de Lorenz", que refleja, en un corte bidimensional de sus soluciones tridimensionales, la órbita de los diferentes estados por los que pasa el sistema en la simulación (Figura 26).

La sensibilidad a las condiciones iniciales mostrada por tales ecuaciones sería conocida, desde entonces, como el efecto mariposa. Dicho de otra forma, dos situaciones climatológicas iniciales similares, y que sólo difieran en el aleteo de un insecto tan delicado como aquél, pueden evolucionar de modo tan distinto con el transcurso del tiempo, que difieran entre sí en algo tan grande como un tornado. Esta es la esencia del efecto mencionado.

\section{FIGURA 26}

LA MARIPOSA O ATRACTOR DE LORENZ

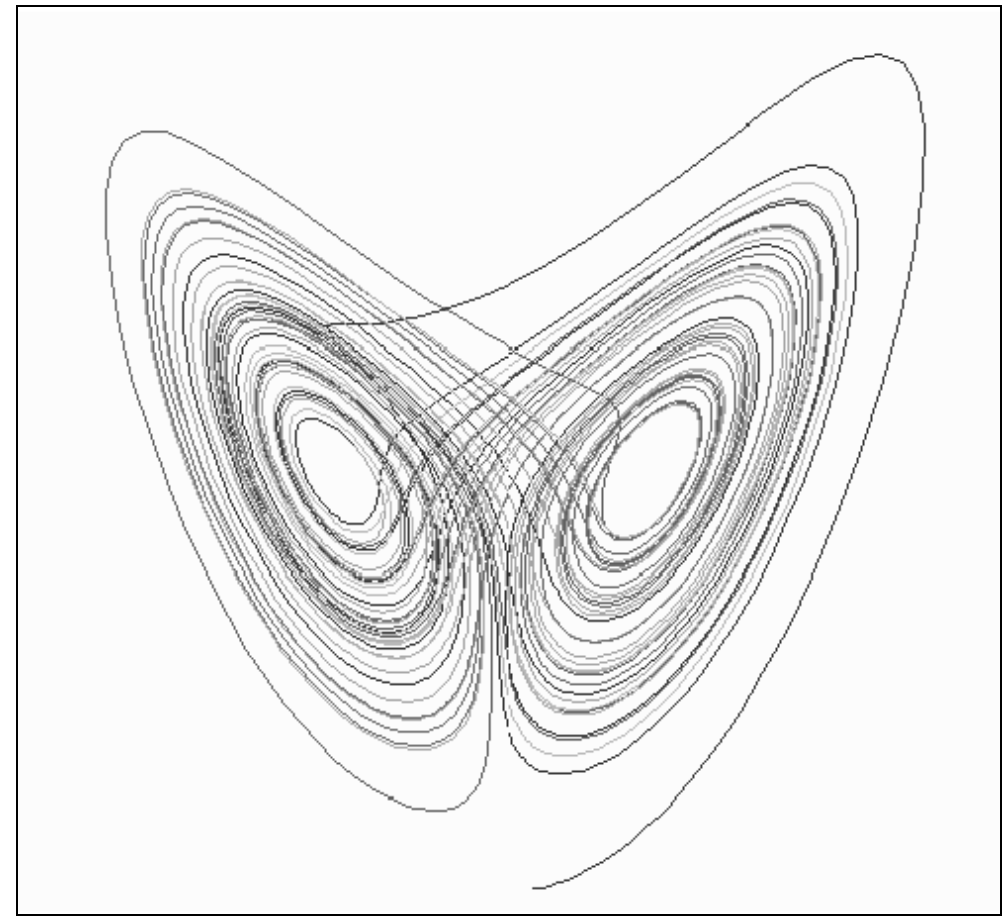

FUENTE: [www.fractales.org]

A partir de sus observaciones, determinismo y predecibilidad han dejado de ir de la mano. La idea que Lorenz viene transmitiendo no es otra que la de que hay que buscar el Caos, en lugar de eludirlo [Lorenz-1993]. 


\section{IV.3.3.2. Los Atractores}

Hemos establecido que es aplicable la Teoría del Caos a un Centro Tecnológico, al ser un sistema alejado del equilibrio. El análisis temporal de algunos elementos caracterizadores del Aprendizaje Organizativo (que se detallarán más adelante), puede dar lugar a un atractor que indique su tendencia, relacionada con los cambios y adaptaciones sufridas por el Centro [Peitgen, Jurgens y Saupe-1992]. Por ello, profundizaremos, a continuación, en el concepto de atractor.

La Topología es la rama de las Matemáticas que se interesa por el estudio de la continuidad de las formas geométricas, centrándose en aspectos tales como la posición relativa y la forma. Se diferencia, así, de la Geometría, centrada más en propiedades como la posición o distancia absoluta, y las rectas paralelas. La Topología recurre, para la realización de sus análisis de formas, al espacio de fases [Goldstein-1987], diagrama en el que se representa el movimiento del sistema. La grafía de dos de las dimensiones del movimiento de un péndulo (eje de abscisas: impulso mecánico; eje de ordenadas: posición) constituye un ejemplo de ello. Daría lugar a una trayectoria circular, que se repetiría continuamente, como el movimiento pendular en sí.

Poincaré, en el siglo XIX, identificó las cuatro formas típicas que pueden darse en el espacio de fases [Wiggins-1991]:

1. Sumideros: puntos concretos hacia los que confluyen todos los puntos vecinos.

2. Fuentes: puntos que actúan como repulsores de los puntos vecinos, alejándose, cada vez más, de ellos.

3. Sillas de montar: puntos que actúan, a la vez, de sumidero y de fuente, dependiendo de la dirección que se tome en consideración.

4. Ciclos límite: conjunto de puntos con disposición cerrada sobre sí misma, que atraen al resto de los puntos. 
Tanto el sumidero como el ciclo límite tienen la propiedad de ser estructuralmente estables, puesto que se trata de puntos o zonas de atracción para el resto de los del espacio de fases. En este caso, estamos ante atractores.

En un sistema dinámico, hay, por el contrario, puntos o estados que repelen al mismo, como las fuentes y las sillas de montar (estas últimas, en una de sus direcciones). Estaríamos ante repulsores.

Tratando de fijar más la idea de atractores y repulsores, podríamos imaginar un relieve similar a valles y montañas, en el que dejamos caer una pelota: es probable que ésta acabe en uno de los valles (atractor gravitatorio) y no se quede sobre una de las cumbres montañosas (repulsor).

Un sistema dinámico puede tener, además, varios atractores y repulsores actuando de manera simultánea.

Existen tres tipos básicos de atractores:

A. Atractores de punto fijo: son sumideros que atraen al sistema hacia una situación muy concreta o estado particular. Volviendo al ejemplo anterior del péndulo, salvo que conste de mecanismo de propulsión, siempre tiende a acabar en el punto de mínima energía potencial, es decir, parado. Este punto será entonces su atractor de punto fijo.

B. Ciclos límite: se trata de una variedad topológica que constituye un tipo de atractor en sí misma. Representa un comportamiento cíclico. El estudio realizado por Baumol y Wolff [1983], sobre la relación existente entre la tasa de crecimiento de la productividad $\left(\pi_{t}^{*}\right)$ :

$$
\pi_{t}^{*}=\frac{\pi_{t+1}-\pi_{t}}{\pi_{t}}
$$


y el nivel de gasto realizado en $\mathrm{I}+\mathrm{D}+\mathrm{i}$ por la industria privada $\left(r_{t}\right)$, constituye un ejemplo de ellos. Obviamente, se espera que un incremento en $r_{t}$ produzca un aumento en $\pi_{t}^{*}$. Sin embargo, dado que la $\mathrm{I}+\mathrm{D}+\mathrm{i}$ es una actividad del sector servicios, con un componente de trabajo más o menos fijo, su coste aumentará por el incremento de la productividad del resto de la economía; provocando, a su vez, una disminución en la demanda de $\mathrm{I}+\mathrm{D}+\mathrm{i}$. El resultado será un ciclo de altas tasas de crecimiento de la productividad y subidas en los precios en $\mathrm{I}+\mathrm{D}+\mathrm{i}$, que conducirá a situaciones restrictivas en las tasas de crecimiento de la productividad y a reducciones en el precio de la $\mathrm{I}+\mathrm{D}+\mathrm{i}$, y así sucesivamente. En última instancia, si los costes en $\mathrm{I}+\mathrm{D}+\mathrm{i}$ aumentaran de forma no equilibrada respecto a la tasa de crecimiento de la productividad, la relación inicial puede generar una curva diferente a la que tiene por atractor un ciclo límite, según los mencionados autores.

La dinámica relacional entre los Centros Tecnológicos y la financiación para llevar a cabo sus actividades puede seguir, igualmente, un atractor de ciclo límite. Imaginemos un contexto en el que determinados Centros Tecnológicos desarrollen sus actividades, disputándose tanto la financiación pública como privada. Habrá ocasiones en las que abundarán los Centros Tecnológicos y, paradójicamente, pasarán apuros económicos (Figura 27).

FIGURA 27

EJEMPLO DE DINÁMICA RELACIONAL ENTRE CENTROS TECNOLÓGICOS Y SU FINANCIACIÓN

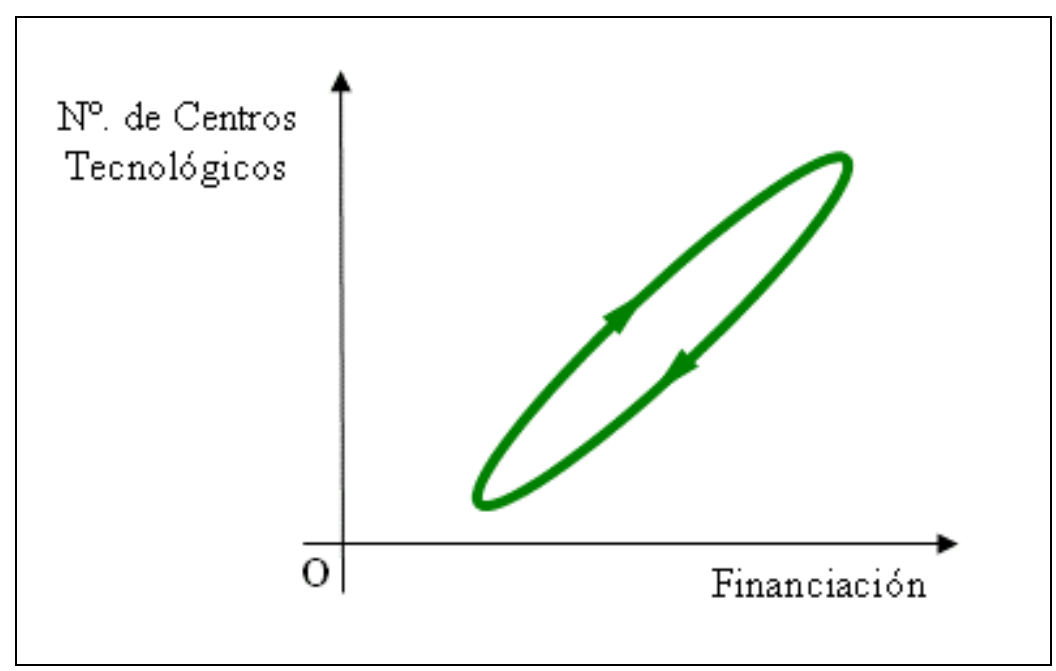

FUENTE: Elaboración propia 
Dicha abundancia de Centros, máxime si no presentan ofertas realmente diferenciadas frente al resto, dará lugar a una puja en $\mathrm{I}+\mathrm{D}+\mathrm{i}$ (ofreciendo valores añadidos para subsistir), atraerá la atención de las empresas (para mejorar su competitividad) y de las Administraciones Públicas (con el objeto de mantener un tejido de científico-tecnológico adecuado) y conducirá a aquéllos a la obtención de nuevos ingresos. Cuando estas partidas económicas hayan aumentado hasta cierto nivel, disminuirá el número de Centros, ante el elevado volumen de ofertas tecnológicas de los competidores, la insuficiente eficacia en la ejecución de proyectos de $\mathrm{I}+\mathrm{D}+\mathrm{i}$ y/o la falta de destreza en la captación de financiación; reduciendo, entonces, los fondos para sus actividades. Transcurrido cierto tiempo, no obstante, las empresas se darán cuenta de que no disponen de oferta en servicios de $\mathrm{I}+\mathrm{D}+\mathrm{i}$ y las Administraciones Públicas, de que no presentan el sustrato adecuado en este sentido, reiniciándose, así, el ciclo, con el aumento de Centros Tecnológicos para satisfacer estas demandas.

En los ciclos límite se pone de relieve, por tanto, cómo la conducta individual (regular o irregular, determinada o al libre albedrío) da lugar a pautas regulares en la del colectivo. Este hecho no sólo se constata en el ejemplo que acabamos de exponer, sino, también, entre investigadores y áreas tecnológicas de un mismo Centro.

C. Atractores extraños: no son periódicos, no se repiten nunca. Su órbita jamás se cruza con otra anterior, constando de un número infinito de curvas y superficies, encerradas en un espacio finito [Hofstadter-1982]. La mariposa de Lorenz es un ejemplo de este tipo. Requieren que las trayectorias se replieguen sobre sí mismas, una y otra vez, de forma que, ampliando una zona del atractor extraño, obtenemos nuevas trayectorias antes no visibles, que seguirán apareciendo ad infinitum. Presentan la propiedad de invarianza bajo escala, es decir, son estructuras fractales 80 [Mandelbrot-1975; Pumariño y Rodríguez-2001].

\footnotetext{
${ }^{80}$ Se trata de estructuras autosimilares. Dentro de un fractal, encontramos pequeñas estructuraciones muy parecidas, cuando no idénticas, a la totalidad. Dentro de estas últimas, a su vez, otras nuevas, aún más pequeñas, que, también, son parecidas o idénticas a la global. Lo más interesante de este hecho es que el grado de irregularidad de todas estas estructuras es el mismo, es decir, la irregularidad de un fractal tiene un carácter regular. Otra de sus características es la de tener una dimensión no entera, que recoge tal grado de irregularidad, y que, como acabamos de indicar, se mantiene constante en sus diferentes escalas.
} 
Un atractor extraño es, consecuentemente, el fruto de una tensión topológica: por un lado, se estira (para dar cuenta del efecto mariposa), por otro, se pliega (para permanecer confinado en un conjunto determinado de estados posibles). Estamos, poniendo un símil ilustrativo en este sentido, ante algo parecido a la tensión que se produce en la concha de un caracol, bifurcada entre crecer y permanecer pequeño.

\section{IV.3.3.3. Los Mapas de Retardo}

En el estudio de la dinámica de un Centro Tecnológico, resulta útil el empleo de un tipo específico de espacio de fases, denominado mapa de retardo, instrumento de uso común en el análisis de los sistemas caóticos.

Se trata de un espacio de fases en el que las dimensiones temporales $(t, t+1$, $t+2, \ldots, t+n, \ldots)$ son tomadas como referencia para representar gráficamente el comportamiento dinámico de un sistema [Durbin y Koopman-2001]. Sigue el rastro de los valores de aquellas variables que cambian con el transcurso del tiempo. Su importancia radica, precisamente, en que sólo requiere conocer una serie temporal de alguna de las variables que forman parte del sistema estudiado ${ }^{6}$. Tomando como base la perspectiva meteorológica bajo la que surgió la Teoría del Caos, un ejemplo de ese mapa sería una serie temporal de unos pocos meses, a fin de caracterizar la dinámica climática de un lugar. Cada valor recogería la temperatura de un día, medida siempre a la misma hora, en el mismo sitio y con el mismo termómetro.

En los Centros Tecnológicos, se podrán tomar los factores que se consideren más relevantes, dentro de los que caractericen el Aprendizaje Organizativo, como variables al uso respecto a una escala temporal adecuada, con la que realizar el pertinente mapa de retardo, asumiendo que la evolución de un componente singular del Centro está determinada por los demás, con los que interactúa. De esta forma, no necesitaremos conocer las ecuaciones que rigen su dinámica (si es que fuera posible, además, deducirlas en su totalidad). Basta con el conocimiento de una serie temporal,

\footnotetext{
${ }^{81}$ Existen softwares de uso libre y gratuito en Internet para el análisis de series temporales no lineales. Un buen ejemplo es TISEAN 2.1 [www.mpipks-dresden.mpg.de/ tisean/TISEAN_2.1].
} 
correspondiente a las variables indicadas, para determinar la naturaleza del atractor (si lo hay), que rige la dinámica del Centro Tecnológico. Para ello se debe disponer de un número significativo de valores para esas variables a lo largo del tiempo (mínimo estimado de ochenta, según nuestras apreciaciones).

\section{IV.3.3.4. Significado y Características del Caos en los Centros Tecnológicos}

En nuestro estudio entrópico de los factores determinantes del Aprendizaje Organizativo en un Centro Tecnológico, es muy importante la relación que R. Shaw [1981] estableció entre la Teoría del Caos y la de la Información. Sirvámonos de un ejemplo. Observemos la siguiente secuencia numérica: $1,3,5,7,9,11,13, \ldots$ Podríamos definirla como la de los números naturales impares. Veamos, ahora, otra secuencia numérica, totalmente aleatoria: 2, 45, 67, 43, 89, 41, 12,..En este caso, cada nuevo número es una "sorpresa", puesto que nos transmite una nueva información. Por tanto, podemos decir que, como ya establecimos al tratar los Centros Tecnológicos como sistemas termodinámicos, cuanto más inverosímil sea un mensaje, más información contiene.

Cercano al azar, pero sin llegar a serlo, el caos supone el máximo alejamiento del orden clásico ${ }^{82}$ en el que se maximiza la información. Se trata de una mezcla de azar y orden, sin llegar a ser ninguna de las dos cosas por separado. De alguna forma, la no linealidad crea información donde no la hay. La explicación de Shaw a este hecho se halla en la relación entre las diferentes escalas. Desde un punto de vista físico, los sistemas caóticos tienden un puente entre las macroescalas en las que se encuentran y se miden los objetos cotidianos, y las microescalas, en las que los átomos se agitan al azar. Al tender este puente, las macroescalas rescatan parte de la información que proporciona el azar de las microescalas. En los sistemas caóticos, ese caos crea información, siendo, esta última, capaz de traspasar las microescalas, para instalarse en las macroescalas.

Su analogía con los fenómenos sociales es evidente, donde, como ocurre en un Centro Tecnológico, se relacionan los de carácter local (investigadores o áreas tecnológicas)

${ }^{82}$ Desde un punto de vista clásico, se puede definir el orden como la diferenciación numerada de configuraciones de un sistema. No obstante, se trata de un concepto más sutil, que se deduce a partir de la definición de desorden, y su relación con la entropía, según se expone en el Anexo B. 
con los de tipo global (el Centro Tecnológico en sí mismo), en consonancia con lo establecido en la consideración de aquél como sistema (véase Figura 22). La teoría de la información hizo corresponder, además, a ésta con la entropía, como ya establecimos, también, al tratar a los Centros Tecnológicos como sistema termodinámico.

En cuanto a las características que configuran el caos, pueden sintetizarse en las cinco que se reseñan a continuación:

1. Todo sistema caótico es no lineal. Esta condición es necesaria, pero no suficiente, por lo que el recíproco no tiene por qué ser cierto. Una organización social, como un Centro Tecnológico, nunca presenta un carácter lineal.

2. El caos tiene un marcado carácter dinámico. Podríamos decir que, para generar caos, hace falta inestabilidad y realimentación. La inestabilidad se consigue con elevadas tasas de no linealidad. La realimentación en un Centro Tecnológico se produce de manera continua, absorbiendo, en tiempo real, la experiencia diaria y los resultados en la ejecución de sus actividades.

3. Las dinámicas caóticas muestran sensibilidad a las condiciones iniciales (el efecto mariposa tratado anteriormente) ${ }^{83}$.

4. El caos se produce en dinámicas regidas por un conjunto finito y reducido de variables, como las que caracterizarán el Aprendizaje Organizativo. Esto implica que no tiene nada que ver con el número de variables definitorias y sí, mucho, con el tipo de relación entre ellas.

\footnotetext{
${ }^{83}$ Por ejemplo, en la ejecución de un proyecto industrial, llega el momento de hacer la puesta en marcha en una instalación. Resulta que falta un pequeño cable específico para activar una entrada del autómata que la gobierna. En ausencia del mismo, se incorpora otro que, de momento, puede servir, se conecta, y, como no es el debido, al cabo de un tiempo deja de hacer contacto. El autómata, entonces, no recibe la señal correspondiente, no se ejecutan adecuadamente las entradas/salidas de la instalación, el ciclo de producción se interrumpe (si no ocurren fallos más graves) y el cliente entiende que la instalación no funciona adecuadamente, rechazándola o posponiendo su entrega. El proyecto en sí y la imagen del Centro Tecnológico han sido dañados. De una aparente simpleza como un pequeño cable, se deriva un efecto muy superior: la no aceptación de una instalación objeto de un proyecto.
} 
5. Es una mezcla de orden y de desorden, a un mismo tiempo. Podría decirse que, en un Centro Tecnológico, los componentes individuales (investigadores) muestran claros rasgos de desorden (por ejemplo el aprendizaje científico de un investigador tomado como individuo aislado), mientras que en el nivel de las "macroescalas" se produce la emergencia de un fenómeno autoorganizativo (la conducta saliente y organizada de todo el Centro Tecnológico).

Nuestras posteriores consideraciones sobre los Centros Tecnológicos profundizarán en la relación existente entre el caos, la información y los procesos autoorganizativos. La idea es la siguiente: un sistema complejo (Centro Tecnológico), con capacidades adaptativas a su entorno, necesita del caos, dado que no es viable su existencia, ni bajo las estrictas condiciones que impone el paradigma del orden newtoniano, ni, tampoco, bajo la plena aleatoriedad, en donde cualquier cosa puede ocurrir con igual probabilidad. La subsistencia de un Centro Tecnológico necesita de desequilibrios, de la flexibilidad que proporciona un cierto desorden. Sin embargo, no hay subsistencia posible alguna en el azar. A su vez, se hace necesario un cierto orden, para almacenar información. Nos adentramos, entonces, en la ruta que conduce del caos al "orden", para la que tendremos en cuenta la Teoría de los Sistemas Alejados del Equilibrio, de Prigogine [1962].

\section{IV.3.4. Aplicación de la Teoría de los Sistemas Alejados del Equilibrio}

Al definir los Centros Tecnológicos como sistema termodinámico, expusimos la extensión que hacía Prigogine sobre el segundo principio, pero sólo de modo superficial, por cuanto no habíamos desarrollado en ese momento los conceptos y consideraciones que se han abordado desde entonces a este punto.

Dado que un Centro Tecnológico es un sistema alejado del equilibrio, presentemos, a continuación, alguna de las características más relevantes de este tipo de sistemas, relacionándolas con las de los que se encuentran en y cerca del equilibrio:

1. Teniendo en cuenta las relaciones (1) y (3), en un sistema en equilibrio nos encontramos ante un estado de máxima entropía (los estados $\Omega$ a los que se puede 
acceder desde el equilibrio son los máximos posibles) y, por consiguiente, su atractor es ese estado de máxima entropía. En un sistema cercano al equilibrio, la producción de entropía es mínima (se tiende a una única configuración $\Omega$, que es el estado de equilibrio), por lo que su atractor es el estado de generación de mínima entropía. En cambio, en un sistema alejado del equilibrio, la producción de entropía es permanente, dados los continuos intercambios con el medio, no existiendo atractor manifiesto.

2. En los sistemas estables (sistemas en equilibrio o cerca del equilibrio), pequeñas causas producen pequeños efectos. En los sistemas inestables (sistemas lejos del equilibrio), las pequeñas causas pueden producir efectos desproporcionados. Por ello, los sistemas alejados del equilibrio son caóticos, presentando una extrema sensibilidad a las condiciones de las que parten.

3. En general, cualquier sistema puede ser estable en algunos de sus elementos, e inestable en otros. Ello guarda consonancia con la idea de perceptivismo, reseñada en la consideración de los Centros Tecnológicos como sistema. Supongamos un lapicero puesto de pie (en posición vertical), al que se da un pequeño empujón. Se puede afirmar que, aunque el lápiz ya no está en su posición erguida, continúa siendo un lapicero. Un ejemplo, en nuestro caso, sería una asociación de Centros Tecnológicos. Una agrupación de este tipo es metaestable, puesto que pocas perturbaciones son capaces de superar su poder de integración, pero esto no significa que sea estructuralmente estable, dado que pueden desaparecer componentes en ella.

4. En los sistemas en y cerca del equilibrio, predominan los procesos lineales, mientras que, en los alejados del equilibrio, los no lineales. Como consecuencia de ello, el azar es quien rige la dinámica del sistema, se pierden las condiciones iniciales y no es posible la reversibilidad temporal, originándose, así, una barrera entrópica [Briggs y Peat-1989]. Se precisaría de una cantidad de información infinita para la recuperación de las condiciones iniciales. Se dice, consecuentemente, que el tiempo tiene una flecha que apunta sólo en la dirección de avance [Prigogine y Stengers- 
1991; Prigogine-1997]. Los Centros Tecnológicos, indeflectivemente, se crean, desarrollan y desaparecen, pasado un tiempo.

5. Teniendo en cuenta la característica anterior, otra de las que definen los sistemas alejados del equilibrio, es el papel que desempeña el azar en sus dinámicas. En los sistemas estables, esta dinámica se caracteriza por ser lineal y ordenada. El continuo y, aparentemente inmutable movimiento de los planetas, sería un ejemplo de ella, donde el azar no juega ningún papel importante en el estado final del sistema. Según Mandelbrot [1996], hablamos de un azar benigno, que se distribuye de manera normal en torno al valor medio, configurando, con ello, una pauta de regularidad final no aleatoria. Al fin y al cabo, es un azar que puede ser tratado con las técnicas estadísticas al uso.

Por el contrario, en los sistemas alejados del equilibrio, esas dinámicas son, esencialmente, no lineales. Ya conocemos lo que ocurre con la mariposa de Lorenz. Aquí es el azar quien decide. La mínima fluctuación, considerada irrelevante en un sistema en equilibrio, decide, ahora, el futuro del sistema. Utilizando la terminología de Mandelbrot [1996], estamos ante un azar salvaje. Las fluctuaciones no se neutralizan, apareciendo, bien grandes desviaciones, bien un compendio de pequeñas desviaciones, todas en la misma dirección. El azar salvaje es el que caracteriza a los Centros Tecnológicos, con la repetición de pautas (largos años de proyectos continuados) y la aparición repentina y brusca de grandes cambios (por ejemplo, llegada de un año muy escaso en subvenciones y proyectos).

A las dos tendencias expuestas en el azar, se les denomina efecto Noé y efecto José [Mandelbrot-1977], en honor de los narradores bíblicos que relataban historias de continuidad y de cambio, respectivamente. El azar salvaje, al mudar continuamente de carácter, requerirá, por tanto, del uso de otro tipo de técnicas para su estudio (mapas de retardo para la búsqueda de atractores, como se sugiere en el Aprendizaje Organizativo), diferentes a las utilizadas en el del azar benigno.

6. Todo lo anterior nos conduce a la existencia de dos concepciones sobre el futuro de un sistema. En los estables, está dado, gracias al determinismo y la predecibilidad de 
su dinámica. Un buen ejemplo, ya comentado, es el de la Astronomía y sus predicciones: el 22 de Septiembre del 2062, a las 8:20h TU (Tiempo Universal), el asteroide X12 pasará a $48.300 \mathrm{Km}$. de nuestro planeta. En los inestables, lo constituye todo un abanico de posibilidades, aconteciendo una de ellas. En el ejemplo anterior, no podemos saber, en este momento, el tiempo que hará la fecha señalada y ningún meteorólogo se atreverá a darnos un pronóstico.

Puede afirmarse, por tanto, finalmente, que en los sistemas alejados del equilibrio, caóticos, como son los Centros Tecnológicos, la dinámica es determinista e indeterminista, al mismo tiempo. Se trata de una nueva paradoja. Es determinista, por cuanto obedece a unas reglas muy concretas. Sin embargo, la mínima variación de las condiciones iniciales hace que pueda pasar a estados muy diferentes. Los Centros Tecnológicos se acogen, así, a un tercer tipo de posibilidad evolutiva en la dinámica de sistemas, comprendida entre el futuro ya escrito en las deterministas (en las que no es posible la aparición de innovación alguna) y frente al desarrollo azaroso de una totalmente aleatoria y absurda (en la que cualquier suceso puede ser el siguiente).

El desarrollo de los Centros Tecnológicos nos invita a pensar en una evolución inestable, a la par que ordenada, incierta y autoorganizada [Levy-1994; Guastello-1995; Kiel y Elliot-1996].

\section{IV.3.5. Caracterización de la Complejidad en los Centros Tecnológicos}

Hoy en día, es muy común hablar de complejidad en las Ciencias Exactas y Sociales. De hecho, así es como son calificadas las organizaciones humanas. Cuando se caracteriza la complejidad, además, se reduce a un sencillo matiz de número, al representar aquello para cuya explicación se hace necesario recurrir a muchos elementos. Lo complejo se confunde, entonces, con lo complicado [Nicolis y Prigogine1994].

En los razonamientos establecidos en los apartados precedentes, ha tenido que quedar patente que la complejidad tiene poco que ver con el número y mucho con la relación [Munné-1994]. De hecho, un Centro Tecnológico es relativamente simple en cuanto al 
número de factores que lo definen, pero presenta una extrema complejidad en sus comportamientos. Es preciso asumir, por tanto, una concepción más cualitativa sobre la referida complejidad.

Al no disponer todavía de una definición suficientemente general, se la trata, frecuentemente, desde sus propiedades básicas. Para Munné [1995], es un objeto inabarcable, no reducible a ninguno de los aspectos en que se manifiesta, matizando que no significa que no podamos conocerlo todo, sino, más bien, que no podemos conocerlo todo a la vez.

Puesto que no se requiere de la totalidad para afrontar el estudio de la complejidad, se pone de relieve el hecho de que no se precisa analizar todas las variables que componen aquélla, lo que justifica el uso de los mapas de retardo. Basta conocer el esqueleto básico de las interacciones más relevantes en el Centro Tecnológico, para que un modelo de él recoja, adecuadamente, la complejidad que reviste.

El sociólogo francés E. Morin [1994] ofrece otra concepción al respecto. Para él es complejo todo aquello que no puede ser resumido en una palabra maestra, lo que no puede retrotraerse a una ley, existiendo una evidente relación entre complejidad y azar. Esta acepción podría llevarnos a pensar que el comportamiento de un Centro Tecnológico es completamente aleatorio, algo que se aleja de la realidad. Se establece, entonces, el concepto de azar hacedor, con el que especularían los sistemas alejados del equilibrio y se explicaría la producción continua de nuevas estructuras y estructuraciones [Wagensberg-1985]. Conduciría, en suma, a una profunda reflexión ontológica, que queda fuera del contexto de la presente Tesis Doctoral.

Por último, cabe distinguir la caracterización que, sobre la complejidad, realiza Kauffman [1993], muy próxima al caos:

1. La existencia del efecto mariposa.

2. La cristalización del orden en sistemas muy desordenados, es decir, la autoorganización. 
3. La existencia de atractores extraños, indicadores de un orden complejo.

Las propiedades primera y tercera mencionas son sendas facetas del caos, siendo nuevo el énfasis que dicho autor pone en la autoorganización, como cristalización de un orden complejo y emergente.

Consecuentemente, podemos afirmar que un Centro Tecnológico es complejo, por cuanto es difícil extraer de él información.

\section{IV.3.6. La Autopoiesis como Forma de Organización en los Centros Tecnológicos}

Vamos a emplear y exponer, brevemente, la Teoría de los Sistemas Autopoiéticos de los biólogos chilenos H. Maturana y F. Varela, la última de las consideraciones metodológicas que haremos en el estudio de los Centros Tecnológicos. Aunque se desmarca, en cierta medida, de todo lo que hemos desarrollado hasta ahora, nos permite entender el fenómeno autoorganizativo, definitorio de los referidos Centros, en su consideración de sistemas caóticos y complejos.

\section{IV.3.6.1. Entidad de la Autopoiesis}

Dicha teoría centra su atención en exponer las características de la vida, de los seres vivos. Está centrada en la organización de lo vivo, pretendiendo responder a la siguiente pregunta: ¿qué tienen en común todos los sistemas vivos, para permitirnos calificarlos como tales?. Para ello, se apartan de la apertura de estos sistemas hacia el entorno y el procesamiento de energía, materia e información (visión propia de la Teoría General de Sistemas), afrontando su estudio en su condición de entes discretos, autónomos, que existen en su vivir como unidades independientes [Maturana-1994].

Sus autores consideran que su autonomía con respecto al medio, es un rasgo obvio de los sistemas vivos [Maturana y Varela-1973; 1980]. Pensemos, para ilustrar esta idea, en una roca que sufre las adversidades de su medio, calentándose cuando sube la temperatura y enfriándose cuando ésta desciende. Un ser vivo, por el contrario, es capaz 
de mostrar su independencia, en un cierto rango, manteniendo una temperatura interna independiente de la exterior. Los seres vivos tienen, por tanto, una gran habilidad para conservarse a sí mismos, para preservar su identidad, a pesar de los cambios continuos en sus entornos, demostrando, con ello, una elevada y continuada capacidad homeostática. Maturana y Varela establecen, consecuentemente, que las dos características esenciales de todo sistema vivo son:

- El mantenimiento de su organización, y

- La conservación de su identidad.

La segunda es, claramente, consecuencia de la primera. De este modo, aprender qué es un sistema vivo es una tarea de comprensión de su organización. Para caracterizar la organización de estos sistemas, introducen el término autopoiesis.

Un sistema autopoiético será, por tanto, aquél cuya característica fundamental y definitoria es la de que se produce continuamente a sí mismo. Esta idea se constituye en una teoría de organización de lo vivo, donde sus seres se tornan diferentes a su medio circundante, preservando su autonomía, pudiendo hacerse extensiva a otro tipo de sistemas no estrictamente biológicos.

\section{IV.3.6.2. Aplicación de la Teoría de la Autopoiesis}

Los sistemas autopoiéticos han tenido evidentes implicaciones en la Biología (disciplina de la que forman parte) e, igualmente, en la Epistemología [Maturana-1995, 1996]. En esta última, sobresale la importancia otorgada a la autorreflexividad del conocimiento, aportación muy tenida en cuenta por la Psicología Social, al estar en el fundamento de la concepción constructivista de la realidad. No obstante, en nuestro caso interesan otras aportaciones del enfoque sistémico que venimos desarrollando.

Siguiendo a Kickert [1993], las dos ideas básicas que aporta la Teoría de los Sistemas Autopoiéticos son, esencialmente, las de ofrecer:

1. Una perspectiva diferente sobre cómo entender las relaciones sistema-entorno, y 
2. Una nueva perspectiva sobre el autogobierno de este tipo de sistemas.

Comencemos por la primera de ellas. Sabemos, ya, que los Centros Tecnológicos son sistemas abiertos (véase apartado IV.2). Según Maturana [1995], aunque los sistemas autopoiéticos pueden satisfacer las imposiciones de la termodinámica en el espacio físico, necesariamente son cerrados en las dinámicas de sus estados. La aparente contradicción de esta afirmación se traduce en que los Centros Tecnológicos serán organizacionalmente cerrados e informacionalmente abiertos. Entendida la autopoiesis como la tendencia a mantenerse igual a sí mismo, entonces, un Centro Tecnológico será un sistema autopoiético, y, como tal, habrá de mantener con el entorno las ligaduras necesarias para el intercambio de energía, materia e información.

Consecuentemente, en el estudio de un Centro Tecnológico no sólo debe tenerse en cuenta el mismo, sino, también, la relación que mantiene con su entorno, que no es de simple dependencia, sino constitutiva del propio Centro. Esta apertura hacia el entorno es entendida como autorreferencia. El Centro mantiene con su entorno una relación acorde con su organización interna, dado que, como sistema autopoiético que es, no puede entrar en interacciones que no estén ya especificadas en su organización. El entorno es percibido, entonces, como una proyección de la propia identidad organizativa. Por ello, de acuerdo con Luhmann [1995] y Leydesdorff [2001], las transacciones con el medio no son más que autorreferencias.

En la segunda de las aportaciones apuntadas, Kickert hace alusión a los sistemas sociales, asumiendo que son autopoiéticos. Con ello, viene a reforzarse la identificación del Centro Tecnológico como tal tipo de sistema, pues ya se expuso en la relación (6), la equivalencia existente entre dicho Centro y organización social, considerándose ahora las relaciones Centro Tecnológico-entorno, para analizar la evolución del primero como organización y con vistas a su gestión.

Se propone, en este sentido, que un sistema organizacionalmente abierto puede ser gestionado $\mathrm{y}$, consiguientemente, gobernado, desde fuera. Un sistema organizacionalmente cerrado es, por el contrario, gobernado desde su interior. Los 
Centros Tecnológicos como sistemas autopoiéticos, caracterizados por su autonomía, circularidad y autorreferencia, sólo pueden ser gobernados desde sí mismos.

En ellos, habrá aportación externa de capital, del que habrá que rendir cuentas en función de las labores de $\mathrm{I}+\mathrm{D}+\mathrm{i}$ desarrolladas con el montante oportuno. También puede constituirse una asociación de empresas que aporte fondos para llevar a cabo tareas específicas en un Centro Tecnológico. Sin embargo, en ambos casos, éste sólo responderá de las labores realizadas en materia de ciencia, tecnología e innovación (de acuerdo a la inyección monetaria y las premisas dadas), aportando resultados y mejoras, obtenidas, o no, en función de su estructuración y colaboración interdisciplinar interna, coordinada y gestionada, siempre, desde dentro del Centro Tecnológico. Es decir, dentro de ese contexto de realidad autoimpuesta que poseen, presentan la capacidad de generar su modo de operar desde directrices internas, más que de la mera imposición exterior.

Como puede apreciarse, el concepto de autopoiesis, con las particularizaciones hechas para los Centros Tecnológicos, es perfectamente compatible con la idea de autoorganización apuntada por las Teorías de la Complejidad (véase apartado IV.3.5). Por ello, los Centros Tecnológicos, como sistemas alejados del equilibrio, en el borde del caos, maximizadores de la capacidad de procesar información, son capaces de generar estructuraciones internas y rebelarse contra las condiciones que les pueda imponer su entorno (por ejemplo, la no realización de determinadas actividades, por cuestiones éticas). Esta es la idea clave de la autoorganización como proceso distinto al de la adaptación, sobre la que siempre, tradicionalmente, se había puesto un mayor énfasis.

La autorreferencia de los Centros Tecnológicos, en este contexto, es la investigación, el desarrollo y la innovación continua en materia científica y tecnológica. Ello les garantiza una dirección y un sentido a seguir constantemente, a la par que les asegura su supervivencia y continuidad. No ocurre lo mismo con las empresas de corte convencional (especialmente las PYMEs), cuya capacidad de respuesta y reorganización, en función de las demandas del mercado, no permite su adecuada autorreferenciación según la información vanguardista captada del exterior, o bien la 
visión de la realidad adoptada por éstas no resulta útil al entorno, lo que les llevaría a su extinción.

\section{IV.4. Modelo Entrópico de Sostenibilidad de los Centros Tecnológicos via el Aprendizaje Organizativo}

De los conceptos expuestos en los apartados precedentes, se deriva un modelo general de sostenibilidad de los Centros Tecnológicos (como sistemas que aprenden sistemática y organizacionalmente), que nos permitirá deducir si tienen o no continuidad. Para establecer dicho modelo y las consideraciones que de él se derivan, iremos recalcando y sistematizando, de nuevo, aspectos ya tratados, pero que deben ser ahora entretejidos de modo conciso.

Sabemos que los Centros Tecnológicos son sistemas (en el sentido propuesto por la Teoría General de Sistemas), entendidos como un conjunto de investigadores que interactúan entre sí y con el exterior, y de cuya interacción surge un comportamiento como un todo, en función de su conocimiento, jerarquización, distribución en áreas tecnológicas, grado de relación y nivel de colaboración entre los mismos y su entorno.

Análogamente, los Centros Tecnológicos son, también, sistemas abiertos y alejados del equilibrio desde el punto de vista termodinámico, siéndoles aplicable el concepto de entropía $(S)$, relacionado con el de probabilidad e información, según la formulación de Prigogine. Esta última separa la producción de entropía interna del sistema $\left(d S_{\text {int }}\right)$, sujeta al segundo principio de la termodinámica, de la producción que dicho sistema pueda intercambiar con su entorno $\left(d S_{\text {ext }}\right)$, aspecto olvidado por el segundo principio.

A su vez, son organizaciones sociales, cuyo interés se centra en los problemas de relación, de estructura e interdependencia, y no en sus atributos constantes. Se configuran, así, una serie de relaciones y flujos internos y externos que van a sentar los parámetros caracterizadores del Aprendizaje Organizativo [Malinen-2000]. Esto nos lleva a efectuar una valoración entrópica del mismo a lo largo del tiempo, como 
referencia de la sostenibilidad y el desarrollo del Centro Tecnológico como sistema, que debe reflejar el mantenimiento de una razón favorable de inputs/outputs.

Partiendo de la ecuación (3), obtenida en la consideración de los Centros Tecnológicos como sistemas termodinámicos:

$$
\begin{gathered}
S_{\text {ext }}=-k_{B} \cdot \sum_{j=1}^{\Omega_{\text {ext }}} e_{j} \cdot \ln e_{j} \\
S_{\mathrm{int}}=-k_{B} \cdot \sum_{j=1}^{\Omega_{\mathrm{int}}} i_{j} \cdot \ln i_{j}
\end{gathered}
$$

donde:

- $\quad k_{B}$ es la constante de Botzman.

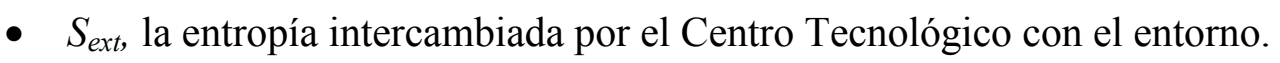

- $e_{j}$, con $j=1, \ldots, \Omega_{e x t}$, es la distribución de probabilidades de los $\Omega_{\text {ext }}$ indicadores independientes que caracterizan el Aprendizaje Organizativo en su acepción externa (intercambio con el entorno).

- $S_{\text {int }}$ la entropía interna generada en el Centro Tecnológico.

- $i_{j}$, con $j=1, \ldots, \Omega_{i n t}$, la distribución de probabilidades de los $\Omega_{i n t}$ indicadores independientes que caracterizan el Aprendizaje Organizativo, a nivel interno.

Teniendo en cuenta que la constante de Boltzmann no es más que un coeficiente de proporcionalidad, que tiene su significado a escala atómica, hecho fuera de nuestro contexto, puede ser omitida en sucesivas consideraciones. 
Las expresiones necesarias para valorar entrópicamente el Aprendizaje Organizativo en sus vertientes externa e interna, serán entonces, las siguientes:

$$
\begin{aligned}
& S_{\text {ext }}=-\sum_{j=1}^{\Omega_{\text {ext }}} e_{j} \cdot \ln e_{j} \\
& S_{\text {int }}=-\sum_{j=1}^{\Omega_{\text {int }}} i_{j} \cdot \ln i_{j}
\end{aligned}
$$

En ambas, deberá verificarse que: $\sum_{j=1}^{\Omega_{\text {ext }}} e_{j}=1$ y $\sum_{j=1}^{\Omega_{\text {int }}} i_{j}=1$, respectivamente.

Los elementos $e_{j}$ y $i_{j}$ no serán tomados como probabilidades en sentido estricto, sino como los pesos normalizados representativos de cada uno de los indicadores externos e internos que caracterizan el Aprendizaje Organizativo, respectivamente. Así expuestas, estas expresiones tienen un carácter completamente general y resultan aplicables a cualquier tipo de organización, con la deducción previa de los indicadores que le conciernen. Cuántos y quiénes son estos indicadores que caracterizan el Aprendizaje Organizativo en los Centros Tecnológicos constituye la particularización a nuestro caso y será el objeto de estudio de los capítulos venideros.

La entropía es una magnitud macroscópica que da cuenta del estado microscópico sobre la que se considera. Enlaza y relaciona ambas escalas. Por ello, en nuestro caso, el aprendizaje de los investigadores (estado "microscópico"), tanto a nivel individual como grupal obtenido internamente en el Centro (factores internos), o por su intercambio de información y de conocimiento, a esos dos niveles, con el entorno (factores externos), hace de la entropía el reflejo de lo que acaece con el Aprendizaje Organizativo en todo el Centro Tecnológico (estado "macroscópico"), en sus respectivas acepciones externa e interna.

Ahora bien, para que un Centro Tecnológico sea sostenible en el tiempo, deberá verificarse que la variación de entropía debida al Aprendizaje Organizativo a que da 
lugar aquél por su interacción con el entorno $\left(d S_{\text {ext }}\right)$, sea mayor que la variación de entropía interna que se produce con dicho tipo de aprendizaje $\left(d S_{\text {int }}\right)$, es decir: $d S_{\text {ext }}>$ $d S_{\text {int }}$. Para evaluar los diferenciales de esta desigualdad se considerarán intervalos temporales adecuados para observar apreciaciones dignas de cuantificación, lo que implicará tener en cuenta dos períodos análogos y consecutivos: $T_{\text {Previo }}$ y $T_{\text {Posterior }}$ (se tratarán en profundidad en el capítulo VI).

De acuerdo con las expresiones (8) y (9), tendríamos, entonces:

$$
\left.\begin{array}{l}
d S_{\text {ext }}=\left[S_{\text {ext }}\right]_{T_{\text {Posterior }}}-\left[S_{\text {ext }}\right]_{T_{\text {Pr evio }}} \\
d S_{\text {int }}=\left[S_{\text {int }}\right]_{T_{\text {Posterior }}}-\left[S_{\text {int }}\right]_{T_{\text {Previo }}}
\end{array}\right\} \quad d S_{\text {ext }}>d S_{\text {int }}
$$

El que los Centros Tecnológicos puedan ser considerados como sistemas alejados del equilibrio, implica, por otra parte, que les sea aplicable directamente la Teoría del Caos, decantándonos, una vez más, por el enfoque que Prigogine ofrece en este sentido. Este autor centra su atención, precisamente, en la aparición de la autoorganización en las estructuras que surgen en condiciones de alejamiento del equilibrio de los sistemas. El análisis temporal de ciertos elementos caracterizadores del Aprendizaje Organizativo puede dar lugar a un atractor que indique su tendencia en relación con los cambios y adaptaciones sufridas por el Centro Tecnológico, en el período de tiempo considerado. La identificación de dichos Centros como sistemas caóticos, nos invita a pensar en una evolución inestable, a la par que ordenada, incierta y autoorganizada para los mismos.

Como, además, son sistemas autopoiéticos, en cuanto que mantienen su organización y, por ello, conservan su identidad, no se adaptan o responden tanto a las necesidades del entorno, como a tratar de definir ese entorno en función de sus intereses y capacidades [Drucker-2003]. Esto hace que sean, organizacionalmente, cerrados e, informacionalmente, abiertos, entendiendo esta apertura hacia el entorno como autorreferencia, que no debe ser otra más que la $\mathrm{I}+\mathrm{D}+\mathrm{i}$ efectiva y continuada. Ello infiere a los Centros Tecnológicos el carácter de sistemas que aprenden de modo "autorregulado", según el caos que gobierna sus dinámicas, permitiéndoles realizar las siguientes operaciones [Leifer-1989; Schaff-Johnson-1993]: 
1. Bifurcarse hacia nuevas posibilidades, lo que significa que se progresa en la dirección preestablecida hasta percatarse de que otra debe ser tomada. Algo no factible, muchas veces, ni económica ni humanamente, en las PYMEs.

2. Poder transformarse mediante estrategias radicales.

3. Experimentar con el trabajo diario, dando lugar a acciones ineficientes.

\section{Resíntesis.}

Esto les posibilita planificar nuevas direcciones en $\mathrm{I}+\mathrm{D}+\mathrm{i}$ o reconducir las anteriores, puesto que el Centro Tecnológico se acostumbra al caos. No obstante, necesitan directrices efectivas para la consecución de sus actividades, dado que, en su consideración de sistemas caóticos, puede aparecer en ellos el efecto mariposa, causando desorden, focalización inadecuada, disipación y bifurcaciones inesperadas.

Un Centro Tecnológico, como sistema que aprende, depende continuamente de la inyección regular del trinomio información/conocimiento/creatividad, donde el conocimiento es el principal capital y mercancía en la economía en que desenvuelve su actividad y, por ello, la fuente de ventajas competitivas del Centro. Si esa inyección se produce en la dosis adecuada, no aumentará bruscamente su entropía interna $\left(S_{\text {int }}\right)$. Consecuentemente, se debe inculcar y educar a los investigadores en la reintegración del aprendizaje diario en la praxis cotidiana como filosofía a seguir. Cada nueva etapa de progreso en el Centro Tecnológico ha de tener su combustible en el Aprendizaje Organizativo.

El conjunto de equivalencias que han permitido abordar el modelado entrópico del Aprendizaje Organizativo en los Centros Tecnológicos aparece sintetizado en la Figura 28. 
FIGURA 28

EQUIVALENCIAS ENTRE LOS CONCEPTOS NECESARIOS PARA ABORDAR EL MODELO ENTRÓPICO DEL APRENDIZAJE ORGANIZATIVO EN LOS CENTROS TECNOLÓGICOS

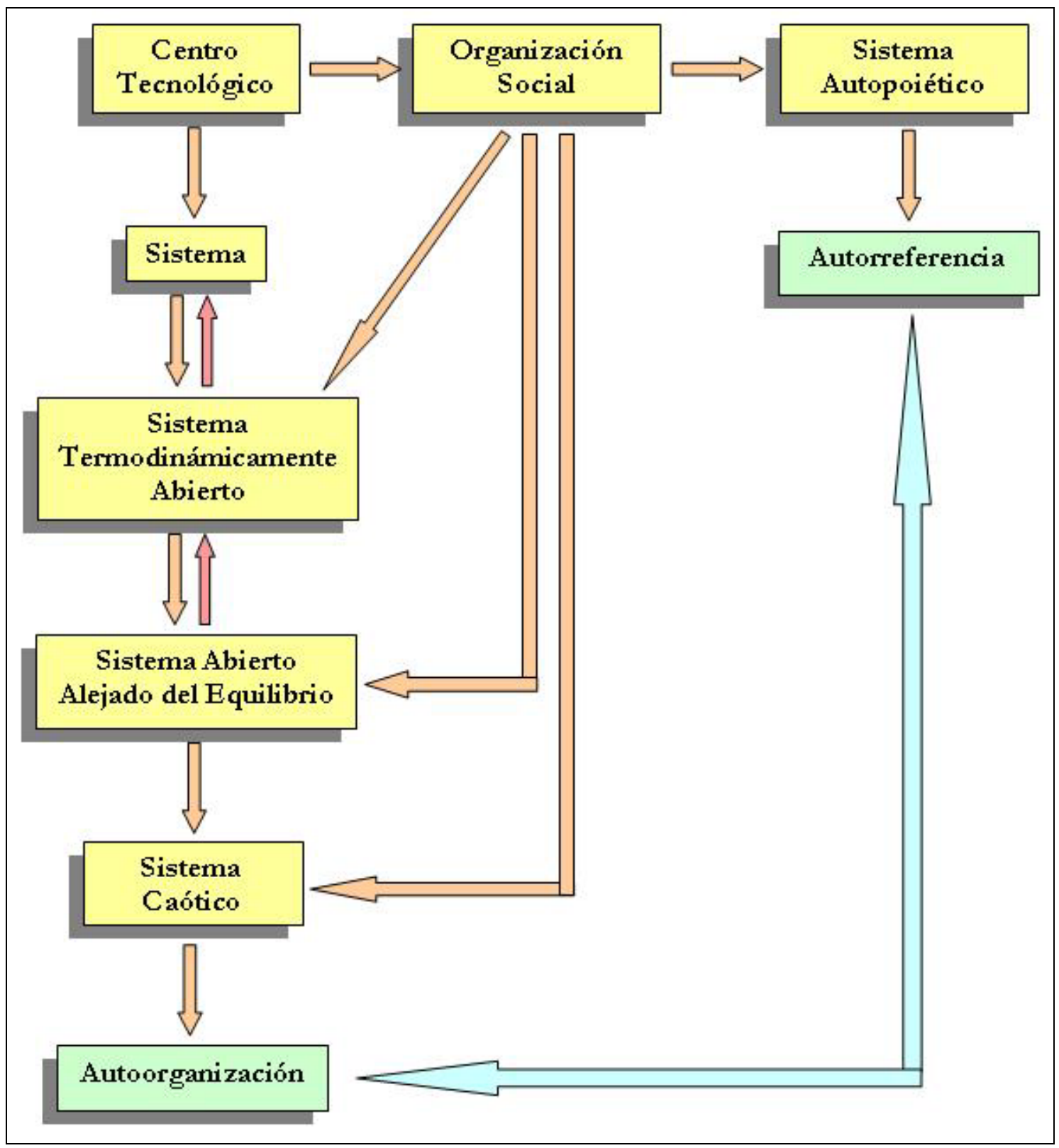

FUENTE: Elaboración propia 
Pedro Martín Lerones Evaluación del Aprendizaje Organizativo en los Centros Tecnológicos y Gestión del Conocimiento Sectorial en Castilla y León 
Capítulo V:

Los Actores Psico-Sociológicos del Aprendizaje Organizativo 
Pedro Martín Lerones Evaluación del Aprendizaje Organizativo en los Centros Tecnológicos y Gestión del Conocimiento Sectorial en Castilla y León 


\section{V.1. Los Actores Internos y Externos del Aprendizaje Organizativo en los Centros Tecnológicos}

El punto de partida del presente capítulo está en los conceptos de aprendizaje y Aprendizaje Organizativo, ya tratados en el capítulo I.

Sabemos que las organizaciones aprenden a través de individuos que aprenden (véase apartado III.4). No obstante, es conveniente destacar que éstos tienen ocupaciones alternativas a las propias de su contexto laboral. Consiguientemente, se desarrolla un aprendizaje paralelo propio y particular, fruto de la relación con sus semejantes y su entorno personal en el devenir de su existencia, que puede afectar, positiva o negativamente, al que obtienen por medio de su quehacer profesional diario, y recíprocamente, dado que la interacción entre ambos es interferencial. De cualquier forma, nuestra atención se centra en el aprendizaje laboral vinculado al ejercicio profesional del investigador.

Además, teniendo en cuenta las premisas reflejadas en los apartados III.5 y III.6, en el Aprendizaje Organizativo de los Centros Tecnológicos confluyen aspectos internos y externos a los mismos, ambos en sus vertientes individual y grupal (Figura 29).

De esta forma, y desde una perspectiva psico-sociológica, se definen los actores internos del Aprendizaje Organizativo como aquellos que contribuyen al mismo intraorganizacionalmente. Así, éste surge internamente por la interacción entre los investigadores del Centro Tecnológico, en función de su jerarquización, distribución en áreas tecnológicas, capacidad e intensidad de su relación humana y profesional, ambiente laboral, disposición personal, adecuación de actividad, realización profesional, y política y objetivos generales de ese Centro Tecnológico.

El razonamiento anterior también es aplicable cuando la aportación al Aprendizaje Organizativo proviene de la interacción con el exterior de aquél. Se habla, entonces, de actores externos, en un doble sentido: de fuera a dentro y de dentro a fuera del Centro. En este caso, el aporte proviene fundamentalmente de los contactos entre investigadores, proveedores y clientes; así como sus estancias en planta para puestas en 
marcha, mantenimiento, etc.; estancias temporales del investigador en entidades especializadas; formación, visitas técnicas, estudios de viabilidad, etc.; incorporación de personal experto a la plantilla; vigilancia y prospección tecnológicas.

FIGURA 29

INTERACCIONES QUE CONFORMAN LOS ACTORES INTERNOS Y EXTERNOS DEL APRENDIZAJE ORGANIZATIVO EN LOS CENTROS TECNOLÓGICOS

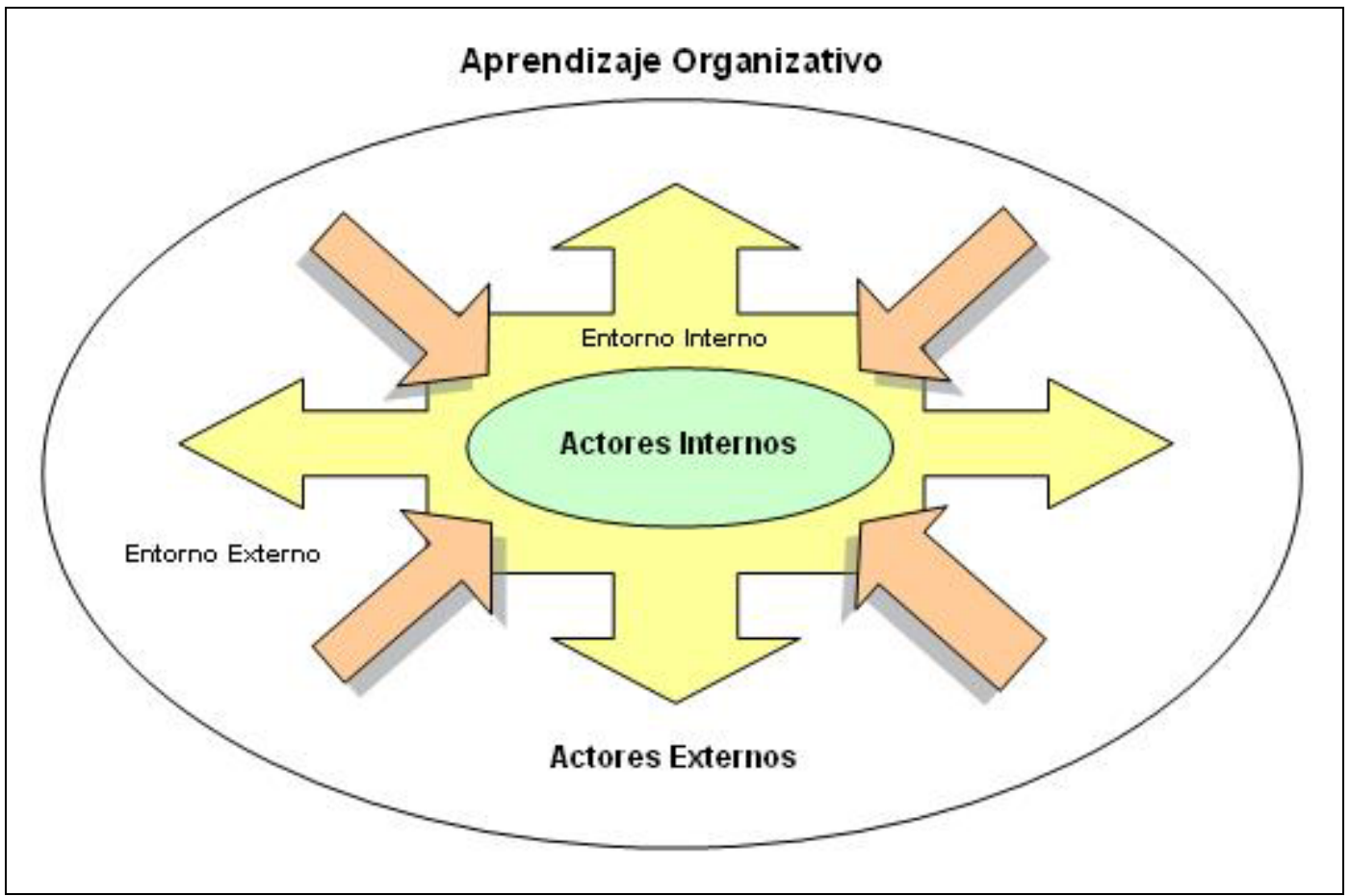

FUENTE: Elaboración propia

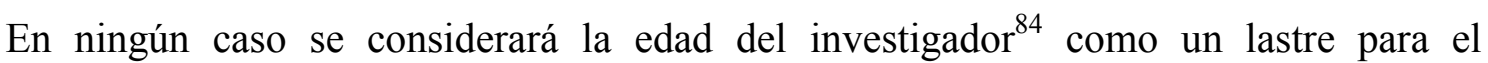
Aprendizaje Organizativo del Centro Tecnológico, pues ésta es baja en comparación con la equivalente para las PYMEs $\frac{85}{\text {. }}$

${ }^{84}$ Según la Sociedad Parques Tecnológicos de Castilla y León, S.A., y considerando los Centros Tecnológicos del Parque Tecnológico de Boecillo (CARTIF, CEDETEL y CIDAUT), que albergan a 507 investigadores en 2005 (lo que representa el 40,89\% del total de personal dedicado a actividades de I+D en ese Parque), la edad media de éstos es de 30 años.

85 Según información relativa a 87 empresas, la media de edad de los trabajadores de las PYMEs Castellanas y Leonesas, considerada toda la gama sectorial, es de 43 años en 2005. 


\section{V.2. Descripción de los Actores Internos del Aprendizaje Organizativo en los Centros Tecnológicos}

Entre ellos, sobresalen: la motivación y su fomento; la influencia de las creencias en el desarrollo de proyectos de $\mathrm{I}+\mathrm{D}+\mathrm{i}$; control, gestión y distribución temporal del investigador; la inteligencia emocional; y la importancia de la jerarquía.

\section{V.2.1. La Motivación y su Fomento}

Históricamente, la ciencia y la técnica han sido actividades que han recortado tiempo de ocio y de sueño de los individuos que a ellas se han dedicado. Incluso han provocado la obstinación en la persecución de un descubrimiento y la enfermedad de quien lo buscaba, como fue el caso de Marie Curie. Ello denota el grado de motivación (prácticamente pasión) que estas labores inducen en el sujeto que con ellas trata.

Al mismo tiempo, estas tareas se han tenido siempre como algo vocacional y propio de escasas personas visionarias, con capacidades intelectivas superiores al resto. Además, la relegación de tales actividades al ámbito exclusivamente universitario, hasta la primera mitad del siglo $\mathrm{XX}^{\underline{86}}$, ha contribuido a la idea, todavía palpable en la sociedad española (no tanto para la tecnología, pero sí para la ciencia), de ser entidades separadas del devenir social y económico que caracteriza a otras actividades profesionales, no pensándose en el científico o el tecnólogo como un ser "productivo" en la acepción empresarial de este término. Aquel siglo se ha caracterizado por un desarrollo científico y técnico sin parangón con cualquier otra etapa anterior en la historia de la humanidad. Desde entonces, y hasta nuestros días, la desinstitucionalización del saber, su salida del ámbito académico, su derivación a entidades privadas con intereses lucrativos, el meteórico crecimiento de la industria, el desarrollo tecnológico y su incidencia en todos los ámbitos y escalas humanas han mutado la figura del investigador en el llamado ingeniero de $\mathrm{I}+\mathrm{D}+\mathrm{i}$ como oficio o profesión admitida (véase apartado III.2), valorada, y

\footnotetext{
${ }^{86}$ Existe consenso en mantener esta afirmación hasta el lanzamiento de las primeras bombas atómicas sobre Japón, que pusieron fin a la segunda guerra mundial, en 1945. Se demostró, así, el poderío que puede otorgar el dominio científico-técnico a una nación (EE.UU en aquel caso).
} 


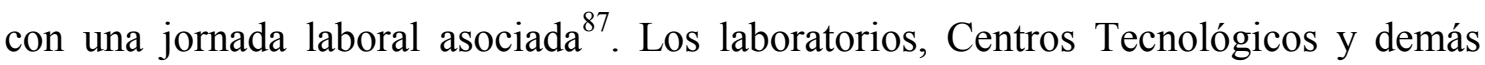
centros de investigación se ven poco a poco como "una empresa más", dedicados a hacer progresar al hombre y su medio, que incluso llegan a agruparse en parques tecnológicos, favorecidos por los gobiernos, tal como lo hacen las empresas convencionales en polígonos industriales.

De cualquier manera, recalcamos, como ya establecimos en el apartado III.2, que la actividad científico-técnica no puede planificarse según los estándares de la productividad, como si existiese un método que garantizase los resultados.

La motivación de los trabajadores en una empresa es un tema ampliamente tratado en los manuales de gestión de recursos humanos y dirección. Quizá, el ingeniero de $\mathrm{I}+\mathrm{D}+\mathrm{i}$ adolece de la necesidad de la motivación intrínseca que proviene de su estirpe de hombre del saber y la pasión por su labor. Esta motivación, que podríamos calificar de rutinaria en los Centros Tecnológicos, no es tan común en una empresa convencional [González Hermoso De Mendoza-2000].

No obstante, el ingeniero de $\mathrm{I}+\mathrm{D}+\mathrm{i}$, presenta, también, su vertiente como empleado y necesita de otra serie de motivaciones extrínsecas, de índole más pragmática, que van asociadas a una situación laboral y un futuro profesional que le permitan tener un nivel de vida conveniente. Por supuesto, existe una influencia mutua entre ambas motivaciones.

En este sentido, no puede darse por sentado que a todo investigador se le puede motivar del mismo modo, puesto que no todos ellos son iguales (formación, desempeño, educación, jerarquía, área tecnológica a la que se adscriben, etc). La personalidad es el factor diferenciador de cada uno, no siendo correcto, ni adecuado, su circunscripción a un mismo modelo de motivación, como ocurre en los entornos productivos de las PYMEs. No hay otra forma de obtener lo máximo de cada ingeniero de $\mathrm{I}+\mathrm{D}+\mathrm{i}$ sino con la personalización. En palabras de Sánchez Ruiz [2002], estaríamos ante la Teoría de la

${ }^{87}$ Debido a la carencia de convenio laboral específico sobre actividades de $\mathrm{I}+\mathrm{D}+\mathrm{i}$, en general, los investigadores se acogen al correspondiente convenio colectivo provincial para el sector de la industria siderometalúrgica. 
Persona Única, que defiende el popular y básico principio de que "cada persona es un mundo". Todo ser humano es diferente y le motivan cosas distintas, de formas diferentes y en momentos distintos. Una idea tan simple y corriente, transladada a un Centro Tecnológico, ha de tener consecuencias muy beneficiosas, puesto que aporta tantas ventajas competitivas como investigadores posea.

Los Centros Tecnológicos deben vertebrarse en torno a los ingenieros de $\mathrm{I}+\mathrm{D}+\mathrm{i}$, como personal con una actividad común y según la predisposición individual al Aprendizaje Organizativo que debe darse en cada uno de ellos (véase apartado III.5). Por ello, estas organizaciones han de saber escuchar a las personas, saber qué necesitan, qué les gusta y qué reprueban (humana y técnicamente). Para el investigador, lo básico consiste en percibir sus propias demandas organizacionales y su capacidad para hacerles frente. De esta manera, se observará si se valora más la necesidad de afiliación, el poder, o la necesidad de logro, habiéndose de equilibrar estas tres necesidades [McClelland-1961; Atkinson-1974].

Por tanto, la consideración de las personas como tales se constituye, entonces, como una actividad de base en el Centro Tecnológico, máxime cuando los investigadores presentan, como ya hemos tratado, una capacidad intelectual que les permite un juicio claro y crítico del lugar en que trabajan, su situación y las políticas que influyen sobre su actividad laboral. Semejante consideración no está reñida con los logros en $\mathrm{I}+\mathrm{D}+\mathrm{i}$, sino todo lo contrario, dado que aumentan a largo plazo [Sánchez Ruiz-2002].

Asimismo, como establecen Hamel y Prahalad [1995], los aspectos comentados no tienen porqué estar ligados al dinero. Teniendo en cuenta la jerarquía de necesidades de Maslow [1954], estas presentan una gradación decreciente, empezando por las fisiológicas y terminando por la realización personal (Figura 30).

Para las personas con grandes capacidades intelectivas, en general, y los investigadores, en particular, la gradación indicada es prácticamente al revés [Alderfer-1977]. La motivación en un Centro Tecnológico se funda en valores y no en los bienes materiales, 


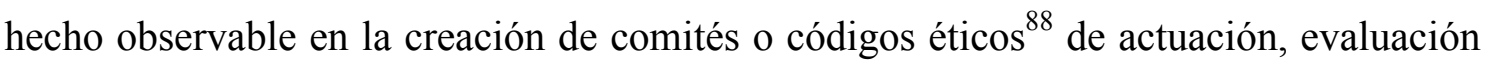
del impacto social de su actividad [Moñux Chércoles et al.-2005], etc., algo, además, muy prestigiado desde el exterior del Centro y, por ello, la apreciación que de su labor tiene el gran público. De manera tradicional en las PYMEs, la lealtad ha venido dada por el ofrecimiento al empleado de un progresivo ascenso jerárquico, un sueldo adecuado y estabilidad laboral. A cambio, aquél aporta fidelidad incondicional e intenso trabajo diario. Para un Centro Tecnológico, los valores determinan en gran medida la lealtad (véase apartado III.6.1). Según Welch [1997], es obvio que toda empresa necesita valores, pero una empresa dinámica más que ninguna, hecho perfectamente aplicable a Centros Tecnológicos. Además, los valores no se pueden inventar: se tienen o no se tienen.

FIGURA 30

JERARQUÍA DE NECESIDADES DE MASLOW

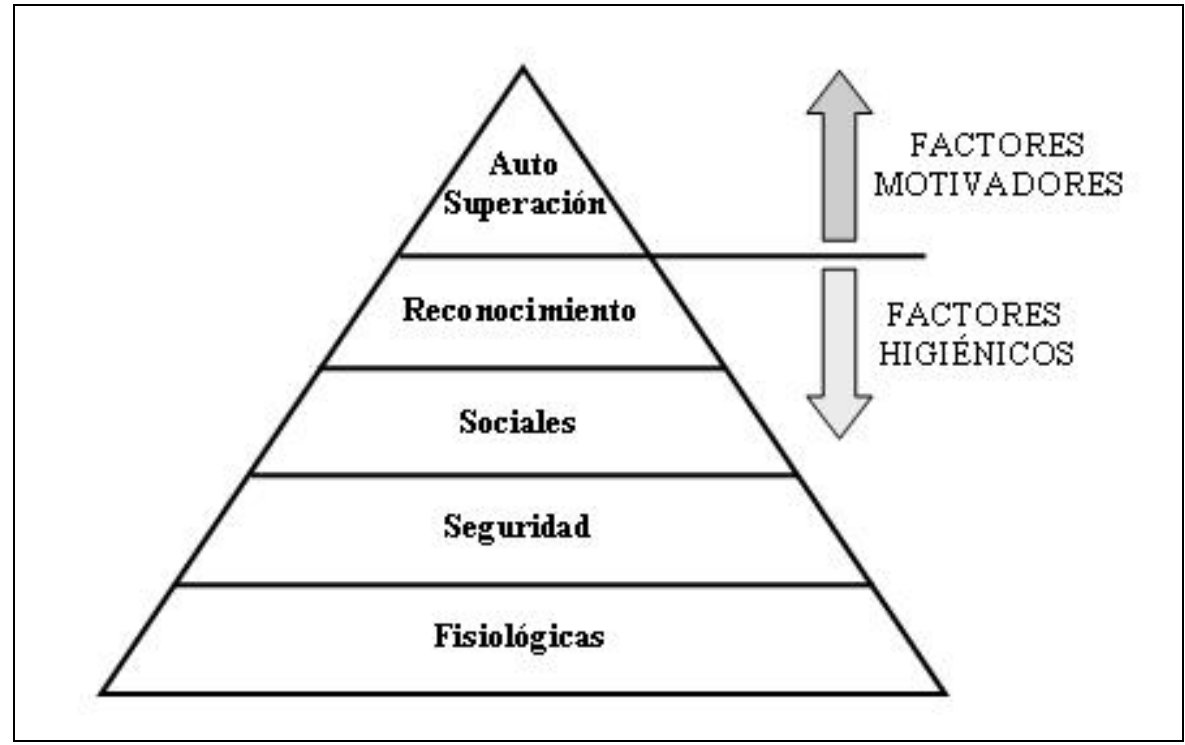

FUENTE: Elaboración propia

Por otra parte, es destacable que España produce el 2,56\% de la ciencia mundial, siendo su PIB muy inferior a esa cifra. Ahora bien, se observa que el rendimiento por investigador permanece invariable, incluso decrece un poco [Guzmán Rodríguez-2004]. Este hecho puede interpretarse como que las condiciones del entorno de los investigadores no son las óptimas para desarrollar su labor, que el sistema no produce

${ }_{88}$ Consultados los seis principales Centros Tecnológicos de Castilla y León (CARTIF, CEDETEL, CIDAUT, CTM, INBIOTEC e ITCL), únicamente CARTIF ha redactado y hace cumplir a sus investigadores un código ético. 
suficientes incentivos, o que, en realidad, se ha llegado a un punto donde para crecer lo realmente necesario es aumentar el número de recursos humanos empleados en tareas de $\mathrm{I}+\mathrm{D}+\mathrm{i}$.

Para concluir, apréciese, entonces, la influencia mutua que existe entre la motivación individual y la grupal durante la ejecución de labores de $\mathrm{I}+\mathrm{D}+\mathrm{i}$, siendo ambas claramente un factor interno y constitutivo del Aprendizaje Organizativo.

\section{V.2.2. Influencia de las Creencias en el Desarrollo de Proyectos de $\mathbf{I}+\mathbf{D}+\mathbf{i}$}

Las creencias, entendidas como asentimiento o conformidad hacia una actividad de $\mathrm{I}+\mathrm{D}+\mathrm{i}$ emprendida en un Centro Tecnológico, tanto desde el punto de vista técnico, como humano, social, político y económico, son los pensamientos que más influyen en la obtención de buenos resultados en esas actividades.

Desde este punto de vista, siguiendo a Hart [1991], una creencia se traduce en lo que un investigador piensa sobre tres aspectos: el entorno en el que desarrolla su labor; en relación a sí mismo; y, en relación a los demás.

Caracterizan al primero de ellos:

- La situación del Centro Tecnológico y contexto de la $\mathrm{I}+\mathrm{D}+\mathrm{i}$ en la región en que opera principalmente.

- Los medios técnicos, la financiación y modo de la misma.

- Los intereses sociales, políticos y económicos de la acción emprendida.

- La utilidad de la actividad que desarrolla.

El segundo se identifica con: 
- Los valores éticos y morales.

- La situación personal y laboral en el equipo de proyecto de $\mathrm{I}+\mathrm{D}+\mathrm{i}$, junto con su nivel de relación.

- La titulación y cultura.

- La cortesía y urbanidad (educación y trato).

- Las acciones a desarrollar (donde se ve involucrado), la misión encomendada y la capacidad para su desempeño.

- Los beneficios a obtener, a nivel personal y laboral.

Finalmente, el tercero será la proyección de los dos anteriores, a nivel grupal.

Las creencias permiten hacer o dejar de hacer, ponen en marcha todos los recursos personales en la persecución de un objetivo, y son capaces de transformar la motivación y la conducta de cualquier investigador. Aplicado a la adquisición de habilidades para la ejecución de una actividad de $\mathrm{I}+\mathrm{D}+\mathrm{i}$, las creencias de los participantes en el mismo constituyen el más poderoso impulso hacia la acción continuada. Por ello, toda actividad de esa índole ha de incorporar un adecuado tratamiento de las mismas, no siendo este hecho algo trivial [Hickson-1987].

Autores como Inkpen y Choudhury [1995] y Etzkowitz, Webster y Healey [1998] establecen, entonces, que deben detectarse las presunciones previas al inicio de una actividad de $\mathrm{I}+\mathrm{D}+\mathrm{i}$, reforzar las favorables y sustituir las desfavorables por otras más útiles a los fines propuestos, tanto en sus etapas iniciales, como en el transcurso de su ejecución. Para García Bermejo [2002], sustituir creencias implica conocer y entender sus procesos de adquisición. También requiere comprender la codificación que los investigadores utilizan para identificar lo que es cierto y lo que no lo es (técnica, humana, social, económica y políticamente) [Inkpen y Crossan-1995]. Y, sobre todo, requiere de la habilidad para lograr la sintonía con los participantes en la actividad, 
hecho válido para todo equipo de trabajo [Pelled et al.-1994; Ransley et al.-1994]. De esta manera, se podrán descubrir los aspectos personales que facilitan el Aprendizaje Organizativo de cada ingeniero de $\mathrm{I}+\mathrm{D}+\mathrm{i}$, más allá de las condiciones que se fundamentan en un igual tratamiento a todos ellos.

Finalmente, las creencias son dinámicas, es decir, se modifican con el tiempo. Démonos cuenta, además, de la realimentación continua que existe entre las creencias individuales y las grupales durante la ejecución de labores de científicas y técnicas, convirtiéndose las mismas en un factor interno y constitutivo del Aprendizaje Organizativo.

\section{V.2.3. Control, Gestión y Distribución Temporal del Investigador}

Los tres aspectos englobados bajo este epígrafe afectan al papel del investigador en el Aprendizaje Organizativo del Centro Tecnológico a nivel interno, debido al grado de consecución de tareas, efectividad y estado anímico que acompaña al aprovechamiento temporal de su jornada laboral.

Según lo expuesto en el apartado V.2.1, debido a que un ingeniero de $\mathrm{I}+\mathrm{D}+\mathrm{i}$ es un trabajador de facto, se haya acogido a las medidas gubernamentales puestas en marcha para conciliar la vida laboral y familiar. Los permisos por maternidad y lactancia, las reducciones de jornada, o la excedencia parental son realidades que han ido surgiendo a partir de la última década del siglo XX y que, de modo general, asumen como cotidiano los empleados del presente siglo XXI [NACIONES UNIDAS-2003]. Estos hechos aseguran, a medio y largo plazo, una rentabilidad adicional para el Centro Tecnológico.

Ciertamente, para un investigador, la ciencia, la técnica y la actividad intelectual que conforman su vida profesional no tienen una agenda concreta. En materia de $\mathrm{I}+\mathrm{D}+\mathrm{i}$, todo el día es tiempo potencial de actividad, pues la perseverancia, la experiencia, el ingenio y la creatividad no se hayan ceñidos a un horario. No puede lograrse que las ideas o los resultados fluyan en el período temporal exacto en el que se establece la jornada laboral [Fernández Rodríguez-1999]. Por ello, el ingeniero de I+D+i debe gestionar su tiempo (personal y laboral) de forma más cuidadosa que un empleado de índole convencional. 
Basándonos en las ideas de Sotillo Hidalgo [2002], los aspectos que condicionan la distribución, control y gestión del tiempo de un investigador desde un punto de vista laboral serían los siguientes:

1. Verificaciones ${ }^{89}$, validaciones $\frac{20}{\text { y revisiones }}$ de los proyectos de $\mathrm{I}+\mathrm{D}+\mathrm{i}$, además de reuniones con carácter específico por motivos especiales.

2. Consultas informales entre investigadores sobre aspectos técnicos de su labor, dentro o fuera de su área. Este hecho es consecuencia de la interdisciplinariedad creciente en materia de investigación y tecnología, y de la especialización de las diferentes áreas de un Centro Tecnológico.

3. Análogamente, destacan las reuniones informales. Tienen su equivalente en las reuniones de seguimiento de proyecto, pero su carácter es netamente inesperado.

4. Conversaciones de índole personal: suelen contribuir a distendir el ambiente y a la interrelación afectiva entre investigadores, hecho que puede redundar en terreno allanado para la generación de Aprendizaje Organizativo en las actividades de $\mathrm{I}+\mathrm{D}+\mathrm{i}$ de los participantes.

\footnotetext{
${ }^{89}$ Verificación: confirmación, mediante evidencia objetiva, de que determinada/s tarea/s específica/s de un proyecto de $\mathrm{I}+\mathrm{D}+\mathrm{i}$ cumple $/ \mathrm{n}$ con los requisitos establecidos. Las verificaciones ayudan a tomar decisiones, a partir de los resultados positivos alcanzados. Por ejemplo: a partir de determinados ensayos/pruebas/tests, se comprueba que los resultados de una etapa cumplen con los requisitos establecidos y puede avanzarse en el proyecto.

${ }^{90}$ Validación: confirmación, mediante evidencia objetiva, de que se cumplen los requisitos específicos para una utilización o uso concreto. El objeto de la validación es dejar constancia de que el cliente (interno/externo) acepta que el proyecto/etapa/producto ha cumplido con los requisitos especificados para el funcionamiento de ese producto y/o para el avance del proyecto. Por ejemplo: a partir de determinadas pruebas o inspecciones, se comprueba que una máquina enmalladora realmente sirve para esta tarea.

${ }^{91}$ Revisión: examen y/o evaluación formal a través de la que se trata de determinar la idoneidad, nivel de adecuación y eficacia del proyecto, o de una de las etapas del mismo, para alcanzar los objetivos establecidos. Las revisiones de un proyecto ayudan a detectar situaciones de conflicto, demoras y posibles modificaciones a la planificación establecida para éste, constituyendo la herramienta adecuada para su seguimiento. Por ejemplo: comprobar y dejar evidencia objetiva de que se están cumpliendo los plazos, el presupuesto previsto, así como registrar las desviaciones respecto al número de horas dedicadas por los investigadores y áreas tecnológicas involucradas en un proyecto de $\mathrm{I}+\mathrm{D}+\mathrm{i}$.
} 
5. Empleo de las nuevas tecnologías: proporcionan al investigador una de las más importantes herramientas de su trabajo diario, pudiéndose distinguir entre:

5.1. Actualizaciones hardware o renovación de equipos informáticos, debido a la adaptación continua a la labor desempeñada por cada uno de ellos.

5.2. Actualización de licencias de software y adquisición de programas específicos para el desarrollo de los proyectos de $\mathrm{I}+\mathrm{D}+\mathrm{i}$.

5.3. Alta velocidad de acceso a Internet: en el caso de Castilla y León, priorizada a través de la red española de I+D (Red IRIS 2 ).

5.4. Empleo del correo electrónico: se trata de un valioso recurso que requiere de dosificación, pues puede restar tiempo de la actividad de $\mathrm{I}+\mathrm{D}+\mathrm{i}$ neta.

Fiedler, Grover y Teng [1996] establecen que el acceso a las nuevas tecnologías no es un factor diferenciador entre Centros Tecnológicos y empresas, pero sí lo es la capacidad para utilizarlas, muy superior en los primeros, respecto a las segundas.

6. Gestiones administrativas (preparación de viajes y estancias temporales fuera del Centro, permisos laborales y sus justificaciones, revisión de presupuestos de proyectos, solicitud de subvenciones, etc.): estos aspectos pueden mermar en demasía la labor de $\mathrm{I}+\mathrm{D}+\mathrm{i}$ específica de los investigadores, $\mathrm{y}$, consiguientemente, aumentar los gastos internos del Centro Tecnológico.

\footnotetext{
${ }^{92}$ En el año 1988, el Plan Nacional de Investigación y Desarrollo puso en marcha un programa horizontal especial para la Interconexión de los Recursos Informáticos (IRIS) de las universidades y centros de investigación. A partir de enero de 2004, RedIRIS se integra como un departamento con autonomía e identidad propias en el seno de la Entidad Publica empresarial Red.es, adscrita al Ministerio de Industria, Turismo y Comercio.

RedIRIS cuenta con unas 250 instituciones afiliadas, principalmente Universidades y Organismos Públicos de Investigación, que llegan a formar parte de esta comunidad mediante la firma de un acuerdo de afiliación.

La red troncal o backbone que soporta los servicios de comunicaciones de RedIRIS está formada por un conjunto de nodos convenientemente distribuidos por el territorio español, conectados entre sí por un conjunto de enlaces que forman una red mallada con un core de 2,5 Gbps, en el que se encuentra Valladolid.
} 
7. Participación en la elaboración y seguimiento de certificaciones ISO: su utilidad se estableció en el apartado III.6.1. La dificultad, complejidad y espectro de las labores de $\mathrm{I}+\mathrm{D}+\mathrm{i}$ hace que éstas no presenten un patrón de actividad estandarizable, como ocurre en las PYMEs, por lo que el llevar estas normativas a un terreno práctico en los Centros Tecnológicos, constituye una ardua tarea [AENOR-2004].

Son varias las normas que rigen las certificaciones de interés para éstos, si bien pueden considerarse otras adicionales, en función de las actividades que desarrollen (por ejemplo, creación de laboratorios acreditados de ensayo y calibración específicos). Las más generales son las que se citan a continuación:

- Norma UNE-EN-ISO 9001:2000. Sistemas de gestión de calidad: requisitos.

- Norma UNE-EN-ISO 14001:1996. Sistemas de gestión medioambiental: especificaciones y directrices para su utilización.

- Normas UNE relativas a la Gestión de la $\mathrm{I}+\mathrm{D}+\mathrm{i}$ :

- 166000:2002 EX: Terminología y definiciones de las actividades de I+D+i.

- 166001:2002 EX: Requisitos de un proyecto de I+D+i.

- 166002:2002 EX: Requisitos del sistema de gestión de la I+D+i.

De todos los puntos expuestos, y continuando con las ideas de Sotillo Hidalgo [2002], no debe deducirse la conversión del ingeniero de $\mathrm{I}+\mathrm{D}+\mathrm{i}$ en un ser incomunicado, de férrea disciplina respecto al tiempo y las relaciones, pero no se ha de perder de vista que su tiempo es valioso y perecedero. Todos los aspectos tratados suelen ofrecer al investigador la sensación de que su jornada laboral resulta escasa. En realidad, esto no es más que una percepción del tiempo "malgastado", entendido como aquél no dedicado íntegramente a labores de $\mathrm{I}+\mathrm{D}+\mathrm{i}$.

Consecuentemente, para obtener el máximo rendimiento laboral del investigador, éste debe proceder a planificar sus tareas de forma rigurosa y sin caer en los influjos que pueden reconducir su jornada. 


\section{V.2.4. La Inteligencia Emocional}

Bajo el presente título se unen dos palabras aparentemente contradictorias: inteligencia y emoción. No obstante, en esta conjunción radica su predicamento. Teniendo en cuenta a Goleman [1995, 1999], se explicita la inteligencia emocional como el modo de utilizar los sentimientos individuales y su orientación hacia la eficacia y eficiencia en el trabajo. No se necesita sólo del saber de los trabajadores, sino, también, de su sentir.

Este término está cobrando gran importancia, y se atisba como clave en el estudio futuro del Aprendizaje Organizativo 23 . Incluso existe un destacado consorcio en EE.UU (The Consortium for Research on Emotional Intelligence in Organizations) cuya misión es avanzar en la investigación y la praxis de la inteligencia emocional en las organizaciones, estableciendo, además, las competencias y modelos que ayuden a reconocer, comprender y gestionar de modo efectivo las relaciones interpersonales y las emociones que las envuelven.

En el caso concreto que nos ocupa, ha de conocerse el modo en que los sentimientos o emociones de un ingeniero de $\mathrm{I}+\mathrm{D}+\mathrm{i}$ influyen sobre su rendimiento en los proyectos científico-técnicos en los que participa. Estos sentimientos le proporcionan una imagen global de toda aquella situación a la que se enfrenta diariamente en su cometido profesional. Así, en el caso de que existan discrepancias entre los valores personales del investigador y los propios del Centro Tecnológico, el resultado puede traducirse, para el primero, en irascibilidad, dudas, ensoñaciones, inquietud o similares. Todo ello origina "ruido emocional", e inspira sentimientos que pueden minar sus esfuerzos.

Es un hecho conocido que las normas que gobiernan el mundo laboral actual están cambiando, y vienen determinadas por el paso de la era industrial a la era del conocimiento. En este contexto, Brown, George-Curran y Smith [2003] establecen que no sólo se juzga a un trabajador por su inteligencia, ni por su formación o experiencia,

\footnotetext{
${ }^{93}$ Actualmente, se vienen analizando muy diferentes tipos de inteligencia. Entre ellos, Peter Senge, en una reciente entrevista, publicada en: www.solonline.org/organizational_overview/next, destaca la llamada "inteligencia interpersonal". En palabras de este autor, este es un término más correcto que la actual acepción de inteligencia emocional. Mediante aquella inteligencia, se pretende que una organización mejore, por medio del trabajo colectivo y colaborativo.
} 
sino, también, por el modo en que se relaciona consigo mismo y con los demás. Esta relación es muy importante en la formación del hilo conductor que, a nivel grupal, origina el Aprendizaje Organizativo. De este modo, teniendo en cuenta a Soler Anglés [2003], para los ingenieros de $\mathrm{I}+\mathrm{D}+\mathrm{i}$, se darían las siguientes premisas:

- La óptima ejecución de su actividad profesional depende más de las competencias emocionales, que de las capacidades cognitivas.

- Incluso en las labores técnicas y científicas que desarrollan, el pensamiento analítico ocupa un tercer lugar, después de la capacidad de influir sobre los demás y del afán de logro.

- En el proceso de toma de decisiones, el primer paso adoptado es siempre deliberado y analítico, pero igualmente importante es la carga emocional que lo rodea, dando lugar a la denominada corazonada o intuición, primordial en la $\mathrm{I}+\mathrm{D}+\mathrm{i}$. La expresión comúnmente utilizada para referirse a este tipo de sensibilidad que nos orienta es: sabiduría (véase apartado III.2).

Relacionaremos, pues, la inteligencia emocional con la intuición. Sobre esta última, Jung [1958] establece que no es contraria a la razón, sino que reside fuera de la misma. Por su parte, Parikh, Neubauer y Lank [1994] la consideran como un acceso a la reserva interna de pericia y experiencia acumulada durante años, y la obtención de una respuesta, o de un impulso para hacer algo, o de una alternativa entre varias, todo ello sin ser consciente de cómo se obtiene. En el campo científico, incluso Einstein [1954] decía que la intuición es lo único que realmente vale. Podemos caracterizarla de la siguiente forma:

a. El grado en que puede ser desarrollada es proporcional a la motivación por saber, por descubrir y por resolver. Individualmente, se denomina serendipidad a la facultad de hacer descubrimientos importantes teniendo en cuenta esta motivación, que algunos investigadores parecen poseer en mayor medida que otros. 
b. Subyace en muchos logros en materia de creatividad e innovación, aspectos básicos para la subsistencia de un Centro Tecnológico, que llevan a ser la clave de éxitos empresariales para quienes presta servicios.

c. Exige comprender apropiadamente lo que debe ser resuelto, hecho que se traduce, para un Centro Tecnológico, en la concreción, aceptación y cumplimento de un pliego de condiciones o convenio a establecer por cada proyecto de $\mathrm{I}+\mathrm{D}+\mathrm{i}$.

La correcta evolución de dichos Centros pasa por el aprovechamiento del conocimiento individual y colectivo disponible, distinguiéndose, como ya fue expuesto, dos tipos: el conocimiento explícito, generalmente fácil de transmitir, y el tácito, difícil de formalizar y comunicar. En este último queda englobado el denominado conocimiento irreflexivo, del que no somos conscientes, y al que se llega por medio de la intuición.

Retornando a la inteligencia emocional propiamente dicha, se observa que la mente humana no está organizada de modo que pueda proporcionar al investigador los argumentos racionales, a favor o en contra de una determinada actividad o decisión. Por el contrario, la mente calibra el poso emocional dejado por experiencias previas (si existen, y si no, se extrapolan con situaciones que se juzgan semejantes), ofreciendo respuestas en forma de presentimiento o sensación visceral. En palabras de Goleman [1999:131]: “Cuando disponemos de los recursos emocionales adecuados, lo que anteriormente parecía amenazador, podemos terminar abordándolo como un desafio y afrontarlo con energía y hasta con entusiasmo".

Por su parte, los investigadores de renombre presentan dos habilidades que se han vuelto cruciales en labores de $\mathrm{I}+\mathrm{D}+\mathrm{i}$ : la formación de equipos para la consecución de un fin común; y la capacidad de afrontar los rápidos y continuos cambios en materia científica y tecnológica. Del mismo modo, los referidos investigadores presentan dos capacidades: ejercer de catalizadores del cambio (enfoque proactivo), y aprovechar la diversidad, en su amplio significado. Para todo ello, deben poseer cuatro competencias: conocimiento del medio (humana y técnicamente), empatía, autodisciplina e iniciativa propias. Continuando con las indicaciones de Goleman [1999], el ambiente entre investigadores debe ser de colaboración, y no de competencia, con lo que se dará la 
situación propicia para el desarrollo del Aprendizaje Organizativo (véase apartado III.6). Así, podrán compendiarse las tendencias relevantes en materia de ciencia y tecnología, forjándose una visión de conjunto que permita la planificación de estrategias de acción futuras (líneas de investigación, atracción y ejecución de proyectos, financiación, etc.).

Igualmente aplicable a los investigadores es el llamado principio de Peter, que afirma que un trabajador se ve promocionado hasta que alcanza su nivel de incompetencia [Peter-1993]. Este principio, focalizado en los Centros Tecnológicos, muestra el hecho de que, aunque una persona pueda ascender escalonadamente de forma progresiva por sus buenos conocimientos $\mathrm{y} / \mathrm{o}$ prestigio, hasta alcanzar niveles gerenciales, no presupone que vaya a ser un buen gestor, ya que la situación de dirigir grupos de personas puede resultar desconocida para él. Es más, continuando con Goleman [1999], en los científicos y tecnólogos, también se da el fenómeno al que se conoce como "incapacidad aprendida", que establece que, de modo general, cuanto más versados son en su materia, mayor es, también, su insuficiencia emocional y social.

Para suscitar el Aprendizaje Organizativo, debe darse, a su vez, un reaprendizaje constructivo de la actividad que se está llevando en $\mathrm{I}+\mathrm{D}+\mathrm{i}$, especialmente a partir de los errores cometidos. Éstos llevan emparejados un tiempo de búsqueda de culpables, junto a la crítica de las equivocaciones personales. De esta suerte, se origina una actitud que emula que todo es correcto, y este comportamiento, que envuelve diversas emociones y sentimientos, es un signo inequívoco de la existencia de los denominados puntos ciegos [Goleman-1997]. Algunos de los más comunes, de acuerdo con Kaplan y Norton [2000], son:

- Ambición: competencia en lugar de cooperación.

- Objetivos utópicos: suelen estar basados en la consecución de beneficios económicos a corto plazo.

- Esfuerzo desmedido de los investigadores para alcanzar los objetivos marcados. 
- Intromisión (o elusión) de tareas.

- Avidez de poder, o necesidad constante de reconocimientos. Estas características son propias del mundo universitario [Juidías y Loscertales-1993], y especialmente la segunda es particular en el ámbito científico [Zamora Bonilla-2002].

- Confusión entre lo que realmente es la labor profesional de un investigador, y lo que ésta, a su juicio, debiera ser. Este hecho puede llevar a una preocupación excesiva por las apariencias.

La función de los puntos ciegos no es otra que la de ocultar el conocimiento distintivo del personal del Centro Tecnológico, y de éste en su conjunto, pues, en caso contrario, se habrían de admitir los propios errores. Bajo estas circunstancias, el Centro sería refractario al Aprendizaje Organizativo. Obviamente, si aquél ha de tener una actitud proactiva ante el cambio, ésta no ha de ser la filosofía a adoptar en la pretensión de que su actividad tenga continuidad. No obstante, los puntos ciegos son hábitos aprendidos, por lo que siempre existe la posibilidad de reformarlos.

Finalmente, apréciese que la inteligencia emocional individual transgrede ese ámbito y, según los aspectos dados, conforma un equivalente grupal durante la ejecución de labores de $\mathrm{I}+\mathrm{D}+\mathrm{i}$, como factor interno y constitutivo del Aprendizaje Organizativo.

\section{V.2.5. La Importancia de la Jerarquía}

Dos importantes factores, inherentes e internos a toda organización, son su estructuración y su jerarquía. La primera es particular a cada una de ellas y su dedicación. Igualmente la segunda, pero es allí donde reside la cadena de responsabilidades y la implicación en la consecución de objetivos.

Centrándonos en la jerarquía, y de acuerdo con Cardona Labarga y Cardona Patau [2002], se viene desarrollando una moda promocionada por grandes figuras de la Psicología y del comportamiento en las organizaciones, que afirman que ha de existir una comunicación fluida entre todos los niveles constituyentes de las mismas. Se 
pretende, así, dar el paso de la "cultura del miedo" (propia de la sociedad industrial) a la "cultura de la confianza" (propia de la sociedad del conocimiento). Esta última, según los referidos autores, pone en juego las denominadas "diez C": cultura organizacional, competencias, compromiso, confianza, clientes, calidad, conocimiento, comportamiento, comunicación y cambio.

La referida tendencia tiene su origen en la erosión de la verticalidad jerárquica, hecho que en las empresas es un fenómeno multifactorial, en el que influyen variables del entorno, modos de pensar y cambios de carácter técnico. El primer apoyo a la erosión del control estricto y a la desjerarquización de las empresas nace con los estudios de Elton Mayo en los años treinta del siglo XX [Mayo-1933], consolidándose en toda una serie de investigaciones realizadas por psicólogos sociales en la postguerra de la segunda contienda mundial. Parten del convencimiento de que los estilos de liderazgo participativo fomentan una mayor eficacia. Esta reflexión no pone en cuestión el modelo general de la empresa capitalista, pero propone reformas en el estilo de liderazgo para incrementar la competencia en el trabajo. Su impacto fue lento, pero constante, de manera que en los años setenta del pasado siglo, en plena revolución cultural, se había desarrollado una masa crítica contra el autoritarismo en la empresa.

Complementariamente a esta corriente de pensamiento, y también desde los años setenta del siglo XX, se imponen en Japón, Europa y Estados Unidos toda una serie de cambios organizativos que han sido denominados de manera conjunta "post-fordismo", "posttaylorismo" o, simplemente, nuevos modelos de gestión. Esta es una amplia etiqueta bajo la que se agrupan los modelos de calidad $\frac{14}{4}$ la reingeniería de procesos, los modelos de excelencia, etc. Estos modelos no asumen la crítica a la verticalidad jerárquica como el objetivo fundamental de sus propuestas, pero al insistir, todos ellos, en la necesidad de la implicación de los trabajadores, la reducción de mandos intermedios y la autonomía en el trabajo, necesariamente acaban proponiendo un nuevo tipo de liderazgo y una nueva relación jerárquica. De esta manera, en la obra de los padres de los modelos de calidad, como Juran [1990], la referencia al poder es muy

${ }^{94} \mathrm{Su}$ objetivo es mejorar el proceso productivo, la rentabilidad empresarial y el ambiente laboral, mediante la formación de grupos de trabajo que matienen reuniones periódicas en las que se analizan los métodos más adecuados para realizar eficazmente su actividad. 
escueta o inexistente, pero en los desarrollos posteriores, o en los manuales de aplicación, se insiste fuertemente en el cambio de estilo de liderazgo [Udaondo Durán1991].

Las propuestas antijerárquicas quedan recogidas en la obra de las principales figuras de los años ochenta y noventa del siglo XX, como Tom Peters, Peter Senge y Hervé Sérieyx. Estos autores, cuya obra ha tenido una gran repercusión en la divulgación de nuevos estilos de gestión, insisten, casi invariablemente, en la necesidad de delegación y en el liderazgo participativo [Peters-1988; Senge-1992; Sérieyx-1994; Senge et al.1995]. Sus propuestas se realizan sin que supongan un cambio estructural en la distribución de poder, pretendiendo un cambio de estilo.

En muchos casos, la obra de los maestros y los "vendedores" de tendencias no es realmente el motor del cambio. Tienen más impacto, en este sentido, las evoluciones culturales y la nueva naturaleza del trabajo, caracterizada por la prioridad de la labor intelectual, donde no tienen demasiado sentido los modelos clásicos de control.

Toda esta serie de factores confluye en la convicción generalizada, durante toda la década de los noventa del siglo XX, de que el liderazgo empresarial debe reconstruirse y renovarse. De manera paralela a todas las rupturas que se anunciaban para el fin de dicho siglo, muchos autores del pensamiento empresarial pronosticaban y prescribían el nacimiento de un nuevo liderazgo caracterizado por la delegación, la participación, el cambio de funciones, la erosión del control personal y el incremento del papel estratégico y evaluativo de la autoridad, en detrimento de las funciones clásicas. Así queda recogido en diferentes obras colectivas [Mc Farland, Senn y Childress-1996; Bennis, Spreitzer y Cummings-2002].

Los resultados de esta dinámica son difíciles de evaluar. Por una parte, la aplicación de los nuevos modelos organizativos no ha sido siempre afortunada. Así, Hammer y Stanton [1997] reconocen el alto porcentaje de fracasos en sus procesos de reingeniería, donde, además, el contexto económico internacional ha favorecido, en ocasiones, los procesos de involución y vuelta a modelos tradicionales. Por otra parte, la reforma en el liderazgo ha sido muy gradual. En ningún caso ha habido rupturas en la forma de ejercer 
el poder, y gran parte de la retórica de transformación de dicho liderazgo se ha quedado en palabras. Las grandes empresas y el sector del conocimiento han avanzado más en esta línea, pero las aplicaciones entusiastas de los principios desjerarquizadores, con frecuencia, se han saldado en fracasos.

Particularizando a nuestro caso, y como ya se expuso en el apartado III.6.1, en un Centro Tecnológico no resultaría adecuado ejercer la autoridad convencional, siendo conveniente dar paso a una autoridad sustantiva. Además, el Centro en sí debe ser humanamente horizontal. Pues bien, esa horizontalidad no puede mantenerse en aspectos estrictamente laborales, que derivan en la consecución de fines científicotécnicos, hecho que no es excluyente, sino complementario a su dimensión humana.

Así, supongamos que en una organización está implementada la comunicación fluida a todas las escalas que anteriormente hemos reseñado. Imaginemos, por tanto, que el máximo responsable de esa organización se comunica con la última persona de la misma por el medio que sea, pero esta persona no hace lo propio con su mando inmediato. Nos encontramos, entonces, ante el talón de Aquiles de toda teoría de desjerarquización, que sólo resulta aplicable, por razones obvias, en empresas de muy bajo número de empleados, como las PYMEs de Castilla y León, donde un 95\% de las mismas está por debajo de 10 de ellos (véase apartado II.4). Este hecho puede hacerse extensivo a empresas de hasta 20 empleados, por encima de los cuales, bajo nuestra consideración, se hace ya necesaria una cadena de mando. En otro caso, no tendría sentido hablar de la figura de los mandos intermedios en las empresas, ni su equivalente: los jefes de proyecto 05 , para los Centros Tecnológicos. Este estrato de personas no encontraría, entonces, su utilidad y ubicación. A pesar de existir una comunicación fluida a todos los niveles, incluso con actitud dialogante, el clima laboral sería regular, como también la ejecución de labores de $\mathrm{I}+\mathrm{D}+\mathrm{i}, \mathrm{y}$, consiguientemente, el cliente no resolvería la situación que ha planteado a dichos Centros. Por tanto, un brillante sistema de comunicación, no suple la jerarquía.

En el caso de estos últimos, como puede comprobarse en los organigramas que explicitan a través de sus páginas web o memorias anuales, se da la paradoja de 
preciarse de su gradación horizontal y establecer, por su propia configuración interna, una jerarquía científico-técnica y administrativa, más o menos rígida, cuyas normas son impositivas en el actuar diario del investigador. En dicha jerarquía, no resulta adecuado implementar la idea defendida por Drucker [2001], consistente en cargar de responsabilidad a los puestos inferiores, pues se eximiría del compromiso correspondiente a los responsables de las diferentes áreas tecnológicas de las que constan. Lo que debe hacerse es pasar de la organización basada en el poder, a la organización basada en la responsabilidad, donde cada escalón jerárquico asuma la que le corresponde, hecho factible, únicamente, si, según Tidd, Bessant y Keith [2001], existe compromiso con la labor funcional y profesional propia de cada estrato. Esta circunstancia no debe confundirse con la desjerarquización. Teniendo en cuenta, en cambio, otras ideas de Drucker [2001], hemos de hablar de responsabilidad y contribución, puesto que el poder sin responsabilidad no se considera tal, sino irresponsabilidad. Con ello se pone de manifiesto que la jerarquía es estrictamente necesaria en los Centros Tecnológicos y, consecuentemente, la responsabilidad.

De esta forma, no estamos ante un asunto exclusivo de índole laboral, sino de enriquecimiento del trabajo, hecho transcendental en labores intelectivas, donde debe proliferar el Aprendizaje Organizativo.

\section{V.3. Descripción de los Actores Externos del Aprendizaje Organizativo en los Centros Tecnológicos}

Establecido en el apartado V.1 lo que se entiende por actor externo del aprendizaje, en su concepción organizativa para un Centro Tecnológico, seguidamente analizaremos los que son fundamentales: la inteligencia profesional y proactiva; la formación en los ingenieros de $\mathrm{I}+\mathrm{D}+\mathrm{i}$; y la esfera de actuación de los referidos Centros.

\footnotetext{
${ }^{95}$ Intermediarios entre el cliente, la directiva del Centro Tecnológico y el equipo de proyecto asociado.
} 


\section{V.3.1. La Inteligencia Profesional y Proactiva}

En términos generales, la inteligencia ha sido definida de muy diferentes maneras por parte de filósofos, médicos, psicólogos y otros investigadores. En consonancia con la establecida en el apartado I.2.1, para Colvin [1912:560], es la "capacidad de aprender y adaptarse al medio". En nuestro caso, esta capacidad de aprender se vincula al Aprendizaje Organizativo y al manejo del conocimiento, mientras que la adaptación al medio debe tener un enfoque proactivo.

Con el paso del tiempo, han aparecido también diferentes formas de inteligencia, como la emocional, de mercado, artificial, etc., según ha sido considerada en diferentes contextos. De esta manera, en el marco en que los Centros Tecnológicos desenvuelven su actividad, puede hablarse de inteligencia profesional y proactiva, que se define como "aquella actitud para procurarse más oportunidades de las que se presenten aprovechando las sinergias del entorno, así como dar un servicio adaptado a las necesidades de los clientes en cada momento" [Pérez Blanco-2002a:1].

Para ello, el Centro Tecnológico, a través de sus investigadores, debe llevar a cabo una serie de prácticas y procesos sistemáticos, para mantenerse atento a los cambios tecnológicos y científicos en que desarrolla su actividad. Esto es factible a través de diferentes acciones, como la creación y continuación de líneas de investigación significativas; la formación/inclusión de/en redes de vigilancia; realización de mapas tecnológicos; análisis sectoriales; vigilancia y prospección tecnológicas (véase apartado III.6.2); estudios de patentes; y, todas aquellas metodologías que se juzguen necesarias. A nivel empresarial, existe, equivalentemente, el término "inteligencia tecnológica competitiva", que no sólo abarca el hecho de permanecer al tanto de los cambios y avances técnicos, sino de los competidores y las oportunidades comerciales [Solleiro, Castañón y Vega-2002].

La pretensión de la inteligencia profesional y proactiva en los Centros Tecnológicos es doble: por una parte, gestionar de forma eficiente y eficaz los recursos y tiempo de los investigadores en su actividad laboral; por otra, mejorar la rentabilidad de las actividades de $\mathrm{I}+\mathrm{D}+\mathrm{i}, \mathrm{y}$, en consecuencia, la correspondiente de las empresas a quien se 
presta servicio. Por supuesto, todo cliente de aquéllos estima un trabajo bien hecho, es decir, acorde con sus necesidades, pero su valor añadido estriba en entender las necesidades actuales y preveer potenciales necesidades futuras, presentando propuestas de forma proactiva en función del conocimiento adquirido.

Se observa, entonces, cómo la inteligencia profesional y proactiva está directamente relacionada con la capacidad de innovación, que es uno de los pilares fundamentales de los Centros Tecnológicos, y garantía de futuro de las empresas. De acuerdo con la visión de Carballo [2003], la innovación es la antesala de muchos fenómenos sociales, económicos y humanos, estando más vinculada a la mejora continua por medio del trabajo diario, que a la creatividad. El conocimiento es, así, un recurso al servicio de la innovación. De esta forma, conocimiento e innovación no son objetos, sino estados de relaciones e interdependencias entre personas, y entre éstas y otras entidades, haciéndose posible, de este modo, la expresión de dicho conocimiento. Los Centros Tecnológicos se mantienen, entre otros apoyos, por lo que saben hacer y cómo son capaces de aplicarlo a lo nuevo, es decir, por la capacidad de innovar. La innovación, como competencia suya, parte del acúmulo de aportaciones individuales de los investigadores vinculados a un proyecto, que posteriormente son analizadas y puestas en común por el equipo del mismo. Se transpasa, así, de lo individual a lo grupal, del mismo modo que, a diferente escala, la innovación en las organizaciones no se construye de forma aislada de empresa en empresa. Son los sistemas de innovación regional (véase capítulo II) los que van tejiendo el espacio propicio, en un esfuerzo colectivo de diferentes entidades, con cultura de equipo, entre las que se cuentan los Centros Tecnológicos [Coriat y Weinstein-2002].

Por ello, transponiendo las ideas de Pérez Blanco [2002b], en la consideración de la inteligencia profesional y proactiva debe tenerse muy en cuenta el conflicto que puede existir entre los intereses individuales de cada investigador, y los colectivos del Centro Tecnológico, pudiendo distinguirse las situaciones siguientes:

1. Ni investigador ni Centro Tecnológico emplean la inteligencia profesional y proactiva: el primero no generará conocimiento, las relaciones internas se deteriorarán, y el no habrá demanda de tareas de $\mathrm{I}+\mathrm{D}+\mathrm{i}$ para el Centro Tecnológico. 
El resultado, a corto plazo, es la muerte profesional del investigador y el fin del Centro Tecnológico.

2. El investigador no utiliza la inteligencia profesional y proactiva, pero sí lo hace el Centro Tecnológico: el valor profesional del primero irá mermando paulatinamente, siendo un resultado posible el desfase entre ambos, que derivará, seguramente, en despido para aquél. El hecho de que la inteligencia comentada no sea utilizada por un investigador de relevancia en un proyecto de $\mathrm{I}+\mathrm{D}+\mathrm{i}$ puede acarrear insatisfacción en el cliente que interactúa con él, generándose tensiones que afectarán negativamente a todo el Centro Tecnológico (imagen y futuras colaboraciones).

3. El investigador utiliza la inteligencia profesional y proactiva, pero no lo hace el Centro Tecnológico: el valor del investigador crecerá, pero su esfuerzo no encontrará respaldo para atraer más proyectos o más clientes. De este modo, la permanencia del investigador en el Centro suele ser un proceso de desgaste, que culmina en su marcha voluntaria hacia otros organismos con los que se siente más identificado.

4. Tanto investigador como Centro Tecnológico utilizan la inteligencia profesional y proactiva: el valor profesional del aquél se verá incrementado, actuando con eficiencia y eficacia con su entorno. Por otra parte, el Centro presentará un ambiente verdaderamente ansiado para el desarrollo de $\mathrm{I}+\mathrm{D}+\mathrm{i}$. El resultado, en este caso, (claramente ideal en España, pero al que hay que tender), es el valor adquirido por ambas partes, dándose un afán de superación constante, sin rotación de personal, junto con más beneficios para el Centro Tecnológico y las empresas en que vuelcan su actividad.

De lo expuesto se desprende, entonces, una clara realimentación entre la inteligencia profesional y proactiva de cada investigador, considerada individualmente, y la del Centro Tecnológico, en conjunto. Ambas están directamente relacionadas con la capacidad de aprendizaje por acumulación de experiencia y saber hacer durante la ejecución de labores de $\mathrm{I}+\mathrm{D}+\mathrm{i}$. Se da lugar, en consecuencia, a una inteligencia 
equivalente, mezcla de las dos indicadas, que es en sí un actor externo y constitutivo del Aprendizaje Organizativo global del Centro.

\section{V.3.2. La Formación en los Ingenieros de $I+D+i$}

La hondura y celeridad de las transformaciones producidas en el mundo empresarial, en la organización y en la gestión del trabajo, desde finales del siglo $\mathrm{XX}$, originan el tipo de competencias requeridas, no ya sólo para los profesionales que se integran en la actividad productiva de una empresa, sino para los investigadores del Centro Tecnológico que para ella desarrolla proyectos de $\mathrm{I}+\mathrm{D}+\mathrm{i}$. Así, para estos últimos, se demandan nuevas capacidades y destrezas, que, actualmente, la formación universitaria que todos ellos poseen no considera, ni en los planes de estudio de las disciplinas científico-técnicas a que pertenecen, ni en sus metodologías de aprendizaje. De acuerdo con Castro Díaz Balrt [2002], cada vez más, lo que define la actividad laboral de un investigador son un conjunto de cualidades intangibles.

Como se deduce de las memorias corporativas y estadísticas anuales de los Centros Tecnológicos, mayoritariamente, los investigadores incorporados a ellos son recién titulados de alto promedio académico y cierto manejo de idiomas, que ven la posibilidad de acumular experiencia y adquirir un perfil profesional en un medio de marcado carácter pragmático, en la vanguardia de las tecnologías, contribuyendo, así, a la competencia y competitividad de las empresas. El que un ingeniero de $\mathrm{I}+\mathrm{D}+\mathrm{i}$ posea las mejores condiciones técnicas en su disciplina es una condición necesaria, pero no es suficiente para el ejercicio de su labor. Según Anzorena [2003], este es un hecho que, de manera general, se observa en toda la producción de bienes y servicios. Siguiendo con dicho autor, las indicaciones para una empresa moderna, convenientemente adaptadas, nos sirven para definir el perfil requerido para un investigador, que viene dado por las

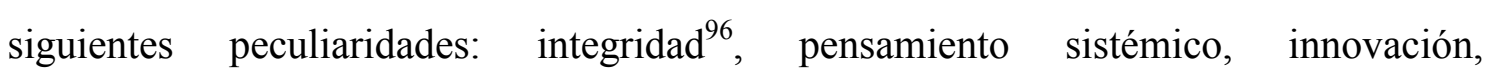
colaboración, búsqueda de alternativas, calidad, flexibilidad, comunicación efectiva y organización.

\footnotetext{
${ }^{96}$ Rectitud, honraded e intachabilidad de la conducta profesional.
} 
Los Centros Tecnológicos tienen ante sí, entonces, la perentoria responsabilidad de formar a sus investigadores en la consecución de estos factores, no ya sólo para obtener el máximo rendimiento de los mismos, sino como contribución social, en caso de revertirlos a un mundo empresarial donde priman estos parámetros. De esta manera, la formación es entendida como un proceso dinámico y continuo. Se trata de un concepto mucho más amplio que el de la simple capacitación, estando en función del antes, durante y después de ésta última [UNESCO-2002]. Las tendencias y directrices en materia de formación, o bien se originan exteriormente al Centro Tecnológico, o bien se vuelcan de éste a su entorno, por lo que, en cualquier caso, aquélla constituye un aspecto externo del Aprendizaje Organizativo que, a nivel grupal, debe considerar dicho Centro.

La capacitación tiene como objeto cubrir la brecha existente entre la formación universitaria y los requerimientos de la actividad empresarial, pero ya ha sido establecido que el énfasis de los Centros Tecnológicos en estas acciones no se orienta mayormente hacia el Aprendizaje Organizativo (véase apartado III.4). La formación aborda temas como la comunicación interpersonal, el trabajo y el aprendizaje en equipo, además de competencias que, hoy por hoy, son indispensables para los trabajadores no manuales, es decir, quienes como los ingenieros de $\mathrm{I}+\mathrm{D}+\mathrm{i}$, desempeñan tareas basadas en el conocimiento. Conforme a las ideas de Castañeda Zapata [2002], esto no quiere decir que la capacitación de los investigadores no resulte necesaria, y que deban recortarse sus partidas presupuestarias en época de crisis, sino que debe enfocarse a la mejora que puede suponer al desempeño del trabajo diario del investigador, en conjunción con los procesos de cambio proactivo en el Centro Tecnológico. La validez de la capacitación exige rigor y acierto en la enunciación de las necesidades correspondientes, así como en sus implicaciones colectivas o individualizadas, que, a su vez, han de desarrollarse conforme a las expectativas por las que fueron elegidas o diseñadas, vigilando, siempre atentamente, su alineación con los objetivos a alcanzar, y reaccionando ante desviaciones no deseadas. El Centro Tecnológico ha de asegurar que las nuevas aptitudes adquiridas, por medio de la capacitación de sus ingenieros de $\mathrm{I}+\mathrm{D}+\mathrm{i}$, se pongan en práctica con el desempeño cotidiano como hecho fundamental, unificándose dichas aptitudes con las actitudes (de acuerdo a los parámetros del perfil del investigador anteriormente descritos) que, de manera complementaria, y según se 
estableció en el apartado III.6, deben adquirir los investigadores para contribuir al Aprendizaje Organizativo. Sólo así puede hablarse certeramente de formación.

De este modo, se concuerda con las ideas de Le Boterf [2001], quien sostiene que las empresas de hoy necesitan modelos organizacionales con empleados que sepan seleccionar, utilizar, comunicar y compartir información, que puedan tomar la iniciativa, anticipar y decidir entre múltiples criterios. Esto colleva que los ingenieros de $\mathrm{I}+\mathrm{D}+\mathrm{i}$ sean capaces de encarar situaciones caracterizadas por la complejidad y la inestabilidad, como se ha tratado ampliamente en el capítulo IV. Supone saber actuar, lo que a su vez implica "saber" y "saber hacer". En ello juega un importante papel el uso de los recursos del entorno (contactos, redes documentales, bancos de datos, instrumentación científica y técnica, etc.).

En esta línea, Reich [1991] acuñó el término "analistas simbólicos" como locución paralela a lo que Drucker [1993, 2003] denomina "trabajadores del saber". Aquél propone tres modalidades de trabajo, en las que una de ellas son los analistas simbólicos. Éstos son profesionales, pero no todo profesional es un analista simbólico, pues son quienes se ocupan de los procesos reflexivos y de comunicación, antes que de una producción tangible. Simplifican la realidad con imágenes abstractas con las que se consigue experimentar, pudiéndose reordenar, alterar o comunicar éstas con otros analistas simbólicos para convertirlas finalmente en una nueva realidad. Para ello los instrumentos en un Centro Tecnológico pueden ser algoritmos matemáticos; principios científicos; métodos inductivos o deductivos; fundamentación técnica; aspectos económicos; de seguridad laboral y normativas aplicables a un proyecto; definición de disciplinas científico-técnicas y papel de los miembros de un equipo; observaciones psicológicas sobre cómo persuadir o entretener; junto con todas aquellas técnicas convenientes para resolver problemas. Para todo lo anterior, el investigador debe poseer una predisposición individual que fue abordada en el apartado III.5.

Por su parte, Rafael Echeverría [2000], va más allá de las ideas de Reich, y plantea que los trabajadores del conocimiento, además de trabajar con símbolos, operan con aspectos más finos, como las posibilidades y los compromisos, hecho con el que nos alineamos plenamente. El objetivo de estos trabajadores es mantener activas las 
posibilidades existentes, generar nuevas y lograr aquellos compromisos que permitan aprovecharlas. Todo esto se hace a través del diálogo. Según este autor, se ha de hablar, escuchar y debatir con el resto, interpretando o generando nuevas inquietudes y creando espacios emocionales, a través de los que, a su vez, surjan nuevas inquietudes y posibilidades.

Obviamente, los Centros Tecnológicos no aprenden en abstracto. Lo hacen a través de sus investigadores y de su capacidad para integrar, transferir y gestionar el conocimiento adquirido. Por tanto, para que la formación de los mismos sea un proceso organizacional de aprendizaje continuo, es imprescindible que los ingenieros de $\mathrm{I}+\mathrm{D}+\mathrm{i}$ sepan aprender a aprender. Este es el auténtico modus operandi del Centro Tecnológico. La obsolescencia del conocimiento lleva a que la velocidad de aprendizaje sea la única herramienta adecuada para sustentar y desarrollar ventajas competitivas en las empresas, hecho especialmente crítico en las PYMEs. Éstas se ven obligadas a mantener su competitividad, por lo que han de transformarse por medio de actualizaciones de otras órbitas, como los Centros Tecnológicos, haciéndose aún más comprensible el inestimable valor de la formación de su personal.

En los momentos actuales, está siendo completada la transformación de un sistema de organización productiva sustentado en el mando y el control, a un sistema productivo basado en la Gestión del Conocimiento. Del primero surgió una formación basada en la disciplina del trabajo, el pensamiento uniforme, la perdurabilidad del conocimiento, la tarea individual y secuencial, junto al conocimiento separado de la fuerza del trabajo. Del segundo, siguiendo las directrices de la OCDE [2004], debe surgir una formación que inculque conceptos y valores como la diversidad; la versatilidad; la reflexión en la acción; la innovación; la autorregulación responsable; deliberar y trabajar en equipo; el pensamiento sistémico; el análisis, la crítica y la creatividad. A esta dinámica han de quedar incorporados, corriente y mayoritariamente, los investigadores. 


\section{V.3.3. Esfera de Actuación}

Bajo este epígrafe se engloban dos importantes aspectos íntimamente relacionados y mutuamente condicionantes entre sí: el entorno geográfico de intervención de los Centros Tecnológicos y las políticas en materia de $\mathrm{I}+\mathrm{D}+\mathrm{i}$ que les afectan.

En cuanto al primero de los aspectos indicados, del mismo modo que un ser humano en su progresivo crecimiento y desarrollo desde la infancia, va ampliando cada vez más su radio de actuación social y geográfico, con lo que aumenta paulatinamente su aprendizaje, así ocurre con los Centros Tecnológicos en el desarrollo de su actividad.

No obstante, es necesario tener en cuenta que la rapidez de los avances científicotécnicos, junto con la creciente aplicación de la tecnología derivada a campos muy distantes de aquéllos en que se generaron, hace inviable la concentración en un único Centro de todas aquellas tecnologías que pudieran resultar de utilidad a determinados mercados.

El concepto de región o Comunidad Autónoma, como entorno geográfico con prioridad en la realización de actividades de los Centros Tecnológicos, es esencial en la innovación que surge de los mismos, así como una constante en su presentación (basta observar sus memorias anuales). Esta vecindad de las personas que trabajan en las empresas para quienes se desarrollan proyectos, junto con el hecho de compartir una cultura y un estilo de vida común, facilita pautas de cooperación e interacción entre los Centros Tecnológicos y tales empresas. A su vez, nos hallamos en una época donde las actividades de $\mathrm{I}+\mathrm{D}+\mathrm{i}$ son obligatoriamente interactivas, la nueva economía del conocimiento es la base de la competitividad, y los procesos de cambio son, básicamente, colectivos y en red. El que la Comunidad Autónoma sea el escenario cercano donde se realicen las principales interacciones, confiere a la territorialidad un papel relevante, pero no cuestiona el hecho de que el entorno en donde los Centros Tecnológicos aplican sus resultados debe ser, cada vez más, de ámbito mundial. Podría decirse que su orientación principal debe dirigirse a cooperar y ayudar a innovar localmente a las empresas para que éstas compitan globalmente [PLA BIT Segle XXI2001]. Esta orientación es, claramente, una externalización de las actividades de I+D+i 
del Centro Tecnológico, y es obvio que constituye una rica fuente de Aprendizaje Organizativo para el mismo, a través del adquirido por los equipos de proyecto que intervienen en ellas. De acuerdo con Rivas Herrero y Pedraza De García [2004], la internacionalización posibilita un posicionamiento en el mercado global y favorece el aprovechamiento de las oportunidades que así se brindan para potenciar la economía local.

Por ello, con arreglo a Sanz Menéndez y Meza [2002], incluso en el caso de Centros de gran tamaño y de importantes recursos (en España los Centros Tecnológicos son relativamente pequeños en el contexto de la Unión Europea [Barceló y Roig-1999]), su oferta cobra más valor en tanto mayor sea su capacidad para conocer y acceder a fuentes adicionales de ciencia y tecnología. La conexión de los Centros Tecnológicos con estas fuentes externas se instrumenta de maneras muy diferentes, sin limitarse al entorno territorial próximo, extendiéndose a universidades y centros equivalentes en otras Comunidades Autónomas, u otros países. Se ha de formar parte, entonces, de redes globales de conocimiento que potencien la capacidad de anticipación de aquéllos, para ofertar propuestas de futuro a las empresas, como indica la Fundación COTEC [2004c].

Dicha fundación establece que los Centros Tecnológicos deben, igualmente, buscar la excelencia en el ámbito mundial en algún campo específico por el que se deberá optar. La única comparación posible para establecer su nivel de calidad es la internacional. Para ello, tienen que atraer y retener a investigadores valiosos (propios o ajenos). Por su parte, estos crearán equipos de personas de elevado prestigio y vitalidad. A la postre, estos grupos de excelencia no han de dedicar íntegramente sus esfuerzos a atender problemas de las PYMEs de su entorno geográfico. En líneas generales, en los momentos actuales, éstas se aprovechan más de la transferencia del conocimiento derivada de los proyectos concertados con los Centros Tecnológicos, que de los resultados prácticos transferibles al mercado surtidos, debido a la dificultad inherente a la actividad de $\mathrm{I}+\mathrm{D}+\mathrm{i}$.

En el sentido apuntado, como ya se trató en el apartado III.3, el objetivo común de las redes de excelencia promovidas por los VI y VII Programas Marco de la Unión Europea, es el fortalecimiento de la excelencia científica y técnica del viejo continente, 
mediante la integración de las capacidades de investigación actuales o en formación, tanto de países como regiones. Estas redes fomentan la cooperación entre recursos de gran calidad de universidades, centros de investigación, empresas (incluidas las PYMEs) y otras entidades de dedicación científica y técnica. Sus actividades se orientan a objetivos multidisciplinares a largo plazo, más que a resultados como productos, procesos o servicios. De este modo, se fomenta el Aprendizaje Organizativo, así como su sedimentación, y no una solución concreta a tiempo y merced de las exigencias empresariales.

Por otra parte, en lo que concierne a las políticas en materia de $\mathrm{I}+\mathrm{D}+\mathrm{i}$, según Quesada Ibáñez [2004], el sistema que conforman estos tres aspectos se relaciona con otros muchos sistemas presentes en el ámbito de una Comunidad Autónoma, como son: el educativo; el financiero; el fiscal (incentivos); el cultural; las políticas sectoriales (industriales, agrícolas, de servicios u otros tipos); y, por último, la política territorial.

Como hemos expuesto, la investigación se desarrolla en un ámbito universal, pero el desarrollo tecnológico está más ligado a las industrias y actividades productivas en un entorno dado. Por su parte, la innovación tiene una implicación directa con el mundo empresarial. De este modo, como establecen Herrera Enríquez et al. [2004] y en consonancia con el ámbito de actuación, es entendible que las políticas de investigación habrían ser definidas en el ámbito de la Europa comunitaria (esfera supranacional), las políticas de desarrollo tecnológico deberían ser nacionales, y las de innovación empresarial, básicamente, autonómicas. Esta distribución no es la actualmente existente, y su consideración haría que no pareciesen aislados la investigación, el desarrollo y la innovación, debiendo existir, adicionalmente, una correspondencia similar en materia de financiación. Perceptiblemente, entonces, el criterio de excelencia es lógico en el ámbito de la investigación, pero ha de pesar mucho menos en el ámbito de la innovación, donde la oportunidad debe tener una importancia superior.

A su vez, Inés Carazo [2004] establece que los Centros Tecnológicos deben ser reconocidos como un instrumento de las políticas de Estado, requiriéndose de la voluntad y compromiso de todos los agentes de la sociedad, con relación a estos instrumentos. Así pues, ha de darse para ellos una sostenibilidad política independiente 
del signo que gobierne en un determinado momento. Igualmente, sostenibilidad institucional, es decir, ciencia, tecnología e innovación deben ser asumidos como una política de Estado. Conjuntamente, Gracia San Miguel [2004] indica que se ha de brindar una relativa y condicionada sostenibilidad económica, de modo que se financie la demanda de labores de $\mathrm{I}+\mathrm{D}+\mathrm{i}$ a satisfacer por los Centros Tecnológicos, y no tanto la oferta generada por los mismos, con lo que se asegura el interés social del cliente. Además, ello sólo resultará de aplicación a los más solicitados, por ser los más adecuados a este tipo de labores, pues si un Centro no va entrar en el puro negocio, es natural que se le apoye en labores de $\mathrm{I}+\mathrm{D}+\mathrm{i}$, en parte con fondos públicos, pues, en caso contrario, sus labores se equiparan con las de una ingeniería, consultoría o equivalente.

Un ejemplo es la reducción de Centros Tecnológicos sufrida en Castilla y León. La Administración de dicha Comunidad Autónoma puso en marcha una red de Centros Tecnológicos en 1992, a la que se adscribieron organismos de muy distinta naturaleza (organizaciones profesionales y empresariales, empresas, centros/institutos de investigación de carácter público y privado, así como laboratorios universitarios), que alcanzaba un total de 32 centros principales. En la actualidad (año 2005), la Junta de Castilla y León mantiene un convenio de financiación estable con seis Centros

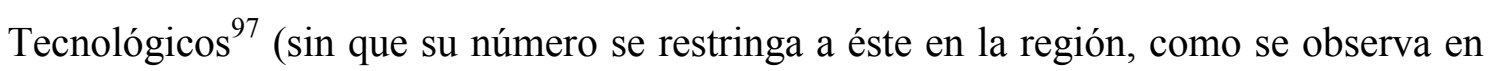
el apartado II.2).

Según la entidad Parques Tecnológicos de Castilla y León, S.A., esta reducción no se produjo de una manera puntual, si no que vino condicionada por una serie de requisitos que los mismos debían cumplir para acceder a determinados apoyos financieros. Estos requisitos fijaban unas exigencias, en cuanto a contratos con empresas, personal contratado en plantilla, etc. Parte de los mismos aparecían enumerados como condición para solicitar o acceder a ayudas en las líneas de apoyo a los Centros Tecnológicos que la Agencia de Desarrollo Económico de Castilla y León convocaba periódicamente. El motivo por el que se establecieron estas condiciones y requerimientos responde a

\footnotetext{
${ }^{97}$ Aquellos asociados a INTENEC (Consorcio tecnológico de Castilla y León para la innovación), que integra los seis Centros Tecnológicos de máxima relevancia en la referida Comunidad Autónoma: CARTIF, CEDETEL, CIDAUT, CTM, INBIOTEC e ITCL. Estos Centros emplean a 700 personas, y facturan cerca de 40 millones de Euros, de los que más de la mitad proceden de contratos de I+D con empresas [Gaceta SOST-2005].
} 
criterios de eficiencia, tal y como aparecen inicialmente en el Plan Tecnológico Regional de Castilla y León [JUNTA DE CASTILLA Y LEÓN-1997], y que se confirman posteriormente en la Estrategia Regional de I+D+i [JUNTA DE CASTILLA Y LEÓN-2002a, 2002b, 2002c], elementos ya tratados en el apartado II.6. 
Pedro Martín Lerones Evaluación del Aprendizaje Organizativo en los Centros Tecnológicos y Gestión del Conocimiento Sectorial en Castilla y León 


\section{Capítulo VI:}

Correlación de los Actores Psico-Sociológicos y Formulación para la Valoración Entrópica de la Evolución del Aprendizaje

Organizativo 
Pedro Martín Lerones Evaluación del Aprendizaje Organizativo en los Centros Tecnológicos y Gestión del Conocimiento Sectorial en Castilla y León 


\section{VI.1. Necesidad de Correlación de los Actores Psico- Sociológicos}

Los actores internos y externos del Aprendizaje Organizativo en los Centros Tecnológicos que se han descrito en el capítulo anterior son un conjunto de elementos de carácter psico-social, que, aún siendo los integrantes reales de ese aprendizaje, resultan imposibles de medir. Para ser utilizados directamente en el modelo entrópico de sostenibilidad propuesto para los Centros Tecnológicos en el capítulo IV, podrían manejarse diferentes técnicas empleadas en las Ciencias Sociales. La más directa de todas ellas consistiría en tratar de evaluar a los actores mencionados mediante encuestas con preguntas previamente preparadas y consensuadas a tal respecto, pero esta forma de operar (característica en disciplinas como la Psicología y la Sociología) no es considerada adecuada, en nuestro caso, como metodología genérica, por dos motivos principales:

- Intencionalidad: las preguntas pueden estar dirigidas a la obtención de una respuesta o sesgo determinado. Este hecho no sólo es factible desde quien formula la cuestión pertinente, sino, también, por parte de quien responde, pues se haya influenciado por sus circunstancias personales hacia el hecho cuestionado (variables en función del lugar y la ocasión), ponderando o reduciendo, subjetiva o deliberadamente, el valor cuantificable de la respuesta.

- Dispersión: la intencionalidad referida, junto con el hecho de estar bajo consideraciones estadísticas, origina que la dispersión de los resultados (medida como desviación estándar) suela ser elevada, habiéndose de considerar tramos discretos de evaluación cuyos datos se interpretan separadamente según diferentes criterios, haciéndose difícil la obtención de un cuasi-certero resultado global. Se da lugar, entonces, a una gran imprecisión, por el propio carácter intangible de las variables examinadas. 
Por consiguiente, los elementos psico-sociológicos tratados (que son observables $\frac{98}{\text {, no }}$ magnitudes) serán transpuestos en otros que puedan cuantificarse. De esta manera, esos

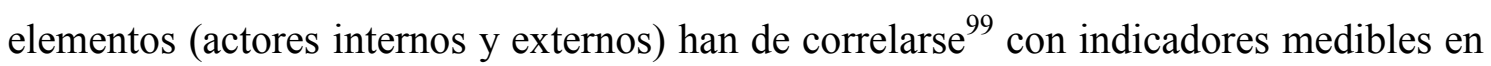
este sentido (internos y externos, respectivamente) en una correspondencia ${ }^{00}$ que no es uno a uno, pues ya de por sí ambos conjuntos (actores e indicadores) tienen distinto número de componentes. No obstante, esta correspondencia lleva aparejadas dificultades metodológicas que derivan de la complejidad de establecer los indicadores indirectos adecuados para dar cuenta de unos elementos que son eminentemente cualitativos e intangibles. A su vez, teniendo en cuenta a Moñux Chércoles et al. [2005], es destacable, en este sentido, el denominado "problema de la atribución y la adicionalidad", que refleja la dificultad de separar los impactos de cada indicador sobre el resto, tanto en su propio contexto (interno o externo), como inclusive en su posible influencia externa, si es interno, y viceversa, debido al carácter proactivo y autopoiético de los Centros Tecnológicos (como se ha razonado en los capítulos precedentes).

Por todo ello, y al objeto de establecer una formulación adecuada para la valoración entrópica de la evolución del Aprendizaje Organizativo, se harán las consideraciones que seguidamente se exponen:

1. Tomando como base lo ya expuesto en el apartado III.6.1, por medio de la correlación referida, obtendremos una estimación de la situación (de ahí el nombre de indicadores), nunca una medición absoluta. Esta correlación se hará principalmente teniendo en cuenta aspectos económicos, por ser realmente datables y mostrar el estado y la realidad del Centro.

\footnotetext{
${ }^{98}$ Un observable es un aspecto perceptible de la realidad examinada que no resulta cuantificable. Un ejemplo, es el dolor físico de una persona. Cualquiera a su derredor puede percatarse de ello, pero no es medible.

${ }^{99}$ En la acepción de existencia de relación mutua.

${ }^{100} \mathrm{La}$ correspondencia indicada no es una aplicación, pues considerados actores e indicadores (ambos, tanto internos como externos, respectivamente) como conjunto inicial y final de modo indistinto, no se verifica que todo elemento del conjunto inicial tenga una imagen y sólo una.
} 
Así, destacamos los que se dan en las dos secciones respectivas del presente capítulo: indicadores internos e indicadores externos para el Aprendizaje Organizativo, que deben evaluarse en un período tipo que se cifra considerando un tiempo base $\left(T_{\text {Base }}\right)$ del siguiente modo:

$$
\mathrm{T}_{\text {Base }}=\mathrm{T}_{\text {Proyecto I+D+i }}+\mathrm{T}_{\text {Explotación y Diseminación }}
$$

Donde se observan dos términos constituyentes:

- $T_{\text {Proyecto de } I+D+i}$, que refleja la duración total de un conjunto de proyectos relevantes ${ }^{101}$ desarrollados por el Centro Tecnológico (teniendo en cuenta sus intersecciones), desde el comienzo del primero de ellos, momento que marca el inicio de la valoración entrópica del Aprendizaje Organizativo. El plazo tipo de un proyecto de $\mathrm{I}+\mathrm{D}+\mathrm{i}$, tanto nacional, como europeo, suele ser de dos años (considerando las convocatorias públicas, en ambos casos).

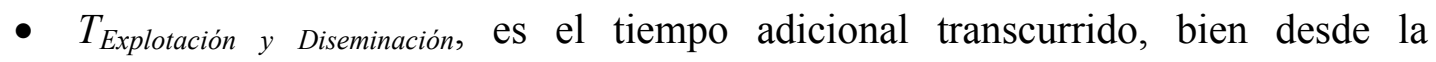
finalización del más tardío de los relevantes, bien de entre varios de ellos que concluyesen a la vez, en cuyo caso se tomaría la duración máxima. Tiene por objeto la difusión científica y técnica, así como la explotación económica de los resultados de los mismos. Típicamente, este tiempo adicional es de dos años (especialmente por la consecución de publicaciones internacionales y patentes).

De esta forma, se someterán a estudio los proyectos de $\mathrm{I}+\mathrm{D}+\mathrm{i}$ que se inicien en un momento dado, y durante un período $T_{\text {Posterior }}=T_{\text {Base, }}$ junto con aquellos desarrollados con anterioridad a ese momento durante un período previo equivalente $\left(T_{\text {Previo }}\right)$, como referimos en el apartado IV.4, para así tener una muestra de mayor

\footnotetext{
${ }^{101}$ De modo general, cuanto mayor es la duración de un proyecto de $\mathrm{I}+\mathrm{D}+\mathrm{i}$ (salvo retrasos previa petición de prórroga), mayor es su envergadura e impacto científico-técnico.
} 
representatividad (Figura 31). Así, se establece un período de evaluación ( $\left.T_{\text {Evaluación }}\right)$, con arreglo a la expresión:

$$
\mathrm{T}_{\text {Evaluación }}=\mathrm{T}_{\text {Previo }}+\mathrm{T}_{\text {Posterior }}=2 \cdot \mathrm{T}_{\text {Base }}
$$

FIGURA 31

PERÍODO DE EVALUACIÓN PARA LA VALORACIÓN ENTRÓPICA DEL APRENDIZAJE ORGANIZATIVO

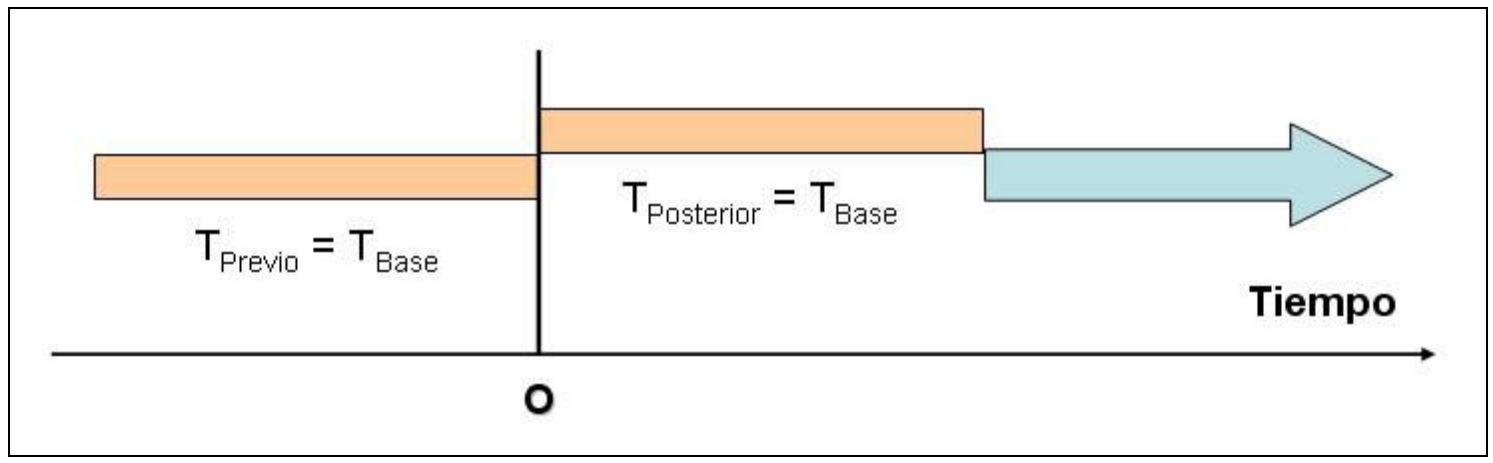

FUENTE: Elaboración Propia

No obstante, los indicadores que se describen en este capítulo pueden registrarse periódicamente para observar su evolución. La mayoría de los mismos están, a su vez, constituidos por una serie de factores relacionados con información datada y accesible en el Centro Tecnológico. Tanto indicadores como factores son autoexplicativos en su significación, si bien algunos de ellos requieren de clarificaciones adicionales que se dan oportunamente.

2. Por otra parte, de acuerdo con lo establecido en el apartado IV.3.4, los Centros Tecnológicos, como sistemas alejados del equilibrio, presentan unas dinámicas que son, esencialmente, no lineales y el futuro es un abanico de posibilidades de las acontecerá una de ellas. Siendo, entonces, impredecible el futuro con las metodologías estadísticas convencionales, se admite que sí pueden ser éstas aplicadas a su pasado desde un momento dado (si se dispone de datos). Puesto que la relación de indicadores y factores que va a relacionarse en los apartados siguientes, tanto internos como externos, hace referencia al manejo de esos datos en $T_{\text {Previo }}$ junto con todo aquel momento de que se disponga de ellos en $T_{\text {Posterior }}, \mathrm{y}$, por 
ende, en el período de evaluación $\left(T_{\text {Evaluación }}\right)$, el valor medio $\frac{102}{\text { puede ser }}$ considerado como cantidad adecuada en las consideraciones del modelo entrópico propuesto para estimar el Aprendizaje Organizativo en el lapso temporal de evaluación indicado.

3. Por último, teniendo en cuenta lo establecido en el apartado V.2.3, como consideración adicional sobre el tratamiento de los indicadores internos y externos del Aprendizaje Organizativo, diremos que no se asumen como tales, ni el sistema de gestión de calidad implantado en el Centro (a través de las certificaciones ISO abrazadas, cuyo objetivo es conducir a la protocolización de metodologías laborales), ni la observancia de las normativas de seguridad e higiene en el trabajo aplicables a cada proyecto de $\mathrm{I}+\mathrm{D}+\mathrm{i}$, pues estos aspectos, a la par que los administrativos, se consideran de base en la actividad laboral de los investigadores. Se trata de actividades de soporte, que aunque sustentan las actividades de $\mathrm{I}+\mathrm{D}+\mathrm{i}$ del Centro Tecnológico, no son propiamente dichas actividades, que son quienes constituyen el valor y la sostenibilidad del mismo.

Establezcamos, seguidamente, los aspectos necesarios para dar lugar a la formulación referida.

\section{VI.2. Relación Matemática entre Entropía, Información e Indicadores del Aprendizaje Organizativo}

Partiendo de las ecuaciones (8) y (9) del apartado IV.4, vamos a reformar las mismas de modo que tenga cabida en ellas la información que en sí constituyen los indicadores que se describirán en los apartados venideros, pues parten de la consideración de datos

\footnotetext{
${ }^{102}$ Existen medidas estadísticas que ayudan a visualizar alrededor de qué valores se distribuyen las observaciones de un suceso dado. Son las llamadas medidas de centralización. Entre ellas, destacan la media (valor medio) y la mediana. Las magnitudes a considerar en la valoración entrópica del Aprendizaje Organizativo van a ser analizadas en un período de evaluación que no permite obtener un gran número de datos para ellas. Unido, este aspecto, a su carácter aleatorio (fluctuaciones de valor), hace que no conformen ninguna distribución determinada. La mediana no es sensible a los posibles cambios bruscos en tales magnitudes, por lo que se toma como bastante buena aproximación para su estudio a la media (calculada como media aritmética), por ser el valor intermedio típico de una distribución de valores numéricos a lo largo de $T_{\text {Evaluación. }}$.
} 
registrados y analizados en el seno del Centro Tecnológico (confidenciales o no), en referencia a un hecho determinado sobre el que se interroga (suceso).

Así, para los indicadores internos, es conocido que la expresión necesaria para valorar entrópicamente el Aprendizaje Organizativo es:

$$
S_{\mathrm{int}}=-\sum_{j=1}^{\Omega_{\text {int }}} i_{j} \cdot \ln i_{j} ; \quad \sum_{j=1}^{\Omega_{\text {int }}} i_{j}=1
$$

En donde $i_{j}$, con $j=1, \ldots, \Omega_{i n t}$, marca la distribución de pesos normalizados de los $\Omega_{i n t}$ indicadores independientes que caracterizan dicho aprendizaje.

Ya fue establecida en el apartado IV.2 la equivalencia entre información y negaentropía, o, simétricamente, entre entropía y negainformación (en cualquier caso se indica la oposición de signo entre ambas magnitudes). De modo general, se define la información asociada a un suceso $s_{k}$ [Brillouin-1960; Denbigh y Denbigh-1985], como:

$$
I\left(s_{k}\right)=\ln \left(\frac{1}{p_{k}}\right)=-\ln p_{k}
$$

Donde: $p_{k}$ es la probabilidad de ocurrencia del suceso $s_{k}$. La información $I\left(s_{k}\right)$ tiene las propiedades que a continuación se detallan:

- $I\left(s_{k}\right) \geq 0$, ya que $0 \leq p_{k} \leq 1 \forall k$ : un suceso podrá aportar ninguna, alguna o mucha información, pero nunca supondrá una pérdida de la misma.

- $I\left(s_{k}\right)=0$ para $p_{k}=1$ : si sabemos de antemano que el suceso $s_{k}$ va a ocurrir con toda seguridad, éste no aporta información.

- $I\left(s_{k}\right)<I\left(s_{k}\right)$ para $p_{k}>p_{k}, \forall k, k^{\prime}$, es decir, a mayor sorpresa (menor probabilidad de ocurrencia), mayor información. 
- $I\left(s_{k} \cdot s_{k}\right)=I\left(s_{k}\right)+I\left(s_{k}\right), \quad \forall k, k^{\prime}:$ la información aportada por dos sucesos concatenados es la suma de las informaciones de cada uno de esos sucesos.

Aplicando el concepto de información a la expresión de $S_{\text {int }}$, para el caso de los indicadores internos, resulta:

$$
S_{\mathrm{int}}=\sum_{j=1}^{\Omega_{\mathrm{int}}} i_{j} \cdot I\left(s_{i_{j}}\right) ; \quad \sum_{j=1}^{\Omega_{\mathrm{int}}} i_{j}=1
$$

En esta expresión, la información $I\left(s_{i_{j}}\right)$ constituye el indicador interno propiamente dicho (correspondiente al hecho examinado $s_{i_{j}}$ ), cuyo peso es $i_{j} \in \mathfrak{R}$. Estos pesos se establecerán teniendo en cuenta la ecuación (13).

Los indicadores internos tienen a su vez la siguiente expresión:

$$
I\left(s_{i_{j}}\right)=\sum_{u} p_{j u} \cdot m_{j u} ; \quad \sum_{u} p_{j u}=1 \quad \forall j=1, \ldots, \Omega_{\mathrm{int}}
$$

Donde: $p_{j u}, m_{j u} \in \Re$ son, respectivamente, el peso (sigla $p$ ) y la medida (sigla $m$ ) del factor $u$-ésimo constitutivo del indicador interno $j$. Los pesos $p_{j u}$ se establecerán de

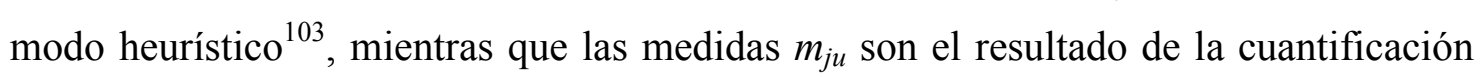
correspondiente a cada uno de $\operatorname{los} u$ factores integrantes del indicador $j$ tratado.

103 Combinando las expresiones (13), (14) y (15) puede pensarse inicialmente en la resolución de un sistema de ecuaciones lineales que nos permitiera deducir directamente, y no de modo heurístico, los pesos $p_{j u}$ y/o los $i_{j}$, aplicando el teorema de Rouché-Frobenius (y si el sistema resultara compatible, reducirlo a un sistema de Cramer) [González y Villanova-1987].

Este hecho no es factible, pues las ecuaciones constituyentes del sistema planteado no poseen incógnitas equivalentes, es decir:

$$
p_{j u} \neq p_{(j+1) u} \forall u \text { con: } p_{j u} \in I\left(s_{i_{j}}\right) ; p_{(j+1) u} \in I\left(s_{i_{j+1}}\right) \forall j
$$

Este razonamiento es, también, aplicable en el caso de los indicadores externos. 
Procediendo de modo análogo con los indicadores externos, la expresión necesaria para valorar entrópicamente el Aprendizaje Organizativo es:

$$
S_{\text {ext }}=\sum_{j=1}^{\Omega_{\text {ext }}} e_{j} \cdot I\left(s_{e_{j}}\right) ; \quad \sum_{j=1}^{\Omega_{\text {ext }}} e_{j}=1
$$

En donde $e_{j}$, con $j=1, \ldots, \Omega_{\text {ext }}$, marca la distribución de pesos normalizados de los $\Omega_{\text {ext }}$ indicadores independientes $I\left(s_{e_{j}}\right)$ que caracterizan el referido aprendizaje (correspondientes a los sucesos $s_{e_{j}}$ ). Los pesos señalados se determinarán siguiendo la ecuación (13). Por su parte, los indicadores externos vienen dados por la expresión:

$$
I\left(s_{e_{j}}\right)=\sum_{v} p_{j v}^{\prime} \cdot m_{j v}^{\prime} ; \quad \sum_{v} p_{j v}^{\prime}=1 \quad \forall j=1, \ldots, \Omega_{e x t}
$$

Donde: $p^{\prime}{ }_{j v}, m^{\prime}{ }_{j v} \in \Re$ son, respectivamente, el peso y la medida del factor $v$-ésimo constitutivo del indicador $j$ conveniente. De modo equivalente a los indicadores internos, para los externos, también los pesos $p_{j v}{ }_{j v}$ se establecerán de modo heurístico, mientras que las medidas $m_{j v}$ son el resultado de la cuantificación correspondiente a cada uno de $\operatorname{los} v$ factores constitutivos del indicador externo $j$ tratado.

\section{VI.3. Indicadores Internos para el Aprendizaje Organizativo en los Centros Tecnológicos}

De acuerdo a las consideraciones del apartado V.1, sabemos que en sus vertientes individual y grupal, en el Aprendizaje Organizativo de un Centro Tecnológico confluyen determinados aspectos que favorecen el mismo intra-organizacionalmente.

En el presente apartado establecemos los indicadores cuantificables para estimar el Aprendizaje Organizativo a nivel interno [III PRICIT-2000; JUNTA DE CASTILLA Y LEÓN-2002b; PCTI-2002; COMISIÓN EUROPEA-2002b, 2003c, 2003d; COTEC- 
2003; IV PRICIT-2004]: especialización de actividades; capacidad para la I+D+i; infraestructuras y equipamientos que favorecen la creación de conocimiento; clima interno; $y$, eficacia y productividad.

\section{VI.3.1. Especialización de Actividades}

Se determina en función de las áreas tecnológicas directamente relacionadas con las actividades industriales $\frac{104}{1}$ clave de cada entorno donde el Centro desarrolle su labor, así como su grado de concreción:

1.1. Proporción de actividades industriales de carácter estratégico a nivel autonómico, con representatividad en áreas tecnológicas del Centro con aplicación en $\mathrm{I}+\mathrm{D}+\mathrm{i}$.

1.2. Proporción de actividades industriales de carácter estratégico a escala nacional con representatividad en áreas tecnológicas del Centro con aplicación en $\mathrm{I}+\mathrm{D}+\mathrm{i}$.

1.3. Proporción de actividades industriales de carácter estratégico a nivel internacional $\frac{106}{,}$ con representatividad en áreas tecnológicas del Centro con aplicación en $\mathrm{I}+\mathrm{D}+\mathrm{i}$.

1.4. Número de proyectos de $\mathrm{I}+\mathrm{D}+\mathrm{i}$ con, al menos, una cuarta parte de doctores dedicados que trabajan en el Centro, sobre el total de proyectos del mismo.

La calificación y número de las actividades industriales estratégicas según marco geográfico se encuentra en las memorias económicas y análisis sectoriales que

\footnotetext{
${ }^{104}$ Estrictamente hablando, los Centros Tecnológicos desarrollan tareas de $\mathrm{I}+\mathrm{D}+\mathrm{i}$ para todos los sectores económicos (primario, secundario y terciario), y no sólo para el sector industrial de cada ámbito geográfico de operación. Sin embargo, su orientación hacia el aumento de la competitividad y competencia de las empresas, hace que las labores de $\mathrm{I}+\mathrm{D}+\mathrm{i}$, así como las subvenciones económicas para las mismas, se focalicen en el sector industrial en su práctica totalidad.

${ }^{105}$ Exceptuándose, en este contexto, aquellas actividades vinculadas, exclusivamente, a Castilla y León.

${ }^{106}$ Entendida como aquélla que excede los límites del estado Español. Los entornos de la UE, EE.UU y Japón, por orden decreciente de importancia para la posibilidad de ejecución conjunta de tareas de $\mathrm{I}+\mathrm{D}+\mathrm{i}$, son los de mayor transcendencia. Para los Centros Tecnológicos de Castilla y León, tal entorno se reduce, prácticamente, a la UE.
} 
periódicamente edita la Administración correspondiente. De este modo, los factores 1.1, 1.2 y 1.3 dan idea del abanico de actividades de $\mathrm{I}+\mathrm{D}+\mathrm{i}$ a que potencialmente puede acceder un Centro Tecnológico. No obstante, esto puede suponer que se pretenda cubrir un amplio espectro, sin profundización concreta en ninguna de ellas, o inclusive, obtener pobres resultados en las mismas.

Esta salvedad se compensa con la consideración del factor 1.4, que informa de que, aparte de hacer llegar el Centro Tecnológico sus servicios a un número más o menos amplio de actividades industriales, existe especialización por su parte. El hecho de tener en cuenta un mínimo del $25 \%$ de investigadores doctores en los proyectos de $\mathrm{I}+\mathrm{D}+\mathrm{i}$ a que hace referencia, implica una cifra significativa de personal de alta cualificación que redunde en peso y calidad tanto para los proyectos, como para los resultados que de ellos se obtengan. Además, del factor 1.4 puede deducirse, indirectamente, no sólo el grado de colaboración entre las distintas áreas tecnológicas internas (por llevar adelante proyectos de finalidad común), sino su orientación científica y/o técnica.

Para establecer los pesos referentes a los factores expuestos, partimos de la ecuación (15), teniendo en cuenta que para el indicador "especialización de actividades" que nos ocupa: $j=1 ; u=1, \ldots, 4$. De este modo: $m_{11}=$ medida del factor $1.1 ; m_{12}=$ medida del factor $1.2 ; m_{13}=$ medida del factor $1.3 ; m_{14}=$ medida del factor 1.4 , con pesos respectivos: $p_{11}, p_{12}, p_{13}, p_{14}$

Se considera un bloque compuesto por los factores 1.1 a 1.3, y separadamente el factor 1.4, dándose las siguientes relaciones:

$$
\left.\begin{array}{l}
p_{11}+p_{12}+p_{13}+p_{14}=1 \\
p_{12}+p_{13}=\frac{1}{4} p_{11} \\
p_{12}=p_{13} \\
p_{11}+p_{12}+p_{13}=\frac{1}{2} p_{14}
\end{array}\right\}
$$

La primera de las ecuaciones del sistema planteado deriva, directamente, de la consideración de la ecuación (15). La segunda, hace hincapié en la especial incidencia 
del tejido industrial de Castilla y León en las áreas tecnológicas del Centro. La tercera ecuación indica la igual significación que para el Centro Tecnológico tienen los sectores industriales nacional y europeo. Finalmente, la cuarta, marca la relevancia de la especialización y cualificación de su personal.

Del sistema formado por las ecuaciones (18) se deducen los siguientes pesos:

$$
p_{11}=\frac{4}{15} ; \quad p_{12}=p_{13}=\frac{1}{30} ; \quad p_{14}=\frac{2}{3}
$$

Con lo que, compendiando con la ecuación (15), el indicador "especialización de actividades" viene dado por la expresión:

$$
I\left(s_{i_{1}}\right)=\sum_{u=1}^{4} p_{1 u} \cdot m_{1 u}=\frac{4}{15} m_{11}+\frac{1}{30} m_{12}+\frac{1}{30} m_{13}+\frac{2}{3} m_{14}
$$

\section{VI.3.2. Capacidad para la I+D+i}

Este parámetro evalúa la vocación de los Centros Tecnológicos para con la $\mathrm{I}+\mathrm{D}+\mathrm{i}$. Teniendo en cuenta que valorar organizaciones no es lo mismo que valorar sus actividades, este indicador permite evaluar la calidad de los recursos humanos, su dedicación real a actividades de $\mathrm{I}+\mathrm{D}+\mathrm{i}$, y el grado de cumplimiento de compromisos con los clientes de proyectos de $\mathrm{I}+\mathrm{D}+\mathrm{i}$.

Otros aspectos relacionados con la calidad del Centro en $\mathrm{I}+\mathrm{D}+\mathrm{i}$, como la producción y transferencia de conocimiento (publicaciones, servicios de apoyo a la innovación, etc.), o su orientación al mercado, se consideran externos para el Aprendizaje Organizativo y serán abordados con posterioridad. De este modo, se toman en cuenta los siguientes factores:

2.1. Proporción de investigadores sobre el total de la plantilla del Centro. 
2.2. Proporción de investigadores con titulación superior, sobre el total de ingenieros de $\mathrm{I}+\mathrm{D}+\mathrm{i}$.

2.3. Proporción de investigadores con titulación superior que han completado cursos de doctorado y han obtenido la suficiencia investigadora o diploma de estudios avanzados, sobre total de titulados superiores.

2.4. Proporción de investigadores en posesión del título de Doctor, sobre el total de investigadores con suficiencia investigadora o diploma de estudios avanzados.

2.5. Proporción temporal invertida por los investigadores en labores no relacionadas con actividades directas de $\mathrm{I}+\mathrm{D}+\mathrm{i}$. Este factor tiene signo negativo respecto al resto del presente indicador.

2.6. Gastos en $\mathrm{I}+\mathrm{D}$ genérica ${ }^{107}$ sobre gasto total en proyectos de $\mathrm{I}+\mathrm{D}$ (autonómicos, nacionales e internacionales).

2.7. Proporción de proyectos de $\mathrm{I}+\mathrm{D}+\mathrm{i}$ obtenidos por seguimiento científico, vigilancia y prospectiva tecnológica, sobre el total de proyectos.

2.8. Proporción de proyectos, sobre el total de ellos, terminados en el plazo establecido con aceptación de la entrega del nuevo producto, proceso o tecnología por parte del cliente.

Obsérvese la consideración de proporciones relativas, y no absolutas (sobre la totalidad de la plantilla del Centro Tecnológico) de los factores 2.1 a 2.4, pues de este modo se tiene una valoración objetiva de la distribución del personal dedicado a $\mathrm{I}+\mathrm{D}+\mathrm{i}$, e incluso poderse proceder a su comparación con Centros equivalentes. Obviamente, la inversión en recursos humanos de esta índole es un factor crucial en el sostenimiento del Centro Tecnológico y la generación de competitividad en las empresas a quien se presta

${ }^{107}$ Se consideran proyectos genéricos aquellos que derivan directamente de las líneas estratégicas de I+D del Centro Tecnológico. Sus resultados no rinden cuentas ante ninguna empresa, y reciben algún tipo de financiación pública para su ejecución. 
servicio. Alcanzar un buen grado de desarrollo profesional en los ingenieros de $\mathrm{I}+\mathrm{D}+\mathrm{i}$, en el sentido de alta calidad y relevancia en su labor, es un proceso lento, pero que, a medio plazo, revierte en claros beneficios, no ya sólo para el Centro Tecnológico y sus clientes, sino para la sociedad en conjunto. Un Centro Tecnológico debe dar lugar a buenos investigadores como garantía de futuro de la región o país donde se encuentre. En este sentido, son de especial consideración los Doctores. Por ello, centrándonos en el factor 2.4, y teniendo en cuenta a la COMISIÓN EUROPEA [2001], se consideran Doctores en ciencia y tecnología a aquellos que hayan realizado sus Tesis Doctorales en las siguientes disciplinas: Matemáticas y Estadística, Física, Ingeniería, Informática, Arquitectura, Biología y Química.

Los becarios y el personal que realiza estancias temporales para labores no vinculadas directamente con proyectos de $\mathrm{I}+\mathrm{D}+\mathrm{i}$ del Centro Tecnológico no son tenidos en cuenta en este indicador (véase apartado III.4).

En cuanto al factor 2.5, diremos que la unidad administrativa de todo Centro Tecnológico suele llevar un conteo de las horas empleadas por cada investigador en las ocupaciones en que se ve involucrado, de cara a la contabilidad de sus actividades. De este modo, puede deducirse la proporción apuntada por este factor, siendo obvia su contrariedad de signo respecto al resto.

El factor 2.7 es directamente deducible de los registros que supone la implantación de la norma ISO 166002:2002 EX en el Centro Tecnológico (si éste adopta la misma). En caso contrario, será el jefe de proyecto quien determine si las labores de $\mathrm{I}+\mathrm{D}+\mathrm{i}$ desarrolladas son consecuencia de algún aspecto de los que da cuenta este factor.

Por otra parte, de los factores establecidos para este indicador, de modo indirecto, y por diferencia de los valores obtenidos correspondientes a un cierto intervalo temporal, pueden deducirse otros aspectos importantes, tales como la variación en el número de investigadores (factor 2.1), el número de Tesis Doctorales presentadas (factor 2.4) y la mejora en tiempos/plazos de ejecución de proyectos de $\mathrm{I}+\mathrm{D}+\mathrm{i}$ (factor 2.8). 
Para determinar los pesos referentes a los factores expuestos, partimos de la ecuación (15), teniendo en cuenta que, para el indicador "capacidad para la $\mathrm{I}+\mathrm{D}+\mathrm{i}$ " que nos ocupa: $j=2 ; u=1, \ldots, 8$. De este modo: $m_{21}=$ medida del factor $2.1 ; m_{22}=$ medida del factor $2.2 ; m_{23}=$ medida del factor $2.3 ; m_{24}=$ medida del factor $2.4 ; m_{25}=$ medida del factor $2.5 ; m_{26}=$ medida del factor $2.6 ; m_{27}=$ medida del factor $2.7 ; m_{28}=$ medida del factor 2.8 , con pesos respectivos: $p_{21}, p_{22}, p_{23}, p_{24}, p_{25}, p_{26}, p_{27}, p_{28}$.

Se considera un bloque compuesto por los factores 2.1 a 2.4, y los restantes de forma separada, dándose las siguientes relaciones:

$$
\left.\begin{array}{l}
p_{21}+p_{22}+p_{23}+p_{24}+p_{25}+p_{26}+p_{27}+p_{28}=1 \\
p_{21}+p_{22}+p_{23}+p_{24}=p_{25}+p_{26}+p_{27}+p_{28} \\
p_{22}=2 p_{21} \\
p_{23}=2 p_{22}=4 p_{21} \\
p_{24}=2 p_{23}=8 p_{21} \\
p_{25}=p_{26}=p_{27}=p_{28}
\end{array}\right\}
$$

La primera de las ecuaciones del sistema planteado es consecuencia directa de la ecuación (15). La segunda implica la igual significación que para el Centro Tecnológico tiene la cualificación de su personal y la dedicación a labores de $\mathrm{I}+\mathrm{D}+\mathrm{i}$ genéricas y de implantación real. La gradación en importancia de la cualificación de los investigadores se da mediante una progresión geométrica de razón dos en la tercera, cuarta y quinta ecuaciones. Para concluir, la sexta ecuación comporta la igual significación de los factores que no conforman el bloque anteriormente aludido.

Del sistema formado por las ecuaciones (20) resultan los siguientes valores:

$$
p_{21}=\frac{1}{30} ; \quad p_{22}=\frac{1}{15} ; \quad p_{23}=\frac{2}{15} ; \quad p_{24}=\frac{4}{15} ; \quad p_{25}=p_{26}=p_{27}=p_{28}=\frac{1}{8}
$$

Y compendiando con la ecuación (15), el indicador “capacidad para la $\mathrm{I}+\mathrm{D}+\mathrm{i}$ ” viene dado por la siguiente expresión: 


$$
\begin{aligned}
& I\left(s_{i_{2}}\right)=\sum_{u=1}^{8} p_{2 u} \cdot m_{2 u}= \\
& =\frac{1}{30} m_{21}+\frac{1}{15} m_{22}+\frac{2}{15} m_{23}+\frac{4}{15} m_{24}-\frac{1}{8} m_{25}+\frac{1}{8} m_{26}+\frac{1}{8} m_{27}+\frac{1}{8} m_{28}
\end{aligned}
$$

En ella, se observa el signo contrario del factor 2.5 .

\section{VI.3.3. Infraestructuras y Equipamientos que Favorecen la Creación de Conocimiento}

Este indicador da cuenta del esfuerzo inversor en productos, procesos, modificaciones y ampliaciones estructurales que permiten un mejor desarrollo y mayor rendimiento en la consecución de los objetivos derivados de las actividades de $\mathrm{I}+\mathrm{D}+\mathrm{i}$ del Centro Tecnológico. Destacamos dos factores, en este sentido:

3.1. Proporción de inversiones en tecnologías de la información y las comunicaciones sobre total de inversiones del Centro: se recogen tanto la inversión en hardware como software, así como los gastos derivados del mantenimiento y actualización de los mismos (por ejemplo nuevos equipos, renovación de vigencias temporales de programas informáticos, actualización de licencias, etc.).

3.2. Proporción de inversiones en acondicionamiento y ampliación estructural sobre total de inversiones del Centro (por ejemplo reformas de instalaciones, nuevos laboratorios, etc.).

En ningún caso se considerarán como gastos imputables a cualquiera de estos dos factores los costes indirectos, ni los derivados de la adquisición de bienes y servicios encaminados al normal funcionamiento de los equipos e instalaciones existentes, pues se trata de desembolsos per se, admitidos por el Centro Tecnológico para llevar a cabo su actividad habitual.

Por otra parte, se supone que todos los investigadores tienen fácil acceso y hacen uso habitual del correo electrónico e Internet. 
Para dar lugar a los pesos referentes a los dos factores expuestos, partimos de la ecuación (15), teniendo en cuenta que para este indicador: $j=3 ; u=1,2$. De este modo: $m_{31}=$ medida del factor $3.1 ; m_{32}=$ medida del factor 3.2 , con pesos respectivos: $p_{31}, p_{32}$. Se establece, así, una única relación:

$$
p_{31}+p_{32}=1
$$

Y otorgando la misma importancia a los dos factores constitutivos de este indicador, resulta:

$$
p_{31}=p_{32}=\frac{1}{2}
$$

Con lo que, compendiando con la ecuación (15), el indicador "infraestructuras y equipamientos que favorecen la creación de conocimiento" tiene la siguiente expresión:

$$
I\left(s_{i_{3}}\right)=\frac{1}{2} m_{31}+\frac{1}{2} m_{32}
$$

\section{VI.3.4. Clima Interno}

Este indicador recoge la valoración del ambiente laboral del Centro Tecnológico, tomada como el resultado de la encuesta de satisfacción de su personal investigador (sobre puntuación máxima).

La utilización de un factor como éste, cuya consideración es necesaria, pero cuya cuantificación (resultado de dicha encuesta) puede no resultar objetiva, queda justificada por no existir alternativa plausible de evaluación al respecto.

Teniendo en cuenta la ecuación (15), en este caso: $j=4 ; u=1$. Aquí: $m_{41}$ es la medida que nos marca el resultado de la encuesta apuntada y $p_{41}=1$ es su peso respectivo. De este modo, el indicador que nos ocupa viene dado por: 


$$
I\left(s_{i_{4}}\right)=m_{41}
$$

\section{VI.3.5. Eficacia y Productividad}

Barema la relación entre el esfuerzo inversor de las Administraciones Públicas (autonómicas, estatales e internacionales) en el Centro Tecnológico y su transferencia al entorno productivo, hecho que depende de la actitud, aptitud y rendimiento que subyacen en aquél. Consideramos los siguientes factores:

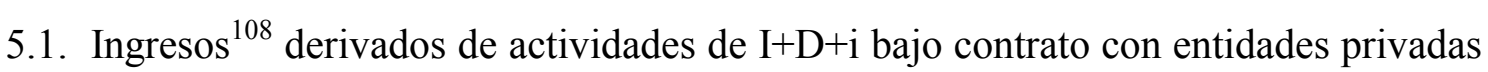
en el ámbito autonómico, sobre ingresos obtenidos por via de la Administración autonómica.

5.2. Ingresos derivados de actividades de $\mathrm{I}+\mathrm{D}+\mathrm{i}$ bajo contrato con entidades privadas en el ámbito nacional, sobre ingresos obtenidos por medio de la Administración General del Estado (AGE).

5.3. Ingresos derivados de actividades de $\mathrm{I}+\mathrm{D}+\mathrm{i}$ bajo contrato con entidades privadas en el ámbito internacional, sobre ingresos obtenidos por via de la Administración supranacional oportuna.

${ }^{108}$ Los fondos de un Centro Tecnológico provienen de dos fuentes: aporte privado y aporte público. El primero implica la participación directa de capital de una organización privada que demanda servicios de $\mathrm{I}+\mathrm{D}+\mathrm{i}$ de dicho Centro.

A su vez, el aporte público proviene de dos vías:

- Participación en programas competitivos: promovidos por organizaciones públicas (autonómicas, nacionales o internacionales), bajo los que compite con otras entidades para la obtención de los fondos que comportan.

- Participación en programas no competitivos: suponen una retribución directa al Centro Tecnológico por organizaciones públicas (autonómicas, nacionales o internacionales), debido a la afinidad de sus labores y funciones con las políticas de apoyo a la $\mathrm{I}+\mathrm{D}+\mathrm{i}$ elaboradas por esas organizaciones. Estas subvenciones fluctúan en el tiempo, instrumentándose mediante convenios entre el Centro Tecnológico y la Administración pública oportuna.

Cabe reseñar que las ayudas económicas para infraestructuras quedan englobadas tanto en los programas competitivos, como en los no competitivos. 
5.4. Cargo de la subcontratación por el Centro Tecnológico en sus labores de $\mathrm{I}+\mathrm{D}+\mathrm{i}$ sobre los ingresos totales (en todos los ámbitos de actuación). Este factor tiene signo contrario a los anteriores.

Tomando en consideración los factores 5.1, 5.2 y 5.3 para este indicador, se puede evaluar de modo indirecto, entre dos cotas temporales, la percepción autonómica, nacional e internacional del Centro Tecnológico como lugar favorable para el desarrollo de la ciencia y la tecnología (crece, o, como mínimo, se estabiliza, la proporción indicada por dichos factores). Por otra parte, y siguiendo la misma metodología de deducción indirecta, pueden tenerse en cuenta los gastos derivados de actividades de $\mathrm{I}+\mathrm{D}+\mathrm{i}$, y no los ingresos equivalentes considerados en esos mismos factores, para determinar la reducción de costes de ejecución de labores de $\mathrm{I}+\mathrm{D}+\mathrm{i}$ de implantación industrial real (por mejoras, optimizaciones, eficiencia energética, etc.), estabilizándose o disminuyendo la proporción a indicar en ese caso.

Igualmente, considerando los tipos de ingresos involucrados en los factores 5.1, $5.2 \mathrm{y}$ 5.3, se da cuenta de la dimensión del Centro Tecnológico (facturación en $€$ ). Así, se ofrece una idea de su competencia y competitividad en comparación con otros equivalentes en el mismo ámbito de actuación geográfico.

Es destacable que aunque no existe una metodología óptima de financiación mixta (pública y privada) de las actividades de $\mathrm{I}+\mathrm{D}+\mathrm{i}$ de un Centro Tecnológico, ocurre que las financiadas con fondos públicos afectan a las financiadas por fondos privados y viceversa. De hecho, es altamente improbable que la aportación de fondos privados, considerada de modo aislado, sufra un aumento significativo. Se ha de prestar atención a los vínculos entre la financiación pública y los incentivos existentes para la financiación privada. Si estos incentivos son acordes a la realidad y están correctamente implantados, pueden servir de resorte para que los inversores privados participen tanto como tales, como incluso de propios ejecutores de actividades de $\mathrm{I}+\mathrm{D}+\mathrm{i}$ de alta calidad.

En cuanto al factor 5.4, el que un Centro Tecnológico tenga que contratar determinadas labores que no le competen, y que son más propias de una empresa, no es algo desfavorable en sí para él, pues indica con ello que se está dedicado a sus quehaceres. 
De cualquier manera, la subcontratación supone un desembolso económico para el Centro Tecnológico (de ahí su carácter negativo frente al resto), por lo general siempre superior al inicialmente estipulado, debido al riesgo inherente de las tareas de $\mathrm{I}+\mathrm{D}+\mathrm{i}$ en la obtención de resultados.

Para establecer la heurística de los pesos referentes a los cuatro factores expuestos para el indicador que nos ocupa, partimos de la ecuación (15) y se tiene en cuenta que: $j=5$; $u=1, \ldots, 4$. De esta manera: $m_{51}=$ medida del factor $5.1 ; m_{52}=$ medida del factor 5.2; $m_{53}=$ medida del factor $5.3 ; m_{54}=$ medida del factor 5.4 , con pesos respectivos: $p_{51}, p_{52}$, $p_{53,} p_{54 .}$

Se considera un bloque compuesto por los factores 5.1 a 5.3, y separadamente el factor 5.4, estableciéndose las siguientes relaciones:

$$
\left.\begin{array}{l}
p_{51}+p_{52}+p_{53}+p_{54}=1 \\
p_{51}=\frac{4}{5}\left(p_{51}+p_{52}+p_{53}\right) \\
p_{52}=p_{53} \\
p_{54}=\frac{1}{3}\left(p_{51}+p_{52}+p_{53}\right)
\end{array}\right\}
$$

La primera de las ecuaciones del sistema planteado deriva, directamente, de la consideración de la ecuación (15). La segunda refleja la característica incidencia económica de las actividades de $\mathrm{I}+\mathrm{D}+\mathrm{i}$ del Centro en el ámbito de la Comunidad Autónoma donde se asienta y, en menor medida, en los ámbitos nacional y europeo. La tercera indica que, para el Centro Tecnológico, los sectores industriales nacional y europeo tienen la misma repercusión. La última ecuación establece un límite superior admisible para los gastos de subcontratación del Centro.

Del sistema formado por las ecuaciones (25) se deducen, entonces, los siguientes pesos:

$$
p_{51}=\frac{3}{5} ; \quad p_{52}=p_{53}=\frac{3}{40} ; \quad p_{54}=\frac{1}{4}
$$


Con lo que, compendiando con la ecuación (15), el indicador "eficacia y productividad" viene dado por la siguiente expresión, en la que se observa el signo contrario del factor 5.4:

$$
I\left(s_{i_{5}}\right)=\sum_{u=1}^{4} p_{5 u} \cdot m_{5 u}=\frac{3}{5} m_{51}+\frac{3}{40} m_{52}+\frac{3}{40} m_{53}-\frac{1}{4} m_{54}
$$

\section{VI.4. Indicadores Externos para el Aprendizaje Organizativo en los Centros Tecnológicos}

Como en el caso de los indicadores internos, y de acuerdo a las consideraciones del apartado V.1, coexiste contribución al Aprendizaje Organizativo de un Centro Tecnológico por la interacción de éste con el entorno exterior en que opera, tanto en su vertiente individual, como grupal.

Seguidamente se exponen los indicadores medibles que permiten valorar la influencia externa en el Aprendizaje Organizativo [III PRICIT-2000; JUNTA DE CASTILLA Y LEÓN-2002b; PCTI-2002; COMISIÓN EUROPEA-2002b, 2003b, 2003c，2003d; CORDIS-2003; COTEC-2004a; IV PRICIT-2004]: conectividad y proyección; intensidad de innovación; acciones formativas relacionadas con $\mathrm{I}+\mathrm{D}+\mathrm{i}$; orientación al mercado; impacto científico-técnico; e, impacto industrial.

\section{VI.4.1. Conectividad y Proyección}

Dentro de la esfera de actuación del Centro Tecnológico, se estima su nivel de excelencia y capacidad de penetración en el conocimiento global 109 en función de los siguientes factores:

\footnotetext{
${ }^{109}$ Según Husso, Karjalainen y Parkkari [2000], el impacto de toda actividad de I+D+i se refleja en cuatro aspectos: impacto científico (acumulación y renovación de conocimiento); impacto tecnológico (nuevas soluciones, productos y procesos); impacto social (bienestar, salud, cultura, territorialidad, política y organización) e impacto económico.
} 
1.1. Proporción de acuerdos de colaboración estables firmados con otros centros y organizaciones autonómicas, sobre el total de acuerdos.

1.2. Proporción de acuerdos de colaboración estables firmados con centros y organizaciones de referencia ${ }^{110}$ nacional, sobre el total de acuerdos.

1.3. Proporción de acuerdos de colaboración estables firmados con centros $y$ organizaciones de referencia internacional, sobre el total de acuerdos.

1.4. Proporción de acuerdos de pertenencia a redes de investigación o de excelencia internacionales, sobre el total de acuerdos.

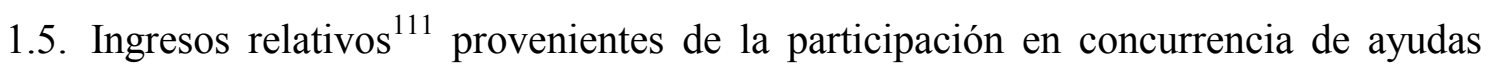
públicas autonómicas, tanto en programas competitivos como no competitivos.

1.6. Ingresos relativos provenientes de la participación en concurrencia en programas nacionales competitivos y no competitivos (Planes Nacionales de $\mathrm{I}+\mathrm{D}+\mathrm{i}$ ).

1.7. Ingresos relativos provenientes de la participación en concurrencia en programas internacionales competitivos y no competitivos (Programas Marco de la Unión Europea, Iniciativas Comunitarias y otro tipo de programas).

1.8. Número de investigadores pertenecientes a comités de expertos, o llamados puntual o permanentemente como profesores universitarios, a comités editoriales, revisores de publicaciones científico-técnicas, o asesores en materia de $\mathrm{I}+\mathrm{D}+\mathrm{i}$ en foros científico-técnicos o empresariales autonómicos (políticos o no), sobre el total de investigadores del Centro Tecnológico.

\footnotetext{
${ }^{110}$ Las entidades de referencia son aquellas que destacan por su brillantez y repercusión en su ocupación y/o demanda de tareas de $\mathrm{I}+\mathrm{D}+\mathrm{i}$, según el ámbito geográfico donde operen.

${ }^{111}$ Están calculados sobre el total de ingresos obtenidos por el Centro Tecnológico.

${ }^{112}$ En dichos planes (el actual es el quinto y comprende el período 2004-2007), se integran las ayudas del Centro para el Desarrollo Tecnológico Industrial (CDTI).
} 
1.9. Número de investigadores pertenecientes a comités de expertos, o llamados puntual o permanentemente como profesores universitarios, a comités editoriales, revisores de publicaciones científico-técnicas, asesores en materia de $\mathrm{I}+\mathrm{D}+\mathrm{i}$ en foros científico-técnicos o empresariales nacionales (políticos o no), o evaluadores de la Agencia Nacional de Evaluación y Prospectiva (ANEP 13 , sobre el total de investigadores del Centro Tecnológico.

1.10.Número de investigadores pertenecientes a comités de expertos, o llamados puntual o permanentemente como profesores universitarios, comités editoriales, revisores de publicaciones científico-técnicas, evaluadores de programas marco (o alternativos), $\mathrm{o}$ asesores en materia de $\mathrm{I}+\mathrm{D}+\mathrm{i}$ en foros científico-técnicos $\mathrm{o}$ empresariales internacionales (políticos o no), sobre el total de investigadores del Centro Tecnológico.

1.11.Proporción de investigadores del Centro cedidos temporal o indefinidamente a grupos científico-técnicos y/o empresas autonómicas por proyectos de $\mathrm{I}+\mathrm{D}+\mathrm{i}$ en los que ejercen su actividad laboral, sobre el total de los mismos.

1.12.Proporción de investigadores del Centro cedidos temporal o indefinidamente a grupos científico-técnicos y/o empresas nacionales por proyectos de $\mathrm{I}+\mathrm{D}+\mathrm{i}$ en los que ejercen su actividad laboral, sobre el total de los mismos.

1.13.Proporción de investigadores del Centro cedidos temporal o indefinidamente a grupos científico-técnicos y/o empresas internacionales por proyectos de $\mathrm{I}+\mathrm{D}+\mathrm{i}$ en los que ejercen su actividad laboral, sobre el total de los mismos.

1.14.Proporción de investigadores del Centro que abandonan el mismo y se incorporan a empresas $\mathrm{u}$ organismos donde no van a realizar tareas de $\mathrm{I}+\mathrm{D}+\mathrm{i}$, sobre el total de los mismos. Este factor tiene signo negativo respecto a los anteriores.

\footnotetext{
${ }^{113}$ Unidad dependiente de la Secretaría de Estado de Universidades e Investigación, del Ministerio de Educación y Ciencia Español.
} 
Los centros y organizaciones referidos en los factores $1.1,1.2$ y 1.3 son aquellos que van a permitir, o para los que se va a realizar alguna actividad de $\mathrm{I}+\mathrm{D}+\mathrm{i}$ (universidades, empresas, etc.). En el caso concreto del factor 1.1, se considerarán todos los posibles organismos en este sentido, por el simple hecho de ser Castilla y León el marco básico donde mayormente repercuten y se desarrollan las actividades de $\mathrm{I}+\mathrm{D}+\mathrm{i}$ del Centro. En cambio, para los factores 1.2 y 1.3 se habla de centros y organizaciones de referencia, debido a que la penetración en el conocimiento global es tanto más acusada cuanto más significativa es la organización para la que se trabaje. Claramente, no existe ningún baremo nacional ni internacional que catalogue de "organismo de referencia" a todos aquellas entidades involucradas en la $\mathrm{I}+\mathrm{D}+\mathrm{i}$. Para dar lugar a una escala en este sentido, debería recurrirse a metodologías como la evaluación por pares (peer review en la literatura anglosajona) u otras adecuadas para determinar su grado de excelencia [Sanz Menéndez-2004]. Por ello, el mismo personal investigador será quien, según su entendimiento, clarifique si el acuerdo firmado se ejecuta con una entidad relevante en las materias a abordar en función de la esfera geográfica de actuación.

Por otra parte, la comercialización de resultados de $\mathrm{I}+\mathrm{D}+\mathrm{i}$, puede ocurrir, ora mediante acuerdos y licencias de explotación (quedan contenidos en el conjunto de posibles acuerdos reflejados en los factores 1.1, 1.2 y 1.3), ora mediante la creación de spin-offs (se tratará más adelante).

El factor 1.4 permite precisar la contribución del Centro para reforzar la excelencia científico-tecnológica del ámbito internacional en que opera como miembro de la red apropiada, con especial relevancia de Europa y las primadas Redes de Excelencia de los VI y VII Programas Marco (véase apartado III.3).

En cuanto a los factores 1.5, 1.6 y 1.7, simplemente señalaremos la significación e intencionalidad de las subvenciones públicas a labores científico-técnicas, hecho del que dan cuenta los mismos. Para ello, es necesario considerar que gobiernos y sector público no se fundan en patrones de rentabilidad económica para con la $\mathrm{I}+\mathrm{D}+\mathrm{i}$. Los gobiernos, bien sean estos regionales, nacionales o internacionales, basan su inversión en actividades de $\mathrm{I}+\mathrm{D}+\mathrm{i}$ en el interés social a largo plazo: bienestar de los ciudadanos, calidad de vida y medio ambiente. Del mismo modo, fomentan la educación y cultura 
científicas, haciéndolas accesibles, y familiarizan la ciencia y tecnología con el gran público.

Tradicionalmente, el objetivo central de las políticas de $\mathrm{I}+\mathrm{D}+\mathrm{i}$ y la razón para la involucración de los gobiernos en estas materias, aparte de cubrir las necesidades de salud y defensa, ha sido la rectificación de los desaciertos e imperfecciones del mercado. Estos desajustes se atajan incrementando la financiación pública en actividades de $\mathrm{I}+\mathrm{D}+\mathrm{i}$ en aquellos sectores económicos con menor dinamismo en este sentido. De acuerdo con Muldur [2001], los desarreglos del mercado tienen una doble vertiente: por un lado, la rentabilidad obtenida a nivel privado por la actividad en $\mathrm{I}+\mathrm{D}+\mathrm{i}$ es inferior a la obtenida a nivel social; por otro, los riesgos de obtener beneficios claros tras la realización de labores de $\mathrm{I}+\mathrm{D}+\mathrm{i}$, disuaden a las empresas de emprender dichas tareas, especialmente las PYMEs, por sus más escasos recursos económicos. Como consecuencia de ambas razones, el aporte monetario privado a la $\mathrm{I}+\mathrm{D}+\mathrm{i}$ está por debajo de lo deseado.

No obstante, es reseñable que la contribución de los gobiernos a la $\mathrm{I}+\mathrm{D}+\mathrm{i}$ va mucho más allá de la financiación de las actividades relacionadas. También comprende becas, desgravaciones de impuestos, relaciones contractuales y aprovisionamiento, lanzamiento de programas orientados a la distribución del conocimiento, soporte y actualización de infraestructuras para $\mathrm{I}+\mathrm{D}+\mathrm{i}$, junto con todos aquellos mecanismos $\mathrm{y}$ medidas destinados a la transferencia de conocimiento y know-how.

En los factores 1.8, 1.9 y 1.10, si diferentes cargas recaen sobre la misma persona, éstas contabilizarán de modo individual.

Los factores $1.11,1.12,1.13$ y 1.14 reflejan la movilidad de los investigadores, que puede tener efectos positivos o negativos si la misma implica también una migración de su conocimiento. Los factores 1.11, 1.12 y 1.13 indican la estancia del investigador en un lugar diferente de aquel de origen, con independencia de quién cubre los gastos derivados de su trabajo. Particularmente, el factor 1.14, cuyo signo contrario al resto entraña pérdida de conocimiento, implica la buena voluntad del investigador que 
abandona el Centro en dar respuesta a la pregunta implícita que plantea su cuantificación.

Procedamos, seguidamente, a fijar los pesos referentes a sus catorce factores constitutivos para el indicador "conectividad y proyección". Para ello, partimos de la ecuación (17), teniendo en cuenta que: $j=1 ; v=1, \ldots, 14$. De este modo: $m^{\prime}{ }_{11}=$ medida del factor $1.1 ; m^{\prime}{ }_{12}=$ medida del factor $1.2 ; m_{13}^{\prime}=$ medida del factor $1.3 ; m_{14}^{\prime}=$ medida del factor $1.4 ; m^{\prime}{ }_{15}=$ medida del factor $1.5 ; m^{\prime}{ }_{16}=$ medida del factor $1.6 ; m^{\prime}{ }_{17}=$ medida del factor $1.7 ; m_{18}^{\prime}=$ medida del factor $1.8 ; m_{19}^{\prime}=$ medida del factor $1.9 ; m^{\prime}{ }_{110}=$ medida del factor $1.10 ; m^{\prime}{ }_{111}=$ medida del factor $1.11 ; m^{\prime}{ }_{112}=$ medida del factor 1.12 ; $m^{\prime}{ }_{113}=$ medida del factor $1.13 ; m^{\prime}{ }_{114}=$ medida del factor 1.14 . Los pesos respectivos son: $p^{\prime}{ }_{11}, p_{12}, p_{13}, p_{14}, p_{15}, p_{16}, p_{17}, p_{18,} p_{19}, p_{110}, p_{111}, p_{112}, p_{113}, p_{114}$

Se consideran cuatro bloques: el primero, integrado por los factores 1.1 a 1.4 , el segundo, por los factores 1.5 a 1.7 , el tercero, por los factores 1.8 a 1.10 , y el cuarto, compuesto por los factores 1.11 a 1.14 . Teniendo en cuenta los mismos, se establecen las relaciones siguientes:

$$
\begin{aligned}
& p_{11}^{\prime}+p_{12}^{\prime}+p_{13}^{\prime}+p_{14}^{\prime}+p_{15}^{\prime}+p_{16}^{\prime}+p_{17}^{\prime}+p_{18}^{\prime}+p_{19}^{\prime}+p_{110}^{\prime}+p_{111}^{\prime}+p_{112}^{\prime}+p_{113}^{\prime}+p_{114}^{\prime}=1 \\
& p_{11}^{\prime}+p_{12}^{\prime}+p_{13}^{\prime}+p_{14}^{\prime}=p_{15}^{\prime}+p_{16}^{\prime}+p_{17}^{\prime} \\
& p_{15}^{\prime}+p_{16}^{\prime}+p_{17}^{\prime}=p_{18}^{\prime}+p_{19}^{\prime}+p_{110}^{\prime} \\
& p_{18}^{\prime}+p_{19}^{\prime}+p_{110}^{\prime}=p_{111}^{\prime}+p_{112}^{\prime}+p_{113}^{\prime}+p_{114}^{\prime} \\
& p_{12}^{\prime}=2 p_{11}^{\prime} \\
& p_{13}^{\prime}=2 p_{12}^{\prime}=4 p_{11}^{\prime} \\
& p_{14}^{\prime}=p_{11}^{\prime}+p_{12}^{\prime}+p_{13}^{\prime} \\
& p_{15}^{\prime}=\frac{4}{5}\left(p_{15}^{\prime}+p_{16}^{\prime}+p_{17}^{\prime}\right) \\
& p_{16}^{\prime}=p_{17}^{\prime} \\
& p_{19}^{\prime}=2 p_{18}^{\prime} \\
& p_{110}^{\prime}=2 p_{19}^{\prime}=4 p_{18}^{\prime} \\
& p_{112}^{\prime}=2 p_{111}^{\prime} \\
& p_{113}^{\prime}=2 p_{112}^{\prime}=4 p_{111}^{\prime} \\
& p_{114}^{\prime}=p_{111}^{\prime}+p_{112}^{\prime}+p_{113}^{\prime}
\end{aligned}
$$


La primera de las ecuaciones del sistema propuesto se infiere directamente de la expresión (17). La segunda, tercera y cuarta ecuaciones implican la igual importancia de los cuatro bloques considerados. De la quinta a la séptima ecuación se establece la relación entre los pesos dados a los acuerdos de colaboración y convenios con otros centros y organizaciones de referencia, con importancia creciente (progresión geométrica de razón dos) a los de carácter nacional e internacional, así como que la suma de tales estipulaciones (autonómicas, nacionales e internacionales) tiene la misma transcendencia que la pertenencia a redes de investigación y excelencia internacionales. La octava ecuación expresa el hecho de que la mayor parte de los ingresos por participación en convocatorias públicas proviene del ámbito autonómico en que el Centro Tecnológico tiene su sede, dándose en la ecuación novena la misma significación a las subvenciones públicas estatales e internacionales. La gradación en importancia de los factores del tercer y cuarto bloque considerados se da mediante sendas progresiones geométricas de razón dos en la décima y undécima ecuaciones, así como en la doceava y treceava, de modo respectivo. Finalmente, la última ecuación significa el grave daño que supone la pérdida de conocimiento por abandono del Centro Tecnológico de personal que no va a continuar su labor profesional en la $\mathrm{I}+\mathrm{D}+\mathrm{i}$, lo que entraña una ralentización del Aprendizaje Organizativo, tanto mayor, cuanto más significativo es el número y validez de ese personal.

El sistema formado por las ecuaciones (27) da como resultado los siguientes valores:

$$
\begin{gathered}
p_{11}^{\prime}=p_{111}^{\prime}=\frac{1}{56} ; \quad p_{12}^{\prime}=p_{18}^{\prime}=p_{112}^{\prime}=\frac{1}{28} ; \quad p_{13}^{\prime}=p_{19}^{\prime}=p_{113}^{\prime}=\frac{1}{14} \\
p_{14}^{\prime}=p_{114}^{\prime}=\frac{1}{8} ; \quad p_{15}^{\prime}=\frac{1}{5} ; \quad p^{\prime}{ }_{16}=p_{17}^{\prime}=\frac{1}{40} ; \quad p^{\prime}{ }_{110}=\frac{1}{7}
\end{gathered}
$$

Y, compendiando con la ecuación (17), el indicador "conectividad y proyección” viene dado por la siguiente expresión: 


$$
\begin{aligned}
& I\left(s_{e_{1}}\right)=\sum_{v=1}^{14} p_{1 v}^{\prime} \cdot m_{1 v}^{\prime}= \\
& =\frac{1}{56} m_{11}^{\prime}+\frac{1}{28} m_{12}^{\prime}+\frac{1}{14} m_{13}^{\prime}+\frac{1}{8} m_{14}^{\prime}+\frac{1}{5} m_{15}^{\prime}+\frac{1}{40} m_{16}^{\prime}+\frac{1}{40} m_{17}^{\prime}+ \\
& +\frac{1}{28} m_{18}^{\prime}+\frac{1}{14} m_{19}^{\prime}+\frac{1}{7} m_{110}^{\prime}+\frac{1}{56} m_{111}^{\prime}+\frac{1}{28} m_{112}^{\prime}+\frac{1}{14} m_{113}^{\prime}-\frac{1}{8} m_{114}^{\prime}
\end{aligned}
$$

En donde se indica el signo contrario del factor 1.14.

\section{VI.4.2. Intensidad de Innovación}

Trata de determinar la evolución tecnológica de los Centros, medida en función de la transferencia de nuevas tecnologías a las empresas.

Así, se considerará el gasto en proyectos de I+D bajo contrato con entidades privadas en los que se ha invertido en tecnología nueva (aquélla generada en los dos últimos años), sobre el gasto total en proyectos de $\mathrm{I}+\mathrm{D}$ (autonómicos, nacionales e internacionales).

A este respecto, la determinación de si en un proyecto de $\mathrm{I}+\mathrm{D}$ se ha invertido en la tecnología desarrollada en alguna parte del mundo en los dos últimos años para su realización será comunicada por el jefe de proyecto. De este modo, se da cuenta del grado de incidencia de la tecnología punta en las actividades que el Centro Tecnológico realiza para sus clientes (obviamente externos).

Teniendo en cuenta la ecuación (17), en este caso: $j=2 ; v=1$. Aquí, $m^{\prime}{ }_{21}$ es la medida determinada por la relación entre gastos señalada, y $p^{{ }_{2}}{ }_{21}=1$ su peso respectivo. De este modo, el indicador que nos ocupa viene dado por:

$$
I\left(s_{e_{2}}\right)=m^{\prime}{ }_{21}
$$




\section{VI.4.3. Acciones Formativas Relacionadas con $\mathbf{I}+\mathbf{D}+\mathbf{i}$}

En este indicador se engloban para con los investigadores, tanto las acciones en materias específicas de $\mathrm{I}+\mathrm{D}+\mathrm{i}$ (incluida su asistencia a ferias y otros foros no académicos en calidad de visitante), como la formación en gestión de la ciencia y la tecnología.

De la misma manera que en el caso del indicador anterior, también aquí consideramos un único factor que valora el gasto relacionado con dichas actuaciones, sobre el gasto total del Centro.

Como ya se trató en el apartado V.3.2, las tendencias y directrices en materia de formación se originan exteriormente al Centro Tecnológico, o se vuelcan de éste a su entorno por proactividad, por lo que estamos ante un factor externo del Aprendizaje Organizativo, y no interno, como inicialmente podría pensarse.

Para establecer la expresión del presente indicador, partimos de la ecuación (17), y observamos que: $j=3 ; v=1$. Aquí, $m^{\prime}{ }_{31}$ es la medida del factor establecido y $p^{\prime}{ }_{31}=1 \mathrm{su}$ peso correspondiente. De este modo, viene dado por:

$$
I\left(s_{e_{3}}\right)=m^{\prime}{ }_{31}
$$

\section{VI.4.4. Orientación al Mercado}

Como su propio nombre indica, evalúa la introducción de resultados de $\mathrm{I}+\mathrm{D}+\mathrm{i}$ en el mercado, así como el grado de satisfacción en las labores de $\mathrm{I}+\mathrm{D}+\mathrm{i}$ demandadas por los sectores empresariales del ámbito de actuación geográfico correspondiente. Se distinguen así los siguientes factores:

4.1. Proporción de ingresos privados autonómicos captados sobre el total de ingresos.

4.2. Proporción de ingresos privados nacionales captados sobre el total de ingresos. 
4.3. Proporción de ingresos privados internacionales captados sobre el total de ingresos.

4.4. Resultado de la encuesta de satisfacción de clientes (proporción sobre puntuación máxima).

4.5. Gastos por presencia en ferias o foros similares como expositor, sobre gasto total en proyectos de $\mathrm{I}+\mathrm{D}+\mathrm{i}$ (autonómicos, nacionales e internacionales). Este factor tiene signo negativo con respecto a los restantes del presente indicador.

4.6. Número de ofertas tecnológicas en foros internacionales (tramitadas por los IRCs, véase apartado II.3) que se han plasmado en transferencia de tecnología o servicios innovadores, sobre el total de presentadas 114 .

Los factores 4.1, 4.2 y 4.3 caracterizan la proporción de actividades de cooperación con empresas. Disponiendo de estos tres primeros factores, y evaluados consecutivamente en un determinado intervalo temporal, de manera indirecta, pueden ser determinados aspectos como el posible aumento del número de proyectos de $\mathrm{I}+\mathrm{D}+\mathrm{i}$ con empresas $\mathrm{y}$ los clientes relacionados. Estos aspectos hacen alusión al grado de utilización de los Centros Tecnológicos por parte de aquéllas.

Igualmente, considerados esos factores, se da cuenta de la importancia de las actividades de $\mathrm{I}+\mathrm{D}+\mathrm{i}$ orientadas a la obtención de beneficios económicos por las empresas (incremento de su competencia y competitividad).

La necesaria consideración del factor 4.4, cuya cuantificación (resultado de dicha encuesta) puede no resultar imparcial, queda exculpada por no hacerse extensiva esta forma de proceder al resto de factores e indicadores externos que venimos abordando (salvo inexistencia de método de evaluación alternativo, como este caso), y su baja repercusión (sólo uno de seis factores), en el contexto del indicador que nos ocupa.

\footnotetext{
${ }^{114} \mathrm{Si}$ no se ha dado lugar a ninguna oferta tecnológica internacional, este factor se considera nulo, para evitar una discontinuidad de salto a infinito.
} 
La negatividad del factor 4.5 es manifiesta, partiendo del hecho de que los factores anteriores manejan ingresos, y éste, en cambio, gastos.

En cuanto al factor 4.6, cabe destacar que únicamente aglutina ofertas internacionales al no existir equivalente nacional, y supone el reconocimiento del Centro Tecnológico como engranaje adecuado en la maquinaria global (en red) de la tecnología y los servicios innovadores. Las ofertas tecnológicas internacionales presentadas directamente por los Centros, quedan englobadas en el factor 4.3. Aceptando, entonces, una adecuada operatividad a los IRCs, toda oferta innovadora lanzada por un Centro Tecnológico por esta vía, y que no haya sido inicialmente rechazada por no procedente, derivará en un plazo de tiempo razonable en algún contacto europeo que la demande, por lo que, de ningún modo, los IRCs constituyen un filtro a los posibles logros innovadores transnacionales de los Centros Tecnológicos al quedar en sus manos ofertas de éstos.

Finalmente, podría pensarse en incluir en este indicador aspectos como la participación de empresas (autonómicas, nacionales e internacionales) en el organigrama directivo del Centro, pero esto no es más que un hecho relacional intrínsecamente ligado a la definición de Centro Tecnológico. Del mismo modo, podría pensarse a la inversa, es decir, tener en cuenta la participación del Centro en foros empresariales, pero sería redundante con los factores 1.8, 1.9, 1.10, expuestos en el apdo. VI.4.1.

De cara a la heurística de los pesos de los factores expuestos para el indicador "orientación al mercado" que nos ocupa, partimos de la ecuación (17), y tenemos presente que en este caso: $j=4 ; v=1, \ldots, 6$. De este modo: $m^{\prime}{ }_{41}=$ medida del factor 4.1 ; $m^{\prime}{ }_{42}=$ medida del factor $4.2 ; m_{43}^{\prime}=$ medida del factor $4.3 ; m^{\prime}{ }_{44}=$ medida del factor 4.4 ; $m_{45}^{\prime}=$ medida del factor $4.5 ; m_{46}^{\prime}=$ medida del factor 4.6. Los pesos respectivos de los factores referidos son: $p^{\prime}{ }_{41}, p^{\prime}{ }_{42}, p^{\prime}{ }_{43}, p^{\prime}{ }_{44}, p^{\prime}{ }_{45}, p^{\prime}{ }_{46}$.

Se distingue un bloque compuesto por los factores 4.1 a 4.3 , y separadamente los factores $4.4,4.5$ y 4.6 , estableciéndose las siguientes relaciones: 


$$
\left.\begin{array}{l}
p_{41}^{\prime}+p_{42}^{\prime}+p^{\prime}{ }_{43}+p^{\prime}{ }_{44}+p^{\prime}{ }_{45}+p^{\prime}{ }_{46}=1 \\
p_{41}^{\prime}=\frac{4}{5}\left(p^{\prime}{ }_{41}+p^{\prime}{ }_{42}+p^{\prime}{ }_{43}\right) \\
p_{42}^{\prime}=p_{43}^{\prime} \\
p_{44}^{\prime}+p_{45}^{\prime}+p_{46}^{\prime}=p_{41}^{\prime}+p_{42}^{\prime}+p_{43}^{\prime} \\
p_{45}^{\prime}=2 p_{44}^{\prime} \\
p_{46}^{\prime}=2 p_{45}^{\prime}=4 p_{44}^{\prime}
\end{array}\right\}
$$

La primera de las ecuaciones del sistema propuesto deriva directamente de la consideración de la ecuación (17). La segunda refleja que la principal captación de fondos, y por consiguiente de actividades de $\mathrm{I}+\mathrm{D}+\mathrm{i}$ con empresas, está en el ámbito de la Comunidad Autónoma donde opera el Centro Tecnológico. La tercera indica la igual importancia de los ingresos por labores de $\mathrm{I}+\mathrm{D}+\mathrm{i}$ con empresas de los sectores industriales nacional e internacional. La cuarta establece una igualdad entre la relevancia del bloque propuesto y los restantes factores del indicador. Por último, la quinta y sexta ecuaciones constituyen una gradación en importancia creciente en los factores 4.4, 4.5 y 4.6 mediante una progresión geométrica de razón dos.

De esta mamera, conformado el sistema por las ecuaciones (31), se deducen los siguientes pesos:

$$
p_{41}^{\prime}=\frac{2}{5} ; \quad p^{\prime}{ }_{42}=p_{43}^{\prime}=\frac{1}{20} ; \quad p_{44}^{\prime}=\frac{1}{14} ; \quad p_{45}^{\prime}=\frac{1}{7} ; \quad p_{46}^{\prime}=\frac{2}{7}
$$

Compendiando, entonces, con la ecuación (17), el indicador "orientación al mercado" viene dado por la siguiente expresión, en la que se observa el signo contrario del factor 4.5:

$$
I\left(s_{e_{4}}\right)=\sum_{v=1}^{6} p_{4 v}^{\prime} \cdot m_{4 v}^{\prime}=\frac{2}{5} m_{41}^{\prime}+\frac{1}{20} m_{42}^{\prime}+\frac{1}{20} m_{43}^{\prime}+\frac{1}{14} m_{44}^{\prime}-\frac{1}{7} m_{45}^{\prime}+\frac{2}{7} m_{46}^{\prime}
$$




\section{VI.4.5. Impacto Científico-Técnico}

Estima la repercusión, a escala mundial, de la actividad científico-técnica neta realizada en el Centro Tecnológico, es decir, sin tener en cuenta el beneficio comercial $\mathrm{u}$ empresarial directo derivado de los proyectos de $\mathrm{I}+\mathrm{D}+\mathrm{i}$ en que se enmarca.

En este sentido, se destacan dos aspectos: primero, los premios y reconocimientos a la labor de $\mathrm{I}+\mathrm{D}+\mathrm{i}$ a título individual, para un equipo de trabajo, o inclusive para el Centro Tecnológico en sil $i^{\mathbb{1} 5}$, y segundo, su relación de publicaciones científico-técnicas.

Los premios y reconocimientos tienen muy diversa transcendencia, y aún existiendo en todos los ámbitos de los tres campos de actuación de un Centro Tecnológico: investigación, desarrollo tecnológico e innovación, están fuertemente ligados a la actividad científica (investigación), suponiendo el respeto y el reconocimiento sobre los hallazgos o avances de significación en la escala que se consideren. El problema de los galardones estriba en que, incluso considerados casi en exclusividad en el ámbito científico, existen muchas actividades de investigación importantes que no están reconocidas, al menos directamente, como candidatas, tal cual puede apreciarse en las convocatorias de los prestigiosos Premios Nobel y Príncipe de Asturias, como ejemplos de mayor significación. A ello añadimos que tales distinciones, generalmente, recaen sobre personas concretas que lideran un grupo de investigación en etapas tardías de su vida profesional. De este modo, han de ser considerados los siguientes factores 116 .

5.1. Premios autonómicos en $\mathrm{I}+\mathrm{D}+\mathrm{i}$ recibidos a título individual o colectivo por miembros del Centro Tecnológico, o por éste en su conjunto, sobre el total de nombramientos a este respecto.

\footnotetext{
${ }^{115}$ Este caso es tanto más factible en cuanto el Centro Tecnológico está íntegramente dedicado a una única labor de $\mathrm{I}+\mathrm{D}+\mathrm{i}$, con excelencia en la misma.

${ }^{116} \mathrm{Si}$ no hay presentación a convocatoria de premios por parte del Centro Tecnológico, el factor correspondiente al ámbito geográfico oportuno se considera nulo para evitar una discontinuidad de salto a infinito.
} 
5.2. Premios nacionales en $\mathrm{I}+\mathrm{D}+\mathrm{i}$ recibidos a título individual o colectivo por miembros del Centro Tecnológico, o por éste en su conjunto, sobre el total de nombramientos a este respecto.

5.3. Premios internacionales en $\mathrm{I}+\mathrm{D}+\mathrm{i}$ recibidos a título individual o colectivo por miembros del Centro Tecnológico, o por éste en su conjunto, sobre el total de nombramientos al respecto.

No obstante, por los motivos expuestos, las publicaciones y las patentes (éstas últimas se abordarán en el siguiente indicador externo) se consideran, entonces, como moneda de cambio al uso para sondear el alcance de los desarrollos científico-técnicos.

En referencia a las publicaciones, por orden creciente de importancia, se tienen en cuenta estos factores:

5.4. Publicaciones generales: artículos divulgativos o informes técnicos en foros específicos y congresos $\frac{\omega 7}{}$, tanto nacionales, como extranjeros.

5.5. Publicaciones en revistas no consideradas en la base de datos $\mathrm{SCl}$, capítulos $\mathrm{y}$ libros de edición nacional.

5.6. Capítulos y libros de edición internacional $\stackrel{19}{19}$

5.7. Publicaciones en revistas de la base de datos SCI.

\footnotetext{
${ }^{117}$ Sólo se valorarán aquellos cuyas actas poseen ISBN.

118 Siglas de Science Citation Index. Se trata de una base de datos internacionalmente reconocida como referente de publicaciones de impacto científico-técnico, desarrollada por la compañía privada ISI Thompson Scientific.

119 Teniendo en cuenta la información que se solicita anualmente al profesorado de las universidades públicas españolas para la evaluación de su actividad investigadora, se considerará libro (o capítulo/s) de edición internacional, aquél que cuenta con un comité científico donde al menos el $50 \%$ de sus miembros son de países diferentes al de edición y posea una difusión universal demostrable.
}

Con esta definición, por complementariedad, se deduce lo que se entiende por libro (o capitulo/s) de edición nacional. 
En todos los casos, se dará la proporción de publicaciones sobre el número total de las presentadas en los foros correspondientes a cada uno de los factores expuestos ${ }^{120}$, para, así, dar cuenta de la transcendencia de los trabajos realizados.

Para contabilizar los libros y capítulos de libro, los investigadores del Centro Tecnológico deben figurar en calidad de autor o coordinador, y no de editor o traductor, al no considerarse estas figuras como creadoras de la actividad de $\mathrm{I}+\mathrm{D}+\mathrm{i}$ objeto de la publicación.

La bibliometría es la técnica que permite la construcción de indicadores cuantitativos de la producción de literatura científico-técnica. Estos indicadores describen las propiedades de ésta, aplicando métodos matemáticos y estadísticos a libros y cualquier otro medio en este sentido [Arnold y Balázs-1998]. La utilización de estos métodos se justifica por las siguientes razones:

- Los resultados de las investigaciones científico-técnicas son publicados, en la mayoría de las ocasiones, en artículos científicos y técnicos.

- Se supone que cuanto mayor sea el número de ocasiones en que se cite un artículo científico-técnico, mayor será la calidad de éste. Bajo esta consideración, es de destacar la relación de la bibliometría con el análisis de citas bibliográficas. Esta técnica trata de valorar la relevancia de una publicación científico-técnica, en función del número de veces que se ha citado en otras publicaciones afines.

- Se permite conocer con exactitud las actividades de $\mathrm{I}+\mathrm{D}+\mathrm{i}$ que se describen en las publicaciones.

Sin embargo, a pesar de su interés, como establece Coronil Jonsson [2003], la utilización de la bibliometría como método de evaluación no está exenta de críticas:

\footnotetext{
${ }^{120}$ Si no hay presentación de publicación al foro marcado, el factor correspondiente se considera nulo,
} para evitar una discontinuidad de salto a infinito. 
i. Los indicadores bibliométricos sólo proporcionan una visión parcial de la difusión de las actividades de $\mathrm{I}+\mathrm{D}+\mathrm{i}$, ya que éstas pueden ser dadas a conocer de forma oral, por simple comunicación personal, o bien con memorias o informes técnicos (como justificación de las actividades desarrolladas, especialmente si se sustentan con financiación pública). Incluso cuando se ejecutan proyectos de $\mathrm{I}+\mathrm{D}+\mathrm{i}$ para grandes empresas, ciertos resultados son mantenidos en secreto por razones estratégicas.

ii. Existe un desfase temporal, más o menos acusado, entre el momento que se obtienen los resultados de la actividad en $\mathrm{I}+\mathrm{D}+\mathrm{i}$, y el momento en que son publicados y se construyen los indicadores, hecho que conlleva pérdida de efectividad. Además, según las disciplinas de las que se trate, se puede tardar meses o años en obtener un resultado publicable (por ejemplo, realizar descubrimientos importantes en Biología pueden llevar un par de meses, mientras que en Física de Partículas, años).

iii. Clara discriminación para las publicaciones de habla no inglesa (e incluso no anglosajonas), respecto a las publicaciones en otros idiomas, a la hora de construir los indicadores bibliométricos.

iv. Escasa presencia de publicaciones que recogen nuevas materias o campos de investigación.

v. En muchos casos, las publicaciones científico-técnicas no ofrecen contribución al conocimiento, hecho que no se tiene en cuenta a la hora de construir el indicador para su posterior evaluación.

Además, no se contemplan como factores de este indicador, ni los documentos de trabajo internos (la llamada "literatura gris"), ni los materiales de difusión y promoción, ni tampoco todas aquellas reseñas que hacen eco de algún logro de $\mathrm{I}+\mathrm{D}+\mathrm{i}$ del Centro Tecnológico en los medios de comunicación. La evaluación de estos dos últimos aspectos está más relacionada con posibles indicadores de impacto social, que con los necesarios para evaluar el Aprendizaje Organizativo. 
Para establecer los pesos de los factores expuestos para el indicador "impacto científicotécnico" que nos ocupa, se parte de la ecuación (17), y se tiene en cuenta que: $j=5 ; v=$ $1, \ldots, 7$. De este modo: $m^{\prime}{ }_{51}=$ medida del factor $5.1 ; m^{\prime}{ }_{52}=$ medida del factor $5.2 ; m^{\prime}{ }_{53}=$ medida del factor $5.3 ; m^{\prime}{ }_{54}=$ medida del factor $5.4 ; m^{\prime}{ }_{55}=$ medida del factor $5.5 ; m^{\prime}{ }_{56}=$ medida del factor 5.6; $m^{\prime}{ }_{57}=$ medida del factor 5.7. Los pesos respectivos de los factores reseñados son: $p^{\prime}{ }_{51}, p^{\prime}{ }_{52}, p^{\prime}{ }_{53}, p^{\prime}{ }_{54}, p^{\prime}{ }_{55}, p^{\prime}{ }_{56}, p^{\prime}{ }_{57}$.

Se distinguen dos bloques: uno compuesto por los factores 5.1 a 5.3 (premios), y otro compuesto por los factores 5.4 a 5.7 (publicaciones), estableciéndose las siguientes relaciones:

$$
\begin{aligned}
& p_{51}^{\prime}+p_{52}^{\prime}+p_{53}^{\prime}+p_{54}^{\prime}+p_{55}^{\prime}+p_{56}^{\prime}+p_{57}^{\prime}=1 \\
& p^{\prime}{ }_{51}+p_{52}^{\prime}+p_{53}^{\prime}=p_{54}^{\prime}+p_{55}^{\prime}+p_{56}^{\prime}+p_{57}^{\prime} \\
& p^{\prime}{ }_{52}=2 p^{\prime}{ }_{51} \\
& p_{53}^{\prime}=2 p_{52}^{\prime}=4 p_{51}^{\prime} \\
& p^{\prime}{ }_{55}=2 p^{\prime}{ }_{54} \\
& p_{56}^{\prime}=2 p_{55}^{\prime}=4 p_{54}^{\prime} \\
& p_{57}^{\prime}=2 p_{56}^{\prime}=8 p_{54}^{\prime}
\end{aligned}
$$

En el sistema formado, la primera ecuación es consecuencia directa de la ecuación (17). La segunda refleja la igual significación que tienen los premios, reconocimientos y las publicaciones científico-técnicas del Centro Tecnológico. La tercera y cuarta ecuaciones establecen una gradación en importancia creciente, mediante una progresión geométrica de razón dos, para los factores del primer bloque considerado. La quinta, sexta y séptima reflejan una gradación equivalente, pero, esta vez, para el segundo bloque citado.

Se deducen, entonces, los siguientes pesos, a partir del sistema propuesto:

$$
p_{51}^{\prime}=\frac{1}{14} ; \quad p_{52}^{\prime}=\frac{1}{7} ; \quad p_{53}^{\prime}=\frac{2}{7} ; \quad p_{54}^{\prime}=\frac{1}{30} ; \quad p^{\prime}{ }_{55}=\frac{1}{15} ; \quad p_{56}^{\prime}=\frac{2}{15} ; \quad p_{57}^{\prime}=\frac{4}{15}
$$

Compendiando con la ecuación (17), el indicador "impacto científico-técnico" viene dado por la siguiente expresión: 


$$
\begin{aligned}
& I\left(s_{e_{5}}\right)=\sum_{v=1}^{7} p_{5 v}^{\prime} \cdot m_{5 v}^{\prime}=\frac{1}{14} m_{51}^{\prime}+\frac{1}{7} m_{52}^{\prime}+\frac{2}{7} m_{53}^{\prime}+\frac{1}{30} m_{54}^{\prime} \\
& +\frac{1}{15} m_{55}^{\prime}+\frac{2}{15} m_{56}^{\prime}+\frac{4}{15} m_{57}^{\prime}
\end{aligned}
$$

\section{VI.4.6. Impacto Industrial}

Valora la repercusión que, para el propio Centro Tecnológico, suponen sus actividades de $\mathrm{I}+\mathrm{D}+\mathrm{i}$ en el tejido productivo (no los beneficios que, desde el punto de vista empresarial, puede obtener el cliente). El presente indicador está constituido por estos factores:

6.1. Relación de patentes concedidas, sobre las solicitadas por el Centro ${ }^{121}$.

6.2. Número de empresas de base tecnológica creadas por el Centro (spin-offs), sobre el total de proposiciones a este efecto 222 .

Los resultados directos de toda labor de $\mathrm{I}+\mathrm{D}+\mathrm{i}$ son las publicaciones (abordadas previamente) y las patentes. A estas últimas hace referencia el factor 6.1. Las patentes reflejan logros técnicos de aplicación práctica, concediendo a su inventor (en nuestro caso, investigadores o Centro Tecnológico) el derecho a explotar y comercializar su invención por un período limitado, y con ciertas condiciones.

Las patentes representan una valiosa fuente de información sobre los desarrollos tecnológicos llevados a cabo por el Centro, pero basándonos en Coronil Jonsson [2003], este factor no está exento de problemas:

- Los requisitos para que una invención sea patentada son diferentes en cada ámbito geográfico de aplicación. Así, podemos distinguir entre las que se realizan en

\footnotetext{
${ }^{121}$ Si no hay solicitud de patentes por parte del Centro Tecnológico, este factor se considera nulo, para evitar una discontinuidad de salto a infinito.

${ }^{122}$ Si no hay proposición de spin-offs en el Centro Tecnológico, este factor se considera nulo, para evitar una discontinuidad de salto a infinito.
} 
España (registradas por la Oficina Española de Patentes y Marcas-OEPM), la UE (registradas por la European Patent Office), EE.UU (registradas por la United States Patent and Trademark Office) y Japón (registradas por la Japan Patent Office), que son los marcos teóricos potenciales de creación de patentes por parte de un Centro Tecnológico. De modo realista, y según la OEPM, las patentes de los Centros Tecnológicos de Castilla y León se realizan en un 75\% en España, y el resto, en la UE, siendo EE.UU y Japón mercados no abordados 123 . Estos datos demuestran la influencia del entorno geográfico cercano en la creación de patentes (denominado home advantage en la literatura anglosajona).

- La propensión a patentar varía según el Centro Tecnológico, la incentivación interna en este sentido, el sector industrial en que ejerce, y el tamaño de las empresas para las que desarrolla su actividad.

- La calidad y el valor de las patentes que se presentan es muy diversa 2 , existiendo muy escasos datos sobre su utilización real.

- No se incluyen desarrollos informáticos (software), ya que no son patentables 25

\footnotetext{
${ }^{123}$ Consultadas las invenciones en español (base de datos OEPMPAT), e invenciones en otros idiomas (base de datos ESP@CENET). Datos estadísticos compendiados hasta el año 2005 para los seis Centros Tecnológicos asociados a INTENEC.

Existen convenios de colaboración entre España y otros treinta países europeos para la tramitación administrativa común de documentos e informes a presentar para la obtención de una patente, con la salvedad de su transcripción al idioma nativo de aquellos países donde pretenda hacerse efectiva la invención correspondiente. Este hecho, unido al mayor coste económico de la patentación europea con respecto al equivalente nacional, conforman un elemento disuasorio a la invención fuera del contexto español (salvo para las grandes empresas).

${ }^{124}$ Las patentes vencen tras veinte años improrrogables desde la fecha de solicitud, y se hallan sometidas al pago de tasas de mantenimiento anuales, desde el comienzo del tercer año de duración de las mismas, abonables una vez concedida la invención. Por lo tanto, si no se procede a abonar estos pagos, se puede inferir con gran probabilidad que una patente no tiene transcendencia, pues no ofrece rentabilidad.

${ }^{125}$ El nombre de un desarrollo informático se puede registrar en la Oficina Española de Patentes y Marcas, y su contenido en la Oficina de la Propiedad Intelectual, de acuerdo a la Ley de Propiedad Intelectual, cuyo texto refundido fue aprobado por el RD 1/1996 de 12 de Abril. De modo semejante se procede en la UE, EE.UU y Japón.
} 
- Tampoco se incluyen aquellos resultados de la actividad industrial que las empresas prefieren mantener en secreto tras la ejecución de un proyecto de $\mathrm{I}+\mathrm{D}+\mathrm{i}$ con un Centro Tecnológico, previendo a éste de realizar patentes mediante cláusulas de confidencialidad, no difusión, etc.

- Se pueden patentar determinados desarrollos por el simple hecho de bloquear las actividades de rivales tecnológicos. Este hecho puede resultar apreciable a pequeña escala, pero queda eliminado a gran escala, pues considerando un elevado número de Centros Tecnológicos (por ejemplo el ámbito europeo), la ley de los grandes números ${ }^{126}$ actúa como difuminadora de micro peculiaridades.

Por estos motivos, no puede considerarse una relación estrictamente proporcional entre el conocimiento técnico generado en el Centro Tecnológico y el número de patentes que solicita, aunque sí quedarán perfectamente recogidas en el factor que las acopia, aquellas que surgen por propuesta no condicionada $a^{127}$ de sus investigadores, en función de los proyectos en que se hayan inmersos.

En lo concerniente al factor 6.2, de modo general, el término spin-off recoge la escisión de una unidad de la compañía inicial que llega a tener entidad por sí misma. Las spinoffs incluyen la posibilidad de que la empresa matriz colabore con la escindida mediante la participación en el capital, o en la subcontratación de actividades, aunque normalmente son inversores independientes quienes adquieren todo o parte de la unidad [Perán González, Antón Freile y Caballero Fombellida-2004].

También se denomina spin-off a toda aquella empresa creada como medio de comercialización de resultados científicos y/o técnicos por parte de organizaciones dedicadas a la $\mathrm{I}+\mathrm{D}+\mathrm{i}$ [Chiesa y Piccaluga-2000]. Así, los Centros Tecnológicos pueden crear estas empresas, bien manteniendo su actividad en el mismo, bien comenzando su andadura profesional separadamente, una vez se domina la ciencia y/o técnica necesaria

\footnotetext{
${ }^{126}$ En Estadística, el valor medio y la varianza se aproximan, cada vez con mayor exactitud, a un valor límite cuando las medidas o elementos considerados crecen en número [Ströbl-1975].

${ }^{127}$ No existen trabas o reservas de la/s empresa/s para quien se trabaja sobre los desarrollos que para ella/s realiza el Centro Tecnológico.
} 
para desarrollar esa actividad. La creación de spin-offs supone ventajas para los Centros Tecnológicos, puesto que al ser instituciones sin ánimo de lucro, no pueden comercializar determinados aspectos de su actividad, $\mathrm{y}$, de este modo, podrán poner en el mercado productos o procesos que sirvan, igualmente, a otras empresas para obtener un mejor posicionamiento sobre sus competidores [Soldevila García y Roca Batllori2004].

Partiendo del factor 6.2, y también equivalentemente para el caso de las patentes, por diferencia entre los valores correspondientes a dos cotas temporales consecutivas, puede deducirse la tasa de supervivencia de las spin-offs creadas. Genéricamente, se consideran períodos tipo al año y a los tres años [COMISIÓN EUROPEA-2003d].

Para dar lugar a los pesos referentes a los dos factores expuestos, partimos de la ecuación (17), teniendo en cuenta que para este indicador: $j=6 ; v=1,2$. De este modo: $m_{61}=$ medida del factor $6.1 ; m_{62}=$ medida del factor 6.2 , con pesos respectivos: $p^{\prime}{ }_{61}$, $p^{\prime}{ }_{62 .}$ Se establece así una única relación:

$$
p_{61}^{\prime}+p_{62}^{\prime}=1
$$

Y otorgando la misma importancia a los dos factores constitutivos de este indicador, resulta:

$$
p_{61}^{\prime}=p_{62}^{\prime}=\frac{1}{2}
$$

Con lo que, compendiando con la ecuación (17), el indicador "impacto industrial" tiene la siguiente expresión:

$$
I\left(s_{e_{6}}\right)=\frac{1}{2} m_{61}^{\prime}+\frac{1}{2} m_{62}^{\prime}
$$




\section{VI.5. Consideraciones y Formulación Finales}

Mediante los indicadores internos y externos establecidos en sus sendos previos apartados, se puede proceder, o bien, a una evaluación global del Aprendizaje Organizativo en el Centro Tecnológico en todos los posibles contextos geográficos donde discurre su actividad, o bien, tomar en consideración separadamente sus factores autonómicos, nacionales e internacionales, para realizar la misma evaluación sólo en el ámbito que se considere oportuno.

Después de todo lo tratado en el presente capítulo, resta únicamente aglutinar las expresiones matemáticas que se han venido estableciendo. Deben compendiarse, entonces, tanto las ecuaciones que relacionan entropía e información, como los indicadores deducidos, en sus vertientes interna y externa.

Teniendo en cuenta lo expuesto en el apartado VI.1, estos indicadores no son estrictamente independientes, dado que existe influencia mutua entre internos y externos, a esos dos niveles, en mayor o menor grado. Para poder emplear la formulación que se viene desarrollando, deberían considerarse entropías que involucran probabilidades condicionadas, como la siguiente, para el caso del conjunto de los indicadores internos $X=A_{j}, \forall j=1, \ldots, \Omega_{\text {int }}$ (equivalentemente, para los indicadores externos):

$$
S\left(X \mid Y=B_{h}\right)=\sum_{j=1}^{\Omega_{\text {int }}} P\left(A_{j} \mid B_{h}\right) \cdot I\left(A_{j} \mid B_{h}\right) \quad \forall h=1, \ldots, \Omega ; \quad \Omega=\Omega_{\text {int }}+\Omega_{e x t}
$$

Donde el condicionante $Y=B_{h}$ denota otro posible indicador, hecho reflejado en la interacción múltiple dada por el elemento $\Omega$, suma de todos ellos: internos $\left(\Omega_{\text {int }}\right)$ y externos $\left(\Omega_{\text {ext }}\right)$. En la expresión anterior se ha de tener en cuenta la fórmula de Bayes [González y Villanova-1987]: 


$$
\begin{gathered}
P\left(A_{j} \mid B_{h}\right)=\frac{P\left(A_{j} \cap B_{h}\right)}{P\left(B_{h}\right)} \quad \forall j=1, \ldots, \Omega_{\text {int }} ; \forall h=1, \ldots, \Omega \\
I\left(A_{j} \mid B_{h}\right)=-\ln \left[P\left(A_{j} \mid B_{h}\right)\right]
\end{gathered}
$$

De modo realista, las probabilidades condicionadas expuestas resultan impracticables de calcular, pues se debería hacer un estudio de la influencia recíproca entre indicadores en un período muy superior a $T_{\text {Evaluación }}$ para así tener consistencia estadística, y observar, si es factible (por la complejidad de sus relaciones), posibles dependencias entre ellos.

Por otra parte, la consideración de la fórmula $S\left(X \mid Y=B_{h}\right)$ anteriormente expuesta, no tiene en cuenta otras dependencias cruzadas entre los mismos conjuntos de indicadores internos y externos: $Z, U$, etc., que están concatenadas a la indicada, y que son del modo:

$$
S\left(X\left|Y=B_{h}\right| Z=C_{l}\left|U=D_{k}\right| \ldots\right) \quad \forall h, l, k, \ldots=1, \ldots, \Omega
$$

Estas dependencias cruzadas también habrían de ser valoradas hasta un cierto orden, agravándose aún más el cálculo indicado.

Ante la inabordabilidad del problema planteado por el uso de probabilidades condicionadas, y con objeto de dar una solución práctica, factible y sencilla al método presentado, se han realizado diferentes y extensas simulaciones con el software MATLAB vs.6.5, otorgando valores arbitrarios a los indicadores internos y externos propuestos en los apartados VI.3 y VI.4, así como a sus posibles interacciones. De este modo, y con el propósito de realizar la valoración marcada por la ecuación (10), se concluye que, en primera aproximación, los resultados obtenidos son consonantes ${ }^{128}$ por dos vías: (1) mediante las simulaciones referidas; y (2) mediante la consideración del valor medio de las respectivas entropías externa e interna en los períodos $T_{\text {Previo }} \mathrm{y}$ $T_{\text {Posterior. }}$ Aunque por ambas vías no se obtienen los mismos valores para $d S_{\text {ext }}$ y $d S_{\text {int }}$, la consonancia referida es debida a que la evolución de cualquier indicador está determinada por los demás con los que interactúa. Este hecho, permite mantener la

${ }^{128}$ Se verifica la desigualdad planteada en la ecuación (10). 
formulación planteada, mediante la que se pretende hacer una valoración entrópica de la evolución del Aprendizaje Organizativo, no una medición del mismo.

Partiendo, entonces, de los indicadores internos para el Aprendizaje Organizativo, se tiene en cuenta la ecuación (14), donde de modo general, $i_{j}$, con $j=1, \ldots, \Omega_{i n t}$, marca la distribución de pesos normalizados de los $\Omega_{i n t}$ indicadores distinguibles $I\left(s_{i_{j}}\right)$ que caracterizan dicho aprendizaje a nivel interno. De acuerdo a lo establecido en el apartado VI.3, realmente $\Omega_{\text {int }}=5$, por lo que la ecuación (14) se transforma en esta otra:

$$
S_{\mathrm{int}}=\sum_{j=1}^{5} i_{j} \cdot I\left(s_{i_{j}}\right) ; \quad \sum_{j=1}^{5} i_{j}=1
$$

Los indicadores internos dados son los siguientes:

- $\quad I\left(s_{i_{1}}\right)$ : Especialización de actividades (con peso respectivo $i_{l} \in \Re$ ).

- $\quad I\left(s_{i_{2}}\right)$ : Capacidad para la $\mathrm{I}+\mathrm{D}+\mathrm{i}\left(\right.$ con peso respectivo $\left.i_{2} \in \Re\right)$.

- $\quad I\left(s_{i_{3}}\right):$ Infraestructuras y equipamientos que favorecen la creación de conocimiento (con peso respetivo $i_{3} \in \Re$ ).

- $\quad I\left(s_{i_{4}}\right)$ : Clima interno (con peso respectivo $i_{4} \in \Re$ ).

- $\quad I\left(s_{i_{5}}\right)$ : Eficacia y productividad (con peso respectivo $i_{5} \in \mathfrak{R}$ ).

Los pesos $i_{j}$, con $j=1, \ldots, 5$, se establecerán teniendo en cuenta la ecuación (13), de modo que:

$$
I\left(s_{i_{j}}\right)=-\ln i_{j} \Rightarrow \quad i_{j}=e^{-I\left(s_{i_{j}}\right)}
$$

Donde los indicadores internos $I\left(s_{i_{j}}\right)$, con $j=1, \ldots, 5$, vienen dados, respectivamente, por las ecuaciones (19), (21), (23), (24) y (26) anteriormente establecidas. Por ello, cada vez que se calcule un indicador interno, se tendrá el pertinente valor para su ponderación, reflejándose, así, su alcance en la expresión de la entropía de que 
participa, siendo esta última la correspondiente a un cierto número de medidas en el período $T_{\text {Evaluación. }}$ Obsérvese que debe acreditarse la condición de normalización dada en la ecuación (37).

Procediendo de modo análogo con los indicadores externos para el Aprendizaje Organizativo, tenemos en cuenta la ecuación (16), en la que de modo general, $e_{j}$, con $j=1, \ldots, \Omega_{\text {ext }}$, marca la distribución de pesos normalizados de los $\Omega_{\text {ext }}$ indicadores distinguibles $I\left(s_{e_{j}}\right)$ que caracterizan el referido aprendizaje en su significación externa. Según lo expuesto en el apartado VI.4, ocurre que en este caso $\Omega_{e x t}=6$, por lo que la ecuación (16) viene dada por:

$$
S_{e x t}=\sum_{j=1}^{6} e_{j} \cdot I\left(s_{e_{j}}\right) ; \quad \sum_{j=1}^{6} e_{j}=1
$$

Los indicadores externos abordados son los que a continuación se citan:

- $I\left(s_{e_{1}}\right)$ : Conectividad y proyección (con peso respectivo $e_{1} \in \Re$ ).

- $\quad I\left(s_{e_{2}}\right)$ : Intensidad de innovación (con peso respectivo $e_{2} \in \Re$ ).

- $\quad I\left(s_{e_{3}}\right)$ : Acciones formativas relacionadas con $\mathrm{I}+\mathrm{D}+\mathrm{i}$ (con peso respectivo $\left.e_{3} \in \mathfrak{R}\right)$.

- $I\left(s_{e_{4}}\right)$ : Orientación al mercado (con peso respectivo $e_{4} \in \mathfrak{R}$ ).

- $I\left(s_{e_{5}}\right)$ : Impacto científico-técnico (con peso respectivo $e_{5} \in \Re$ ).

- $I\left(s_{e_{6}}\right)$ : Impacto industrial (con peso respectivo $e_{6} \in \mathfrak{R}$ ).

Los pesos $\mathrm{e}_{j}$, con $j=1, \ldots, 6$, se establecen por medio de la ecuación (13), con lo cual:

$$
I\left(s_{e_{j}}\right)=-\ln e_{j} \Rightarrow e_{j}=e^{-I\left(s_{e_{j}}\right)}
$$

No debe confundirse el número de Euler (e), base de los logaritmos neperianos y la función exponencial de ésta última ecuación, con los pesos $e_{j}$. Los indicadores externos 
$I\left(s_{e_{j}}\right)$, con $j=1, \ldots, 6$, vienen marcados por las ecuaciones (28), (29), (30), (32), (34) y (36), que han sido establecidas con anterioridad. Asimismo, cada vez que se calcule un indicador externo, se obtendrá el valor respectivo para su ponderación por medio de la ecuación (40), mostrándose así su significación en la expresión dada por la ecuación (39). Debe comprobarse la condición de normalización servida en esta expresión, toda vez que se han calculado el resto de indicadores externos de forma paralela y bajo el mismo muestreo temporal que los internos.

Ahora bien, según fue determinado en los apartados IV.3.2 y IV.4, sabemos que para que un Centro Tecnológico sea sostenible en el tiempo, debe verificarse que:

$$
d S_{\text {ext }}>d S_{\text {int }}
$$

El período temporal considerado para registrar las variaciones $d S_{\text {ext }}$ y $d S_{\text {int }}$ es $T_{\text {Evaluación, }}$ desglosado en dos períodos iguales y consecutivos: $T_{\text {Previo }}$ y $T_{\text {Posterior }}$. Entonces, de acuerdo con la ecuación (10), tendríamos:

$$
\left.\begin{array}{l}
d S_{\text {ext }}=\left[\bar{S}_{\text {ext }}\right]_{T_{\text {Posterior }}}-\left[\bar{S}_{\text {ext }}\right]_{T_{\text {Pr evio }}} \\
d S_{\text {int }}=\left[\bar{S}_{\text {int }}\right]_{T_{\text {Posterior }}}-\left[\bar{S}_{\text {int }}\right]_{T_{\text {Pr evio }}}
\end{array}\right\}
$$

Siendo: $\left[\bar{S}_{\text {ext }}\right]_{T_{\text {Posserior }}},\left[\bar{S}_{\text {ext }}\right]_{T_{\text {Previo }},},\left[\bar{S}_{\text {int }}\right]_{T_{\text {Posterior }}},\left[\bar{S}_{\text {int }}\right]_{T_{\text {Previo }}}$ los valores medios de las entropías externa e interna en los períodos temporales $T_{\text {Posterior }} \mathrm{y} T_{\text {Previo }}$ respectivamente.

Los datos para obtener dichos valores medios serán los correspondientes a los indicadores internos y externos constitutivos de las ecuaciones (37) y (39), tomados año tras año (tiempo adecuado para observar apreciaciones dignas de cuantificación en cuanto al Aprendizaje Organizativo se refiere) durante los tiempos $T_{\text {Posterior }}$ y $T_{\text {Previo, }}$, dándose lugar a las siguientes expresiones: 


$$
\begin{aligned}
& {\left[\bar{S}_{\text {ext }}\right]_{T_{\text {Posterior }}}=\frac{\sum_{t=1}^{T_{\text {Posterior }}}\left[S_{\text {ext }}\right]_{t}}{n_{T_{\text {Posterior }}}}} \\
& {\left[\bar{S}_{\text {int }}\right]_{T_{\text {Posterior }}}=\frac{\sum_{t=1}^{T_{\text {Posterior }}}\left[S_{\text {int }}\right]_{t}}{n_{T_{\text {Posterior }}}}}
\end{aligned}
$$

Ecuaciones, en las que: $t \in \mathrm{N}=1, \ldots, T_{\text {Posterior }}$ es la relación consecutiva de $n_{T_{\text {Posererior }}} \in \mathrm{N}$ años de que se compone el período $T_{\text {Posterior }}$.

$\mathrm{Y}$, equivalentemente:

$$
\begin{aligned}
& {\left[\bar{S}_{\text {ext }}\right]_{T_{\text {Pr evio }}}=\frac{\sum_{t=1}^{T_{\text {Pr evio }}}\left[S_{\text {ext }}\right]_{t}}{n_{T_{\text {Pr evio }}}}} \\
& {\left[\bar{S}_{\text {int }}\right]_{T_{\text {Pr evio }}}=\frac{\sum_{t=1}^{T_{\text {Pr evio }}}\left[S_{\text {int }}\right]_{t}}{n_{T_{\text {Pr evio }}}}}
\end{aligned}
$$

Fórmulas en las que: $t \in \mathrm{N}=1, \ldots, T_{\text {Previo }}$ es la relación consecutiva de $n_{T_{\text {Previo }}} \in \mathrm{N}$ años de que consta el período $T_{\text {Previo }}$.

Ténganse en cuenta que como: $T_{\text {Base }}=T_{\text {Previo }}=T_{\text {Posterior }}$, ocurrirá que: $n_{T_{\text {Posterior }}}=n_{T_{\mathrm{Pr} e v i o}}$.

Tomando en consideración el hecho de que: $d S_{\text {ext }}>d S_{i n t}$, junto con las ecuaciones (41), (42) y (43), queda establecida, entonces, la praxis de evaluación entrópica de la evolución del Aprendizaje Organizativo de los Centros Tecnológicos, que permite observar si en éstos crece y se desarrolla el mismo, y, por tanto, si son sostenibles. 


\section{Capítulo VII:}

Líneas para la Gestión del Conocimiento en las PYMEs de

Castilla y León 
Pedro Martín Lerones Evaluación del Aprendizaje Organizativo en los Centros Tecnológicos y Gestión del Conocimiento Sectorial en Castilla y León 


\section{VII.1. Introducción: Consideraciones Iniciales}

Ciertamente, el dominio de la Gestión del Conocimiento constituye una de las prioridades de las PYMEs castellanas y leonesas que pretendan conseguir una posición competitiva y sostenible en la nueva economía globalizada, usuaria de las tecnologías de la información y de las comunicaciones. De hecho, el éxito de Castilla y León en esta nueva economía no sólo dependerá de su capacidad de crear conocimiento, sino, también, de su habilidad para comercializar tecnología, así como absorber y explotar el conocimiento creado en cualquier otra parte.

En los capítulos precedentes se ha comprobado cómo las organizaciones presentan una mutua realimentación entre lo que ellas mismas son a nivel a interno, y su interacción con el entorno. El ambiente intrínseco y organizacional, la capacidad e intensidad en el uso de las tecnologías de la información y de las comunicaciones junto con, especialmente, la creatividad y el potencial de innovación de todos sus miembros, configuran las principales peculiaridades internas de las pequeñas y medianas empresas. La información procedente del mercado marca, a su vez, las interacciones con el exterior.

Esta interacción interna-externa, siempre entendida como sinergia, origina las relaciones esenciales que han de conducirles a lograr sus objetivos estratégicos: supervivencia, crecimiento y rentabilidad. Su necesidad será tanto mayor, cuanto más grande sea la distancia entre las denominadas "vieja" (sectores tradicionales) y "nueva economía" (sectores emergentes), basada, esta última, en el uso de las tecnologías de la información y de las comunicaciones, y la Gestión del Conocimiento [Jiménez-Ridruejo Ayuso-2003]. La Tabla 16 recoge, esquemáticamente, algunas de las diferencias existentes entre ambas.

Hasta el momento presente, la adaptación a los sectores emergentes de las PYMEs regionales (mayoritariamente pertenecientes a la vieja economía), como en otras áreas geográficas, ha sido entendida y abordada, únicamente, desde el punto de vista 


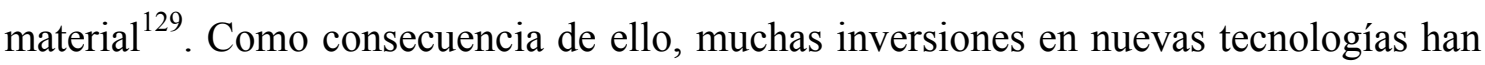
arrojado resultados frustrantes. Las compañías han tendido a utilizar dichas tecnologías para mecanizar sus formas tradicionales de hacer negocio, dejando el proceso existente intacto y utilizando éstas, meramente, para acelerarlo [Hammer y Champy-1990].

TABLA 16

DIFERENCIAS ENTRE LA VIEJA Y LA NUEVA ECONOMÍA

\begin{tabular}{|c|c|c|}
\hline & SECTORES TRADICIONALES & SECTORES EMERGENTES \\
\hline 口 & $\begin{array}{l}\text { Entorno de negocios predecible (no exento } \\
\text { de dificultad). }\end{array}$ & $\begin{array}{l}\text { E Entornos turbulentos e incapacidad de } \\
\text { predicción. }\end{array}$ \\
\hline 口 & $\begin{array}{l}\text { Supervivencia determinada por la capacidad } \\
\text { de optimización de procesos actuales. }\end{array}$ & $\begin{array}{l}\text { Supervivencia determinada por la capacidad } \\
\text { de innovar y desarrollar nuevos procesos. }\end{array}$ \\
\hline 口 & Énfasis en la eficiencia. & Énfasis en la eficacia. \\
\hline 口 & $\begin{array}{l}\text { La información sirve para controlar el } \\
\text { personal, el material, la distribución de } \\
\text { recursos y el grado de cumplimiento de los } \\
\text { objetivos preestablecidos. Se trata de } \\
\text { encontrar la respuesta correcta. }\end{array}$ & $\begin{array}{l}\text { La información sirve para ayudar a repensar } \\
\text { todos los supuestos, procesos y prácticas de la } \\
\text { organización, incluso sus metas y objetivos. } \\
\text { Se trata de formular la pregunta correcta. }\end{array}$ \\
\hline 口 & $\begin{array}{l}\text { La competencia es local o nacional, y nunca } \\
\text { debe cooperarse con ella. }\end{array}$ & $\begin{array}{l}\text { La competencia es regional o global. Es } \\
\text { necesario cooperar para competir. }\end{array}$ \\
\hline
\end{tabular}

FUENTE: Perán González y Miguel Hernando [2000]

El desconocimiento de las implicaciones cualitativas que conlleva la incorporación de las nuevas tecnologías, frente al mero escalamiento cuantitativo propiciado por la capacidad de procesamiento, es, precisamente, una de las características de la llamada "paradoja de la productividad de las tecnologías de la información y las comunicaciones" [Brynjolfsson-1993; Sáez Vacas-1996].

Obviamente, la utilización de las últimas tecnologías constituye un catalizador importante de la compartición de conocimiento en las empresas, pero aquéllas no son quienes lo generan. Al tener un componente humano, no todos los procesos y acciones pueden ser automatizados y reflejados directamente por las nuevas tecnologías, con todas las implicaciones que ello conlleva. En cierto modo, y con muchas reservas, es

${ }^{129}$ Equivaldría a la pretensión, por poner un ejemplo gráfico a través de un símil, de hacer piloto de Fórmula-1 a una persona (regalándole un coche) que ni siquiera entiende que tiene que obtener el carnet de conducir. 
posible idear un método para guardar y compartir los conocimientos explícitos con las tecnologías de la información y las comunicaciones, tanto individuales como colectivos; pero de ninguna manera podrán almacenarse sus procesos de generación y transmisión 130 , que son los verdaderamente importantes, los que deben conocerse y favorecerse, ni, por supuesto, el conocimiento tácito. Incluso cabe poner en duda que la información recolectada, estructurada y almacenada mediante la implantación de las nuevas tecnologías en las empresas, sea realmente mantenida y empleada por ellas de forma habitual.

Siguiendo a Suárez Burguet et al. [2004], las dificultades que encuentran muchas empresas de Castilla y León para hacer brotar conocimiento de la colección de datos que se almacenan en sus sistemas de información constituye otra de las consecuencias derivadas de la aplicación del enfoque centrado en el escalamiento cuantitativo de la organización preexistente a través de ellos, y de la escasa atención que prestan al impacto organizativo de las nuevas tecnologías, esto es, a la integración de su sistema de información con la estrategia corporativa, ya sea por falta de tiempo; por ausencia de incentivos para lograr una, a su juicio, incierta mejora (cuando tienen asegurado un cierto cupo de mercado); o, simplemente, porque no saben, o no pueden hacerlo sin el personal cualificado que les ayude a entender la importancia de la integración señalada.

El reto que plantea la nueva economía, como se reflejó al comienzo de la presente Tesis Doctoral, no radica, sin embargo, en potenciar el simple procesamiento de la información o los procesos productivos de las organizaciones. Antes bien, implica conocer el potencial que ofrece la tecnología para el desarrollo, difusión y gestión de su conocimiento como ventaja competitiva; junto con una clara concienciación de sus directivos en este sentido; tiempo para asimilarlo; así como una estrategia de integración de la información en las pequeñas y medianas unidades productivas.

\footnotetext{
${ }^{130}$ Lamentablemente, numerosas consultoras se dedican, en la práctica, a la venta de "software de almacenaje" (al igual que buena parte de la bibliografía aparecida en este sentido) o, en ciertos casos, a orientar sobre cómo hacer uso de aquél. Por esta vía se estarían tratando, únicamente, los efectos, pero no las causas; como cuando un paciente con una dolencia acude al médico, éste toma nota de todos sus síntomas, pero desconoce el tratamiento que ataje el origen de su mal.
} 
Las modernas tendencias que han ido surgiendo para paliar dichas dificultades vienen canalizando sus esfuerzos hacia la recogida de la información que se va generando en cada momento y su posterior almacenamiento, conforme a una "lengua común" que la haga disponible a cualquier persona de la empresa. Persiguen, en suma, obtener a la postre un conocimiento de la realidad (interna y externa) que permita actuar con la mayor certeza posible, no sólo a sus directivos, sino a todos aquellos mandos que desarrollen tareas donde sea necesaria la información, adaptando ésta a cada proceso del negocio. Entre los útiles creados para la mencionada recogida de información,

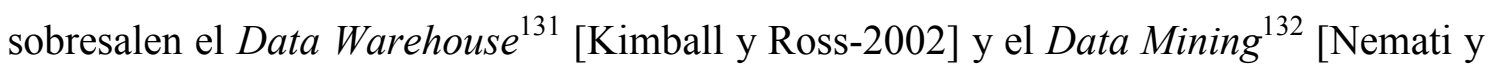
Barko-2003].

La génesis de conocimiento y el Aprendizaje Organizativo debieran encontrar en esos útiles un entorno adecuado para su desarrollo y están siendo empleados, con un éxito relativo, en grandes empresas. Ahora bien, requieren de personal específico dedicado a la captación, almacenamiento y distribución de la información, hecho difícilmente aplicable las PYMEs regionales, por cuanto, aunque se plasman en aplicaciones software a medida (exclusivamente informáticas y de tratamiento estadístico), éstas no se emplean en la práctica (por las razones ya comentadas) y olvidan el factor humano, verdadero artífice de la dinámica del Aprendizaje Organizativo, como base de la Gestión del Conocimiento.

En cualquier caso, para que la implantación de un sistema de Gestión del Conocimiento tenga éxito en las organizaciones, deberá dar respuesta a ciertas preguntas a las personas involucradas en él (¿en qué me afectará?, ¿cómo me beneficiará?, etc.), así como recompensar, tomar como ejemplo y considerar valiosos a aquellos empleados que crean y comunican su conocimiento de manera activa dentro de la propia empresa.

\footnotetext{
131 Consiste en crear un almacén de información temática (productos, clientes, etc.), que permita la gestión, control y apoyo a la toma de decisiones.

132 No sólo permite el análisis de información que es realmente importante y diferencial, sino que, también, plantea y descubre, automáticamente, los hechos, hipótesis, patrones, reglas, grupos, funciones, modelos, secuencias, relaciones, correlaciones, etc., que, correctamente interpretados, pueden desembocar en una diferencia competitiva unida a un aumento de la eficacia y productividad de la empresa.
} 
Establecido en los capítulos precedentes cómo debe procederse a la evaluación del Aprendizaje Organizativo, pilar fundamental de la Gestión del Conocimiento de los Centros Tecnológicos, el objetivo del presente es, de forma complementaria, orientar en cómo debe procederse a tal gestión en las PYMEs castellanas y leonesas que se enmarcan en los tres principales sectores estratégicos de la economía regional analizados en el capítulo II: agroalimentario, automoción y tecnologías de la información y de las comunicaciones, dado que en los relacionados con la conservación del patrimonio y la biotecnología, al no haberse articulado todavía la estructura empresarial de los mismos, no es posible hablar de Gestión del Conocimiento ni, por tanto, de sus posibles directrices.

Para lograrlo, se partirá de la consideración, ya contrastada en los epígrafes precedentes, de que los Centros Tecnológicos son la fuente de las capacidades competitivas y de adaptación a las nuevas tecnologías de las PYMEs que solicitan sus servicios, pudiendo aportarles tanto elementos materiales de última generación, como novedosos procesos (con implicaciones organizativas) orientados a su supervivencia y ajuste a los sectores emergentes.

Debe tenerse presente, no obstante, que la garantía del desarrollo e impulso de la capacidad competitiva de los pequeños y medianos establecimientos de la región, por parte de los Centros Tecnológicos, estará, a su vez, condicionada por el crecimiento continuo del Aprendizaje Organizativo en ellos mismos, debiéndose hacer extensiva esta filosofía de subsistencia, también, a las empresas de la mencionada Comunidad Autónoma.

\section{VII.2. Directrices para el Sector Agroalimentario}

Una de las claves para el desarrollo del sector agroalimentario de Castilla y León es la necesidad de llevar a cabo una agrupación de microempresas en PYMEs de mayor tamaño, de forma que se garantice su colaboración, competitividad y supervivencia. Dado que, según Blanco et al. [2000], buena parte de las personas que trabajan en ellas 
se dedica, únicamente, al tratamiento, fabricación y envasado del producto, estimamos que sólo se podrá aplicar la Gestión del Conocimiento, en sentido estricto, en aquellas entidades que cuenten con un mínimo de 100 empleados.

La importancia de esta agrupación radica en que, por un lado, el conocimiento generado en el sector se produce a tal velocidad que surgen numerosas dificultades en el seguimiento del devenir del mercado, particularmente para las más pequeñas. Por otro, en que los trabajadores estructuran y originan aquél sobre una base común, pero, frecuentemente, de forma independiente entre sí, como demostró el "proyecto SARA, 133 .

Consecuentemente, si se exceptúa el núcleo de las grandes firmas agroalimentarias que se ubican en Castilla y León, las empresas de esta Comunidad Autónoma no explotan suficientemente el enorme potencial de conocimiento que presenta el sector (productos, sus adaptaciones a las demandas de cada momento, variantes, diseño, análisis de mercado, comercio exterior, etc.) [Perán González, Antón Freile y Caballero Fombellida $-2004]$.

Como ocurre en otras actividades industriales, el avance tecnológico marca la adecuación de sus productos a la demanda; viéndose influenciado e, incluso, reforzado por las modas que imprimen los nuevos hábitos de vida y las campañas, tanto de concienciación, como publicitarias asociadas ("comer sano", "comer bien”, etc.).

Aunque el referido impacto de la moda en los productos fabricados es, también, especialmente significativo en el sector de las tecnologías de la información y de las comunicaciones, el avance en éste, a diferencia de lo que acontece en el de las industrias agroalimentarias, se halla determinado por el de la tecnología, que parece ilimitado. En

\footnotetext{
133 SARA (Supply Arrangements Enriching Innovation) fue una iniciativa desarrollada dentro del programa "Innovación y PYME”, del V Programa Marco de la Unión Europea.

El objeto de este proyecto, fue la creación de una nueva herramienta integrada mediante la transferencia de conocimiento en diversas áreas (análisis del valor, Gestión del Conocimiento aplicado a la gestión de las cadenas de suministro y, por último, gestión de redes), para la mejora de la competitividad de las PYMEs agroalimentarias mediante su uso en redes empresariales, permitiéndoles enriquecer y aumentar su interactividad con otras compañías del sector.
} 
cambio, desde hace siglos, en la agroalimentación la materia prima continúa siendo la misma, no registra más avances que los que la ética permite al tratamiento genético, y ha de ofertar con ello productos diferentes, según la demanda. Esto implica una reinvención continua sobre la materia originaria, lo que origina pérdidas de flexibilidad, rápido desarrollo del producto y proximidad de las PYMEs en sus relaciones con clientes y socios. La empresa no puede entenderse, entonces, más que como un medio de aprendizaje continuo [Martínez León, Ruiz Mercader y Ruiz Santos-2001].

Tomado como base lo expuesto por Regidor [2000], se deducen dos posibles posturas a adoptar por las pequeñas y medianas firmas del sector, en este contexto:

- Trabajar de manera rutinaria para y según las especificaciones de las grandes unidades productivas, salvando, así, el problema de tener que aprender continuamente para subsistir.

- Convertirse en una empresa de la nueva economía, en cuyo caso, si cuenta con un número de empleados suficiente como para dedicarse a tareas diferenciadas de las ofrecidas por la exclusiva producción y administración, se le abre la oportunidad de poder utilizar diferentes metodologías de Gestión del Conocimiento, basadas, en principio, en las dos características siguientes:

(a) La creación de un sistema que retenga y establezca como referencia el conocimiento de los empleados de mayor edad y mayor permanencia en la empresa, para cuando éstos abandonen la misma.

(b) Motivar a aquellos trabajadores que quieran desarrollarse profesionalmente dentro de la organización, independientemente de la labor que realicen.

Dichas metodologías no han de implantarse ni de modo súbito, ni por imposición directiva, ni tampoco en la totalidad de las PYMEs. Deberán iniciarse, de forma totalmente experimental, en uno o varios departamentos de la empresa de probada trascendencia para el sostenimiento y significación de su actividad, haciendo que los 
empleados tomen parte activa y considerando, a nuestro juicio, cuatro fases en su puesta en marcha (Figura 32):

1. Análisis previo: tiene por objetivo el estudio de la compartición actual de conocimiento entre los diferentes departamentos de interés, así como en el interior de los mismos; identificando las secciones en las que se pueden mejorar los métodos y procesos laborales, mediante una transmisión real de dicho conocimiento.

2. Focalización en las áreas de interés: tomando como punto de partida los resultados obtenidos en la etapa anterior, la pequeña y mediana empresa deberá centrarse en aquellos departamentos que, al desempeñar un importante papel en el desarrollo de productos, originan beneficios comerciales tangibles; evaluando tanto los objetivos propuestos, como la expectación surgida, el nivel de ambición, el conocimiento previo en procesos paralelos, y el estado actual de la situación.

3. Propuesta de valor: esta etapa debe orientarse, fundamentalmente, a la búsqueda y colocación en el mercado de productos relevantes ${ }^{134}$. Para ello, se requiere del uso de las tecnologías de la información y las telecomunicaciones. Consecuentemente, las PYMEs agroalimentarias deberán asesorarse sobre su correcta utilización, su adecuado dimensionamiento $\frac{135}{y}$ su implantación, permitiéndoles dar, así, el primer paso hacia su ajuste a la nueva economía. Los siguientes pasarán por la reconducción oportuna de sus procesos productivos, el empleo de esas nuevas herramientas y la formación continua de todo el personal (directivos y trabajadores). Con ello, no sólo lograrán aumentar su cuota de mercado, sino, también, la adaptación de sus productos a las nuevas demandas.

4. Benchmarking: trata de lograr mejoras palpables en los procesos y productos finales de las PYMEs que desarrollan estas fases, contrastando la incidencia de productos

${ }^{134}$ Un ejemplo lo constituirían aquellos productos que son comunes en nuestra dieta habitual, pero que suscitan gran interés y beneficio económico (incluso como productos de lujo), por su posible negocio en otros países. De acuerdo con Pérez Gil [2005], este es el caso del jamón de porcino, exportado a Estados Unidos. 
similares de empresas semejantes en el mismo mercado. De esta forma, se adquiere una mínima capacidad de previsión para intuir el devenir de éste e ir logrando un cierto posicionamiento estratégico, nuevas alianzas, futuras ampliaciones, etc.

Transcurrido un tiempo prudencial (que cada empresa estimará de forma efectiva), en el que se analizarán y remozarán (si es necesario) las fases apuntadas para la implantación de un sistema de Gestión del Conocimiento, éste se validará y hará extensivo a toda la empresa. Desglosemos, seguidamente, el contenido de cada una de ellas.

\section{VII.2.1. Análisis Previo}

Para identificar dónde pueden mejorarse los métodos y procesos laborales a partir de la compartición del conocimiento, han de realizarse una serie de reuniones y entrevistas personales con los empleados de base, a objeto de tener una visión realista y crítica de los que se están llevando a cabo en el conjunto de la empresa. Las opiniones vertidas se contrastarán con las de los encargados y directivos. Si se desea, se pueden contratar los servicios de apoyo de una consultora externa, o los de un Centro Tecnológico inclusive, para determinar qué se debe preguntar o proponer, a quién, cómo, etc. Los datos recopilados en este sentido habrán de plasmarse en un informe que contenga los requisitos que han de observarse para compartir conocimiento en cuatro ámbitos:

- Dentro de cada departamento.

- En la comunicación con otros departamentos.

- En la comunicación con los clientes.

- Con las subcontratas (si existen).

\footnotetext{
${ }^{135}$ Es común observar ordenadores personales (PCs) de última generación, o bien con características muy avanzadas para el tipo de tarea a que están destinados, o bien cuya rentabilidad se ve restringida por la aptitud de quien los maneja.
} 
Asimismo, el informe deberá tener en cuenta aquellas formas de conocimiento explícito resultantes del empleo de las tecnologías de la información y las comunicaciones (cuantitativa y cualitativamente), directorios y manuales para formación de personal, gama y descripción de productos, especificaciones de requerimientos, etc. También deberá mostrar, consecuentemente, las principales barreras que limitan la compartición del conocimiento, así como las principales recomendaciones para hacerlas desaparecer.

Como se ha referido anteriormente, podrá corroborarse que el conocimiento no sólo aparece diseminado por los diferentes departamentos, sino por toda la PYME, y que se concentra, principalmente, en los trabajadores, individualmente considerados. Dado que en el sector agroalimentario la mayor parte de los mismos realiza, únicamente, labores de producción (específicas e individualizas), sólo ellos advierten cómo mejorar su eficiencia y su eficacia; debiéndose favorecer e incorporar rutinas que faciliten el asentamiento y transmisión del conocimiento, haciéndolo explícito sobre la base del aprendizaje y el diálogo entre empleados y directivos, para su reutilización y creación de nuevo. El proceso será, ciertamente, lento y no estará exento de dificultades, puesto que el conocimiento en estas empresas, aunque se encuentre localizado en sus individuos, no se haya, todavía, estructurado.

\section{VII.2.2. Focalización en las Áreas de Interés}

Identificadas las áreas en las que pueden mejorarse los métodos y procesos laborales a través de una compartición real de conocimiento, es preciso seleccionar, a continuación, las que involucran departamentos con una cierta influencia en el desarrollo de aquellos productos que dan lugar a beneficios comerciales efectivos. Una vez detectadas, la PYME debe plantearse, entonces, quién conoce qué y quién ha trabajado con tal clase de metodología o sistema, o en tal tipo de proyecto, para colocar en el mercado un producto de éxito, permitiéndole comprobar, según Westhead, Wright y Ucbasaran [2001], que:

- El conocimiento no se reutiliza de manera eficiente. 
- Impera una pérdida de perspectiva de los resultados del conocimiento existente, originándose reinvenciones que se derivan de la utilización de la misma materia prima a lo largo del tiempo.

- Hay también pérdida de perspectiva de las competencias y recursos existentes.

- Coexisten la presión continua para disponer de nuevos y mejores productos, y la falta de voluntad para compartir experiencias 136 .

- No hay compartición de éstas entre dos proyectos afines, por razones similares a las ya apuntadas anteriormente, máxime si hay movimiento de personal, tanto a nivel interno como externo a la PYME.

- No se solicita ayuda cuando se precisa de información, lo que implica un gran costo temporal y económico para encontrar la solución oportuna.

Estos aspectos, junto con una cierta pasibidad, son, en cierta manera, inherentes a la mentalidad individualista de la ciudadanía castellana y leonesa. Los productos agroalimentarios comarcales, las denominaciones de origen, etc., de algún modo, tienden a enfatizar ese sentimiento, al igual que el de pertenencia al microentorno del contexto rural de una Comunidad Autónoma con carencias en su vertebración [Blanco et al.-2000].

Por lo tanto, la elección del departamento/s con el/los que finalmente se vaya a experimentar la implantación de la Gestión del Conocimiento en la PYME deberá evitar, en la medida de lo posible, las cuestiones anteriormente señaladas y delinear las competencias individuales de los empleados involucrados: su configuración departamental e interdepartamental, necesidades que será preciso cubrir para alcanzar el éxito comercial, etc.

\footnotetext{
${ }^{136}$ Este último hecho es frecuente cuando el mercado laboral es inestable, como el de Castilla y León, en el que sólo el 6,7\% de las contrataciones del año 2004 son fijas, según el Instituto Nacional de Empleo (INEM), y donde las únicas empresas que ofrecen una relativa estabilidad en el sector son un reducido núcleo de grandes firmas. Consecuencia de ello es que sus trabajadores guardan para sí su saber como garantía de supervivencia laboral.
} 
FIGURA 32

FASES METODOLÓGICAS PARA LA IMPLANTACIÓN DE UN SISTEMA DE GESTIÓN DEL CONOCIMIENTO EN PYMES DEL SECTOR AGROALIMENTARIO

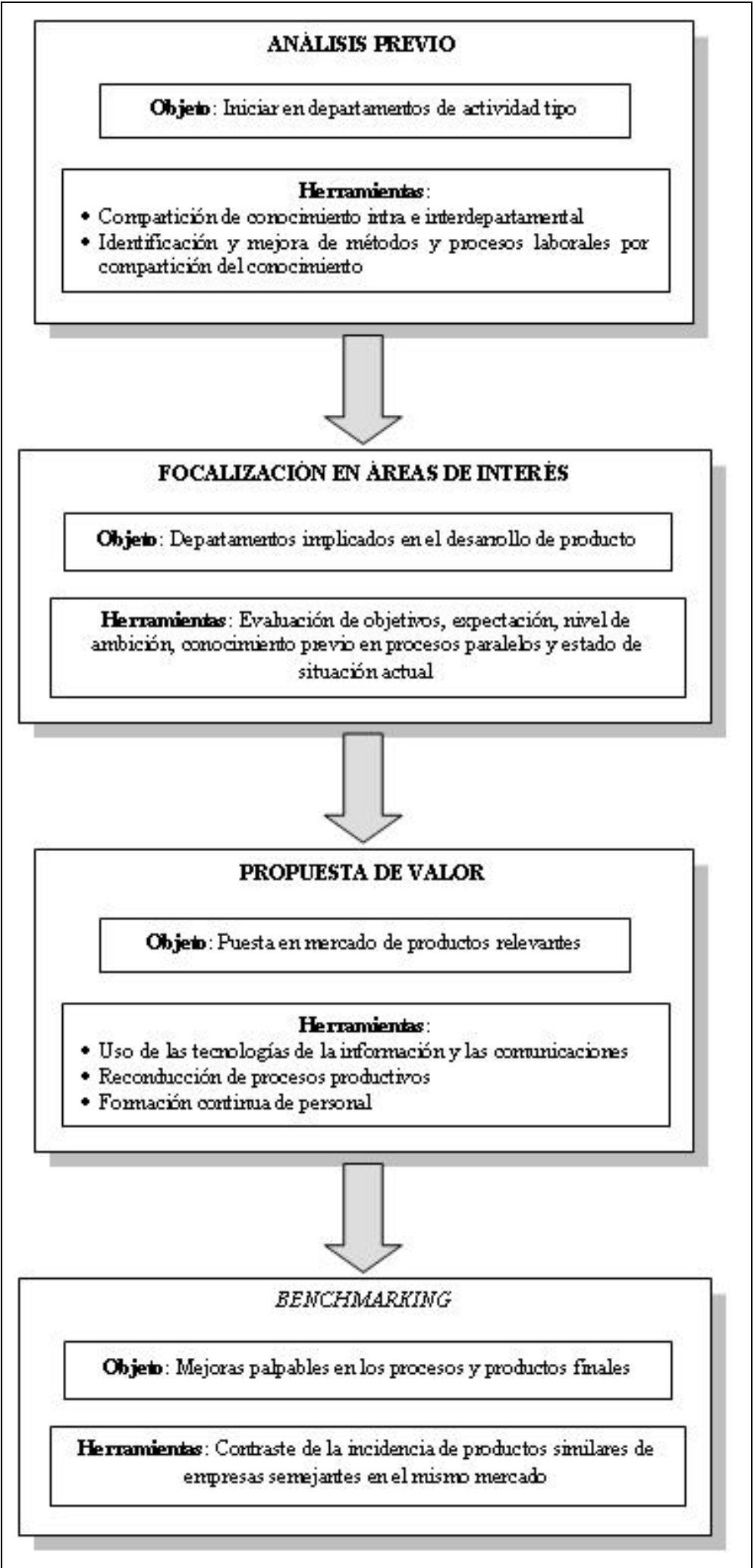

FUENTE: Elaboración Propia 


\section{VII.2.3. Propuesta de Valor}

Completadas las dos fases previas, la PYME de Castilla y León deberá estar preparada para lanzar al mercado sus productos agroalimentarios, lo que implica nuevos conceptos y modelos competenciales, que, a tenor de lo establecido en aquéllas, observamos requerirán de los siguientes factores:

- Gestión y planificación por parte de los directivos (quienes primeramente han tenido que cambiar su tradicional forma de pensar para seguir manteniendo su objetivo de generar beneficios) de modo que se favorezca la compartición y depósito de conocimiento en un ambiente laboral favorable; orientación hacia el crecimiento profesional de sus empleados; e identificación continuada de qué conoce cada uno.

- Uso administrativo racional. Debe simplificarse la burocracia en estas PYMEs, que no están acostumbradas a más formalismo que el imperante en las normativas legales o de calidad que les son aplicables, además de las tareas de secretaría rutinarias. La Gestión del Conocimiento implica el afloramiento y la circulación de éste por vía del Aprendizaje Organizativo, lo que lleva parejo un cambio de filosofía en su actuar, pero no en la proliferación de registros administrativos.

- Creación de un sistema documental, de fácil acceso, y una comunicación interdepartamental efectiva, que minimice pérdidas de tiempo en la búsqueda de información y la génesis de conocimiento. Esto no implica, ni siquiera, personal específico dedicado a esta actividad. Simplemente, la intención y asunción de esta nueva filosofía (plasmándose tanto en las nuevas tecnologías utilizadas en la gestión de los proyectos cuyo objetivo sea el lanzamiento de productos -incluida su promoción y marketing-, como en la documentación técnica que originan), e igualmente dotar de formación continuada a los trabajadores implicados. Entonces, la PYME debe tener presente este sistema a la hora de ofertar en el mercado sus productos, así como especificar sus requerimientos para desarrollarlos, con las tecnologías de la información y las comunicaciones como herramienta de soporte. 


\section{VII.2.4. Benchmarking}

Su propósito es comprobar las consecuencias del proceso de Gestión del Conocimiento insertado momentáneamente en la PYME de forma experimental (o definitivo, una vez avalado). Antes de llevar a cabo la primera valoración, se necesitarán una serie de medidas previas, puesto que, en caso contrario, no existiría ningún referente que permitiera evaluar el impacto de la incorporación del sistema de Gestión del Conocimiento elegido, ni cómo éste ha culminado con la mejora del producto y de su índice de ventas. Esta evaluación debe realizarse de modo anual y ser llevada a cabo por el departamento comercial, al ser quien puede hacer esta apreciación de forma tangible.

\section{VII.3. Directrices para el Sector de Automoción}

El sector de automoción de Castilla y León, como ya se puso de manifiesto en el capítulo II, se encuentra en una etapa de constantes cambios, de elevados incrementos de la productividad y de la competitividad, así como de fuertes presiones en los plazos de entrega de los vehículos. Por tanto, se debe pensar en una gestión inteligente (adaptada a las exigencias de la nueva economía) y tener en cuenta las opiniones y experiencia de los trabajadores, de manera que pueda fluir el conocimiento y se proceda a su gestión; diferenciándose, claramente, lo que ocurre en las grandes multinacionales del sector y lo que acontece en las PYMEs de su derredor.

\section{VII.3.1. El Referente de las Grandes Empresas: RENAULT-Palencia}

Las principales aportaciones del personal de las grandes compañías al conocimiento se ubican, especialmente, en las esferas de la ingeniería y la gestión ${ }_{137}^{137}$ por su elevada cualificación, su contacto con los proveedores y su mayor visión global. En el ámbito

${ }^{137}$ Los sistemas de gestión de las multinacionales del sector se pueden originar teniendo en cuenta las particularidades nacionales/regionales en donde se localizan, pero, muy probablemente, acabarán siendo inherentes a todo su tejido continental, o, incluso, mundial. Entre los estudios en este sentido, destacan los realizados por Ordóñez De Pablos [2002] a escala nacional, no exento de generalidad, y Gómez Vieites [2002], quien, tras establecer qué se entiende por conocimiento en la nueva economía, analiza un caso práctico y su impacto en la automoción. 
productivo, se centran en el mantenimiento de las instalaciones, la ergonomía y la mejora de los tiempos de proceso. De cualquier forma, la realimentación entre ambos niveles (ingeniería/gestión-producción) debe ser continua y no pueden operar separadamente.

La firma TOYOTA es la pionera mundial en Gestión del Conocimiento [Taiichi-1988], con gran anticipación a Europa e, incluso, a Estados Unidos, lo que demuestra la capacidad previsora y organizativa de la mentalidad japonesa.

De acuerdo con Perán González y Miguel Hernando [1999], en las grandes empresas del sector automoción español, dicha gestión suele acogerse a los dictámenes centrales de cada marca, pues resulta tremendamente difícil la creación de un sistema propio que facilite la integración y generación de nuevo conocimiento por múltiples personas de muy diferentes cualificaciones y actividades profesionales. Particularizando a Castilla y León, tan sólo RENAULT aplica un sistema de Management Integral, que trata de conseguir la eficacia en los procesos a través de una gestión efectiva (donde se incluye el conocimiento), según los parámetros just in time, stock cero y calidad de acabado, ya comentados en el apartado II.5.2, y que llevan implícito el uso de las tecnologías de la información y las comunicaciones al más alto nivel.

Este sistema fue iniciado en su factoría de Palencia, una de las más punteras y productivas de esta marca, por lo que, por su origen e importancia, se describe detalladamente en lo que sigue.

Certificada dicha factoría bajo la norma ISO 9000, y de acuerdo con las entrevistas y datos provistos en 2004 por el Sr. Enrique Espinel (Director de Comunicaciones y Benchmarking de RENAULT-España), cuenta con una forma de dirección participativa, basada en los tres principios siguientes:

- Cada unidad debe desarrollar su labor asumiendo la responsabilidad que le corresponde según nivel jerárquico, y respetando el principio de delegación. 
- La organización debe facilitar que cada unidad desarrolle su tarea de forma natural.

- Debe darse la máxima coherencia en el desarrollo de los objetivos en todos los niveles de la organización, potenciándose al máximo la creatividad y la participación.

En RENAULT, la Gestión del Conocimiento es entendida como el cambio que debe experimentar la empresa para que su cultura se oriente hacia el trabajo, con objetivos claros y contando con las personas. Según los especialistas de la compañía, dicha gestión existe desde el nacimiento de la organización, pero el verdadero desarrollo de una estrategia de este tipo, y su éxito, dependen de que se crea en el potencial del personal y se fomente su creatividad. De esta manera, forman parte del sistema de Gestión del Conocimiento implantado en todas las fábricas de RENAULT, los siguientes elementos:

- El sistema de sugerencias, en el que participa más del 95\% del personal, con una media de 10 sugerencias por persona y año, aplicándose el $90 \%$ de ellas.

- Los denominados Clubes Metiers, foros donde periódicamente se exponen las mejores prácticas desarrolladas.

- Actividades de benchmarking, donde se capitalizan las experiencias.

- Programa de acogida para los nuevos ingresos.

- Sistema de información transversal.

Esta cultura laboral se extiende transversalmente a todos sus centros a nivel mundial y RENAULT-Palencia la potenció a partir de 1989, fundamentalmente, ante una situación difícil del mercado, en la que se necesitaron tomar decisiones importantes para poder seguir compitiendo en el mismo. Es, entonces, cuando se planteó un plan fuerte de progreso, buscando la colaboración de todo el personal. 
Para ello, se eligieron diez operarios de fabricación, con la condición de que fuesen creativos, con inquietudes y capaces de contagiar entusiasmo. Estas personas recibieron la formación adecuada y se les propuso un plan de mejora continua para cada puesto de trabajo. El objetivo era que todo el mundo realizara su labor en condiciones de excelencia, analizando puesto a puesto y englobando todos los aspectos que influían en cada uno, tales como calidad, seguridad, etc. Una vez analizada cada función, se explicaba a los operarios cómo tenía que desarrollarse el trabajo para continuar con el proceso.

Se dio lugar, así, a un proyecto con una duración de dos años y tres meses. Durante este periodo, se analizaron todos y cada uno de los puestos de la factoría, con el propósito de maximizar su rendimiento. Los resultados obtenidos fueron importantes, concretándose, entre otros muchos, en la mejora de la calidad, la productividad y la comunicación, así como en la disminución de los accidentes, suponiendo un ahorro estimado de 24 millones de euros por año [Perán González y Miguel Hernando-1999: 87].

El éxito de esta acción se debió, básicamente, a la buena elección de los animadores del proyecto, que fueron capaces de integrar e implicar en el proceso al resto de la plantilla, facilitando la adecuación de los trabajadores a las nuevas definiciones de cada uno de los puestos de trabajo. Gracias a este plan, la Gestión del Conocimiento en la referida factoría recibió un fuerte impulso, fundamentándose en el Aprendizaje Organizativo, haciéndose extensiva al resto de unidades de la Comunidad Autónoma de modo progresivo, constatándose que el número de sugerencias sufrió un aumento significativo desde 1998 a 2003, y observándose su concordancia, en términos generales, con la producción real de vehículos (Figura 33).

Otro de los aspectos importantes de la acción comentada fue la forma de tratar los proyectos transversales. La Dirección se dio cuenta de que estos proyectos, por su carácter horizontal, no se podían llevar a cabo satisfactoriamente con la estructura jerárquica funcional tradicional. Ésta debería facilitar el trabajo diario.

Los proyectos transversales, al ser los que provocan el progreso de la empresa, deben desarrollarse con personal propio y de gran experiencia, no con personal externo. Todos 
los Mandos, además de desarrollar su trabajo ordinario, están implicados en ellos. Necesitan de un animador que fomente y siga su desarrollo y aplicación, además de una implicación clara y concreta de la directiva.

FIGURA 33

INFLUENCIA DE LA IMPLANTACIÓN DE UN SISTEMA DE GESTIÓN DEL CONOCIMIENTO EN LA PRODUCCIÓN DE VEHÍCULOS DE LAS FÁBRICAS DE RENAULT EN CASTILLA Y LEÓN
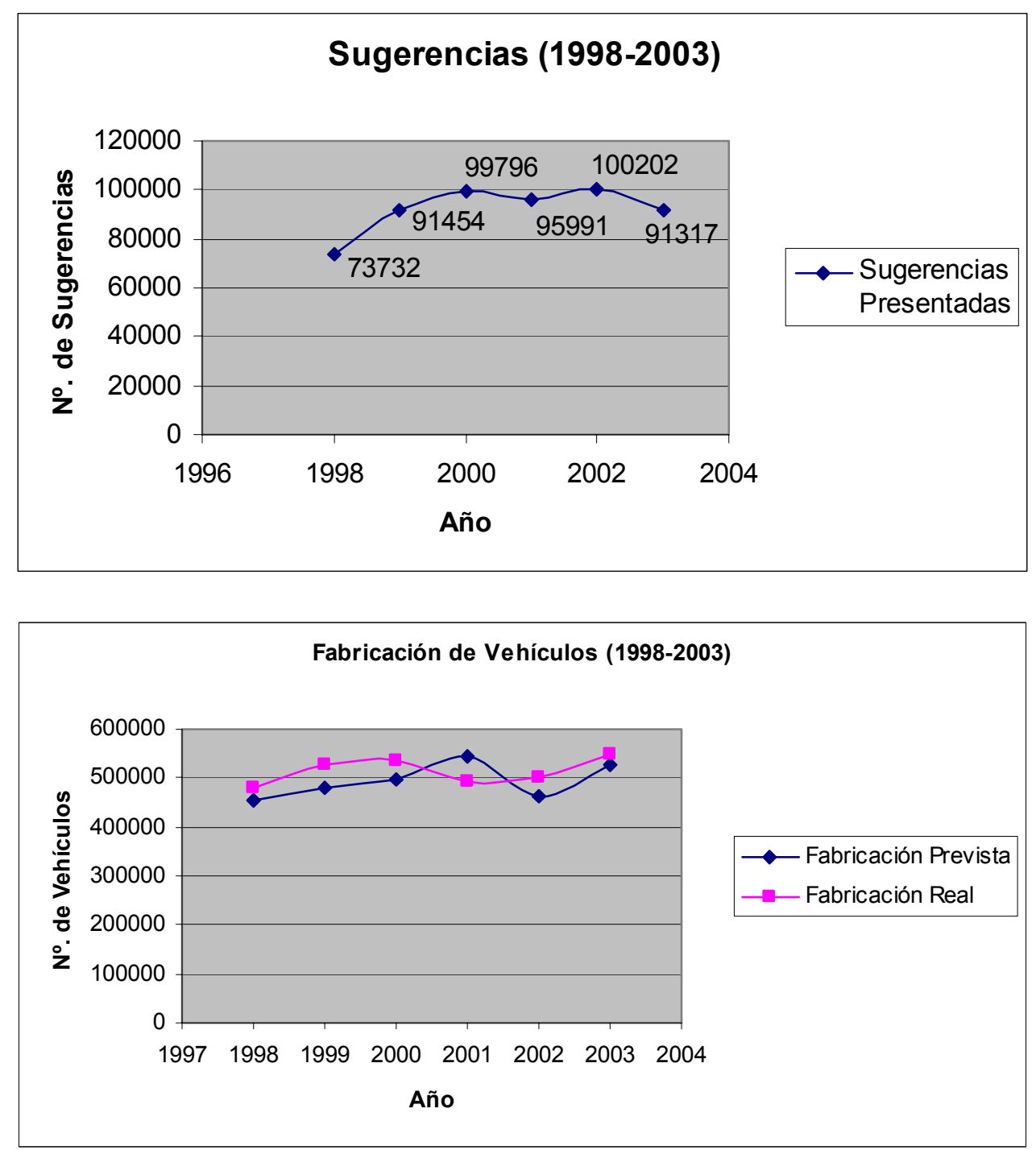

FUENTE: RENAULT

La mayor barrera a la que se enfrenta cualquiera de esos Mandos es la falta de entusiasmo. Por este motivo, requieren líderes convencidos y animadores constantes. Además, la inicial resistencia al cambio de buena parte de los trabajadores que realizan tareas rutinarias suele ser importante en los primeros momentos del proyecto, por lo que 
se debe explicar, siempre claramente, que el objetivo perseguido con la herramienta que se pretende implantar es una mejora de los resultados económicos y de las condiciones de trabajo.

Los expertos de RENAULT-Palencia recomiendan a las empresas los siguientes factores a tener en cuenta, para obtener unos resultados positivos en este tipo de acciones:

1. Invertir en formación, para dotar a todo su personal de los conocimientos necesarios para que puedan desarrollar sus funciones correctamente. Esta es, precisamente, una de las causas más importantes de fracaso de aquellas PYMEs que, ante el elevado desembolso que, principalmente, supone una formación de alto nivel, no la realizan.

2. Definir claramente las competencias de cada puesto, para que no surjan incompatibilidades.

3. Conocer, creer y hacer crecer a las personas que forman parte real de la empresa, el factor más importante del éxito de una estrategia de este tipo.

4. Dejarse ayudar, no creerse autosuficientes y ser conscientes de que se puede progresar acercándose a otras organizaciones.

5. Contar con personas con experiencia y motivadas con el proyecto a emprender.

6. Favorecer el trabajo en equipo y la comunicación vertical en un doble sentido.

7. Implantar un sistema de sugerencias comprometido con la empresa.

No obstante, esta implantación realista y ejemplar de la Gestión del Conocimiento para el caso de RENAULT, dista mucho de ser la existente en las PYMEs sectoriales de Castilla y León, como seguidamente se expone. 


\section{VII.3.2. Situación de las Pequeñas y Medianas Empresas}

La subsistencia de las PYMEs regionales del sector de automoción es la que se encuentra más amenazada, tanto por su situación intrínseca, como por los factores indicados en el análisis sectorial de Castilla y León (véase capítulo II).

No son ajenas a la Gestión del Conocimiento y se centran en fases muy concretas del proceso productivo de la/s multinacional/es a quien prestan sus servicios, con un número de empleados muy por debajo del de las mismas (lo que las hace más fácilmente analizables). No obstante, no integran aquella verdaderamente en su actividad como parámetro básico de supervivencia [Gómez Vieites-2002; Ordóñez De Pablos-2002].

El diseño, la producción e implantación de sistemas y elementos de alta tecnología canalizan la principal demanda hacia estas PYMEs, lo que redunda en plantillas en las que gran parte de sus trabajadores desarrollan labores de ingeniería [Perán González y Antolín Giraldo-1999], debiendo tener, por tanto, elevada cualificación técnica, conciencia de innovación y conocimientos de Calidad.

Sus principales problemas, más ligados a su ambiente externo que a su estructura interna, proceden de la rapidez con que cambian las tecnologías y los componentes que utilizan, con sistemas cada vez más complejos (combinación de los previamente existentes), así como de tener que incorporar especialidades como la microelectrónica y la óptica $\frac{138}{13}$, como establece el informe NANOSPAIN [2003]. De dicho informe se desprende, consecuentemente, que para mantener su competitividad, han de poseer un alto grado de experiencia en estas disciplinas, que, aunque sean ya maduras desde el punto de vista científico, resultan relativamente novedosas en la industria, al alcanzarse en los momentos actuales el grado de robustez necesario para su implantación.

\footnotetext{
${ }^{138}$ El ejemplo más significativo es la Visión por Computador, disciplina altamente demandada en los procesos productivos desde finales del siglo XX [Triadó Aymerich-1998].
} 
Las consecuencias que se derivan de tales problemas, repercuten en la organización de las PYMEs, planteándoles, a nuestro juicio, la difícil elección entre:

- Incorporarse a la dinámica de competir en los costes, lo que les conduce a trabajar con proveedores internacionales y aceptar las fluctuaciones que ello supone, o bien,

- Centrarse en la innovación tecnológica y en el seguimiento de sus avances. Inclinarse por esta alternativa constituye una estrategia que conduce a las empresas a tener que saber cómo emplear su conocimiento para sobrevivir, y a sus directivos a cómo gestionar este recurso fundamental.

La Gestión del Conocimiento se convierte, de esta forma, en una de las prioridades estratégicas de la organización productiva.

\section{VII.3.2.1. Propuesta Metodológica de Gestión del Conocimiento}

La implantación de un sistema de Gestión del Conocimiento siempre es un aspecto delicado en la empresa, puesto que supone una negociación individual, nunca una imposición. Por ello, considerando los estudios del perfil de las PYMEs del sector de automoción de Castilla y León [Rodríguez Enríquez-2002; UGT-2002], se sugiere que la mejor manera de integrar dicho sistema es constituir un grupo de personal voluntario (formado por directivos, ingenieros y técnicos) surgido de ellas.

Este grupo se organizará de modo análogo a cómo lo harían en un proyecto típico a desarrollar por la empresa, y teniendo un coordinador que, por la experiencia acumulada, conocimiento de la compañía y alta cualificación, bien pudiera ser alguien retirado de la PYME. Con esta figura se lograría, además, una completa disposición, muy baja influencia de las presiones laborales, y no tener que destinar a ello personal de plantilla, siempre muy ajustada. Análogamente, se establecerá un cronograma de actuación, que, teniendo en cuenta el dinamismo y percepción de cambios organizativos importantes que caracteriza a estas empresas, se fijará en dos años $\frac{139}{1}$. Por último, se deberá disponer de los recursos humanos y técnicos necesarios, cuando sea preciso. Su 
objetivo final será proponer un sistema de Gestión del Conocimiento global que pueda ser finalmente aceptado por la mayoría de los trabajadores (Figura 34).

FIGURA 34

FASES METODOLÓGICAS PARA LA IMPLANTACIÓN DE UN SISTEMA DE GESTIÓN DEL CONOCIMIENTO EN PYMES DEL SECTOR AUTOMOCIÓN

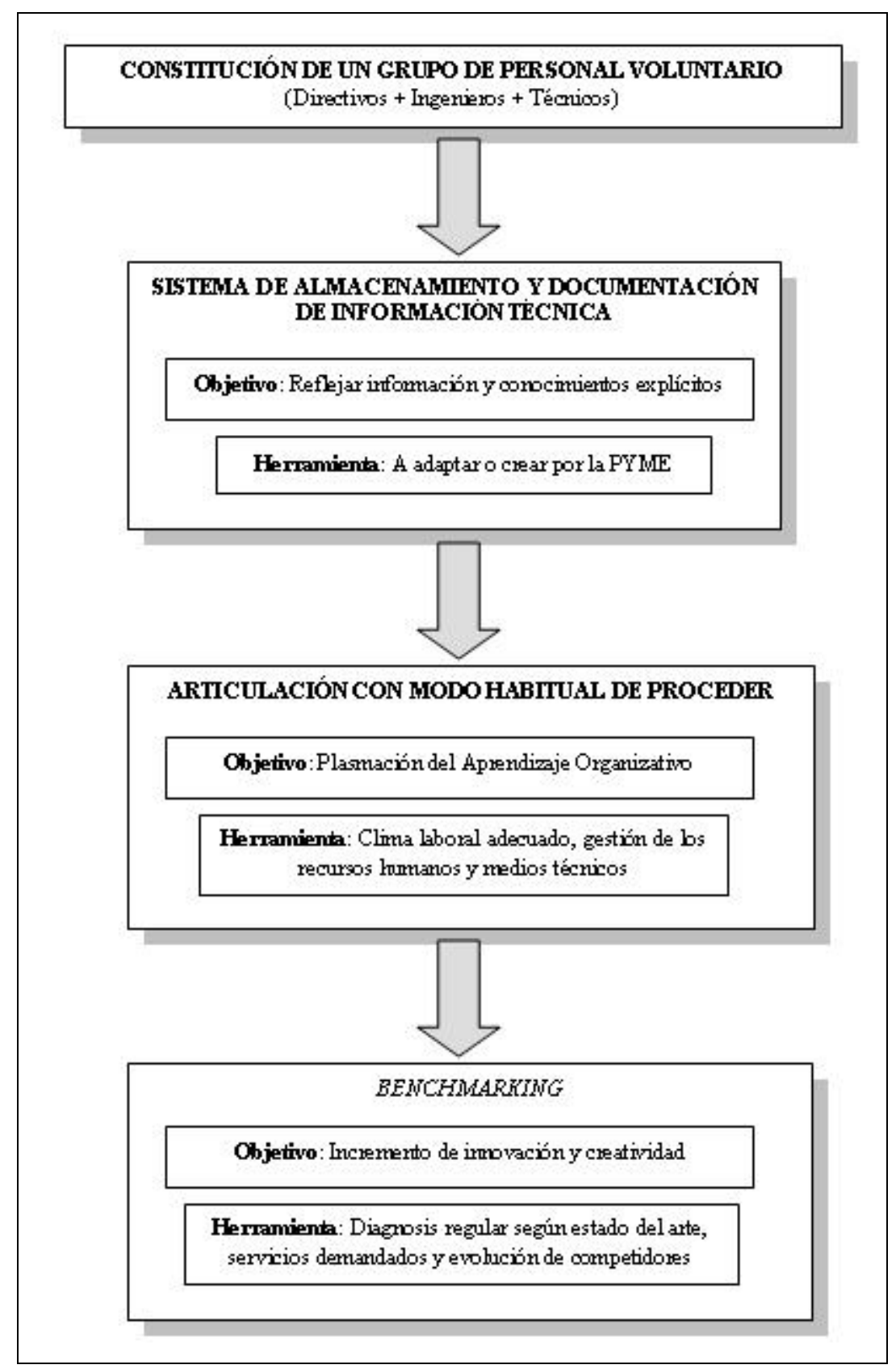

FUENTE: Elaboración Propia

\footnotetext{
${ }^{139}$ Tomándose como referente el tiempo indicado en el apartado VII.3.1 para RENAULT-Palencia.
} 
El equipo del proyecto debe iniciar su andadura poniendo en marcha estos aspectos:

1. Un sistema de almacenamiento y documentación de información técnica (si no está ya implantado en la PYME), que sea concreto, de fácil manejo y acceso para quien lo necesita, así como realista en cuanto a su utilidad e integración. Es necesario involucrar en él al personal de aquellas especialidades que lo necesiten y articularlo en su modo diario de proceder. Con ello se obtiene un sistema en el que se plasman conocimientos específicos para beneficio personal y del resto de la empresa (lo que puede favorecer la colaboración interprofesional y la plasmación del Aprendizaje Organizativo), en lugar de una simple fórmula de almacenaje (como las aplicaciones informáticas al efecto). Todo ello siempre que el clima laboral de la PYME sea el adecuado, se favorezca el diálogo y se tengan en cuenta las opiniones de los empleados. En caso contrario, el referido sistema puede ser abandonado, empleado sólo para cubrir expediente, o, incluso, encauzado a la exculpación de fallos, afán de protagonismo personal (beneficiándose de acciones ajenas) y transferencia de información a terceros. Puesto que la responsabilidad sobre el clima laboral recae, en su mayor parte, sobre la directiva de la PYME y sus políticas, su grado de implicación e importancia en la Gestión del Conocimiento es decisivo.

2. Ejercitar el benchmarking con clientes y proveedores.

Con la implantación de estos dos aspectos se persigue un doble objetivo:

- Que se reduzcan los costes y tiempos de entrega, a través de la reutilización e intercambio de experiencia y conocimiento.

- Que se incremente la innovación y la creatividad, es decir, la combinación de saber hacer (know how) y saber qué hacer (know what), en todos los ámbitos de la actividad empresarial. En este sentido, juega un papel importante el hecho de que, muy frecuentemente, los empleados de la PYME trabajan no sólo según las premisas de sus clientes, sino físicamente en sus propias instalaciones, lo que mantiene muy viva y actualizada la información sobre procesos, metodologías y tecnologías. 
Puesta en marcha la Gestión del Conocimiento, a continuación, se debe implementar, también, un sistema de diagnosis regular, que permita determinar las fortalezas y debilidades que se van observando en ella, teniendo en cuenta el estado del arte de las tecnologías manejadas, la demanda de servicios de los clientes y la evolución de los competidores. Esta evaluación deberá hacerse anualmente, pudiendo ser necesario, al menos en sus comienzos, recurrir a un servicio de consultoría externo. El diagnóstico resultante pretende revisar el estado de la experiencia tecnológica de la PYME, a la par que analizar las áreas potenciales de desarrollo, en aras a determinar el cambio o evolución de su actividad.

\section{VII.3.2.2. Las Fuentes del Conocimiento}

Para mantener su competitividad, las PYMEs del sector de automoción de Castilla y León recurren, con cada vez mayor asiduidad, al apoyo y servicios de la universidad 140 y los Centros Tecnológicos $\frac{141}{\text {, }}$ a objeto de tener un grado adecuado de conocimiento respecto a los avances científicos que, antes o después, tendrán que incorporar a sus actividades [JUNTA DE CASTILLA Y LEÓN-2002b].

También es muy importante el conocimiento que emerge de su propia experiencia interna, que observamos tiene un triple origen 142 .

- Preguntas frecuentes (Frequently Asked Questions: FAQ), que son soluciones adoptadas o desarrolladas como resultado de las consultas de los clientes.

- Batería de ideas todavía no implementadas.

\footnotetext{
${ }^{140}$ Es reseñable, en este sentido, la labor que realizan distintos departamentos de la Escuela Técnica Superior de Ingenieros Industriales de la Universidad de Valladolid.

141 Por orden de importancia, sobresalen: CIDAUT (diseño de elementos con materiales poliméricos, análisis de vibraciones, comportamiento ante impacto, acústica de vehículos, combustibles y sistemas de inyección a baja presión), CARTIF (cálculo y simulación de elementos mecánicos, así como mejora de procesos industriales), e ITCL (mejora de la gestión de calidad).

142 Deducción realizada tras entrevista personal en 2004 a cinco empleados de relevancia de las principales empresas subcontratadas por RENAULT-Valladolid: POLYMONT y PYSSA.
} 
- Relación de problemas surgidos durante el diseño e implantación de proyectos previos y propuesta de soluciones en la actividad de la PYME, teniendo en cuenta sus disfunciones y fracasos.

Todo ello contribuye, por un lado, a conformar lo que podríamos llamar la "memoria tecnológica" de la empresa, ayudándole a reaccionar rápidamente ante las demandas de sus clientes, reduciendo costes y demoras en la entrega de sus productos, gracias a la reutilización de su conocimiento. Por otro, al desarrollo de su creatividad y a la eliminación de problemas equivalentes en diferentes proyectos, sobre todo en la fase de diseño y planificación, al existir un intercambio de aprendizaje entre las diferentes especialidades técnicas y su cuerpo de profesionales.

A su vez, conducirá a la fertilización de un campo de soluciones innovadoras que apunten directamente al mercado real y potencial de la PYME; así como a la optimización de su proceso de decisión, tanto en lo relativo al personal a emplear, como en lo concerniente a la selección de metodologías y tecnologías.

\section{VII.3.2.3. Gestión Paralela de los Recursos Humanos}

Desde el momento en que el conocimiento se convierte en el núcleo de los recursos estratégicos de la PYME del sector de automoción, se plantea la cuestión de la protección de la propiedad intelectual en su interior, por cuanto la experiencia y el saber hacer, depositados en personas individuales, redundan en acciones colectivas.

Alles [2000] establece que dicha protección debe asegurarse a través de la ética profesional y del sentimiento de pertenencia a la empresa por parte de sus empleados. Este hecho es factible en un ambiente profesional adecuado, sobre el que, como ya ha sido comentado, han de volcarse sus directivos. Dado que los beneficios y presupuestos de que éstos disponen suelen ser ajustados, no se tiene margen de acción para premiar a las personas realmente involucradas en el proceso de creación de conocimiento. Por este motivo, deberán implementar un ambiente laboral agradable (especialmente cuando la dedicación no sea únicamente la de producción), favorecedor de las relaciones cordiales y del Aprendizaje Organizativo. 
Sin embargo, es sabido que un ambiente muy distendido puede originar una progresiva merma de productividad, o un distanciamiento de las grandes presiones a que se ven sometidas las PYMEs del sector automoción en Castilla y León. Así, pues, se deberá llegar a una solución de compromiso, en la que, además del clima de propagación del Aprendizaje Organizativo creado por la directiva, los empleados se hagan valer y demuestren su experiencia. Consecuentemente, se recomienda que cada empleado sea evaluado anual y correctamente, aplicando diferentes criterios, en función de los resultados obtenidos en su trabajo, su práctica profesional y su contribución a la consecución de objetivos en los proyectos en los que ha participado.

Es muy probable que, durante la puesta en marcha del sistema de Gestión del Conocimiento en la PYME, los trabajadores manifiesten expectación y reticencia hacia el mismo, y que sólo los ingenieros y técnicos de alta cualificación aprecien lo que supone, participando rápidamente en aquél. El equipo de proyecto establecido para esta implantación deberá limar, por tanto, las resistencias que se originen. Los empleados sólo necesitan ser convencidos de que, realmente, constituye un medio para mejorar profesionalmente y como empresa; facilita el trabajo de todos; y no es un proceso administrativo.

De esta manera, el sistema de Gestión del Conocimiento irá penetrando, progresivamente, en la empresa y se emplearán las herramientas implementadas en este sentido (creadas por los propios trabajadores, en algunos casos, como síntoma de su aceptación). Entre ellas sobresale el benchmarking, dado que ayuda a entender cómo ha sido de exitosa, o no, la introducción de un sistema de este tipo en otras empresas. La más importante fuente de información para estas PYMEs del sector de automoción de Castilla y León, y muy cercana a las mismas, son las grandes compañías para quien prestan sus servicios (especialmente RENAULT), puesto que habrán de testear diferentes metodologías.

Finalmente, el equipo encargado del referido sistema de gestión deberá tener al corriente, en todo momento, a la directiva de la PYME sobre la progresión alcanzada y las decisiones que es preciso adoptar para su completa aceptación, haciendo intervenir a aquélla en su diseño. 


\section{VII.3.2.4. Mejoras Esperadas}

Tras la adopción del sistema de Gestión del Conocimiento, la PYME de automoción deberá observar un incremento en sus beneficios económicos y, ante todo, un avance en su nivel profesional en alta tecnología con respecto al de sus competidores directos.

Ciertamente, la medición exacta de la cuantía de estos resultados es inverosímil, sobre todo durante los dos primeros años de la implantación gradual del sistema elegido, a los que habrá que sumar el tiempo que reste, en cada caso, para que el total de la plantilla lo asuma como algo cotidiano. No obstante, de acuerdo con Santidrián Arroyo [2003], cuando finalice dicho proceso, habrán de identificarse, al menos, los siguientes beneficios:

- En términos cuantitativos, uno de los más reveladores será la mejora de la reacción y la capacidad de respuesta ante las demandas de los clientes, aun cuando los proyectos se tornen, incluso, cada vez más sofisticados.

- Cualitativamente, se observará que los empleados se sentirán inmersos en un ambiente de aprendizaje continuo. Su interés por el trabajo aumentará, así como su grado de implicación.

Puede afirmarse, en suma, que la puesta en marcha de un sistema de Gestión del Conocimiento es crucial para la supervivencia de las PYMEs del sector de automoción que poseen un potencial de alta cualificación, pero disponen de escasos recursos económicos y medios materiales. No debe suponer, sin embargo, un sofisticado y tedioso proceso, sino la creación de un substrato de conocimiento, que vaya germinando y creciendo en un entorno constructivo, ajustado a las necesidades de los trabajadores (técnicas y organizativas).

A continuación, es preciso asegurarse de que este conocimiento es realmente utilizado. Depositarlo en bases de datos u otras aplicaciones existentes en el mercado para su almacenaje y control es, realmente, una utopía. Depende, en mayor medida de lo que 
ocurre en las grandes compañías del sector, de las competencias individuales y del quién es quién en la experiencia e innovación colectiva de la PYME.

\section{VII.4. Directrices para el Sector de las Tecnologías de la Información y las Comunicaciones}

Hasta la década de los años noventa del siglo XX, la implantación de empresas de las tecnologías de la información y de las comunicaciones en Castilla y León se reducía, básicamente, a las delegaciones territoriales de TELEFÓNICA y sus asociadas, para prestación de servicios de telefonía, mantenimiento de líneas, contrataciones y sus derivados [JUNTA DE CASTILLA Y LEÓN-2003a].

Desde entonces, según el informe de TELEFÓNICA [2003], la rápida evolución que han venido experimentando las tecnologías de la información y las comunicaciones, ha supuesto un drástico cambio en el modo de proceder de las grandes empresas del sector, probablemente las más influenciadas por el incesante avance tecnológico, adaptándose continuamente al mismo, para lograr cada vez mayor cuota de mercado.

De acuerdo con la JUNTA DE CASTILLA Y LEÓN [2002a, 2002b, 2003a], el desarrollo tecnológico se concentra, sin embargo, en un reducido número de grandes firmas multinacionales, donde, a su vez, sólo TELEFÓNICA desarrolla labores de $\mathrm{I}+\mathrm{D}+\mathrm{i}$ propias. El resto lo conforman estructuras administrativas, comerciales y de soporte técnico. A estas últimas actividades están orientadas, también, las PYMEs satélite de aquéllas. En un ambiente tan cambiante, con grandes empresas fuertemente consolidadas, donde la principal preocupación es de tipo comercial y de mantenimiento de la infraestructura, resulta complicado hablar de Gestión del Conocimiento. Sobresalen los esfuerzos realizados, en este sentido, por VODAFONE [Cañibano Calvo et al.-2002] y TELEFÓNICA [Temboury Redondo-2003].

En Castilla y León, las grandes, medianas y pequeñas empresas del sector fundamentan el control de su información en softwares que permiten mantener al día la relación de clientes, la localización de averías, automatizar las ventas, el marketing y los servicios, 
tanto a través de los canales convencionales (centros de llamadas, puntos de venta y franquicias), como por medio de los nuevos canales electrónicos (Internet). El material comercial (paquetes de programación, hardware, etc.) para el desarrollo de aparatos y aplicaciones específicas, constituyen las restantes herramientas que utilizan [JUNTA DE CASTILLA Y LEÓN-2002b, 2003a, 2004].

Conformes con De Aldama [2002], hasta el año 2001 (momento en que se apunta una ralentización del sector), todas las empresas pasaron por un período de incorporación masiva de personal. Se hace imperativo, entonces, asegurar que el conocimiento de los empleados veteranos, junto con el que progresivamente van adquiriendo los restantes trabajadores de la empresa, debe aprovecharse y mantenerse de modo efectivo.

\section{VII.4.1. Modo de Proceder en las Empresas}

Siguiendo a Almansa, Andreu y Sieber [2002], el conocimiento en las empresas del sector no está organizado. Su información se localiza en un servidor central, pero determinados datos y procedimientos no tienen cabida en sus aplicaciones, o en los campos recogidos por sus programas de almacenamiento. En numerosas ocasiones, la materia prima del conocimiento a compartir, muy extenso, no se encuentra disponible, estando almacenado en el ordenador de individuos particulares.

Es posible, además, que la compañía no sea consciente de este hecho. Es igualmente plausible observar que las empresas del ramo caen, a veces, en la propia trampa de creer que, perteneciendo a un sector de gran significación económica y social, pueden almacenar e interpretar procesos entre personas, y el conocimiento generado, como si se tratase de los datos que ellas mismas manejan diariamente en ingentes cantidades, mediante la tecnología a quien sirven y desarrollan, situación de la que no está exenta Castilla y León.

Iivonen y Huotari [2004] exponen cuatro motivos principales que avalan la necesidad de implantar un sistema de Gestión del Conocimiento en estas empresas:

- El mercado es cada vez más competitivo. 
- Las empresas han pasado de un período de rápida expansión a uno de crecimiento sostenido.

- Se necesita ampliar la relación de clientes.

- La apertura hacia nuevos o incipientes mercados.

Para afrontarlos, en el sector de las tecnologías de la información y las comunicaciones de Castilla y León, se ha de crear una estructura colaboracionista entre la empresa correspondiente y sus subcontratadas. Sólo cooperando entre ellas, en lugar de entender su relación como supeditación de las segundas a la primera, podrán desafiarse los retos que los referidos motivos plantean. Esta relación debe dar lugar a una simbiosis en la que es necesario disponer del conocimiento de todos los empleados, hecho que dará lugar a prestaciones más eficaces, eficientes, y a ofrecer a los clientes nuevos productos y servicios. Consecuentemente, no haremos distinción entre grandes firmas y PYMEs asociadas.

La particular característica de que toda su actividad se lleva a cabo a través de sistemas informáticos, permite examinar cómo a medio plazo las empresas pueden crear y mantener su conocimiento explícito de modo centralizado, cubriendo todos sus aspectos de negocio.

La implantación del sistema de Gestión del Conocimiento debe comenzar concentrándose en uno de dichos aspectos, únicamente, haciéndose sobre él las validaciones oportunas (fase inicial), para finalmente hacerse extensivo a toda la gama de productos y/o servicios, y a la totalidad del conjunto empresarial.

De este modo, se seleccionarán dos grupos de personas, uno dedicado al diseño de producto y otro equivalente, a su venta (que incluso pudieran ser de empresas distintas, aglutinadas bajo un fin común). Se observará, entonces, cuál es la interacción entre ambos y el conocimiento que intercambian. El problema que se plantea a continuación estriba en cómo formalizar y gestionar el flujo de conocimiento entre los dos grupos, haciéndolo disponible para todo aquel que lo necesite. Posteriormente, validado el 
sistema de gestión para ambos, se hará partícipe del mismo a las áreas de asistencia técnica y restantes de interés de la estructura empresarial.

Se propone, por tanto, crear una Intranet (red interna), fundamentada en las dos concepciones que conforman todo conocimiento: como producto (contenido) y como proceso (continente), aunque esta última acepción, con frecuencia, no es tenida en cuenta. La herramienta que se construya debe tener presente las formas de colaboración de las áreas o empresas implicadas, un procedimiento de búsqueda avanzada de fácil manejo, y la posibilidad de poder acceder a la información documental (técnica y administrativa) que se requiera. Para su creación, se han de realizar entrevistas y conversaciones que permitan la identificación y focalización del conocimiento en la empresa y/o sus asociadas, pudiéndose recurrir a los servicios de una consultora externa, para llevarlas a cabo (Figura 35).

\section{VII.4.2. Las Fuentes del Conocimiento}

Las entrevistas y conversaciones referidas en el apartado anterior permitirán identificar, en mayor o menor medida, las siguientes fuentes de conocimiento en la empresa o asociación de las mismas, propuestas por Whitman y Woszczynski [2004]:

1. El conocimiento proveniente de los empleados, debiéndose tener en cuenta sus capacidades, experiencia, destreza en el desarrollo de los cometidos asignados, y su habilidad para generar sugerencias de mejora y nuevas ideas.

2. El conocimiento estructural: aglutina las metodologías de gestión de proyectos (con su asignación de recursos humanos) y creación de productos (junto con los patentados - hardware o software -).

3. El conocimiento del mercado: grado de conocimiento de los modos de proceder y productos de la competencia, $\mathrm{I}+\mathrm{D}+\mathrm{i}$, necesidades reales de los clientes, etc. 
FIGURA 35

FASES METODOLÓGICAS PARA LA IMPLANTACIÓN DE UN SISTEMA DE GESTIÓN DEL CONOCIMIENTO EN EL SECTOR DE LAS TECNOLOGÍAS DE LA INFORMACIÓN Y LAS COMUNICACIONES

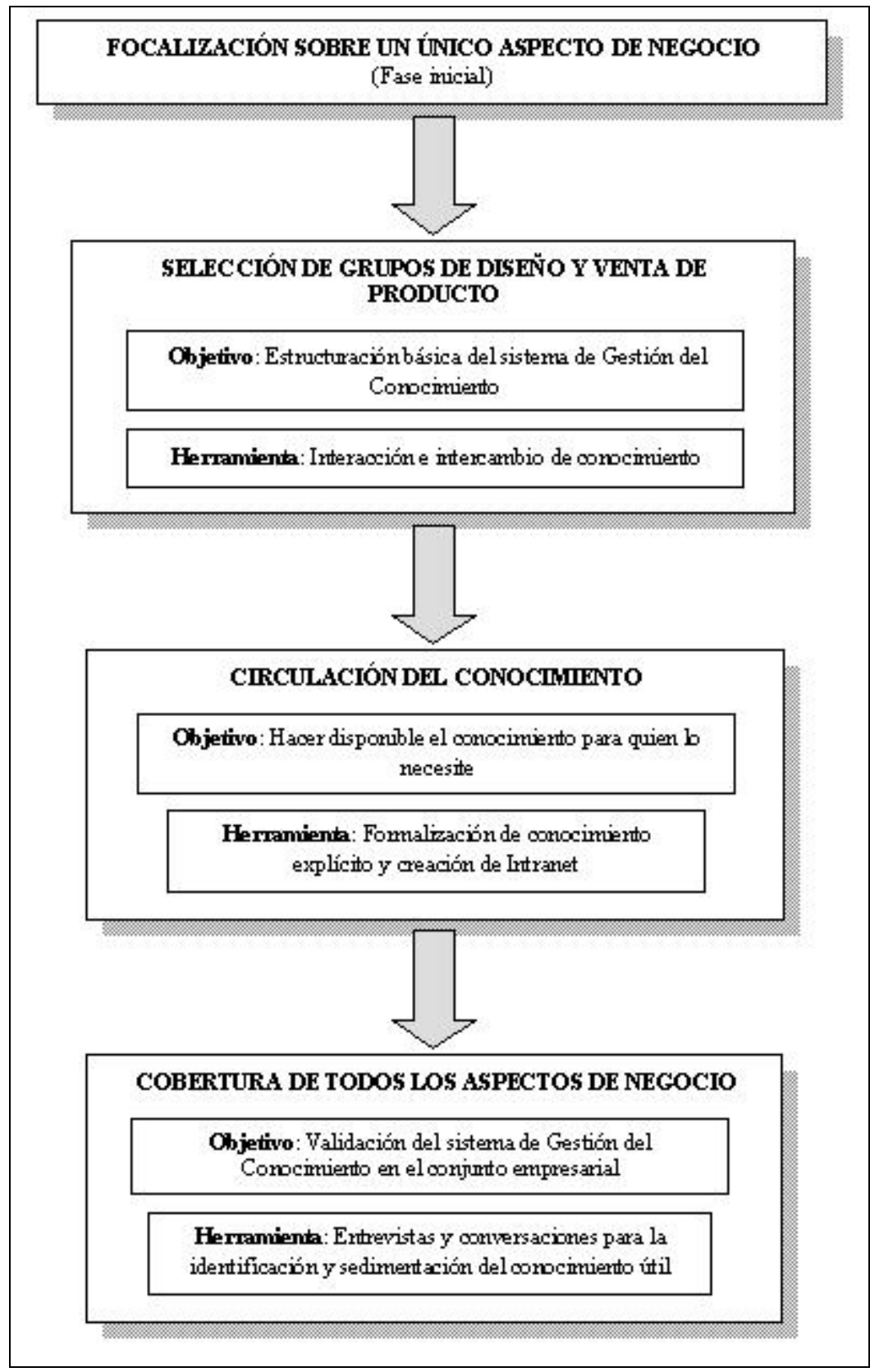

FUENTE: Elaboración Propia

Tanto en la celebración de las entrevistas, como en su interpretación, la presencia e involucración de los empleados de mayor permanencia en la empresa adquiere gran importancia, puesto que ubicarán los resultados obtenidos en un marco global no alcanzable por otros trabajadores. Análogamente, cada persona entrevistada debe 
entender, claramente, la razón de la propuesta de un sistema de Gestión del Conocimiento y las expectativas para con él (sobre todo, en la fase inicial), involucrarse en el proyecto y desear ser beneficiario de las ventajas que de dicho sistema se espera. En todo momento, existirá la figura del coordinador, que irá definiendo las bases sobre las que se cimienta el conocimiento de la/s empresa/s involucrada/s, su estructuración y la implementación de su gestión. Dicho conocimiento debe ser entendido, entonces, como una capacidad.

\section{VII.4.3. Los Instrumentos}

En las empresas de las tecnologías de la información y de las comunicaciones, es natural que todos los empleados que participan en las tareas que puedan generar conocimiento tengan acceso a Internet y a su Intranet. Además, por sus funciones laborales, obviamente están acostumbrados a las nuevas tecnologías, y su manejo es algo cotidiano, lo que supone una clara ventaja frente a otros sectores en Castilla y León.

De acuerdo con las propuestas dadas por Martínez Arévalo [2001], las características que debe poseer la red interna, como instrumento para la Gestión del Conocimiento, son: detalles de los empleados (localización, teléfono/Fax, correo electrónico, etc.); metodologías para la gestión de proyectos y la puesta en el mercado de los productos; calendario de eventos (lanzamientos y versiones); sugerencias; uso del correo electrónico; y página web propia de la empresa y de sus asociadas. El servidor central proveerá, asimismo, de la información relativa a los proyectos en curso y los previos; su documentación técnica; iniciativas de negocio; campañas de marketing (con ventajas y preferencia para con los empleados); junto con folletos, presentaciones, informes y procedimientos administrativos, en formato electrónico unificado, para proyectar la misma imagen al exterior.

Todo ello, gracias, principalmente, a la mencionada estandarización, creará un foro virtual de colaboración, que deberá ir acompañado de un clima laboral agradable, para tratar de mejorar la comunicación entre grupos de trabajadores y áreas implicadas. Sus comunicaciones informales cubren aspectos relacionados con errores de software y/o 
hardware, asuntos generales, formas de mejora y todo tipo de cuestiones que afectan a la funcionalidad de la empresa. Se reducen, además, a grupos afectivamente cercanos y no permiten disponer, a quien pudiera necesitarlo, de las ideas y conocimiento emanados de las mismas. Por la vía de Intranet, en cambio, la comunicación despreocupada que acabamos de citar, queda canalizada y formalizada. Se permite cubrir así, en parte, la concepción de la generación de conocimiento como proceso.

De este manera, no sólo se mejora la comunicación entre miembros de una misma o distinta área laboral (como las de diseño y venta de producto, en la fase inicial), sino, también, la que se da entre diferentes oficinas y filiales de la/s empresa/s. La necesidad de comunicación y colaboración por esta vía es esencial, sobre todo entre grupos implicados en un fin común, que están situados en diferentes localizaciones, hecho frecuente en este sector, sobre todo en lo que a la elaboración de software se refiere [Bianchi y Kluzer-1997]. Por ello, tanto la red interna como los perfiles de entrada de cada trabajador deben ser accesibles desde cualquier ubicación de la/s empresa/s; produciéndose, así, una mutua realimentación entre las necesidades surgidas y la Intranet, reteniéndose el máximo conocimiento generado (poniendo en el servidor informes, planificaciones, etc.) y pudiendo ser gestionado.

No obstante, ante la rapidez de desarrollo del sector y la necesidad de consolidar o buscar nicho de mercado, semejante accesibilidad puede plantear problemas de seguridad para la empresa que deben ser controlados por alguna via (restricción de acceso según perfil profesional u otras), como propone UIT [2003].

\section{VII.4.4. Obstáculos Presentados}

Se ha señalado anteriormente que, en un principio, el sistema de Gestión del Conocimiento sólo se pondría en marcha en dos áreas (diseño/venta), y que las personas involucradas en las mismas harían una primera evaluación de aquél.

Como establecen Koumpis y Roberts [2003], se detectará en la plantilla una resistencia inicial a modificar o protocolizar las formas convencionales de comunicación sobre aspectos de índole laboral, que se irá venciendo a medida que los propios empleados 
observen tanto que realmente se crea conocimiento por la nueva vía, como relacionen conceptos y resultados (en la magnitud en que se logren), a la par que se les haga comprender (en la fase previa a su puesta en marcha, y a lo largo de su integración, mediante seminarios y reuniones grupales) qué es y para qué sirve la Gestión del Conocimiento. Este modo de proceder debe ser igual en todas las delegaciones de la/s empresa/s con áreas involucradas.

Puesto que nos encontramos ante empresas del sector de las tecnologías de la información y las comunicaciones, no se prevén problemas en la introducción y uso de nuevos sistemas basados en redes de ordenadores, pero, se presume que sí surgirán en su personal. Éstos habrán de resolverse mediante una gestión efectiva de los recursos humanos. Obviamente, el coordinador del sistema será el primero en asumir los cambios que supone la implantación planteada. Los demás trabajadores necesitarán, únicamente, ser convencidos de que el cambio es a mejor. De hecho, la mayor resistencia partirá, probablemnete, de su concepción de que aumentará la carga de trabajo, sin beneficio aparente para los usuarios del sistema.

\section{VII.4.5. Beneficios Esperados y Forma de Evaluación}

Una vez que se ha fundamentado el sistema de Gestión del Conocimiento y sus utilidades mediante la fase inicial, se hará extensivo a la/s empresa/s asociadas para la consecución de un fin común en el sector de las tecnologías de la información y las comunicaciones. De esta forma, de resultar efectivo el sistema implantado, siguiendo a Koumpis y Roberts [2003], se reconocerá a la referida gestión como uno de los medios por los que la/s empresa/s puede/n mantener o ganar posición en el mercado, ante la mejora de la competencia y competitividad dentro de las áreas involucradas en el desarrollo de su labor, a través de una certera comunicación entre ellas, tanto si están en la misma o en distinta localización geográfica.

Lutchen [2004] estima que la evaluación del sistema podrá realizarse mediante un cuestionario, de periodicidad anual, dirigido a grupos clave dentro de la/s empresa/s. De esta forma se permitirá comprobar si existe o no una cultura real de compartición del conocimiento, y si la estrategia elegida para su gestión es la correcta, o si, por el 
contrario, debe reorientarse de alguna manera. No obstante, deberá prestarse atención a los incentivos y premios a aquellas personas o áreas que hayan contribuido, de forma especial, al afán por el conocimiento y la mejora del sistema implantado.

De acuerdo con el último autor referido, los resultados obtenidos a través del cuestionario anual, pueden correlacionarse con los siguientes parámetros:

1. El tiempo transcurrido hasta la puesta en el mercado de un nuevo producto o versión (time to market). Éste debe ser apreciablemente inferior al que correspondería sin la Gestión del Conocimiento, hecho que constituye el principal factor en un sector de elevada obsolescencia de producto y sus formas de uso.

2. El número de ideas y sugerencias de mejora que originen los nuevos productos comercializables: aumento de la innovación y de la oferta.

3. El grado de satisfacción de los clientes.

4. La mejora de la calidad del producto.

5. El bienestar laboral interno.

Asimismo, la estrategia seguida para la Gestión del Conocimiento deberá tener en cuenta los siguientes aspectos:

- Análisis de qué conoce cada trabajador y las labores que le son propias.

- Asegurar que, en la medida de lo posible, el conocimiento esté centralizado y siempre listo para ser usado por los empleados que lo necesiten.

- Cerciorarse, en relación con el punto anterior, de que el "repositorio de conocimiento" es sencillo de entender y manejar. 
Con todo ello, la Gestión del Conocimiento y su evaluación constituyen un ente vivo que canaliza el dinamismo y diversidad interna para contribuir a la mejora continua de la empresa/s. 
Pedro Martín Lerones Evaluación del Aprendizaje Organizativo en los Centros Tecnológicos y Gestión del Conocimiento Sectorial en Castilla y León 
Pedro Martín Lerones Evaluación del Aprendizaje Organizativo en los Centros Tecnológicos y Gestión del Conocimiento Sectorial en Castilla y León 
En virtud de las consideraciones expuestas a lo largo de los siete capítulos de que consta la presente Tesis Doctoral, se pueden extraer las siguientes conclusiones:

1. Existe insuficiencia de lenguaje y carencia, tanto de terminología como de esquemas conceptuales apropiados, para analizar el papel que desempeña el conocimiento en la economía, aún cuando el número de publicaciones relevantes al respecto venga aumentado de forma considerable. Así, el conocimiento se define como el proceso humano y dinámico que consiste en justificar una creencia personal hacia la certeza.

Aunque, según distintos autores, existen diferentes modalidades de conocimiento, se han considerado dos tipos fundamentales, derivados del enfoque propuesto por Polanyi sobre su concepción: el conocimiento explícito y el conocimiento tácito. Ambos hacen referencia al grado en que algunos de los elementos que lo componen pueden ser escritos y transferidos. Además, se complementan y su interacción es evolutiva.

2. El proceso de creación de conocimiento puede desarrollarse en cuatro niveles ontológicos: el individuo, el grupo, la organización y el entorno interorganizativo. Dentro de estos niveles se incluyen los conocimientos especializados de las unidades que los integran, así como los relativos a la forma de coordinarlos.

De este modo, las organizaciones son sistemas sin fronteras, multiniveles, que no se dedican a la simple captación de factores productivos, sino al mantenimiento de relaciones orgánicas y dinámicas con otras entidades que producen y aplican conocimiento. Aunque este último tiene su origen en los individuos, su condición de miembros de una organización hace que no deban ser contemplados aisladamente, sino como integrantes de una red de relaciones más o menos estructuradas, en la que los conocimientos son compartidos por medio de la interacción hasta llegar a trascender a la organización. Ésta constituye, por tanto, un medio eficiente para la transferencia y creación de conocimiento.

3. El conocimiento en un entorno geográfico dado se desarrolla y difunde a través de lo que se denomina el Sistema de Conocimiento, una estructura que integra la 
Investigación (I), el Desarrollo Tecnológico (D) y la Innovación (i), es decir, las interacciones que se producen entre el sistema científico (representado por la universidad y los centros de investigación), el sistema tecnológico (centros de desarrollo y transferencia tecnológica entre la universidad y la industria), el sistema productivo (la industria en sentido amplio) y el sistema institucional (instituciones públicas y privadas existes en un territorio concreto).

Las organizaciones del Sistema Ciencia-Tecnología-Industria, las del Sistema Público-Institucional de Innovación, las personas y los grupos constituyen sus agentes sociales. Juntos configuran el contexto en el que se desarrolla la generación de conocimiento y la innovación. Difieren entre sectores, regiones y países. En general, se especializan de acuerdo con su base de conocimiento.

4. El conocimiento constituye la principal fuente de diferenciación de las organizaciones en un entorno altamente complejo, dinámico y de difícil predicción, cada vez más competitivo y global; produce beneficios sustanciales; permite innovar; y otorga a las empresas posiciones de ventaja en el mercado, de forma sostenida en el tiempo.

Se trata, por tanto, de un recurso estratégico en la creación de valor en la organización, que se concreta en un conjunto de factores inmateriales agrupados bajo la denominación de Capital Intelectual.

5. El Capital Intelectual (Intellectual Capital) es el conocimiento organizativo, es decir, el conocimiento acumulado por una entidad en un determinado periodo de tiempo en relación con sus productos, servicios, procesos, mercados y clientes.

En función de su contenido básico, puede revestir diversas formas: capital humano (genérico y específico), capital estructural (tecnológico y organizativo) y capital relacional (de negocio o comercial y social o comunicacional), aunque sus fronteras no están muy definidas y exista una interacción continua entre todas ellas. 
6. Uno de los grandes problemas que presenta el Capital Intelectual es realizar una adecuada medición de los activos intangibles o variables que lo componen. Los intangibles pueden medirse en términos de inputs, es decir, de inversiones y esfuerzos destinados a producir bienes y servicios para el consumo futuro, o de activos generados por dichas inversiones y esfuerzos.

En este sentido, algunas de las iniciativas que han gozado de un mayor predicamento, aunque teniendo en cuenta, eso sí, que son aplicables, principalmente a grandes empresas y no a las PYMEs, destinatarias últimas de la presente investigación, son: el Balanced Business Scorecard (Cuadro de Mando Integral) y el Navigator (Navegador) de SKANDIA, en el ámbito internacional; así como el Modelo Intelect, en el nacional.

7. El interés de las organizaciones por el Capital Intelectual ha ido evolucionado en tres direcciones: la medición del referido capital, el Aprendizaje Organizativo y la Gestión del Conocimiento.

En cuanto a la segunda de ellas, genéricamente el término "aprendizaje" designa situaciones muy diversas, pudiendo llevarse a cabo en tres niveles complementarios: individuos, grupos y organizaciones. En cualquier caso, puede definirse como el proceso de construcción del conocimiento. A su vez, el conocimiento adquirido puede modificar el modo de aprender.

Sin embargo, durante muchos años ha sido imposible dar una definición clara del aprendizaje en una acepción que implique productividad económica. De este modo, sólo a través del aprendizaje individual y de procesos de captación, estructuración y transmisión de conocimiento corporativo, podemos llegar a hablar de Aprendizaje Organizativo (Organizational Learning), que requiere instrumentos o mecanismos que dejen convertir el conocimiento de las personas y equipos de la organización en conocimiento colectivo. Permite aumentar las capacidades de ésta para reducir la brecha entre los conocimientos existentes en la organización y los que son necesarios para responder eficientemente a las exigencias percibidas del entorno. 
Asimismo, viene especificado por la complejidad de la tarea a realizar y por su novedad, dando lugar a resultados diferentes en términos de aprendizaje.

8. Son tres las principales perspectivas desde las que ha sido abordado el análisis del Aprendizaje Organizativo: el enfoque del cambio, el enfoque del conocimiento y la perspectiva mixta entre las dos anteriores.

Desde la perspectiva del cambio, los estudios relacionados con el enfoque adaptativo del Aprendizaje Organizativo se llevan a cabo, mayoritariamente, durante los años sesenta y setenta del siglo XX, mientras que la casi totalidad de los que se enmarcan en el enfoque proactivo se realizan en los años ochenta y noventa. En estas dos décadas, y especialmente en la última de ellas, se empieza a vincular el Aprendizaje Organizativo a aspectos relacionados con la gestión y manejo del conocimiento en las organizaciones, surgiendo tanto la perspectiva del conocimiento, como la mixta del cambio y el conocimiento.

Desde entonces, hasta el momento presente, se vienen destacando dos tendencias en el estudio del Aprendizaje Organizativo: (1) la búsqueda de sus elementos constitutivos, su dinámica, vertientes y causas, así como su influencia en la generación y transmisión del Conocimiento en las organizaciones; (2) la aplicación de las dos últimas perspectivas indicadas a problemas y entidades reales, hecho que está conformando las corrientes de pensamiento sobre la Gestión del Conocimiento efectiva de las organizaciones y la nueva figura del gestor.

9. Habida cuenta de las múltiples perspectivas bajo las que es posible enfocar el Aprendizaje Organizativo, se han asumido las aportaciones de Schaff-Johnson y Nonaka, por dos motivos: (1) poseen la doble óptica de generación de conocimiento y de transformación, factores que, en la situación socio-económica actual, no pueden abordarse de modo separado como hacen los respectivos enfoques, individualmente considerados, del cambio y del conocimiento; (2) al ubicar el concepto de organización que aprende en la Teoría del Caos, se permite su examen desde una perspectiva científica, empleando el concepto termodinámico de Entropía. 
Ahora bien, hasta ahora, las perspectivas del Aprendizaje Organizativo, entre las que figura la adoptada como base en la presente Tesis Doctoral, conciernen casi en su totalidad a aquellas contribuciones que se sitúan en el ámbito organizativo del aprendizaje, siendo todavía incipientes y no consensuadas sus definiciones en el ámbito individual, el grupal, y la interacción entre ambos. Tampoco se describen completamente sus vertientes interna y externa a las organizaciones, constatándose, además, su debate en aspectos procesales humanos no cuantificables. Por ello, se ha perseguido un modelo para evaluar el Aprendizaje Organizativo que salve estos aspectos, teniendo en cuenta su particularización a Centros Tecnológicos de la Comunidad Autónoma de Castilla y León.

10. La Gestión del Conocimiento (Knowledge Management) puede definirse como la capacidad de una organización para administrar la creación, difusión, adaptación y utilización de conocimientos valiosos y para integrarlos en negocios, sistemas, procesos, productos y servicios. Se trata, por tanto, de un concepto dinámico, es decir, de un flujo. Como las capacidades y conocimientos de una organización son parte sustancial de su Capital Intelectual, la Gestión del Conocimiento es una actividad clave en la configuración de dicho Capital Intelectual en cualquier organización, esto es, el conjunto de competencias personales, organizativas, tecnológicas y relacionales, conocidas y valoradas a través de indicadores genéricos y específicos.

Por otra parte, al revestir dos facetas: la de administrar el conocimiento disponible (Knowledge Management, en sentido estricto) y la capacidad de aprender mediante la generación de nuevos conocimientos (learning organization), presenta un carácter sistémico y concreto.

El principal reto de la Gestión del Conocimiento no es tanto la creación de éste como su captura e integración. Así, entre los modelos para proceder a la gestión aludida, el de Nonaka es el más conocido y aceptado. Creado en 1994, describe los caminos por los que se genera, transfiere y re-crea en las organizaciones. 
11. Se ha establecido un lazo funcional entre los conceptos relacionados con la Gestión del Conocimiento, pues, en general, la terminología no ayuda a aclarar las relaciones entre ellos, y, en ocasiones, se introducen las mismas ideas con denominaciones diferentes.

De este modo, el Aprendizaje Organizativo, la Gestión del Conocimiento y la medición del Capital Intelectual son conceptos interconectados y complementarios. Así, el Aprendizaje Organizativo es la base de una buena Gestión del Conocimiento, y ésta es la base para la generación de Capital Intelectual y capacidades organizativas.

12. Analizado el Sistema de Conocimiento de Castilla y León se observa que cuenta con un amplio y variado mosaico de agentes que lo generan, utilizan y transmiten, tanto en cantidad como en calidad. No obstante, aunque existe una cada vez mayor conciencia social y voluntad política en la región para impulsar su correcto funcionamiento, a sabiendas de que es vital para el futuro económico de la Comunidad Autónoma, su desarrollo pasa por corregir/eliminar ciertas debilidades que se observan todavía en la base sobre la que se sustenta: inadecuada articulación territorial y/o sectorial; bajo esfuerzo tecnológico global, con desigual comportamiento sectorial, $\mathrm{y}$, consecuentemente, elevada dependencia tecnológica del exterior; fuerte predominio de micropymes con conocimientos parcelados en fuentes monopersonales y escasa o nula actividad innovadora, utilización y aplicación global de las últimas tecnologías, cualificación, capacidad de aprendizaje organizativo y gestión del conocimiento; así como notable ausencia de una cultura de compartir información y conocimientos entre empresas, empleados, clientes y socios comerciales, a través del diálogo, la discusión, la observación, la imitación y la práctica.

13. En la economía del conocimiento, se hace esencial la existencia de infraestructuras de apoyo a la $\mathrm{I}+\mathrm{D}+\mathrm{i}$, especialmente en tejidos industriales y productivos en los que las empresas son mayoritariamente PYMEs de sectores de intensidad tecnológica media-baja, como es el caso de Castilla y León. Dentro de estas infraestructuras, 
destacan los Centros Tecnológicos, por el valor que pueden aportar, al transformar el saber generado por el sistema científico en valor para el sistema económico.

14. El Aprendizaje Organizativo permite aumentar las capacidades de los Centros Tecnológicos, al desarrollar éstos actividades científicas y de tecnología punta de cada vez mayor complejidad, donde se requiere de la adecuada sincronización de equipos multidisciplinares cuya consecución de objetivos revierta en ventajas competitivas y económicas para sus clientes. Se trata de aprender colectivamente a resolver problemas con una efectividad determinada.

15. Aún cuando los Centros Tecnológicos sólo aprenden a través de sus investigadores, éste aprendizaje individual no garantiza el Aprendizaje Organizativo. Es más, el aprendizaje en dichos Centros no es el sumatorio de los aprendizajes de sus miembros. De este modo, las distintas áreas científico-técnicas que los conforman tienen escaso valor aisladamente, incluso sus investigadores, salvo cuando interactúan con las/os otras/os. Por ello, dichos Centros precisan de instrumentos de apoyo para la toma de decisiones que conviertan los datos, la información, el conocimiento y la sabiduría en diálogos de red, que fluyan continuamente, tanto en su interior, así como entre él, sus alianzas y entorno (los consumidores finales de sus servicios).

16. Se requiere, por tanto, de una modelización del Aprendizaje Organizativo que marque indicadores de la consistencia/inconsistencia de las labores desarrolladas en los Centros Tecnológicos y de su continuidad.

Para ello, se ha tenido en cuenta que los sistemas humanos y los físicos coinciden en lo fundamental, aunque difieren en su grado de complejidad. Así, los primeros responden de forma orientada ante las acciones de otras partes del sistema, en contra de la aparente libertad ejercida en la toma de decisiones. Los seres humanos vivimos y conformamos entornos donde las acciones se basan en las condiciones actuales, a su vez las acciones afectan a las condiciones del momento, y la modificación de éstas proporciona el fundamento para las acciones siguientes. Se concibe, entonces, al Centro Tecnológico como un organismo vivo. 
17. Se entiende a un Centro Tecnológico como un sistema global (en el sentido propuesto por la Teoría General de Sistemas) del que resultan una serie de propiedades, fruto de las interacciones entre sus elementos característicos (tomados como la mínima unidad discernible con potencial para ello y que ejecutan las labores propias de aquél: los investigadores), y entre éstos y el exterior del Centro en su actividad profesional, en función de su conocimiento, jerarquización, distribución en áreas tecnológicas y grado de relación y colaboración entre los mismos y su entorno.

18. Los Centros Tecnológicos son sistemas abiertos y alejados del equilibrio desde el punto de vista termodinámico, siéndoles aplicable el concepto de entropía $(S)$, relacionado con el de probabilidad e información, según la formulación de Prigogine.

Así, para que un Centro Tecnológico sea sostenible en el tiempo, ha de verificarse que la variación de entropía debida al Aprendizaje Organizativo a que da lugar aquél por su interacción con el entorno $\left(d S_{\text {ext }}\right)$, sea mayor que la variación de entropía interna que se produce con dicho tipo de aprendizaje $\left(d S_{\text {int }}\right)$, es decir: $d S_{\text {ext }}>d S_{\text {int }}$. Para evaluar los diferenciales de esta desigualdad se considerarán intervalos temporales adecuados para observar apreciaciones dignas de cuantificación.

Las expresiones de cada una de esas variaciones entrópicas son función de una serie de indicadores, habiéndose de deducir aquellos que caracterizan el Aprendizaje Organizativo en los Centros Tecnológicos.

19. Asimismo, dado que los Centros Tecnológicos son sistemas alejados del equilibrio, les es aplicable directamente la Teoría del Caos, habiéndose considerado, una vez más, el enfoque que Prigogine ofrece en este sentido, basado en la aparición de la autoorganización en las estructuras que surgen en condiciones de alejamiento del equilibrio de los sistemas. La identificación de dichos Centros como sistemas caóticos, nos invita a pensar en una evolución inestable, a la par que ordenada, incierta y autoorganizada para los mismos. 
20. Además, son sistemas autopoiéticos, en cuanto que mantienen su organización y, por ello, conservan su identidad. No se adaptan o responden tanto a las necesidades del entorno, como a tratar de definir ese entorno en función de sus intereses y capacidades. Esto hace que sean, organizacionalmente, cerrados e, informacionalmente, abiertos, entendiendo esta apertura hacia el entorno como autorreferencia, que no debe ser otra más que la $\mathrm{I}+\mathrm{D}+\mathrm{i}$ efectiva y continuada. Ello infiere a los Centros Tecnológicos el carácter de sistemas que aprenden de modo “autorregulado", según el caos que gobierna sus dinámicas.

21. En el Aprendizaje Organizativo de los Centros Tecnológicos confluyen aspectos internos y externos a los mismos, ambos en sus vertientes individual y grupal.

Desde una perspectiva psico-sociológica, se definen los actores internos del Aprendizaje Organizativo como aquellos que contribuyen a éste intraorganizacionalmente. Así, el Aprendizaje Organizativo, surge, internamente, por la interacción entre los investigadores del Centro Tecnológico.

Cuando la aportación al Aprendizaje Organizativo proviene de la interacción con el exterior del Centro, se habla, entonces, de actores externos, en un doble sentido: de fuera a dentro y de dentro a fuera del mismo, donde el aporte proviene fundamentalmente de los contactos entre investigadores, proveedores y clientes.

Entre los actores internos han sido destacados: la motivación y su fomento; la influencia de las creencias en el desarrollo de proyectos de $\mathrm{I}+\mathrm{D}+\mathrm{i}$; el control, la gestión y distribución temporal del investigador; la inteligencia emocional; y la jerarquía.

Entre los actores externos del aprendizaje en su concepción organizativa para los Centros Tecnológicos, sobresalen: la inteligencia profesional y proactiva; la formación en los ingenieros de $\mathrm{I}+\mathrm{D}+\mathrm{i}$; y la esfera de actuación de los referidos Centros. 
En ambos casos se aprecia la realimentación existente entre sus vertientes individual y grupal durante la ejecución de labores de $\mathrm{I}+\mathrm{D}+\mathrm{i}$.

22. Los actores internos y externos psico-sociológicos tratados son observables, no magnitudes. De esta manera, para ser empleados en el modelo entrópico de evaluación del Aprendizaje Organizativo, han sido correlados con indicadores medibles (internos y externos, respectivamente), teniendo en cuenta, principalmente, aspectos económicos, por ser realmente datables y mostrar el estado y situación del Centro.

Así, se establecen unos indicadores para el Aprendizaje Organizativo que permiten valorar éste en un período tipo que se cifra considerando un tiempo base $\left(T_{\text {Base }}\right)$, constituido por dos términos: $T_{\text {Proyecto de } I+D+i}$, que refleja la duración total de un conjunto de proyectos relevantes desarrollados por el Centro Tecnológico; y,

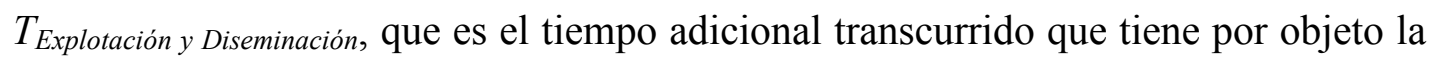
propagación científica y técnica, así como la explotación económica de los resultados de los mismos.

De esta forma, se someterán a estudio los proyectos de $\mathrm{I}+\mathrm{D}+\mathrm{i}$ que se inicien en un momento dado, durante un período $T_{\text {Posterior }}=T_{\text {Base }}$, junto a los desarrollados con anterioridad a ese momento durante un período previo equivalente $\left(T_{\text {Previo }}\right)$, para así tener una muestra de mayor representatividad, con lo que se establece un período de evaluación: $T_{\text {Evaluación }}=2 \cdot T_{\text {Base }}$. No obstante, los indicadores pueden registrarse periódicamente, para observar su evolución. A su vez, la mayoría de ellos están constituidos por una serie de factores relacionados con información anotada y accesible en los Centros Tecnológicos.

Éstos, como sistemas alejados del equilibrio, presentan unas dinámicas que hacen impredecible el futuro con las metodologías estadísticas convencionales. Sin embargo, se admite que sí pueden ser aplicadas a su pasado desde un momento dado (si se dispone de datos). De este modo, en el período de evaluación ( $\left.T_{\text {Evaluación }}\right)$, puede tomarse el valor medio como cantidad adecuada en las consideraciones del 
modelo entrópico propuesto para estimar el Aprendizaje Organizativo en el lapso temporal indicado.

No se asumen como indicadores, ni el sistema de gestión de calidad implantado en el Centro, ni la observancia de las normativas de seguridad e higiene en el trabajo aplicables a cada proyecto de $\mathrm{I}+\mathrm{D}+\mathrm{i}$, pues estos aspectos, a la par que los administrativos, se consideran la base en la actividad laboral de los investigadores. Se trata de actividades de soporte, que aunque sustentan las actividades de $\mathrm{I}+\mathrm{D}+\mathrm{i}$ del Centro Tecnológico, no son propiamente dichas actividades, que son quienes constituyen el valor y la sostenibilidad del mismo.

23. Relacionando matemáticamente los conceptos de entropía e información, se reforman las expresiones planteadas para la entropía debida al Aprendizaje Organizativo a que da lugar el Centro Tecnológico por su interacción con el entorno $\left(S_{\text {ext }}\right)$, y la correspondiente a la entropía interna que se produce con dicho tipo de aprendizaje $\left(S_{i n t}\right)$, de modo que quedan integrados en ellas los indicadores externos e internos del Aprendizaje Organizativo, respectivamente.

Dado que éstos parten de la consideración de datos registrados y analizados en el seno del Centro Tecnológico en referencia a un hecho determinado, resultan ser función de una serie de pesos y medidas. Los primeros se establecerán de modo heurístico, mientras que las segundas son producto de la cuantificación correspondiente a cada uno de los factores integrantes del indicador tratado.

24. Se han establecido como indicadores cuantificables para estimar el Aprendizaje Organizativo a nivel interno en los Centros Tecnológicos: la especialización de actividades; la capacidad para la $\mathrm{I}+\mathrm{D}+\mathrm{i}$; las infraestructuras y equipamientos que favorecen la creación de conocimiento; el clima interno; y, la eficacia $y$ productividad.

Por su parte, los indicadores medibles considerados para valorar la influencia externa en el Aprendizaje Organizativo, son: conectividad y proyección; intensidad 
de innovación; acciones formativas relacionadas con $\mathrm{I}+\mathrm{D}+\mathrm{i}$; orientación al mercado; impacto científico-técnico; e, impacto industrial.

25. Para dar lugar a la enunciación final para la valoración entrópica de la evolución del Aprendizaje Organizativo en un Centro Tecnológico, deben compendiarse entonces las ecuaciones que relacionan entropía e información con los indicadores deducidos, en sus vertientes interna y externa.

Dado que estos indicadores presentan el "problema de la atribución y la adicionalidad", y puesto que resulta impracticable la consideración de probabilidades condicionadas, se han realizado diferentes y extensas simulaciones, otorgando valores arbitrarios a los indicadores internos y externos propuestos, así como a sus posibles interacciones. Por medio de estas simulaciones, se concluye que, en primera aproximación, los resultados obtenidos son consonantes (mantenimiento de la desigualdad $d S_{\text {ext }}>d S_{\text {int }}$ ) por dos vías: (1) mediante las simulaciones referidas; y (2) mediante la consideración del valor medio de las respectivas entropías externa e interna en los períodos $T_{\text {Previo }}$ y $T_{\text {Posterior. La }}$ consonancia señalada es debida a que la evolución de cualquier indicador está determinada por los demás con los que interactúa. Este hecho, permite mantener la formulación planteada, estableciéndose la praxis evaluativa necesaria para observar si en los Centros Tecnológicos crece y se desarrolla el Aprendizaje Organizativo, y, por tanto, si son sostenibles.

26. Paralelamente, el dominio de la Gestión del Conocimiento constituye una de las prioridades de las PYMEs castellanas y leonesas que pretendan conseguir una posición competitiva y sostenible en la nueva economía globalizada, usuaria de las tecnologías de la información y de las comunicaciones. De hecho, el éxito de Castilla y León en esta nueva economía no sólo dependerá de su capacidad de crear conocimiento, sino también de su habilidad para comercializar tecnología, así como absorber y explotar el conocimiento creado en cualquier otra parte.

El ambiente intrínseco y organizacional, la capacidad e intensidad en el uso de las tecnologías de la información y de las comunicaciones, junto con, especialmente, la 
creatividad y capacidad de innovación de todos sus miembros, configuran las principales peculiaridades internas de las pequeñas y medianas empresas. La información procedente del mercado marca, a su vez, las interacciones con el exterior.

Esta interacción interna-externa, siempre entendida como sinergia, origina las relaciones esenciales que han de conducirles a lograr sus objetivos estratégicos: supervivencia, crecimiento y rentabilidad. Su necesidad será tanto mayor, cuanto más grande sea la distancia entre las denominadas "vieja" (sectores tradicionales) y "nueva economía" (sectores emergentes).

27. Hasta el momento presente, la adaptación a los sectores emergentes de las PYMEs regionales (mayoritariamente pertenecientes a la vieja economía), ha sido entendida y abordada, únicamente, desde el punto de vista material.

Obviamente, la utilización de las últimas tecnologías constituye un catalizador importante para la compartición de conocimiento en las empresas, pero aquéllas no son quienes lo generan. Al tener un componente humano, no todos los procesos y acciones pueden ser automatizados y reflejados explícitamente por las nuevas tecnologías, con todas las implicaciones que ello conlleva. En cierto modo, y con muchas reservas, es posible idear un método para guardar y compartir los conocimientos explícitos con las tecnologías de la información y las comunicaciones, tanto individuales como colectivos; pero de ninguna manera podrán almacenarse sus procesos de generación y transmisión, que son los verdaderamente importantes, los que deben conocerse y favorecerse, ni, por supuesto, el conocimiento tácito. Incluso cabe poner en duda que la información recolectada, estructurada y almacenada mediante la implantación de las nuevas tecnologías en las empresas, sea realmente mantenida y empleada por ellas.

28. Las dificultades que encuentran muchas empresas de Castilla y León para hacer brotar conocimiento de la colección de datos que se almacenan en sus sistemas de información constituye otra de las consecuencias derivadas de la aplicación del enfoque centrado en el escalamiento cuantitativo de la organización preexistente a 
través de ellos, y de la escasa atención que prestan al impacto organizativo de las nuevas tecnologías, esto es, a la integración de su sistema de información con la estrategia corporativa, ya sea por falta de tiempo; por ausencia de incentivos para lograr una, a su juicio, incierta mejora (cuando tienen asegurado un cierto cupo de mercado); o, simplemente, porque no saben, o no pueden hacerlo sin el personal cualificado que les ayude a entender la importancia de la integración señalada.

29. Establecido cómo debe procederse a la evaluación del Aprendizaje Organizativo como base de la Gestión del Conocimiento de los Centros Tecnológicos, se ha determinado, entonces, de forma complementaria, cómo debe procederse a dicha gestión en las PYMEs castellanas y leonesas que se enmarcan en los tres principales sectores estratégicos de la economía regional: agroalimentario, automoción y tecnologías de la información y de las comunicaciones. En los otros dos sectores de importancia creciente (conservación del patrimonio y biotecnología), al no haberse articulado todavía la estructura empresarial de los mismos, no es posible hablar de Gestión del Conocimiento, ni, por tanto, de sus posibles directrices.

Para lograrlo, se ha partido de la consideración de que los Centros Tecnológicos son la fuente de las capacidades competitivas y de adaptación a las nuevas tecnologías de las PYMEs que solicitan sus servicios, pudiendo aportarles tanto elementos materiales de última generación, como nuevos procesos (con implicaciones organizativas) orientados a su supervivencia y ajuste a la nueva economía.

De las conclusiones enunciadas, la continuidad inmediata del trabajo que constituye la presente Tesis Doctoral, se materializará en las dos líneas de investigación siguientes:

Puesto que la garantía del desarrollo e impulso de la capacidad competitiva de los pequeños y medianos establecimientos de Castilla y León, por parte de los Centros Tecnológicos, está condicionada por el crecimiento continuo del Aprendizaje Organizativo en ellos mismos, el modelo propuesto para valorar la evolución de dicho aprendizaje debe aplicarse de modo realista y funcional, al menos, a los seis principales Centros de la región, realimentándose, con ello, los indicadores establecidos y afirmándose la heurística de pesos para los factores que los 
conforman. Los resultados derivados de esta aplicación se correlarán con los patrones de rentabilidad de los referidos Centros, que en una segunda fase, bien pudieran ser ampliados a todo el territorio nacional.

Esta filosofía de subsistencia basada en el Aprendizaje Organizativo debiera hacerse, también, extensiva a las empresas de Castilla y León, en especial a las PYMEs, procediéndose al empleo de la Dinámica de Sistemas para establecer modelos que resulten en una adecuada Gestión del Conocimiento en compañías tipo, a nivel particular, o sectoriales, de modo general. 
Pedro Martín Lerones Evaluación del Aprendizaje Organizativo en los Centros Tecnológicos y Gestión del Conocimiento Sectorial en Castilla y León 
Pedro Martín Lerones Evaluación del Aprendizaje Organizativo en los Centros Tecnológicos y Gestión del Conocimiento Sectorial en Castilla y León 
1. ADE (1998): Memoria de Actividades. Ed. Agencia de Desarrollo Económico de Castilla y León, Valladolid (España).

2. AENOR (2004): "I+D+i: Futuro y Competitividad". UNE, no 180.

3. Akgun, A.E.; Lynn, G.S. y Byrne, J.C. (2003): "Organizational learning: A socio-cognitive framework". Human Relations, vol. 56, nº 7, p. 839-868.

4. Alderfer, C.P. (1977): "Critique of Salandik and Pfeffers examination of need-satisfaction theories". Administrative Science Quartely, vol. 22, $\mathrm{n}^{\circ}$ 4, p. 658-669.

5. Alles, M.A. (2000): Dirección estratégica de recursos humanos: Casos. Ed. Granica, Buenos Aires (Argentina).

6. Almansa, A.; Andreu, R. y Sieber, S. (2002): La Gestión del Conocimiento en España-2001. Ed. IESE Business School (Universidad de Navarra) y Cap Gemini Ernst \& Young, Barcelona (España).

7. Amponsem, H. (1991): Organizational learning through internal systems. Strategic alliances and networks. Tesis Doctoral. Queen's University, Kingston (Canadá).

8. Andreosso-O'Callaghan, B. (2003): The Economics of European Agriculture. Ed. McMillan Press/Palgrave, London (Reino Unido).

9. Andreu, R. y Ciborra, C. (1994): "Information Systems for the Learning Organization". Ponencia presentada en: Information Technology and Organizational Change, Nijenrode University (Holanda).

10. Andreu, R. y Ciborra, C. (1995): "The role of IT in creating an effective knowledge base for the learning organization”. European Forum for Management Development Review, 95/1.

11. Andreu, R. y Ciborra, C. (1996): "Core capabilities and information technology: an organizational learning approach". En: Moingeon, B. y Edmondson, A.: Organizational learning and competitive advantage. Ed. Sage, Thousand Oaks-CA (EE.UU).

12. Andreu, R. y Sieber, S. (1998): "Knowledge and problem solving. A proposal for a model of individual and collective learning". Working Paper, $n^{\circ}$ 99/1. IESE Business School (Universidad de Navarra), Barcelona-Madrid (España).

13. Andreu, R. y Sieber, S. (1999): "La gestión integral del conocimiento y el aprendizaje". Economía Industrial, $\mathrm{n}^{\mathrm{o}} 326$, p. 63-72.

14. Anzorena, O. (2003): "La formación de los trabajadores del conocimiento". XI Jornadas de Reflexión Académica, Universidad de Palermo, Quito (Ecuador).

15. Aracil, J. y Toro, M. (1993): Métodos cualitativos en Dinámica de Sistemas. Ed. Secretariado de Publicaciones de la Universidad de Sevilla, Sevilla (España).

16. Aramburu Goya, N. (2000): Un estudio del aprendizaje organizativo desde la perspectiva del cambio: implicaciones estratégicas y organizativas. Tesis Doctoral. Universidad de Deusto, San Sebastián (España).

17. Argote, L. (1999): Organizational learning: creating, retaining and transferring knowledge. Ed. Kluwer Academic Publishers, Boston (EE.UU).

18. Arnold, E. y Balazs, K. (1998): "Methods in the Evaluation of Publicly Funded Basic Reasearch". Informe para la OCDE. Publicado en: www.technopolis.co.uk/reports.

19. Atkinson, J.W. (1974): Motivation and achievement. Ed. Winston \& Sons, Washington DC (EE.UU).

20. Auckenthaler, B. y D'Huy, P. (2003): L'innovation collective. Editions Liaisons, Paris (Francia).

21. Barceló M. y Roig, A. (1999): "Centros de innovación y redes de cooperación en España". Economía Industrial, $\mathrm{n}^{\circ}$ 327, p. 75-85.

22. Barnes, S. (2002): Sistemas de gestión del conocimiento. Teoría y práctica. Thomson Editores, Madrid (España).

23. Baumol, W.J. y Wolff, E.N. (1983): "Feedback from Productivity Growth to R\&D". Scandinavian Journal of Economics, $\mathrm{n}^{\circ} 85$, p. 147-157.

24. Benavides Velasco, C.A. y Quintana García, C. (2003): Gestión del conocimiento y calidad total. Ed. Díaz de Santos - Asociación Española para la Calidad, Madrid (España).

25. Bennis, W; Spreitzer, G.M. y Cummings T.G. (2002): El futuro del liderazgo. Ed. Deusto, Bilbao (España).

26. Bertalanffy, L.V. (1978): Historia y situación de la teoría general de sistemas. Ediciones G.J.Klir, Tendencias...Alianza Universidad, Madrid (España).

27. Bianchi, A. y Kluzer, S. (1997): "The information society and regional development in Europe". FAIR Working Paper, n ${ }^{\circ} 27$.

28. Blanco, A.; Caballero, P.; Franco, F.; Hernández, A.; Manero, F. y Vega, C. (2002): Envejecimiento y mundo rural en Castilla y León. Estudios de la Fundación Encuentro-Caja España, Madrid (España). 
29. Blanco, A.; Cárcel, L.M.; Franco, F.; Gordo, P. y Manero, F. (2000): Retos de la industria agroalimentaria de Castilla y León. Estudios de la Fundación Encuentro-Caja España, Madrid (España).

30. Bleger, J. (1977): Temas de Psicología: Entrevista y Grupos. Ed. Nueva visión, Buenos Aires (Argentina).

31. Bollinger, A.S. y Smith, R.D. (2001): "Managing Organizational Knowledge as a Strategic asset". Journal of Knowledge Management, vol. 5, $\mathrm{n}^{\mathrm{o}}$ 1, p. 8-18.

32. Boltzmann, L. (1909): Wissenschaftliche Abhandlungen (vol. I, II y III). Ed. Fritz Hasenöhrl y Barth, J.A., Leipzig (Alemania).

33. Boluda Manzanares, F. (1999): “La gestión de intangibles". Boletín Económico de Información Comercial Española, no 2629 , p. I-VIII.

34. Bontis, N. (1999): "Managing organizational knowledge by diagnosing intellectual capital: framing and advancing the state of the field". International Journal of Technology Management, vol. 18, $\mathrm{n}^{\circ} 5$ 8, p. 433-462.

35. Boulding, K. (1956): "General Systems Theory: The skeleton of science". Management Science, vol. 2-3, p. 197-208.

36. Briggs, J. y Peat, F.D. (1989): Turbulent Mirror: an illustrated guide to chaos theory and the science of wholeness. Ed. Harper \& Row Publishers, Inc., New York (EE.UU).

37. Brillouin, L. (1960): Science and Information Theory. Ed. Academic Press, New York (EE.UU).

38. Brooking, A. (1996): Intellectual Capital. Core Asset for the Third Millennium Enterprise. Ed. International Thomson Business Press, London (Reino Unido).

39. Brown, C; George-Curran, R. y Smith, M.L. (2003): "The role of emotional intelligence in the career commitment and decision-making process". Journal of Career Assessment, vol. 11, n 4, p. 379-392.

40. Brynjolfsson, E. (1993): "The productivity Paradox of Information Technology". Communications of the ACM, vol. 36, $\mathrm{n}^{\mathrm{o}} 12$, p. 66-77.

41. Brynjolfsson, E. (1994): "Information assets, technology and organization". Management Science, vol. 40, no 12 , p. 1645-1662.

42. Bueno Campos, E. (2001a): "La Sociedad del Conocimiento: un nuevo espacio de aprendizaje de las personas y organizaciones". Revista Valenciana D'Estudis Autonómics, no 37, p. 21-42.

43. Bueno Campos, E. (2002): "Dirección estratégica basada en conocimiento: teoría y práctica de la nueva perspectiva". En: Morcillo, P. y Fernández Aguado, J. (coords.): Nuevas Claves para la Dirección Estratégica. Ed. Ariel Economía, Barcelona (España).

44. Bueno, E. (2001b): "Propuesta integradora del concepto de Dirección del Conocimiento". En: Arbonies, A.L.: Cómo Evitar la Miopía en la Gestión del Conocimiento. Cluster del ConocimientoDíaz de Santos, Madrid (España).

45. Bueno, E. (2001c): "Creación, medición y gestión de intangibles: propuesta de modelo conceptual". En: Formas y Reformas de la Nueva Economía. Monografía 1, Revista Madri+d, Febrero, p. 43-48.

46. Bueno, E. (2003): “Creación, medición y gestión del conocimiento: el reto de las organizaciones en el siglo XXI”. $8^{\circ}$ Congreso de Economía Regional de Castilla y León, Valladolid (España).

47. Bueno, E. y Salmador, M.P. (2000): Perspectivas sobre dirección del conocimiento y capital intelectual. Ed. I.U. Euroforum Escorial, Madrid (España).

48. Bueno, E. y Salmador, M.P. (2001): "Influencia de las dimensiones del conocimiento y de la complejidad en el proceso estratégico". XI Congreso de la Asociación Científica de Economía y Dirección de Empresas (ACEDE), Zaragoza (España).

49. Bueno, E.; Casani, F. y Lizcano, J.L. (1999): "Formación de la Estrategia Empresarial: un análisis de las dinámicas del proceso estratégico". Revista Española de Financiación y Contabilidad, n 100 , p. 195-218.

50. Canals, A. (2003): Gestión del Conocimiento. Ed. Gestión 2000, Barcelona (España).

51. Canals, J. (1991): Competitividad internacional y estrategia de la empresa. Ed. Ariel Economía, Barcelona (España).

52. Cangelosi, V.E. y Dill, W.R. (1965): "Organizational learning: Observations toward a theory". Administrative Science Quarterly, vol. 10, p. 175-203.

53. Cañibano Calvo, L.; Sánchez Muñoz, M.P.; García-Ayuso Covarsi, M. y Chaminade Domínguez, C. (2002): Directrices para la gestión y difusión de información sobre intangibles (informe de capital intelectual). Proyecto MERITUM. Ed. Fundación Airtel-Vodafone, Madrid (España). 
54. Caracostas, P. y Muldur, U. (1998): Society, the Endless Frontier: A European Vision of Research and Innovation Policies for the First Century. Science, Research and Development Studies. European Commission, Bruselas (Bélgica).

55. Carballo, R. (2003): “Innovación, conocimiento y espacios de aprendizaje: de los inhibidores a los sublimadores". En: "Estrategia, conocimientos e innovación: una mirada al futuro". Revista de Investigación en Gestión de la Innovación y Tecnología (Madri+d), Monografía 8, p. 31-48.

56. Cardona Labarga, J.Mª y Cardona Patau, S. (2002): Del miedo a la confianza, iDesarróllese como directivo!. Ed. Díaz de Santos, Madrid (España).

57. Cardona Patau, S. (2002): "Reflexiones entorno al aprendizaje". Publicado en: WwW.gestiondelconocimiento.com

58. CARTIF (2005): "Tendencias en economía y gestión de la innovación: perspectivas para un centro tecnológico en el contexto europeo". Curso interno del Centro de Automatización, Robótica y Tecnologías de la Información y la Fabricación, Valladolid (España).

59. Castañeda Zapata, D.I. (2002): “CCapacitación o aprendizaje organizacional?”. Publicado en: Www.gestionhumana.com

60. Castillo, J. y Haarich, S. (2003): "Evaluación de las actividades de I+D+i en las regiones objetivo 1. Resultados y perspectiva". En: Ogando, O. y Miranda, B.: Evaluación de programas e iniciativas comunitarias: experiencias, nuevas orientaciones y buenas prácticas. Ed. Universidad de Valladolid e Instituto de Estudios Europeos, Valladolid (España).

61. Castro Díaz-Balrt, F. (2002): Ciencia, Innovación y Futuro. Ediciones Grijalbo, Barcelona (España).

62. Chiesa, V. y Piccaluga, A. (2000): "Exploitation and diffusion of public research: the general framework and the case of academic spin-off companies". R\&D Management, $\mathrm{n}^{\circ} 30$, p. 329-340.

63. Coghlan, D. (2004): Managers Learning in Action. Ed. Routledge, London (Reino Unido).

64. Colvin, S.S. (1912): "Marks and the Marking System as an Incentive to Study". Education, May, p. 560 .

65. COMISIÓN EUROPEA (2001): Towards a European Research Area. Key Figures 2001. Special Edition. Indicators for benchmarking of national research policies. Ed. Directorate General for Research, Bruselas (Bélgica).

66. COMISIÓN EUROPEA (2002a): La agricultura de la UE y la ampliación (Fact-sheet). Ed. Dirección General de Agricultura, Bruselas (Bélgica).

67. COMISIÓN EUROPEA (2002b): Science, Technology and Innovation: Key Figures 2002. Ed. Office for official publications of the European Communities, Luxembourg (Luxemburgo).

68. COMISIÓN EUROPEA (2003a): Convocatoria de Propuestas Acción Piloto Regiones del Conocimiento. Cód. COM (2003/C 182/08). Diario Oficial de la Unión Europea, 1.8.2003, p. 25-33.

69. COMISIÓN EUROPEA (2003b): Entrepreneurial innovation in Europe. A review of 11 studies of innovation policy and practice in today's Europe. Innovation papers $n^{\circ} 27$. Ed. Office for official publications of the European Communities, Luxembourg (Luxemburgo).

70. COMISIÓN EUROPEA (2003c): Raising EU R\&D Intensity. Improving the Effectiveness of Public Support Mechanisms for Private Sector Research and Development: Direct Measures. Ed. Directorate General for Research, Bruselas (Bélgica).

71. COMISIÓN EUROPEA (2003d): Third European Report on Science \& Technology Indicators. Cód. EUR 20025. Ed. Office for official publications of the European Communities, Luxembourg (Luxemburgo).

72. COMISIÓN EUROPEA (2005): Commission proposal for the $7^{\text {th }}$ research framework programme. Ed. Office for Official Publications of the European Communities, Luxembourg, (Luxemburgo).

73. CORDIS (2003): European Innovation Scoreboard 2003. CORDIS focus supplement. Ed. Enterprise Directorate-General, European Commission, Luxemburgo (Luxemburgo).

74. Coriat, B. y Weinstein, O. (2002): "Organizations, firms and institutions in the generation of innovation". Research Policy (Elsevier), n 31, p. 273-290.

75. Coronil Jonsson, A. (2003): La política económica de la UE: Fundamentos teóricos y evaluación económica. Tesis Doctoral. Universidad San Pablo-CEU, Madrid (España).

76. Corral, J.L.F. (2001): "El Plan tecnológico triunfa más en Europa". En: Corral, J.L.F.: Economía de Castilla y León 2001. Ed. Diario El Mundo, Valladolid (España).

77. COTEC (1998): El Sistema Español de Innovación. Diagnóstico y Recomendaciones (Libro Blanco). Ed. Fundación COTEC, Madrid (España).

78. COTEC (2003): Las infraestructuras de provisión de tecnología a las empresas. Ed. Fundación COTEC, Madrid (España). 
79. COTEC (2004a): El sistema español de innovación: Situación en 2004. Ed. Fundación COTEC, Madrid (España).

80. COTEC (2004b): Los incentivos fiscales a la innovación. Documentos COTEC sobre oportunidades tecnológicas. Ed. Fundación COTEC, Madrid (España).

81. COTEC (2004c): Nuevos papeles de los centros tecnológicos: empresas, redes y desarrollo regional. Encuentros Empresariales COTEC Nº10. Ed. Fundación COTEC, Madrid (España).

82. Cox, P. (2003): "Por qué necesitamos el crecimiento económico". Revista del Parlamento Europeo, $\mathrm{n}^{\mathrm{o}} 1$, p. 3 .

83. Cyert, R.M. y March, J.G. (1963): A Behavioural Theory of the Firm. Ed. Prentice-Hall, Englewood Cliffs-NJ (EE.UU).

84. Davenport, T. y Prusak, L. (1998): Working knowledge. Ed. Harvard Business School Press, Boston-MA (EE.UU).

85. David, P.A. y Foray, D. (2002): “Una introducción a la economía y a la sociedad del saber". Revista Internacional de Ciencias Sociales, $\mathrm{n}^{\circ}$ 171, p. 8-28.

86. De Aldama, E. (2002): “Convergencia y Sociedad: Retos Sociales de los Nuevos Medios". Congreso TELEFÓNICA, Madrid (España).

87. De Diego Vallejo, R. y Valdivieso Pastor, J.D. (coords.) (1998): Psicología del Trabajo. Ediciones Pirámide, Madrid (España).

88. De Geus, A. (1997): The Living Company. Ed. Harvard Business School Press, Boston (EE.UU).

89. De Quijano, S.D. y Navarro Cid, J. (1999): "El ASH (Auditoría del Sistema Humano). Los modelos de calidad y la evaluación organizativa". Revista de Psicología General y Aplicada, $\mathrm{n}^{\circ}$ 52, $\mathrm{p}$. 2-3.

90. De Quijano, S.D. y Navarro Cid, J. (2000): El ASH como modelo de evaluación organizativa. Psicología del trabajo, de las organizaciones y los RRHH: Nuevas aproximaciones. Ed. Biblioteca Nueva, Madrid (España).

91. De Rosnay, J. (1995): L'Homme Symbiotique. Ed. Seuil, Paris (Francia).

92. Denbigh, K. y Denbigh, J. (1985): Entropy in relation to incomplete knowledge. Ed. Cambridge University Press, Cambridge (Reino Unido).

93. Dogson, M. (1993): “Organizational Learning: A Review of Some Literatures". Organization Studies, vol. 14, n 3, p. 375-394.

94. Drew, S. (1999): "Building knowledge management into strategy: Making sense of a new perspective". Long Range Planning, vol. 32, nº 1, p. 130-136.

95. Drucker, P. (1993): La Sociedad Poscapitalista. Ed. Apóstrofe, Barcelona (España).

96. Drucker, P.F. (2001): Management challenges for the 21st century. Ed. Harper Collins, New York (EE.UU).

97. Drucker, P.F. (2003): La empresa en la sociedad que viene. Ediciones Urano, Barcelona (España).

98. Duncan, R.B. (1974): "Modifications in decision structure in adapting to the environment: some implications for organizational learning". Decision Sciences, $\mathrm{n}^{\circ}$ 5, p. 705-725.

99. Duncan, R.B. y Weiss, A. (1979): “Organizational learning: implications for organizational design”. En: Straw, B.M. y Cummings, L.L. (eds.): Research in Organizational Behaviour. Ed. JAI Press, Greenwich-CT (EE.UU).

100.Durbin, J. y Koopman, S.J. (2001): Time series analysis by state space models. Ed. Oxford University Press, Oxford (Reino Unido).

101.Echeverría, R. (2000): La Empresa Emergente: la Confianza y los Desafios de la Transformación. Ed. Granica, Buenos Aires (Argentina).

102.Edvinsson, L. y Malone, M. (1999): El Capital Intelectual: cómo identificar y calcular el valor de los recursos intangibles de su empresa. Ed. Gestión 2000, Barcelona (España).

103.Einstein, A. (1954): Ideas and Opinions. Ed. Bonzana Books, New York (EE.UU).

104.Elkin, J. y Schvarstein, L. (1989): Identidad de las organizaciones, invariancia y cambio. Ed. Paidos, Buenos Aires (Argentina).

105.Escobar Espinar, M. (2000): El comercio electrónico. Perspectiva presente y futura en España. Ed. Fundación AUNA, Madrid (España).

106. Escorsa i Castells, P. y Maspons, R (2001): De la vigilancia tecnológica a la inteligencia competitiva. Ed. Financial Times-Prentice Hall, Madrid (España).

107.Etkin, J. (2003): Gestión de la complejidad de las organizaciones. Ed. Oxford University Press, New York (EE.UU).

108.Etzkowitz, H.; Webster, A. y Healey, P. (1998): Capitalizing Knowledge: the Intersection of Industry and Academia. Ed. State University of New York Press, Albany (EE.UU). 
109.EUROFORUM (1998): Proyecto Intelect. Medición del capital intelectual. Ed. EUROFORUM, Madrid (España).

110.Fernández Ramos, Ma'Y.; Pérez Martín, V. y Martín Cruz, N. (2004): “La gestión del conocimiento individual y grupal. Un análisis experimental en Castilla y León". $9^{\circ}$ Congreso de Economía de Castilla y León, Palencia (España), vol. 1, p. 33-49.

111.Fernández Rodríguez, M.C. (1999): “Alianzas estratégicas de carácter tecnológico". Economía Industrial, vol. 6, no 330 , p. 31-41.

112.Fernández Sánchez, E.; Montes Peón, J.M. y Vázquez Ordaz, C.J. (1998): “Los recursos intangibles como factores de competitividad de la empresa". Dirección y Organización, no 20, p. 8398.

113.Fiedler, K.D.; Grover, V. y Teng, J.T.C. (1996): "An empirically derived taxonomy of information technology structure and its relationship to organizational structure". Journal of Management Information Systems, vol. 13, $\mathrm{n}^{\mathrm{o}}$ 1, p. 9-34.

114.Frydman, B.; Wyer, J.; Wilson, I.M. y Senge, P. (2000): The power of collaborative leadership: lessons for the learning organization. Ed. Butterworth-Heinemann, St. Louis (EE.UU).

115.Fundación AUNA (2003): Informe sobre el Desarrollo de la Sociedad de la Información en España: eEspaña 2003. Ed. Fundación AUNA, Madrid (España).

116. Gaceta SOST (2005): “Dimensión Regional de la I+D+i”. Gaceta SOST, nº 63, p. 13-15.

117.Gadner, J.; Buber, R. y Richards, L. (2003): Organizing Knowledge: Methods and Case Studies. Ed. Palgrave MacMillan, Basingstoke (Reino Unido).

118.Gallego, D. y Ongallo, C. (2003): Conocimiento y gestión: la gestión del conocimiento para la mejora de las personas y las organizaciones. Ed. Prentice-Hall, Madrid (España).

119.Gallouj, F. (2002): Innovation in the service economy: The New Wealth of Nations. Ed. Edward Elgar, Cheltenham (Reino Unido).

120.Gallupe, B. (2001): "Knowledge management systems: surveying the landscape". International Journal of Management Review, vol. 3, nº 1, p. 61-77.

121.García Bermejo, S. (2002): "El papel de las creencias en la formación en habilidades". Publicado en: Www.gestiondelconocimiento.com

122. García Morales, V.J. (2002): "La generación de nuevo conocimiento a partir de los errores". Revista Galega de Economía, vol. 11, n 1, p. 1-18.

123.Garvin, D.A. (1993): "Building a Learning Organization". Harvard Business Review, July-August, p. 78-91.

124.Garvin, D.A. (2003): “Crear una organización que aprende”. En: Harvard Business Review: Gestión del Conocimiento. Ediciones Deusto, Bilbao (España).

125.Gibbons, M.; Limoges, C.; Nowotny, H.; Schwartzman, S.; Scout, P. y Trow, M. (1997): $L a$ nueva producción del conocimiento. Ediciones Pomares-Corredor, Barcelona (España).

126. Giral Mañas, J.M. (1999): "Los centros tecnológicos: modelo y financiación". Economía Industrial, $\mathrm{n}^{\mathrm{o}} 327$, p. 88-94.

127. Global-RENAULT (2005): "Las Alianzas". Revista de Información de RENAULT, n⿳ Especial de Mayo de 2005, p.12-13.

128. Goldstein, H. (1987): Mecánica clásica. Ed. Reverté, Barcelona (España).

129.Goleman, D. (1995): Emotional Intelligence. Ed. Bantam Books, New York (EE.UU).

130.Goleman, D. (1997): El Punto Ciego. Psicología del Autoengaño. Ed. Plaza \& Janés, Madrid (España).

131.Goleman, D. (1999): La Práctica de la Inteligencia Emocional. Ediciones Kairós, Barcelona (España).

132.Gómez Vieites, A. (2002): Las claves de la economía digital. Ed. Alfaomega-Rama, Madrid (España).

133.González Hermoso De Mendoza, A. (2000): Creación de empresas de base tecnológica: la experiencia internacional. Ed. Dirección General de Investigación de la Comunidad de Madrid, Madrid (España).

134.González, F. y Villanova, J. (1987): Curso Práctico de Matemáticas COU. Ediciones y Distribuciones Universitarias, S.A., Barcelona (España).

135.Gorelick, C.; Milton, N. y April, K. (2004): Performance Through Learning: Knowledge Management in Practice. Ed. Elsevier Butterworth-Heinemann, Burlington-MA (EE.UU).

136.Goshal, S. y Barlett, C.A. (1989): Managing Across Borders: The Transnational Solution. Ed. Hutchinson Business, London (Reino Unido).

137.Gould, J.L. y Gould, C.G. (1994): The animal mind. Ed. Scientific American Library, New York (EE.UU). 
138.Gracia San Miguel, R. (2004): "Centros Tecnológicos: ¿Subsidio o Rentabilidad?". I Congreso Iberoamericano de Centros Tecnológicos, Valencia (España), Libro Blanco, p. 147.

139.Grant, R.M. (1996): Dirección estratégica. Conceptos, Técnicas y Aplicaciones. Ed. Civitas, Madrid (España).

140.Guastello, S. (1995): Chaos, catastrophe, and human affairs: applications of nonlinear dynamics to work, organizations, and societal evolution. Ed. Lawrence Erlbaum, Mahwah-NJ (EE.UU).

141.Gupta, J.D. (2003): Creating Knowledge-Based Organizations. Ed. Idea Group Publishing, Hershey-PA (EE.UU).

142.Guzmán Rodríguez, J. (2004): "Políticas de Apoyo a la Innovación de la Unión Europea". I Congreso Iberoamericano de Centros Tecnológicos, Valencia (España), Libro Blanco, p. 69-73.

143.Hamel, G. y Prahalad, C.K. (1995): Compitiendo por el futuro. Ed. Ariel Sociedad Económica, Buenos Aires (Argentina).

144.Hamilton, M.S. (1980): "Estimating Lengths and orders of delays in system dynamics models". Elements of the system dynamics method, Part IV, p. 162-183.

145.Hammer, M. y Champy, J. (1994): Reengineering the Corporation. Ed. Harper Business, New York (EE.UU).

146.Hammer, M. y Stanton, S. (1997): La revolución de la reingeniería. Ed. Díaz de Santos, Madrid (España).

147.Hansson, S.O. (2002): "Las inseguridades en la sociedad del conocimiento". Revista Internacional de Ciencias Sociales, $\mathrm{n}^{\circ} 171$, p. 48-59.

148.Hart, S.L. (1991): "Intentionality and autonomy in strategy-making process: Models, archetypes and firm performance". Advances in Strategic Management, vol. 7, p. 97-127.

149.Hedberg, B. (1981): "How Organizations Learn and Unlearn". En: Nystrom, P.C. y Starbuck, W.H.: Handbook of Organizational Design (vol. 1). Ed. Oxford University Press, Oxford (Reino Unido).

150.Herrera Enríquez, L.; Zapico Aldeano, L.M.; Del Caño Rojo, S. y Nieto Antolín, M. (2004): "Efecto de la política de estímulo a la innovación según el contexto regional". 9 Congreso de Economía de Castilla y León, Palencia (España), vol. 1, p. 494-506.

151.Herreros, C. (1999): “Cómo crear organizaciones que aprenden”. Conferencia pronunciada en la reunión sobre "Organizaciones que aprenden”, por APD, en el Hotel Palace de Madrid, Junio de 1999.

152.Hickson, D.J. (1987): "Decision making at the top of the organisation". Annual Review of Sociology, $\mathrm{n}^{\mathrm{o}} 13$, p. $165-192$.

153. Hidalgo Nuchera, A.; León Serrano, G. y Pavón Morote, J. (2002): La gestión de la innovación y la tecnología en las organizaciones. Ediciones Pirámide, Madrid (España).

154.Hofstadter, D. (1982): “Atractores extraños”. Investigación y Ciencia, nº 64, p. 103-113.

155.Holsapple, C.W. y Joshi, K.D. (1999): "Knowledge Selection: Concepts, Issues and Technologies”. En: Liebowitz, J. (ed.): Knowledge Management Handbook. Ed. CRC Press, Boca Raton-FL (EE.UU).

156.Huber, G.P. (1991): "Organizational Learning: The Contributing Processes and the Literatures". Organization Science, vol. 2, $\mathrm{n}^{\mathrm{o}} 1, \mathrm{p} .88-115$.

157.Husso, K.; Karjalainen, S. y Parkkari, T. (2000): The state and quality of scientific research in Finland. A review of scientific research and its environment in the late 1990s. Ed. Academy of Finland, Helsinki (Finlandia).

158.IHOBE-Sociedad Pública de Gestión Ambiental (2003): Monografía sobre vehículos al final de su vida útil. Estudio para el Dpto. de Ordenación del Territorio y Medio Ambiente del Gobierno Vasco. Ed. IHOBE, Bilbao (España).

159.III PRICIT (2000): Plan Regional de Investigación Científica e Innovación Tecnológica 2000-2003. Ed. Dirección General de Investigación, Comunidad de Madrid, Madrid (España).

160.Iivonen, M. y Huotari, M. L. (2004): Trust in Knowledge Management and Systems in Organizations. Ed. Idea Group Publishing, Hershey-PA (EE.UU).

161.Inés Carazo, M. (2004): "Centros Tecnológicos: ¿Subsidio o Rentabilidad?". I Congreso Iberoamericano de Centros Tecnológicos, Valencia (España), Libro Blanco, p. 141-144.

162.Ingvar, D.H. (1985): "Memories of the Future: An Essay on the Temporal Organisation of Conscious Awareness". Human Neurobiology, vol. 4, nº 3, p. 127-136.

163.Inhelder, B. (1975): Aprendizaje y Estructuras del Conocimiento. Ed. Morata, Madrid (España).

164.Inkpen, A. y Choudhury, N. (1995): "The seeking of strategy where it is not: toward a theory of strategy absence”. Strategic Management Journal, vol. 16, nº 4, p. 313-323.

165.Inkpen, A.C. y Crossan, M.M. (1995): "Believing is seeing: joint ventures and organizational learning". Journal of Management Studies, vol. 32, n 5, p. 595-618. 
166.IV PRICIT (2004): Plan Regional de Investigación Científica e Innovación Tecnológica 2004-2007. Listado de Indicadores por Programas. Ed. Dirección General de Investigación, Comunidad de Madrid, Madrid (España).

167.Jacobs, J. (1969): The economy of cities. Ed. Jonathan Cape, London (Reino Unido).

168.Jashapara, A. (2005): "The emerging discourse of knowledge management: A new dawn for information science research?". Journal of Information Science, vol. 31, n 2, p. 136-148.

169.Jiménez-Ridruejo Ayuso, Z. (2003): "Economía: el significado de las transformaciones productivas". En: Manero, F. (coord.): Veinte años de Castilla y León (1983-2003): la entidad recuperada. Ed. Ámbito, Valladolid (España).

170.John-Steiner, V. (2000): Creative Collaboration. Ed. Oxford University Press, New York (EE.UU).

171.Juidías, J. y Loscertales, F. (1993): El rol docente. Un enfoque psicosocial. Ed. Muñoz Moya y Montraveta, Sevilla (España).

172.Jung, C.G. (1958): The undiscovered self. Ed. Mentor, New York (EE.UU).

173.JUNTA DE CASTILLA Y LEÓN (1997): Plan Tecnológico Regional de Castilla y León (19972000). Ed. Junta de Castilla y León, ADE de Castilla y León, y UE, Valladolid (España).

174.JUNTA DE CASTILLA Y LEÓN (2002a): Estrategia Regional de Investigación Científica. Desarrollo Tecnológico e Innovación $(I+D+i)$ de Castilla y León 2002-2006. Vol. I: Investigación y Ciencia. Ed. Junta de Castilla y León, Valladolid (España).

175.JUNTA DE CASTILLA Y LEÓN (2002b): Estrategia Regional de Investigación Científica. Desarrollo Tecnológico e Innovación $(I+D+i)$ de Castilla y León 2002-2006. Vol. II: Innovación. Ed. Junta de Castilla y León, Valladolid (España).

176.JUNTA DE CASTILLA Y LEÓN (2002c): Estrategia Regional de Investigación Científica. Desarrollo Tecnológico e Innovación $(I+D+i)$ de Castilla y León 2002-2006. Vol. III: Resumen. Ed. Junta de Castilla y León, Valladolid (España).

177.JUNTA DE CASTILLA Y LEÓN (2003a): Estrategia Regional para la Sociedad de la Información de Castilla y León (2003-2006). Ed. Junta de Castilla y León, Valladolid (España).

178.JUNTA DE CASTILLA Y LEÓN (2003b): Guía de servicios turísticos de Castilla y León 2003. Ed. Junta de Castilla y León, Burgos (España).

179.JUNTA DE CASTILLA Y LEÓN (2003c): Estadística de Comercio Exterior e Intracomunitario. Castilla y León, 1996-2001. Ed. Junta de Castilla y León (Consejería de Hacienda), Valladolid (España).

180.JUNTA DE CASTILLA Y LEÓN (2004): III Plan Director de Infraestructuras y Servicios de Telecomunicación de Castilla y León (2004-2006). Ed. Junta de Castilla y León, Valladolid (España).

181.Juran, J.M. (1990): Juran y el liderazgo para la calidad. Ed. Diaz de Santos, Madrid (España).

182.Kallas, Z. y Gómez-Limón Rodríguez, J.A. (2004): "Multifuncionalidad de la agricultura y política agraria: una aplicación al caso de Castilla y León”. $9^{\circ}$ Congreso de Economía de Castilla y León, Palencia (España), vol.1, p.306-326.

183.Kaplan, R.S. y Norton, D.P. (1992): "The Balanced Scorecard - measures that drive performance". Harvard Business Review, September-October.

184.Kaplan, R.S. y Norton, D.P. (2000): El Cuadro de Mando Integral. Ed. Gestión 2000, Barcelona (España).

185.Kauffman, S. (1993): The origins of order: self-organization and selection in evolution. Ed. Oxford University Press, New York (EE.UU).

186.Kickert, W.J.M. (1993): “Autopoiesis and the science of (public) administration: essence, sense and nonsense". Organization Studies, vol. 14, n² 2, p. 261-278.

187.Kiel, L.D. y Elliot, E. (1996): Chaos theory in the social sciences: foundations and applications. Ed. The University of Michigan Press, Ann Arbor (EE.UU).

188.Kim, D.H. (1993a): A Framework and Methodology for Linking Individual and Organizational Learning: Applications in TQM and Product Development. Tesis Doctoral. Massachusetts Institute of Technology, Massachusetts (EE.UU).

189.Kim, D.H. (1993b): "The Link between Individual and Organizational Learning". Sloan Management Review, vol. 35, $\mathrm{n}^{\mathrm{o}}$ 1, p. 37-50.

190.Kimball, R. y Ross, M. (2002): The data warehouse toolkit: the complete guide to dimensional modeling. Ed. John Wiley, New York (EE.UU).

191.Kogut, B. y Zander, U. (1992): "Knowledge of the Firm, Combinative Capacities and the Replication of Technology". Organization Science, vol. 17, nº 3, p. 383-397.

192.Kogut, B. y Zander, U. (1996): "What firms do?. Coordination, Identity and Learning". Organization Science, vol. 7, $\mathrm{n}^{\mathrm{o}}$ 5, p. 502-518. 
193.Kosko, B. (1994): "Fuzzy systems as universal approximators". IEEE Transactions on Computers, vol. $43, \mathrm{n}^{\circ} 11$, p. 1329-1333.

194.Koumpis, A. y Roberts, B. (2003): “A framework for Situation Room Analysis and Exploration of its Application Potential in the IT Sector". Proceedings of First International Conference on Performance Measures, Benchmarking and Best Practices in New Economy (Business Excellence '03), Guimaraes (Portugal).

195.Lam, A. (2000): “Tacit Knowledge, Organizational Learning and Societal Institutions: an Integrated Framework". Organization Studies, vol. 21, nº 3, p. 487-513.

196.Landsberg, P.T. (1990): Thermodynamics and Statistical Mechanics. Ed. Dover Publications, Inc., New York (EE.UU).

197.Le Boterf, G. (2001): Ingenieria de las competencias. Ed. Gestion 2000, Barcelona (España).

198.Leifer, R. (1988): "Matching computer-based information systems with organizational structures". Management Information Systems Quaterly, vol. 12, n 1, p. 63-73.

199.Leifer, R. (1989): "Understanding organizational transformation using dissipative structure model". Human relations, vol. 42, $\mathrm{n}^{\circ} 10$, p. 899-916.

200.Levy, D. (1994): "Chaos theory and strategy: theory, application, and managerial implications". Strategic Management Journal, $\mathrm{n}^{\mathrm{o}}$ 15, Summer spec., p. 167-178.

201.Leydesdorff, L. (2001): A sociological theory of communication: the self-organization of the knowledge-based society. Ed. Universal Publishers, Parkland (Finlandia).

202.Lorenz, E.N. (1963): "Deterministic non-periodic flow". Journal of Atmospheric Sciences, n” 20, p. $130-141$.

203.Lorenz, E.N. (1993): The essence of chaos. Ed. University of Washington Press, Seattle (EE.UU).

204.Luhmann, N. (1995): Social Systems. Ed. Stanford University Press, Stanford (EE.UU).

205.Lundvall, B-A. (1999): "La base del conocimiento y su producción”. Ekonomiaz, Revista Vasca de Economía, no 45 , p. 14-35.

206.Lundvall, B-A. y Johnson, B. (1994): “The learning economy". Journal of Industry Studies, vol. 1, $\mathrm{n}^{\mathrm{o}} 2$, p. $23-42$.

207.Lutchen, M. (2004): Managing IT as a Business: A Survival Guide for CEOs. Ed. John Wiley \& Sons, Hoboken-NJ (EE.UU).

208.Lynn G.S.; Reilly, R.R. y Akgun, A.E. (2000): "Knowledge management in new product teams: Practices and outcomes". IEEE Transactions on Engineering Management, vol. 47, n 2, p. 221-231.

209.MAEC (2004): Tratado por el que se establece una constitución para Europa. Ed. Ministerio de Asuntos Exteriores y de Cooperación, Ministerio del Interior y Ministerio de la Presidencia de España, Madrid (España).

210.Malinen, A. (2000): Towards the essence of adult experiential learning. Ed. SoPhi, University of Jyväskylä, Jyväskylä (Finlandia).

211.Mandelbrot, B. (1975): "Limit theorems of the self-normalized range for weakly and strongly dependent processes". Zeitschrift für Wahrscheinlichkeitstheorie und Verwandte Gebiete, n 31, $\mathrm{p}$. 271-285.

212.Mandelbrot, B. (1977): The fractal geometry of nature. Ed. Freeman and Company, New York (EE.UU).

213.Mandelbrot, B. (1996): "Del azar benigno al azar salvaje”. Investigación y Ciencia, no 243, p. 14-20.

214.MAPA (2003): Libro Blanco de la Agricultura y el Desarrollo Rural. Ed. Ministerio de Agricultura, Pesca y Alimentación, Madrid (España).

215.March, J.G. y Olsen, J.P. (1976): "Organizational Learning and the Ambiguity of the Past". En: March, J.G. y Olsen, J.P. (eds.): Ambiguity and Choice in Organizations. Ed. Universitetsforlaget, Bergen (Noruega).

216.Marengo, L. (1991): Knowledge, Coordination and Learning in an Adaptive Model of the Firm. Tesis Doctoral. Sussex University, Sussex (Reino Unido).

217.Margulis, N. y Raia, A.P. (1974): Desarrollo organizacional: valores, proceso y tecnología. Ed. Diana, Méjico D.F. (Méjico).

218.Marquardt, M.J. (1996): Building the Learning Organization. Ed. McGraw-Hill, New York (EE.UU).

219.Marshall, A.P. (1923): Industry and Trade. Ed. MacMillan, London (Reino Unido).

220.Marsick, V. (2002): Strategic organizational learning: how innovative companies use learning to address business challenges. Ed. J.M. Huber Institute for Learning in Organizations, Columbia University, New York (EE.UU). 
221.Martín De Castro, G. y García Muiña, F.E. (2003): "Hacia una visión integradora del capital intelectual de las organizaciones. Concepto y componentes". Boletín Económico de Información Comercial Española, no 2756, p. 7-16.

222.Martín De Castro, G.; López Sáez, P. y Navas López, J.E. (2004): “Dinámicas de aprendizaje organizativo". Boletín Económico de Información Comercial Española, n ${ }^{\circ} 2793$, p. 25-34.

223.Martínez Arévalo, P.D. (2001): “Gestión del Conocimiento Estructural por Intranet”. Publicado en: http://www.ilustrados.com/documentos/gestionconocimiento.pdf

224.Martínez García, F.J.; Peñalver Martínez, A. y Salamanca García, J. (2002): “Gestión estratégica del conocimiento". Reunión Técnica Internacional sobre la Gestión del Conocimiento, México DF (Méjico). Publicado

en: http://purace.unicauca.edu.co/gestionconocimiento/web/ponencias.htm

225.Martínez León, I.; Ruiz Mercader, J. y Ruiz Santos, C. (2001): “Aprendizaje organizacional en PYMES”. XI Congreso de la Asociación Científica de Economía y Dirección de Empresas (ACEDE), Zaragoza (España).

226.Mas, F. y Cubells, L.E. (1997): "Servicios a empresas y centros tecnológicos: un análisis comparado de modelos europeos". Economía Industrial, no 313, p. 141-155.

227. Maslow, A. (1954): Motivación y personalidad. Ed. Sagitario, Barcelona (España).

228.Maturana, H. (1994): "Design of a generator of optimization-based decision support systems". TIMS/ORSA Joint National Meeting, Boston (EE.UU).

229.Maturana, H. (1995): Fundamentos biológicos de la realidad. Ed. Anthropos-Univ. Iberoamericana-lteso, Barcelona (España).

230.Maturana, H. (1996): Fundamentos biológicos del conocimiento. Ed. Anthropos-Univ. Iberoamericana-lteso, Barcelona (España).

231.Maturana, H. y Varela, F. (1973): De máquinas y seres vivos. Editorial Universitaria, Santiago de Chile (Chile).

232.Maturana, H. y Varela, F. (1980): Autopoiesis and Cognition: the realization of the living. Vol. 42 of Boston Studies in the Philosophy of Science. Ed. D. Reidel Publishing Company, Dordrecht (Holanda).

233. Mayo, A. y Lank, E. (1994): The Power of Learning. Ed. Institute of Personnel and Development, London (Reino Unido).

234.Mayo, E. (1933): The human problems of an industrial civilization. Ed. The McMillan Company, New York (EE.UU).

235.McClelland, D. (1961): The achieving society. Ed. Free Press, New York (EE.UU).

236.McFarland, L.J; Senn, L.E. y Childress, J.R. (1996): Liderazgo para el siglo XXI. Ed. McGrawHill, New York (EE.UU).

237.McGill, M.; Slocum, J. y Lei, D. (1992): "Management practices in learning organizations". Organizational Dynamics, vol. 21, p. 5-17.

238. Medellín Cabrera, E. (2002): "Elementos para la gestión de activos intangibles en una organización”. Reunión Técnica Internacional sobre la Gestión del Conocimiento, México DF (Méjico). Publicado en: http://purace.unicau ca.edu.co/gestionconocimiento/web/ponencias.htm

239.Medina Vásquez, J. (2002): "Por un nuevo liderazgo para facilitar el desarrollo de comunidades y cultura del conocimiento en la formación avanzada". Reunión Técnica Internacional sobre la Gestión del Conocimiento, Méjico DF $\quad$ (Méjico). Publicado en: http://purace.unicauca.edu.co/gestionconocimiento/web/ponencias.htm

240. Miles, R.H. y Randolph, W.A. (1980): "Influence of Organizational Learning Styles on Early Development". En: Kimberly, J.H. y Miles, R.H. (eds.): The Organizational Life Cycle. Ed. JosseyBass, San Francisco (EE.UU).

241.Miller, J. G. (1978): Living Systems. Ed. McGraw-Hill, New York (EE.UU).

242.Modrego Rico, A. (2004): "Los Centros Tecnológicos en España: Modelos y Políticas". Jornada sobre la Competitividad en la Sociedad del Conocimiento y las Instituciones de Ciencia y Tecnología. Ponencia presentada en: Instituto Valenciano de Investigaciones Económicas, Valencia (España).

243.Montuschi, L. (2001): "La economía basada en el conocimiento: importancia del conocimiento tácito y del conocimiento codificado". UCEMA Working Papers, no 204 (Diciembre). Publicado en: http://www.cema.edu.ar/ publicaciones

244. Montuschi, L. (2002): "Conocimiento tácito y conocimiento codificado en la economía basada en el conocimiento". Anales de la Asociación Argentina de Economía Política (AAEP). Publicado en: http://www. aaep.org.ar 
245.Moñux Chércoles, D; Miranda Escolar, B.; Aleixandre Mendizábal, G. y Gómez González, F.J. (2005): "Condicionantes políticos y problemas metodológicos en la evaluación de impacto social de las políticas de I+D e innovación”. Revista Iberoamericana de Ciencia, Tecnología y Sociedad, vol. 2, $\mathrm{n}^{\mathrm{o}}$ 4, p. 173-200.

246.Moreno Rodríguez, J.M. (coord.) (2005): Evaluación Preliminar de los Impactos en España por Efecto del Cambio Climático. Proyecto ECCE. Ed. Ministerio de Medio Ambiente y Universidad de Castilla-La Mancha, Madrid (España).

247.Morin, E. (1994): Introducción al pensamiento complejo. Ed. Gedisa, Barcelona (España).

248.Muldur, U. (2001): "Is capital optimally allocated in the over-all process of European innovation?". En: Número Especial: What Policies in Support for R\&D?. Revue d'Economie Industrielle, $\mathrm{n}^{\circ}$ 94, $\mathrm{p}$. 115-152.

249.Munné, F. (1994): “Complejidad y caos: más allá de una ideología del orden y el desorden”. En: M. Montero (coord.): Conocimiento, realidad e ideología. Ed. AVEPSO, Caracas (Venezuela).

250.Munné, F. (1995): "Las teorías de la complejidad y sus implicaciones en el comportamiento social". Revista Interamericana de Psicología, nº 29, p. 1-12.

251.NACIONES UNIDAS (2003): Aplicación del pacto internacional de derechos económicos, sociales $y$ culturales. Cód. E/C.12/4/Add.1. Consejo Económico y Social. Cuartos informes periódicos presentados por los estados partes a propósito de los artículos 16 y 17 del Pacto (adición: España), 14.1.2003, p. 25-33.

252.Nahapiet, J. y Ghoshal, S. (1998): "Social Capital, Intellectual Capital and the Organizational Advantage". Academy of Management Review, vol. 23, no 2, p. 242-266.

253.NANOSPAIN (2003): Informe sobre la situación de la nanociencia y de la nanotecnología en España y propuesta de acción estratégica dentro del Plan Nacional de I+D+I (2004-2007). Ed. Red Española de Nanotecnología (NANOSPAIN), Madrid (España).

254.Navarro Cid, J. (2001): Las Organizaciones como Sistemas Abiertos Alejados del Equilibrio. Tesis Doctoral. Universidad de Barcelona, Barcelona (España).

255.Navas López, J. E. y Nieto Antolín, M. (2003): Estrategias de innovación y creación de conocimiento tecnológico en las empresas industriales españolas. Ed. Thomson Civitas y Fundación Eduardo Barreiros, Madrid (España).

256.Navas López, J.E. (1994): Organización de la empresa y nuevas tecnologías. Ed. Pirámide, Madrid (España).

257.Navas López, J.E. (2000): “Caracterización y tipología del capital intelectual en la empresa”. $7^{o}$ Congreso de Economía Regional de Castilla y León, Soria (España), Comunicaciones I.

258.Nelson, R. y Winter, S.G. (1982): An Evolutionary Theory of Economic Change. Ed. Belknap Press, Cambridge (Reino Unido).

259.Nemati, H.R. y Barko, C.D. (2003): Organizational Data Mining: Leveraging Enterprise Data Resources for Optimal Performance. Ed. Idea Group Publishing, Hershey-PA (EE.UU).

260.Nevis, E.C.; Dibella, A.J. y Gould, J.M. (1995): "Understanding Organizations as Learning Systems". Sloan Management Review, Winter, p. 73-85.

261.Nicolis, G. y Prigogine, I. (1977): Self-organization in nonequilibrium systems. Ed. John Wiley, New York (EE.UU).

262.Nicolis, G. y Prigogine, I. (1994): La estructura de lo complejo. Ed. Alianza, Madrid (España).

263.Nonaka, I. (1988): "Creating Organizational Order out of Chaos: Self-Renewal in Japanese Firms". California Management Review, Spring, p. 57-93.

264.Nonaka, I. (1991): "The Knowledge-Creating Company". Harvard Business Review, vol. 69, nº 6, p. 96-104.

265.Nonaka, I. (1994): “A dynamic theory of organizational knowledge creation”. Organization Science, vol. $5, \mathrm{n}^{\mathrm{o}} 1, \mathrm{p} .14-37$.

266.Nonaka, I. e Ichijo, K. (1997): "Creating Knowledge in the Process Organization". En: Shrivastava, P.; Huff, A.S. y Dutton, J.E. (eds.): Advances in Strategic Management (vol. 14). Ed. JAI Press, Inc., Greenwich-CT (EE.UU).

267. Nonaka, I. y Byosière, P. (2000): "La creación de conocimiento regional: un proceso de desarrollo social". En: Las sociedades del conocimiento, Bilbao: Cluster Conocimiento.

268.Nonaka, I. y Johansson, J.K. (1985): "Japanese Management: What about the 'Hard' Skills?". Academy of Management Review, vol. 10, nº 2, p. 181-191.

269.Nonaka, I. y Kono, N. (1998): "The concept of ba: building of foundation for knowledge creation". California Management Review, vol. 40, no 3, p. 40-54.

270.Nonaka, I. y Takeuchi, H. (1995): The knowledge creating company: how Japanese companies create the dynamics of innovation. Ed. Oxford University Press, New York (EE.UU). 
271.Nonaka, I.; Reinmoeller, P. y Senoo, D. (1998): "The 'Art' of Knowledge: Systems to Capitalize on Market Knowledge". European Management Journal, vol. 16, nº 6, p. 673-684.

272.Nonaka, I.; Tomaya, R. y Byosière, P. (2001): “A theory of organizational knowledge creation: understanding the dynamic process of creating knowledge". En: Dierkes, M.; Berthoin, A.; Child, J. y Nonaka, I. (eds.): Handbook of Organizational Learning and Knowledge. Ed. Oxford University Press, New York (EE.UU).

273.OCDE (1996): The Knowledge-Based Economy. Head of Publications Service (OECD), Paris (Francia).

274.OCDE (2003): Manual de Frascati 2002. Propuesta de Norma Práctica para Encuestas de Investigación y Desarrollo Experimental. Ed. Fundación Española de Ciencia y Tecnología (FECYT), Madrid (España).

275.OCDE (2004): Career Guidance and Public Policy: Bridging the Gap. Cód. 912004011P1, Paris (Francia).

276.OCDE (2005): Oslo Manual: Guidelines for Collecting and Interpreting Innovation. OECDPublications, Paris (Francia).

277. Olazaran, M. y Gómez Uranga, M. (2001): Sistemas regionales de innovación. Ed. Universidad del País Vasco, Bilbao (España).

278.Ondategui, J.C. (2002): "Parques científicos e innovación en España: quince años de experiencia". Economía Industrial, vol. 4, n 346, p. 147-160.

279. Ordóñez De Pablos, P. (2002): "Knowledge management and organizational learning: typologies of generic knowledge strategies in the Spanish manufacturing industry from 1995 to 1999". Journal of Knowledge Management, vol. 6, $\mathrm{n}^{\mathrm{o}}$ 1, p. 52-62.

280. Ordóñez De Pablos, P. (2004): "Algunas claves para entender las fuentes de la competitividad empresarial. Evidencias empíricas sobre el mapa de conocimiento organizativo". Boletín Económico de Información Comercial Española, $\mathrm{n}^{\mathrm{0}}$ 2818, p. 51-65.

281.Parikh, J.; Neubauer, F. y Lank, A.G. (1994): The New Frontier of Management (Developmental Management). Ed. Blackwell Publishers, Oxford (Reino Unido).

282.Pavitt, K. (1984): "Sectorial patterns of technical change: Towards a taxonomy". Research Policy, vol. 13, p. 343-373.

283.PCTI (2002): Investigación Estratégica. Plan de Ciencia, Tecnología e Innovación 2001-2004. Ed. Departamento de Industria, Comercio y Turismo, Gobierno Vasco, Vitoria-Gasteiz (España).

284.Pedrosa Sanz, R. et al. (1997): Efectos de la Innovación Tecnológica en el Sistema Productivo de Castilla y León. Ed. Junta de Castilla y León, Valladolid (España).

285.Pedrosa Sanz, R. y Miranda Escolar, B. (2001): La economía de Castilla y León ante la Europa de las regiones. Ed. Secretariado de Publicaciones e Intercambio Editorial, Universidad de Valladolid, Valladolid (España).

286.Pedrosa Sanz, R.; Aleixandre Mendizábal, G. y Martín Lerones, P. (2005): "La Base de Conocimiento en Castilla y León: Especificidades Locales y Sectoriales". Boletín Económico de Información Comercial Española, $\mathrm{n}^{\circ}$ 2839, p. 35-48.

287.Peitgen, H.Z.; Jurgens, H. y Saupe, D. (1992): Chaos and Fractals: New Frontiers of Science. Ed. Springer-Verlag, New York (EE.UU).

288.Pelechano, V. (1980): Modelos básicos de aprendizaje. Ed. Alfaplus, Valencia (España).

289.Pelled, L.H. et al. (1994): "Antecedents of Intergroup Conflict in Multifunctional Product Development Teams: A Conceptual Model”. IEEE Transactions on Engineering Management, vol. 41, no 1 , p. 21-28.

290.Perán González, J.R. y Antolín Giraldo, G. (coords.) (1999): La industria de componentes de automoción y el medio ambiente en Castilla y León. Ed. Universidad de Valladolid, Valladolid (España).

291.Perán González, J.R. y Miguel Hernando, J. (coords.) (1999): Mejores prácticas en la gestión de la innovación. Ed. Centro de Automatización, Robótica y Tecnologías de la Información y la Fabricación (CARTIF), Valladolid (España).

292.Perán González, J.R. y Miguel Hernando, J. (coords.) (2000): La innovación en la gestión empresarial. Ed. Centro de Automatización, Robótica y Tecnologías de la Información y la Fabricación (CARTIF), Valladolid (España).

293.Perán González, J.R.; Antón Freile, M. y Caballero Fombellida, L. (2004): Guía sobre innovación y medio rural. Ed. Oficina de información LEGITE y Centros Tecnológicos Asociados a INTENEC, Valladolid (España).

294.Perán González, J.R.; Moñux Chércoles, D. y Aleixandre Mendizábal, G. (2004): Evaluación de proyectos de innovación tecnológica. Guía práctica para las pymes de Castilla y León. Ed. Centro de 
Automatización, Robótica y Tecnologías de la Información y la Fabricación (CARTIF), Valladolid (España).

295.Pérez Blanco, C. (2002a): "IPP: Inteligencia Profesional y Proactiva". Publicado en: Www.gestiondelconocimiento.com

296. Pérez Blanco, C. $(2002 b)$ : "IPP y el Dilema del Prisionero". Publicado en: Www.gestiondelconocimiento.com

297. Pérez Fernández, A.F. (2004): "Situación y estrategias de Castilla y León en relación con las TIC". $9^{\circ}$ Congreso de Economía de Castilla y León, Palencia (España), vol. 1, p. 78-90.

298.Pérez Gil, J.L. (2005): “El Sector Porcino Ibérico en España”. Mundo Ganadero, no 176, p. 58-64.

299.Peter, L.J. (1993): The Peter Principle. Ed. Buccaneer Books Inc, New York (EE.UU).

300.Peters, T. (1988): Thriving on Chaos: Handbook for a Management Revolution. Ed. Perennial, New York (EE.UU).

301.PLA BIT Segle XXI (2001): Estrategia de Innovación y Transferencia de Tecnología de las Illes Balears. Ed. Govern de les Illes Balears, Mallorca (España).

302.Polanyi, M. (1958): Personal Knowledge: Towards a Post-Critical Philosophy. Ed. University of Chicago Press, Chicago (EE.UU).

303.Polanyi, M. (1966): The Tacit Dimension. Ed. Routledge and Kegan Paul, London (Reino Unido).

304.Popper, M. y Lipshitz, R. (2000): “Organizational learning: Mechanisms, culture and feasibility". Management Learning, vol. 31, nº 2, p. 181-196.

305.Pozo, J.I. (1989): Teorías Cognitivas del Aprendizaje. Ed. Morata, Madrid (España).

306.Prigogine I. y Stengers I. (1991): Entre el tiempo y la eternidad. Ed. Alianza, Madrid (España).

307.Prigogine, I. (1945): "Moderation et transformations irréversibles des systèmes ouverts". Académie Royale de Belgique, Bulletin de la Classe des Science, n 31, p. 600-606.

308.Prigogine, I. (1962): Non-equilibrium statistical mechanics. Ed. John Wiley, New York (EE.UU).

309.Prigogine, I. (1997): Las leyes del caos. Ed. Crítica, Barcelona (España).

310.Probst, G. y Büchel, B. (1995): La Pratique de l'Entreprise Apprenante. Ed. Les Éditions d'Organisation, Paris (Francia).

311.Pumariño A. y Rodríguez J.A. (2001): "Coexistence and persistence of infinitely many strange attractors". Ergodic Theory and Dynamical Systems, no 21, p. 1511-1523.

312.Quesada Ibáñez, J. (2004): "Políticas Regionales de Apoyo a la Innovación". I Congreso Iberoamericano de Centros Tecnológicos, Valencia (España), Libro Blanco, p. 75-77.

313.Quinn, J.B. (1992): Intelligent Enterprise. Ed. Free Press, New York (EE.UU).

314.Ransley, D.L. et al. (1994): "A Consensus on Best R\&D Practices". Research Technology Management, vol. 37, $\mathrm{n}^{\mathrm{o}}$ 2, p. 19-26.

315.Rapoport, A. (1990): Experimental Studies of Interactive Decisions. Ed. Kluwer Academic Publishers, Dordrecht (Holland).

316.Redding, J.C. y Catalanello, R.F. (1994): Strategic Readiness. Ed. Jossey-Bass, San Francisco (EE.UU).

317.Regidor, J.G. (2000): El Futuro del Medio Rural en España. Agricultura y Desarrollo Económico. Ed. Consejo Económico y Social, Madrid (España).

318.Reich, R.B. (1991): The Work of the Nations. Propering Ourselves to XXI Century Capitalism. Ed. Knof, New York (EE.UU).

319. Revilla, E. (1995): Factores Determinantes del Aprendizaje Organizativo: un Modelo de Desarrollo de Productos. Tesis Doctoral. Universidad de Valladolid, Valladolid (España).

320.Ricart, J.E.; Rodríguez, M.A.; Blasco, J.L.; Elorriaga, J.F. y Castilla, Ma .L. (2002): Código de gobierno para la empresa sostenible. Ed. IESE Business School (Universidad de Navarra), Fundación Entorno y PricewaterhouseCoopers. Publicado en: http://www.empresasostenible.info/pdf/versioncodigo.pdf

321. Ritchie-Dunham, J. y Rabbino, H.T. (2001): Managing from clarity: identifying, aligning and leveraging strategic resources. Ed. John Wiley \& Sons, New Jersey (EE.UU).

322. Rivas Herrero, L.A. y Pedraza De García, P. (2004): "Presencia actual y oportunidades futuras para la empresa castellano-leonesa en la UE ampliada". $9^{\circ}$ Congreso de Economía de Castilla y León, Palencia (España), vol. 1, p. 350-367.

323. Rivero Rodrigo, S. (2000): "Gestión del conocimiento: una vía hacia la ventaja competitiva". $D Y N A$, vol. LXXV, $\mathrm{n}^{\mathrm{o}} 3$, p. 6-15.

324. Rodríguez Enríquez, E. (2002): “Análisis económico-financiero del sector de la automoción en España”. Boletín Económico de Información Comercial Española, no 2747, p. 13-22.

325. Rolland, N. (2002): "Strategic executive learning and development in French multinationals". En: Boshyk, Y.: Action learning worldwide. Ed. McMillar Business, London (Reino Unido). 
326. Rowland, G. (2004): "Shall we dance?. A design epistemology for organizational learning and performance". Educational Technology Research and Development, vol. 52, n 1, p. 33-48.

327.Rummler, G.A. y Brache, A.P. (1991): Improve performance. How to manage the white space on the organization chart. Ed. Jossey-Bass Pub., San Francisco (EE.UU).

328.Sáez Vacas, F. (1996): "Nuevos paradigmas empresariales y tecnológicos. Innovación, modelos socioeconómicos y groupware". Revista TELOS, n 44, p. 28-41.

329.Sánchez Ruiz, E. (2002): "Teoría de la Persona Única". Publicado en: WwW.gestiondelconocimiento.com

330.Sánchez, R. y Heene, A. (1997): Strategic Learning and Knowledge Management. Ed. John Wiley \& Sons, New York (EE.UU).

331.Santidrián Arroyo, A. (2003): Relevancia de los indicadores de rendimiento en la generación e incorporación de conocimiento. Estudio de un caso del sector de automoción. Ed. Universidad de Burgos, Burgos (España).

332.Sanz Menéndez, L. (2004): Evaluación de la investigación y sistema de ciencia. Documento de trabajo 04-07. Unidad de Políticas Comparadas, Consejo Superior de Investigaciones Científicas (CSIC), Madrid (España).

333.Sanz Menéndez, L. y Meza, R. (2002): Identificación de los centros de I+D con mayores capacidades científico-técnicas en las diversas comunidades autónomas. Ed. Secretaría de Estado de Política Científica y Tecnológica, Ministerio de Ciencia y Tecnología, Madrid (España).

334.Saslow, W.M. (1999): “An economic analogy to thermodynamics". American Journal of Physics, vol. $67, \mathrm{n}^{\mathrm{0}} 12$, p. 1239-1247.

335.Schaff-Johnson, D.K. (1993): Learning Organizations: Towards an Evolutionary Paradigm/Chaos Development Model. Tesis Doctoral. Walden University, Minnesota (EE.UU).

336.Senge, P. (1990): The Fifth Discipline. Ed. Doubleday, New York (EE.UU).

337.Senge, P. (1992): La Quinta Disciplina. El arte y la práctica de la organización abierta al aprendizaje. Ed. Granica, Barcelona (España).

338.Senge, P.; Ross, R.; Smith, B; Roberts, Ch. y Kleiner, A. (1995): La Quinta Disciplina en la práctica. Estrategias y herramientas para construir la organización abierta al aprendizaje. Ed. Granica, Barcelona (España).

339.Senge, P.M. y Sterman, J.D. (1992): "Systems Thinking and Organizational Learning - Acting Locally and Thinking Globally in the Organization of the Future". European Journal of Operational Research, $\mathrm{n}^{\mathrm{o}}$ 59, p. 137-150.

340.Sent, E.-M. (1999), "The Economics of Science: Survey and Suggestions". Journal of Economic Methodology, $\mathrm{n}^{\circ}$ 6, p. 95-124.

341.Sérieyx, H. (1994): El big bang de las organizaciones. Ed. Edit, Barcelona (España).

342.Serradell López, E. y Juan Pérez, A.A. (2003): "La gestión del conocimiento en la nueva economía". Publicado en: http://www.uoc.edu/dt/20133/index.html

343.Shannon, C.E. (1948): "A mathematical theory of communication". The Bell System Technical Journal, vol. 27, p. 379-423, 623-656.

344.Shaw, R. (1981): "Strange attractors, chaotic behavior and information flow". Zeitschrift für Naturforschung, $\mathrm{n}^{\circ}$ 36a, p. 80-112.

345.Shrivastava, P. (1981): Strategic Decision Making Process: The Influence of Organizational Learning and Experience. Tesis Doctoral. Pittsburgh University, Pittsburgh (EE.UU).

346.Shrivastava, P. (1983): "A Typology of Organizational Learning Systems". Journal of Management Science, vol. 20, p. 2-24.

347.Siliceo, A; Casares, D. y González, J.L. (1999): Liderazgo, Valores y Cultura Organizacional: Hacia una Organización Competitiva. Ed. McGraw-Hill, Méjico DF (Méjico).

348.Soete, L. y Miozzo, M. (1990): "Trade and development in services: a technological perspective". MERIT Research Memorandum 89-031, Maastricht (Holanda).

349.Soldevila García, P. y Roca Batllori, E. (2004): La contabilidad de gestión en las organizaciones sin ánimo de lucro. Ed. Universidad Pontificia de Comillas, Madrid (España).

350.Solé, R.V. y Manrubia, S.C. (2001a): Orden y caos en sistemas complejos. Fundamentos. Ediciones UPC, Barcelona (España).

351.Solé, R.V. y Manrubia, S.C. (2001b): Orden y caos en sistemas complejos. Aplicaciones. Ediciones UPC, Barcelona (España).

352.Soler Anglés, R.M. (2003): Estrategia de Desarrollo de Recursos Humanos. Ed. Gestión 2000 EPISE, Barcelona (España). 
353.Solleiro, J.; Castañón, R. y Vega, R. (2002): Manual de Inteligencia Tecnológica Competitiva. Ed. Centro de Instrumentos de la Universidad Nacional Autónoma de Méjico - CamBioTec, Méjico DF (Méjico).

354.Sotillo Hidalgo, R. (2002): “Tiempo para trabajar, tiempo para vivir. Tiempo y vida". Publicado en: www.gestiondelconocimiento.com

355.Spender, J.C. (1996): "Making Knowledge: the basis of dynamic theory of the firm". Strategic Management Journal, vol. 17 (S2), p. 45-56

356.Sterman, J.D. (2000): Business dinamics: system thinking and modeling for a complex world. Ed. Mc Graw-Hill/Irwin, New York (EE.UU).

357.Stewart T. (1997): A Intellectual Capital. Ed. Currency Dubleday, New York (EE.UU).

358.Stewart, T.A. (1994): "Your company's most valuable asset: intellectual capital". Fortune, October 3, p. 68-74.

359.Ströbl, W. (1975): Herder Lexikon: Mathematik. Ed. Verlag Herder KG, Freiburg im Beisgau (Alemania).

360.Suárez Burguet, C.; Martínez Zarzoso, I.; Márquez Ramos, L. y Sanjuán Lucas, E. (2004): "Medición del efecto de las TIC sobre el desarrollo económico. Análisis desde una perspectiva regional". $9^{\circ}$ Congreso de Economía de Castilla y León, Palencia (España), vol.1, p. 385-400.

361.Sveiby, K.E. (1997): The new organizational wealth. Ed. Barrett-Koehler Publisher, Inc., San Francisco-CA (EE.UU).

362.Swieringa, J. y Wierdsma, A.F. (1992): Becoming a Learning Organization. Ed. Addison-Wesley Publishing Company, Inc., Emeryville-California (EE.UU).

363. Taiichi, O. (1988): Toyota Production System: Beyond large-scale production. Ed. Productivity Press, Shelton-CT (EE.UU).

364. Tapscott, D. (1997): La economía digital. Ed. McGraw-Hill, Santafé de Bogotá (Colombia).

365. Teece, D.J. (2000): Managing intellectual capital. Organizational, strategic, and policy dimensions. Ed. Oxford University Press, Oxford (Reino Unido).

366. Teece, D.J.; Pisano, G. y Schuen, A. (1997): "Dynamic capabilities and strategic management". Strategic Management Journal, vol. 18, nº 7, p. 509-533.

367. TELEFÓNICA (2003): La Sociedad de la Información en España 2003. Ed. TELEFÓNICA S.A., Madrid (España).

368. Temboury Redondo, M. (2003): "La Gestión del Conocimiento en las Empresas de Telecomunicaciones. Caso Práctico: TELEFÓNICA, S.A.”, I Jornada sobre Gestión del Conocimiento: de la Teoría a la Práctica, Barcelona (España).

369. Therin, F. (2002): "Organizational Learning and Innovation in High-Tech Small Firms". IEEE Computer Society, Proceedings of the $36^{\text {th }}$ Hawaii International Conference on System Sciences (HICSS'03), Hawaii (EE.UU).

370.Tidd, J.; Bessant, J. y Keith, P. (2001): Managing Innovation: Integrating Technological, Market, and Organizational Change. Ed. John Wiley \& Sons, New York (EE.UU).

371.Toffler, A. (1985): La Empresa Flexible. Ed. Plaza \& Janes, Barcelona (España).

372. Triadó Aymerich, J. (1998): "Visión artificial: Aplicaciones en la industria". Automática e Instrumentación, $\mathrm{n}^{\circ} 283$, p. 59-65.

373.Trullén, J.; Lladós, J. y Boix, R. (2002): "Economía del conocimiento, ciudad y competitividad". Investigaciones Regionales, $\mathrm{n}^{\mathrm{o}}$ 1, p. 139-161.

374. Tsoraklidis, L. (2002): "Towards a new motor vehicle block exemption: Comission proposal for motor vehicle distribution, adopted on 5 February 2002". EU Competition Policy Newsletter, n 2, p. 31-34.

375.Udaondo Durán, M. (1991): Gestión de calidad. Ed. Diaz de Santos, Madrid (España).

376.UGT (2002): Análisis económico del sector componentes de automoción. Ed. Unión General de Trabajadores (Sección Metal, Construcción y Afines). Federación Estatal, Madrid (España).

377.UIT (2003): La seguridad de las telecomunicaciones y las tecnologías de la información: Visión general de asuntos relacionados con la seguridad de las telecomunicaciones y la implementación de las recomendaciones UIT-T existentes. Ed. Unión Internacional de Telecomunicaciones, Ginebra (Suiza).

378.Ulisse, R. y Sage-Ripoll, R. (1992): "Entreprise, lieu de formation, l'enjeu capital de l'alternance". Actualité de la Formation Permamente, n ${ }^{\circ}$ 116, p. 69-74.

379.UNESCO (2002): Technical and Vocational Education and Training in the Twenty-First Century: New Roles and challenges for Guidance and Counselling. Cód. ED-2003/WS/4, Paris (Francia). 
380.Vicente Hernández, E. (2004): "Patrimonio cultural y empleo: Nuevas oportunidades para la economía castellano-leonesa". $9^{\circ}$ Congreso de Economía de Castilla y León, Palencia (España), vol. 1, p. 437-451.

381.Vickery, G. (1999): “La medición de la economía del conocimiento: medición y presentación de intangibles". Ekonomiaz, Revista Vasca de Economía, n 45, p. 160-187.

382.Vilaseca Requena, J.; Torrent i Sellens, J. y Lladós, J. (2001): “De la economía de la información a la economía del conocimiento: algunas consideraciones conceptuales y distintivas". Publicado en: http:// www.uoc.edu/web/esp/serveis/observatorio/tm/one12 imp.html

383. Von Neumann, J. (1991): Fundamentos Matemáticos de la Mecánica Cuántica. Ed. Consejo Superior de Investigaciones Científicas, Madrid (España).

384.Wagensberg, J. (1985): Ideas sobre la complejidad del mundo. Tusquets Editores (Serie Metatemas), Barcelona (España).

385.Wagensberg, J. (1998): Ideas para la imaginación impura. Ed. Tusquets, Barcelona (España).

386.Watkins, K.E. y Marsick, V.J. (1993): Sculpting the Learning Organization. Ed. Jossey-Bass, San Francisco (EE.UU).

387.Wattenberg, E. (1996): “Patrimonio cultural de Castilla y León”. En: García Simón, A. y Ortega Valcárcel, J. (eds.): Historia de una Cultura, Vol. IV, Castilla y León / Informe. Ed. Junta de Castilla y León (Consejería de Educación y Cultura), Valladolid (España).

388. Welch, E.J. (1997): "Business ethics in theory and practice: Diagnostic notes. A prescription for value". Journal of Business Ethics, vol. 16, n 3, p. 309-313.

389. Wernerfelt, B. (1984): “A resource-based view of the firm”. Strategic Management Journal, vol. 5, p. 171-180.

390.Westhead, P.; Wright, M. y Ucbasaran, D. (2001): "The internationalisation of new and small firms. A resource-based view". Journal of Business Venturing, vol. 16, nº 4, p. 333-358.

391.Whitman, M.E. y Woszczynski, A.B. (2004): The handbook of information systems research. Ed. Idea Group Publishing, Hershey-PA (EE.UU).

392. Wiggins, S. (1991): Introduction to applied nonlinear dynamical systems and chaos. Number 2 in Text in Applied Mathematics. Ed. Springer-Verlag, New York (EE.UU).

393.Wiig, K.M. (2000): "Knowledge Management: an emerging discipline rooted in a long history". En: Despres, C. y Chauvel, D.: Knowledge horizons. The present and the promise of knowledge management. Ed. Butterworth-Heinemann, Boston-MA (EE.UU).

394.Zamora Bonilla, J.P. (2002): "Scientific Inference and the Pursuit of Fame: A Contractarian Approach". Philosophy of Science, $\mathrm{n}^{\circ}$ 69, p. 300-323.

395.Zulauf, C.A. (2001): The big picture: a system thinking story for managers, leaders and other visionaries. Ed. Linkage Press, Burlington-MA (EE.UU). 
Pedro Martín Lerones Evaluación del Aprendizaje Organizativo en los Centros Tecnológicos y Gestión del Conocimiento Sectorial en Castilla y León 


\section{Anexo A: Definiciones de Investigación, Desarrollo}

Tecnológico e Innovación 
Pedro Martín Lerones Evaluación del Aprendizaje Organizativo en los Centros Tecnológicos y Gestión del Conocimiento Sectorial en Castilla y León 


\section{Definición de Investigación y Desarrollo Tecnológico}

Según el “Manual de Frascati 2002” [OCDE-2003: 30], la Investigación y el Desarrollo Tecnológico (I+D) se definen como "el conjunto de trabajos creativos que se emprenden de modo sistemático a fin de aumentar el volumen de conocimientos, incluido el conocimiento del hombre, la cultura y la sociedad, así como la utilización de esa suma de conocimientos para concebir nuevas aplicaciones".

El proceso de $\mathrm{I}+\mathrm{D}$ se supone compuesto por tres etapas, aunque cada vez es más difícil pensar en ellas como elementos independientes y claramente distinguibles [Perán González, Moñux Chércoles y Aleixandre Mendizábal-2004: 119]:

- Investigación Básica: "trabajos originales, teóricos o experimentales, que se emprenden principalmente con el fin de adquirir nuevos conocimientos sobre el fundamento de los fenómenos y de los hechos observables, sin estar dirigida a una aplicación o utilización determinada".

- Investigación Aplicada: "trabajos originales emprendidos con la finalidad de adquirir nuevos conocimientos. Sin embargo, está dirigida hacia un fin u objetivo práctico determinado".

- Desarrollo Tecnológico: "trabajos sistemáticos basados en conocimientos existentes, obtenidos mediante investigación y/o experiencia práctica, con vistas al lanzamiento de la fabricación de nuevos materiales, productos o dispositivos; al establecimiento de nuevos procesos, sistemas y servicios; o a la mejora sustancial de los ya existentes".

En España, las actividades de $\mathrm{I}+\mathrm{D}$ dan derecho a practicar una deducción de la cuota íntegra, en las condiciones establecidas por la Ley 43/1995 de 27 de Diciembre del Impuesto de Sociedades (actualizada ${ }^{143}$ ). Por ello, aunque la definición de I+D dada en

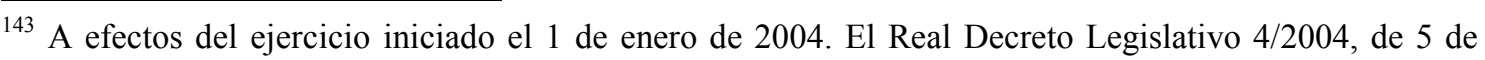
Marzo, contempla el texto refundido de la Ley del Impuesto sobre Sociedades, que no modifica sustancialmente la Ley 43/1995.
} 
el "Manual de Frascati" es internacionalmente aceptada (nuestro país figura entre los firmantes), y será también la que hagamos valer en la presente Tesis Doctoral, a efectos fiscales, únicamente es aceptable la definición fiscal de $\mathbf{I}+\mathbf{D}$, recogida en el artículo 33.2 de la citada Ley:

- Investigación: “indagación original y planificada que persiga descubrir nuevos conocimientos y una superior comprensión en el ámbito científico o tecnológico".

- Desarrollo: “aplicación de los resultados de la investigación o de cualquier otro tipo de conocimientos científicos para: la fabricación de nuevos materiales o productos; el diseño de nuevos procesos o sistemas de producción; y la mejora tecnológica sustancial de materiales, productos, procesos o sistemas preexistentes".

La Ley referida incluye como actividad de investigación y desarrollo:

○ La materialización de los nuevos productos o procesos en un plano, esquema o diseño.

○ La creación de un primer prototipo no comercializable.

- Los proyectos de demostración inicial o proyecto piloto, siempre que los mismos no puedan convertirse o utilizarse para aplicaciones industriales o para su explotación comercial.

- El diseño y la elaboración del muestrario para el lanzamiento de los nuevos productos. Se entenderá como lanzamiento de nuevo producto la introducción del mismo en el mercado, y como nuevo producto aquél cuya novedad sea esencial y no únicamente formal o accidental.

○ La concepción de software avanzado, siempre y cuando suponga un progreso científico o tecnológico significativo mediante el desarrollo de nuevos teoremas y algoritmos, o mediante la creación de sistemas operativos y lenguajes nuevos, o 
siempre que esté destinado a facilitar a las personas discapacitadas el acceso a los servicios de la sociedad de la información.

Fiscalmente, se incentiva el esfuerzo realizado en $\mathrm{I}+\mathrm{D}$, independientemente de los resultados en que culmine.

\section{Definición de Innovación}

El "Manual de Oslo" es la fuente universal de directrices para la recogida y análisis de información referente a la innovación, con el ánimo de recolectar datos internacionalmente comparables. Su tercera edición [OCDE-2005], que actualiza la anterior de 1997, es el reflejo de la necesidad de ampliar esos criterios y recomendaciones al sector servicios, que no está directamente relacionado con la $\mathrm{I}+\mathrm{D}$.

Según el referido manual: "innovación es la implementación de un producto (bien o servicio) o proceso nuevo o con un alto grado de mejora, o un método de comercialización u organización nuevo aplicado a las prácticas de negocio, al lugar de trabajo o a las relaciones externas" [OCDE-2005: 33].

Estableciendo una breve definición para cada uno de los tipos de innovación contenidos en este concepto [OCDE-2005: 34-37]:

- Innovación de producto: "introducción de un bien o servicio nuevo o con un alto grado de mejora, respecto a sus características o su uso deseado. Ésta incluye mejoras importantes en especificiaciones técnicas, componentes y materiales, software incorporado, ergonomía u otras características funcionales".

- Innovación de proceso: “implementación de un método de producción o distribución nuevo o con un alto grado de mejora. Ésta incluye mejoras importantes en técnicas, equipo y/o software”.

- Innovación de comercialización (marketing): “implementación de un nuevo método de comercialización que entraña importantes mejoras en el diseño del 
producto o en su presentación, o en su política de emplazamiento (posicionamiento), promoción o precio".

- Innovación organizacional: “implementación de un nuevo método de organización aplicado a las prácticas de negocio, al lugar de trabajo o a las relaciones externas de la empresa".

En España, las actividades de innovación tecnológica dan derecho a practicar una deducción de la cuota íntegra en las condiciones establecidas por la Ley 43/1995, de 27 de diciembre, del Impuesto de Sociedades (actualizada). Por ello, aunque la definición de innovación dada en el "Manual de Oslo" es más general e internacionalmente aceptada (nuestro país figura entre los firmantes), y es, también, la considerada en la presente Tesis Doctoral, a efectos fiscales, únicamente es aceptable la definición fiscal de innovación tecnológica, que no integra los tipos de marketing y organizacionales, y es recogida en el artículo 33.3 de la citada Ley, definiéndose como: "la actividad cuyo resultado sea un avance tecnológico en la obtención de: nuevos productos o procesos de producción; y mejoras sustanciales de los ya existentes. Se considerarán nuevos aquellos productos o procesos cuyas características o aplicaciones, desde el punto de vista tecnológico, difieran sustancialmente de las existentes con anterioridad".

Esta actividad incluirá:

○ La materialización de los nuevos productos o procesos en un plano, esquema o diseño.

○ La creación de un primer prototipo no comercializable.

○ Los proyectos de demostración inicial o proyectos piloto, siempre que los mismos no puedan convertirse o utilizarse para aplicaciones industriales o para su explotación comercial. 
- También se incluyen las actividades de diagnóstico tecnológico tendentes a la identificación, la definición y la orientación de soluciones tecnológicas avanzadas realizadas por universidades, organismos públicos de investigación o centros de innovación y tecnología, reconocidos y registrados como tales según el Real Decreto 2609/1996, de 20 de diciembre, con independencia de los resultados en los que culmine.

La innovación tecnológica requiere la existencia de novedad subjetiva, es decir, que el producto o proceso sea nuevo para la empresa, con independencia de su existencia anterior en el mercado.

La redacción actual de la Ley permite contabilizar como gasto en innovación tecnológica el esfuerzo por realizar la innovación, independientemente de que ésta se implante finalmente o no.

Es reseñable en tal texto la práctica indistinguibilidad de ciertas actividades de $\mathrm{I}+\mathrm{D}$ con las que a innovación tecnológica se refiere [COTEC-2004b]. 
Pedro Martín Lerones Evaluación del Aprendizaje Organizativo en los Centros Tecnológicos y Gestión del Conocimiento Sectorial en Castilla y León 


\section{Anexo B: Demostración de la No-Equivalencia de los Conceptos de Entropía y Desorden}


Pedro Martín Lerones Evaluación del Aprendizaje Organizativo en los Centros Tecnológicos y Gestión del Conocimiento Sectorial en Castilla y León 
De acuerdo con Landsberg [1991:366], se define el desorden de un sistema como la función:

$$
D(\Omega)=\frac{S(\Omega)}{a(\Omega)}
$$

Donde $S$ y $\Omega$ son, respectivamente, la entropía y el número de estados diferentes accesibles para el mismo; $a(\Omega)$ es una función que puede ser expresada del siguiente modo:

$$
a(\Omega)=b \cdot \ln (\Omega) ; \quad b>0 \in \Re
$$

Con ello, la expresión del desorden se transforma en:

$$
D(\Omega)=\frac{S(\Omega)}{b \ln (\Omega)}=-\frac{1}{b} \sum_{i=1}^{\Omega} p_{i} \frac{\ln p_{i}}{\ln (\Omega)}=-k \sum_{i=1}^{\Omega} \frac{1}{\ln (\Omega)} \cdot p_{i} \ln p_{i} ; \quad k=\frac{1}{b}=c t e \in \Re
$$

para cuya deducción se ha tenido en cuenta:

$$
S(\Omega)=-\sum_{i=1}^{\Omega} p_{i} \ln p_{i}
$$

Siendo: $p_{i} \leq 1 \in \mathfrak{R}$, la probabilidad asociada a cada uno de los posibles estados del sistema.

Evaluemos, a continuación, los ritmos de crecimiento del desorden y la entropía:

\section{Ritmo de crecimiento del desorden:}

$$
\begin{aligned}
& \frac{d D(\Omega)}{d t}=-k \sum_{i=1}^{\Omega}\left\{\left[\frac{1}{\ln (\Omega)} \cdot \frac{d}{d t}\left(p_{i} \ln p_{i}\right)\right]+\left[\left(p_{i} \ln p_{i}\right) \cdot \frac{d}{d t}\left(\frac{1}{\ln (\Omega)}\right)\right]\right\}= \\
& =-k \sum_{i=1}^{\Omega}\left[\left(p_{i} \ln p_{i}\right) \cdot \frac{d}{d t}\left(\frac{1}{\ln (\Omega)}\right)\right]=k \sum_{i=1}^{\Omega} p_{i} \ln p_{i} \cdot \frac{1}{\Omega} \cdot \frac{d \Omega}{d t} \cdot \frac{1}{(\ln \Omega)^{2}}
\end{aligned}
$$


Habiéndose considerado que: $\Omega=\Omega(t) ; \quad p_{i} \neq p_{i}(t) ;$ tiempo $=t \in \Re$, es decir, existe dependencia temporal para el número de estados accesibles del sistema, pero no así para la probabilidad asociada a los mismos.

De esta manera se observa que: $\frac{d D(\Omega)}{d t} \leq 0$, puesto que para los sistemas biológicos (símil empleado para los Centros Tecnológicos) ocurre que: $\frac{d \Omega(t)}{d t} \geq 0$, y el único factor negativo (o nulo) de la expresión deducida para analizar el ritmo de crecimiento del desorden es: $\ln p_{i}$.

Por tanto, el desorden disminuye con el tiempo. Veamos lo que ocurre con la entropía.

\section{Ritmo de crecimiento de la entropía:}

$$
\begin{aligned}
& \frac{d S(\Omega)}{d t}=\frac{d}{d t}[b \cdot D(\Omega) \cdot \ln (\Omega)]=b \cdot D(\Omega) \cdot \frac{d}{d t} \ln (\Omega)+b \cdot \ln (\Omega) \cdot \frac{d D(\Omega)}{d t}= \\
& =b \cdot D(\Omega) \cdot \frac{1}{\Omega} \cdot \frac{d \Omega}{d t}+b \cdot \ln (\Omega) \cdot \frac{d D(\Omega)}{d t}=A(\Omega)+B(\Omega)
\end{aligned}
$$

Donde hemos empleado la expresión del desorden inicialmente establecida, remarcándose que: $\Omega=\Omega(t) ;$ tiempo $=t \in \mathfrak{R}$.

En la expresión del ritmo de crecimiento de la entropía: $A(\Omega) \geq 0$, pues todos sus factores constitutivos son positivos o nulos $(D(\Omega) \geq 0$ por su propia definición); y $B(\Omega) \leq 0$, pues $\frac{d D(\Omega)}{d t} \leq 0$, como hemos establecido anteriormente (el resto de los factores que lo conforman son positivos o nulos).

Por tanto, en lo que a la entropía se refiere, su variación en el tiempo puede ser positiva o negativa, dependiendo del valor absoluto de los sumandos establecidos: $|A(\Omega)|,|B(\Omega)|$. 
Concluimos entonces que para sistemas fuera del equilibrio, puede ocurrir que: $|A(\Omega)| \geq|B(\Omega)|$ y entonces: $\frac{d S(\Omega)}{d t} \geq 0$, siendo $\frac{d D(\Omega)}{d t} \leq 0$, consecuentemente: la entropía aumenta con el tiempo mientras el sistema se ordena con el mismo, c.q.d. 

2 